\title{
SVMMA PLANTARVM
}

QVAE HACTENVS INNOTVERVNT

\section{METHODO LINN ÆANA}

PER GENERA ET SPECIES

DIGESTA ILLVSTRATA DESCRIPTA

\section{A FVLGENTIO VITMAN \\ A B. VALLVMBRDS.}

IN R. MEDIOT. IYC. PVBL, BOTANICES PROF.

ET PIVR. ACAD, SOC.

TOMVS I.

$x^{2}$

1

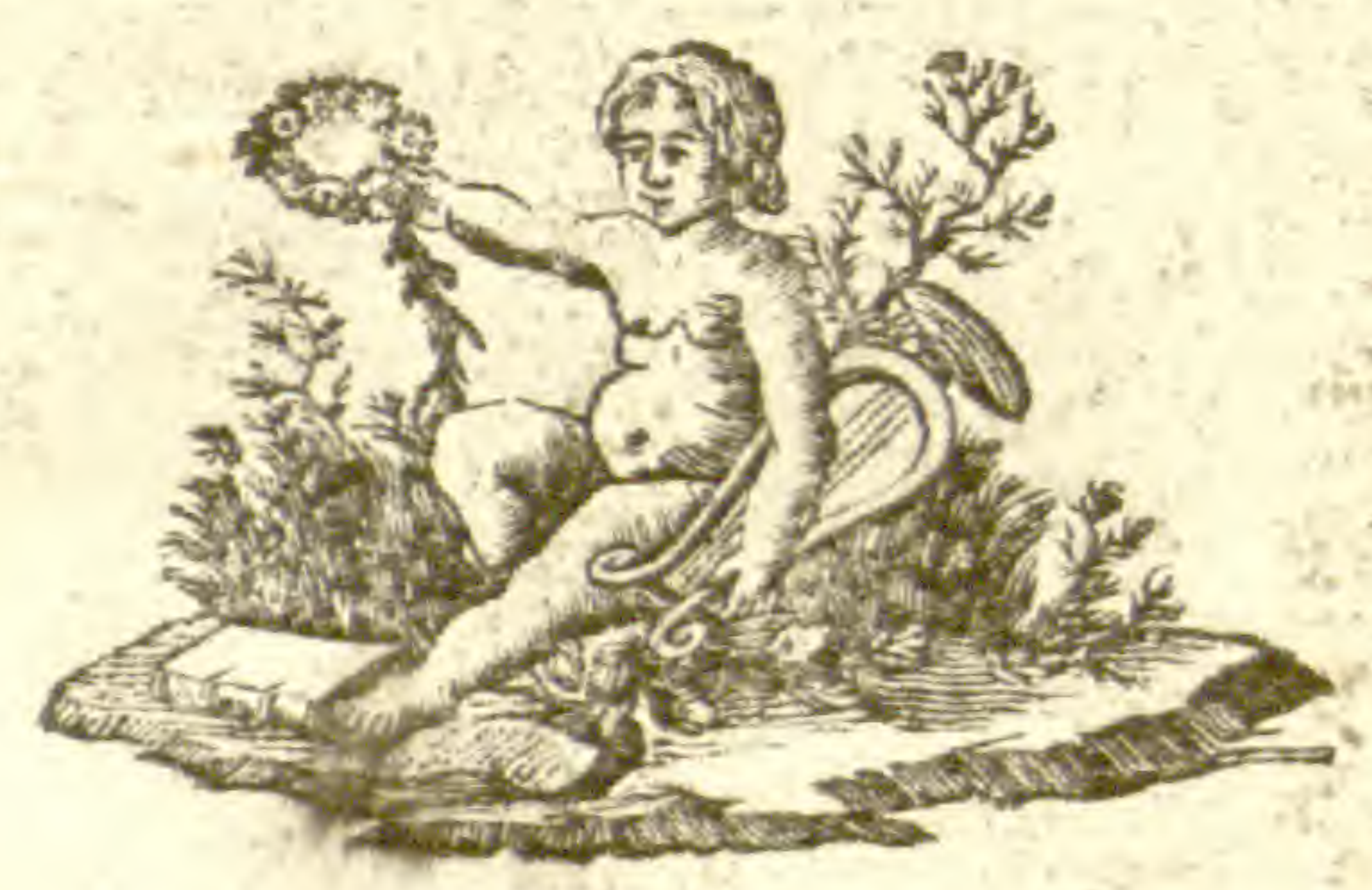

MEDIOLANI. MDCCLXXXIX.

TYPIS IMPRR, MONAST, S. AMBROSII MAJORIS. SVIERIOKVM PERMISSV. 


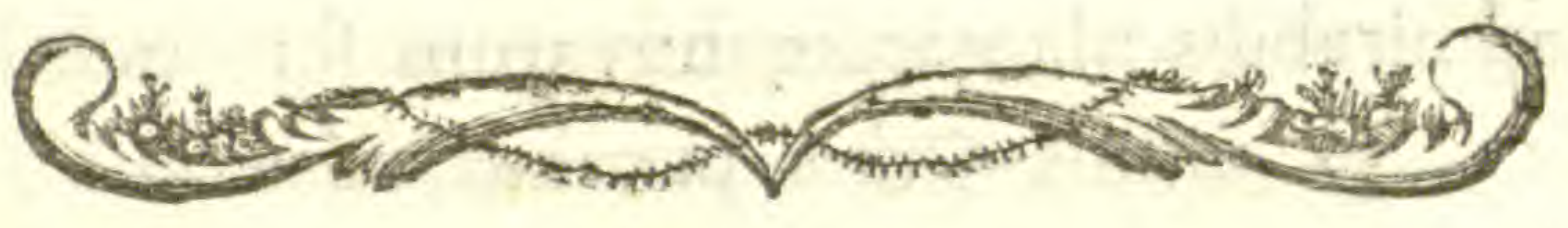

\section{P R A E F A T IO}

Uodnam fit huiufce operis argumentum; quæve utilitas ex ipfamet infcriptione fatis luculenter eruitur: hinc confilii ratio prorfus fupervacanea. Fervet paucis ab hinc annis Botanices ftudium; itinera; Societates; Horti novas plantas in dies proferunt: deficiunt pene novis ftirpibus nomina . Nec mirum; cum ftrenui Viri nunc exftent, qui nec itinerum labore; nec cœli conditione; neve impenfarum onere deterriti, id unum curarunt, ut Hiftoriam, quam aiunt, naturalem novo cenfu augerent; cum præfertim principum Virorum favore. Teftes fint Bancks, qui plurima a fortuna mutuatus prafidia ad laudem, optato fibi focio Solandro, magna fufcepit, perfecit: Cook, qui in præruptife fimis montium, ubi vel caprini gregis veftigium fruftra quæfiviffes, diu eft commoratus: Thumberg, qui Japoniam europæo pedi antea imperviam, femel, ac iterum, plantarum novarum avidus, pauco affumpto viatico, fractis viribus perluftravit: Sonnerat; Mutis; Pallas; Commerfon; Aublet; Dombay, aliique plures magni nominis Viri, quorum inventis Botanices ftudium multo felicius nunc adoleviţ 
iv

Hinc admirabilis plantarum novarum fere quotidiana fupellex, ex diffitis Orbis partibus advecta.

Opportunum itaque mihi vifum eft plantarum omnium cenfum renovare; eumque qua revocatis; qua noviter inductis herbis amplificare; \& quicquid in hac re fuit detectum, proferre. Sedenim, ut qua decet, fincera fide agam, plantas fingulas huc relatas dicere non audebo. Effet quidem opus utilifimum : at quis tot effe fe viribus glorietur? Res quidem tanta fufcipi non poteft fine maximis præfidiis; potiflimum vero fine nuperorum omnium inventis. Cum in patriam reduces erunt fummi Viri, qui generofa quadam alacritate ducti, pridem iter fufcepere ad extremas Orbis partes, Beauvoir nimirum in Africam: Billiardiere ad Orien. tales terras: Blond ad Anthyllas, \& Cayanam: Richard in Americam: Le Maffon ad Promontorium Bonæ Spei (Botanicorum Athenæum ): Greber ad Martinicam: De Haye ad Hifpaniolam infulam: Hendenfor ad Tartariam Præcopenfem: Geofroy ad Senegam: Badier ad Guadalupiam: La Peysoufe Orbem cauffa luftrandi: $\mathrm{Hi}$, inquam, cum redierint, quicquid novi attulerint, alternis annis in vulgus edam, fi fata fiverint. Sufficiat interim huc referre quæ potiflimum in Vegetabilium ed. 14. defiderantur, quæque vulgata iam dudum funt, plures videlicet ftirpes, quæ in Historia Helvetica Halleriana; quæ in Scopoli Flora Carniolica; fere omnes Aublet in Flora Guianenfi; Hacquet in noya 
alpium Carniolicarum luftratione, poft $\mathrm{Cl}$. Scopoli peracta, legere eft. His cumulavi quæ puft modo dictam editionem in lucem prodiere. Et quidem primo qux in Cl. Allioni numquam fatis com. mendata Flora Pedemontana, cui, utpote numeris omnibus abfoluta, nulla antefertur; paucæ pares numerantur. Quæ in Heritier Stirpibus novis: Scopoli Deliciis Infubricis: Ludwig Stirpibus cryptogamis. Sonnerat ad Indos itineribus. Quas omnes fi, fide tantum translatitia, ad proprias fedes non revocem, dabunt mihi veniam, cum de nonnullis anceps adhuc fim, an revera fint nova fpecies, an varietates tantum; cumque nihil ftatuere folitus fim, nifi poft experimenta iterum, ac fæpius eadem de re capta. Non inde tamen quis dicere audebit, non fatis acutam oculorum aciem tantos viros habuiffe ad minimas plantarum diffimilitudines nofcendas. Nemo enim ignorat, pro foli natura modo contrahi ftirpes, modo produci: modo minora, \& aridiora : maiora modo, \& craffiora effe folia, quam* vis una, eademque fit plantæ fpecies; ut propterea nullum notandum effe difcrimen videatur. Idem fentiendum de aliis, quas in lucem nondum proditas puto: an novæ fint incertus hæreo. Tot enim occurrunt ambages, utpote pluribus viciffitudinibus obnoxia, ut is expediendis, unius vix fufficeret hominis vita.

At fortaffe Sunt hæc quidem viliora, quam nonnulli fibi fuaferint. Ne itaque Colleetoris 'tantum. 
perfonam induere videar, eo potiflimum fpectant mea confilia, ut cum Species, tum Genera, qux hactenus vel folertioris indaginis defeetu; vel novarum fimilium additamentis, manca Botanicis funt vifa, nunc rectius definita (Cl. Allioni, \& Cyrilli veftigiis infiftendo) tutis, inconcuffifque characteribus adpareant; ut omnis perturbationi locus tandem occludatur . Quod fi Genera, Speciefque omnes examini fubiicere minus fuit conceffum, nonnullas emendafe iuvabit .

Hoc ut rite peragerem, non parum fubfidio mihi fuere \& Cl. Virorum tum noftratum, tum exterorum confuetudo: \& illuftris Halleri Bibliotheca, quæ cum aliis non minoris famæ in hoc Braydenfi Iycæo ex copiofis, felectifque Auctorum Difciplinis, fervatur: qua duce comperi, tum Genera, tum Species plurimas in nuperibus editionibus relatas, exteram fedem agnofcere; quas ad eam, quæ eis congrueret, an referre deberem, diu anceps fui. Verum enim vero ordinis perturbatio; Botanicorum diffenfus quò illæ pertineant, nihil innovandum docent. Sed in tanta rerum obfcuritate quid egomet fentiam, ordine, \& loco fuo, ingenue propono.

At etiam, ut grati animi monumentum præbeam, non parum, ad meum propofitum adfequendum, profuerunt Cl. Vahl Haphnienfis Antecefforis notitiæ, \& quafi lumina ex repetitis itineribus haufta . Hicce enim Vir rei herbariæ peritiflimus, ut forte nulli fecundus, polt peragratas diverfas Orbis, \& 
quidem a fe diffitas plagas, ex Africa in Europam redux, Londinum fe contulit, Hortum atidum Linnæi exploraturus. Omnibus inde fpeciminibus rite perfpectis, nonnulla a communi mente difare intellexit. Idem dicendum de Plucknetii potiffimum Phytologia ob incongruæ Synonimiæ cauffam. Neque in is conftitit tanti Viri fedulitas. Exemplaribus Forskælianis cum defcriptione collatis, plurimas plantas ad Floram Ægyptio-Arabicam relatas, iamdiu innotuiffe comperit .

Quod fi Specierum definitiones tyronibus ad claram, diftinctamque illarum notionem concipiendam incertæ adhuc videantur, ut omnis inde erroris fufpicio e medio tollatur, cuilibet fpeciei brevis quidem, \& concifa, fed tamen apta additur totius plantæ defcriptio. Notas autem in definitionibus adpofitas, in plantæ defcriptione renovandas non duxi, ne fruftra longus evaderem.

Nomina, quæ audiunt, trivialia religiofe fervo, utpote Specierum notioni coniuncta; etfi plantæ indolem pluries deftruant potius quam defignent.

Utque tandem de Speciei effentia ne dubitatione aftuemus, Auctorum tantum Synonima, qui de Plantarum figuris diferte egerunt, me retuliffe gratum fore confido: quorum opera Botanice tantum habet nune temporis honorem, quantum nullo umquam fe confecuturam fperaffet; cum ex prifis herbarum imaginibus divinare potius, quam fcire videamur, quid illa fibi velint. 
จiii

Extremum moneo. Non ego mei tam audax aftimator fum, ut omnium votis fatisfecifle me fperem. Iter fum ingreffus : conficiant alii \& viribus, \& doctrina præftantiores.

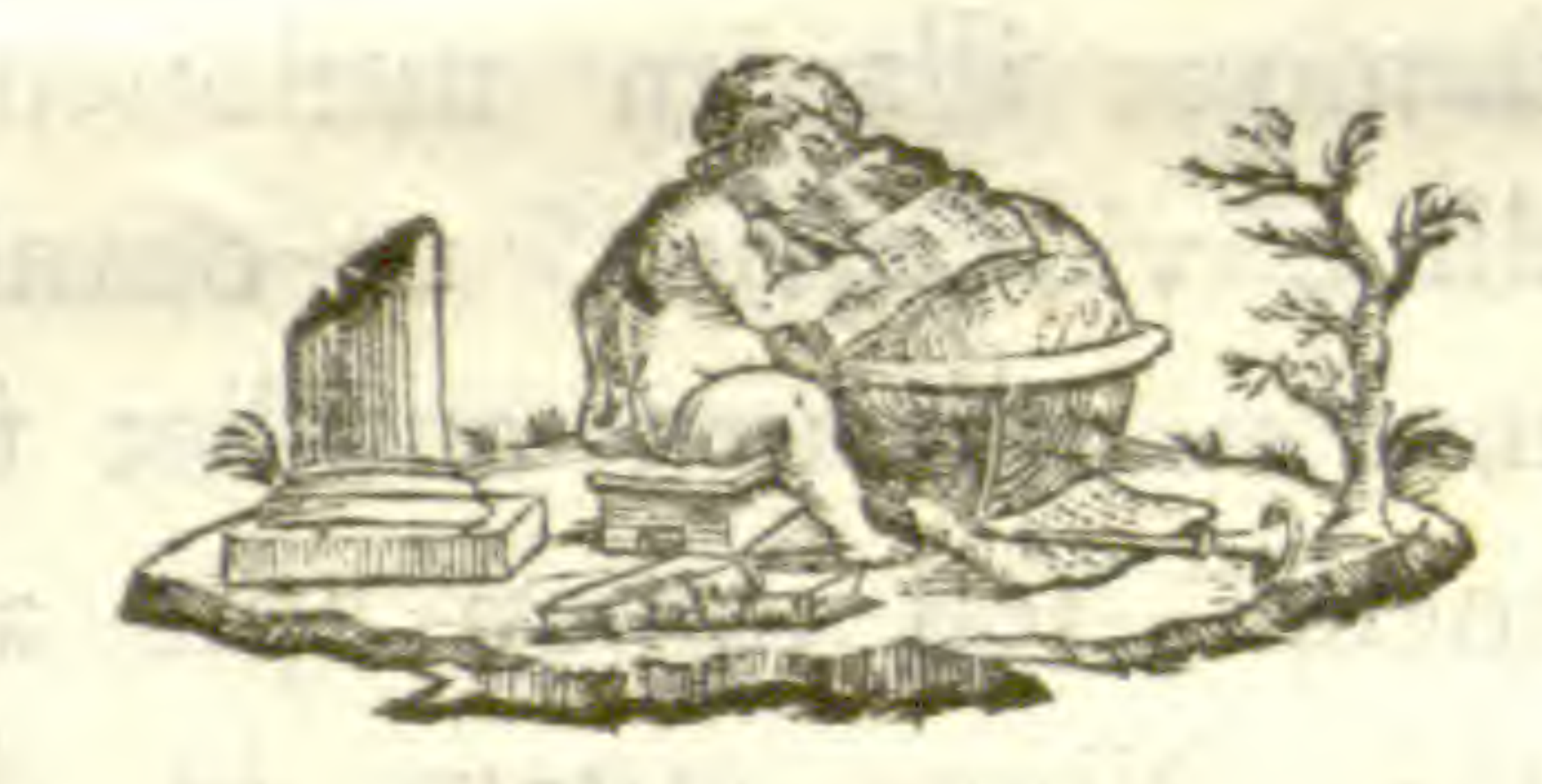




\title{
C L A S S I S I.
}

\section{O N A N D R I A.}

\author{
$\sim$ \\ $M O N O G Y N I A$
}

* Scitaminea, infera: fructu losulari, infero.

2. Renealmia. Cal, I-phyll. Cor. 3-fid. nectario oblongo, Bicca carnofa.

3. Amomum. Cor. 4-fid. lacinia prima patente (In A. Zingibere, \& Zerumbet limbus cor. 3-fid. feu bilabiatus, lab, fuper. integro, infer. divifo, intra quem nectar. 3-lob. In A. Cureuma limb. cor. 6-fid. nifi tres lacinis internas nectarium pariter nominandas ducas.)

8. Curcume. Cor. 4-part. lab. ovato. Stam. 4. fterilia, 5. fertili.

Io. Thalia, Cor. 5-pet, undulata. Drupa nucleo 2-locul.

7. Maranta. Cor. ringens, 5-6 fid. lab. magno, laciniis 2 alternis, patentibus.

5. Myrofina. Cal, duplex, exter. 3-phyll, inter. 3-part, Cor. irregul. 5-part.

9. Kampferia . Cor. 6-part. laciniis 3 maioribus patulis, unice 2-part. Stigma bilamellatum .

1. Canna. Cor, irregul. 6-part. lab. 2-part, revoluto. Filam. 0 . Anth, lineares adnatæ margini nectarifero lacinia fuperioris .

6. Alpinia. Cor. ventricofa, 6-fidd, lobis lateralibus binis emarginatis .

4. Coftus, Cor, interior inflata, ringens, lab. infer. 3-fido, lacinia media emarginara.

* Valeriana rubra, Calcitrapa.

** Monosperma.

1I. Boerhasvia. Cal, o, cor. I-pet, campanulata, plicata. Stam. I-2 Sem, I. nudum, inferum.

I3. Hippuris, Cal. \& cor. o, Stigm, fimpl, Sem. I, Fol, verticcillata. 
Differt ab Equifeto, articulis digito compreffis, cum frepitu difflientibus.

12. Salicornia , Cal. I-phyll, ventricofus, integer, Cor. O. Sem, I. Habitus plerumque aphyllos, Caulis teres, fucculentus, sæpe articulatus .

$$
\text { D I G Y N I A. }
$$

14. Corispermum . Cal. o. Petal. 2. Sem. I, ovale, nudum. 15. Callitriche. Cal. o. Petal, 2. Cap. 2-4 locul, 4-fperm. 16. Blitum, Cal. 3-fid, Cor. o. Sem. I calyc, baccato contentum. Fl. pl. in glomerem collecti. Habitus Chenopodii .

17. Mniarum, Cal, 4-part. fuperus. Cor. o. fem. I. ** Graminea.

18. Cinna. Cal. gluma 2-valv, I-fl. Cor. gluma 2-valv,

\section{MONOGY I A.}

1, CANNA, Spathæ vix ullæ, Cal. 3-phyll, erectus, colo= ratus. Cor. irregularis, 6-fida, laciaiis tribus interioribus longioribus, quarum una reflexa, reliquæ erecta. Filamentum oblongum, craffum. Anth. oblongæ, 2-locul.

Folia integerrima, firma, Sem, oblonga, nigricantia, dura.

3. indice. C. fol, ovatis, utrimque acuminatis, nervofis , Syft. veg. ed. 14. Knorr. del. hort, 2, tab. C. 2 . Cannacorus \&c. Rumph. amb. 5. $t a b, 7$ I. f. 2 , Katu-bala . Hort, mal. I1, tab, 43.

Inter tropicos Afia, Africa, America 24.

Caul. 2-cubital. Fol, ampla, pedem longa, femipedem lata, alterna, amplexicaulia, pallefcentia. Cor. coccinea, aut lutea .

2. enguffifolia . C. fol. lanceolatis, petiolatis, nervofis . Syft. Veg. ed. 14.

Arundo \&c. Moris . hift. 3. S. 8, tab. II, f. 6 , Albara. Pif, Bras. 213. f. bona.

Inter iropicos America, locis umbrofis, Jpongiofis 24. Priore humilior, \& anguftior. Petal. 3 interiora emarginata, ut in priore, quorum alterum las terale ita flectitur, ut intermedium evadat, 


\section{MONANDRIA MONOGYNIA.}

3. glau6a. C. fol. lanceolatis, petiolatis, enervits. Syft.
veg. ed. 14.

Cannacorus \&c, Dill. elth. $t a b .59$. f. 69.

In Caroline aquofis 4.

Caulis felqui-2-cubital. Fol, petiolis fe invicem amplexanilbus, palidi ra, glauca; media \& fuperiora latiora, \& longiora. Fl, sæeris majores, flavi, immaculati.

juncea. C. fol. linearibus nervofis. Retz. Obf. fafc. I.

In China 4.

Fol. gra ninea, bafi vaginantia, nervis 5. elevatioribus, propè radicem fibris capillaribus obtecta, fpitham-pedal. Scapus vaginis pl. lanceolat, inftructus, paucifl. Cor. parva, obfcurè ruf . Fruetus muricatus.

2. RENEALMIA. C 1, 1-phyll. Cor. 3-fid, nectar, oblongo.

I, exaliata. R. Syjt. veg. ed. I4. Lin. Suppl.

Globba \&c. Rumph. Amb. 6. tab. 62, 63.

In Surinamo $\$$.

Arb. recta, I'-ped. fpadice nutante. Caul. \& fol. Cannæ, fed anguftiora, \& longiora, 2-3 pedal. lanceolatd, acumine retufo, glaberrima, nervis obliquis. Racemus cum bracteis aiternis, lanceoldt. canaliculatis, nervofis, glabris, deciduis. Pedunc, in axillis bractearum, folitarii, breves, incurvati, depreffi, pubefcentes, fpatha terminati. Spatha I-phyll. apice dehifcens ut calyx, in 2-3 lacinias, ut exeant fl. Inter fpatham hanc adeft flos, \& alia fpatha 2-fl. fic fingulus pedunculus evadit 3-fl. Calyx fpathis omnino fumilis, ut effet ipatha, nifi germini infideret. Fructus in racemo compofito dependent, fig. \& magnitudine fructus Momordica Elaterii. Caro craffa, corricalis, rubicunda, calida, in medio locuJum 3-gon. diffepimentis membranaceis, mollibus, fuccofis. Sem. parva, nigra, glaberrima, Amomi Cardanomi fimillima. Fruct, conditus gratus incolis Surinami.

3. AMOMUM. Cor. 4-fid. lacinia prima patente. (In A. Zingibere, \& A. Zerumbet limbus cor. 3-fid. s. bilabiat. lab. fuper. integro; infer. divifo, intra quem nectar. 3-1ob. In A. Curcuma limb. cor. 6-fid. nifi 3 lacinias internas nectarium pariter nominandas ducas.) 
I. zingiber. A. fcapo nudo: fpica bracteis inflato-concavis, latioribufque protuberante: fol. anguftis .

A. fcapo nudo, fpica ovata. Syft. veg. ed. I4. Jac. horc. I. $t a b .75$. Rumph. Amb. 5. tab. 66. f. I. Intchi. Hort. mal. I1, tab. 12.

In India orient. E in Jamaica 24.

Caul. 2-3 pecl. Fol, vaginantia, enfiformia, integerr. plana. Scapus pedal, totus vaginis veftitus. Bractea arcte imbricatæ, fl. unicum continentes. Spatha membranacea. Cor. fordide flava.

2. zerumbet. A. fcapo nudo: fol. latis: fpica fuperficie æquifima .

A. fcapo nudo: fpica oblonga, obtusa. Syft. veg. ed. I4. Comm. Gott. 1775. tab. 2. Jacq. hort. 3. tab. 54. Ehret. pict. tab. 14. f. 1. Mill. Diat. tab. 25. Black, tab. 402 .

In India 4.

Odor aromaticus . Bulbi conmati, fubrotundí. Caul. erecti, 3-6 ped. inferne aphylli, vaginis amplexicaulibus. Fol, alterna, petiolata, elongato-lanceolata, acumin, obfcure liseata, fubdificha, integerr. nitida, fupra læte virent. fubtus pallidiora ; infima breviora, fumma anguftiora, intermedid longifima. Scap. aphyll. oblique adfurgens, vertice obtufo. Spica ovata, dein oblonga, ex fquamis imbricatis, concavis, poft efflorefcentiam rubens. Spathæ albidæ. Cor. ochroleuca .

3. cardamomum. A. fcapo fimpliciff. breviff. bracteis alternis laxis . Svft. veg. ed. I4. Black. tab. 385. f. 1. 2, 3. \& tab. 584-585. Rumpk. Amb. 5. tab. 65. f. I. Elettari 2. Hort, mal. II. tab. 6.

In India umbrofis 24.

Rarl. obliqua, nodofa, tuberculofa. Caul. rectus, 3-ped. rotundus, inferne rubens. Fol. pedal. tres digitos lata, alterna, apice longo, angufto, longitudinaliter friat, glabra. Fl. flaccidi, albi, macula lutea intus notati.

4. granum A. fcapo ramofo, brevifimo. Syft. veg. ed. I4. paradifi. Black, tab. 385 . f. 4 .

Elettari. Hort. mal. $11, t a b .6$.

In Midagafcar, Guiniea, Zeylona 4.

Planta etiamnum obfcura. Fructus rubicundi, fapore fervido. 
5. cursuma, A. fcapo fpathis laxis, ex centro foliorum. Syft. veg. ed. I4. Iacq. hort. 3. tab. 4. Herm. Lugd. tab. 209. Black. tab. 396.

Manjella Kua. Hort. mal. II. tab. II. Rumph, Anzb. 5. tab. 67.

In India 4.

Rad. tuberofa pendula, crocea. Petioli 2-4. ped. caulem mentiuntur. Fol. radicalia, plura, 6-pedal. ovalia, lineata, glabra, fupra læte, fubtus pallide virentia. Bract. fpicam efformant femipedalem, oblongæ, obtufæe, al= bæ, margine purpurafcente, quarum fingula continet fl. ternos, odoros. Spathæ meinbranac. ovare, pellucida, albæ. Cor. tubo flavo-albente, limbo albo .

6. mioga. A. fcap. brevifimo: fol. enfiformibus acutis: capfula ovara. Syft. veg. ed. 14. Thumb. Japon. Kemph, am. exot. fafc. V. p. 806.

In Japania.

Rad. fufform. fibrofa, aromatica, Caul. ped. \& ultra, debilis, totus folior. vaginis decursentibus rectus. Fol. fpitham. alterna, vaginantia, parentia, multinervia, glabra. Scap. florifer diftinctus. Fl. fafciculati, feffiles, fquamis imbricatis obvoluti. Squamæ alterna:, amplexicaules, alba. Cor. laciniæ exteriores regulares, alba; intima cæeteris diffinilis, ovata, obtula, valde coacava, inferne biaurita, flava. Caps, obtufa. Fol, maxime accedit ad $A$. Zingiber, \& Zerumbet: differt fpica fl, radica$l i, a b f q u e$ ullo fere fcapa.

repens.

A. Sonnerac. Voyag. 2. $t a b .136$.

Elettari. Hort. mal. 7. tab. 4. 5.

In Malabaria. 24.

Caul. pl. 8-ro ped. fimplices. Fol. alterna, lanceol. acumin. 8-1s poll. longa, 2 lara, fubtus nervofa, nervo medio albido; lateralibus, obliquis, paralellis. Racemi radicales, fefquiped. compoliti. Fl. albi, lineis purpureis proti.

unguftifolium. A. Sonnerat. Voyag. 2. tab. 137.

In Madagafoar. 24.

Quoad fol. angulta, videtur. A. Zingiber, sed differt fl. fpica, fi genuina eft Rheedi fig. kort, mal, 2, tab, I2,

A iij 
4. COSTUS. Cor. interior inllata, ringens, lab. infer, 3-fid.

4. arabicus. C. Syf. veg. ed. I4. Black, tab. 394.

In India utraque. 24

Caul. I-2 ped. fuberecti, geniculati. Fol. dilute viridia, nitida. Spica frobili Abietis fimilis. Spatha fimplex. Cal, ruber. Cor. alba.

Alpinia fpicata. Jacq. amer. 1. tab. 1, edit. 2. pią. tab. I.

Zingiber \&c. Sloan. Jam. I. tab. 105. fo 2. credo quad fit fp. diverfa.

Fol. oblonga, acumin. bafi adtenuata, alterna, breviter petiolata, integerrima; flordia fub fpica pleruınq. quarerna. Spica folicaria, conica, denfe compacta, e fpathis imbricatis, coccineis, I-fl. Cor, flava.

5. MYROSMA. Cal. duplex; exterior 3-phyll. interior 3-part. Cor. irregular. 5 - part.

I. cannafolia. M. Syft. veg. ed. 14. Lin. Suppl.

Naru-kila. Hort. mal. II. tab. 54? fed fruzaus nimis magnus.

In Surinamo. b.

Frutex more Cannae. Rad, horizontal, brevis, apice adfcendens, carnofa, ovata, leviter compreffa, ut in Amomo, anulis cincta, tecta vaginis alternis, amplexantibus, adpreffis, ovatis, latis, fibrofis. Fol. ut in congeneribus ovalia, venofa, glabra; inferiora petiolis elongatis, dilatatis, radicatis, caulem formantibus : fuperiora petiolis extra caulem. Petioli verfus infertionem fol. elevantur is anulum cylindricum. Scapi teretes, fubpilofi, terminati articulo, ex quo folium caulins fimillimum ; \& pedunculus vagina petioli involutus. Racemus inftar amenti Lupuli, imbricatus fquamis bractearum alternis. Bract. 2 -phyll. 2 -f. exferior amplexicaulis, latior, ovata, membranacea; interior brevior, anguftior, oblonga.

6. ALPINIA . Cor, ventricofa, 6-fid. lobis 3. pitentibus .

1. racemofat A, fl, racemofis. Syje, veg.ed. 14. Plum. ic. tab, 20, Amomum \&c. Rottboel. in Collea. Soc, med. Haun. II. $t a b, 2$.

Zingiber \&c. Sloa. Jam, hift. 1. tab. 105. f. I, In Amer. calidiore 4.

Rad, nodofa. Caulis breviffimi. Stolones fafciculum formant intricatum. Fol. Acori, alter- 


\section{MONANDRIA MONOGYNIA.}

na, vagin ntia, acuminata, fubundulata, ftriata, nervofa. Racemus grandis. Fruct. ovat. ftriatus, umbilicatus . Pertinet ad Amomi genus.

2. Spicata. A. fl. fpicatis, Sylt, veg. ed. 14. An Coftus Arabicus?

multicanlis. A. Aubl. Guian. I.

Paco-fcrocca \&c. Plum. MSS. 5. tab. 27. 28. In Cä̈enna.

Fruct. parum fucculentus. Sem. Cardamomo fimilia.

7. MARANTA. Cor. ringens, $5-6$ fid. laciniís 2 alternis, patentibus.

1, arundinaied. M. culmo ramofo. Syfto veğ. ed, 14. Mart. cent. $t a b, 39$.

In America calidiore 24.

Rad. tuberculata. Caul. 2-ped. fubramofus, fubcompreffus, lavis. Fol. alterna, ovata. glabra, integerr. nitida, fibris para!ellis. Rami pauci, fubnudi, fubdivifi in pesuncul. floriferos, Cor, alba.

2. galanga. M, culmo fimplici; fol.fubfefflibus, lanceolatis. Syft. veg. ed. 14. Rumph. Anb. 5. tab. 63.

In India orientali $\mathcal{~} 4$.

Rad, articulata, Caul. pl. 7-8 ped. nudi, inferne folior. involucris cincti. Fol. alterna, fuper. femper maiora, glabra, nervo medio. Fl. corymbus vix fpitham. Cor. fordide albefcens. Galanga hac eft Offic.

3. comofa. M. coma foliol, reflexis. $S_{j} j t$. veg, ed. 14. Lin。 Suppl.

In Surinamo 4 .

Fol. Cannæ fimilia, radicalia, petiolata, lævia . Scap. 3-ped. craflitie pennæ cigneæ, teres, lavis. Coma terminalis, foliol. numerofis, confertis, feffilibus, ovatis; inferioribus fenfim minoribus. Fl, inter fo! inferiora comæ, felfiles, fingulis bracteis bifariis, 3 parium; vaivulis fuperioribus bicarinatis; inferioribus æqualibus Flofc. terni ,

Perian, fuperum, caducum, foliol. 3 lanceolat. petaloidibus, longitudine cor.

Cor. 1-pet, tubus longitudine fere calyc. Limbus 5 part. lacin. 4 lanceolat, quinta 2 -fid.

Filam. breve, tubo infidens. Anth. erecta, oblonga.

A iv 
Pift. Germ. breve: Styl. filiform. clavatus, inferne tubo adnatus: figm. fimpl. anguftum.

Peric. Capf. 3-locul.

Sem. plurima.

An novum genus? Certe facies a reliquis aliena.

erouma.

M. caul. inferne nudo. Aubl. Guian. I.

Bermudiana \&c. Plum. MSS. tab́, 23. 24.

In Caribais 24.

tunkat. M. rad nodola. Aubl. Guian. I.

Arundaftrum. Rumph. Amb. 4. tab. 7.

In Guiana 24 .

allovia. M. fol. amplis, ovato-rotundatis: fcapo nudo: capitulo foliofo, varieg to. Aubl. Guian. I, Plum. MSS. 5. tab. 35. f. 5.

Naru Kila. Hort. mal. II, $2 a b .34$.

In Guiana 4.

Rad. tuberculara. Fl. capitati, albi.

sumilis, $M$. culmo ramofo, fol, breviore: radicibus tuberolis. Aubl. Guian, 1.

In Cä̈eña 24.

Rad, tuberculofa. F! albi .

Spicate. M. fol, ovato-cblong. fubfalcatis: caul, gudo. Fl. fpicatis. Aubl. Guian, I.

In Guiane.

Folior. nervi longitudinales ufque ad apicem non perveniunt, \& apex eft inclinatus. Spath. coriaceæ. Fl. albi .

lutea. M. ampliffmo folio. Aubl. Guilun, I.

Bermudiana \&c. Plum. MSS, tab, 21, 22.

In Guina .

malacenfis. M. culmo fimplici: fol. petiolat. ovatis. Burm. Ind.

In India.

Culm. erectus, villofus. Fol. e viridi tomento$\mathrm{fa}$, lineata, ut in Canna. Fl. 12, alterni .

8. CURCUMA. Stam. 4. fterilia, 5. fertili .

I. rotunda. C. fol, lanceolat-ovatis; nervis lateralibus rariffimis. Syft. veg. ed. 14.

Mania-Kua. Hort, mal. II. zab. Io.

In India 4.

Rad. bulbota, intus flava. Fol. 4-5, radicalia, petiol. longo, fefquiped. lata 5-6-pollic. erecta, acuminata, Galangæ fimillima, Fl, albi, fubrus rubri. 
9. KEMPFE-Cor. 6-part. Jaciniis 3. mioribus patulis, uniRIA. ca 2-pirr. Stigm. bilamellarum.

*. galanga. K. fol. feflilibus ovatis. Syf. veg. ed. 14. Hort, Cliff. $t a b .3$.

Calceolus \&c. Pet. gaz, zab. I9. f. 2.

Wabbom, Kamp. am. tab. 902.

Sonchorus. Rumph. Amb. 5. tab. 69. f. 2 ,

Katsjula-Kelengu. Hort. mal, II, tab. 4I.

In lndia 24.

Planta humilis. Rad. obtúa, plerumq. glandifirmis, nonnullis minoribus tateralibus mixta, alba. Fol. radicalia, in orbem pofita, Curcu. ma. fimilia, fed breviora, craffiora, 3-4 pollic. longa, 3 digitus lat, breviter petiolata, mucrone brevi, fupra obfcure virid. fubtus albida, margine undulato, nervofa ut in Plintagine, longitudisaliter Rriata. Cor. albo-cœruleo-purpurafc.

2. roumda. K. ful. petiviat, lanceolatis. Syft. veg. ed. I4, Black, tab. 399.

Mal n-kua. Hort. mal. in, tab. 9.

In Initia 24 .

Rad. bulbifera, extus cinerea, intus alba. Caul. cubital. Fl. radicales. Spath. membranacea, alba, 4-5 f. Cor, ex rubicundo-albo-luteo. purpareog. col. mixta. Stam. purpur.

10. THALIA . Cor. 5-petal, undulata . Drupa nucleo 2-locul. I. sericulata. T. Syft. veg. ed. 14. Rottíal. collea. hav. 2. tab 2.

Cortula \&c. Plum. gen. ie. 108. f. I.

In Amer, meridion 24.

Rad, tuberofa, nodofa . Caul. plufquam orsyal. fuperne ramofus. Fol. alterna, vaginantia, ovat-oblonga, nervis tranfverfis parale!lis? Spatha I-2 A. Petal, 3. maiora furfum erecta. concava, \& quafi lacera: 2. infer. minora, urceolata, \& quafi revoluta. Fiuct. ovatus, glaber.

II. BOERHAAVIA. Cal. o. Cor. I-pet. campanulata, plicata . Sram. I-2. Sem. I, nudum, inferum.

7. erecte. B. caule eresto: fl, diandris. Syjt. veg. ed. I4. Jacq. hort. tab. 5. 6.

B. di sidra, Burm, Ind, tab. I. f. I.

In Vera Cruce 24.

Caul, debilis, inferne vifcofus, atro-purpurafs. 
adfperfus atomis, feu pilis breviffmis. Fol. oppofita, petiolat. ovata, acuta, undulata, margine fcabra, fubtus pallidiora, petiol. fubrubris. Racemi inæquales. Cor. minima, cylindrica, albo-rufefcens, laciniis acutis, denticulis interiectis. Stam. 2. Stigm. capitatum.

2. diffufa, B. caul. lævi, diffufo: fol, ovatis. Syft. veg. ed. I4.

Vulerianella \&c. Herm, par. tab. 237.

Talu-dama Hort. mal. 7. tab. 56 .

In Indin 24.

Caul. pufilli. Fol, oppofita, obtufa, fubtus albida. Pedunc, axillar, Politar. Fl. capitati, terni, monandri, fubfeffil. purpur. Sem. oblong. angulata, villofa.

3. hitfuta. B. caul. diffufo, pubefcente: fol. ovatis, repandis. Syft. veg, ed. I4. Jacq. hort, tab. 7.

In Jamaica 24.

Caul. I-fefquiped. plerumque dichotomus. Fol. oppofita, petiolata, craffuufcula, margine pilofo, fubtus albida. Pedunculi fæpe 3-fl. Cor. pu: pur. Stam. 2. Fruct. fulcatus, 5-gon, truncatus .

4. Jcandens. B. caul, erecto, ramis fcandentibus: fol. cordatis, acutis: fl. diandris. Syft. yeg. ed. I4. Jacq. hort. tab. 4 ,

Solanum \&c. Pluk, alm, tab, 226, f. 7.

In. Jamaica 4 .

Caul. frutefcens, 6-ped. ftrictiffmus, lavis, fub. trichotom, Rami alterni. Fol. oppofita, petiolat. obfolete angulata, glabra, utrimq. concoloria. Pedunc. Jaterales. Umbellæ 6-fl. Involuc, 5-phyll. Cor. campanulata, plicata, viridi-flavefcens. Sem. filiform. truncata, apice tuberculata .

S. repens. B. caul. repente. Syft. veg. ed. I4.

In Nubia 24.

Caul. fubped. nodofi, fucculenti. Fol. oppefita, magnitudine inæqualia, majora vix femipull. Iongiora, fubundulata, fuprá læate virencia, veniśs purpurafcentibus picta, fubtus albida, lanuginofa. Variet. omnibus partibus minor.

6. anguftifolia. B. fol. linearibus acutis. Syft. veg. ed. I 4. Habilat......

12. SALICORNIA . Cal, ventriculofus, integer. Cor, o. Sem. 1. Habitus plerumq. aphyllos.

1. herbacea. S. herbacea, patula, articulis apice compreffis, 
emarginato-2 fidis, Syjt. veg. ed. 14. Fl. Dan。 tab. 303. Pallas it. 1. tab. A. f. I. Black. tab. 598. Baft. fubf. 2. tub. 50. Dod. pempt. 82.

In Europre, Virginia litoribus maritimis $\odot$.

Frutex fæe cubito altior, erestus. Articuli cylindrici, apice raffiores. Spica articulata. Fl. terni, adproximati, parvi, lutei.

2. fruticnfa. S. caul. erecto, fruticolo. Syfoveg.ed. 14. Gmel. Sib. 3. tab. t. f. I. ?

In Europe maritinis 1$)$.

Sempervirens, erecta, longeq. ma. a priore videtur diverfa.

3. virginica. S. betbacea, ere $\mathrm{Aa}$, ramis fimpliciffimis . Syft. veg. ed. 14 .

In Virginia.

Planta viridi-coerulefcenti farina tenui obducta . Rami uppofiti, terminati fp ca longa, articulata. Diftinguenda ab herbacea, quæ etiam in Virginia crefit. In fpecie quadam Virginiana erat valyx fquama ovara, cochleatis inftar concava, erecta. Stam. certe 2. Pilt. fuperum.

4. crabica. S. fol, alternis, vaginalibus, obtufs, binc dehifcentibus. Syjt. veg. ed. 14. Pallaj. it. I. tab. A. f. 3 .

K.li \&c. Morif. hift. 3. 5. 5. tab. 33. f. 7 .

In Arabia $\hbar$.

Facses Tamarifci, vel Anabafeos. Fruticuli ereAi, fubped. creberrimi, alterne ramofi . Spicæ terminales, fub 4, parvulæ, alternæ, torulof .

5. eafpica. S. fruticofa; articulis cylindricis: fpicis filiformibus. Syft. veg.ed. I4. Patl. it, I. tab. A. f. 2. Kali \&cc. Buxb, cent. I. tab. II.

In mari Cafpio Ecc. 古.

Facies e longinquo Tdmaríci. Frutex 2-3 ped. Ramuli tenuiores denfe nafcentes.

6. foliata. S. fol. linearibus, alternis, amplexicauli-decurrentibus. Syja. veg. el, 14, Lin. Suppl.

In Sibiria 5 .

Frutex ramis fimplicibus alternis. Fol. carnofa.

frobilacea.

S. Pall. it. 1. $t a b$. B. f. 1. 2 .

Ad mare $\mathcal{C}$ afpizm $\delta$.

Planta e longinquo confpecta vix ab Ansbafi aphylla diftinguirur. Rad, pafim fobolifera. 
Caul. ad terram proftrati, \& flexuofi, fubped. fruticofi. Surculi erecti, ramofi, nodofi, partim gemmis utrinq. prorumpentibus, partim adultis fpicis enatis. Spica in crucem alternatim oppofitæ, feffiles, cylindricæ, obtufæ; maturitate, vel maceratione, ftrobilorum inftar, fquamatim folvendæ: in harum qualibet fl. fub 20.

foliata. S. Pall. it, 1, tab. C. f. 1. 2.

pallas.

In paludibus Dauurie 5 .

Facies fquallida, \& morbofa: forfan var. S. arabicu. Fruticuli diffuliufuli, fubped. informes, caulibus ramofiffmis. Fol, ita alterne pofira, ut 4-fariam a cauliculis pateant. Surculi adultiores, \& a Gallis non corrupti, omnibus ramis fpicas alternas proferunt. Planta iuniores, \& in ficciore loco natæ vix folia proferunt.

cruciata. S. pedunculor. articulis cruciatis; caulis vero globofis. Forsk. AEg-Arab.

Alexandrie b.

Caul. procumb. fruticofus, teres, brunneus: rami conferti, erecti, arriculati, virides. Articuli inferiores fteriles, minores, fubglobofi, tuberculati fextuplici ordine fquamarum; geniculis pallidis, fquamatis, arctatis : fuperiores floriferi majores, tranfverfe cylindrici: fl. fparfi, nudi ad apicem fquamarum, quæ fucculentæ facile rumpuntur, fi dilatare velis.

perfolidta. S. fol. carnofis, urceolat-orbiculatis, caule perfoliatis. Forsk. $\mathbb{E}_{g}-A r a b$.

In Arnbia.

Erutex diffufus, pedal. Caul, non articulatus. Spica axillar. \& terminales, fefquisoll. teretes, fl. ternatim pofitis, ut in S. europaa. Fol. contigua, in frugiferis orbiculata, verfus peripherian caule perforata, alterna: in innioribus non frugiferis vagina craffa, urceolata; decurrentia.

13. HIPpURiS. Cal. O, Cor. O. Stig. fimpl, Sem. r. Fol. verticillata. Differt ab Equifeto, articulis cum digito compreffis cun ftrepitu diffilientibus. An plante gynardra?

I. yulgaris, H. fol, octonis, fubulatis, Syf, yzg, ed, $24 . \mathrm{Fl}$. Dan, tab. 87 . 
Limnopeuce, Vaill. Aaz. paris. $272 g, t a b .2, f .3$. Polygonum fem. Camy epit. 649 .

In Europe fontibus Ec. 24.

Caul. erectus, I-2 ped. articulatus, albidus. Fol. facie Equifeti fylvatici, obtufiufcula, plana, integerr. glabra, læte viridia .

2. tetrapliylla. H. fol. quiternis, oblongis, obtufis. Syft. veg. ed. $2 / 4$. Lin. fuppl.

In Svecia .

Fol. fpathulat-ovata .

lanceolata. H. fol. lanceolat. inferioribus quaternis, fuperioribus quinis. Retz. Obs, fafs. 3. tab. z.

In Finlandia.

Facies Elatines Alfinaftri.

D I G Y N I A.

14. CORISPERMUM . CAl, O. Pet, 2. Sem. I., ovale, nudum.

1. hyJopifolium . C. fl. lateralibus. Sift. veg. ed. I4.

Rhagoftris \&xe. Buxb. cent, 3. tab. 55 .

Monfpelii Ec. (.).

Caul. palmar. \& ultra, diffufus, villofus, fed non faber. Fol. Graminea, alterna.

2. fquarrofum. C. fpicis lquarrofis Syft. veg. ed. I4.

Rhageftris \&c. Buxb. cent. 3. $2 a b .55,56$.

In Tarturic $\odot$.

Caul. dodrant. angulatus, friatus. Fol. arundinacea, rigida, ftriata, iscana. Sem. duplici aculeo.

i5. CAllitriche. Cal. O. Pet. 2. Caps. 2-4locul. 4-fperm.

I. verna. C. fol. imis linearibus, fuperioribus fubrotundis.

C. fol. fuperioribus ovalibus $\mathrm{f}$. androgynis. Syft. veg. ed. 14. Fl. Dan. tab. 129.

In Europe foffis aquofis $\odot$.

Hæc major eft, etiam pedal. Fol. oppofita, integerrima, vel 2-fida, folitaria, flaccida, glabra, lære virent. Superiora in aqua fuperficie in rofulas congefta. Fl. terminales, albidovirent .

2. autumnalis. C. fol. omnibus linearibus.

C. fol, omnibus linearibus apice 2-fid. $\mathrm{fl}$, hermaphrodit. Syft. veg. ed. 14. Gmel.Sib.3. tab. I. f. 2 .

Lenticula \&c. Loef. pruff. tab. 38.

In Europa folis aquofis (0. 
Fol. pallide virentia; quæ in rofulis paulo las tiora, fed non fubrorunda, ut in priore.

16. BLITUM, Cal.3-fid. Cor, o. Sem. I, calyc-baccato. $\mathrm{Fl}_{\mathrm{f}}$ pl, in glomerem coliguntur. Habitus Chenopodii .

1. capitatum, B. capitellis fpicatis, rerminalibus, $S_{y j} f_{\text {. }}$ veg. ed. 14. Knorr. del, hort. I. tab. E. 3.

Atriplex \&c. Moris. hift. 3. $\int .5 . t a b .32$. f. II. In Helvetia, Rhatia, Iyrolo 8 c. $\odot$.

Caul, pedal. fimplex. Fol. longe petiolat. haftata, femitriloba, quandoque int gra, dentata. Giobuli florales, feffil. coccinei.

2. virgatum, B. capitellis fparfis, lateralibus. Syft.veg. eit. 14. Atriplex \&c. Morif. hift, 3. .. 5. tab. 32. f. 2. In Hifpania, Gallın Narbonenfi Ec. $\odot$

Caul. fubped. ramofi, angulati. Fol. angulata . Globuli maturi rubri. Var. fol. lanceulat. integerrm. B. Chetopodioid. Syft. veg. ed.13. eft var, monftrofa huius.

17. MNIARUM . Cal, 4-part. fuperus, Cor, o. Sem. I.

I. biflorum, M. Syft. veg. ed. I 4, Lin. Suppl. Forft. gen. In nova Zeelandia.

Facies Minuartiæ. Planta dichotoma, glaberrima, undique veftira fol, adproximatis, connatis, acerofis. Fl. terminales, bini, fubfeffil. fol. fere breviores.

18. CINNA. Calyc, gluma 2-valv, I-fl. Cor, gluma 2-valv, Sem. I, 3. arundinacea. C. Sylt. veg. ed. I4.

In Canada.

Gramen magnitudine Avenæ, Culmi plurimi, glabri. Fol. lasiufcua, glab a, margine fcabra. Paniculı oblonga, attenuata, fecunda, compreffuícula.

\section{NOVA G E N R A}

Q UALEA.

Cal. Periant. I-phyll, , profunde 4-partitum, lacin. ovaris, concavis, coriaceis, inæqualibus, lateralibus ma:

Cor, 2-pet. Petalis ungue cal, fundo infertis, 
fuperiore lato, fubrotundo, erecto, emarginato, extus albo, intus carneo, bafi definente in nectarium corniculatum, obtufum, intra cal. lacinias fuperiores prominens; inferiore lureo, verfus unguem albo, longiore, ampliore, expanfo, reflexo.

Stam. Filam. 1. incurvam, bafi germinis infertum: anth, oblonga, incurva, 2 -locul.

Pift. Germ, orbiculatum. Stylus longus, incurvus: Stigma obtufum.

Sem. Plurima, in pulpa nidulantia .

I. Rofea, Q. fl. amplis, carneis.

Aub. Guian, tab. I.

In Caribais $\hbar$.

Arb. 6o-pedal. in apice rami pl. nodofi, latè, \& undique fparfi: ramuli oppofiti. Fol. oppofita, ovata, acuta, obtufa, rigida, glabra, pallide virentia, nervo longitudinali fubtus prominente, \& nervis lateralibus innumeris paralellis infignita. Stipulæ binæ, laterales ad bdfin petioli, deciduæ. Fl, terminales, paniculati. Bracteæ binæ, exiguæ, deciduæ ad bafin ramulorum, Fl, expanti odorem fuavem fpirant ,

3. Corulea, Q, fl. parvis

Aub, Guian, tab, 2.

In Caribais $\mathrm{b}$.

Arb. 60-80, pedal, rami, \& ramuli ut in priore. Fol, oppofita, vel fuboppofita, petioldta, acuta, obtufa, integerrima, glabra, fubviridia, nervo longitudinali fubtus prominente, \& nervulis paralellis, fimplicibus, lateralibus infignita. Stipula binæ, laterales ad petiolorum bafin, deciduæ. Fl, terminales, paniculati . Cal. intus villofus, cinereus, Pet. duo oppofita; fuper. erectum, fubrotundum, emarginatum, extus cinereum, intus fubcoruleum; infer. majus, latius, \& profundius emarginstum, reflexum, violaceum, verfus unguem lureum, nigris maculis notatum. 


\section{L A S S IS II. \\ D I A N D I A.}

MON OGYNIA.

* Fl. inferi, monupetali, regulares.

23. Olen. Cor. 4-fid, tubo brevi, lacin, fubovatis, Styl. 2-fid. Drupa I-fperm.

24. Chionanthus. Cor, 4-fid. Jacir. longiffim, Drupæ nucleus Ariatus .

22. Phylitrea. Cal. 4-dent. Cor. rotata, 4-fid. Bacca I-fperm. 21. Liguftrum. Cor. infundibulifor. 4-fid. Bacca 4-fperm.

25. Syringa. Cor. infundibulif. 4-fid, laciniis linearibus. Capf. 2-locul, 2-valv. 2-fperm.

27. Eranthemum, Cor. 5-fid. tubs filiform. lacin. obovatis, planis. Anth. extra tubum. Stig. finpl. Gifp.

20. Iafminum. Cul. tubulofus, 5-dent. Cor. infundibulifor. 5-fid. Anth. extra tubum. Bucca 2-cocca. Sem. arillata.

19. Nyctanthes. Cal. 8-10-12-fid. Cor. 8-fid. Bacca 2-cocca. ** Fl. inferi, monopet. irregulares. Fruct. capfular.

30. Paderota. Cal, s-part. Cor. 4-fid. Cap. 2-locul.

29. Veronica . Cal, 4-fid. Cor, rotate, 4-par. lacinia infina anguftiore. Caps. 2-locul. Sem, 2.

33. Gratiola. Cal. 7-phyll, foliol. 2. exterioribus patulis. Cor. tubulofa , 2-lab. galea emarginata; barba 3 -fid. Stam. 2 tantum fertilia. Caps. 2-valv. 2-locul. polyfper.

34. Schwenkia, Cor. fubægual, fauce plicata, glandulofa. Stam. 3. fterilia, Capf, 2-locul, polylper.

31. Jufticia. Cor. ringens. Stam. anthera ungue fingulari . Caps.2-locul, ungue elantico diffiliens.

32. Dianthera. Differt a Jufticia, quod ftamen fingulum duabus anth. alternis fit praditum.

35. Calceolaria. Cal. 4-part. xqualis. Cor. ringens, inflata. Caps. 2-lacul. 4-valv.

36. Pinguicula. Cal. 2-lab. 5-fid. Cor. tubulofo-ventricofa, calcarata, patens : lab. fuper. 2-fid. infer. 3-fid. 
3-fid. Stam. bifurca. Capf, 2-valr. I-locular. polyfper.

37. Utricularie, Cal, 2-phyll, equal. Cor, ringens, calcarata. Cafp. 2-valvis, 1-locul. polyfper.

38. Wulf nia. Cor. ringens, calcarata, femihians, ad faucem barbata.

\section{* Bigronia Catalpa.}

*** Fl. inferi, monopet. irregular. Frä̌us gymnofpermi .

39. Verbena. Cal lacinia fuprema breviore. Cor. infundibulifor. fubæqual. curva. Stam. 2-4, Sem. 2-4. nuda.

40. Iycopus. Cor. fubæqual. 4-fid. lacinia unica emarginata. Stam. diftantia. Sem. 4, retufa.

4r. Amethyftea. Cal. fubcampanulat, Cor, 5-fid. fubrequal. lacin. intima patentiore, concava.

43. Ziziphorn.Cal. filiform. Cor. ringens, galea reflexa, integra. Sem. 4 .

44. Monarda. Cor. ringens, galea lineari, obvolvente genitalia .

45. Rofmarinus, Anth. arctifime coniuncta, ut unicam antheram componere videantur filamentis liberis, Cor, ringeas: lab. fuper. longum, reflexum, emarginatum: infer. 3-fid. lacinia media maiore, oblonga, in ambitu crendta, profunde emarginata, bafi angulta; lacinis lateralibus ovatis, obtulis, marginibus reflexis. Galea a lab. inferiore recta divergit .

46. Salvia Cor. ringens. Stam. bifurcata, pedicello nimirum, five filamento cor. inferto tranfverfe imponitur filamentum antheriferum.

42. Cunila. Cor. ringens; galea erecta, plana. Filam. 4. duo caftrata. Sem. 4.

47. Collinfonia. Cor. fubringens; lab. inferiore capillari, multifido. Serm. I. **** $\mathrm{Fl}$. inferi, tetrapetali.

50. Thouinia. Cal. 4-part. Cor. infera, 4-petala. Anth. feffiles. $* * * * \mathrm{Fl}$. inferi, pentapetali.

26. Dialium. Cal. o. Cor. 5-petal. Stam. ad latus fuperius. $* * * * * * * F l$. Superi.

48. Morina. Cal. floris 2-fid. cal. fructus dentato-ariftatus. Sem. I, fub cal. floris.

28. Circa, Cal, 2-phyll. fuperus. Petal. 2 , obcordata . Fruct. 2-locul. 2-fperm.

49. Globba. Cal, fuperus, 3-fid. Cor. æequal. 3-fida. Caps. 3-locul. Sem, plurima.

$$
\text { Tom, } I \text {. }
$$


3I. Anciftrum, Cal. 4-ariftatus, ariftis terminatis glochidibus cruciatis. Cor, 4-fid. Stigm. penicillacum .

* Valeriana cornucopia.

Boerharvia diandru; fcandens : ereça .

D I G Y N I A.

52. Antho-xanthum. Calyc, gluma 2-valv. I-fl. Cor. gluma 2-valv. acuminata. Sem. I. Avence proximum eft, fed duabus tantum ftaminibus a reliquis Graminum generibus differt.

$$
T R \perp G \text { Y N I A. }
$$

53. Piper, Cal. o. Cor, o. Bacca I-fperma.

\section{$\mathrm{MONOG} \mathrm{Y} \mathrm{N} \mathrm{I} \mathrm{A.}$}

19. NYCTAN- UAl, 8-10-12 fid, Cor, 8-fida . Peric, dis THES. coscum.

8. arbor trifis, N. caule 4-gono: fol, ovatis, acuminatis: pericarpiis membranaceis, compreffis. Syft. veg. ed. 14. Mont. Zann. tab. I5.

Mania-pumeran. Hort. mal. I. tab. 2 I.

Scabrita fcabra, Lin, monente Vahl.

In Indie. ந.

Arbor grantis, denfis, \& opacis frondibus late fparfis, diametro unius brachii, Rami noduIof, cortice fpadiceo. Fol. oppofita, breviter petiolata, craffa, afpera, e viridi fufca, nitida, fubrus diluriora, Pedunc. ex fingula ala ramofi. Fl, in fingulis pedicellis 5 , albi , odore mellis. Fruct, rotundo-plani, virides, ficei capfulares.

2. Sambace N. fol. inferioribus cordatis, obtufis; fuperioribus ovatis, acutis. Syft. yeg. ed. 14 .

Jafninum \&ce, Burm. Zeyl. tab. 58. f. 2. Till. pis. tab. 31. Clus, cur. tab.3.

Flos manoræ. Rumph. Amb. 5, tab. 30.

In Indiu. $\hbar$.

Caul. fruticofus. Fol. alterna, vel oppofita, fapius terna, breviter petiolata. Fl, corymbofi. Petala alba, odora. Vor. fl. pleno.

3. undulate, N. fol. ovatis, acuminatis, undulatis: ramis te. retibus. Syft. veg*ed. I4. 


\section{DIANDKIA MONOGYNIA.}

Tfieregam-mulla. Hort. mal. 6. $2 a b$. 55 .

In Malabaria. $\$$.

Caul, orgyalis: rami late fparfi. Fol. oppolita, e viridi-nitentia. Fl. terni-quinati, Petal. 6-7-8. albida, odora.

4. hirfutn. N. petiolis, pedunculifque villofis, Syf.veg. 6d. I4. Kava-pon, Hurt, mal. 4. tab. 48 ,

In India. \$.

Arb. procera: ramuli atro-purp. Fol, decuffatim oppofita, petiolis rufis, obl-rotunda, acumi nara, craffa, nitida, fupra atro-viridia, fubtus fubviridia. Pedunc. rufi. Fl, congelti, candidi, odore Tuberofæ. Fructus virides.

5. anguftifolia. N. fol. lauceolatis, ovatifq. obrufis. Syft. veg. ed. 14 .

Katu-pirfiequam mulla, Hort. mal. 6, tab. 33.

In Malabaria arenofis. $\hbar$.

Surculi fufcefientes. Fol. obfcuro virore niten. ria. Pet. 7-11. longa, acumin. eæreris fpeciebus anguftiora, candida, ore rufefcente, odora.

6. elengata. N, fol. cordatis, lanceol. acutis, elongatis, minoribufq. ramis teretibus. Syft, yeg. ed. 14. Lin. Suppl.

Berg. AZ. Angl, an. 1772, tab, II.

In India Orientali. $\hbar$.

Fol. infer. cordato - ovata . Fl. terminales, $5-6$. fubumbellati. Cal. minimus, lacin. fubulatis, pilofis. Cor. tubus fuperne incraffarus.

7. glauca, N. glauca: caule tereti: fol. lanceol. acutis, trinerviis: pedunculis 3-fidis . Syfz veg. ed. 14 . Lin. Suppl, Ad cap. b. Spei . 万.

Frutex ramis oppofitis. Fol. oppofita, petiolata. Fl. Jafinini Officin, maiores.

triflora.

N. fol, alternis ; ramulorum oppofitis, ovatis : pedunculis terminalibus ternis: pedicellis $\mathbf{I}-\mathrm{fl}$, Burm. Ind. tab. 2.

In Inva. 方.

Caul. fruticofus, teres, glaber, samis oppofitis, divergentibus. Fol, fubpetiol. lanceol-ovata, integerrima, glabra, fubcus fufca. Cal. 6-fid. fegmentis breviff. linwribus. Cor, longitudine pedicellorum. 
multiflora. N. pedunc, terminalibus multifloris: fol, ovatis . Burm. Ind, tab. 3. f. I.

In China, \& Malabaria b.

Caul. erectus, fruticofus, ramofus, teres, pubefcens. Fol. oppofita, petiolata, integerrima, glabra. Fl. capitati.

acuminata. N. fol. lanceol-acuminatis: pedunc. bigeminis, 2-fl. Burm. Ind. \& Zeyl. tab. 59.

20. JASMINUM . Cal tubulofus, s-dent. Cor, infundibulifor. tubulofa, 5-fida. Antheræ intra tubum. Bacca dicocca. Sem. arillata.

I. officinale. J. fol, oppofitis; foliolis diftinctis. Syft. veg. ed. I4. Black. tab. 13. Du Hamel. 1, tab. 122. Lob. ic. Io6.

In Inaia; nunc Europa planta indigera. 5 .

Caul. 6-pedal infirmus. Fol. fubfeptena, ovatoatgute la ceol.; impari ma. lanceol. Cor. alba, odora .

3. grandiflorum. J. fol. oppofitis, pinnatis; foliolis extimis confluentibus. $\delta y /$. veg. ed. 14. Merian. Surin. $t a b .46$.

In Malabaria $\hbar$.

Simile priori, fed caul, rectus, nec fcandens. Foliola cauli propicra, magis ovata, nec minora; extina 3. confluentia ex petiolo dilatato. Cor. ma. fubrus rubra .

3. azoricum. J. fol. oppofitis, ternatis. Syft. veg.ed. 14. Comm. hort. 1. tab. 82 .

J. fylv, Burm. Zeyl, tab. 58. f. I.

J. alburi, ec. Pluk. Alm. tab. 393. f. I. phye. 1ab. 423 . f. 6.

In India $\hbar$.

Ful, longe petiol. obl-acuminata, obfcuro virore nitentia, I. Offic. productiora, \& latiora. Fl. terminales longe pedunculati, albi, odor Lilii convallium.

Var. foliolo impari (meiore) cordato .

4. fruticans. J. fol. alternis, ternatis, fimplic bufq. ramis angulatis. Syft. veg. ed. 14. Hort. Angl. tab. 6. Trifolium fruricans, Dod. pempt.

In Oriente, \& Europa auffrali. $\hbar$.

Virgulæ 2 cubital. \& ultra. Lineæ 2, elevata ad bafin periolorum decurrunt in caulem. Fol. impar maius. Cal. profunde 5 -fidus . Cor. lutea. 
9. humile J. fol. alternis, acutiufculis, ternatis, pinnatifq. ramis anyul tis Syft. veg. ed. I4. Knorr. del. Hort. 1, tab. 1. Besl. eyft. aft. tab. 40. f. 2.

Habiut... 万.

Frutex humilis . Fol. lateralia ovata, impari duplo ma. ovato-dcumin. Cal, vix s-fidus . Cor. lutea.

A. odoratifinum. J. fol. alternis, obtufis, ternatis, pirna'ifq. ramis teretibus.' Sylt, veg. ed. I4. Barr. zc. 62.

In India $\mathrm{D}$.

Frutex ramis rubicundis. Foliola ovata, vix acuminara, glabrd. Fl. fl vi, odori.

ablongum. J. fol. opp fuis, fimplicibus; pedunulis alternis, axillaribus, I-fl. Burm. Ind. tab. 3. f. 2.

In Iava b.

Rami finpl. teretes. Fol. petiolata, ovalia cum acumine, integerrims, glabra. Fl.lutei, mia. quan in $\mathbf{J}$. odoratifimo.

21. LIGUSTRUM . Cor. infundibulifor, 4-fida . Bacca 4fperma.

3. vulgare. L: fol. lanceolatis, acutis; paniculæ pedicellis oppofitis. Syft. veg. ed. I4. Matth.

a. fol. deciduis .

b. italicum, fol. fempervirentibus .

Black 2. $t a b$, I4.2.

In Europiz collibis ad fepes $\hbar$.

Arbufcula 6-pedalis. Fol. breviter petiol. ovata, crafla, nitida, fature virentia. Racemi con ci, Fl. albi, graveolentes. Bacca ovata, nigra, pulpofa. Var.fol.ternis; auratis; fruzu albo.

2. latifulium . L. fol. ovatis, acuminatis: panicula decompofita, trichotoma. Syft. veg. ed. I4.

Thumb. Jap. tab. r.

In Japonia $\hbar$.

Frutex fefquiorgyal. Rami oppoliti, teretiufcuii, erecto-patentes, rugofi, cinerei. Ramuli virgati. Fol. fefquipollicem longa, pollic. lata, oppofita, petiolata, integerr. patenti-erecta, fupra viridia, fulco medio exarata, fubtus pallida, nervo medio donata, glabra. Perioli unguiculares. Fl. terminales, paniculati. Bratteæ fub fingula dichotomia binæ. Cor. laciniæe ovaræ, reflexæ. Bäcca magnitudine Pifí, ovata, glabra. 
22. PHILlYREA. Cal, 4-dent. Cor, rotata , 4-fid. Baces I-fperm.

I. media. P. fol. ovato-lane. fubintegerrimis. Syft, veg, ed. 14. Matth. P. III. Cluf, hift. 52.

In Europe collibus euftralibus b.

4. anguffifolie. P. fol. lineari-lanceol. integerrimis. Syft, veg. ed. I4. P. IV., \& V. Cluf. hift.

In Itatia, \& Hifpania b.

Var. fol. linearibus.

3. latifolia. P. fol ovato-cordatis, ferratis. Syft, veg.ed. I4. Cluf. hift, sI,

In Europa auftrali 5 .

23. OLEA - Cor. 4-fida, tubo brevi, lacin. fubovatis. Drups I-fperma. Stylus 2-fid.

๘. europea . O. fol. lanceolatis. Syjt. veg. ed. 14. Blask. tab. 199.

Olivo Matth.

b. Sylveftris. Black, tab, 213.

In Europa Auftrali $\$$.

Arb. fempervirens. Fol. oppofita, integerr. fupre viridia, fubtus albida. Fl. fubalbidi.

a. eapenfis. O. fol. ovatis. Syft. veg. ed, I4.

Iiguftrum \&c. Dill. Elth. tab. 170. f. 194.

Ad cap. b. Spei $\hbar$.

Arbufcula parum ramofa, cortice ex fufco-nigricante, fublirfuto, punctis cinereis variegato. Fol. oppofita, petiolara, 2-pol'icar. craffa, fubtus pallidiora. Cymæ trichotomæ. Cor. alba, odore, Liguftri .

3. americana . O. fol. lanceolato-ellipticis .

Syft. veg. ed. 14. Caztef. I. tab. 6I。

In Carulina $\mathrm{b}$.

Arb. 16-pedal. Fol. oppofita, petiolata, integerr. nitida, fature viridia, fempervirentia. Racemi axill. breves, brachiati, pedicellis oppofitis . Cor. alba, laciniis revolutis. Drupa fpeciofa, globofa, lævis, violacea. Nux obovara, fubftriata, bafi perforata.

4. fragrans. 0. fol. lanceol. ferratis: pedunculis lateralibus aggregatis, I-fl. Syft. veg. ed. I4. Thumb. Jap. tab. 2 .

Mokfei Kamp. enr. fafe. V. p. 844.

In Japonia $\mathbf{b}$.

Arb. vafta. Rami, \& ramuli trichotomi, oblodete 4 -goiri, glabri. Fol, digitalia, decuffata, 
petiolata, margine fubreflexo, paralello-nervofa, reticulata, glabra, fupra fature viridia, fubrus pallidiora; in ramulis frequentia. Petioli femiunguicul. Fl. in ranulis umbellatoaggregati, 6-8. pedunculati. Cor. flavo-alba.

24. CHIONANTHUS . Cor. 4-fida, lacin. longiffmis. Drupa nucleus ftriatus.

x. virginica. C. pedunc. 3-fidis, 3-fl.

Syft, veg. ed. I4.

Amelanchier \&c. Catef. 1. tab. 68.

In America feptentrionali $\$$.

Frutex 6-In, pedal. Fol. Limonio fimilia, dilute viridia. Fl. racemofi, pedunculati . Cor. alba. Drupa purpurafcens. Var. cor. 4-5-6. fida, \& faminibus 2.

3. zeylanica. C. pedunc. paniculatis, multifloris. Syjt. veg. ed.14. Arbufula \&c. Plak. alm. tab. 24r. f. 4 . In Zeylona $\hbar$.

Arb. fol. oppofitis, fubpetiol. obverfe ovatis, integerrimis, glabris. Panicula axillar. pedunculis fubdivifis. F1, albi .

Ad hoc genus fpectat Mayaped guianenfis. Aubl. Guian. tab. 3 r.

25. SYRINGA. C. infundibulif. 4-fid. Capf. 2-valv. 2-locul. 2-fperma .

1. sulgeris. S. fol. ovato-cordatis, integris. Syft, veg. ed. I4. Krorr. del. Hort, 2. tab. S. II.

Lilac. Duham, arb, 2, tub. 138.

In Perjia, \& collibus Italicis \&c. b.

Arb. Io-ped. Fol, oppofita, longe petiolat. late virent. nitida, glabra. Fl. thyrfoidei. Cor. alba, purpuro-ccerul. vel fature purpur.

2. perfice. S. fol. lanceolatis, integris. Syft. veg, ed. 14, Mill. dia. tab. 164, f. I. Munting. tab. 57. Pluk. alm. tib. 227 . f. 8.

b. S. laciniata. An Jpec. diver $\int a$ ?

In Perra D.

Frutex 3-4. cubital. cortice fulon-rubente. Fl. laxe racemoli, minores quam in priore, dilute purpurafc. odore fuaviore.

3. fufpenfa. S. fol, ovatis, ferratis, teraatifque. Syf. veg. ed. 14. Thumb, Jap. tab. 3 .

In Japonia D.

Caul. fruticofus, flexuofus, adf'cendens, dein iependers, parum kimafus, fub 4 -gon, sw 
berculis parvis, fparfis muricatus. Rami oppofiti, remoti, divaricati. Fol. e gemma plura, unguicular. petiolata; prima fimpliciter ovata, acuta, tenuia, glabra, fub florefcentia erumpentia, dein ternata. Petioli longitudine fol. $\mathrm{Fl}$. e gemmis oppofitis, $\mathbf{1}-\mathbf{2}-\mathbf{3}$., pedunculati, flavi, peduncul. unguicularibus rugofis.

Differt a congeneribus calyc. profundius incifo; cor. campanifor. nee infundibulif.

26. DIALIUM. Cor, s-pet. Cal. o. Stam, ad latus fuperius. 1. indum, Dialium. Syft, veg. ed. 14.

Cortex \&c., Rumph, amb. 3, tab, 137. Sed mei fol. non Serrata.

In India b.

Arb. Fol. alterna, pinnata, foliolis 7 . ovatoobl. acuminatis, breviter petiolac. integerrimis, lævibus, palmaribus. Fl. paniculati, nutantes, rubelli.

27. ERANTHEMUM. Cor. 5-fida, tubo filiformi. Anth. extra tubum. Stigma fimplex .

x. capenfe. E. fol. lanceolato-ovatis, petiolatis. Syft. veg. ed. I4.

In Ethiopia.

Habitus Chironia. Caulic, articulati. Fol. fape oppofita, craffiufcula, glauca. Fl. terminales, fubumbellati, punicei .

3. enguftifolium. E. fol. linearibus, remotis, patulis. Syft. veg. ed. 14 .

Thymelæa \&c. Burm. Afr, $t a b, 47$. f. 3. Pluck. mant. $t a b, 445$. f, 6 .

In Athiopia b.

Frutex erectus, ramofus. Fol. infer. conferta, feffilia, glabra, viridia. Racemi terminal. fimpl. erecti, longiff, purpurafc, Fl. minimi . Cor. tubo longiff. filiformi; limbo parvo, 5-part. obtufo.

3. parvifolium. E. fol, ovato-linearibus imbricatis. Syft. veg. ed. 14.

Frutex \&c. Comm. Hort. 2, tab. 60.

Ad Cap. b. Spei \$.

Frutex. Fol, brevia, feffilia, carinata, glabra . Spica cylindric $x$, bract. ovatis, pallidis. Cor. fubregul. alba, lacin. obtufis, planis, una paulo latiore, 2-fida.

4. salfoloides. E, frutisofum, fol, dinearibus, teretiufculis, 
carnofis, glaberrimis: racemis axillaribus, calycibufque pubefcentibus; tubo recurvo. Syft. veg. ed. 14. Lin. Suppl.

In Barrancas circa oppidum s. Crux.

Frutex fol. fimillimus Salfolæ.

28. CIRCEA. Cal. 2-phyll. fuperus. Cor. dipetala. Fructus bilocul. 2-fpermus.

I. Lutetiana. C. caule erecto: fol. ovatis: racemis pl. Syft. veg.ed.14. Fl. Dan. 256. Kniph, orig. tab, 22. L.ob. ic, 266 .

In nemoribus 24.

Caul. cubital, ramofus. Fol, longe petiol. fubferrata, opaca, villofula, tenera, fature virentia, venofa, glabra. Rac mi laxi, nudi; terminalis longior. Fi. albido-rubentes. Fruct. ovati, villis uncinatis hirti.

b. C. Canadenfis, latifol. fl. albo. Tourn, inft.

2. ulpina. C. caul, proftrato: foliis cordatis (dentatis, glabris): racemo unico. Syft. veg. ed. I4. Fl. D n. tab. 210.

C. minima . Col. ecphr. 2. tab. 80.

In montibus 24.

Caul. triental-6. unc. Fol. fordide virentia, fufco tincia, venofa. Cal, rubellus. Cor, albida .

29. VERONICA. Cal. 4-fid. Cor. rotata, limbo 4-part. lacin. infima anguftiore. Capf. 2-locul. Sem. 2.

\section{sifiticar * Spicata.}

sibirica. V.fpicis terminalibus: fol.verticillatis, fubfenis: caul. fubhirto. Syft. veg. ed. I4. Amm, rutk. זab. 4 .

In Danria 24.

Caul. 4-pedal. Fol. V. Virginica latiora. Pedunc. terminal, folitarii ; laterales foliolis 2 . oppofitis, ovalibus. Cal. 5-fid. Cor. corulea .

In hortos translate duplo ma, evadit.

2, virginica. V. fpicis terminslibus: fol. ternis-quaternis-quinifq. Syjt. veg. ed. 24. Pluk alm, tab. 70. f. 2.

In Virginta 24.

Altitudo humana. Fol. breviter petiolata, ovata, longe acuminata, ferrata. Spica terminalis pedalis, axillares breviores. Cor. limbo acuto, lacinia infima reflexa.

3. Spuria. V. V. ficis terminalibus : fol (plerumq) ternis, lanceolaris, æqualiter ferratis. Syjt. veg. ed. I4.

Gmel.' it. ג. $t a b .39$. 
V. mas \&c. Barr. ic. 691.

In Europa auftrali 4.

Caul. pedal. \& ultra, inferne, \& ad genicula coloratus, filtulofus, fuperne pubefcens. Fol. petiolata, pendula, glabra, fupra concava, canaliculata, viridia, fubtus nervofa, dilutiora. Spica pubefcens. Cor. cœruleo-purpur.

$V_{\text {ar. fol. oppofitis, vel fummis alternis. }}$

4. maritima. V. fpicis terminalibus: fol. ternis, inæqualiter ferratis. Syft, veg. ed. I4. Fl. Dan. 374. Knorr. del. hort. 2, tab. V.

In maritimis Europe macris apricis 24.

Caul. erectus, fefquiped. Fol. oppofita, ovatoobl., accedente fæpe impari, infer. variz magnttudinis; fuper. obtufiora. Spicæ 5-6. Jaxio. res. Cor. cœrul.

5. longifolia. V. fpicis terminalibus: fol. oppofitis, lanceol, acuminat. ferratis. Syft. veg. ed. I4. Sabb. H. rom. 2. tab. 48. Clus. ic. 346 . bona.

In Auftria, Svecia ec. 4.

Caul. pedal. \& ultra, apice plerumq. ramofi. Fol. petiolala, femiamplexicaul. craffa, trifte yiridia, fubtus quandoq. purpurafc. Spicæ longæ, denfæ. Cor. violac.

Var. fol. latioribus \& anguftioribus.

6. incana. V. f picis terminalibus: caul, erecto, tomentofo: fol. obtufis, crenatis; (inferioribus plerumq.) oppofitis, Syft. veg. ed. I4.

In Ucrania, Samara 4.

Planta incana. Caul. fuitham. \& ultra. Fol. oblonga, infer. petiolata, crenata, fuper. feffilia. Cor, cœrul. vel alba .

7. Spicata, V. fpica terminali: caule adfcendente, fimpliciffimo: fol, oppofitis, obtufis, crenatis. Syjt. veg. ed. 14. Fl. Dan. tab. 52. Vaill. par.tab. 33. f. 4. Eph. n. cur. Cent. 5-6. tab. II.

In Europe campis 4.

Similis $V$. longifolia. Mire ludit. Caul, pedal. lanuginofus. Fol. fubhirfuta, dura, ficca, firma; fuper. acutiora, ima ovata. Spicalonga. Cal. hirfutus . Cor. cœrul-alba-carnea .

8. hybrida. V. fpicis terminalibus: caule adfcendente: fol. oppofitis, obtufe ferratis, fcabris. Syft. veg. ed. 14.

V. fpicata \&c, Raii. Angl, 3. teb, II, f, I. In Europa rarius 4. 
Caul, vix pedal, fimpl. Fol. ovalia, obtufiufcula, pubefcentia, utrimg. viridia, ferraturis groffis, obtufis , Petioli margine dilatato. Spica terminalis, oblonga.

9. pinnate, V. fpica terminali : fol. linearibus, dentato-pinnatis. Syft, yeg. ed. I4. ACt, Petrop. 1770. tab. 29. f. 1 .

In Sibiria 24 .

Caul. palmar. diffufi. Fol. oppofita, confertiufc. glabra, dentibus utrinq. fapius 3. linearibus elongatis. Cal. aqualis. Cor. dilute cœrul. Caps. ovalis .

In Sibiria fi. confertiffimi.

10. offcinalis. V. ipicis lateralibus pedunculatis: caul. procumbente : fol, oppofitis. Sy/t. veg. ed. I4. Fl. Dam, tibb, 248. Ludvvig. ect. tab. 100. Knorr. del. hort. 2. tab. V. I. Black. tab. 143.

b. V. repens \&ac, Altien. Spec. 1. tab. 4. f. 3. Fl. Ped. tub. 4. f. 3.

V. mas \&c. Pluk. pisy:. 223. f. I.

In Eutopa fylveftribus fierilibus 24.

Caul. cefpitofi, duri, villofi. Fol. refii. ovata, ferrata, ad bafin fape integra, hirfuta. Racemi longe pedunculati, denfi, inferne nudi. Foliola cal. æequalia. Cur. pallide cœiulea, lineata.

** Corymbofo-racemolee.

11. aphylla. V. corymbo terminali : fcapo (fæe) nudo. Syjt. veg. ed. 14.

V. alpina \&c. Bocc. mus, 2. tab. 1. 9.

V. parva \&c. Seg. Ver. tab. 3. f. 2.

In alpitius Europa Auftralis 4 .

Caul. radicans, villofus. Fol. 4-5. ovata, fubcrenata, villofula, mollia. Racemus fub 7 - $\mathrm{fl}$. Cor, cœrulea . Var. caul. fuliofo.

12. kamtchatica. V. hirta ; racemo 3-fl. elongato; laterali aphyllo: fol. ovaris, feu oblongis, ferratis: pilis articulatis. Syft. veg. ed. I4. Lin. Suppl. In Kamtfchatka.

Similis priori, fed fol. ma. \& ferrata. Singularis pilis articulatis, ut Confervæ. Caul. procumb. elongati.

33. bellidioides. V. corymbo terminali; caule adfcendente, 2 phyllo: fol. (plerumq.) obtulis, crenatis : cal. hirfutis, Syft, reg. ed, 14. 
V. caule Scc. Hall. helv, tub. 15. f. I.

In. Pyrenais, \& alpibus. Helvetice 24.

Differt a $V$. alpina, cui fmilis, habitu duriore; fol. conlinis paucis; racemo congefto.

Caul. radicans, inde erectus, dodrant. fimplex, lanuginos. Fol. ad terram congefta; caulina I-3. iuga, dura, fcabra, hirfuta, eiidm acuminata. Raceni 6-7-12-fl. Cal. hirfutifs. Cor. coerul.

14. fruticulofa. V. corymbo terminali: caul. fruticul. fol. lanceol. obrufurfculis. Syft. veg. ed. 14. Fl. Dath 342 ,

V. alpina \&c. Pluk. phyt. teb. 232. f. 5.

In alpibus Heivetice, Aufria, Pyrenais. 24.

Facies V. ferpillifoliz, Caul. dodrant. ad terram ramofi, fubhirfuti, inferne procumb. perennantes, fuperne erecti, annotini. Fol.feffilia, plana, ferpillacea, fubcrenata, fuperne ma. Gemma caulinæ. Cal, fub 4 fid. glaber, fub. pubefcens. Cor. magna, alba, ftriis fanguineis, nee ut in V. alpina violac, Capfula magua. Var. fatura kumiliore, multicauli, \& fol. rutundioribus.

35. alpina. V. corymbo terminali: fol. oppofitis: cal. hifpidis, Syft, veg. ed. I4. Fl. Dan. tab. 16.

V. caule \&c. Fl. Lapp. tab.9. f. 4. Hall. Helv. tab. I5. f. 2.

In alpibus Europe 24.

Caul, humilis, triental. frutefcens, fimpl. fubhirfutus. Fol, ovato-rotunda, ferrulata, glabra. Spica brevis, 8-10-fl. Cor. obfcure carulea, vel alba. Var.fol. ovatis, integerrimis; calyc. lavi.

I6. Saxatilis. V. corymbo terminali : fol. oppofitis, glabritsfculis: pedunculis fol. floralia fuperantibus. Syft. veg. ed. 14 Lin. fuppl.

V. fruticans, Cluf. hift. r. p. 347.

In Alpibus 24.

Caul. diffufi, ramofi. Fol. ovata, integerr. plana. Cal. obtufus. Cor, maxima, coerul.

17. ferpyllifolia. V. racemo terminali fubfpicato: fol. ovatis, crenatis, glabris . Syfz. veg. ed. 14. Fl. Dan. 492.

In Europa, \& Amer. Septentr. ad vias, agros 24. Caul. pl. palmar. ad bafin repentes, dein erecti, ex viridi-albentes. Fol, ima oppofita, funma 
alterna. Fl. exigui. Cor, alba, lineis cœrul. picta, fed imuin fegmentum immaculatum. Var. habitu altiore; fol. ma. rotundis; fl. parvo, fature currul.

38. Beccabunga. V. tacemis lateralibus : caul, repente: fol. ovatis, planis, Syft, veg, ed. 14. Fl. Dan, tab. 51I. Ludw. ea. tab. 30. Sub. H. Rom. II. tab. 50. Black, tab. 48.

In Eurepa folfis.

Planta fucculenta. Fol. breviter dentata, nitida, glabra. Cor. fature corul. ad bafin fegmenti 2. lineola alba. Differt a feq. fol. ovatis, fo. lidioribus: fl. ma. fature corul.

I9. anagallis. V. racemis lateralibus: fol. lanceol. circumferratis: caul. erecto ( foliofo, \& florifero ). Syft. veg. ed. I4.

In Europe fofis 24.

Caulis fluitans. Fol. bafi latiufcula caulem amplexante, glabra, \& tenera. Racemi multi. Fl. longe peduncul. Cor. exigua, carnea venis coccineis, vel alba.

20. foutellata . V. racemis lareralibus, alternis; pedicellis pendulis: fol. linearibus. Syft. veg. ed. 34. Fl. Dan. tab. 209.

In Europe inundatis 4.

Caul, procumb. radicans, dein erectus, angulatus. Fol. Graminea, rariter ferrata. Pedunc. longi, ramofi. Racemi capillares, laxi, divaricati, paucifl. Cor. fegmentis $\mathrm{m}$. rofeis lineis picta. Capf. latior. Var. fol. ovat-lanceol.

2I. Teucrium. $V$. racemis lateralibus longiffimis: fol. ovatis, obtufiufculis, rugofis, dentatis : caulib. (fæpe) procumbentibus. Syft. veg. ed. 14.

Chamædrys \&rc. Fuchj. 871.

Teucrio II. Matth.

In Germania, Helvetia 4.

Caul. pedal. ramofi, rubentes. Fol. brevia, ferfilia, vel amplexicaulia, firma, dura, niticla, fuper. anguftiora. Ex fummis alis pedunc. longi. Racemi denfi, Aricti, fubfpicati; Cor. cœruleo-violacea, fegmento fuperiore ma: $V a r$. fl. pleno.

22. pilofa, V. racemis fubfpicatis: fol, ovatis obtufis, plicatis: caul, proftrato, pilofo. Syft, veg.ed, 14 * Bauh. kift. 3. p. 286 . 
Teucrium 2. Cluf. f. 5.

In Auftria. 24.

Caul. decumbent. apice adicendentes, ramofift. Fol. ferratd, petiolata, fumma feffilia. Spica fubterminal. folitar. Bract. ovatæ, infima bali dentatæ. Cal. l cin. 2. exter. ma. Cor. albidocœrulefc.

23. profirata. V. racemis lateralibus: fol, oblongo-ovatis, ferratis: caul. proftratis. Syft. veg. ed. I4. Fl. haff. I. tab. I.

Chamædrys incana \&c. Bauh. hift. 3. p. 287.

In Eurofe collibus 24.

Convenit cum $V$. Teucrio, Hall.

Caul. duriufculi, canefcentes, fubtomentofi. Fol. obtufa, fubpetiol. excepris fuperioribus, e quorum alis racemi longi. Fl. conferti. Cal. 5fid, inæqual. Cor. late violac.

24. peçinate. V. racemis lateralibus, foliatis: fol. oblongis, pectinato-ferratis : caulibus proftratis. Syft. veg. ed. 54 .

V. Conttantinopolitana \&c, Buxb, cent. I, tab.39. Conftantinopoli 24 .

Caul. palmar. bafi fuffruticofi, pubefcent. Fol. Chamærryos, elliptica, profunde ferrata inftar pectinis, oppofita, fubpetiol. pubefcentia. Pedunc. palmares, fol. 5-6 fumilibus, fed alternis, feffilibus. Cal, s-fid. Cor. pallide coerul.

29. montana, V. racemis lateralibus pauci fl.cal. hirfutis: fol. petiolatis, ovatis, crenatis, rugofis: caule debili. Sygt.veg.ed. 14. Jacq. Auftr. 2, tab. 109. Alyffon \&zc. Col. ecphr. I. tab. 288.

In umbrofis 4.

Caul. femi-fefquiped. fufco-purp. Fol. lata, obtufa, raro pilofa, frepe glabra, fubtus rubra. Racemi ut in V. foutellata, capillacei, fol. multo lougiores, paucifl. Cor.purpuro-corul. lacin. infina immaculata; reliquæ cum venis faturatioribus . Caps, orbicul. bafi, apiceq. emarginata.

26. Chamadrys . V. racemis latezalibus: fol. ovitis, (plerumq.) feffilibus, dentatis, rugofis: caul. bifariain pilofo. Syft. veg. ed. 14, Fl, Dan, tab, $44^{8}$. Riv. $t a b .94$.

In Europe pratis $2 \%$. 
Caul. infirmus, fuperne brachiatus. Fol. villofa, ad bafin integra; ima fubrotunda, retufa; fuper. longe acuminata. Racemi ex fummis alis, longi, erecti. Fl. fub 20. Cal. fegmenta inæqualia, lanceol. Cor. fature corul, venofa, ungue alto.

V. chamadrys, montana, \& Teucrium valde $\int_{2}-$ miles funt. Differt vero montana fol. petiolatis: $V$. Chamadrys fol. Seffilibus, imis ovalibus; fuper. cordatis. V. Teucrium fol. fefflibus, imis fubovatis; fuperioribus ellipticis.

27. auftriace. V. racemis lateralibus: fol, lineari-lanceol, pinnato-dentatis. Syft. veg. ed. I4. Jacq. Auftr. 4. tab. 329.

Chamædrys fpuria \&c. Moris 3. tab. 23. f. 17. In Auftria, \& Siberia 24.

Caul. terme fefquipedal, villofi. Fol, varie ludunt, plerumq. Abrotani fimilia . Racemi longi. Cor, pallide, vel fature cœrulea.

28. multifida.V. Viderur yar, prioris.

29. urticafolia. V. racemis lateralibus: fol, ovato-lanceol. hirtis, argure ferratis: caul. erecto. $\left.S_{\mathrm{Y}}\right\}_{\text {t. }}$ veg. ed. I4. Jacq. Auftr. I. tab. 59.

In Sylvis 4.

Similis $V$. latifolia. Caul. pl. pedales, \& ultra, fimpl. erecti, aut fubinclinati, Atricti, villofi, inferne purpurafc. Fol. oppofita, feffil. anguftiora, modo magis lata, ad balin vix cordata, acuca, rugofa, utrimq. fubhirfuta ; inferiora obtufiora. Racemi ex alis fuperioribus, longi. Cor. laciniæ obtufæ; fuperior duplo ma, pallide carnea .

30. latifolia. V. racemis lateralibus: fol. cordatis, rugofis, dentatis: caule ftricto. Syft. veg. ed. 14. Jecq. Auftr. I. tab. 60 .

V. pratentis. Buxb. cent. I. tab. 34.

In Germania, Helvetia \&c. 24.

Differt a $V$. Chemadry fol. longioribus \& longius acuminatis. Caul. 3-pedal. erectus, ramofus, durus. Fol. fubfelini. Jata, fubhirfuta, circumferrata; ima fubrotunda, fuper. longe acumin. Racemi multi, longi, inferne nudi, Jaxi. Pedunc. fructiferi ita demum inflectuntur, ut emarginatura capfulæ fcapum refpiciat , Cal, foliola 5. æqualiz, ovata, integerrima, Cor, albo- 
violac, lineis faturatioribus villofula . Cap? compreffa, villis ciliata .

3I. panieulate. V. racemis lateralibus longifs.: fol. laneeol. ( plerumq.) ternis, ferratis: çaule adfceidente. Syft. veg. ed. I4.

In Tartaria 4.

Statura V. latifoliæ, fed fol. anguftifime lanceol. Fl. fature cœrulei, ad tria fuper. genicula terni . C 1. 4-fid.

*** Pedunculis I-fl.

32. agreftis. V. fl. folitar. fol. obcordatis, incifis, pedunculo brevioribus. Syft. veg.ed.14. Fl. Dan. tab. 449.

V. folio \&c. Riv. $t a b .97$.

In Europe agris, \& arvis $\odot$.

Caul. pl. primun erecti, dein procumbent. femiped, fubvillofi. Fol. breviter petiol. fubhirfuta.Fl. poft efflorefcentiam reflexi. Cal. foliola ovata, æqualia. Cor. fature cœrulea, lineata, fegmento infer. pallidiore; vel alba.

33. arvenfis. V. fl. folitar. fol. cordatis, (plerumq.) incifis, pedunculo longioribus. Syft. veg. ed. $14 . \mathrm{Fl}_{\text {. }}$ Dan. tab. 515 .

In Europe arvis cultis $\odot$.

Priore magis villofa. Caulic, dodrant. erecti, a terrd ramofi. Fol. ad terram multa; caulina pauca, fubfeffil. ovata, uno, alterove dentium pare; fuper. fape lanceol. integerr. Fl. longa ferie plurimi, Cal, foliola lanceol. inaqualia. Cor. calyce minor, corul. Var. fol. alternis.

34. hederefolia. V. fl. folitar. fol. cordatis, planis, 3-5 lobis. Syft. veg. ed. I4. Fl. Dan. tab. $4<8$.

Alfine \&c. Riv. tab. 97. Baul. hift. 3. p. 368. b. V. chia \&c. Buxb. cent. I. $t a b .39$. f. I.

In Europa ruderatis $\odot$.

Caul. procumb. dein erecti, ramofi. Fol. plus, minus periolata; ima oppofita; fub fl. alterna, varia, lobo medio ma. modo ampliora, modo min. Pedunc. longi, cernui, hirfuti . Cal. foliola cordato-obl. Cor. calyce min. pallida, lineis faturatioribus, vel alba. Sem. umbilicata funt huic propria.

35. triphyllos. V. fl. folitar: fol. digitato-partitis: peduncul, ca. lyce longioribus. Syft. yeg. ed, 14. Fl. Dan. tab. 627 .

V. folio suta, Ris, tab, 96 .

Alfine 
Alfine \&c. Lob. ic. 464. Bauh. hif. 3. p. 367.

In Europe agris ().

Caul. femiped, erecti, ramofi. Fol, feffil. vel fubpetiol., ima 5-fumma 3-partita, fubrus rubella; ina oppofita, alias ferrata; fumma integra. Cor. fature coerul.

36. verna. V. Al, folitar, fol, digitato-partitis: pedunculis calyce brevioribus. Syjt. veg. ed. I 4. Fl. Dan. 252.

In aridis apricis $\odot$.

Cayl. procumb. dein erectus, plerumq. fimplex, ramo uno, longo, pedali, villofo. Fol, infer. oppofita, fuper, alterna: primum caulino. rum par breviter petiolatum, ovatum, tridentatum, \& crenatum: quod fequitur priori fimile, fed magis incifum, \& laciniatum: tertium fere femper ad caulis divifionem pinnanatum, aut digitato-partitum, Jacinia media longiore, latiore. Cor. pallide coerulea, cum venis purpurafcentibus.

37. romana. V. fl. folitar. fubfeffilibus. Fol, oblong. fubdent, caul. erecto. Syft, veg. ed. 14.

In ugris Europa auftralioris $\odot$.

Planta palmar. glabra . Fol. infer. oppofita, ovata; fuper. alterna, lanceol, obruta, dente uno, alteroq. obfoletiore ; fuprema integerr, Fl. axillares, albi .

38. acinifolia. V. fl. folitar, pedunculatis: fol. ovatis, crenatis, glabris: caul. erecto, fubpilolo. Syft. veg. ed. 14 .

V. minima \&c. Bucc. muf. 2, tab, 102, Vaill. paris. tab. 23. f. 3. optima .

In Europa auftrali $\odot$.

Caul. palmar. ramis oppofitis. Fol. caulina oppofitd ; floralia alterua, breviter petiol, remota, fuborbiculata, denticulis latioribus. Cor. corulea. Differt a $V$. arven $\sqrt{2}$, cui fimilis, pedunculis fl. longis, $A, V$, chamadrifolia caul. erezo, duriufculo; cum qua tamen convenit fol. flore, \& frualu.

39. peregrina. V. fl, folitar. fefflibus, Fol. lanceol-linearibus, obtufis, glabris, integerrimis; caule erecto, Syf. veg. ed. I4. Fl. Dan. 407.

V. terreftris \&c. Moris. hift. 3. S. 3. tab. 34. f. I9.

In Europe hortis, \& arvis $\odot$.

Caul. digital-fpitham. Fol. alterma, exceptis Tom. I, 
ultimis, feffilia . Fl. axill. Cor. parva, \& fere nulla, alba.

40, marilandica, V. fl. folitar feffilibus: fol, linearibus: caulibes diffufis. Syft. veg. ed. 14. Comm. Gott, 1782. tab. 3 .

In Virginia .

Caul. pufilli . Fol, rigila, glabra. Fl. minimi, albi.

nummularia . V. fl. axillar. folitar, fubfeflil, fol. 1uborbiculat. integerrim. caul. proftrato, fruticufo. Gouan. Illus, tab. 1. f. 2 .

V. nummularia fol. Pyrenaica. T. I. R.H.

In Pyrencis 4.

Diverfa a V. fruticulofa. Caul. ramos, bafi nudus, nodofus, proftratus, dein erectiufcul. Fol. imbricata, feffil. glaberr. bafi ciliata, quædam vix crenata. Cal. pilofus. Cor. cœerul. extra bracteam producta.

octrnee, V. fl. carneis, Hall, hift.

In Helvetie.

Differt a $V$. alpina, caulibus procumbentibus, craffioribus, fol. maioribus, lanceol: fl. copioftoribus, eaneis, cum venis purpureis, in fpicam langiorem difpofitis; cal. hirfuto.

tenella. V. repens, fol. rotundis, crentatis; ramis breviter racemofis. All. Fl. Ped. tab. 22. f. 1 .

In umbrofis alpium Sylvis 2 .

Cauliculi reptantes, \& novas rad. emittentes. Fol. oppofita, petiolata, tenera, raro crenulata, rugofa, glabra, Fl. purpur. Fol. floralia alterna, cvata, aut elliptica, pedunculis breviora. $\dot{V}$. Serpyllifolia differt al hac fol. duris, firmis, E omnino lavibus, floribufq. denfius racemofis, feu fpicatis in ereato cauliculo.

Bellardi, V. hirfuta; caule erecto, fimplici, toto florige. ro: fol. linearibus: fructu fubfeffili brevioribus . All. Fl, Ped. tab, 85. f. I.

In pafcuis prope arcern Feneftrellarum $\odot$.

Cauliculus dizital, Fol, breviter petiolara, alterna, obtufa, integerrima, il excipias foliola 2 rodici proxima. Fl. axillar. parvi, læte cœrul. Fructus pro ratione planta magnus. Tota plunta hirfuta.

fucculenta, V. erecta, fpicata, fol. fucculentis; caulinis pin$\mathrm{n}$ to-dentat. floralibus integerrimis, All. Fl, Ped, tab. 22, f. 4 . 
In faxofis apricis $\odot$.

Caul. digitalis, aut fpitham. erectus, filiformis, duriufculus. Fol. oppofita, petiolata, linearia, utrimq. dentata, viridia, glabra. Spica longa, \& rara. Proxima $V$. verna.

pumila. V. caale fimplici, fl. congeftis terminato: fol. ovatis, acutis, dentatis. All. Spec. Ped. tab. 3. f. 3. Fl. Ped. tab. 22, f. 5.

In alpium faxofis 24.

Fol. acutiora V. alpinæ, non crenata, fed dentata, rugofa.

30. P压EROSA. Cal. 5-part. Cor. 4-fid. Capf. 2-locul.

Differt a Veronica cul. 5-part. Segmento uno longiore.

1. bona Spei. P. fol. pinnatis. Syjt. veg. ed. I4.

Veronica \&c. Pluk. 320. f. 5.

Ad cap. b. Spei.

Caul. proftratus, pedal. Fol, ima terna; fumma fæe alterna; petiolata, lanceol. obtufa, pinnatifida. Fl, axill. alterni, pedicellati. Cor. purpur. cum lineis albidis.

2. Agerin, P. fol. ferratis; inferioribus alternis, Syft, veg. cd. 14. Jacq. H. 2. tab, I21.

Habitat.....

Differt a P. Bonarota fol. infinis neque oppofitis, neque flaccidis: cor. galea 2-fida.

Caul, erectus, yillofulus. Fol. ficca, acute ferrata, fupra non lucida. Racemus rerminalis, oblong. Cor. lutea.

3. Bonarote, P. fol. ferratis; (infimis) oppofitis, rotundis . Syf. veg. ed. I4. Jacq. App. tab. 39.

Bonarota, Mich, gen, tab. I5. f. 12, Pluk, phyt. tab. 233. f, 3 .

In alpibus Italicis, Auftriacis 4.

Caul. ad fummum pedal. debiles, villofi . Fol. terna, fubfeffil. lanceol-ovata, acuta, fubvillofa. Racemus denfus, nutans. Cor. violac.

4. carulea, P. cor, Jabin fuper, indivifo, Syft. yeg. ed. I4. Lin. Suppl,

In Auftria.

5. lutea. P. cor, labio fuper. 2-fido, Syft, veg. ed. I4, Lin. Suppl.

In Aufria.

Haec fol. longioribus.

3r. JUSTICIA. Cor, ringens. Capf. 2-locul, ungue elaltico diffiliens, Stam, anth, fingulari. 
* Fruticofa.

1. Adhatoda. J. arborea; fol. lanc ol-ovatis: bracteis ovatis, perfiftentibus (enerviis) : cor, gdea conciva, Sylt. yeg. ed. 14. Sabb. hort. 3. tab. 10. Herm. Lugd. tab. 643. Pluk, Alm. tab, 173. f. 3.

In Zeylona D.

Frutex. Fol. oppofira, breviter petiolata, integerr. Fl. 1́ica axillar. folitaria, inferne nudæ. Cor. magna, alba, lineis rubris trrata.

2. Eebolium, J. fiuticofa; fol. lanceol-ovatis: fpicis 4-gonis: bract. ovaris, ciliatis; cor. galea reflexa. Syfto veg. ed. 14 .

Adhatoda \&c. Burm. Zeyl. tab. 4. f. x.

Carim-curini. Rheed. Mal.2, tab.20. Pluk. Alm. tab. 37 I. f. 4 .

In Malabaria, Zeylona 5.

Arbor facie, \& fol, prioris, fed fpica conftat bract. ov t. planis, apice aculeis armatis, deciduis. Caul. fruticof. teretiufc, articulatus, compreffus. Fol. petiolata, acuminata, integerr. glabra. Spica terminal. ftrobiliform, bracteis imbricatis. Cor. tubus filiform. incurvus, bractea longior: limbus corulefcens: lab. fuper. lineari, anguttiff. refracto, apice 2-fido: $1+b$. infer. 3-fido, media latiore. Anth. ad refracturam labii fuper.

Differt a $J$. infundibulif. quod huic fpice terminalis feffrlis.

3. pulckerrime. J. fruticofa; fol, ovatis, utrimq. acuminatis. petiolaris : fl. terminalibus, 4-yon. erectis ; bracteis ovatis. Syft. veg. ed. 14. Lin. Suppl.

J, fl. tetrandris. Jicq, amer, tab, 2. f. 4. ed. 2. piz. $t a b .259$. f. I.

In Cartagena fylvaticis montibus \&c.

Planta 6-pedal. erecta. Caul. ex eadem rad. fape pl. vix ramofi. Fol. oppofita, breviter petiolata, margine obfulete denticulatn, fupta glabriufcula, fubtus tomentofa, 8-pollicar. Spie cæ 3-pollicar. erectæ, 4-zonæ, denfæ: axilJares oppofitæ; terminalts binæ-quaternæ. Bract. fubrotundo-cordacæ. Fl. fæe 2-pollic. rubore pulcherrimo, inodori.

4. Betonica. 3. fruticof ; fol. lanceol-ovatis : bracteis ovatis, acuminatis, venofo-reticulatis, coloratis. Sy ffo yeg. ed. 14. Pluk, phyt. tab, 241. f. I. 
Bem-curini. H. Mal. 2, tab. 2 r.

In Iidin b.

Caul. magis herbac. Fol, min. remotiona - Cor. galea laia, ut in J. Adhatoda, fed lab. fuperius aliter conftractum.

3. fcorpioides. 1. fruticufa ; fol. lanceol-ovat. feffilibus hirfutis: fpicis recurvatis. Syjt. yeg. ed. I4.

In vera Cruce $\hbar$.

El. axillares.

6. piäa, J. fruticofa; fol. lanceol-ovat. pictis: cor. fauce inflatis. Syf. veg. ed. I4.

Folium bracteatum. Rumph, amb. 4. tab. 30.

Tiude-inaram. Rhad, mal. 6. tab. 60.

In $A$ fia $b$.

Caulis ftriatus. Fol. oppofita, fubpetiol. acuta, integerrimi, plabra, fufca, macuia lucida, flava. Fl. ampli. Cal. parvus, 5-dent. Cor. ampla, ringens, fanguinea, fauce inflata: lab. fuper. incurvum, emarginatum; infer. parens, 3-fid. xquale.

7. infundibuliformis. J. fruticofa; fol. lanceol-ovatis, quaternis: bracteis tanceol. ciliatis. Syft. reg.ed.14. Manja-Kurini, Hort, mal. 9. tab. 62.

In India $b$.

Frutex ramis teretibus. Fol. longe petiolata, integerr. glabra. Pedunc. ad frugula caulis ge. nicula folitar., laeves, longitudine fol. Spica oblong. diftiche inbricata. Cal, apice pilofus. Cor. fpeciofa, alba ; tubo filiformi, limbo magnitudine Narcifi Poetici, lobis 5. expanfis, infimo ma.

8. Spinofa. J. frutic $f a ;$ fpicis axillaribus: pedunculis lateralibus, Syft. veg. ed. I4.

3. monanthera \& c. Jacq. Am, 2, tab. 2. f. I. ed. piaz tab. 2.

In America b.

Frutex saped. ramis longirl. foliofis. Fol. fubfemipoll. oppofita, petiolata, ovata, vel lanceol-ovata, obtufa, integerr. nitida. Spina oppofitæ, fubulatæ, patentiff. Pedunc. breves, oppofiti, terni-quaterni. Cor. purpur. lab. fuper. 2 fido.

9. fafiuofa, J. fruticofa; fol, elliptico-lanceol, thyrfis terminalibus. Syft. veg. ed. I4.

Gratiole \&c, Pluk, phyt. f, 3 . 
J. paniculata. Forsk. Egyp. monente Valal.

In Tranquebaria, Arabia felici b.

Caul, teres, lævis. Fol. 2-pollic. oppofita, petiolata, integerr. venis alternis, fubtus, margineq. pilofa. Racemus longus, fl. copiofis; racemuli axillar. Cal. lævis, magnitudine grani Tritici. Cor. tubus cal. longior: limbus fauce compreffa, dilatata, tubo longior. Lab. fuper. obtufum, 3-dent; infer. anguftius, lan. ceol. indivifum. Nect. cingens germen, campanul, poftice fiffum, lacinia utraq. hinc feta terminali .

ro. Jeffilis. f. fruticora; fl. axillaribus feffilibus. Syft, veg. ed. 14.

J. Dianthera \&c. Jacq. Am. tab, 2. f. 2. ed. piäa tab. 3.

In America b.

Caul. fub. 2-ped. Fol. oppofita, breviter petiol. ovato-acut, obfolete crenata. Bract. florales plerumq. 2. exiguæ, acutæ. Fl. folitar. Cor. purpur. lab. Tuper. integerrimo.

II. orchioides .J. fructicofa; fol. ovatis, fefflibus : fl. axillaribus, folitar. pedunculatis. Syft. veg. ed. I4. Lin. Suppl.

Ad cap. b. Spei Ђ.

Frutex rigidus, glaberrimus. Fol. parva, rigidiffima, apice fere pungente.

I2. Gandaruffa . J. fruticofa, glabra: fol. lanceol, elongatis: fpicis verticillatis. Syft. veg. ed. 14. Lin. Supplo Rumph. Amb. 4. tab. 28.

In Malabaria Ec. $\hbar$.

Caul. erectus, teres, geniculdt. glaber. Fol. fubpetiol, decuffata, glabra, venis rubris. Spica fl. oppofitis. Bract. lanceol, apice fetaceo. Cor. lutea.

I3. verticillata.J. villofa; fol, ovatis, integris: fl. axillaribus, verticillat. feffilibus. Syft, veg. ed. I4, Lin. Suppl. Ad cap. b. Spei, $\hbar$.

14. tranquebarenfis. J. fuffruticofa; caul. tereti; fol. orbiculatis: fpicis terminalibus: fl. folitariis; bracteis obcordatis. Syft. veg. ed. 14. Lin. Suppl.

In Tranguebar. $\hbar$.

Caul. teres, ruber, pilis mollibus, albicantibus obfitus. Fol. quandoque ovalia, petiolata, fubcarnofa, undulata, minora. 
15. hylfopifolia. 3. fruticofa; fol, lanceol. integerrimis: peduncul. 3-fl. ancipitibus: bracteis cal. brevioribus. Syft. veg, ed. I4. Mill. ic. $2 a b$ I3.

Ecbolii \&c. Pluk, Alm, tab,280, f. 1. Phyt, tab. 3I3. f. I.

In infulis Fortunatis $\mathrm{b}$.

Corolla alba,

$$
\text { ** Herbacea. }
$$

16. acuulis 。 J. Syft. veg. ed. 14. Lin. Suppl.

In Tranguebaria 24.

Radix rufefceus. Fol. radicalia, palmaria, ovalia, crenulata, nuda, fxpius lyrata; alia tamen in eadem planta integra. Scapi fimpliciff. foltis duplo longiores, imbricati, fquamis minutis, adpreffis, acutis. Spica oblonga .

17. ciliaris. J. herbacea; fol, lanceolatis: fl. oppolitis, fefflibus: bracteis, calycibufque fetaceis, hitpidis, flore longioribus. Syft. seg. ed. 14. Lin. Suppl. Jacq. H. 2. $t a b .104$.

In Zeylona.

Tota planta fcabra. Caul. pl. fefquipedal., erecti, debiles, fuperne ramofi, pilofi. Fol. oppofita, petiolat $\curvearrowright$, obrufiufcula, ciliato-dentata, hirfuta, fupra atro-virentia. Fl. dxillar. parvi, inorlori. Cor. alba, cum punctis fulvis.

18. procumbens. J. fol. lanceol. integerr. fpicis terminalibus, lateralibufque alternis; bract. fetaceis: caule procumbente. Syft. veg. $c d .14$.

Euphrafia \&c. Pluk. Alm, tab. 56. f. 1. E tab. 393. f. 4 .

In Zeylona 4.

Caul. herbaceus, ramis alternis. Fol. oppofita, petiolata, fcabra. Spicæ fubnudæ.

19. pezinata . J. diffufa; fpicis axillaribus, feffilibus, tomentofis, fecundis, dorfo imbricatis : bract. femilanceolat. SyJt. vez. ed. I4.

In Afia.

Habitus fequentis. Fol, oppofita, petiolata, oblonga, integerr. lavia. Flofculi minimi.

20, repens. J. fol. ovaris, fubcrenatis: fpicis terminalibus: bracteis lanceol. caule repente. Syft. ieg, ed. I4.

Adhatoda \&c. Burm. Zeyl. tab. 3. f. 2.

In Zeylona 4.

Habitus Thymi Acinos. Caul. geniculati, radices agentes, xamofiff, Fol, oppofita, viridia, ica$\mathrm{C}$ iv 
bra. Bract, utroq. margine late membranacea,

Cor. albicans. Var. fol. lanceol. feffilibus.

2r. chinenfls. J. herbacea; fol. ovatis: fl. lateralibus, pedunculat. 3-5-f. bract. ovalibus. Syjt, veg. ed. I4.

J. fexangularis. Forskal Egyp. monente Vahl. Burm. Ind. tab. 4. f. I.

In China .

Caul. pedal. angulati, inferne ramofi. Fol. oppofita, petiolata, acumin ta, obtufiufcula, vix crenata. Pedunc. axill. $2-3$. breves, involuc. 3-phyllo, feraceo, nudo. Cor. tubus albidus; limbus violac.

22, echioides . J. fol. lanceol-linearibus, obtufis, fefflibus: racemis adfcendenti-fecundis: bract. fetaceis. Syjt. veg. ed. I4.

In Indie fubhumidis.

Caul pedal. Fol. oppofita, digitum longa, uriguem lata, late viridia, fubafpera. Racemi axill. fimplic, patuli. Fl. remoti, feffil. erecti . Cal. longus, feraceus. Cor. bafi candida, alioquin purpurafcens. Sem. ex fufco-flavefcentia.

23. fexangularis. J. pertinet al priorem.

24. carthaginenfis. J. fol, lanceol-ovalibus: fl. fpicatis: bract. oblongo-cuneatis. Syft. veg. ed.14. Jacq. Am. tab. 5. ed. piża tab. 7 .

In America.

Caul. 3-6. pedal. Fol, femipedal. oppofita, breviter petiol. integerr. fupra fcabriufcula, fubtus nitida. Spicæ lateral-terminal. Bract. fub fingulo fl. terna. Fl. fefquipollic. Cor. purpurafcens, filamentis candidis.

25. affurgers. J. fol. ovat. integerr. bract. fubulatis: ramis hexagonis. Syft. veg. ed. I4. Brow. Jam, tab.2. 1, I. In Jamaica.

Similis priori, fed bract. anguftæ, acuminatæ .

26. nefuta. J. fol. lanceol-ovat. integerr. pedunc. dichotomis. Syft. veg. ed. 14 .

Pulcolli. Rheed. Mnl. 9, tab. 69.

In India.

Caul. 3-4. pedal, ramis obfolete angulatis. Fol. obtufe acumin. minus glabra. Fl. feffiles, carnei; bracteis minimis, lineatis. Cal. minimus. Cor. rubus longus, filiform. Limbi lab. fuper. lineare, angultum, brevius, reflexum, Lab. 


\section{DIANDRIA MONOGYNIA.}

infer. æquale, 3-fid. Stam. extra faucem prominentia.

4.7. biyalvis, J. fol, ianceol-ovat. pedunc. 6-fl. pedicellis lateralibus 2-fl, bract. ovatis, paralellis. Syj. yig. ed. 14 .

Adel-orlagam. Rheed. Mal. 9. tab. 43. Sed differt fol. ferratis, ofl. albo.

In Afia indica.

Caul. brachiarus. Fol. oppofita, integerr. Pelunc. breves, involuc. 2 phyll. fetaceo; pedunculifque 4. parvis, paraleilis; medis duobus $\mathrm{I}-\mathrm{fl}$. lateralibus iterum diphyll. 2 -fl. Cor. lab. fuper. lanceol., inferius ovatum.

28. purpurea. J. fol.lato-ovat. utrimque mucronatis, integerr. glabris: caule geniculato: $f_{p}$ cis fecundis . Syft. veg. ed. 14 .

Folium tinctorum. Rumph, amb. 6. $t a b .22$, f. $\mathrm{r}$. In China.

Facies Galeopfidis Tetrahit. Caul. pedal, ramofiff. radicans, brachiatus. Fol. petiolata. Geniculi tumidi, Spicæ lateral-terminales. Bract. angufxe. Cor. purpur. labiis erectis, altero lineari, anguftif., altero lato, trilobo. Stam.

29. gangetica, $\mathrm{J}$. fol, ovatis : racemis fimplicibus, longis: $\mathrm{fl}$. alternis, fecundis: brak. obfoletis. Syjt. veg. ed. T4. Burm, Ind. tab. 4 .

Carua Caniram. Rheed. Mal. 9. tub. 56.

In Afia indica.

Caul. ad genicula pilofus. Fol. oppofita, breviter petiol. integerr. Racemi ex alis fuper. erechi, folitar. Fl. remori, erecti, fubfeffil. Bract. geminæ, minimæ. Cal, oblong, hifpidus . Cor. maiufcula, alba.

30. juponisa. J. fol. ovatis, ferratis: fpicis terminalibus: bracteis fetaceis: caule patulo. Syft. veg. ed, r4. Thumb. Jap.

In Japonia .

Caul. fubdecumb. 4-gonus, pubefcens, ramis oppofitis. Fol, unguicul-pcllicar. oppofita, petiolata, acura, villofa, fupra viridia, fubtus pallida, inæqualia. Spicæ pollic. Bract, ciliatæ.

eradurenfis. J. fruticofa; fol. ovalibas obtufis, dentatis: $\mathrm{fl}$. axillaribus folitariis. Burm, In tnb. 4. f. 3.

In Madura to 
Caul. teres, glaber, albicans. Fol. oppofita, fubpetiol. apice vel emarginara, vel acumin. Bract. 2. decidua. Fl, rarores . Capl. oblong, acutiufc. bafi anguftata.

moretiana. J. herbacea: fol, lanceol. integerr. : fl. axill, folitar. Burm. Ind. Rumph. amb. 6. tab. 23.

In India arenofis.

Caul. angularus. Fol, remota, oppofita, fubpetiol. acuminata. Capf, ut in priore.

nutens.

coscined.

J. herbacea; fol. lanceolat. denticulat. pedunculis terminalibus cernuis: bract. fetaceis. Burm, Ind. tab. 5. f. I.

In India.

Caul. erect. teres, ftriatus. Ramis axillaribus, alternis. Fol. 2-pollic. oppolita, petiolata, glabra. Pedunc. brevifs. Bract. lanceol., fingulo pedicello tres. Cor. lutéa.

J. ful. ovat-obl. acutis : f. amplis, fpicatis . Aubl. Guian. tab. 3.

\section{In Cä̈enna.}

Caul. 5- 6 ped. fimplex, erectus. Fol. petiolis longis violac. innixa, integerr. glabra. Fl. verricillato-fpicati, bracteati. Cor. tubulofoventricofa, utrimq. compreffa, incurva, phœnicea ; lab. fuper. longo, erecto, acuto, concavo; infer. 3 -fid. lacin. reflexis, acutis, intermedia longiore.

variegata. J. fol. ovatis: fl. fpicatis, Aubl, Guian. tab. 4. In Guiana b.

FruteX 5-pedal. ramis longis, rectis, cylindraceis. Fol. fubfeffli. acuta, integerr. glabra. Fl. terminal. bracteati, verticillis 4 -fl. floribus utrimq. binis, fubfefflibus. Cor. tubulofo-ventricofa, incurva, alba: lab. fuper. erecto, 2-fido; infer. 3-fid. laciniis lateralibus corul. intermedia crocea, punctis violac. adfperfa.

triflora.

J. inermis; pedunc, axillaribus, folio longioribus, apice 3-4 fl. Forsk. $\bar{A}_{\mathbf{g}}$.

In Arabia 24 .

Caul. cubital. annuus, diffufo-decumb. brachiat. articulat. villofus. Articuli 3-pollic. 6-fulcati, fxpe bafi incraffati, tenues. Fol. fefquipollic. ovat-lanceol. denticulata, pubefcen. petiolis connatis, canaliculat, ciliatis, villofis. Stiptla nulla. Pedunc, 2-pollic, erecti, folitar., 
utrimq. parvo foliolo petiolato præditi, Fl. albi. Cor. labia erecta; fuper. integrum, infer. 3-dent. in fauce violaceo-punctatum. Bract. 2. erectæ, apice reflexæ, adpreffæ, cal. exteriorem mentientes, longe lanceol. villofæ, exrer. maiore.

carulea.

J. inermis; fol. ovato-oblong. ciliatis : fl. verticillatis, feffilibus. Forsk. $\mathbb{E}_{\mathrm{g}}$.

In Arabia .

Petioli femipollic, villofi. Fol. acuta, integerr. fubpilofa. Fl, in fummis alis utrimq. terni, coerulei: fol, mutatis in bros. parvas, lanceolat.

faitid.

J. Forsk, FE.

In Arabia.

Fol. 3-pollic. petiolo femipollic. oppofita, ovatobl. integerr. glabra. Stipula nulla. Var. fl. viridi, vel carul.

Dum Vacca plantam edunt, lac inficitur odore Alliaceo.

viridis.

J. fpinofa; fol. oblongis, integris: fpinis terminalibus imbricatis: bracteis ovato-acutis; galea lineari, 2-dent, reflexa. Forsk. 玨g.

In Arabia.

Fol. oppofita, Spicæ digitum craffe. Bract. latæ. Cor. tubus albidus, villofus, pollic. cylindric: fuperne anguftior, curvatus : limbus viridis: lab, inferius latum, trilobum, patens, lobis ovat-acumin. medio latiore. Capf. fpathulato-acuta, 2-locul. Var. fl. corul. \& viridi-carul.

trifpinofa.

J. fol. lanceol-ovat. fpicis terminalibus, imbricatis: lab. cor. fuper. brevi. Forsk, 死g.

In Arabia b.

Fruticulus. Fol, unguicul, oppofita, petiolata, integra, ciliata, margine fcabro. Spinæa axill. Bract. lato-ovatæ. Flos fulvo-flavus, bracteis duplo longior, refupinatus. Cor. lab. infer.

bifpinofa. J. fpnnis axillaribus, 2-fid. cor. labiis æqualibus. Forsk. 足g.

In Arabia.

Differt a priore, ut ex definitione. Cor, alba, vel pallide cocrul. 
appreffa.

I. fpinis axillaribus, compofitis: fl. fulvo; labs fuper. breviore. Forsk, $\mathbb{E g}$.

In Arabia t).

Priori funilis. Frutex diffufo-cerpitorus, vix ped.1. Spina 3-4-duplex, femper uno ramo ere cto, \& cauli adpreffo. Lab fuper. ftaminibus brevius; inferius 4 . lobis crenatis, obtufis, margine non imbricantibus, fed paralello intervallo diftantibus.

lanceata. J. fol. inermibus: fpinis ftipularibus: bracteifq: foliaceis, margine fpinolis. Forsk. Eg.

In Arabia.

Fl. fubfolit. feffiles, erecti: bracteis litis, ovatis.

32. DIANTHERA. Cor. ringens. Capf. 2-locul, ungue elaftico diffiliens. Sran, fungulum antheris 2. alternis.

I. amerivana, D. fpicis folitar. alternis. Syft. veg. ed. I4.

Gratiola \&c. Pluk, alm. tab. 423. f. 5.

In Virginia, Florida 24.

Caul, fimplex. Fol. linearia. Spicæ ovatæ, terminal. imbricatæ, bracteis lanceol. Pedunc. atterni, longitudine folior. Cor. flava, vel dba.

2. comata. D. fpicis filiformilus, verticillatis; inferioribus umbellatis. Syjt, veg. ed. 14 .

Antirrhinum \&c. Sloan. Jam. 1. tab, 103. f, 2。 In Jamuica .

Fol, lanceol-ovata, Cor, dilute cœrul.

3. malabarica. D. fl. paniculatis; pedicellis 2-3. fir. fl. bicaly. culatis: lacinia dorfali ma. Syft, veg. ed. 14. Lin. Suppl.

D. bicalyculata. Reta. Aż. Holm. 1775. tab. g。 Cara-carinam. Rheed. Mal. 9. tab. 56.

In Malabaria graminofis $\hbar$.

Caul. fruticof, angulat. hirtus. Fol. oppofita, petiolata, ovata, integert. Panic. terminalis. Cor. purpur.

4. pecteralis. D. panic. dichotoma, rerminali. Syft. veg. ed. I4. Jacq. Amer. tab. 3. ed. picta tab. 4.

In Damingo, \& Martinica (อ.

Flanta $2-3$. pedal. erecta, berbacea. Fl. numerofi, feffiles, rubelli, bract. fetaceis. Cor. lab. fuper. integrum, concavum. Tote plante odorent fpirat faeni recentis.

5. euftackiane. D. fol, lanceol-obl, pedunc, multifl, bracteis linearibus, apice latiufculis, acuminatis. Syft. veg. ed. 14. Jacq. Am. tab. 4. ed. piza tab.5. In collibus apricis infule S. Euftachii b. 
Frutex 3-ped, erectus. Fol. 3-pollic. breviter petiol. integerr. glabra. Pedunc. racemofi, parum divifi, terminales multifl, axiliares fub 3-fl. Bract. plerumq. terna. Fl. fefquipollic. inodori. Cor. purpur.

6. martinicenfis, D. fol. ovat-acumtnatis: pedunc. 3 -tl. bracteis ovatis, cal. longioribus. Syft. veg. ed. I4. Jacq. Am. pia. tab. 6. Hors. r, tab. 22.

In Martinica ad fepes, \& margines fylvarum.

Planta 2-pedal. fuberect, ramola, geniculata, adfiendens. Caules obfolete 6-angular. glabri . Fol. oppofitd, in petiolum tenuem attenuata, jutegerr. glabra; infima 5-pollic. reliqua fenfim min., fumma vix femipollic. Pedunc. axill. breves, oppofiti, 3-fid. Brait. oppofitæ, feffiles, acumin. concavæ, integerr. glabræ. Fl. tere fefquipollic inodori. Cor. rubra .

7. japonica, D. pedunc. axillar. folitario, fub 4-f1. bracteis oblongis, ciliaris. Syf. veg. ed. I4. Thumb. Japon. tab. 4.

In Japonia (-).

Radix fibrofa. Caul. pedal, erect. herbaceus, 6gonus, leviter villofus, parum ramofus, fupra genu tumidus. Fol. femi-2. pollic. fuperior. fape ma.oppofita, petiolata, ovato-obl. inferne attenuara, apice acumin. integerrima, villofa, patentia, inæqualia, petiol. unguicularibus. Pedunc. villofi. Bract. 2. oppofitæ. Cor. purpur. bracteis paulo longior. Differt a J. fexangulari braacis oblong. nec cuneatis . A. D. Chinenfz, cui fimilis, fl. pedicellatis, non aggregatis, \& ex una tantum ala Esc.

hirfuta,

D. (Jufticia) fol. lanceol-acumin. fl. fubfpicatis : bracteis fetac, caule hịfuto. Jacq. Am. p. 4 . In Martinice fruticetis $\hbar$.

Planta fruticofa, 4-ped, erecta, ramulis hirfutis. Fol. femiped. oppofita, periolata, fupra glabra, fubtus hirfuta. Racemi terssinal, femiped. villofi, bracteati. Cor. candida; lab. fuper. femi 2 -fid. inferioris lacinia intermedia paulo lateralibus latiore; punctis rubris variegati.

nitida , D. (Jufticia) fol. lanceol-acumin. fl. fubfpicatis ? bracteis fetaceis: caule nitido.Jacq. Am。 In Martiniga ad ripas torrentum b. 
Frutex totus nitidiffmus, cæterum priorifimilis . Fol. craffiufcula.

hyfopifolia. D. fl.terminalibus, pedunculat. fol. lanceol. fcabris. Burm. Ind. tab. 5. f. 2.

In Java.

Caul, herbaceus. Fol, petiolata. Pedunc. ex involuc. fuper. fol. pollic. 5. erecti, circa medium frepius divifi. Bract. 2. lanceol. calycem obvolventes.

trifulca. D. Forsk. IIg.

In Arabia b.

Planta fpeciofa, \& charazere novi generis. Frutex ramis brachiatis. Fol. conferta, oppofita, breviter petiol, inferiora decidendo cicatricem relinquunt; ovata, obtufa, integra, glabra, margine utrimque incurva, venis fimplicibus oppofitis. Pedunc, ex axilla fuper, 2-fl. utrimq. bractea pro fingulo fl. lanceol. flava. Periant. duplex; exterius 2-phyll. interius triplo longius, I-phyll. 5-fid. lanceol. villofum, viride. Cor. decuplo longior cal. infra villofa, flavorubefcens; labio tuper, multo latiore.

odora.

D. Forsk. $\AA_{g}$.

In Arabie.

Frutex ramis confertis, articulatis. Fol, vix pollic: oppofita, petiolata, ovat-obl. obtufa, integra, margine fubciliato. Flos in ramulis ultimis axill. folitar. fefflis, flavus. Cor. extus villofa, lab. fuper. flavo-virefcente, venis violac. inferius totum flavum, Caps, 4-gono-fubulata .

verticillata, D. Forsk. Ag.

In Arabia.

Fol. lanceol. ovata, integra. Fl. capitato-verticillati, feffles, violac. bracteis ciliatis, cal, ma.

debilis. D, fol. oblong. Ppicis axill. imbricat, : bracteis late ovatis, ciliatis, quaternis. Forsk. $\overparen{E g}$.

In Arabia.

Caul. cubital. villofi, articulis bafi ventricofis. Fol. oppofita, petiolis fenfim dilatatis in fol. pollicare, obtufum, integrum, fubvillofum. Spicæ fefquipoil. 4-gonæ, bracteis imbricatis. Fl. bini, feffil. I-lateral. Cor. tubus albus; lab. fuper. apice violac: infer. fuperne violac, venis obfcuriuribus. Caps, I-fperma. 
33. GRATIOLA . Cor. tubulofa, 2-lab. Galea emarginata: barba 3-fida. Stam. 2. fterilia. Caps. 2-loc. polyfper. Cal. 7-phyll. 2, exterioribus patulis.

3. Officinalis. G. fol. Janceol. fuperne ferratis: fl. pedunculatis. Syft. veg. ed. I4. Fl. Dan. tab. 363. Ludw, eat. tab. 61. Sabb. hork. rom, 2. tab. 87. Black. tab. 4ir.

In Europe locis humidis 24.

Caul, pedal. ramos. Fol. feffili-femiamplexic. Pedunc. axill. folitar. I-fl. Bract. 2 , lineares, cal. longiores. Cor. dilute purpurafc. vel alba.

3. Monnieria. G, fol. ovali-oblong. pedunc. I-fl. caule repente. Syft. veg. ed. I4. Jacq. obf. I. $t a b$. I. amer. ed. 2. piza tab. 26I. f. 64. Ekr, piä. 14. f. 2. Pluk. phyt, tab. 130, f. I.

Anagallis \&c. Stoan. Jam. I. tab. 129. f. I. In Jamaica .

Caul. 6-7. pollic. Fol. breviter petiol. obtufa, craffiufcula, plana, integerr. glabra. Pedunc. axillar. Cor. nivea, vel ex albo-corul, Stam. 4. antherif $\mathrm{ra}$. Stigma capitutum .

3. roturdifolia. G. fol. ovatis, trinerviis. Syft. veg. ed. I4.

Thianga-pufpam. Rheed, mal. 9. tab. 57.

In Malabaria arenofis.

Caul. digital. $\downarrow$-goni, laves, bafi repentes . Fol. feffil. obtufa, lavia, ferratura una, alterave obfoleta. Pedunc, axill. folit. alterni, nudi, I-fl, fol. longiores. Cil. s-part. Cor. coerul, Caps. fubrot. compreffa .

4. hy fofioides. G. fol, lanceol-fubferrat, articulo caulino brevioribus. Syft. veg. ed. I4.

G. indica \&c. Pluk. Alm, tab. 193. f. I.

In Tranquebarice agris oryzaceis $\odot$.

Caul. erect. pedal, filiform. lavis, articulis fol. pluries longioribus. Fol, feffit, ovat-lanceol. levia; inferiora una, alterave ferratura. Pedunc, axill. folitar, aiterni, I-fl. fol, multoties longiores. Cal. minimus. Cor. ringens, fol, multo maior.

5. virginica, G. fol, lanceol, obtufis, fubdentatis, Syft, veg. ed. 14 .

Gratiola \&c. Pluk. Alm. tab. I93. f. 2.

Tfieria Maya nari Rheed, Mal. 9. tab. 85. In Virginia, Malabaria. 
Cául. procumb, varians magnitudine. Fol. feffil. verfus apicem ferratd; variant trifita. Pedunc. axill. I-fl. Cor. ccerul.

6. peruviena. G. fl. fubfeffilibus. Syft, veg. ed. I4. Fewil. peruv, 3. tab. 47.

In Peru.

Fol, offeinali ma. 15. lineas longa, 6. lata, dcumin, denticul. pulchìe virentia. Cor, alba.

Iobelioides, G. caul, fubnudo, ftipulato: fol lineari-oblonge integerr. panicul. dichotom. capful, fubglobofis. Ret?. Fafc. 4.

In Trinquebaria.

Caul. erect. pedal. varius, fupta medium divifus, articulis plerumq. 5. Fol. fupra radicem $2 \mathrm{~m}$. 1. $3 \mathrm{~m}$, parium, oppofita, fefill, erecta, fubftriata, pollic. quandoq. bafi, potiffimum fubtus, colorata. Stipul. 2, feffil. femiovat. integerr. parva. Panicula laxa, rara. Pedunc. remoti, fúbrubro-virides. Bract. parva, ftipulis fimil, Cor. tubo col. obfcuriore ftriato: limbo coeruleo, albo-variegato .

grandifloru. G. caulibus decumbentibus: fol, ovatis, ferratis: peduncul, oppofitis: capfulis fubulatis. Ret\%: Obf. fafc. 4 .

In Tranquebaria \&c.

Caul, angulof, bifidi, glabri.Fol. oppofita, fæpe etiam crenata, glabra. Fl, ratione reliquarum partium magni.

veronicifolic. G. caul, repente: fol. ovato-lanceol. acute ferratis: fl. terminalibus, oppofitis , Reth. Obf. fafi. 4 .

Crefcit cum priore.

Caul. radicantes. Fol. oppofita, feffil. Fl. peduncul, bracteati, parvi, fature coerulei. Capso fubulata.

oppofitifolia. G. caul. adfcendente: fol. lanceolat. ferratis: peduncul, oppofitifol. Reti. $Q b f$. fafc. 4 .

In Tranquebaria.

Caul. 4-gon. ftriati. Fol, nuda; inferiora oppofita. Ca s, fubulata.

34. SCHWENKIA. Cor. fubrequal. fauce plicata, glandulofa. Stam. 3. fterilia. Capf. 2-locul polyfperma.

I. americana, S. Syft. veg. ed, I4, Sclwwenk. Hort. Med. Hag.

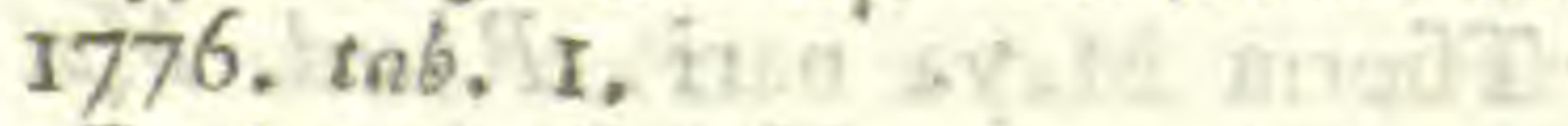

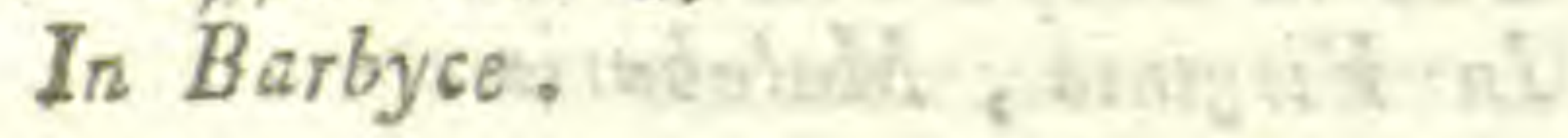


Fol. petiol., ovalia, integerr. In ordine naturati. Browalliis proxima. Fol. etiam alterna.

35. CAICEOLARIA. Cor, ringens, inflata. Capf. 2-locul. 4-valv. Cal. 4-part. æqualis.

I. pinnata. C. fol. pinnatis. Syft. yeg. ed. 14. Aa. Stock. 1770. $i a b .8$. Fewil. 3. peruv, tab. 12. f. 7 .

In Peru lacis humentibus $\odot$.

Caul. erect. 2-ped, teres, brachiatus, fragilis, denfiffime pubefc. I6-20. articulatus. Bafis caul. muricata tuberculis radicantibus, Rami axillares, oppofiti, fimiliter brachiati . Fol. oppofita, exltipulata, fragilia, mollia, patentia, internodiis longiord, fupra pube fetacea, pellucida, rorida, fubtus nuda atomis fubvifidis. Foliol. 7-Ir. fubalterna, feu oppofita, ferrata, pinnatifida, (fumma 2 -pinn.) feffil. obrufiufcula, finu latiore, purpurafcente feparata. Petioli teretes, fupra plani, bafi utrimq. coeuntes, magifve pubefcent. Fl. e fingulis apicibus \& caul. gemini, pedicellati . Cor. flava, Lab. fuper, minimum, fubylobofum, inflatum, antice emarginatum : infer, saximum, inflatum, fubglobofum, margine antice courctato, totaliter inflexum apice fubemarginato. Capf. fubrotunda, 2-locul. apice compreffor, acuminato .

2. integrifulia. C. fol. ovatis, indivifis, ferratis. Syft.veg. ed. 14. AŻ. Stock, 1770. Fewil. peru. 3. tab. 7. Mutis emer. I. tab. 2.

In Peru.

Similis reliquis. Caul. pilofus. Fol. petiolata, inæqualiter ferrata .

3. perfoliata. C. fol. perfoliat. fpathulato-fagittatis. Syft. veg. ed. 14. Lin. Suppl. Mutis Am, 1. tab. 3.

In nova Granada .

Hæc magnitudine reliquas fuperat; villofifima, cor. excepta. Caul, teres. Fol, oppofita, petiolis attenuatis. Fl, reliquis ma.

96. PINGUICULA. Cal. 2-lab. 5-fid. Cor. tubulofo-ventri$\operatorname{cof} 2$, patens: lab. fuper. 2 -fid. infer. 3 -fid. Sram. bifurca. Capf. 2-valv, 1-locul, polyfperma.

I. Iufitanica, P. nectario apice incraffato. Syjt, yeg. ed, I4.

In Lufluania \&c. 24.

Fol. margine reflexa, \& veluti convoluta, fubTom. I. 
ftriat3, fubpellucida, venis rubentibus. Calcas pralongum. Fl. carnei, vulgari min.

2. vulgaris, P, nectario cylindraceo, longitudine petali. Syft. veg. ed. I4. Fl. Dan. tab. 93.

In Europa uliginofis ad radices alpium 4.

Planta parva. Fol. 6-7. elliptica, craffa, compacta, nitida, e virídi lutea. Fl. magni, nutantes. Cor. purpurea, violac. alba .

3. alpina. P. nectario conico, petalo breviore. Syft, veg. ed. 14. Fl. Dan. tab. 453. Fl. Lapp. tıb. 12. f. 3. Gunn, norv, tab. 4. f. 4 .

In alpibus Helvetivis \&c. 24.

Similis priori, fed cor. alba, media barba 2. maculis luteis adfperfa: calcaris finis flavus, aut ruber.

4. villosa. P. fcapo fubvillofo. Syft. veg. ed. 14. Fl. Lapp. tab. 12, f. 2.

In Japonia, Sibiria, Pedemontio 4.

Differt \& P. vulgari, quod fextuplo omnibus partibus minor. Scapus fetaceus, vix manifefte pubefcens, Fol, rubro col, ftriata. Flos vio* Jac. vel carneus, calcare exferto.

37. UTRICULARIA, Cal. 2-phyll, æqualis . Cor. ringens, calcarata. Cupf. I-locul., 2-valv. polyfperma.

r. alpins. U. nectar. fubulato: fol. obovatis, integerr. Syft. veg. ed. 14. Jacq. Am, tab. 6. ed. 2. picta tab. 8.

In alpibus Martinica.

Radix tuberculofa. Scap. femiped. erect. fimpl. I-2-fl. Fol. 2. oppofita, bafi in petiol. attenuata, fefquipollic. acura, nitida, craffiufc. avenia, convexa. Flos magnus, elegans, albus: cal. \& nectar. tinctis levi flavedine.

2. foliofe, U. nectar, conico: fructibus cernuis : radicul. th triculo deftitutis. Syft. veg. ed. 14.

Linaria \&c. Plum. ic. 165. f. 2.

In America Auftrali.

Simil. U. vulgari, fed radix repens: fl. in feapo pl. 6-2o. \& nulli utriculi ad radiculas. Planta paludofa. Radix repens. Scapi pauci, axillat erecti. Fol. alterna, foliol. alternis, ramofis. Fl. alterni, fparfi, erecti, peduncul. flavi.

3. salgaris, U. nectar. conico; fcapo paucifloro. Syft. ye", ed. I4. Fl. Dan. tab. 138.

In Europa foffis, paludibus \&c. 4. 
Caul. longi, ramofi. Ad divifiones fol, veficulæ feffiles, cava, purpur. Spica brevis. Fl. magni . Pedunc. fquamofi - Cal. lividus . Cor. flava. Nectar. labio infer. adproximatum . Faux claufa palato gibbo,

4. minor. U. nectar. carinato. Syft, veg. ed. 14. Fl. Dan. tab. 128.

Lentibularia \&c. Petiv, herb. Brit. tab. 36.f. I2.

Millefolium \&c. Pluk. alm. tab. 99. f. 6.

Aparine \&c. Bocc. mus, I. talb. 4.

In Europa foffes rarius.

Omnia fere prioris, fed fl. parvi, pallide flavi, ficuti tota planta. Nectar. obfuletum, deorfum fpectans. Faux hians, \& pervia, abfque gibbo palato.

5. Subulate. U. nectar, fubulato. Syft, veg. ed. I4.

In Virginia.

Scap. I-2. fl. Fol. capillacea . Cor. alba .

6. gibba. U. nectar. gibbofo. Syjt. veg. ed, I4.

In Virginia.

Scap. 1-2. fl.

7. bifula. U. fcapo nudo, 2-fid, Syft. veg. ed. 14. Ofb. it. a $a b .3$. f. 2.

In China.

Scap. digit-palm. filiform. teres, duplici racemo. Bract. minutæ, alternæ, ovatæ. Fl. parvi, lutei.

8. ccrulea. U. fcapo nudo: fquamis alernis, vagis, fubulatis. Syft. veg. ed. 14.

Nelipu. Rheed. mal. 9. tab. 70.

Scap. femiped. erect. ramofus. Fl, terminal. pauci, fubfeffil, Cor. cœerulea .

9. fellaris. U. verticillo utriculario bractearum ciliari. Syft. veg. ed. 14. Lin. fuppl.

U. inflexa. Forskal, Ag. monente Vakl.

In Indice aquojis.

Radices abfque urriculis. Scap. digital. filiform. apice ramofus. Folliculi vercicillari $4-6$. feffil. ovati, ciliati, 2-locul. in medio feapi. Cor. deftitura nectario: lab. infer. faccato.

38. WULFENIA. Cor, ringens, ecalcarata, fewihians, ad faucem barbata.

I, carinthiaca. W. Syft. veg. ed. I4. Jacq. mifc. auft. 2. tab. 8. f. 1 .

Caul. pl. remoti, flavo-fufcefcent. Scap. I-2.

D ij 
Spithameus, teres, viridis, villofus, tandem nudus. Folior. loco fquamulæ foliaceæ, remo. te f parfse, feffil. lanceol. Fl. fpica terminalis, 2-3 pollic. fecunda, \& veluti difticha. Fl. breviter pedunculati, bracteis ex virure fufcefeentibus, ficuti cal. Peralum coerul. barba lab. infer. denfa, crifpa, nivea. Fol. tondem radicalia mulıa, magna, craffa, oblong-oval, obtura, crenata, in petiolum decurrentia, fature virid. glaberrima, nitida, fupra veluri canaliculata, \& rubra.

39. VERBENA . Cor. infundibul. fubaqual, curva . Cal, unico dente tsuncato. Stan, 2-4. Sem. 2-4. nuda.

I. orubice, V. diandra; fpicis longiffmis, foliolis. Syfo veg. ed. 14. Pluk. alm, tab. 228. f. 4. \& 327 . f. 7 . Sherardia \&c. Ehret piat. tab. 5. f. I.

In Orube infule Amer. Septentrionalis.

Caul. 3-pedal. lignofus. Fol. ovata, acuta, ferrata, fenfim in petiolum definentia. Spica fefquiped. foliis integris. Cor. 2-fidd, violac. cum macula nigra.

\$. indice. $\quad$. diandra ; fpicis longiff. carnofis, nudis : fol. lanceol-ovat, oblique dentatis: caul. lævi. Syft. veg. ed. I4. Jacq. obf. 4, tab. 86.

In Zeilona $\odot$.

Differt a feq. caulibus, ramifque glabris: fol. anguftiuribus, vere lanceol. utrimq. attenuatis. Spica endem, fed cor. purpur. Caul. viridis. Fol. undulata, minime ciliata.

3. jamaicenfis. V. diandra; fpicis longiff. carnofis, nudis: fol. fpathu'-ovatis, ferratis: caule hirto. Syft. veg. ed. I4. Jacq. obf. 4. tab. 85. Sloen. Jam. tab. 107. f. 1 .

In Iamaica, \& Caribais.

Caul. 3-4. ped. diffufus, valde ramofus, purpur. Fol. fenfim in petiol. attenuata, gl bra, bafi ciliata. Rami 2. oppofiti ex ultimis alis. Spica terminal, pedal., ftricta, virens. Cor. pallide ccerul.

4. prifmatica . V.diandra ; ficis laxis : calycibus alternis, prifmaticis, truncatis, ariftat.: ful. ovat. obtuf. Syft. veg. ed. 14. Sloan. Jam, 1, tab. 107, f. 2. Pluk. Alm。 tab. 70. fo I.

In Jamaice.

Elanta parva. 
9. mexicana. V. diandra; fpicis ldxis, calycibus fructus reflexis, rotundato-didymis, hifpidis. Syft. veg. ed. 14. Dill. elth, tab. 302. f. 389.

In Mexico 24.

Caul. fefquicubit. margine fcabro. Rami oppofiti, fuperne dichotomi. Fol. oppofita, breviter petiol. cordata, oblonga, fcabra, venis multis obliquis exarota, fubtus pallidiord. $\mathrm{Ra}=$ cemi dichotomiz longi. Cor. dilute purpur.

6. lappulacea. V. tetrandra; calycibus fructigeris fubrot-inflatis: feminibus echinatis. Jyft. veg. ed. 14. Jacq. obf. 1, tah, 24. Amer. plä. sab. 9.

Scorodoniz \&c. Stoan. Jam. 1, tab. IIO. f. I. In Jamaica $\odot$.

Caul, I-3. ped. herbac. erect. ramis oppofitis. Fol, oppofita, breviter petiol. ovata, ferratocrenata, fcabriuf. venofa. Spica fpithompedil. Fl. alterni fubfeffi. Cor, pallide purpur. Sem. 2-locul.

7. curaJavisa, V. diandra; fpicis longis: calycibus ariftatis: fol, ovatis, ferratis. Syft. veg. ed. T4.

Tamonea fpicata. Aubl. Guian, tab. 268.

In Curadao.

8. ftachadifoliz. V. diandra; fpicis ovat-obl, obtuf.: fol. lanceol. ferrato-plicatis : caul. fruticofo. Syjt. veg. ed. I4.

Lavandula Plum, ic. 162. f. I.

V. fuffruticofa. Aubl. Guian. Brow. tab. 3. fo I. Burm. Amer. tab. I62, f. 2.

In Amer. Gallia equinoz.

Rami nodofi. Fol. fubpetiolata. Pedunc, axill. oppofiti, longiff. Cal. parens.

9. Aubletie, V. tetrandra; fpicis folitar. cor, fafciculatis : fol. fubcord. incifo-ferratis. Syft, veg. ed. 14. Jacq. kurt. 2. $t a b$. 176 .

Buchnera canadenfis. Syft. yeg. ed. 13.

Erinus Peruvian. an hujus var.?

In America $\odot$.

Caul. pedal. brachiat. erectus, dichotom. 4-gonus, fubhifpid. Fol. oppofita, petiolata, fublubara, rugofa, fcabriufc. ftipul. nullæ. Spica terminal. folitar. Fl. peduncul. Cor. fanguinea .

80. nodiflore. V.tetrandra; fpicis capitato-conicis: fol. (ovatis) ferrotis, caul. repente. Syjt. veg. ed. 14 . V, capitata, Forsk, Egyp, hac pertinet, monents 
Vahl. Barr. ic. 855. Pluk, phyt, tab. 232. f.4. Burm. Ind. tab. 6. f. 2. fimillima ereda, minus glabra, fol. lanceolat.

In Virginia, \& Sicilia.

Planta albida. Fol, ovata, vel cuneiform. craffa, afpera. Pedunc, axill. foliis longiores. Cor. cœrul.

11. bonarienfis. V. tetrandra; fpicis fafciculat.: fol. amplexicaul. lanceol. Syft, veg. ed. I4. Dill. elth. tab. 300, f. 387 .

In agro Bonarienfi 24 .

Altitudo hña. Caul. hirfutus, bicanalicul, Fol. longa, rugofa, afpera, venis obliquis. Spicze per maturitatem craffiores. Cor. purpur.

12. hofiata; V. tetrandra; fpicis longis, acuminatis: fol. haftatis. Syft. veg. ed. 14. Herm. par, tab. 242.

In Canada humidis 24 .

Priore humilior. Caul. 6-ped. Fol. Urticafor. fpithamam longa, palmum lara, integra, vel laciniata. Spicæ digitum longæ, filiform. Cor, pufilla, purpuro-coerul. $V_{\text {ar. fri. lanceol. }}$

13. caroliniana, V. tetrandra ; fpicis filiformibus: fol. indivitis, lanceol. obtufufc. ferratis, fubfefilibus. Syft. veg. ed. 14. Dill, elth, tab. 301. f. 388.

In Amer. Septentrion. 24.

Caul. fefqui-2. ped. ramofi, hirfuti. Fol. Meliffæ fimil. afpera. Fl. parvi, pallide purpur.

14. urticefolia, V. tetrandra; fpicis filiform, paniculatis: fol. indivifis, ovatis, acutis, ferratis, petiolat. Syft. veg. ed. 14, Sabb. hort, rom. 3. tab. 55 . Moris. hift. 3. f. I1. $t a b .25$, f. 3 .

In Virginia, 6 Canada 4.

Caul. 3-ped. \& ultra, ex albo-purpur. Fol. bre: viter petiol. , duplicato-ferrata, hirfuta, nervofa, fcabra, fature viridia.

15. Spurie. V.tetrandra; fpicis filiformibus: fol, multifido-lacin.: caulibus numerofis, Syft, veg. ed. I4.

In Canada, Virginia.

Differt a V. officin. quod. duplo maior fit.

16. officinalis. V. tetrandra; fpicis fliform, paniculatis: fol, multifido-laciniat. caul. folitar. Syft. veg. es. 34. Fl. Don. T. 628. Ludw. eส. T. 149. Sabb, H. rom. T. 56. Black. tab. 41 .

In Europa ruderatis $\odot$.

Caul. plerumq. pl, 1-2, ped, ramofi, purpur. 
Fol. feffil. oblong. ad bafin anguftiora, rugofa. Fl, axill-terminal. Cor, ex albci-cœrul. vel albo-rufefc. $V_{u}$ r. fol. 3-part, dentiti: quandoq. vix diffectis: \& fummis lanceol-obl. integerr.

:7. fupina. V. tetrandra ; fpicis filifurm. folitar. fol. 2-pinnatifid. Syft. veg. ed. 14.

V. procumbens. Forsh. $\mathbb{E}$ g. hui pertinet monente Vahl.

In Hifpenia.

Caul. fupinus, teretiufcul. fubcompreffus, fubpubefc. Cor. cœrul.

sriyklla.

V. tetrandra ; fl. paniculatis: fol. (plerumq.) ternis: caul. fruticofo. Herit. firp. nov. fifc. 2. $t a b, \mathrm{II}$.

Aloylia Citridora. Ortega, \& Palau. Dilf. $m \mathbb{l}$. In Chile, Bonaria, Montivideo $\hbar$.

Diagnofis.

Caul. fruticofus. Fol, vericillata. Fl. paniculati. Stam. 4. Sem. 2. O.tor. Citri.

Susfrutex totus odore Citrı. Caul. erectus, orgyal. ramofior, odoratus, fubrimofus. Rami Marticillati, terni-quaterni, parentiff. fiabri. Ramuli hexagoni. Fol. verticillata, breviter petiolat. lineati-lanceol. utrimque acuta, patentia, fupra, \& margine vix manifefte muricata, reclinata, fcabra, nervofa, læte viridia, odorariffima, 2-3. pollic. longa, 6-8. lineas lata: iuniora lanceol. laxe dentara, feu ferrata. Panicula villofa, bracteata, inferme fpicis nonnullis immixtis, 3. pollic. longa, $2 \frac{2}{2}$ pollic. lata. Spicæ ternatim verticillaræ, $\mathrm{pa}-$ tentes, imis axillaribus, fummis nonnumquam verticaliter duplicibus. Fl. erecti, feffil., ex violac-albidi, odorati, 2 . lineas longi, $1 \frac{3}{2}$ lin. lati, Filam. 4. breviffima, quorum 2 luper. breviora. Sem, 2.

globiflord. V. tetrandra: fl. capitatis: caul. fruticofo. Herit. Stirp. fafc. 2. tab. I2.

Nepeta \&c. Sloan. Jam. hift. 1. tab. 108. f. 2. In America calidiore $\hbar$.

Differt a $V$. ftochadifol. fol. Lanceol, planis, nec linearibus plicatis: a $V$. triphylla fl. capitatis, nec paniculatis: fol. oppofit. nec verticillat. a $V$. nodiflore caul, fruticofo. 
Frutex humilis, odore gravi, ingrato . Caul, altitudine humana, erectus, cinereus, ramis ramulofis. Fol. oppofita, raro terna, breviter petiol. lanceol. utrimq. acura, patentia, crenata, ima bafi integra, in petiolum attenuata, nervis alternis, erectis, venofiffima, rugofa, villofa, fcabra, reclinata, perfiltentia, fragrantia, I. $\frac{t}{2}$ pollic. longa, 8 . lin. lata, Capitula axillar. pedunculata, fubrotunda, imbricata, bracteata, 3. lin. lata. Fl. albi, $\mathbf{1}, \frac{2}{2}$ lin. longi. Bact, oyatæ, acutæ, hirfutæ, calyc. Iongriores. Stam, brevilima, quorum 2. altiora. Sem, 2.

40. IYCOPUS. Cor. 4-fid. lacinia unica emargin. Stam. diPtantia. S m. 4 retufa.

1. europeus. I. fol, finuato-ferratis. Syft. veg. ed. I4. Sabb. h. rom. 3. tab. 53.

Marrubium \&c, Riv, tal,. 21.

In Europa ripis humentibus 4.

Planta modo glabra; modo villofa. Caul, 2-ped. Fol. varia: 1. $0^{\circ}$ ovato-lanc. acute, \& magnis dentibus incifa. $20^{\circ}$ petiolata, tribus paribus pionarum augetur, $30^{\circ}$ integ.e pinnata. Verticił. fl. denfiffimi. Cor. jarvi, alba. Var. caul., 4-ped. fl. oninibus femin.

2. virginicus. L. fol. xqualiter ferratis. Syjt. veg. ed. I4.

In Virginia 4.

Fol. lanceol. tenuiffime ferrata .

3. exaltatus. L. fol. bafi pinnati fid-ferratis. Syft, veg. ed, 14. Lin. Suppl.

L. fol. in profundas lacin. divifis. Tourn, inf?. In Italic 24 .

Altitudo hña, qua nota a L. europeo differt. Caul. ramofus, angulat. fcaber. Cor. alba, fegment, rubro-punctatis .

41. AMETHYSTEA. Cor. 5-fid. lacinia infina patentiore, Stam. adproximata. Cal. fupcampanul. Sem. 4 gibba.

1. corvilea. A. Syft. veg. ed. 4. Comm. Gottin, 1751. tab. 10. Act. $U_{p \int}$. 1742. f. I.

In Sibiria montofis $\odot$.

Planta fragrans. Caul, erect, pedal. totus ramofus, fem. maturo, cœrulefc. Fol. infer. petiol. fuper. feffil. parva, digitara, 3-fid. ferrata. Flofc. veluti umbellati, comofi, e, cœrul-janthini. 
42. CUNILA. Cor, ringens: lab. fuper. erect, plano . Filam. caftrata 2. Sem. 4.

I. mariana. C. fol. ovatis, ferratis: corymb. terminalibus, dichotomis. Syft, veg. ed. I4.

Calamintha \&cc. Pluk mant, tab. 344. f. 1. phys tab. 163. f. 4. Moris 3. $f$. 11. tab. I9. f. 7 .

In Virginia.

Odor, \& fapor aromaticus . Caul. erect. pedal. lignofi, ramis oppofitis. Fl. fuperne plurimi . parvi .

2. pulegioides. C. fol, lanceol-ovat, bidentat: fl. verticillatis . Syft. veg. ed. I4.

In Virginia, \& Canada $\odot$.

Planta fpitham. brachiata. Fol. fcabriufc. fuper. anguftiora. Verticilli per totam longitudinen caulis. Bract. utrimq. 2. fl. ssaiores, præter alias min. Cor. alba, fauce violac.

3. thymoides, C. fol. ovalibus, integerr, fl, verticillatis : caul. 4-gono. Syf. veg. ed. I4.

Acinos \&c. Moris 3. f. II. tab. 19. f. 6. Monfpelii $(1)$.

Habitus prioris. Caul. erectus, fpitham, ramis paucis, brevibus, fimplicibus. Fol. obtufa, glabra, fubtus friata. Verticil. ut in priore.

4. eapitata. C. fol, ovat. fl: terminalibus; umbella fubrotunda. Syft. yeg. ed..14. Lin. Suppl.

In Sibiria.

Caul. palm. Fol. oblongiufcula, nuda. Cor. purpur. anth. nigra.

43. ZIZIPHORA. Cor. ringens; lab. fuper. reflexo, integro. Cal. filiform. Sem. 4 .

I. capitata, Z. fasciculis terminalibus: fol, ovalibus, Sy/t. yeg. ed. I4.

Clinopodium \&c. Pluk alm, tab, 164, fo 4.

Thymus \&cc. Buxb. cent. 3. tab. SI. f. I.

In Syria, Armenia, Sibiria $\odot$.

Caulic, palm. brachiati. Fol. Acini, fer ma. Fl. terminal. fafciculati. Cor. abfque macula palati, quæ in $\mathrm{Z}$. tenuiore.

2. hispanica. Z. fol ovat. fl. racemofo-fpicatis; bracteis obovat. acut, nervolis. Syft. yeg. ed. I4.

In Hifpania $\odot$.

Caul. brachrar. Fol. petiolata, vix crenata. Fl. terni intra fingulam bracteam. Cor. parva.

3. tenvior. Z. fol, lanceol, A. Jateralibus. Syf, yeg. ed, I4. 
Acinos \&c. Murif. 3. 1. 11, tab. 19. f. 3. 4. In Syria $\odot$.

Var. Z. capitata. Caul, femiped. pubefc. Fol. fæpe integerr. Fl. 3-4. Cor. dilute violac.

ncinoides, Z. fol. ovat, fl. lateralibus. Syjt. veg. ed. 14.

In Sibiria $\odot$.

Habitus Thymi Acinos, fed omnia s-tuplo ma.

Fol. Z. capitata: fl. laterales ut in Z. tenuiore, fed copiofiores. Planta incana. Caul. I-fefquiped. crebro-genicul. Fol. femuncem raro longiora, fæpe breviora, breviter petiol. lavia, rigidiufc. nervofa. Fl. in capitula laxa difpofiti, fuave rubentes.

44. MONARDA. Cor, inæqualis; lib. fuper, lineari, filamenta involvente. Sem. 4.

I. fiftulofa, M. capitul, terminalibus, caule obtufangolo. Syft. veg. ed. 14. Mill. ic. tab. 122. f. 2.

Origanum \&c. Corn. Canad, tab. 14.

b. M. mollis .

In Canada 24.

Tota planta fubincana lanugine pubefcit. Caul. cubiral. ramofi, geniculati, fubhirfuti. Fol. oppofita, 2-3. unc. longa, uñ. lata, breviter petiol. acuta, pauci-crenata, fubhirfuta, dilute virid. Fl. longi, dilute purpurafs. Var. fol. integerr.

2. didyma, M. fl. capitatis, fubdidynamis: caul. acutangulo. Syjt. veg. ed. i4. Trew. Elsret, tab. 36 .

In Penfylvania, Noveboraco 24.

Caul, 4-gon. concavus. Fol. oppofita, petiolata, ovat-acumin. ferrata, fature virid. fumma canefcentia . Nerticilli denfiff, Invol, multiplex. Cor. coccinea.

3. clinopodia, M. fl. capitatis: fol. leviff. ferratis. Syft. veg. ed. 14 .

In Virginia 24.

Facies prioris quoad ftaturam, at fol. Clinopodii incani: fpica purpur, nec fl. tetrandri \& fol. glaberr. Radix repens. Caul. 4-gon. magis quam in prima minus argute quam in fecunda Capitulum bracteis radiatum. Cor. pallida.

4. punzata. M. fl. verticillatis: cor. punctaris : bracteis coloratis. Syft. veg.ed. I4. Sabb.h, ramt, 3, talb.86. 57 . Clinopodium \&c. Morif. 3. f. 1. tab. 8. f. 8. mala Pluk. Alm. tab, 24, f. I.

In Virginie 4. 
Caul. pedal. ignofi. Fol. oppolita, petiol. 2. unc. longa, femunc. lata, angufa, macronata. Bract. fubviol. 4. ma. 4. min. præter fol, verticill. Cor. lutea, punctis purpur.

5. ciliata. M. fl. verticillatis: cotollis involucro longioribus. Syft. veg. ed. I4.

Clinopodium \&c. Morif. hift. 3. f. II. tab. 8. f. 6. Pluk. Alm, isb. I64. f. 3 .

In Virginie.

Caul. pedal. \& ultra, hirtus, ftolonibus procumbentibus. Fol. unci.1. oppofita, petiolata, inferiora fubrotun.; fuper. feffil. longa, \& angufta. Verticil. ampli. Fl. ampli, coerul. lab. fuper. maculis atro-purpur.

45. ROSMARJNUS . Anth. faminum arctifime coniuncta, adeo ut unicam antheram componere videantur filam. liberis. Cor. ringens. Lab. fuperius longum, reflexum, emarginatum; inferius 3-fid. laciniis lateralibus acutis, media ma. oblonga. Galea a lab, inferiore recta divergit.

I. officinalis. R. Syft. veg, ed. 14. Black. tab. 159. Riv. tab. 39. Sabb. h. rom. 3. tab. 67. Luiw. ea. tab. I96. b. R. anguftifol.

In Europe collibus $\hbar$.

Frutex Io-pedal. cultus ramofiff. Fol. feffil, linéar. fupra hilari - virent. fubtus albefient. margine revoluto. Fl. axill. Cal. fubtoment. Cor. fubcoerul.

46. SALVIA. Cor, ringens. Stam. bifurcata, pedicello nimirum, five filamento cor. inferto tranfverfe imponitur filamenturn antheriferum.

r. agyptiaca. S. fol. lanceol. denticulat. fl. pedunculatis. Syft. veg. ed. 14. Jacq. h. 2. tab. 108.

In Átgyto o".

Caul. pedal. ftrietus, brachiatus. Fol, feffil. nuda, fcabra, fubtus rugofiff. odora, parum aromatica. Rami elongati. $S_{i}$ icæ quafi fpinofa, verticillis raris. Bract, parvæ̂. Fl. bini-terni, pedicellati, minutiff. albi: lab. fuper. breviff. emarginato, non compreffo; iofer, 3 fid. in-

2. oretica, S. fol. lanceolatis: punctata. Fl. Sape tetrandri. ed. 14. Pluk. phyt, tab. 57. f. I. Sine flore.

In Cretenfi infula.

Caul, toment, bafi lignofi. Petioli filifor. Fol. 
oppofita, obtufa, crenulata, rugofa, toment. Fol. floralia feffil. ovata, integerr. concava, fubrus tomentofa.

3. Iyrata. S. fol. radicalibus lyratis, dentat, cor, galea breviffima. Syft, veg. ed. I 4 .

Horminum \&c. Morif. Hift. 3. ., 11. tab. 13. f. 27.

b. Horminum Virginicum. Sp. plant. In Europe hortis fl. clandeftinis.

Meliffa \&c. Dill. elth, tab. 175. f. 216.

In Virginia, Caralina.

4. officinalis. S. fol. lanceol-ovat, integris, crenulatis : fl. fpicat. cal. acutis. Syjt. veg. ed. 14. Black. tab. 10. Kniphof. orig. cent. XI. tab. $8 \%$.

b. S. minor aurita, \& non aurica. Black. tab. 71. Kniphof. orig. cent. 2, tab. 79.

In Europe auftralis collibus incultis 24.

Planta aromatica. Caul. frutelcens. Fol. rugola, fubalbida. F!. laxe fpicati. Cal, ruber. Cor. coerul. aut cœerul-purpurafc.

5. pomifera. S, fol. lanceol-ovat. integris, crenulatis: fl. fpicat. cal. obtufis. Syft. veg. ed. 14. Tourn. it. I. $t a b .92$.

S. nivea Allion. auz.

In Creta.

Caul. frutefc. Petioli longiff. Fol. longa, brumali præfertim tempore incana, \& crifpa. Cor. ccerul.

6. urticifolis. S. fol. ovat-oblong. duplicato-ferraris; cal. trident. lacinia fumma trident. Syft. veg. ed. I4:

Horminum \&c. Pluk. alm. tab. 420. f. 1. Morif. hift. 3. f. II. $a b$. I3. F. 3 I.

In Virginia, Florida $\hbar$.

Planta valde hirfuta. Fol. Urtica, aut Scrophulariæ amula. Cor. parva, purpur. lab. fuper.

- brevi. Piftil. lab, fuperiore longius. Var. col. labio Surer. integro.

7. Serutina. S. fol, cordat. ferratis, mollibus: fl. racemofofpicatis: cor. vix cal. excedentibus. Syft. veg. ed. I4. Arduin. Sp. 1. tab. I.

In Chio? os. 5 .

Caul. fuffruticof. fefquiped. brachiat. 4 -gon, vis tomentor. ramis inferior. caulefcentibus. Fol. undulata, tenuiffme ferrata, vix toment. fub tus pallidiora. Spicæ vix peduncul. Cor, cortul Odor Nepetæ ingratus, validus. 
8. yiridis, S. fol. obl-obtuf. crenatis: cor. galea femiorbiculata: cal, fructiferis reflexis. Syft, veg, ed. I4. Jacq. ic. pl. rar.

Habitat ... . ०.

Caul. herbac, fubpilofi. Fol, infer, longe petiol, fuper. feffil. floralia cordata, integerr. Fl. verticilli utrinq. fubterni. Coma viridis. Convenit cum S. Hormino, habitu, fol. modo florendi, odore \&c. In hai flos brevior eft, galea recta: ftyli non porreçi \&c.

9. vifcofa, S. fol. oblong, obtuf. fuberolis, crenatis, vifcidis : fl, verticillatis: bract. cordat. acutis, Sy/t. veg. ed. I4. Jacq. ic. rar. tab 14.

Habitat...

Caul. pl, erecti, fefquiped. herbacei, parum ramofi, ut tota planta odori, \& obfiti villis capitato-glandulofis, \& vifcidis . Fol. petiolata, bafi cordara, obfolete crenulata, rugofa, venola. Verticil. diftantes, breviter peduncul. 6. A. Galea purpuro-fanguin, extus villofo-vifida: lab. infer. col. dilutiore, lacin. lateralibus oblong.

10. Horminum . S. fol. obtuf. crenatis : bract. fummis fterilib. maioribus coloratis, $S_{y f t}$, veg. ed. I4. Gefn, fafc. 17. tab, II. f. 21 .

In Gracia, Apulia, Pedemuntio, fecus arva $\odot$.

Caul. articulat. ramofus, villofus, fubruber . Fol. infer. petiol. fuper. feffil. Fl. terminal. verticillati. Bract, purpuro-violac. rubræ, aut virid.

Ir. Sylveftris.S. fol. cordato-lanceol. undulat. biferratis, (interdum) raculatis : bract. ovat. coloratis, (3-fl.) flore brevioribus. Syf. veg.ed. 14. Jarq. Auftr. 3. tab. 212.

In Germania, Pedemontio, collium Sylvis 4 .

Caul. cubital. fubvillofi. Fol. fubtus villofa, ex incano-fordide virent. Fl. longe fpicati. Cal. quandoq. purpur. Cor. cyanea, purpur. vel alba, galea compreffa.

12, nemorofa. S. fol. cordato-lanceol. ferratis, planis: bract. colorat, cor, lab. infimo reflexo. $S_{y f f}$. veg.ed. I4.

In Auftria, Tartaria $\sigma^{2}$.

Caul. palm-cubital. pubefc. fæpe fufce punctati. Fol, radical. cordata; caulina ovat-lanceo!, 
xqualiter ferrata, fupra nuda, fordide virid. fubtus fubtomentofa, glatica. Spicæ ante efflorefcentiam exacte 4-gonæ, bract. coloratis fl. brevioribus. Galea albido-cœrul. barba faturdtior, lacin. media arcte sub cal. reflexa.

13. Syriaca, S. fol. dentatis; inferioribus repandis: bracteis breviter cordat, acutis: cal, tomentofis. Syjt. veg. ed. I4.

Horminum \&c. Bauk. prod, tab. 114.

In Oriente, Palefinina.

Planta 2-triennis, fuaveolens. Statura S. pratenfis. Caul. obtufe angulati, pilofi. Fol. radical, elliptica, petiol: fuper, ovata, feffil, rugofiff. fubtoment, Panicula brachiata, virgdta. Bract. cal, breviores, cordatæ, Fl. in quolibet verticil, 6. Cal. tomentofus. Cor. parva, alba. Styl. galed duplo longior.

I4. kamatodes.S. fol, cordato-ovat, rugofis, tomentos, calycibus hifpidis: radice tuberofa. Syft. veg. ed. 14. Triumph. obf tab. 69. Barr rar, tab. 185.

In Italia, Iftria 24.

Planta tota hifpida. Caul. erect. vifcidus. Fol. repanda, fuora lavia, maculis ferrugin. fumma parva, feffil: Verticilli multifl, aridis bract. inftruati. Pedune, inæqual. Cor, cœrul. S. Sylv. lab. fuper. falcato; infer. 3-fid. media latiffima, emarginata, faccata, reflexa: flyl. galet longior. Anth. nigræ.

35. auftrieca. S. fol. cordat-ovat. crenat. incifis, vel lobatis, fupra nadis: caul. calyc. bracteifque hirfutiffim Syft. veg. ed. I4. Jacq. Auftr, 2. tab. 11 2.

In collibus herbidis.

Caul. I-raro 2-ped. fimpl, vel fuperne ramof. villof. Fol. radical. in orbem pofita, lata, obtufifl. pinnatifide incifa, inæqualiter ferrata, magis, minufve cordate, rugofa, fupra atrevirent. glaberrima, fubtus pallida, petiolat. caulina feffil. minora, acuta. Bract. cordati, integræ. Fl. terni, breviter peduncul. Cal. glurinofus. Cor. albida, vel pallide ochroleuca.

16. pratenfis. S. fol. (inferior.) ovat-obl. (caulinis cordato. fagittatis ) crenatis; fummis, amplexicaulibus: verticillis fubnudis : cor. galea glutinofis. Sy th veg. ed. I4. Black. tab. 258 ,

In Eurepe pratis 4. 
Caul. cubital, inferne pilofi. Fol, infer. longe petiol. quandoq. finuata, fquallida. Verticilli ad 6-fl. diffiti. Cal. coloratus. Cor, purpur. corul, rubra, alba. Var. fol, profundius incifis.

37. indica. S. fol, cordatis, lateralibus lobatis: fummis feffilibus: verticillis fubnud, remotiffim. Syft. veg, ed. 14. Jacq. H. I. tab. 78 .

Horminum \&c. Morif. hiff. 3. f, Ir, tab. 13. f. 16. In India 24.

Caul. 3-ped. herbac. 4-gon, obtufus, albo-pilof. uti petioli. Fol. rugofd, nudiufc. fubtus pilo$f_{d}$, fuberofa, petiolata: floralia parva, acuta, integra. Cor, magna, cœrul, lab. fuper, compreflo, emargin. inferiore 3 -fid. intermedia magna, faccata, biloba, fundo albido, lobis maculis violac. margine albo, mox iuteo.

I8. dominica. S. fol. cordat, obtufis, crenat. fubtoment. cor. calyce angutioribus. Syf, veg. ed. I4.

In Dumingo.

19. Verbenaca. S. fol. finuatis, ferratis, laviufe. cor. calyce anguftioribus. Syft. veg. ed. I4.

Horminum \&c. Barr, ic. 208. Triumf, obf. tab. 66.

In Europe, \& Orientis pafcuis 24.

Caul. frutic. ramis oppofitis. Fol. radical. humifufa, Verbenæ form. fed apice rotundiore, petiolata. Fl, fpicat-verticillati. Cor. purpur.

20. nilotica. S. fol. finuar. angulatis, crenato-dent. calycin. dentibus fpinofis; angulis, margineq. faucis ciliatis. Syft. veg. ed. 14. Comm. gott. 1778, tab. 2. Jacq. H. 5. tab, 92.

Odor, \& fapor paucus, nec gratus. Caul. 2pedal. eresti, vel adfcendent. ramofi, hirfuti, fubvifcofi. Fol, oppofita, fubvifcofa, utrimg. villofa, rugofa, venofa, mollia; infima obl. obrufa, longiufcule petiolata; fubfequa ovata; fumma feffil. curdata, acuta. Fl. in caule $e-$ longato, \& ramis: verticilli diftantes, 6-fl. bracteæ parvæ, cordatæ, acuminatæ. Pedunc. femper horizontal. Cor. exigua, purpuro-corul.

2r. nubie. S. foil. lanceol-ovat. duplicato-crenat. tubo cor. incurvato. Syjt, veg. ed. 14. Comm. gott. 1778. tab. 3 .

In Nubin, \& Abiffinia.

Habitus tomentofus . Caul. erectus, fefquiped. ramofus . Rami decuffatim oppofiti, prater in- 
fimum. Fol. cordata, rugofiff. radicalia multa, petiolata, fefquipalm, obrufa ; caulina feffil. latiora. Spica decompofita: fpicula ovaræ, verticilli 6-fl. Bract. latæ, cordatæ. Cal. corul-virid. Cor. calyce longior, tubo albo, limbo pallide ccerul.

22. clendeftine. S. fol. pinnatifid. ferrat. rugofifumis: fpica truncata: cor. calyce anguftioribus. Syft. veg. ed. 14 .

Horminum \&c. Barr. rar. tab, 220.

In Italia $\sigma^{\circ}$.

Herba S. Verbenace: fol. S. ceratophylle, pumila; unde potius var. S. Verbenaca.

Caul. adfcend. fpitham. 4-goni, obrufi, villofi ; ramis fuperne fæpe 2. Fol. petiolat, oblong. obtula, crenata; in caule $2-3$. paria. Verticil. remoti. Bract. cordatæ, 3-fl. Cal, pilis glutinofis. Cor. violac. labii infer. lobo medio albo.

23. pyrenaica. S. fol, obtuf. erofis: ftaminibus cor. duplo longioribus, Syft. veg. ed. I4.

Horminum \&c. Herm. par. tab. 187.

24. difermas. S. fol. (plerumq. ovato-lanceol.) erofis: ftaminibus cor. æquantibus. Syft. veg. ed. 14. Arduin. Spec, I, tab, 1.

Horminum \&c. Barr. ic. 187. bona .

In Syria 4.

Planta tota pubefc. villis apice glutinof. Caul. 2-3. ped. erecti, frutíc. ramofi. Fol. rugofa. Brdct. cordata, acutiufc. villofæ. Cor. alba, lab. fuper. erecto; infer. concavo, lacin. lateralibus porrectis. Anth, exertæ. Siyl, albus. Fol. in caldario cordata.

25. mexicane. S. fol. ovat. utrimq. acuminat. ferratis. Syft. veg. ed. I4.

Sclarea \&c. Dill. elth, tab. 254. f. 330.

In Mexici humentibus $\hbar$.

26. hifpanica. S. fol. ovat. petiolatis, utrimq. mucronatis: fpicis imbricat. calycibus 3 -fid. Syft. veg. ed. 14. Kniph. orig. tab. 2. Sabb. hort. rom. tab. 22. Arduin. Sp. $t a b, 2$.

Selarea \&c. Tabern. Hift. ic. 374.

In Itulia, Hifganic $\odot$.

Caul. fefquiped. 4-gon. obtufus, 4-fulcat. fuperne pilis reflexis, albis obfitus. Fol. acuta, ferrata, rugofa, bafi aeuta. Spica 4-gona. Bract. 
ovatæ, ciliatæ. Cor. cœrul. galea breviore fubvillofa; lab. infer. bafi maculis 2 . pallidis. 27. verticillata. S. fol. cordat, crenato-dent, verticillis fubnud. ftylo cor, labio infer. incumbente. Sy/t. yeg. ed. I4. Kniph. orig. VI. tab. 79.

In ruderntis 4.

Caul. pilofus, fuperne purpuro-violac. Fol. pilofa, rugofa, fcabra, Pedunc. purpur. Cor. violac-purpur. fauce patula; galea ovali, 2-fid. claufa, bafi coarctata.

28. napifolia. S. fol, cordat, crenato-dent, verticillis fubnud. cor. labio fuper. cordato-emarginato. Syft. veg ed. 14. Jacq. Hort. 2, tab. 152.

In Caldario.

Habitus, \& fol. S. verticillate: cor, vero fature purpur. labio fuper. cordato, emargin, obtufo, patente; inferioris laciniæ laterales fubovatæ. Fol. radical. terræ incumbentia.

29. virgata. S. fol. cordat. cresatis, erofis, rugofis: verticillis in ramis virgatis longiff. Syft. veg. ed. 14. Jacq. hort. 1. tazb. 37.

Caul, erect. 4-ped. hirfutus: rami longi, ad angulum acurum adfcendentes. Fol, radical, obl. obtufa, petiolata, finuato- undulata: caulina infer. petiol. fuperiora feffil. crenato-dent. vix hirfuta. Bract. cordat. acut, integra. Fl. terni , breviter peduncul. Cor, nivea; pallide rofea; cœrulef́c.

30. glutinofa. S. fol, cordato-fagittat, acutis, ferratis. Syft. veg. ed. 14. Kniph. orig. IV. tab. 70. Sabb. hort. rom. tab. 21 .

In Europe umbrofis 4.

Planta vifcida odore ingrato. Caul. cubital, ramofus. Fol. longe petiol. hirfuta; infer. palmaria. Spica Jaxa. Verticilli 6-fl. Cal. trilobus. Cor. ampla, falcata, flava, fufco-punctata; lab. infer. intermedia crenata.

3I. canarienfis. S. fol. haftato-triangularibus, oblong. obtuf. crenatis. Syft. veg, ed. 14. Kniph, orig. cent. 6. tab. 77.

Horminum \&c. Morif, hift. 3. f. II, tab. I3. f. 17. Pluk, phyt, tab. 30r. f, 2.

In Canariis b.

Altitudo humana. Caul, tomentof. Fol. longe petiolat. rugofa, cum binis auriculis: caulida Tom, $I$. 
parva, mucropata, fubrubent. Geniculi rari,

Cor. ampla, purpur,

32. africane, S. fol. fubrotundis, ferratis, bafi truncat. dentatis. Syft, veg. ed. 14. Comm, hort. 2. tab. 9I. Horminum \&c. Pluk. alm, tab. 301. f. 2.

Ad cap, b. Spei, locis argillojis 24.

Caul. 3-4. ped. rąmofus, dein fufcus. Fol, unc. longa, mediam laia, fubpetiol. rigida. Caul. \& pedunc, araneofa lanugine obfiti . Cor. violac.

33. nurea, S. fol. fubrot, integerr. bafi truncatis, dentat. Syjt. veg. ed, 14.

S. africana \&c. Comm. kort. 2, tab. 92.

Ad cap. b. Spei iuxta rivulos 5 .

Caul. 4-pedal. lignofus, ramofus, fufcus. Fol. craffa, glauca, maiora plicata. Fl. inagni, aurei. Cal. campanul, trilobus, bafi viliofus ,

34. colorata, S. fol. ellipticis, fubintegerr. tomentofis: cal. limbo membranac. colorato. Syjt. veg. ed. I4. Ad eap. b. Spei litora maris,

Caul. 6-ped. inferne radicantes. Fol, pollic. petiolata ; inferioña ferrata, raro auri ulata; fumma integerr. Cal. campanul. laciniis rotundatis; demum evafuri ampli, fcariofi, fanguinei.

35. peniculate. S. fol. obovat-cuneiformibus, denticulatis, nudis : cau'. frutefcente. Syjt. veg. ed. I4. Morif. hiff. 3. f. I1. tab. 16. f. 1. Mill. ic. tab. 225. f. 1. Breyn, cent. tab, 5 .

In Africa $\hbar$.

Caul. erect. frutefc, teres, purpurafc. fcaber. Fol. parva, fubpetiol. venofa, lavia. Cal. 3 -fid. vix pilofus. Cor. cœerul. galea labio vix longior. Stylus cor, longior.

36. soccinea, S. fol. cordat. ovat, acutis, ferratis, fubtus molliffime tomentofis: racemo terminali, verticillato. Syft. veg. ed. 14. Lin. Suppl. Comm. gott. 1778. tab. 1 .

In IEthiopia 44.

Habitus tomentofus, Caul. pl, recti, fed debiles, 3-ped. Rami elongati, oppofiti, patentes. Fol. petiol. obtufe ferrata, rugofa, varie fle$\mathrm{Xa}$, fature virid. fupra pubefcentia. Petioli patentifl. fufci. Spica elongata, verticill. 6-fl. Pedunc. fufci. Bract. 2. oppofitæ. Cor, magna, coccinea, extus tomentofa. 


\section{DIANDRIA MONOGYNIA.}

37. acetabulofa. S. fol, obovat. dentat. cal. campanulatis, patentibus pilofis: caul. fruticulofo. Syft. veg. ed. I4.

In Oriente $\mathrm{b}$.

Rami brachiati . Fol. petiolata, verfus bafin dentara, fubtus tomentofa. Racemi elongati, remote verticillati, Fl. utrimq. 3. pedicellati; Bract. ovatæ, acumin. integerr. ciliatæ, glabræ. Cor. albida, lab. fuper. 2-fid. patulo, non falcato, feu elongato; infer. 3-fido, media ma. Stam. longitudine cor. Stylus cor. duplo longior.

38. Spinofa. S, fol. oblong. repandis: cal. fpinofis: bracteis cordat, mucronat. concavis, Syft. veg. ed. 14. Horminum \&c. Morif. hift. 3. f, I1. tab, I6. f. 2. In Agypte $\sigma^{\circ}$.

Caul. pedal, obfolete 4-gon. brachiat. hirfutus. Fol, petiol. fubcord. feu ovata, obtufiufc. rugofa, fubtus magis pilofa; fumma acumin. feffil, ferrato-crenata. Verticill, utrimq. 3-fl. feffiles. Cor. alba, galed erecta, fubfalcata, emargin. longitudine tantum lab. inferioris. Lab. 3-fid. media ma. concava, 2-luba, lateralibus deflexis, Stam. alba, galea longiora. Anth. flavæ. Styl. purpur.

39. Sclarea. S, fol, cordat, oblong. ferrat., rugofis, villofis: bracteis coloratis cal, longioribus acuminat. concavis, Syft. veg. ed. 14. Ludw, ea. tab. I7 1 ,

Horminum \&c. Blackw, tab. 122.

In Syria, Italia $\sigma^{\prime}$.

Altitudo humana. Fol. magna, canefcent. Hircum olentia, Fl, yerticill. Cor, purpuro-cœrul.

40, ceratophy lla. S. fol, pinnatifid. rugofis, albefcentibus: verticillis fummis fterilibus. Syft. veg. ed. I4. Kniph, arig. cent. 6. $t a b, 78$.

Horminum \&cc. Pluk. elm. tab. I94. f. 5. Moris. hift. 3. f. II. tab. 3. f. 6.

In Perfia or.

Caul. pedal, \& ultra, ramofus. Fol. radical. in urbem pofita, pallide virid. in patrio folo incana; floralia mucronata, margine e viridi purpurafc: Cor. purpuro-violac.

4I. Ethiopis. S. fol, oblong. erofis, lanatis: verticillis lanatis: cor. labio crenato: bracteis recurvatis, 
fubfpin. Syft, veg. ed. I4. Jacq. Auftr. 3.tab. 211. Sabb. h, rom. 3. tab. 23. Barr. rar. tab. 188.

Marum \&c. Veft. alp, tab. 212.

In Europa o".

Altitudo fere humana. Caul. articulatus, ramo. fus. Fl, verticillati. Cor, diluce carnea Lab. infer. antice cohoret, \& Jaccum format.

42. pinnate. S. fol. lyrato-pinnatis, Syjt. veg. ed. I4. Boerh. Lugd. 1. tab. 167.

Horminum \&c. Pluk. alm. tab. 164. f. 6. In Oriente, \& Arabia.

Caul. pilofus. Fol. erefa, impari ma. fupreme minus pinnard. Cal. hirtus, ovatus, inflatus, ore compreffo, obtufo, abfq. dentibus. Cor. non falcata, parva, purpur.

43. argentea. S. fol. oblongis, dentat-angulat. lanatis: verticil. fummis fterilibus: bracteis concavis, $S_{y} f$. veg. ed. 14.

In Creta o .

Media inter S. Sclaream, \& Aethiopem. Fol. erofa, in fterili maxime tomentofa. Panicula minus brachiata, pubefcens, vifcofa, ramorum fummitatibus fterilibus, quafi fpinufis . Bractea muticæ. Cor. alba, galea purpurafcpubefcente; lab. flavicante. Siylus cor. longior.

44. eeratophylloides. S. fol, pinnatifid. rugofis, villofis: caule paniculato, ramofiffimo. Syft. yeg.ed. 14. Ardo fp. 2. $t a b .2$.

In Sicilia, Rgypto.

Media inter $S$. clandeftinam, \& ceratophyllam. Caul. pl. fefqui-2 cubital, \& ultra, brachiato-ramofi, pilofi, fuperne punctis arro-purpur. adfperfi. Fol. infer. petiol. profundius pinnatifida ; fumma feffil. finuata; pinnulis 2 . inferio. ribus auriculat. FI. ldxe verticillari . Bract. fub quolibet verticillo 6. In cateris partibus frudificat converit cum $S$. pratenfi.

45. Forskalei. S. fol. lyrato-auriculat. caule fubaphyl. cor. gak lea femibifida. Syjt. veg. ed. 14.

In Oriente 4.

Caul. fecundi anni florens, erect. fefquiped. Ra. mi 2. oppofiti, infra verticil. infinum. Fol. radical. ovata, obtufa, repando-crenata, vil- 
lofa, virid. Bract. cordatæ, acura, integerr. Verticil. utrimq. 3-5. A. Cal. pilis vilordis. Cor, cœiul. calyce triplo ma. Galea filcaia, femi 2 fid: lobs incumbentibus. Lab. 3-lob. intermed. 2-luba, ma. crenata, bail punctis cœerul, reticulatum. Stylus cor. duplolongiur. Facies $S$, nutentis.

46. nutans. S, fol. cordatis inæqualiter bafi excilis: caul, fubnudo: fpicis ante florefcentiam cernuis. Syft. veg. ed. 14. Nov. Aa. Petrop. T. I. tab. I4. Comm. gott. i75r. tab. II.

In Imperio Rutheno 4.

Caul. 2-cubit. totus rumolus, incanus. Fol. ram dical, petiolata 5. fere unc. longa, \& 4 . circa bafin lata, fupra intenfe virid nitida, obtufa, rugofa, fubundulata, crenata; caulina infer. petiol. fumma feffil. fpicæ ternæe. Cor. labium fuper. viviac. extus punctis candidis.

47. aby Jinica. S. fol. cordat-ovatis, rugofis, erofis: bract. integerr. lavibus. Syf. veg. ed. I4. Lin. Supplo An S. nubia Murr.?

In Abylfinia.

$\mathrm{C}\rfloor$ ul. pedal. erect. fimpl. herbaceus, obtufe 4gon. fcaber. Fol, radical. cordat-obl. fereq. lanceol obtufiufc. bafi trinerv. viridia: caulina 2-3. iuga, margine fere erofa, bafique fublaciniata : fumma feffil. Panicula brachiata $\mathrm{ex}$ verticil. 6-fl. fubaphyllis. Cor. corul. Odor Humuli gravis .

48. triloba. S. tomentofa; fol petiolat. rugofiff. trilobis; lobo intermedio producto, oblon., lateralibus ovat. obtufis. Syft. veg. ed. 14. Lin. Suppl.

In monte Sypili $\hbar$.

Habicus S. afficin. Tota cana ex tomento. Singuldris fuliis bafi quafi auriculatis.

49. aurita. S. villofa; fol, ovato-dentatis, auriculatis: fl. verticillato-f picatis. Syft, veg. ed. 14. Lin. Suppl.

Ad cap. b. Spei.

50. fcabra. S. fatbra; fol, lyrato-dentat. rugofis: caul. paniculato-ramolo. Syf. yeg. ed. 14. Lin. Suppl. Ad cap. b. Spei.

y1. runcinata. S. fcabra; fol. runcinato-pinnatifid. dentat.: flo fpicatis, verticillatis. Syft. yeg. ed. 14. Lino Suppl.

did cap. b. Spsi.

E iij 
52. japoniea. S. fol. inferior. 2-pinnat. glabris. Syfto veg. ed. 14. Thumb. Jap. tab. 5 .

In Japonia $\odot$.

Differt a S. pinnata, cui adfinis, fol. inferior. 2-pinnat. plantu infra nuda, glabra: fl. paniculato-yerticillat.

Caul. I-2. ped. fimpl. erect. glaber. Fol. pinnis ovat. acut, fubpetiol. finuato-dentat. fuperiora pinnata, brevia, petiolata: fumma, feu peduncularia lanceol. integra. Fl, verticillati, paniculati, panicula trichotoma. Bract. lanceol. glabræ. Cor. duplo longior calyce, extus pilofa, rubra.

mierjamua.

S. fl. verticillatis, feffilibus, coerul. caule fubnudo: fol. oblong. fubcrenat. rugofis. Forsk. Eggp. In Arabia.

formosa. S. fol. fubcordat. cor. galea barbata: calycibus trilobis: caule frutefcente. Herit, ftirp. fefc. 3. $2 a b .21$.

S. pyrifolia . Domb. per. MSS.

S. Leonura. Piä. reg. \&c.

In faxofis Perue b.

Suffrutex venuftus, altitudine humana. Caul. erectus, brachiatus, fubnodofus, laxe rimofus, cinereus . Rami, \& ramuli oppofiti, patentes, bafi denudati, rufi. Fol. oppolita, fat denfa, petiol. patentia, in horto obtufufcula, crenato-ferrata, fubrugofa, venofa, fubcoriacea, virentia, fubtus fquallide pallidiora, plana, fragrantia, 2-3. poll. longa, 2 . pollic. lata. Fl. plurimi, fecus turionem axillar, uti vertiticillati : in horto fæpius s,e fingula ala, quorum inferi 2 ferotini, pedunculis horizontal, coccin. I, $\frac{3}{2}$ poll. long. Pedunc. breves, $\mathrm{pa}-$ tuli, I-fl. apice articulati. Bract, nonnullæ, duæ ma. e fingulo latere fingula, foliac. acutæ, reflexæ. Cor. lab. fuper. rectum, elongato-galearum, fubintegrum, denfe barbatum, lateribus conniventibus, Lab. infer, ad angulum rectum dependens, fubrotun, obtufum, 3-fid. villofum; Jacin. lateralibus obtufis; extima lata, brevi, emarginara.

Spielmunio S, caule, ramifque verticillo terminatis: $\mathrm{fl}$, me- 
dio erecto; cæteris horizontalibus patentibus. Scop. Delic. Infub. fafc. 3. tab. 15 .

Habizat ....

Caul. fub 2 ped. obtufe 4 -gonus, rigidus, pilofus; ramuls angulum acutum cum caule efficientibus ramulufis. Fol. ovara, crenata, rugofa, nervo medio dimidia parte albicante; inferiora petiolata, fuperiora fefflia. Verticil. 6-10-fl. remoti. Cal. io. angulat. dentibus brevi, rubella fpinula terminatis; villofus. Cor. rubro-violac, galea obrufa, compreffa, villofa, labio vix longior: labio pallidiore, trilobo; lubo thedio maiore, emarginato, fubrotundo, furfum concavo; lateralibus parvis, obrufis, fubetlipricis: tubo albo. Sem. 2-4. fufca.

47. COLLINSONIA. Cor, inæqual. lab. infer. multifido, capilluri. Sem. 1. perfectum.

1. canadenfis, C. Syft. veg. ed. I4. Act. Upf. 1743. pag. 85. Cold. noveb. 8.

In Virginia, Canada fylvis 4.

Caul. fimpl. vel brachiar. Fol. magna, oppofita, longe petiol. ovato-acumin. ferrata. Spica laxæ. Cor, dilute lutea. Odor Meliffa.

48. MORINA. Cor. inzequal. Cal. fruetus I-phyll. dentat. Cal. floris 2-fid. Sem, I. fub calyce floris.

1. perfica. M. Syft. veg. ed. I4. Tourn. it. 3. tab. 132. In Perja ad Hifpalian 4.

Caul. 2-ped. \& ultra, purpurafi. Fol. Carlinze æmula, 4-5. poll. long, pollicem lata; lacinits undulatis, fpinis fubluteis. Fl. fpicati, albi, aut purpur. margine albefcente, odore Caryophylli.

49. GLOBBA. Cor. æqualis, 3-fid. Cal. fuperus, 3-fid. Capf. 3-locul. Sem. plurima.

1. marantine. G. fpica terminali, erecta. Syft. veg. ed. 14. In India orient. 24.

Catul. herbac, fimpl. Fol. alterna, petiolata, (omnino Marantre) petiol. membranac. vaginantibus vaginis apice truncatis. Spica fl, remotis : bract. ovatæ, fl. longiores.

2. nutans. G. fpica terminali, pendula. Syft. veg. ed. I4. Rumph. amb. 6. tab. 62, 63. (In Suppl. hos Synon. ad Renealminm pertinet.)

In Indin Orisus. 
Datur ma. \& min. In ma. caul. 14-18. ped. Fol. alterna, 3-ped. \& ultra, 2-palmos lata, tenuia, glabra, venis paralell. tranfuerfalibus. F1. rubri. Fruet. ovi columbini magnitudine, rubri. In min. caul. 2-3. ped. 2-phyl. Fol. magis vaga, \& angufta; inferiora acut. Fl. racemofi, albi, rufi, lutei .

3. uniformis. G. fpica laterali. Syft. veg. ed. I4, Rumiph, amb. 6. $t a b .69$. f. 2 .

In India Orient. 24.

Radix articulata. Caul, I2-14. ped, in Amboina 7-8. Fol. poll, 14-16. longa, 5-6. digit. lata, fupra glabra, intenfe virid., fubtus lanuginofa, pallidiora. Fl, albidi. Baccæ paulo ma. uvis, albefcentes; ficcæ nigræ, e rotundo-angulofæ.

4. japonica. G. racemo terminali cernuo: fol, enfformibus, integris. Syft yeg. ed. 14. Thumb. Jap.

Jamma Myoga. Kemp. Amen. ex. Fafc. V. pag. 827.

In Japonia.

Sc p. 2-ped. \& ultra, fimpl. fol. vaginatus, ftriatus. Fol. pauca, pedalia, 2-poll. lata, glabra, fupra fature viridia, fubtus pallidiora. Fl. multi . Capf. ovata .

50. THOUINIA. Cal. 4-part. Cor. 4-pet. Anth. feffiles.

I. nutans. T. Syft. veg. ed. I4. Lin. Suppl.

In Zeylona.

Arbor glabra. Fol, oppofita, breviter petiol. elliptica, obtufufc. integerr. glaberrima, venofa. Panicul, axill. folitar. Fl. nutantes, purpur. Singularis eo quad ftam. singulum conttiset 2. petala.

3I. ANCISTRUM . Cal. 4-ariftat, ariftis terminatis glochidibus cruciatis . Cor. 4-fid. ftigma penicillatum.

1. Sanguiforba. A. Syft. veg. ed. I4. Lin. Suppl. A. Anferinafolium . Forft. Gen.

In nova Zeelandia.

Herba, \& efflorefcentia refert Sanguiforbam. Fol. alterna, impari-pinn, foliol. cuneiform. profunde ferrat. fubtus canis. Stipul. profunde jncifa. Pedunc, terminal. folitar. longus. Cà pitulum globofum, fl, aggregatis. Cal, cum cor. extus hirfutus. Singularis ariftis calycir. lateis, glochidatis, feu hamis vulpium fimilibus. 


\section{I G Y N I A.}

52. ANTHO- Cal, gluma 2-valv. I-fl. Cor. gluma 2-valv. XANTHUM, acumin. fem. I. Avence proximum eft, fed duobus tantum faminibus a reliquis Graminum generibus diftingultur.

I. aculeatum. A. fpicis fubglobofis: involucr. foliaceo, brevi, mucronato. Syjt. veg. ed. I4. Lin. Suppl.

Schonus aculeatus $f p$. plant.

Agrostis aculeata. All. Fl. Ped.

Phleum Schanoides. Jacq. Auftr, r. tab. 7. Schreb. gram. tab. 32. Licet Jacq cum Lin. iun. duo ftam. modo numeret, ob defeäum tamen neçarii, ariftalium dorfalium, removet ab hoc genere; \& vel Phleis adnumernatum, vel pro fingulari genere habendum cenfet Jacq.

In Hifpania, Sibiria, \& agro Nicaenfi 24.

Culm. pl. diffufi, palm. ramofi, vaginis fol. veftiti. Fol. Graminea, lavia, margine fcabra; fuper. fenfim latiora. Spica fubglobofa, fere faftigiata, fl. fere feffilibus in finu involuc. Involuc. 3-phyll, foliaceum, fpica paulo longius . Foliola feffil. ovata, oblonga, apice mucronata. Tertium in finu paucos fl. continet. Reliqua, glumæ inftar, fl. in capitulum fipicatos gerunt.

2. Qdoratum. A. fpica obl, ovata: flofc. fubpeduncul. arifa longioribus. Syft. veg. ed. I4. Fl. Dan, tab. 666. Schreb, gram, tab. 5. Scillingbl. mifc, tab. I. Gifech. ic. fafc. I. f. 2.

Gramen Alopecurum \&c. Moris. Hift. 3. tab. 7. f. 25 .

Gramen avenaceum \&c. Monti. ic. 84 .

In Europa pratis 24.

Culm. I-2, ped. Fol. hirfuta, fuper. breviter lanceol, attrita odore Afperula odorata. Spica ex finu folii, laxa, flavefcens. Gluma glabræ. Var. Spica multo longiore, \& interrupta.

3. indicum. A. fpica lineari; fofculis fefillibus, arifta brevioribus. Syft. veg. ed. I4.

In India.

Caul. pedal, adfcendens, articulatus. Fol, breyia, lata. Spica anguftiff, rara. 
4. criniıum. A. penicula fpicafor, cylindrica, ariftata, ariftis longis, patentibus, laxis. Syft. veg. ed, 14. Lin. fuppl.

In nova Zeelandia.

Gramen altum, glabrum. Panicula coarctata , Gluma corallina, ariftata.

5. panisulatum. A. fl. pasiculatis. Syft. veg. ed. I4.

Gramen \&c. Rudb. elys. I. f. I4.

In Europa auftrali.

Habitus A, odorati. Panic. flavefc, Cal, 4-fl, Fl, mutici .

avenaceum, A. fpica fecunda: calyc. pilos: flofculi arifta longa, torta, g=niculata. Retz. Obf. falc. 3. In Tranquebaria.

Facies om ino Avera propter ariftas, fed ftam. tantum 2.

\section{T R I G Y N I A.}

53. PIPER. Cal. o. Cor. o. Bacca monofperma .

I. nigrum, P. fol. ovat. fubleptemnerviis, glabris; petiol. fimpliciff. Syft, veg. ed. 14. Pluk. alm, tab. 437. f. I. Moris, hift. 3. 1. 15. tıb. 1. f. 1. Black, $t a b, 348$.

Melago codi. Rheed, mal. 7. tab. 12. In India $\hbar$.

Caul. articular. dichorom. fpongrofus, lævis. Fol. alterna, periolat, obtufiufc. crafla , integerr. Spica oblong peduncul, conftans baccis multis, feffilibus.

2. Betle. P. fol. oblonginfc acumin. 7-nerviis, petiolat. 2-dentat. Syft. veg. ed. 14. Burm. Zeyl. tab. 82. f. 2 .

Beteld-codi . H. mal. 7. tab. 15. In India $\hbar$.

Caul angulati, ftriati, læves. Fol. bafi fubobliqua, Spica cylindrica, fæpe pendula.

3. Malamiri. P. fol, ovat. acutiufcul. fubtus fcabris: nervis

5. fubtus elevatis. $S_{y j}$. veg. ed. I4. Siriug. Rumph. amb. 5, tab. I16, f. 2 . 
Amalago. H. mal. 7. tab. $\div 6$.

In India utraque.

Frutex caul. volubili, ftriato, tereti. Fol. tenuia, fupra virid. fubtus cinereo-fcabra .

4. Amalago. P. fol. lanceol-ovat. 5-nerviis, rugofis. Syft. veg. ed. 14. Sloan, hift. 1. tab. 87. f. 1.

P. frutex \&c. Pluk, alm, tab. 215. f. 2. Rumph. $a m b$. 5. tab. 116 . f. I.

In Jamaica .

Rami flagelliform. Ad nodos folia folitaria, $5-6$. poll. longa, palmum lata, petiolata, fupra glabra, parum nitida, quandoq. auriculara. Pedunc. axillar. Var. fol. ma, nigrovirentibus, aut flavefcentibus.

5. Siriboa. P. fol. inæqualiter cordatis, fubfeptemnerviis, venofis. Syjt. veg. ed. 14. Rumph. amb. 5. tab. 117 . f. 2.

Betela. Bont. jav, tab. 9r.

In India.

Caul. lavis. Fol. fpithamea, alterna, petiolata, acuta . Spica tenuis, angufta.

6. longum. P. fol. cordatis, petiolat. feffilibufe. Syft. veg. ed. I4. Black, tab. 356. Rumph. amb. 5. tab. 116. f. 2, Pluk. alm. tab. I04. f. 4 .

Cattu-tirpali. Rheed. mal. 7. tab. 14. In India .

Facies Ariftolochiæ Piftolochiæ. Fol. fuper. fæpe feffil. anguftiora. Rami dichotomi.

7. decumanum. P. fol. cordatis, 9-nerviis, reticulatis. Syft. veg. ed. 14.

Saururus \&c. Plum, Am, tab, 6.

Sirum \&cc. Rumph, amb. 5, tab, 27.

In Indiis $\hbar$.

Adfinis nimis $P$. reticulato, ut forte varietas.

Caul. articulat. Fol, magna, fub 7-pedal. 5-6. poll. lata, petiolata, rugofa, fcabra, fubtus pallidiora; inferior fol, pars plerumq. brevior eft fuperiore. Fruct. primum pallide vir:dis, dein fufcus.

8. reticulatum. P. fol. cordatis, 5-ilerviis, reticulatis. Syft. veg. ed. 14.

Saururus \&c. Plumi, Am, tab. 75.

Jaborandi , Marcgr. bras.

In Martinica, Brafilia.

Frutex farmentofus, fcandens. Spica axillar. 
9. aduncum. P. fol, ovat-lanceol, nervis alternis: fpicis uncinatis. Syft. veg. ed. I4.

P. longum \&c. Slonn. Jamb. I. tab. 87. f. 2.

Saururus \&c. Plum. Am. tab. 77.

In Janaica.

Frutex. Caul. pl. ramofi. Fol. Lauriform. 8. poll. longa, 3. lata, rudia, fubrus faturatiora. Fruct. aduncus .

10. pellucidum . P. fol. corlatis, petiolat. caul. herbaceo. Syft. veg. ed. 14. Hort. cliJf. tab. 4.

Saururus \&c. Plum. Am. tab. 72.

In Americn calidiore $\odot$.

Caul, pedal. anceps, unctuofus, fubdiaphanus: rami alterni, ramofi. Fol. Cub fingulo rumo unicum, fubrotundum, alb fcens, fubdiaphanum. Spicz axill. longitudine digiti dimidii . Fl. \& fpica virid. Comeditur crudum ut Lactuca.

11. acuminatum. P. fol. lanceol-ovat. nervofis, carnofis. Sy/ veg. ed. 14 .

Saururus \&c. Plum. Am, tab. 7 i.

In America calidiore.

Similis obtufifolio, fed fol. acuminata .

12. Cubeba. P. fol. oblique ovat. feu oblong. venofis, acutis ; fpica folitar. peduncul. oppofitifol. fruc. tibus pedicellatis. Syft. veg, ed. 14. Lin. Suppl.

In Java.

Frutex gldberrimus. Caul. flexuofus, articulat. Fol. non tenera, ut in pl. huius generis peciebus, alterna, periolata, integerr. venofa: margo in uno latere non tam longe decurrit, quam in altero. Spicæ breves, in quibus baccæ illa: pedicellatæ, qua in Offic. nomine Cubebarum funt notæ.

13. capense. P. fol. ovatis, acuminat. nervofis, nervis villofis. Syft. veg. ed. I4. Lin Suppl. Ad cap. b. Spei.

Differt a reliquis maioribus hujus generis, quibus funillimum, venis pagina inferior. villolis.

14. retufum. P. fol, obovat. retulis. Syft. veg. ed. 14. Lin. Supplo Ad cap. b. Spet.

15. larifolium. P. fol. cordatis, multinerviis, petiolatis: fpicis axillar. plurimis pedunculatis. Syft. veg, ed. 14. Lin. Suppl.

In Trheiti. 
Fol. magna, fubrotunda, profunde cordata, acuta, integerr. glabra, tenera, nervofa, petiol. bafi dilatatis, \& amplexicaul. Spicz 5-pl. r6. obufifolium. P. fol. obovatis, enerviis. Syjs. veg. ed. I4. Saururus \&c. Plum, am. tab. 70.

In America calidiore.

Caul. volub. ramofi, nodofi. Fol. fubfeffil. 3. poll. longa, $1 \cdot \frac{\pi}{2}$ lata .

77. rosundifolium. P. fol. orbiculat. folitar. carnofis. Syf. veg. ed. 14.

Saururus \&c. Plum. am, tab. 69.

In America calidiore.

Fol. parva, odore fragranti, craffa, læte virentia.

18. maculofum . P. fol. peltatis, ovatis. Syf. peg. ed. 14. Saururus \&c. Plum. am. tab. 66.

In Domingo.

Caul. volubil, maculatus. Fol. femiped. \& ultra longa, 4. poll. lata, ad bafin emarginata, tenera, fucculenta, fubtus fatuiora.

Ig. peltatum . P. fol. peltatis, orbicularo-cordit. obtulis, repandis: fpic, umbellatis. Syft. veg. ed. I4.

Saururus \&ac. Plum. am. tals. 74.

Lomba. Rumph, amb. 6. tab. 59. f. I.

In Indiis.

Frutex fol, amplis .

20. difachion. P. fol. ovat, fpicis coniugatis. Syft.veg. ed. I4,

Saururus \&c. Plum. am. tab. 67.

In America Gallia aquinoz.

Caul. farmentofi, ramofi, maculati. Fol. longe petiol. 4-poll. longa, 2-lata. Spicæ pedunculata.

2I. umbellatum. P. fol, cordat, fubrot, acut. venofis: fpicis umbellatis. Syft. yeg. ed. I4.

Saururus \&c. Plum. am, tab. 73.

In Domingo .

Caul. 4-5. pollic. nodofus, verrucofus, medullofus. Fol. ampla, 2-pedal. petiolata, fubtus faturiora .

22. trifolium. P. fol. ternis, fubrotundis. Syft. veg. ed. I4.

Saururus \&c. Plum, am. tab. 68.

In America Gellie aquinoz.

Caul. nodofi, albefcentes. Fol. fucculenta, af $\rightarrow$ pera, fubru; faturiora. 
23. quadrifolium. P. fol. quaternis, cuneiformibus, feffilibus. Syft. veg. ed. I4.

Saururus \&c. Plum, ic. tab. 242. f. 2.

In America meridionali.

Planta humilis, repens, ramofa, dichotoma. Cauliculi erecti, Folia craffa, emarginata, nervofa. Spica terminal, fimplex, ftrigola.

24. reflexum . P. fol. quaternis, ovatis, obtuf. reflexis: caul. fulcato. Syft. veg. ed. I4. Lin, Suppl. Ad cap. b. Spei.

Refert Valantiam.

25. verticillatum. P. fol, verticillat, ovatis, trinerviis. Syfi. veg. ed. 14.

In Jamaica $\odot$.

Planta tenera, digital. erecta. Fol. petiolata, obtufa, integerr. fucculenta. Spica fimpl. foliis multo longiores.

erboreum. P. ampliffin. foliis, Aubl. Guian. Sloan. Jam. hift. I. tab. 88. f. I.

In Jamaica \&c.

\section{NOVA GENERA.}

\section{G Y M N A N D R A.}

Cal. feffil. bafi hinc gibbus, biangulat, compreffus, inæqualiter truncato-3. dent. dentibus lateralibus obrufangul. geminatis, infero acuto, altius difcreto.

Cor. parva, ringens; tubus cernuus: labia parva; fuper. obl. obtufo.

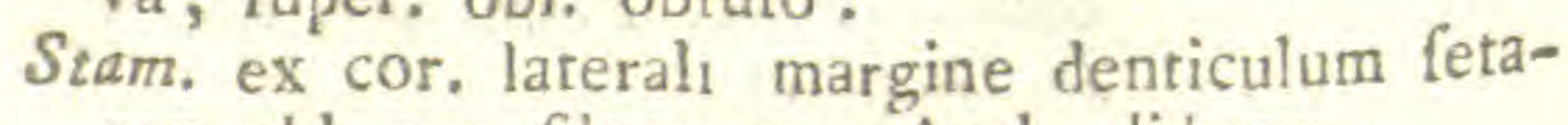
ceo-obl. pro filamento. Anth. didyma.

Pift. Germ. ovatum: ftylus cor. longior: ftigma capitatum, didymum,

Peric. Cap1. ovato-acuta, compreffa, apice $4^{-}$ dent. dehifsens, ut in Pediculari; 2 -loc.

Sem. in fuggulo loculo unicuin, oblon. utrimq. acurum, fulcat. luteum .

Ordine naturali, licet diandra, Bartia, \& Pediculari proxima videtur. 
r. boralis, G. Pall. it. 3, tab. A. f. I.

In rupibus Dauurice 24.

Caul. dudrant. fimpl. erect. inferne nudus, ad apicem foliis vel 2. parium oppofitis, vel 4. ufque ad flores, alternis, feffilibus, ovat. fubferrat, vel integris. Spica florida vix pollic. confertim imbricata; gravida triplo longior. Bract. feffil. ovat-acut, coerulefc, venofa, cal. maiores, Cal, bracteis concolor, feffil. fubdiaphan. Cor. coerul. Var. fol, latu-lanceol. ferratis: Spica tenui : fl.paucioribus dijtantibus.

\section{A ROU N A.}

Cal. Perian, I-phyll, minimum, 5-part. lacis. acutis .

Cor. nulla .

Stam. Filam. 2. oppofita, difco piftil. inferta. Anth. fubrot. 2-locul.

Piftil. Germ, conicum: Atyl. tenuis, incurvus: ftig. obtus .

Peric. Capf. 2-fperma, ab uno latere fulcata .

$S_{e m .}$ 2. pulpa rufefcente, acida obvoluta; frepe unum abortiens.

I. Guintenfis, A. Aubl. Guian. tab. 5.

In Guiana b.

Arb. 30-40. ped. fuperne ramofus, ramulis hine inde divaricatis : Fol. alterna, impari-pinn, Foliol. alterna, ovata, obtufe acumin. glabra . Stipul. 2. deciduæ. Fl. racemofo-pannicul. numerofi, virid. Capf. fufca .

\section{O C H I.}

Cal. Periant. I-phyll. 4-part, lacin. fubrot, ad oras villotis; duabus ma.

Cor. 4-petal. petalis inæqualiter calyci infertis: fuperius pone elongatum in tubum obtufum, incurvum, claufum; pars fuper. expanditur in lobum erectum, oblong. emarginatum, limbo utrimq. incurvo. Petala 2. lateral. min. ungue lato inferta, mutuo conniventia; inferius amplum intra lateralia pofitum, ipfifque incumbeas. 
Stam. Filam. unicum, oblong. latum, inembranac: apice concavum, cal. fundo infertum. Anth. 2. oblon. nigricantes, in cavitate filam. partim reconditæ.

Piftil. Germ. fubrot. fubtrigon. Styl. longus, incurv. carnofus. Stigma ab una parte convexum, ab altera complanatum .

Peric. immaturum, tranfverfe fectum, 3-locul.

Sem. plurima.

I. Guianenfis. V. Aublet. Guian. tab. 6.

In Sylvis Sinemarienfibus $\hbar$.

Arb. 60-80. ped, fuperne ramofus: rami multi, erecti, concinne fparfi. Fol. oppofita, breviter petiol. ovata, acuta, integerr. glabra, e luteo-virentia. Stipul, 2. breves. Fl, recemofi, bracteati, lutei, odori .

\section{Y R T A N R A.}

Cal. Periant, I-phyll, inferum ovat-obl. 5 -fid. fub 2-lab. lacin. acuminatis, 2, inferior. profundius divifis .

Cor. monopet. irregul. Tubus cylind. erect. dein parum inflexus, bafi oblique fciffus, ad faucem ampliatus, cal. longior. Limb. 5-part. lacin. orbiculatıs; 2. fuper. min. planis; 3 . inferior. patentiff, concavis. Nectar. brevilf. urceolatum, germen ambiens.

siam. Filam, 2. brevia, filiform, fpiralia, in face cor. labio infer. adnata. Anth. ovat. compreflæ. Rudimenta 2. filamentorum tenuia, infra ftam. fertilia tubo infer

Piftil. Germ. conicum. Stylus cylindric. rectiulc. longitudine tubi. Stigm. clavatum, 2-lab.

Peric. Bacca obl. fucculenta, 2-locul.

Sem. plurima, minima, in arcubus involutis difpofita .

Adfinis Besleria.

x. Biflora. C. involucr. 2-floris. Forft. gen.

2. cymofa, C. peduncul. nudis, Forft. gen, 
Cal, nullus.

Cor. monopet, tubulofa. Tubus cylindric. Limb. 4-part. pdtenti-reflexus, lacin. aqualibus, ovalibus tubo brevioribus.

Stam. Filam, 2. fauci inferta, recta, filiform. fere longitudine tubi cor. Anth. ovatæ.

Piftil. Germ, ovatum. Styl. filiform. longitudine tubi. Stig. maiufc.

Peric. ovat, villofum, I-locnl, non dehifiens. Sern. folitar, involucr, oblong. glabrum.

r. Gnidia. B. fol, fubpetiolat. lanceol. rigidis. Furft. ger.

2. tomentofa. B. fol. fubpetiolat. oblon. flaccidis, pilofis. Forft. gen.

3. proftrata. B. fol, lefflibus, ovat-oblong, cannofis. Forft. ger.

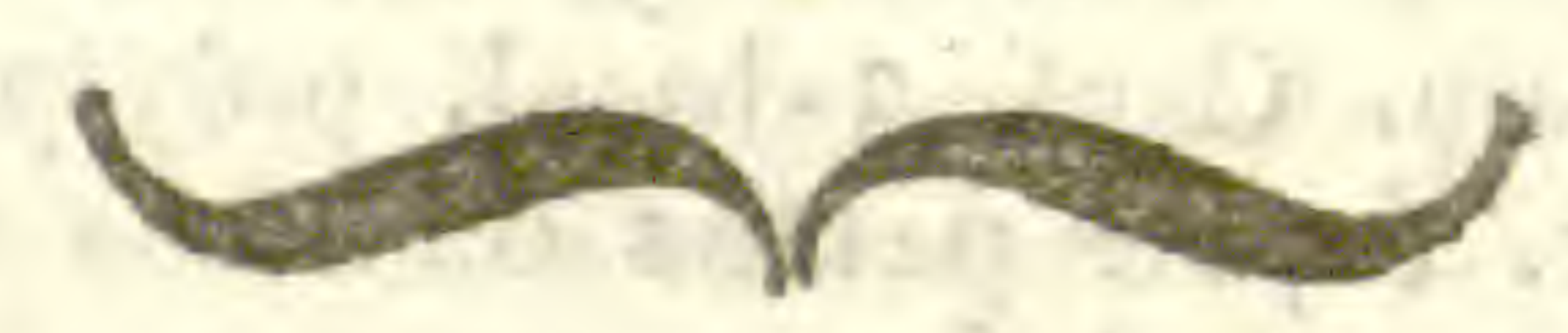


82

\section{L A S S I S III. \\ T R I A N D R I A.

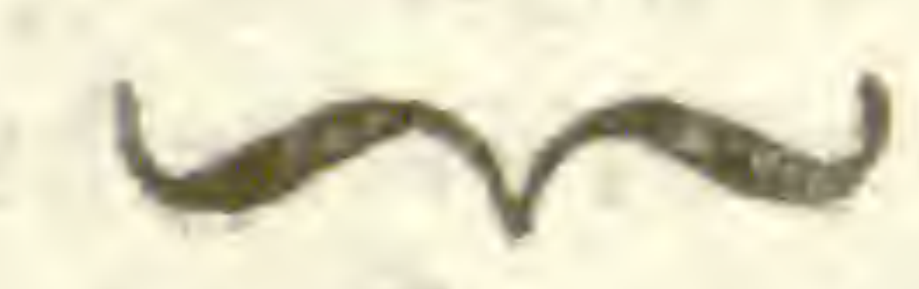

M O N O G Y N I A.

* Fl. fuperi.

54. Valeriana. Cal, o. Cor. I-pet. fupera, bafi hinc gibba, 61. Melothria. Cal. 5-fid. Cor. I-pet, campanulata. Bacca 3locul, polyfper.

67. Crocus, Cor, 6 fid. erecto-patula, Lacinia 3 minores, quæ filamenru n ungui adnexum non habent, ad bafin gerunt barbulam, pl. pilis compofitam. Barbula hac in $r$ Irquis limbi lacinis defider tur. Stigmata convoluta, colorata. $\mathrm{Ca}$ plula fubrotunda. Numero farm. \& Spatha duplici differt a Colchico.

72. Iris, Cor. 6-part. Jaciniis alternis, reflexis. Tuba apex 3-fid. abit in 3 lacinias petalifor. tegentes ftam. Capf. 3-locul, polyfp r.

73. Moraa. Cor. 6-pet: peralis omnibus patulis .

71. Antholyza, Cor. tubulofa, recurvatd, irregular. 6-fid. Capt, infera.

70. Gladiolus, Cor. 6-part. ringens; petal. 3 fuperioribus convergentibus. Stam, adfcendentia. Tuba 3 -fid.

68. Witfenia, Cor. cylindrica, 6-part. Stigma emarginatum.

69. Ixia, Cor. I-pet. tubulofa, tubo recto, filiformi ; limbo campanulato, 6-part. aquali, patente. Stigm. 3, fimplicia.

74. Dilatris, Cal, o. Cor. 6-pet. hirfuta. Filam. tertium re liquis minus. Stigm. fimpl.

$$
\text { ** Fl. inferi. }
$$

75. Wachen-Cal. o. Cor. 6-pet. iaæqual, patens, Capf. 3dorfia. locul.

76. Commelina, Cor. 6-pet. Pet. 3-4 calyciformia. Nect. 3 crt ciara, filamentis propriis inferta.

66. Hippocrutea. Cal. 5-part. Cor. 5-pet. Capf, 3 , obcordatz, 2-valv. 
64, Leslingia. Cal, 5-phyll. Cor. 5-pet. minima. Capl. 3-valv, I. locul.

6o. Willichia, Cal. 4-fid. Cor. 4-fid. Capf. 2-locul. polyfper. 56. Tamurin-Cal. 4-part. Cor. 3-pet. Nectar. fetis 2 brevibus dus. fub fildmentis. Legum. pulpofum .

77. Callifia. Cal, 3-phyl!, Cor, 3-petal. Antherat gemina. Capf. 3-loc. Adfinis Commelina, fed Nectur. orbata.

57. Rumplia. Cal. 3-fid. Cor. 3-pet. Drupa nucleas 3-locul, 58. Cneorum, Cal. 3-dent. Pet. 3, xqualia. Bacca 3-cocca. 78. Xyris. Glumæ 2-valv. in capitulum. Cor. 3-pet. æqualis, urenata. Capf. 3-locul.

59. Comocladia. Cal, 3-part. Cor. 3-part. Styl, o. Drupa oblenga, nucleo 2 -tobo.

55. Olax. Cal. integer. Cor. infundibulif. 3-fid. nectar. 4phyll. Glanf.

62. Rotala. Cal. 3-dent. Cor. 0. Capf. 3-loc. polyfper.

63. Ortegia. Cal. 5-phyll. Cor. O. Capf. I-locul. 3-valv. polysper.

65. Polychre-Cal, 5-phyll. Fol. inæqual. lanceol. petaliform. mum. Sem. 1, fubnudum, lanceolat, involucro fericeo inclufum.

*** Fl. Graminei, valvulis Gluma calycina.

79. Schcrnus. Glumæ paleaceæ, I-valv, congeftæe, Cor. $0^{\circ}$ Sem. I, fubrotundum inter Glumas. Differt a Scirpo Squamis omnibus fertilibus. A Cypero, glumis folliculi incerti numeri, laxe fine ordine congeftis, aut laxe imbricatis. Loculta, five fpica multifl.

8o. Cyperus. Pl. Cpicæ in capitulum congeftæ, multifl, complanatæ. Glumæ paleaceæ, diftiche imbricatæ.

81. Scirjus. Glumæ paleaceæ, undique imbricatæ. Cor. o. Sem. I, imberbe. Differt a Cypero fpicis non diftiche imbricatis, \& non complanatis, fed obefis, \& fem. fetulis circumvallato.

84. Eriophorum. Spica brevis, paucifl. imbricata, fquamis oblongis, Cor, o. Sem. I, lana longiffima cinctum, ut capitulum reddat tomentofum.

85. Nardus. Fl, folitar, fpicati. Glume folliculi binæ, anguftæ, acuminatæ, etiam ariftatæ. Sem. lanigerum.

87. Iy geum. Cal. fpatha I-phyll. Cor, binze fupra idem germen. Nux 2-locul.

82. Kyllingia. Amentum ovatum, oblong. imbricatum. Cal. \& cor. 2-valv. 
83. Fuirena. Ament. imbricatum fquamis ariftatis . Cal. o. Cor. glumis 3 , petaliformibus, obcordatis, cirrho terminatis .

86. Pomme- Cal. turbinatus, 2-valvis: valvulæ 4-fid. dorfo reulla. ariftatæ .

\section{I G Y N I A. \\ * Fl. uniflori, vagi.}

88. Bobartia. Cal, multivalv, imbricatus . Cor. gluma 2-valv. fupera.

93. Panicum. Cal. 3-valv, valvula tertia dorfali minima, poft alteram polita .

89. Cornuto- Involuc. comm. I-phyll, infundibulif. crenatum, pia, multifl. Cal. 2-valv. Cor, 1-valv, Alopecuro nimis adfine.

I12. Ariftida. Cal, 2-valv: Cor. 1-valv, ariftis 3 terminalibus. 95. Alopecurus. Cal. 2-valv, Gluma cor. five folliculi 1-valv. 94. Phleum. Cal. glamæ 2-valv. cufpidatæ, \& intus truncatæ.

9r. Phalaris, Cal.2-valv. carinatus, acuninatus, aqualis longitud. corollam includens.

92, Pafpalum . Cal, 2-valv. valvis fubrotundis fig. cor. Stigmat. penicilliform.

96. Milium. Cal, 2-valv. I-fl. valvulis ventricofis, fubæqualibus, cor. maioribus. Stigmat. peniciliform.

97. Agroftis. Gluma cal, \& folliculi acumin. aut etiam ariftatæ; fed glumæ follic. calycin. glumis longiores. Fl, diftantes .

103. Daftylis, Cal. 2 valv. compreffus, altera valvula maiore, carinara, Cor. compreffa.

107. Scipa, Cal, 2-valv. I-fl. Cor. valvul, exter, arifta terminali, bafi articulata. Dignofcitur glume co. roltina arifta longifJuma.

Iro. Lagurus , Cal, glumæ ariftatæ, arifta villofa. Follicul. 2glumis, valvula maiori, terminata duplici arifta, cum tertia dorfali retorta; valvula altera min. acuminata, Sem. oblongt: ariftatum, folliculo arcte inclufum.

90. Sacchorum. Cal. lanugo longa extra calyc, in que differt ab Arundine. Cor. 2-valv.

* Arundo epigejos, calamagroftis, arenaria.

$$
\text { ** } \mathrm{Fl} \text {. biflori, vagi. }
$$

98. Aira, Cal, 2-valv, 2-fl. Flofculiabfque rucimento tertii. 
99. Melica. Corpufcul. pedunculatum inter flofculos (rudirontum fl.) characterem effentialem prabet. Cd. 2-valv. 2-fl. glumis ovatis, muticis, æqualibus. Follic. glumæ muticæ, inæquales? * Tripfacum hermaphroditum.

*** Fl. multifl. vagi.

102. Uniola. Cal, multivalv, carinatus. Spicula ovata, carinata .

IOI. Briza. Locufta muitifl. mutica. Cal. glume cordato-concava, aquales, obtufa. F!. in fpican cordatam, difticham collecti. Folliculi valva inferior ventricofa, maior, glumis calycin. fimilis: fuperior minor, plana. Sem. ex folliculo fecedens .

100. Poa. Cal. 2-valv, multifl. Spicula ovata, valvulis margine fcariofis, acutiufculis. Serm. folliculo arcte involurum.

105. Feftuca. Locufta tenuis, multifl. Cal. in aquivalv. 2-glum. giumis acuminatis, muticis. Fullicul. 2-valv. valvula infer. ma: acuminata, aut etiam ex dorfio ariftata.

106. Bronus. Cal. glumæ acumin. muticæ, infer. min. Follic. gluma infer. ma: concava, apice 2-fid, ariftam rectam infra apicem emittens: fuper. min. eft, matica. Sern. follicula ârcte inclufum .

108. Avena. Cal. 2-glum. multifl. glumis ventricofis, non ariftatis. Arifta e dorfo cor. articulata, contorIIr. Arundo. Cal. 2-valv. Flofc. vagi, congefti, lana cincti. Sem. Inuginofo folliculo arcte inclufum. 109. Anthifti-Cal. æqualiter ad bafin fiffus in lacinias 4 ,
ria. æquales.

* Dactylis glomerata.

**** Spicati receptacula fubulato.

116. Secale. Cal, oppofitus, 2-fl. 2-valv. folitarius.

118.Tritioum. Cal. 2-valv. folitarius, fub $3-f$. Flos obtufufcus lus, acutus. Scapus alterne flexuofus, \& forobibus excifus. Solus fitus fpicular. diftinguit Triticurn a Bromis.

317. Hordeum. Locufta 3 -fl. five ex 3 dillinctis fi. conftans. Cal. comm. 6 anguftis folial. componitur; duobus nempe ; glumarum inftar, fingulo follicnlo fubiestis, \& ariftatis. Follicul, 2-valv. valvula ex- 
teriore ventricola, in aritam longam definente; inter. plana. Sem. follic, arcte involutum. Scapus alterne flexuofus, \& forobibus excifus . I14. Rottböella. Rachis articulata, teretiufcula, in pl. filiformis. Cal. ovat-lanceol. planus, fimpl. feu 2part. Flofcul. alterni, in rachi flexuofa.

II Elymus. Fl, dentibus flexuofi fcapi infidentes. Locuftr gemina, multifl: qualibet fpicula duabus noa glumis, fed rigidis fetis excipitur. Follic. quilibet 2-valv, valvula exter, ariftata; inter. plana.

113. Lolium. Fl. fpicati, diftichi, locuft. multifl. ad flexuofum fcapum fefflibus. Fovea nimirum in fcapo eft loco valvæ calycina, atque ex altera parte gluma una, longa, clycina, five foliol. in cuius ala fedet fpicula. Follic. quilibet 2-glu. mis ex valvis inæequalibus. Sem. nudum.

104. Cynoforus. Cal. 2-valv. multitl. Receptacul. proprium unitater. foliaceum. Differt a Phleo follicul. integerrim.

\section{T R I G Y N I A.$$
\text { * Fl. inferi. }
$$

123. Holofteum, Cal. 5-phyll. Petal. 5. aqualia, emarcida, Capf. fubcylindrac. I-locul. apice dehifcens, polyfper.

125. Polycarpon. Cal. 3-5. phyll. Cor. 5-pet. minima, ovata, emarginata, perfiftens. Capf, I-locul. 3-valv,

I29. Lechea. Cal. 3-phyll. petal. 3. linear. Capf. 3-locul. 3-valv. valvulis totidem interioribus. Sem. I.

119. Eriocaulon. Cal. comm. capitulum imbricatum. Pet. 3. æqualia. Stam. fupra germen. Sem, I, coronatum cor.

120. Montia. Cal. 2-3. phyll. Cor. parva, I-pet. irregular. 5-part. lacin. 3. alternis minoribus.

126. Mollugo . Cal. 5-phyll. Cor. o. Capf. 3-loc. 3-valv.

I27. Minuartia . Cal. 5-phyll. Cor. o. Capf. I-locul. 3-valv. Sem. nonnulla.

128. Queria. Cal. 5-phyll. Cor, 0. Capf, 3,valv. I. locul. Ifperma. Simil. Minuartiae, fed differt femtin. numero.

124. Koenigia . Cal. 3-phyll, Cor. O, Sem, I., ovatum, nudum. 
722. Triplarss. Cal, maximus, 3-part, Cor, O. Nux triquetra intra cal.

* Tillara.

** Fl, superi.

221. Proferpinaca. Cal. 3-part, fuperus. Cor. O. Sem. I., trie locul.

\section{O N O G Y N I A.}

54. VAleria- Cal. o. Cor. I-pet. bafi hinc gibba, fu= NA. pera, 5 -fida. Sem. I.

3. rubra.

V. fl. monandris, caudatis: fol. ovato-lanceol. fubintegerr. Syft. veg. ed. 14 .

V. marina \&uc. Moris. hijt. Pect. 7. tab. I 4. f. Is.

In Iealice, Helvetia \&ic, mirtis, \& ruderatis 4.

Caul. cubital. ramofus. Fol. ima petiolat. fuper. fefflia, lævia, interdum pene cordata, quantoq. dentata. Cor. purpur. vel albs.

2. calsitrapa.V. A. monandris: fol. pinnatifit. Sygt. veg. ed. 14. Moris. hift. 3. f. 7. $t a b$. I4. f. 7 .

In Lufitania, Oriente $\odot$.

Caul. cubital. ramofi. Fol. humifufa, Cor. diftute rubra.

3. cornucopia . V. fl, diandris, ringentibus : fol. feffilibus, ovatis . Syft. veg. ed. 14 . Sabb. hort. rom, 2, tab. 19.

Pfeudo-Valeriana \&c. Moris. hift. 3. f. 7. tab. I6. f. 27.

In America, Hifpania, Sicilia $\odot$.

Caul. pedal-cubit, tenellus, pleruraq. ad fingulos nodos in 2. ramos divifus, ac fubdivifus. Fol. pauca, pallide virent: fuper. quandoq. finuata. Pedunc. incrafy ti. Sern. abfq. pappo.

4. dioica. V. fl. triand. diaicis: fol. (caulinis) pinnatis, integerr. Syft. veg. ed. I4. Fl. Dan. tab. 687. Moris. umb, tab. Io. Black, tab. 284. Riv. mon. $t a b .2$.

In Europa, \& Orientis campis uliginofis 24.

Fl. numquam dioici, fed hermaphroditi, feu mo= noici. Scop. Fl. Carn. Ex rad odorata exeuns ftolones foliofi. Caul, pedal, trichotomus. Fol. radicalia ovata, \& eiliptica. Cor. fubrubella. 5 iv 
5. ofjeinalis. V. fl. triandris: fol, omnibus pinnatis. Syft, vego ed. I4. Fl. Dan, tab. 570. Ludw. ect. tab.99. Black. tab. 27 r.

In Europa nemoribus paludofis 24 .

Altitudo humana. Coul. fulcatus. Fol, valde incifa, dentata, croffis venis, fubtus fubbirfuta. Cor, ex albo-purpurafe. Vur. fol, angujtistibus, \& latioribus, Splendentibus .

6. Phu, V. fl, triandris: fol. caulinis pinnat, radicalibus (plerumq.) indivifis. Syjt. veg. cd. I4. Ludw. ect. tab. 98. Black. t, bb, 250.

In Alfotia, Silefia $2 f$.

Differt a priore caule non fulcaro; \& foliol. exterior. ma. Variat fol. radicalibus lyratis.

7. tripteris. V. fl. triandris: fol, dentatis: radicalibus cordat. caulinis ternatis, ovat-oblon. Syfe, yeg, ed. I4. Jacq. Auftr. tab. 268.

V. alpina \&c. Pluk. alm, tab. 23I. f. 7. Barrel. tab. 742 .

In alpibus Helvetice, \& Auftrice 2.

Radix odora. Caul, fubped. Fol, radical. longe petiol. caulioa non precife ternata, fed 3 -fid. lacinia intermed. ma. lanceol. fumma linear. \& indivifa. Involuc. propria funt 2 -phyll. fetacea. Ft. purpurafc. quandoq. albi, odori.

8. montana. V. fl. triandris: fol. ovat-oblong. fubdent. callle fimplici, Syft, veg. ed, 14. Jacq. Auftr. 3. $t a b, 269$.

In alpibus Helyeticis, Pyrenaicis, Auffriacis \&c. 24. Differt a $V$. tripteri, fol. indivifis, \& paniculd denfiore.

Radix quandoq. odora. Fol, radical, petiolat. bafiq. attenuata, obtufa: fuper. oblong. acumin. dentata: fumma feffil. Fl. fæpe purpur.

9. celrica, V.tl.triandris: fol, (inferior.) ovat-oblong. obtuf. integerr. Syft. yeg. ed. I4. Jacg. Vind. 203.

In alpibus Helverice, Auftria Es. 24.

Radix obliqua, fibrofa, capillaris, nigricans, odore fragranti, fapore aromat. Ramuli procumbent. palmar. tenues. Fol, parva, radical. petiolara, craffa, fucculenta, e virid-flavefcent. Fol. 2. caulina linear. obrufa. Fl, verticill. bini-terni. Cor, pallida .

10. tuberofa, V. fl. triandris: fol. radicalibus lanceolat. integerr, reliquis pinnatifid. Syft, veg, ed. Is In Dalmatia, Siciila \&c. 24. 
Radix Olivæform. Fol. caulina utrimq. pinnis 2. II. Saxatilis.V. fl. triandris: fol. fubdentat, radicalibus ovat. caulinis lineari-lanceol. Syjt. veg. ed. 14. Jacq. Auftr. 3. $2 a b$. I67. Clus, hift. I. p. 256. bonu. In alpibus Auftria, Baldi Ec. 4.

Planta nitida. Caul. fpitham. fimpl. Fol. fubtrinervia, ad ords obfolete pilofa: radical. 4. caulina 2. oppofita. Rami brachiati. Pedunc. oppofiti. Fl. paniculat. Cor. alba.

I2. elongata. V. fl. triandris: fol. radicalibus ovatis : caulinis cordatis, feffilibus, incifo-fubbaftat. Syjt. yeg. ed. I4. Jacq. Augtr. 3. tab. 219.

In alpibus Auftria inferioris.

Differt a V. montana, gemnut radicali : caul. paniculato Ec. A. V. tripteri, fol. dentat. radicalibus petiolo proprio femper longioribus, \& caulinis ovatis.

Caul. Erect. fpitham. finpl. Fol, radical. longe petiol. obtufa, raro fubdent. caulina amplexicaul. Racemus terminal. erectus, longus; pedicell, oppofitis, dichot. breviufc. Bract. linear. Cor. fufco-flava.

13. pyrenaica. V. fl. triandris: fol. caulinis cordatis, dentat. petiolat, fummis ternatis. Syft. veg. ed. 14.

V. Oientalis \&cc, Buxb. cent. 2, tab. II.

In Pyrenais 4 .

Fol. Alliariæe fimilia . Cor. alba .

I4. foandens. V. fl. triandris: fol, ternatis: caul, fcandente o Syft. veg. ed. I4.

\section{In Cumana.}

Caul. dichotom. Fl, lateral, paniculati. Cor. e viridi-rofea. Sem. ovata, compreffa .

15. chinenfis. V. fl. triandris: fol, omnibus cordat. repandolobat. Syft. yeg. ed. 14. Burm. Ind. tab.6. f. 3. In China,

Simil. Boerhravia fcandenti, fed oppofztis ramis, E peduncul.

Caul. herbac, erecti, plufquam ped. ramis florifer. oppofit. Fol. petiolata, acuta, glabra, lobis Jateralibus utrimq. binis, obrufis. Umbel. proliferæ, feu paniculatæ. Fruet. min.

I6. Locufta. V. f. triandris : caul, dichot.: fol. linearibus .

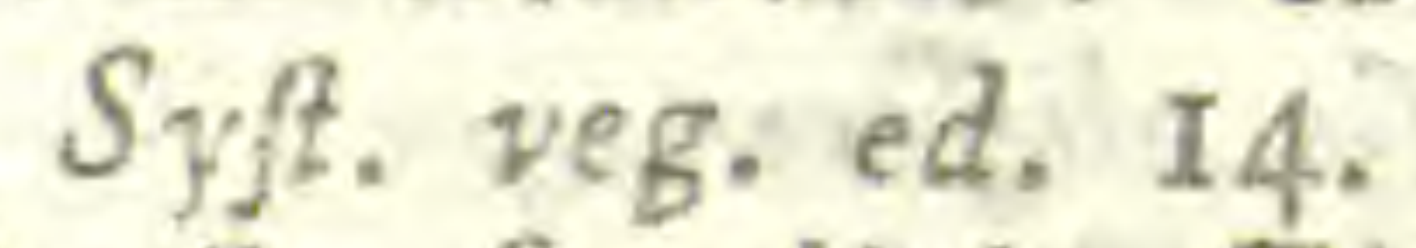

* vlitoria, Fructu fimplici. Fl, Dan, $2 a b, 738$.

Caul, dichot. Fol, lanceol, yel integer, dentata. Sem, nada. 
b. veficaria. Cal, inflatus, dent. 6. inflexis: involuccel, 9. pbyl. 3-fl. Boer. Lugd. I, tab. 75 .

Caul. dichotom. Fol. lanceol. ferrata.

c. coronate. Fructu fubdent. Colum: ecph. I. tab. 209.

Caul, dichotom. Fol. Janceol. dentata .

d. difcoider. Fructu 12-dent: hypocrater. acurninibus I2, retrorfum unsinat. Moris, hift. 3. f. 7. tab. I6. f. 29 .

e. dentatu. Seminis corona 3-dent.

Caul. dichotom. Fol. oblon. fubferrata. Monftrofa evadit.

f. radiata. Involucro fi. cingente.

g. pumila. Caul. dichotom. fol. imis dentat: fummis linearibus inultifid.

Phu \&rc. Lob. ic. 716.

In Europa $\odot$.

17. mixta. V. fl. triandris: caul. 4-fid. fol. imis 2-pinnatifid: fem. pappo plumofo. $S_{y f t}$ veg. ed. I4. Morfpelii.

Sxpe 4. rami oriuntur a radice abfq. caul. Sem. umbilic. hirfutum .

I8. echinata. V. fl. triandris, regularibus: fol. dentat. fruct. lineari, 3 dent. extimo ma: recurvato. Syft. veg. ed. 14. Colum. ecphr. tab. 204. f. 206.

In Italia, \& Monfpelii $\odot$.

Caul. dichorom. Fol. feffil. lanceolata, obtufa, Fl. e dichotomia folitar. feffil. Cor. S-fid. alba. Summi fl. in fpicas dichotonas, coallunatas, obtufas.

19. Supine. V. fl. tetrandris: involuccel. 6-phyll. 3-fl. fol. integris. Syft. veg. ed. 14. Arduin. Sp. 2, tab. 3. Barr. rar. zab. 868 . Sed maior.

In alpibus Italicis, Carinthice 24.

Radix repens, odore V. celticre. Caul. pollic. vix Bellide ma. Fol. fubhirfuta, limbo ciliato: radical, petiolata, obovat. integerr: caulina feffil, Janceol. Corymb. terminal, e pedunc. oppofitis . Cor. purp. vel alba .

20. fibirica, V, fl. teirandris, æqualibus: fol. pinnatifid, fem. palea ovali adnatis. Syft. veg. ed. 14. Amm, Ruth. tul. 3. Comm. gott. 175I. tab. 9. b. Anonimos \&c. Pluk. alm. tab. 443 . f. I. Videtur potius Sp. differens.

In Sibiria campls $\odot$.

Radix lignofa, fufca. Caul, ped-cubit, teres, 
glaber, plerumą. rubens. Fol. radical, quandoque pinnat-dentata, margine ferrata, raro ovata: caulina feffil. lanceol., ; impari pinnarifido, fupra fature virid. fubtus pallidiora. Fx fummis alis ramuli foliofi, hirfuti . Cor, flava. 2I. villofa. V. fl. tetrandris, æqualibus: fol. inferior. auriculat, fuperior, destat, villofis. Syft. yeg. ed. I4. Thumb. Jap. fig. 6.

In Japonia.

Planta tota denfe hirfuta. Radix fibrofa. Caul. erect. pedal, fimpl. Fol. radical. aggregata, palmar, petiolat, ovat, auriculato-lyrata, lobo terminal, ovat. maximo, 2. poll. longo, I. poll. lato, inæqualiter incifo-ferrato. Caulina femipoll. oppofita, feffil, ovata, acuta, incifofublyrata, dentata. Petioli in folium fenfim dilatati. F1, axill, \& terminal. paniculat, trichorom. bracteati. Cor, fubrotata, flava. Differt a $V$. fibirica, hirfutie totias planta, \& fol. ovatis.

anguftifolia. V. All. Fl. Pedem. Bauh. hift. 3. p. 211 .

In vallibus \& lacis lapidajis.

Differt a $V$. rubra fol. anguftifsrmis.

faliunca. V. All. Fl. Ped. tab. 70. f. I.

Lugd. p. $9 \mathrm{~S}_{2}$.

In editis alpium iugis.

Rad. craffa, fublignofa, fapore acri, valde aromatico. Fol. rofula ad terram. Fol. lingulata, ovata, aut elliptica, firmula, glabra. Caulic. 3-4. unc. uno, aut altero pari folior. qua interdum tridentata . Cor. infundibulif. fubringens, odore Heliotropii Mexicani .

55. OLAX. Cal. integerr. Cor. infundibulif. 3-fida: Nectar. 4-phyllo.

1. Zeylanica. O. Syjt. veg. ed, I4.

In Zeylona 5 .

Arb. ramis flaccis, rugofis. Fol. alterna, petiolat. ovata, glabra, avenia. Pedunc. axill. breviff. fubramofi.

56. TAMA- C l. 4-part. Pet. 3. Nect. fetis 2, brevibus fub RINDUS. filamentis. Legum, pulpofum.

I. indica. T. Syft. veg. ed. I4. Jacq. Am. tab. 10. \& 179. f. 98. ed. piza tab. I3. Black, tab. 20I. 22I. Rumph. amb. 2, sab. 23. 
Balam-pulli. Rheed. mal. I, tab. 23.

In India, America, Egypto, Arabia $\$$.

Arb. vafta, coma ampla, denfa, ramis numerofis . Fol. 5-pollic. alterna, pinnata : foliola parva, oppofita, oblonga, obtufa cutn exiguo acumine, integerr. glabra. Racemi fimpl.pen duli, fub I2-fl. Cor. lutea, cum venis rubris, olora. Legum, oblong. craffum, maturum ferrugineum. Sem. numero varía.

57. RUMPHIA . Ca1. 3-fid. Pet. 3. Drupa 3-locul.

I. amboinenfis. R. Syft. veg. ed. I4.

Tfiem-tani, Rhieed, mal. 4. tab. Ir.

In India $\hbar$.

Arb. valta. Fol, inordinata, petiolata, e rotundo-acumin. ferrara, \& horrentia, afpera, hirfuta, nervofa, venofa, fupra atro-virid. fubtus vividiora, odore aromatico. Fl. racemofi, longe peduncul. Pet. oblon-rotunda, reflexa, candida. Drupa pyriform. umbilicata, cortice viridi, fpinulofa. Caro odorata, amara.

58. CNEORUM . Cal, 3-dent. Pet. 3. 2qualia. Bacca 3-cocca.

I. tricoccum. C. Syft. veg. ed. I4.

Camelea. Matih.

In Hifpanice, Narbone, Ec. glareofis b.

Frutex humilis. Fol. feffil. oblong. angufta, integerr. Pedunc. folitar. I-fl. Cor. lutea, Bacca rubra, dein fufca.

59. COMO- Cal. 3-part. Cor. 3-part. Drupa oblong. nucleo CLADIA . 2-lobo.

I. integrifo- C. foliol, integris. Syft, veg. ed. I4. Jacq. am. lia. piaz. 12.

Prunus \&c. Sloan. Jam, 2, tab. 222. f. I.

In America calidiore b.

Arb. 20-ped. ramis paucis. Fol. ad apicem pinnata, glabra. Pinnæ plerumq. 8-iugæ, cum impari, 4-pollic. periolat. ovato-lanceol, integerr. lateralibus revolutis. Racemi axill. penduli, ramofi, laxi, fefquiped. Fl. exigui, feffil. fature rubentes. Drupa rubra, nitida. Succus aqueus, dein niger.

3. deniata. G. foliol, ipinofo-dentatis. Syft. veg.ed. I4. Jacq. am. tab. 173 . f. 4. ed. 2. piza tab. 259. f. 2 . iquord folium.

In Ameriça.

Arb. fimilis priori, odore ftercoris . Succus niger 
vix eluendus. Fol. pinnata cum impari i pinnarum iuga 6-10, oblon-acumin, fubtomentofa . Arboris umbra fubtus dormienti lathatis.

o. WILLICHIA. Cal. 4-fid. Cor. 4-fid. Capf, 2-locul, polyfperma .

1, repens, W. Syft. veg. ed. 14 .

In Mexico $\odot$.

Radix fibrofa. Caul, repens, herbac. fub 2-ped. filifor. ramofus, hirfutus. Fol.. aiterna, petiolat, remotiufcula, orbicul. fubpelt. crendta, hirfura, fubtus rubefcent. polfic. Petioli longiff. craffi, hirfuti. Pedunc. Jaxillar. gemini, filiform. hirfuti, I-fl. longitudine petiol. Fl。 parvi, rolei, cal. hirfuto.

6r. MELO- Cal. 5-fid, Cor. campanulata, I-pet. Bacca 3THRIA. locul. polyfperma.

I. pendula. M. Syft, veg. ed. 14 .

Cucumis \&c. Pluk, alm, tab. 85. f. 5, Sloạn. Y. tuib. 142. f. I.

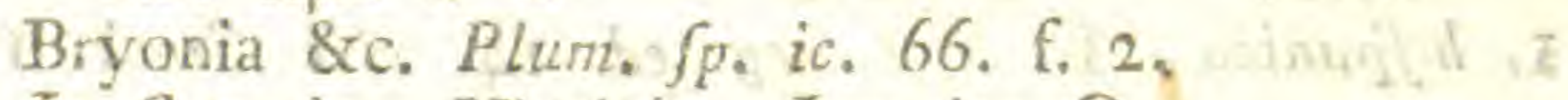

In Canada, Virginia, Jamaica $\odot$.

Caul. 2-ped. debilis, angulat. ftriatus, lævis . Fol. magnitudine 2. pollic. tranfverforum, petiolat. cordata, palmato-5. angulata, fcabra. Cirrhus axillar. folitar. longus. Pedunc. axill. filiform, laxi, 1-fl. Cor. lutea. Fruct. Olivæfor. pendulus, tuberculatus, niger. Mire variat .

Vidi 2-fl. mafculos prater hermaphroditos, femel. 62. ROTALA . Cal. 3-dent. Cor. o. Caps. 3-loc. polyfperma. I. vericillaris, $\mathrm{R}$. fol. verticillatis $S_{y j t .}$ veg. ed. I4.

Ehapæl. Rheed. mal. 9. tab. 8I.

In India Orient. (-). . .

Radix fimpl, repens. Caul. adfcendens, palmar. articular, teres, levis. Rumi fumplic. ftricti, infer. oppofti, fuper. alterni, rariores; articulis inferne terecibus, fuperne fub-4 gonis . Fol. quaterna ( raro in ramis 5-8.) fellit. linearia, acutiufc., lavia, fubcarinata, patentia. Fl, quaterni, (ex fingulis fol. alis finguli) minuti, feffil. Verticilli remoti. Cal. totam capl. obveltiens, tenuiffime membranac. Fruct. magnitudine fem. Sinapios.

63. ORTE- Cal. 5-phyll. Cor. o. Caps, I-loc, 3-valv, poGIA. Iyfper. Sem, plurima. 
I. hifpanica. O. caul. fimpl. fl. fubverticillatis. Sy.f. veg. ed. 14 .

Juncaria. Clus. hift. I74.

In Caftilia, Betica, Salmantice.

Caul, ereet. fprtham. articulat. 4-gon. friatus, fcabriufcul. Fol. femiunc. oppofita, feffit. linearia, vel lanceol-linear. acuta, erecta, f:abriufc. Fl. corymbofi, conferti, feffil. albi .

2. dichotema. O. caul, dichotomo: fl. axillar, folitariis, Syft. veg. ed. 14. Allion, aliq. tab. 4. f. I,

Prope Javenium in Saxofis 4.

Caul. erect. rigens, fcabriufc. utrimq. canalicatus, genicul. incraffatis. Fol, oppolita, linear. patentia, dorfo minime glabra. Stipulæ 2. utrimq. inter fol. oppofitiones, minut: , fetacea, bafi craffiufcula colorata. Rami alterni . Panic, terminal. Adfinis maxime Palycarpo,

64. LQFLIN-Cal. 4-phyll, Cor. 5-pet, minima. Caps. I-loc. GIA . 3-valv.

I. hifpanica, I. Syft. veg. ed. 14. Aa. Stock. 1758, tab. I. f. 1. Lafl. it. tab. 1. f. 2.

In Hifpanier collibus apricis .

Habitus Scleranthi. Radix tortuofa. Caul, fubprocumb. digital, articularus. Fol. minima, oppofita, mucronata : infer. lineari-acuta, ad bafin denticulo acuto; fuper. fubulato-trident. Rami proftrati, alterni, pubefcent. vifcidi . Fl. axillar. feffil. in fpicis lateralibus, alternis conferti, imbricati. Bract. parvæ, imbric. fubulatæ, 3-dent. Cor. pallida.

65. POLY- Calyc. fol. 5. inæq⿴al. lanceol. petaliformia.

CHNEMUM . Sem. I. fubnudum, lenticulatum, involucro fericeo inclufum.

I. arvenfe. P. Syft, veg.ed. 14. Jacq. Auftr. 4. tab. 365.

In Italia, Gallia, Germenice arvis $\odot$.

Planta procumb. vel erecta, glabra. Caulic. a 2. unc. ad fefquiped. longi, toti fuliofi, quandoq. purpurafc, Fol. fparfa, feffil. fubulata (ficuri flipulæ) fupra plana, fubtus teretia, arifta alba terminata. Fl. axill, parvi, folitar. feffil. Cal. allidus .

fclerafpermunt, P. Pallas it. 3. tab, M. f. 2. \&c.

In Daunria.

Planta glauca, fucculenta. Caul, digit-dodrant. 
rami, præter duos infimos, alterni. Fol. teretia, fpinula mucronata: radical. 2. oppofita; reliqua alterna. Fl, axill, folitar. inter 2 , foliola fubulato-mucronata .

motandrum. P. Pallas it. I. tab. D. f. I.

In Daumria 24.

Caul. pl. recti, fere $a b$ imo ad fummum toti ramulis fubflexuofis, floriferis confertim obfiti. Fol. linear. acuta, tomentofa, exfucca. Fl. alterni, difpofiti inter foliol. vaginale. Stam. conftanter I.

triandrum. P. Pallas it. I. tab. D. f. 2, $6 t a b$. E. f. I.

In Dauuria 24.

Planta fæe cubital. diffufior, ramofiff. in ficcis vix Cpitham. hifpiclior, \& fl. fol. magis confertis. Fol. alterna, elongata, filifurmi-atienuata, fucculenta, tomento glauca, bafi vaginant. Cor. 3 glum. Ptam. 2-3.

oppofitifolium, P. Pallas it. I, tab. E, f. 2.

In Dauuria $\odot$.

In paludibus falsis fæe fubcubital. ramofior, vel fubfimplex. Caul, erecti, geniculdti, pallidi. Fol. ad genicula vaginant: infer. oppofita ; fuper. \& ramea alterna, femicylindricoattenuata, apice in cuneum compreffi, carno$\mathrm{fa}$, tomentofo-glaucefcen. Rami axill. fubfaftigiati, flexuofi. Fl, alterne fpicati, minuti, Graminei, intra foliol. vaginale feffiles. Cor. 2-glum. ftam. semper 5.

66. HIPPOCRATEA. Cal, 5-part, Pet. 5. Caps. 3. obcordatze. x., yolubilis. H. Syjt, yeg. ed, 14.

H. fcandens. Jacq. amer. tab, 9. ed. pia. tab. I2. Coa \&cc. Plum. gen. ic. 88 ,

In America auftrali $\hbar$.

Arb. ramis longiff. fcandentibus . Rami foliofi, \& florigeri. Fol. oppofita, petiolat. interdum femipedal, ovat-lanc, nitida, pinguia, denticulis fubtilibus. Corymb. axill, raro terminal. oppofiti, ramofi, ampli. Fl. exigui, e luteovirent. Caps. fufcæ, glabræ. Sem. fufca.

67. CROCUS. Cor. 6-fida: laciniæ 3. min, quæ filamentum utigui adnexum non habent, ad bafin gerunt barbulam, pl. pilis compofitam. Barbula hæc in reliquis limbi laciniis defideratur. Stigmata conveluta, Cap. fubrotanda. 
I. fativus. C. fpatha radicali, I-valv, cor. tubo longifl, $S_{y f f}$. $v e g . e d .14$.

officinalis. a autumnalis, fol. anguftioribus margine revolutis. Black, tab. 144. f. 1. Morif, hift. 2. f. 4. tab. 2. f. I.

vernus.

6. vernalis, fol. lutioribus, margine patulo. Jacq. Auftr. 5. tab.36. Black. tab. I44. f. 2. Kniph. orig. cent. 1. tab. 21 .

In alpibus Helveticis, Pyrenais \&c. 24.

Bulbi alii aliis impofiti, orbiculati, e quibus fol. exeunt Graminea, bina-terna. Cor. expanfa, mire varians col., albo, ex purpura rubente, ccrul. luteo \&c.

C. Sativus a fpontaneo diverfus tuba profunde 3-fida, in 3. longa fegmenta divifa, quorum finis xque 3-fid. eft, uti tota tuba fpontanea verni croci. Dein ea tria tuba cornua odosata funt, \& aromatica; non ita fpontanei , $\&$ in officinas Croci nomine recipiuntur: unde Species diverfa.

68. WITSENIA. Cur. cylindr, 6-part. Stigm. emarginatum.

1. maura. W. Syft. veg, ed. 14. Lin. Suppl. Thumb. DiJf. nov. gen. AZ. Medic. Syec. T. 1. cab. 17. Antholyza maura. Syft. veg. ed. I3.

Ad cap. b. Spei 24 .

Caul, 2-ped. anceps, tectus vaginis folior. Fol, enfiformia, alterna, adproximata, anguita, friata ; fuper. caule longiora, vaginis imbricatis. Spica compofita e fpicul. alternis, inbricat.: fpathulis laxis, fcariofis, lanceol. fub 2-fl. Cor. tubo atro; limbo luteo; lacin. 3. exterior. extus tomentofis. Stam. alba.

69. IXIA. Cor. I-petala, tubulofa; tubo recto, filiformi ; limbo 6-part. campanulato, æquali, patente. Stigm. 3. fimplicia .

$$
\text { * caule, ramifq. foliosis. }
$$

3. fruticofa. I. caule ramofo; fol. imbricatis tecto. Syft. yes. ed. 14. Thumb. diff. de Ixia.

Ad cap. b. Spei.

Caul. femiped. fruticor. fufcefcens, cicatricibus tranfverfis. Fol. in apice ramorum, pollicar. fimilia Sifyrinchio, enfiform, equitantia. Fl. terminal, teffil, coerul, 
** Scapo folits breviore.

2. minuta. I. fcapis I-fl. fol. lavibus. Syft. vegi ed, i4, Thumb, loc. cit.

Ad cap. b. Spei.

Plantula pufilla.

3. Bulboco - I. feapo ramofo; fl. folitariis: fol, fulcatis, redium.

flexis. Syft. yeg. ed. 14. Thumb. loc. cit.

I. rofea. Syf. veg. ed. I3. videtur huc conveniro. Sifyrinchium \&.c. Col. esplsr. 2. tab. 7. f. I.

Romulea Maratti.

In alpibus Italicis 4.

Planta parva. Fol. fubulata. Spatha 2-valv, glúmiform. longirudine fere cor. corrul. fundo flavo.

4. kumilis. I. fcapo ramofo: fl. fecundis: fol, fulcatis, erectis. Syft. veg. ed. 14. Thumb. loc. cit. *** Scapo fol. longiore.

a. hirfuta.

5. pilosa. I. fcapo fimpl.: fol. linearibus pllofis: fl, altérnis. Syft. veg. ed. 14. Thumb. loc. cit. Ad cap. b. Spei.

6. hirta. I, fol. enfiformibus hirtis: fl. fecundis. Syft. veg. ed. 14. Thumb. loc, cit.

7. fecunda. I. fol. elliptico-enfiformibus, fcapo villofo-fcabro. Syft. veg. ed. 14. Thumb. loc. cit.

An I. Scillaris. Syft. veg. ed. 13.

I. fecunda. Berg. Fl. cap.

Ad cap. b. Spei.

Radix bullofa. Caul, dodrant. erectus, teres, a flore ad forem valde arcuarus. Fol, vix fpitham. alterna, vaginant. erecta, linearienfiform. Fl. fpicæ fub 3. laxæ, cernua, flexuofæ, Fl, 5-6, remoti, feffil, fecundi, Cor, fauce purpurafc. limbo fature coerul.

b. glabra.

a. fol, crifpis.

タ. $\operatorname{crifpe.~I.~fol:~linearibus~crifpis:~fl.~alternis.~Syft,~veg.~}$ ed. 14. Thumb, loc, cit.

Ad cap. b. Spei.

Fol. longitudine vix digiti, radicalia. Scap. erect. fpitham-filiform. fpicatus. Fl, difantes. Gluma, e qua flos exit, hyalina. Tubus filiform. Limbus lacin. obovat, oblong. Tom, I, 
9. cinnamo- I. fol, lanceol. crifpis: fl. alternis. Syft. veg. mea. ed. 14. Thumb. loc. cit.

Ad cap. b. Spei .

Spica fecunda. Fl. odore Cinnamomi .

Io. corymbe- I. fol. lanceol, crifpis : feapo ancipiti. Syf. vego Sa. ed. 14. Thumb. Lac, cit.

Ad cap b. Spei .

Caul. femiped. vagina membranacea cinctus. Fol. I-2. verticalia. Fl. corymbofi, corul. cal. 2valv. initructi. Germen inter cor. \& fpatham. b. folits aqualibus.

II. linearis. I. frapo fimpl, erecto: fol. linearibus. Syfto vego ed. '4. Thumb. luc. cit. Ad cap. b. Spei .

Fol. convexd, ftriata .

I2. capillaris. I. fcapo polyftah hio: fol, linearibus, fpathis fcariofis. Syjt. veg. ed. I4. Thumb. loc, cit. Ad cap. b. Spei .

Fol. erecta. Scap. mulrifl, peduncul. erectis.

I3. Setacea, I. fcapo flexuofo, glabro: fol. linearibus. Syjt. veg. ed. 14. Thumb. loc. cit.

14. fcillaris. I. fol. linearibus: fl. fecundis; rachide flexuofa. Syft. yeg. ed. I4. Thumb. loc. cit.

I5. arifata. I. fol. linearibus, fpath, aritato-dentatis. Syft. yeg. ed. I4. Thumb. loc. cit.

76. pendula, I. fcapo polyftachio : fol. lineari-enfiformibus: fpicis pendulis. Syjt. veg. ed. 14. Thumb. loc, cit.

I7. bulbifere. I. fol. entiformibus, fpathis membranac, fetaceolaceris. Syft. veg. ed. 14. Thumb. loi. cis. Mill. ic. tab. 2,6. f. 2.

Ad cap. b. Spei 4 .

Radix bulbofa, Scap. pedal. fimpl. Fol, 2-3, alterna, angufta, linea laterali elevata. Fl. 2-3.

38. ereäa Cor. campanul. fl vefcenti-albida, fundo flavo.

3. fol. enfiformibus, fcap. polyltachio: fl, alternis, immaculatis. Syft. veg. ed. 14. Thumb. loc. cit. Mill. ic. I55. f. 2. bann.

Ad cap. b. Spei .

Radix bulbofa. Fol. 4-6. radicalia, angufta, lævia, interiora caulem arcte involventia. Spicæ multifloræ, præter terminalem, eriam nonnullæ inferius, alterna. Fl. diftantes. Cor. infundibulif. lacin. patentibus, ovat-lanceol. obtufis, niveis punctis adfperfa. Filam, \& piftil, violac. 
I9. meculata.I. fol. enfiform. fcapo polyftachio: $\mathrm{fl}$, alternis; cor. bafi maculatis, Syft, veg. ed. I4. Thumb. loc. cit, Mill, ic, tab. 156. f. z.

Ad cap. b. Spei 24 .

Spica rarior fl. feffilibus. Petala fublanceol. flava, bafi interiore nigricant. Stam, \& piftil. flava. Statura I. bulbifere.

20, crocata. I. fol. enfiformibus: fl. fecundis : cor, bafi hyalino-feneitratis, Syft. veg.ed. 14. Thumb. loc, cit。 Lin. fil. Dec. I3. tab. 7. Mill. ic, tab. 239. f. 2. Ad cap. b. Spei 4.

Radix bulbofa. Scap. pedal. erect. fimpl, fufcus, fuperne nudus, inferne fublutefcens, fol, involutus. Fol. 4-5. radical, vaginant, erecta, longitudinaliter nervofo-ftriata. Vaginæ longæe. Suicæ fape 2. Fl. rari .

2I. lancea. I. fol. enfiformibus, fcap. fimpl. flexuofo: fl. fecundis. Syft. veg. ed. 14. Thumb. loc. eit.

22. pentandra.I. fol. enfiformibus, fl. pentandris. Syft. yeg, ed. 14. Thumb. loc, cit. An Ixia Scillaris Lin. $\int_{p}$. pl.? Ad cap. b. Spei.

23. falcata. I. fol. enfiformibus, reflexo-falcatis. Syft. veg.ed. I4. Thumb. loc, cit, eum, ic. Ad cap. b. Spei.

24. excifa. I. fol. ovatis : fcapo flexuofo: fl. fecundis. Syft. veg. ed. 14. Thumb. loc. cit, cum ic.

Ad cap. b. Spei.

Radix bulbofa. Scap. digital. fimpl, frepe etiam altero ramo, filiform. Fol. oblong. lato-lanceol. lavia, latere interiore excifa. Fl, alterni, feffiles. Glumæ breviff. ovatæ. Cor. tubus filiform. limbus violac.

longiflora.

1. polyftachia; tubis cor. filiform. longt11. nutantibus. Berg. Fl, cap.

Ad cap. b. Spei.

Radix bulbofa. Scap, fpitham, erect, teres, $1 x$ vis, fublutefc. ramofus, fuperne nudus. Fol. fub 6. trifpitham, radical. erecta, lineari-enfiform. longitudinaliter ftriato-nervofa, glabra, virid-lutefcent. Fl. fpicæ pl, fl, alternis, diftantibus, nutantibus, huteis .

inflexa. I, caul. ad angulum inflexo: fl. erectis, fecundis: Spatha exter. calycina cor. fere longitudine, $D_{e}$ la Roshe. Pl, nov. IG ij 


\section{Ad cap. b. Spei.}

Bulbus fimpl. fquamarus. Scap. ped. fimpl. inflexus ad fpicam. Fol. lineari-enfiform. raris villis adfperfa, fcapo breviora. Fl. fpica horizontal. fecunda, col. obfcuro-fubviolac-luteo. Spathæ marcefien. Pet. orato lanc.

quadrangula, I, bulbo fquamato, fquamis exterioribus maximis : fcap. fimpliciff. fol. canalicul-quadrangulis breviore. De la Roche. Pl. nov.

Ad cap. b. Spei.

Bulbi 2. alter alteri impofitus. Scapus foliorum $\mathbf{v} \rightarrow$ ginis veftitus. Fol. pauca, vaginant. ftricta. Fl. pauci, laxe fpicati. Spathæ perfiftentes. Pet, ovata .

imbricate, I. bulbo fquamis imbricatis tecto: fcapo erecto, ramofo: fpatha exter. calycina tubi cor. longitudine. De la Roche. Pl. nav.

Ad cap. 6. Spet.

Scap. dodrant. Fol, vaginant. linearia, fcapo breviora. Fl. laxe fpicati. Pet. 3. extus rubro col, tincta, omnia intus luteo-alba .

Fabricii, I. fcap. dichotomo, ancipiti, dentato. De la Roche. Pl, now.

Ad cap. b. Spei.

Scap. fpitham. Fol. caulina oppofita, vaginant. axillar. line ri-lanc. Fl, fpicati, fubviolac. Spatha perfiftentes.

Bulbocodioi- I. fcapo foliis breviore, ramis I-fl. De la Roch, des. $\mathrm{Pl}$. nov.

Ad cap. b. Spei.

Bulbus parvus. Scap. 3-4. pollic. ramofus. Fol. radical. nonnulla, linearia: caulinum unicum ad axillam rami; omnia fcapo paulo longiora. F1, folitar. magni, lutei. Spathæ perfiftentes.

thyrfiflore,

I. fcapo polyfachio: fpicis alternis, caulr adproximatis: germinibus intra fpathas pedunculatis. $D_{c}$ la Ruche. Pl. nov.

Ad crip. b. Spei.

monanthos, I. fcapo I-fl. fol. lanceol-linearibus longiore. De la Roche. Pl. nov.

Ad cap. b. Spei.

Scap. dodrantal. erect, fimpl, inferne articulat. Fol. radicalia lineari-lanc. caulina vaginant. at articulos. Flos unicus, términal. luteus. Pet. is medio macula nigricante notata. Spatha laceræ, marcefcentes. 
latifolia. I. fcapo erecto, fimpl. fol, enfiformibus. $D_{\epsilon}$ th Roche. Pl. nov.

Ad cap. b. Spei .

Scapus pedal. \& ultra. Fol, vaginantia, nervofa, fcapo paulo breviora - Fl. fpicati, cœruleo-purourafc. Spathre marcefcent. pellucida. Cor, laciniz ovatæ.

aronadelpha, I. filamentis ftaminum coalitis: fcapo ramofo: fol, lineari-enfiformibus. De le Rocke. Pl, nvv. Ad cap. b. Spei.

Scap. pedal. erect. Fol, vaginant. fcap breviora .

Fl. laxe fpicati, cctruleo-purpurafc. Spatha coloratæ, marcefcentes. Cor. laciniæ ovatolanceol.

grandiflora. J. fcapo fimpliciff. fol. lanceol-linearibus: fl. diftichis. De la Rache. Pl. noy.

Ad cap. b. Spei.

Scapus dodrant. Fol. caule breviora. Fl. ter $=$ minal. magni, fature violac. Spathæ marcefcentes. Cor. lacinia lineares, ad apicem dilatatx .

flabellifolia, 1. fol. flabelliformibus: cor. tubo fpathis calycinis duplo longiore. De la Roche. $\mathrm{Pl}$. nov.

Ad cap. b. Spei .

Scapus pedal. ramofus . Fol. radicalia fub 7 . lineari-enfformia, margine exteriore vaginantia : caulina 2. vaginantia; fpathæform. axillar. marcida. Fl. fpicæ fecundæ. Cor, albido-cœrulefc,

Iridifolia. I. fol. flabelliformibus : genitalibus declinatis. De la Racke. Pl. nov.

I. crocata, Syft. veg. ed. 14. Ad cap. b. Spei.

paniculate. I. caule paniculato: tubo $\mathrm{fl}$. longifl, arcuato. De la Rache. Pl. nav. tab. I.

Ad cap. b. Spei.

Scap. 2-3. ped l, divifionibus alternis, remotis, patentibus. Fol, tantum radical, vaginant. enfiform. Atriata. Fl. laxe fpicati, alterni, flavi . Spathæ membranac. ficcæ. Cor. laciniæ lineares, obtufa, leviter emarginatæ: alterne latiores, apice recurva: fuperior. 3. leviter adproximatæ. .

amoricane. I. fol, enfformibus, plicatis, glabris: caule rae G iij 
mofo. Aubl. Guian. Burm. Amer. tob. 46. f. 2 .

In America 24.

Radix bulbofa, tunicata. Fol. petiolat. ftriata, nervofa, longitudinaliter fecundum nervos plicata.

70. GLADIO. Cor, 6-part. ringens, petalis 3 fuperioribus conLUS. vergentibus. Stam. adfcendentia. Tuba $3 \cdot$ filda.

I. communis. G, fol. enfiformibus, fl. diftantibus. Syft. veg. ed. 14. Ludw. ect. tab. 24. Knorr. del. Hort. I. $t a b$. A. S.

In Europa auftrali 24.

Bulbi alii aliis impofiti. Caul. pedal. \& ultra, anceps, foliofus. Spatha inferior fæpius cor. longior. Fl, unilateral. 4-5. purpur. vel albi. Cor. laciniæ inferior. lanceol, cum maculis albis .

2. imbricatus. G. fol, enfiformibus: fl. imbricatis. Syft, yeg. ed. I4 In RuJfia citeriore 24.

Fl. parvi, verfus unum larus imbricati.

3. ulatus. G. fol, enfiformibus : petalis lateralibus latifimis. Syjt. veg. ed. I4.

Sifyrinchium \&c. Pluk, phyt. 224. f. 8.

Ad cap. b. Spei 4 .

Caul. fpitham, inter $\mathrm{fl}$. flexuofus. Fol. obtufiufc. ftriata, lævia: floralia diftiche digefta .

4. plicatus, G. fol. enfiformibus, plicatis, villofis: fsapo la. terali : cor. regularibus.

Ixia \&c. Mill. ic. I59. f. I.

Sifyriachium \&c. Breyn prod. 3. tab. 9. f. 2.

In Ethiopia 24.

Bulbus tunicatus. Scap. 2-3 fl. Bract. terna,

3. triftis. angufta. Petal. violac-alba.

G. fol. lineari-cruciatis : cor. campanulatis. Syft. veg. ed. 14. Mill. ic. $t a b .235$. f. r. Breyno prod. 3. tab. 7. f. I. Trew, ehret. tab. 19.

In EEthiopia 4 .

Fol. fingularia, fubenfiform. fed utroq. latere carinata, carina elevata, obtuff. ut fere qua. drangulo-cruciata. Var. a caule $2-f l$. ad multifl. \& tum fol. rite enfiformibus. Cor. col. trifti, fed xftivatione omnino Gladioli ; petalo fupremo intra lateralia proxima.

6. unduletus. G. fol. enfiformibus: petal. fubaqual, lanceol. undulatis. Syft. veg, ed, 14.

$I_{n}$ Ethiopia 24. 
Statura G. communis . Culn. fefquipedal. Fol. ftriata. Fl. diftiche alterni. Spatha propria 2 phyll, valvula interiore min. Cor tubus longus, thliform. limb. 6-part. Petala in formam Lilii dig fta, alternis imprimis undulatis. Me* dia inter Ixins, \& Gladiolos.

7. racurvus. G. fol. enfiformibus: petal. fubæqualibus, lanceol. recurvatis. Syft. veg. ed. 14. Mill. ic. tab. 235. f. 2 .

Ad cap. b. Spei.

Differt a priore, petal. non undulatis, minufq. dcuminatis; \& tubo cor. non filiformi, laxo, aut pendulo: caterum adfinis.

8. fpicatus. G. fol. linearibus caul. firmpliciff. fl. fpicatis . Syft. veg. ed. I4.

In Africa 4.

9. slopecuroi- G. fol. linearibus: fpica difticha, imbricata. Syft. des. veg. ed. I4.

In Ethiopia.

Caul. pedal, veititus foliorum vaginis ancipitibus', latiufculis, nervofis, in folium lineare, acum tum terminatis. Spathæ ovatæ, duplicatæ . Spica ut in Plantagine, obtecta fl. parvis, numerofitf. fed difticha.

10. anguftus. G. fol. linearibus: fl. diftantibus; cor. tubo limbis longiore. Syft. veg. ed. I4. Mill. ic. 142. f. 2. Hort. Cliff. tab. 6.

In Africa 24.

Caul. fimplex . Fl, alterni, carnei, macula rhombæu purpurea præditi.

Ir. ramofus. G. caut. ramofo: fol, linearibus. Syft. veg. ed. In ${ }^{14}$ Africa 4.

12. capitatus. G. caul. ramofo: capitul, pedunculat. rad. tuberofa. Syft. yeg ed. 14 .

In Africa 24.

Planta maxima. 'Fl. coerul.

23. crifpus, G, fol. lanceol. crenatis, undulatis: fl. fecundis; fpicis duabus tubo filiformi, longo. Syft. veg。 ed. 14 .

Ad cap. b. Spei 24.

Differt omnino ab Ixia crifpa in pluribus. Caul. 2-pedal. uno, alterove fol, inftructus, crenat to, undulato. Eol, longa. 
14. itriceus. G. fol. lato-ianceol. culmo ramofo: fl. fecundis, ftylo 6-part. Syft. veg. ed. 14.

Ad rap. b. Spoi .

Cu'm. palmar. filiform. lævis, uno, alterove ramulo patulo. Fol. culmo dimidio breviora, Jævia. Fi. alterni, feffil. Glumæ ovatæ, integræo. Cor, violac. tubo filiform, limbo lon: giore.

rs. anceps. G. fol. enfiformibus, undulatis: caule ramofo, ancipiti, divaricato. Syjt. veg. ed. I4.

Ad cap. b. Spei.

Fol. caule breviora, in caulem decurrentia, ftri ta, carina crifpa. Fl. dd apices ramorum, alterni . Spathæ obtufiff. ore purpureo. Cor. tubus limbo ter, quater longior.

Adfinis Ixice corymbofa; fimilis caule angulato, fed differt ab illa, \& a palmari tubis cor. lont gis, filiformibus.

16. gremineus , G. petal. lanceolat. fetaceo-acuminat. Syft. veg. ed. 14 .

Ad cap. b. Spei .

Caul. plufquam pedal. teres, lavis, ramis aliquot floriferis. Fol, graminea, longitudine fere caulis, lavia, laxa, nervofa. Fl. terminal. Spathæe ovatæ, acuminata. Cor. parva, abfque fubo, 6-part. albida, fundo violac.

17. margina- G. fol. cartilagineo-marginatis, glabris, multitus. nerviis: fpica elongata : fl. alternis nutantibus. Syft, veg. ed. 14.

Ad cap. b. Spei.

Caul. craffitie pennæ anferinæ. Fol. pedalia, gladiiform. marginibus triplo crafforibus. Spica leviter a flore ad florem flexucfa. Spatba diftantes. Bractea fæpe apice laceratæ. Cot. tubus fpathis duplo longior. Limbi lacinia fubæqual. oblong. ellipticæ, purpur .

18. montanus, $G$, fol. enfiformibis, nervofis, glabris: fl. fpicatis; cor, ringente. Syft. veg. ed. 14. Pluk. phyt. 24. f. 8. Ad cap. b. Spei.

Bulbus cortice fibrofo. Fol. radical, linearia, angufta, linea latitudine, longitudine fere fcapi, lavia. Scapus teres. Spica oblong. fl. remotiufeulis. Bractea propria, ovata, 2-valy. Cor, galea 3-part. lacinia media incurva; la- 
terales divaricatie, recurvata. Lab. 3-part. aquale.

19. frlcatus, G. eaule fimpl, : fol. falcatis: fl. alternis; ftylo 3-fido. Syft. yeg. ed. 14.

Ad cap. b. Spei .

Similis $G$. iunceo ,

zo, flexuofus. G. caule fimpl, flexnofo: fol, linearibus: A. fpicatis, ringentibus, tubo longo. Syjt. veg.ed.14. Ad cap. b. Spei.

21. longiflo- G. caule tereti, tubo longiff, : fpathis, foliifque rus.

linearibus, glabris. Syft. veg. ed. 14 . Ad cap. b. Spei.

22. tubiflorus. G. caule tereti, tubo longiff: : fpathis, foliifque hirfutis. Syft. veg. ed. 14. Ad cap. b. Spei.

23. Spatha- G. caule ramofo: fl. fpicato-imbricat. Ppathis ceus, membranaceis, ariftatis: fol, plicatis. Syft. veg. ed. 14.

Ad cap, b. Spei .

24. latifolius. G. caule ramofo. fol. infimo filifor. fetaceo: cor. ringente. Syft. veg. ed, I4. Ad cap. b. S Sei .

permeabilis. G. coule ramofo: fol. fubulato-quadrangulis : flo imbricat, fecundis. De la Roche. Pl, nov. tab, 2. Ad eap. b. Spei .

Bulbus fpharicus . Scapus fefquiped. divifus . Rami nudi florigeri. Fol. caulina váginz nt. patentia, fumma brevia, fpathæform. Fl. terminal. $f_{p}$ icis fecundis, inbricatis . Cor. laciniæ trapeziform. plicatæ, fimbriatæ, fauce inflata, permeabili. Color dilutiff. viclac. ex purpura, luteoq. variegatus. Spathæ perfifentes. Ludit num. ftam. a 3-6.

involutus. G. ciule ramofo: fol. linearibus: fpicis diftichis . De la Rucke. Pl. nuv, tab. 3, Mill. ic, tab. 236. f. 1. Ad cap, b. Spei.

Bulbus compreffus. Scap. fefquipedal. erectus, arriculat. divifus. Fol. caulina vaginant. patentia. Fl. rofei, fed laciniz lateral. lab. inferior. purpur. Cor laciniarum extrema revoluta. Ludit in fiuaificationis partium numero.

ourness. $G$. caule fimplicifl.: pet.l. fuperior. divergentib. fol. enfifor mibus, Da los Roctie, Pl, nov, tab, 4 . Ald cap. b. Spei, 
Scap. pedal. fimpl, rectus, articulat. Fol. radical. pauca, vaginant. acumin. nervofa, caule breviora: caulina brevia, acumin. vaginant. Fl. laxe fpicati, diffichi, carnei .

7I. ANTHOLYZA. Cor. tubulofa, irregul. recurvata . Capf. infera.

I. ringens. A.cor. labiis divaricatis, fauce compreffa. Syft. veg. ed, I4

Gladiofo \&c. Comm. hort. 1. tab. 41. Rudb. elyfo 2. f. I5.

Gladiolus \&c. Breyn. ic. tab. 8. f. I.

In Ethiopia 24.

Caul. fefquifpitham. hirfutus, purpur. Fol. ras dical. 6 7. bipalmar, femiunc, lata, breviter petiolat. erecta, fulcata. Pedunc. hirfuti . Cor. extus primum ex viridi - flava, dein pallide rubens; intus fanguinea.

2. plicata. A. fol. plicatis: caule ramofo, hirfuto; cor. ringente, ftaminibus breviore. Syft. veg. ed. I4. Ad cap. b. Spei.

Differt a priore habitu, \& pracipue quod orgam na generationis non adeo elongata, ut in illa.

3. Cunonia. A. cor. fubpapilionaceis; labii lobis duobus externis latioribus, adfcendentibus. Syf. veg.ed. 14. Mill. ic. II3. Buttn, cun, tab. I.

In Perfía 4 .

Radix undique emittit fibras filiform. apice bulbiferas. Caul. pedal. fpica longa, difticha. Cor. frepe papilion. monopet, coccinea. Vexil. inter alas, cocbleariforme, alis longius. Ala 2. pares, laterales, ovatæ, adfcendentes. Car. minima, rudis, viridis, 3-fida, gibba, complicata inftar nectarii fub cor.

4. Athiopica. A. cor. incurvatis; labii 5-part. lobis 2. alternis, patulis, maioribus lanceol. Syft. veg. ed. I4. Gladiolus \&c. Morif. hift. 2. $\int .4 . t_{a} b .23$. f. I. Rudb. elyf. 2. f. r4.

Hyacinthus \&c. Pluk. phyt. 195. f. 2.

In Et liopia 4 .

Bulbus guftui acerrimus. Thyrfug ex nigro-put= purafc. Cor. tubulofa, coccinea; lab. fuper. maximo, lanceol.

Hac cum priore Gladiolis valde edfinis.

3. Meriana. A. cor. infuntibul, fol. enfiformibus. Syft, veg. ed. I4. 
Watfonia Mill, ic, tab. 276.

Meriana. Trew, ehret, cab. 40.

Ad cap. b. Spei 24.

Cor. Polyanthis, fupera, æeftivatione Gladioli, fere regularis, dependens, rubra.

6. Merianella. A. cor. infundibulifor.: fol, linearibus. Syf. veg。 ed. 14.

Watfonia \&c, Mill, ic, tab. 297, f, 2.

Habitat.....

Radix bulbcfa. Culmus fefquiped. teres, lavis . Fol. alterna, 3-4. vaginant. ftriata, pubefcentia, præter vaginas, brevia. Fl. 3. alterni, feffles, fecundi. Glumæ lanceol. 2-valv. Cor. tubus incurvus, purpurafc. limbo longior. Limb. 6-part. æqual. laciniis ovat. acutiufc. flavis. Stam. adfcendent. longitudine cor. Anth. linear. adfcendent. Stylus filiform. Stigm. 3. filiform.

Meriana differt facie, fed limites a Gladiolis, o Ixiis feparantes non foccurrunt. Fl. in hac pal. lide rubri, in priore ruberrimi.

7. Lucidor. A. fol. radicalibus; bafi filiformi, apice dilatatofubulatis, fulcatis : caul. fimpl. foliofo fpicato. Syjt. veg. ed. I4.

Ad cap. b. Spei.

Radix bulbofa. Fol. bafi quafi in longum petiolum anguftata. Caul. fefquiped. teres. Fl. alterni, feffiles, elongati, parum incurvati, fuperne purpur. laciniis 6. inæqualibus. Spathæ 3-valv.

72. IRIS. Cor. 6-part. laciniis alternis, reflexis. Tube apex trificl. abit in 3. lacinias petaliform. tegentes stam. Capf. 3-locul. polyfperma.

* Barbatce (quarum petala patentia pilis iftruuntur ,) a. fol. enfiformibus.

I. ciliata. I. barbara, fol. enfiformibus ciliatis, Syft. veg. ed. 14 .

Ad iap. b. Spei.

Folia unduldta.

2. minuta. I. barbata, fol. enfiformibus, glabris; fcapo I-f. petal. oblong. acutis. Syft. veg. ed. I4. Ad cap. b. Spei .

3. pumils, I. barbata, fol. enfiformibus, glabris: fcapo I-fl. petal. oblong. obrufis. Syft, veg. ed. 14. Jacg. Auftr, I, zub, x. 
b. I. angultifol. maritima, min. Bauh, pin.

c. Chamæiris fl. luteo, \& pallide luteo, Bauh, pin.

d. Chamæiris faxatilis \&c. Bauh. pin.

In Auftrice, Pannonia collibus apricis 24.

Radix extus fufcefc. intus alba. Caul. plerumq. breviff. interdum fol, longior evadit. Fol, nuae f. breviora, nunc longiora, acuta. Petala cœrul. purpur. per ætatem rubentia, alba, pallida, flavefcent. variegata . Barba extus corul. intus alba, apicibus lute is .

4. Sufana. I, barbata, fol. enfiformibus glabris: fcapo I-fl. petal, rotundatis. Syft. veg. ed. I4. Knorr. del. hort. 1. tab. L. 6. Morif. hift. 2. f. 4. tab. 6. f. 6.

In Oriente 4.

Caul, reres. Fol. lata. Flos omnium fpecierum maximus, cum venis obfcuris in campo cinereo difcurrentibus. Persla 3 . interiora ma, reflexa. Germ. 3-gono-teretiufc.

5. flarentina . 1. barbata, fol. enfiformibus, glabris, breviorib. fcapo fub 2-fl. Syft. veg. ed. I4. Knorr. del. hort. I. tab. L. 7. Black, tab, 4I 4.

In Europa auftrali $\boldsymbol{4}$.

Simil. 1. Germanicæ, fed radix candidior, \& odoratior. Fol. glauciora. Cor. alba, petal. integris; inferioribus marginum bafi reflexis; fuperioribus magis erectis. Stigm. magis trecta, \& parum ferrata.

6. biflora. I. barbata, fol. enfiformibus, glabris, breviorib. fcapo fub 3-fl. Syft. yeg. ed. I4. Besl. eyft. verna. II 4 .

In Luftatanic rupibus, \& Sibiria 4.

Caul, teres. Fol, extrorfum fubfalcata. Germ. teres, exaratum 3. Ariis. Cor. violac. non emarginata. Petala erecta, barba alba, adiectis ftriis albis, ramofis. Floret bis quotannis.

7. apliylla. I. barbata, fol enfiformibus, glabris, aquantibus: fcapo multifloro, fubnudo. Syft. veg. ed. I4. Habitat. ....

Cor. lutea, variegata.

8. variegata. I. barbata, fol. enfiformibus, glabris, aquantibus: fcapo multifl. Syft, veg. ed. I4. Jriq. Auftr. tab. 5. Knorr. del. hort, I. tab. L. 2. Ehret, pict. tab. 10. f. 3 .

In Hungaria 24.

Radix foris fufca, aut favef6, intus albida . Caul, 
fubflexuofus, fubcompreffus. Fol. pallide viv rentia, Petala luted, fubodora; in reflexis venze atro-purpur, Barba lutea.

9. germanica: I, barbata; fol, enfiformibus, glabris, falcatis, brevioribus: fcapo multifl. Syft. veg. ed. I4. Bluck, tab. 69. Ludw. ea., tab, I12.

In Germania, Etruria, Helvetia \&c. muris votuftis 24.

Radix grandis, cylindrica. Caul. cubital. paucifl. Fol. pedal. difticha, plana, Spatbæ albæ. Fl. magni, odori. Petala-extus ex livido col. in cinereum; intus violac. cum venis albis: infer. plana; interiora integerr.

10. Sambucina. I. barbata, fol. enfiformibus, glabris, erectis, brevioribus: fcapo multifloro, petal, deflexis, planis. Syft. veg. ed. I4. Jacq. hort, tab. 2.

In Europa auftrali 4.

Simil. I. Germanicæe, fed deflexa petala faturatius violac. plana, fed fubemargin. Erecta pallide, faturatius tamen, coerul. \& emarginata. Stigm, ferrata, acutiufc. carina cœrulefc.

11. fquallens. I. barbata: fol. enfiformibus, glabris, erectis, brevioribus: fcapo erecto, multifl. petal. deflexis, replicatis. Syft. veg. ed. I4.

In Europa auftrali 2.

Simil. I. Germanica, fed petala deflexa, in medio replicata, faturatius violacea, venis albis flavefcent., \& in medio corulefcentib. Erecta petala, uti \& ftigmata fquallide flava, valde emarginata.

12. compreffa . I. barbira; fol. enfiformibus, glabris : fcapo paniculato, compreflo. Syft. veg. ed. I4.

Ad cap. b. Spei.

13. dichotomı. 1. barbata; fol. enfiformibus, glabris: caul. pani* culato, tereti. Syft. veg. ed. 14. Pall, it, 3, tab. A. $f, 2$.

In Dauuria 4 .

Fol. radical. alterne vaginantia, difticha. Caul. e vagina fol. femiuln. \& ultra, vix compreffus, fubflexuof,, quandog. dichotomus, foliolo uno, alterove axillari. Fl. ex fpatha 2-phylla, 2-3-raro 4 omnium confpecierum rinimi, dilute purpurafc. Pet. exter. paulo ma: villis vix confpicuis barbata, violac. albo punctata: interiora erecta, faturatiora, extrema latiufcula, biloba.

b. fol, lincaribus. 
I4, tripetala. I. barbata; fol. linearı: fcapo I. fl. petal. alternis, fubulatis. Syft. veg. ed. 14 .

Ad cap. b. Spei .

Caul. glaberrimus. Fol, radicale, unicum, canaliculatum .

35. tricufpis. I. barbata; fol. lineari, Iongiore fcapo fub-2f. petalis alternis, 3-fid. Syft. veg. ed. 14.

I6. plumaric. I. barbata; fol. linearibus: fiapo multifl. ftigma* tibus fetaceo-multifidis. Syft. veg. ed. 14.

Moræa Iriopetala. Lin. Suppl.

M. iuncea Syft. ed. 13.

Ad cap. b. Spei 4.

Bulbus fquamis latere connexis, bafi diftinctis. dentibus I0. compreffis, totidemq. alternis brevioribus. Culmus ramis 3-4. Gluma 2-valv. 2-fl. Fl. albidi.

M. vegeta Syft. ed, 13, ubi citatur Mill. ic. tab, 238. f. n. II. Bulb. fquamis bafi connexis, 2-fid. depreffis, non compreffis. Gluma 2-valv, 2-fl. Fl. pl. quam duo, coerul.

$$
\text { ** Imberbes. }
$$

a. foliis enfiformibus.

17. Xiphium. I. imberbis; fol. enfiformibus, canaliculato-fubulutis, brevioribus: fcapo fub 2. fl. Syft. veg. ed. I4. Knorr, del. hurt. I, tab, L. 9.

In Hifpunia, \& Sibiria 4.

Radix bulbofa. Fol. lata, margine connivente. Cor, plerumq. cœruleo-violac.

I8.p seudo-aco-I. imberbis; fol. enfiformibus: petalis alternis, [us. ftigmate minoribus. Syft, yeg. ed. I4. Fl. Dant. tab. 494. Knor, del. hort. I. tab. L. \&. Ludw. $e \mathfrak{c}$, $t a b$. ror.

Acorus adulterinus. Black, $t a b, 26 \mathrm{I}$.

In Europa ad ripes folfarum \&'c. 24.

Caul. 4-ped, alterne reflexus, foliofus. Fol. longiora, \& anguftiora I. Germanica. Spatha 3-fl. Cor. Iutea, cum lineis nigris. Pet. exter. utrimq. ad filamenta dentem exferunt. Germ. 3-gonum, angulis fulco 2-fid.

9. fatide. I. imberbis; fol. enfiformibus: fcapo uniangulato. Syft. veg. ed. 14 .

Spatula \&c. Black, tab. 188.

In Europa 24.

Caul. teres, hinc angulatus, longitud. fol. obtectus 
foliis fotidiff. Cor. ccerulefcenti-triftis, ingratiff. col. nec noctu odora. Pet. exter. ungue fubtus plicis rugolo: interiora ftigmate maiora, patentia . Germ. 3-gonum, angulis fulco 2-fid.

20. yirginica. I. imberbis; fol. enfformibus: fcapo ancipiti . Syft. veg. ed. 14.

In Virzinia 4.

Radix reptans. Fol. angufta. Cor. ex pallidocœrul. \& nigra variegata .

2I. yerficolor. I, imberb. fol. enfiformibus: fcapo tereti, flexuofo: germinibus fubtrigonis. Syft. veg. ed, 14. Dill. Elth, tab. 155. f. 187. Ehret, pia. tab. 6. f. 2 .

In Virginie, Marilandia \&c. 4 .

Fol. ad alterum latus inclinantia. Scap. fol, non altior, 2-3 fl. Cor. variegata. Per. inter. longitudine ftigmatum. Stigm. linearia .

22. ochroleuca, I, imberb. fol. enfiformibus: fcapo fubtereti : germinibus hexagonis. Syft. veg. ed. :4.

In Oriente 24.

Adfinis I. Spuria, facie tamen diffmilis; at cor. non ccrulea; fol. magis friata; florefcentia ferior.

Caul. pedal. fere teres, ut vix manifefte compreffus. Fol. alterna, $5-6$, erecta, ftriata venis eminentibus, I. Germanica dimidio anguftiora. Spathæ 4-fl. lanceol. acumin. Germ. oblong. profunde 6-angul, angulis obtufis. Pet. reflexa, bafi dilatata, 'venis obfcurioribus, limbo flavo, marginibus albis. Pet. erecta, longitudine exteriorum, nivea, bafi venis flavefcentibus. Stigm. nived fupra anth. ochroleucas .

23. fpathacea I. imberb. fol. enfiformibus, rigidis: fcap, tereti, 2-fl. fpat his longiff. Syft. veg. ed. I4. Thumb. diff. de lride.

Ad cap. b. Spei 24.

24. ramosa. I. imberb. fol. enfiformibus: caul. paniculato, multifl. Syft, veg. ed. 14. Thumb. diff. de Iride .

Ad cap. b. Spei 4.

b. fol. linearibus.

25. Sifyrin- 1, imberb. fol. linearibus, undulatis, reflexis: chium. fcapo I-fl. Syft, veg. ed. 14. Clus, hift. I. po 216.

In Hifpania, Lufitania 24. 
Scap. fpitham. multifl. Pet. purpur. macula Iutea loco barbæ. Bulbus ex gemino bulbo, altero alteri impofito, ut in Gladiolo, Croco.

26. vernn. 1. imberb. fol. linearibus, planis: fcap. I-fl: petal, alternis, rquantibus. Syft. veg. ed. I4 Pluk. Alm. tab. 196. f. 6.

In Virginia 4.

Radix reptans . Cor, ex violac. \& aureo variegata, vel alba, odora.

27. perfica. I. imberb, fol. linearibus, planis: fcap. I-A. petal. alternis brevioribus. Syft. veg. ed. I4, Rudb. elys, 2. f. 9. Dodart. mem. 83. jig. bona.

In Perfia 24.

Bulbus exferit gemmam e duobus paribus fquamarum, intra qua fol. \& flos unicus fpatha fimplici. Scap. parvus, carnofus, inferne albus, fuperne dilute coerul. Fol. plerumq, utrimque 3. fubulato-canaliculata, caule longiora.

28. angufta. I. imberb. fol. filiformi-lineari, erecto, glabro: fcap. glabro, fub I-A. fpathis obtufis. Syft. veg. ed. I4. Thumb. diff. de Iride.

29. fetacea. I. imberb. fol. filiformi-lineari, erecto, glabro: fap. glabro 1-fl. fpathis acutis, membranaceis . Syjt. veg. ed. I4. Thumb. diff. de Iride tab. I. Ad. cap. b. Spei.

30. tenuifolia , I. imberla fol. fi formi-linearibus : fcap. 2-fl. Syft. veg. ed. 14. Thumb. diff. de Iride. Pall, it. 3. $t a b$. E, f. 2.

In Dautria 24.

Fol. fubfolitar, fcap. multo longiora, craffiufc. utrimque convexa, ftriata. Scap. breviff. foliolo enfifor, vaginante. Cor. pollide coerul. odore caryophylli. Petal. longa, angufta.

3r. graminea, I, imberb. fol, linearibus: fcap, fub 2-fl. ancipiti : germinibus hexagonis, Syjt. veg. ed. I4. Jacq. Auftr. 1. tab. 2.

In Auftria, \& Italia ad rad. montium 4.

Radix extus nigra, itstus alba. Caul. fol, duplo brevior, compreffiff. bifol. ante anthelin procumbens. Folia quandoq. latiora. Perala odore Pruni: in reflexis inferior pars purpur: exterior albida, venis coeruleis; in erectis color violaceus.

32. Spuria, I. imberb, fol, linearibus: fcap. fub 2-fl, tereti : germinibus 


\section{IRIANDRIA MONOGIN IA.}

germinibus hexagonis. Syft, yeg. ed, if, $F l$. Dan. tab. 734. Jacq. Aujtr. I. tab. 4.

In Germania, Sibirice pratis 24.

Radix nigricans. Caul. 2-3. pedal. Fol. fortida. Fl. inodori. Cor. ex purpuro-cocrul.

33. Jibirica. I. imberb. fol. linearibus: fcap. fub 2-fl. tereti: germinibus trigonis. Syf. veE. ed. I4. Jacq. Auftr. X. tab. 3 .

In Helvetia, Germania Ec. 24.

Radix cefpitofa. Caul. 3-ped. fol altior. Spathæ aridæ, ut in I. verficolore. Petala ex purpuro-cœrul. fuaveolentia. In reflexis ungues fufcefcunt, tranfverfim albefiunt, parte fuper. cyanaea: petala inter, erecta. Germ. non fulcarum.

34. flexuofa. I, imberb. fol. linearibus flexuofis: caul. 3-fl. tereti, craffo: germinibus 3 -gonis. Syjt. veg. ed. 14. Murray Comm. Gott. 1776. tab. 4.

Similis priori, Cor, alba.

35. martini- I. imberb: tol. linearibus: petal. bafi foveolis cenfis. glandulofis: germinibus trigonis. Syft. yeg.ed. 14. Jacq. Am, 7. tab. 7. el. 2. picta tab. 10. Xiphion \&c. Flum, ic. tab. 26r. f. I.

I Martinic 24.

Caul. 2-pedal, finpl. vel bifariam divifus. Fol. parva, difticha. Fl. pauci, peduncul. flavi, inodori, a congeneribus in mulis ftructura diverfi.

36. pavonia. I. imberb. fol. lineari glabro: fcap. fub. I-fl. Syff. veg. ed. 14. Thumb. diff. de Iride tab. I. Ad cap. 6. Spei.

Caul. fubtoment. Cor. aurantiaca, macula bafeos corul.

37. crifpa. I. imberb. fol, linearibus, crifpis. Syf. veg. ed. 14. Thumb. diJf. de Iride tab. 1. Ad cap. b. Spei. Planta glabra.

38. papiliona- I, imberb. fol, linearibus, reflexis, hirtis, Syjt. cea. veg, ed, 14. Thumb, did, de Iride tab, 2. Ad cap. b. Spei. Planta parva.

39. edulis. I. imberb. fol. lineari, pendulo, glabro, multifl. Syft. veg. ed, I4. Thumb. dig. de Iride. Ad cap. h. Spei. Tom. I. 
7 Folium radicale fcap. vaginans, longiffimum. Bulbus edulis Hottentottis.

40, triftis. I. inberb: fol. linearibus, glabris : fapo hirto, ramofo. Syft. veg. ed. 14. Thumb. diff. de Iride.

Ad cap. b. Spei .

4I. polyfta- I. imberb, fol. linearibus, planis: fcap. glabro, chia. ramofo. Syft. veg. ed, 14. Thumb. dill. de Iride .

Ad cap, b. Spsi.

42. vifcarin, I. imberb. fol. Iinearibus, planis: fcapo vifcolo. Syft. veg. ed. Thumb. diff. de Iride.

Ad cap. b. Spei.

Caul. ramofus, bituminole olidus.

43. bitumino- I. inberb. fol. Ine ribus, fpiralibus: fcap. vifco-

ja. fo. Syft.veg.ed.i 4. Thumb. diff. do Iride tab. 2. Ad cap. b. Spei.

Rarnofi, bituminofa, ut in priore. c. fol. tetregonis :

44. tuberofa, I, imberb: fol, tetragonis, Syft. veg. ed. I4. Moris. hift. 3. f 4. tab. 5. f. 1.

In Arabia, \& Oriente 24.

Rarlix tuberofa. Fol, canaliculata. Cor. obfesre puipur. \& nigra.

ventricofa.

I. Pall. it. 3. tab. B. f. I.

in Dausria 24.

Fol. pauca, caule longiora, anguftiff. linearienfiform. Caul. dodrant, folio vaginante, latiufc. lanceol-enfiformi. Sfatha ventricofd, 2-fl. Fl. tubo elong. elevati. Petal. imberb. oblongo-linear. pallite coerul.

halophyla, I. Palt. it. 3. tab. B. f. 2.

In Dauuria 4.

Differe a priore ftatura proceriore: caul. folios: fratha minus ventricufa: petal. latioribus, extimis apice dilatatis: figmatis laciniis brevibus, latiafcul. obtufis.

Fol. Pfeudo-Acori, glaucefcent. Scapi fæpe fefquiped, foliis longiores, foliofi, 3 -fl. Spathre magna, inflatæ, margine membranaceo. Fl. minimi. Petala imberbia, pallida .

flavifima, I. Pall. it. 3. Gmel. Silir. tab. 5. f. 2.

In Dauuria 24.

Adfinis I.pumila: differt fol, anguftioribus: fcap. 
proceriore, tenuiore, longius inter 2. fol. exferto. Petala intenfe flava, venis fufcefcentibus ftriata; exter. barba flaviffima .

73. MOR\&A. Cor, hexaper. Petala 3. interiora patentia : reliqua Ireos.

I. polyanthos. M. caul, ramofif, fol. fubulatis, glabris: petalis alternis minoribus: ftigmatibus bifidis. Syft. yeg. ed. 14. Lin. Suppl.

Ad cap. b. Spei.

2. Spatiacea. M. fcap tereti: fol, teretibus, dependentibus, longis: fl. aggregatis, capitatis. Syft, veg. ed.I4. Lin. Suppl.

Ad cap. b. Spei.

Fol. \& caul. omnium tenaciffimi, filiform. glaberrimi. Spatha 2-phyll. cum capitulo fl. fpathis minoribus fubulatis obvallato. Cor. lutea . Stigm. 3 .

3. Iugens. M. caul. ancipiti, I-2-fl, fol, enfiformibus, infimis fubfalcatis: fl. terminalibus. Syft. veg. ed. 14. Lin. Suppl.

Ad cap. b. Spei.

Petala alterua ; 3 . exter. alba ; 3 . interiora nigra, min. Stig. multipart.

4. Spiralis. M. caul. compreffo, articulato, multifl. fol. enfiformibus, erectis: fl. axillaribus. Syft. veg. ed. I4. Lin. Suppl.

Ad cap. b. Spei.

Cor. æqualis, extus albo-virefc, intus alba, per nocter fpiralit, convalvitur. Stig. fimpl. villofum.

5. chinenfis. M. caul, compreffo: fol enfiformibus : panicula dichoroma, fl. pedunculat. $S_{y j t}$, veg. ed. I4.

Ixia Chinenfis. Syft. veg. ed, 13. Trew. ehret. tab. 52. Ad. Petrop. 6. tab. 7. Rheed. Mal. II. tab. 37 .

In India 24 .

Caul, 2-pedal, F]. crocei, maculati,

6. aphylla. M. fcap. compreffo, nudo, glaberrimo: fpatha longiff. fubulata: fl. cápitatis. Syft. veg. ed. 14. Lin. Suppl.

Ad cap. b. Spei.

Omnino aphylla. Fl, ut in Junco laterales. Cor. flava. Stigm. 3 .

7. gladiata. M. fcap. compreffo: fpatharum fquamis muticis; ftylis 3. Syft. yeg, ed. I4. 
Ixia gladiata. Lin. Suppl.

Ad cap. b. Spei .

Scap. longus, anceps, lavis. Fol. angufto-enfiform. longiff. lævia, fubtiliter ftriata. Spicæ terminal. fxpe 3. imbricatæ, glumis amplectentibus, obtufiufc, muticis. Bractea enfiform. fpicis non longior. Cor.lutea, petal, exterior. extus rubris.

8. filiformis. M. fcapo, foliifque filiformibus: fl. terminalibus, folitariis. Syft, yig. ed. 14. Lin. Suppl.

Ad cap. b. Spei.

Fl. cuin fpathis referunt fl, Dianthi. Cor. lutea . Stimg. 3 .

9. flezuofa, M. caul. tereti, articulato, ramofo: fol. planis, laxis, revolutis: fpica flexuofa. Syjt. veg. ed. 14. Lin. Suppl.

Jxia longifolia. Jacq. kort. 3. tab. פ०.

Ad cap. b. Spei.

Caules fub 2 -pedal. flexuofo-ereti, raro in horto ramofi. Fol. longiff, vaginant. Petala obl-acuta, pallide flavefien. Capf. oblon-acumin. fufcefcens .

50. africana. M. Al. capitatis: fpathis laceris. Syft. veg. ed. I4.

Ixia afric. Syft. veg. ed. 13. Burm. Afric, tab. 70, f, 2 .

Ad cap. b. Spei.

Caul. fpirham. purpureus. Fol. radical, graminea, nervofa. Pedunc, axill. Spatha ex fquamis hirtis. Fl, pl. porvi coerul.

II. iridioides, M. fol. gladiatis."Syft. veg. ed. 14. Gifech. ie. fafc, I, tib. 3. Mill, ic, tab. 239. f, I.

Iris \&ce. Till. pif, tab. 33 .

In Oriente, Conftantinopoli 4.

Caul. fpitham, erectiufc. longitudine fol, Fol. difticha. Fl. ex alis fupremis fol. 3. Spatha propria 2-valv, Germ. pedicellat. fub 3-gon. ftriata. Cor. hexapetala. Petal. 3. exter. ubovata, oblonga, patula, barbata, patentia, macula lutea in medio. Petald 3. interiora alba, immaculaı, , facie exteriorum, patentia. Styl, brevis, craffus. St:gm. 3. petaloidea, min. patentia, coerulefc. 2-fida, ut in Iride. Stam. 3. albida fub ftigmate. Capf. exferta, truncata.

Diff rt ab Iride cor. tota patente; modo hac fufficiant. 


\section{TRIANDRIA MONOGYNIA:}

82. fugax. M. fol. gramineis, tandem convolutis: Atigm。 petaloideo: petal. imberbibus. Jyjt. veg. ed. I4. Jacq. hort. 3. tab. 20.

Bulbus fubrotund. Caul. unc-peddl. gracilis, ex latere bulbi aphylli. Fol. 2. fublinear. plana, fupra nitida, fubtus tenuiter Rriata, acutd, involuta, unum altero maius. Spathæ amplexantes, membranacex. Fl. pl. iuaveolentes, Petala patentiff. acutiufcula, ex carneo-purpur. Capf. oblung.

74. DILA- Cal. o. Cor. 6-pet. hirfuta. Filamentum tertium TRIS. reliquis minus. Scigma fimpl.

I. umbellata. D. petalis ovar. corymbo faftigiato, hirfuto. Syjt. veg. ed, 14. Lin. Suppl.

Wachendorfia umbellata. Syft. ed. 13 .

Dilarris Fl. Cnp. 1. $t a b$. 3. f. 5 .

In camisis arenofis cap. b. Spei 4 .

Planta tota cana, villafiff. exceptis fl. interne. Ridix fibrofa. Fol. radicalia, cyperina, erecta, lævia, ftricta: caulina 1-2. lanceol. brevia. Umbel. faftgiata, regularis. Involuc, univerfale hexaphyll. lanceol, breve. Radii peduncul. fub 6. biportiti; brachio utroq. racemofo; fl. alternis, adfcententibus, pedicellatis. Cor. intus fubglabra, atro-purpur. petalis ovalibus connexa. Tubus nullus. Frue. inferus.

2. vifcasa. D. peral. linearibus: corymbo faftigiato, villofo, vifcofo. Syft. veg. ed. 14. Lin, Suppl. Ad cap. b. Spei.

3. paniculata. D. petal, lanceol. panicula oblong. villofa, vifcofa. Syf. veg. ed. I4. Lin. Suppl.

Ad cap. b. Spei.

F1. purpureo-flavefcent.

75. WACHENDORFIA . Cor. 6-petala, inæqualis, infera: Capf. trilocul, fupera.

I. thyr fiflora. W. fcapo finplici. Syft. veg. ed. I4. Burm. monogr. 2. f. 2. Nov. aद. N, C. I, tab. 2. f. I。 Ad cap. b. Spei 24.

Kadix tuberofa, phœnicea. Fel, maiora 2-pedal.

3. digitos lata, 5-nervia, flabelli inftar plicata, lanceol, late virentia. Scap. 4-pedal. cum fol. vaginantibus, fuperne pilofus cum maculis rubris. Thyrfus pedal. Fl. extus crocei, intus lutei . Capf fubovata, triquetra, hirfuta? 2. paniculata, W. fcapo polyflachio. Syft. veg. ed. I4. Burms H iij 
monogr. 4. f. I. Noy. act. N. C. I. tal, 2, f. I0.

Afphodelus \&c. Breyn. prodr. 3. tab. 9. f. I.

Ad cap. b. Spei 24.

Fol, vaginantia, enfiformia, trinervia. Scap. nodofus. Fl. quini in fingulo pedunc. colore, ut in priore.

3. graminifo- W. caul. polyftachio, hirfuto: fol. enfiformibus, lia. canaliculatis, glabris. Syf. veg. ed. I4. Lin. Suppl.

Ad cup. b. Spei.

Rariffima inter Liliaceas capenfes.

76. COMME-Cor. 6-pet. Nectaria 3. cruciata, filamentis proLINA. priis inferta.

$$
\text { * Dipetala, ob 2. petala mainra. }
$$

I. communis, C. cor. inæqualibus: fol. ovat-lanceol, acutis: caul. repenre, glabro. Syf. veg. ed. 14.

C. procumbens \&c. Dill. Elth, tab. 73, f. 89.

In America ().

Caul. ramofus. Fol. vaginantia, margine imberbi. Pedunc. bini eadem fpatha vaginati; alter I-fl. longior, alter fub 4-fl. Cor. corul.

Confer plantam Kamph. Jap. tab.899. cum tinçura inde paranda.

2. africana. C. cor. inaqualibus: fol. lanceol. glabris: caul, decumbente. Syft. 1'eg, ed. I4.

In Ethiopia.

Caul. 2-fid. Fol. 2-pcllic, bafi vaginant. Pedunc. axill. plerumq. 2-fl. Petala lutea.

3. benghalenfis, C. cor, inæequalibus: fol. ovat. ubtufis: caule repente. Syft. veg. ed. 14. Murr. Commr. gott. 1779. tab. 5.

C. cucullata. Syft. veg. ed. 13.

Ephemerum \&c. Pluk. alni. tab. 27. f. 3 .

In Benghala.

Caul. pedal, articulati, hirfuti. Fol. horizont2lia, petiolata, pubefcenti-uodulata. Petala 2. interiora fature cœrul, reliqua pallidiora. Variat $f l$. flavo.

4. ereäa. C. cor. inaqualibus: fol, ovat-lanceol: caul, erecto , fubhirfuto, fimplicilf. Syft. veg. ed. I4. Dill. Elth, tab. 88.

In Virginia 24.

Caul. fefquiped. Petioli vaginant. fcabri. Cor, pallide corul. 
** Tripetala: Zanonia, Pl. petalis 3. ma:

5. virginica. C. cor. fubrqualibus : fol, lanceol. fubpetiol. ore barbotis: caulibus erectis. Syft. veg. ed. 14. Ephemerum \&c. Pluk, alm. tab. 174. f. 4.

In Virginia 24.

Caul. 2-pedal. fimpl. laves. Fol, fupra retrorfum fcabra, vaginis nervofis, fubpubefcent. pilis ferrugineis. Suatha terminal. fubcordara. Cor, corul. Peial. cordata, integerr. inferiore brevius pedicellato.

6. tuberofa. C. cor. æqualibus: fol. fefilibus, ovato-lanc. fubciliatis. Syft. veg. ed. 14, Dill. Elth. tab. 79. f. 90 .

In Mexico 24.

Radix tuberofa. Caul. debilis, dichotomus, in aquiofo folo repens. Fol. plana, vifcidula. Cur. pallide coerul.

7. Zanenia. C. cor. æqualibus: fol, lanceol, vaginis tumidis, margine hirfutis: peduncul. incraffatis : bracteis geminis. Syft. veg. ed. I4.

Periclymenum \&c. Sloan Jim, I, tab. I47. f, 1 . In America Gallia aquinodiali.

Caul, erccuss. Fol. Gentianæ fimil: vaginæ lat ffrmæ, \& a caule diftantes. Bract. lanceol. oppofita.

8. vaginata. C. cor. aqualibus: fol. linearibus: fl. diandris, inyolucro vaginatis. Syft. veg. ed. 14 .

In India orientali $\odot$.

Caul. multi, adfcendentes, fubfcabri. Fol. feffil. vaginania, acuta. Pedunc. terminal. \& axillar, elongari . Involuc. lanceol. Atriatun, convolurum ut fere cylindricum. Cal, apice coloratus .

9. nudiflore, C. cor, æqualibus: fol. linearibus: pedunc. $\mathrm{Ca}-$ pi!laribus: involuc, nullo: $\mathrm{fl}$. diandris. Syf. veg. ed. 14 .

Ephemeruin \&c. Pluk. alm, tab. 27. f. 4.

In Indice Or. aridis graminofis $\odot$.

Caul, erectufc. bafi decumbens, fpitham. fubfuber. Fol. feffl, vaginant. acura. Pedunc. terminal. duo, major, minorve. Fl. 4-6. pedicellati, nutantes. Cul. foliol. ovat-lanceol. acutis, cor. minoribus. Petala ovatd, inæquale liter eiftributa, infima magis diftentia. 
audicaulis .

C. cor. æqualibus: fcapo indivifo: fol. lanceol. radicalibus. Burm. Ind, tab. 8. f. $\mathbf{I}$.

\section{In Java .}

Radix repens, fibrofa. Caul: procumbens. Fol. radical. ad ortum vaginantia. Scap, erectus, filiform. in cuius medio bractea revoluta. Fl. bini, corrul.

pepilionacea. C. involuc. 3-phyll, alterum recipientibus: caul, repenre: fol, lariceol-linearibus. Burm. Ind. tab. 7. f. $\mathrm{I}$.

Habitat Coromandeli.

Radix fibrola, alba. Caul. 2-pollic. articulatus, ad fingula genicula radicans, e rubro-virid. Fol. feffil. yagina latiufcula, breviff. acuta, fubciliata, fuccofa. Spatha terminal. cordata, complicata, fubciliata, fub qua foliola 2. lanceol. lunata .

difufa. C. cor, æqualibus: pedunculis capillaribus: fol. ovat-oblong. involuc, nullo. Burm. Ind. tab. 7. f. 3 .

Commelinoi- C. ramis panicula fpicatis, lateralibus; arifta cades.

hexandra. lyce $\mathrm{fl}$, longiore. Forsk. $\mathbb{E}$ Eyp.

In Arabia.

C, fl. ramois, coruleis. Aubl. Guian, tab. 12.

In Cä̈enna, \& Guiana 24.

Caul. pl. 3-pedal. \& ultra, flexuofi, nodofs. Fol, alterna, fubpetiolat. periolo vaginam oblongam, ventricofam, pilis coronatam efformante; ovata, acuta, ftriata, integerr. Fl. terminales, racemofi, racemulis 4 -fl. Petala inæequalia, ovata, concava, cœrul.

77. CAllisia. Cal. 3-phyll. Petal. 3. Anth. gemina. Capf. 2-locul.

I. repens. C. Syff. veg. 14.

Adfinis Commelina, fel Necariis orbata.

Hapalanthus \&c. Jacq. am. tab. Ir.ed. pia. tab. 14.

In Americe meriod. locis umbrofis $\odot$.

Planta herbacea, repens, viridis, fuperne erectiufcula, bafi ramofiufcula, glabra. Caul. digital-fpitham. teres. Fol, alterna, vaginant. ovat-acum. bafi fubcord. integerr. craffiufc, pinguia, nitida, margine purpur. Fol. fumma adgregata, \& imbricata in rofulam patentem. 
Fl. axill. parvi, plerumq. terni, feffiles, tenelli, vicentes.

73. XYRIS, Cor. 3-pet, xqualis, crenata. Gluma 2-valv, in capitulum. Capf. fupera.

I, indica. X. fol. gladiatis. Syft. yeg. ed. I4. Gladiolo \&c. Pluk. ulm. tab. 416. f. 4.

Gramen \&c. Moris hift. 3. f. 8. $2 a b, 9$. f. 28. Rheed. Mal. 9. tab. 13\%. f. 7 .

In India.

Caul. pl. plufquam pedal, iuncei. Fol. graminea, pedal. Capirnlum terminale, ovale, fquamatum, lucens, col. ex Juteo, \& pallido variegatum.

americana.

X. fol. fetaceis : fl. coerul. Aubl. Guian. tab. 14. In Guiana 24.

Planta herbacea. Fol. parva, fafciculata, bafi fe muruo amplexantia, angufta, acuta, plana, rigida. Scapi numerofi, 3-4. unc. nứi, compreffr, anulati. Capitul. fquamofum, fquamis ovdis, concavis, flores diftinguentibus.

79. SCHQ- Glum $x$ paleaceæ, I-valv, congefta. Cกr. o. NUS. Sem. I. fubrotund. inter, glumas. Differt a Scirpo fquamis ominibus fertilibus.

$A C_{y p e r o}$ glumis folliculi incerti numeri, laxe fine ordine congeftis, aut laxe imbricatis. Locufia, five ficica multiflora.

\section{Culmo tereti.}

x. Marifcus. S. culmo tereti; foliis margine, dorfoq. aculeatis. Syjt. veg. ed. I4:

Pfeudo-Cyperus \&c. Scheucht. gram, tab. 8. f. 7. 11 .

Cyperus \&c. Moris hift. 3. f. 8. tab. 11. f. 24. Gramen \&c. Bocc. Sic. tab. 39.

In Europa paludibus,

Culm. 2-cubital. Fol, pene triquetra, nervo valde eminente. Aculei marginis dorfique digitos fere vulnerant. Panicula fubfpitham. valde ramofa. Pedunc, axill alterni, ramofi. Stipula fub panicula longa, fufca. Locufta ovat-acum. lignea.

2. mucronetus, S. culm. tereti, nudo: fpicul. ovatis, fafciculat, involuc. fub-6-phyll, fol. canalicul. Syjt, veg. ed. 14 . 
Juncus \&x. Barr. ic. 203. f. I.

Gramen \&c. Moris, hift. 3. 5, 8. tab. 9. f. 6.

Suirpus \&c. Scheucht, gram, tub. 8. f. I.

In Europa maritimis arenofis 24.

Radix repens. Fol. plurima, radical. in fafciculum collecta, longiff. candiculata, fubteretia, margine fabra (non carnofa, nec plana). Culm. folifs crafftor, longeque breviur, firmus, lavis. Involuc. foliola inaqualid.

Proximior eft $\mathcal{C}_{\text {ypero, }}$ quam Scherno: fpicula enim conftant ex glumis laxe quidem, fed tamen ut in Cypero, frbi allerne fuccedentibus, \& imbricatis.

3. nigricans, S. culm, tereti, nudo: capitulo ovato; involucri diphylli valvula altera longa, fubulata. Syjt. veg. ed. 14.

Juncus \&c. Moris. hift. 3. f. 8. $t a b$. 10. f. 28.

Juncus \&c. Magn, mon/p. tab. I44.

Junco \&c. Scheuchz. gram. tab. 7, f. 13. 14. I5.

In Europe prilludibus ceftete exficcatis 24.

Planta cefpitora. Culm, pedal-c bital. Fol. carinata, convexa. Involuc. 2-phyll. inæquale. Spicæ multæ, adpreffæ, peduncul atro-ipadic.

4. ferrugineus.S. culmo tereti, nudo: fpica duplici; involucri valvula ma. Fpicam aquante. Syft. veg. ed. I4. Gramen \&c. Morls. hift. 3. . 8. tab. 12. f. $4^{0}$. In paludibus 4.

Adfinis priori, fed brevior, \& anguftior. Num. \& magnitudine fpicarum; divifione, \& proceritate paniculæ infigniter varit .

5. fus is. S. culmo tereti, foliofo: fpiculis fubfafcicul. fol. filiformibus, canaliculatis. Syft. veg. ed. I4.

Cyperus \&e. Moris, hift. 3. f.8 tab. II. f. 40 .

In Europa paludibus cefpitofis 24.

S. fafciculato fimillimus fiutura, facie, loco: differt fpiculis glomeratis, fufcis, nec faftigiatis, albis: prececius floret.

Culm. digit-palm. obtufe triquet. Fol, canaliculata, pafin cum maculis furcis.

6. compar. S. culm. tereti, nudo: fpica compofita: fpiculis geminatis. Syst. veg. ed. 14. Rottbcel. defor. Es ic. plant. l. J. $t a b$, 18. f. 4 . Ad cap. b. Spei.

Culmi pedal. læves. Spica terminal. plerumq. ex 6. congefta. Spiculæ pares, feffil. ovatæ, ferrugin, 
7. ustulatus. S. culm. tereti, foliofo: fpicis pedunculat. pendulis, oblong. ariftatis. Syst, veg: ed, I 4. Ad cap. b. Spei 24.

Culm. 2-pedal. abfque geniculis. Fol. caulina pauca, pedal. filiform. lavia, laxa, acuta, canaliculata, vagina ftriata, fuperne fufcefiente. Fol. floralia 2. alterna, culnum non $\mathrm{fu}$ perantia, vagina dilatata, ferruginea. Pedunc. e fingulis vaginis fapius duo, laxi, ut fere membranacei, longitudine fpicæ. Spicæ compofiræ, atro-ferrugineæ, fufrulta bractea concol. ariftata. Differt a S. glomerato fricls oblong.

8. radiatus. S. culmo teretiuf. capitulo fubrotun. involucr. 8-phyll, longiff, Syft. veg. ed. 14. Lin. fuppl. Ad cap. b. Spei.

Fol. plura, fpitham. linearia, canaliculata, lævia, rigidiufcula. Capirulun magnitudine Pruni. Involuc. flavum. Foliola alia inter florum acervos, involucro fimilia.

\section{** Culmo triquetro.}

9. bilbofus. S. culm. triquetris, nudis: fl. glomerulis alternis: fol. lineari-filiformibus. Syft. veg. ed. I4. Scirpus \& c. Rottbeel. defcr. \& ic. plant. I. I. tab. I6. f. 3 .

Ad cap. 6. Spei 4 .

Radix bulbofa, veftita foliorum præteritorum rudimentis. Fol. numerofa, fetacea, erecta, friata, longitudine fere culmi, bafi membanacea, alba . Culmi fpithamai, fol. vix longiorefq., latiorefque. Glomeruli 3-4 feffiles . F1. parvi, rubri. Singulis glomerul. folium fetaceum fubiectum. Facies $J_{u n c i} b_{u l b o f i}$.

10. compref- S. culm. fubtriquetro, nudo: fpica dilticha; infus. volucr. I-phyllo. Syft. yeg. ed. I4. Pollick. Pal, tab. I. f. 2 .

Gramen \&c. Pluk. alm. tab. 34. f. 9. Scheuchz. gram. tab. Ir. f. 6 .

Cyperella \&e. Mich. gen, tab.33. Synonima C2ricis uliginofi ad hunc refert Hall.

In Europa.

Culm. pedal-cubital. compreffus, fulcatus. Fol. plana. Spica fufca e finu culmi, ut in Juncis: locufta elliptica, fpadicea, nitida. Sem. arillis 6. obfitum. 
Huius etiam fpicula ita componuntur, ut ab aliis Schoeni fpeciebus longe recedant, atque Cyperi fpiculas referant.

11. glomera- S. culm. triquetro, foliofo: fl. fafciculat. fol. tus. planis: pedunculis lateralibus geminis. Syft. veg. ed. 14 .

In Virginia.

Diffincza eft species.

12. iermalis. S, culm. triquetro, foliofo: capitulis lateralibus, compofits, fubfeffilibus : fol. enliformibus, carinatis. Syft. veg.ed. 14. Rottboel. defir. pl. l. I. $t a 2 b, 12 . f, 2$.

Ad aquas calidas Cap. b. Spei 24.

Culni 6-ped. crafintie pennæ cignea, lignofi, fubrigentes, laves. Fol. vaginant. erecta, ftri$\mathrm{cta}$, lavia. Capitula verfus fummitarem culmi, alterna, fubfeffil. fingulum e vagina fuliacea.

13. albus. S. cu'm. fubtriquetro, foliofo: fol, fetaceis: flo fafciculatis. Syft. veg.ed. I4. Fl. Dan. tab. 320.

Cyperus \&c. Morif. hift. 3. F. 8. tab. 9. f. 39.

Gramen \&c. Pluk. alm, tab. 34. f. II. Sckeuch. grnm, $t a b$. II. f. II.

In Europa paludofis 24.

Fabri. S. culm. compreffo: capitul. folitar, involucro maximo tectis; apicibus exteriorum fquamarum longiff. folio terminatis. Rottboel, defcr. pl. $l$. 1. tab. I9. f. 2.

Flos, \& tota ftructura novum genus indicare videntur.

Culm, aitus, flexuof. geniculat. compreffus, ftriatus. Fol. longiff. linear. dependentia, flexuofa, carinata, ftriata, bafin verfus præcipue pilofa. Capitula lateralia, \& terminalia maxima; erecta, fquanis coriaceis hirfutiff. Totum receptaculum intus fl. pedicellatis obrectum.

feteceus, $S$, culm. triquetro: fol. fetaceis: fpicis aggregatis, fl. diandris. Roteboel. defcr. pl. l. I. tab. 21. f. 2 .

In Suriname.

Culm. fpitham. fimpl. fetaceus, debilis . Fol. alterna, longiff. præter fupremum, quod fafciculo fl. terminalium vix longius eft. Pedunc. axill. inferior. folitarii, fuperior. 3-4. breviffimi, in fafciculum sollecti, Spica $3-4$. 
cufpidatus. S. culn. teretib. fubnudis: panicula tenuiffima, lineari : bract. anularibus, obliquis, breviff. mucrone longiff. terminatis. Rottboell. defc. pl.l. I. $t a b, 18$. f. 3 .

Culm. pl, fefquiped, iuncei. Vaginæ fanguinea, vel ferrugineæ. Panicul. fefquiuncial. Rami breves, fafciculati, fubdichotomi. Bract. brunnex. Spic. axill. \& terminal. parva, 3. lineas longæ, diltichæ, ferrugin.

fafciatus, S. culmis, folifque fetaceis, longiff. fl, tenuiffm. ariltatis. Rottboell, defcr. pl. l. x. $t_{a b}$. 19, f. 5 .

Culm. pl. pedal. ad bafin fufci, telaque cancellata atro-purp. cincti. Fol, ad radicem fafciculata, convoluto-fetacea; caulina alterna, remota, vagina cylindrica, atro-purp. Pedunc. axil. fub 3-A., inferior. folitarii ; fuper. biniterni. Spicæe vagina fpathacea.

furinamenfis . S. culm. triquetro, foliofo: pedunc. corymbofis, inferioribus alternis, fuperioribus in umbellam aggregatis, Rottboel. defor.pl.l. 1, tab.4. f. r. Culmus altiffm. ftriatus, fcaber. vaginæ laxæ, uno latere mucrone obtufo; fol. longiff. lineari, carina, \& margine acule to, terminatæ. Corymbi laterales, pedunculati, compofiti. Spicæ terminal. adgregatæ, cylindricofubulatæ, ferrugineæ, vel rufæe, 3-lineares. incanus. S. Forsk. Agypt.

In Arabia.

Caul, \& fol. villofo-tomentofa, aculeata. Fol. 3-pollicar. bafi obliqua, margine finuato-repando-obrufo. Cal. tpinofus . Fruct. globofus, lefquipollic, diametro, flavus .

deuftus. S. culn. tereti, nudo, folia æquante: capitul. oblong. glumis calycinis fubæqualibus, mucronatis, fpicam involventibus. Berg. Fl. Cap.

Ad eap. b. Spei.

Differt a S. nigricante fol. glabris, nec margine fcabridis: culmo longitud. folior. vaginis membranac. glumis maximis fpicam involventibus.

Gramen paludofum. Radix bulbis ovatis. Culmi pl. finguli ex fuo bulbo, palmares, \& ultra, ftriati . Fol, plurima, radical. bafi vaginant. lineari-femifubulata, erecta, glabra, fuperne concava. Vaginæ membranac. Spica terminal. folitaria.

tuberofus. S, culm, triquetro: capitul, ternis, feffilibus in- 
volucro longiff, viridi : radic, tuberofa, Burm. Ind.

Mottenga, H. Mal, I2, tab. I2.

In Java, \& Malabaria.

paniculatus. S. culm. triquerro, foliofo: panicula alterna, colorata; calycibus ariftatis: feminibus globofis, lavibus. Burm. Ind.

Carex \&c. Rumph. 6. tab, 8. f, I.

In India.

Fol. alterna : panicula axillar, fetæe plurima, pollic. Sem. fplendentia, ut Lithofpermi, fæpe nigricant,

-doratus, S. fpica compacta, fubrotunda, viridi. Aubl. Guian. Sloan. hist, I. tab. 78. f. 2.

In Guiana,

cyperoides, S, culmo compreffo, femitereti, nudo: fpicis feffilibus, lanceolat, tortis; infima involucrata. Retz. Obf. fufi. 4 .

In Zeylona,

Culm. folitar, ped. \& ultra, ftriatus, Fol, filiform. vaginis fufcis. Spicæ 2-7 forma, \& torfione Cyperi monoffachii, fed plus duplo 12tiores, nitidæ. Squam. cymbiform, compreflæ.

Bobartia, S. culmo compreffo: capitul, terminali ; involucr. 5-phyll. Retz. Obf, fafi. 4.

In Zeylone,

Rad, veluti bulbofæ. Fol. linearia, laxa. Culm. fubpedal. Capitul. breve, fpiratum. Spicul. pl. fquamis fub 5. oyatis, feariofis, cavis .

80, CYPE- Pl. fpiçæ in capitulum congeftæ, multifl. comRUS. planatæ. Glumæ paleaceæ, diftiche imbricatæ, Cor, o. Sern. I, nudum, triquetrum.

\section{* Culmo tereti.}

I. articulatus.C, culmo tereti, nudo, articulato. Syf. veg. ed. I4.

Juncus \&c. Sloan. Jam, hift. I, tab, 8I, f. I. Cyperus Nilaticus, Forsk. Atgyp. monente Vahl. In Jamaica rivulis 4.

Culm. pedal, \& ultra, col. cæfio. Umbella nuda, fubfimpl; radii 8-9. flexuofi, inæqual. apice fub-3. fid. Spica conferta, lineares, ferrtginea.

2, minimus, C. culm, tereti, nudo; (picis fub apice. Syft. yeg. ed, I4. 
Gramen \&c. Pluk, alm, tab. 300. f.,5. Sloan, Jum. hift. I. tab. 79. f. 3 .

In Jamaica, Africa.

Culm. Ppitham. Fol, capillacea. Spica 3-5. compactæ, imbricatæ, ovatæ. Sem, triquetrum.

3. Lateralis. C. culmo teretiufc, nudo: Cpica laterali, feffili . Syjt. veg. ed, 14. Lin. Juppl.

Ad cap. b. Spei $\odot$.

Culmi pl, longitudine acicula, fetiform, non rigidi. Spica ovata, fquamis 7-9. diftichis, acutiufcul. Irevibus.

4. Monti. C. culn. tereti: foliis carina lavibus: umbella fupradecompos. Lin. fuppl, Syjt. veg. ed. 14. Mont. Gram. tab. I, f. 2 .

In India, nunc in Italia, lacis inundatis 24.

Culm, teres, apyll. Fol, longiff. Invol, longiff. 6-phyll. Spicul. ovatæ, ferrugineæ.

5. tenellus, C. culm. nudo, fetaceo: fpicis folitariis, geminifq: feffilibus, Lin. Suppl. Syft. veg. ed. I4.

Ad cap. b. Spei.

Culmi digito breviores, crafitie $f_{t}$ æe equinæ. Spicæ intra apicem culmi, comprelfæ, ancipites, ovitæ; Iquamis IO-I 2.

\section{** Culmo triquetro.}

6. monofta- C. culm, triquetro, nudo: fpica terminal fimpl. chyos. ovata; fquamis mucronatis. Syft. veg. ed. I4. Rottbal. defcr. pl. l. I. tab. 13. f. 3 .

In India Orient.

Fol radical, numerofa, linear. anguftiff. laxa, lævia, fpitham. Culm. vix pedal: tiliform. debilis. Spica magnitudine fem, Cucumeris, imbricata, compreffufc. Iavis, fquamis carinatis. Foliolum fub f pica 1-raro 2. fubulatum, longitudine fpica.

7. lavigatus. C. culm. triquetro, nudo; capitulo 2-phyllo; fl. lavigatis. Syst, veg, ed. I4. Rottbcel. defor. pl. l. 1. tab. I6. f. I.

Ad cap. b. Spei 4.

Culm, 2-ped. læves. Capitul, terminal, fubrotun. e fpicul, pl, feffilibus. Involucr. foliol, $p$ anocanalicul. fubulat. capitulo longioribus, ftrictiufe. ma: erecto, inferior. patulo. Spicæ obl-ovatæ, imbricatæ, glaberr. obtulufc. fquamis oratis. 
8. Haf̧an. C. culn. triquetro, foliofo: umbella fupra decompos: fpicul. umbellato-feffilibus. Syst. ves. ed. 14. Rottbcel. defir. pl. l. p. tab. 6. f. 2.

Gramen \&c. Pluk. alm. tab. I92. f. 2.

In India, Ethiopia 4.

Culm. pedal. Fol, ovata. Involucr, 2-phyll, vix umbella longius. Umbel. fparfa. Spicula in apice ex eoden puncto ortæ.

9. longus. C. culm. triquetro, foliofo : umbella foliofa, fupradecompos: pedunc. nudis ; fpicis alternis. Syst. veg. ed. I4. Moris. hist. 3. f. 8. tab. II. f. 13 .

In Italia, Gullia, Carniola \&c. paludibus 24. Radix longa, odorata. Culm. angulis afperis. Umbellulæ crafla, rufefcentes, e variis fpicarum congeftarum agminibus conftantes, quarum medium brevi pediculo infidentibus pl. fpicis conftat; reliquæ, quæ illud circumftant, pediculo oblongo inhærent.

xo. efculentus. C. culm. triquetro, nudo: umbella foliofa: radicum tuberibus ovatis; zonis imbricat. Syft. veg. ed. I4. Moris. hift. 3. f. 8, tab. 11, f. 10. Lol, ic. 75 .

In Italia, Oriente 24.

Fol. graminea, acuta, dorfo triquetra.

II. rotundus, C, culm. triquetro, fubnud. umbell. decompofita: fpicis alternis, linearibus. Syft. veg. ed. I4.

C. hexaflachyos. Rottbel. defcr. pl. l, I. tab. 14. $f 2$.

In Indiu.

Radix aliquot bulbos gerit. Culmus fubped. inferne veltitus fol. 4. alternis, gramineis. Involucr, 2-3. phyll, longitudine umbella.

22. fquarrofus.C, culm. triquetro, nudo: umbella foliofa, glomerata: fpicis ftriatis, fquarrofis. Syft. veg. ed. 14. Rottboel. defor. pl. 1. 1, tab. 6. f, 3 . Gramen \&ci. Pluk. alm. tab. 397. f. 2.

In Afia.

Culmi pl. conferti, pollic. Fol. graminea, bafi culmum obvolventia. Involuc. 3-4-phyllum umbella longius, bafi latius. Umbella nulla diffincta, fed radii umbella undique fpiculis confertis.

33. difformis, C. culmo triquetro, fubnudo: umbella fimpl. 2-phylla, 


\section{TRIANDRIA MONOGYNIA.}

2-phylla, 3-fid. fpicis cufpidatis, ir rmedia feffili. Syft, veg, ed. I4. Rotibuell. defcr. pl. 1, I. $t a b, 9, f, 2$.

Gramen \&c. Pluk, alm. $t a b, 3$ 17. f. r. phyt. tab. 417 . f. 5.

In India.

Culm, pedal. ad bafin uno, alterove fol, veftitus. Involuc. foliol, altero longiff. Partiale nullum. Spicæe numerofæ, feffil. Janceol. fquamis ovatis, concavis, obtufis, latere fcariofis.

I4. Irit.

C. culm. triquetro, feminudo: umbell. foliofa, decompofita: fpiculis alternis, granis diftinctis. Syft. veg. ed. 14.

Gramen \&c. Pluk, alm. tab, 191, f. 7 .

Iria \&c. Rheed. Mal. 12, tab. 56.

In India.

Culm. pedal. ftriatus. Fol. lanceol-linear, vaginant. ftriata, carinata, mollia. Involuc. univerfale 3-phyll. umbella longius . Partialis fquamz fetacex, flexuofæ, pedicellis fubiectæ. Pedunc. in umbella plurimi, apice umbelliferi : umbella ex 3-4. radiis. Grana triquetra, obtufiff. vix inanifefte palea veftita, paruin diftantia. Color bafeos culm. \& radiorum ferrugin: culmi reliqui, \& fol, incanus: fpicarum fulvus, micans.

I5. el atus. C. culm. triquetro, nudo: umbel. fupradecompofita, foliofa; fpicis digitalibus, imbricatis; fpicul. fubulat. (diftichis). Syft, yeg, ed, I4. Rottboell. defcr. pl. l. I. tab. IO.

\section{In India.}

Gramen altum. Umbell, inæqual. Involucr, univerfale longiff. Partial, fpicis brevius. Spica feffil. ferrugin.

16. glomera- C. culm. triquetro, nudo: umbell. fupradecomtus. pof. 3-phylla: fpicis glomerato-rotundatis; fpicul. fubulatis. Syft. veg. ed. 14. Segu. Ver. 3. $t a b .2$. f. 2. Mont. gr. $t a b$. I. f. 1. In Italia paludofis, of in India $\odot$. Simil. priori, fed brevior. Spica congeftæ.

17. glaber. C. culm, triquetro, nudo, lævi: umbella 3-phyl. fl. glomeratis; inferior. brachiatis: fol. gla bris. Syft, veg. ed. I4. Segu. Suppl, tab. 2. f. I. In Verona \&c, humentibus $\odot$.

Culm. palmar. Fol, radical. erecta, longitudine Tom. I. 
culmi, Umbel, fimpl. fl. fefflibus, alternis, in fimis pedicellat, Fl, ovati, compreffi, diftiche imbricati, per maturitatem fufceftentes.

78. elegans, C. culmo triquetro, nudo: umbella foliofa; pedunc, nudis, proliferis: fpicis confertis, mucronibus patulis. Syst. yeg. ed. 14. Rottboel. defor, pl. l. t. tab. 6. f. 4. Sloan. Jam. hift. I. $t a b, 75$, f. $\mathrm{I}$.

In Jamaica paludofis maritimis.

Culm, pedal, \& ulcra, afper. Fol. longiff. linear. vagin + nt. carinata, involuta, fcabra. Umbell. decompof. Atrictiff, Radii fub 8. Spicæ pl. breves, ovatæ ,

I9. odoratus, C, culmo triquetro, nulo: umbella decompor. fimpliciter foliofd; pedicellis diftiche fpicatis. Syjt, veg. ed, I4. Burm, Ind, tab. 8. f. 2. Sloan. Jam. hift. I. $t a b .74$. f. 1 . \& $t a b .8$. f. 1.

In America ad fluviorum ripas.

Gramen giganteum. Culm. craffitie digiti. Umbell. lelquiped ramofiff. Radii principal. 24.

20. compref- C. culmo triquetro, nudo: umbella univerfali trifus. phylla, glumis mucronat., lareribus membranac. Syft, veg. ed. 14. Jaeq. hort. 3. tab. 12. Rortboel, defor. pl. l. I, tab.9. f, 3. Slon. Jam. hift. I. tab, 76. f. I.

In Amer: Septentrion. pretis arenofis, \& in $\mathrm{Pe}$ demontio 4.

Dignofcitur panicula, \& fpicis viridibus; glumis mucronatis, non patulis; \& marginibus lateralibus memóranac. Umbel. partial. nuda; univerfilis glomerata.

Planta inodora. Radix tuberculata, extus nigra, intus alba. Culm. I-2. pedal, nitidus. Fol. angufta, acuta, canaliculata, retrorfum fcabra. Involuc. foliola exter, longiff, , intima breviffima .

2r. flayefcens, C. triquetro, nudo, umbella 3-phyll. pedunc. fimplicibus, inæqualibus: fpicis confertis, $1+10-$ ceol. Syft. veg. ed. I4. Morif. hift. 3. S. 8. tab. II. f. 37 .

b. Gramen \&c. Scheucht. gram, tab. 8. f. 3.

In Europa paludofis $\odot$.

Caulic. cefpitofi, ad fummun dodrant. Spicze ad 15. oblong. Spicul. conglomeratæ, ovatæ,

diftichæ, ex viridi-fubluteæ. 
b. Culm. 2-unc. Fol. capillac. lineæ quadrantem lata. Spicul. 2-3. minima.

22. fufcus. C. culmo triquetro, nudo: umbella 3-fid, pedunc. fimplicibus, inæqualibus : fpicis confertis, linea. ribus. Syft. veg. ed. 14. Fl. Dan, tab. 179. Leerf. herborn. tab. 1. f. 2. Murif. hift. 3. f.8. tab. 9. f. 38. Pluk. phyt. tab. 191, f, 3 .

In Europa, \& Egypti prutis humidis $\odot$.

Differt a priore vix manifefte, culmis ad terram Jparfis : fol, magis fiabris: Spicul, anguftioribus, fufcis.

Raro altitudo pedal, Fol. linearia . Panicula laxior, \& ramofior. Spicæ nigro-purpur.

23. pumilus. C. culmo triquetro, nudo: umbella compofita, 2-phylla: ipicul. alterno-digitat, lanceol. glumis inucronatis. Syft, veg. ed. I4.

Gramen \&c. Pluk, alm. tab. 191. f. 8.

In Indie.

Simil. C. compreffo, fed brevior, diftinctus glumis minus imbricatis, \& apice mucronat, Involucrun umbella longius.

24. triflorus. C. culm. triquerro, nudo: umbella triftachya; intermedia feffrli: fpicul. lævigatis, Syft. veg. ed. I4.

In India orient. $\mathbf{4}$.

Culmi pedal. Iæves. Involuc. terminale, 2-phyll. fubulatum, fpica brevius. Spicæ 3. ovatæ, compreffæ, ancipites, læves, acutæ, fquamis acumisat.

25. frigofus, C, culmo triquetro, nuda: umbella fimpl, fpicul. confertiff. linearib. horizontalib. Syft, veg. ed. 14.

Cyperus \&c. Sloan. Jam. hift. 1. \$ab. 74. f. 2.3. In Jamaica, Virginia paludibus.

Radix fubrotunda. Culm, pedal, Fol, inæqual. panicula longiora, lanceol-linearia, canalicul. glauca. Umbellæ radii fimpl, erectiufe, inftructi fpicul. longiufcul. numerofis, ferrugineis.

26. ligularis. C. culmo triquetro: umbella fpicul. capiratis, feffilibus, oblong, involuc. longifi. ferrato-afperis. Syft. veg. ed. I4. Rottboell. defer. pl, h.I. tab. 11. f. 2. Staan. Jam. hift. 1. tab. 9.

Ira. Rheed. mal. 12, tab. 55 .

In Jamaica .

Culm. altifim. craffus, glaucus. Capirula terminal. \& lateralia, inæqual. folitar. oblong, craf- 
fa. Umbellæ decompof. intermedia feffili . Radii 5-6. inæquales, patentes. Spicæ cylindrico-fubularæ, diftichæ, ferrugin. \& coccineæ.

27. Papyrus, C. culmo triquetro, nudo: umbella involucris longiore: involucell. 3-phyll, fetaceis, longioribus : fpicul. ternis. Syft. veg. ed. 14.

Cyperus \&c. Mich. gen. tab. 1\%. Murif. hift. 3. f. 8. tab. II. f. $4 \mathrm{I}$.

In Calabria, Sicilia, Syria, IEgypto .

Culm. craffus, triquet. Color totius plantx glaucus, vel albidus. Involuc. 8-phyll. foliol. exterioribus 4. latioribus. Umbel. univerfalis fubrequal. copiofiff. radiis baft vaginatis. Umbellul. peduncul. ternis, breviffm. Spicul. pl. alternæ, feffil. fubulatæ.

38. Spatha- C. culmo vaginis fol. veltito: pedunc. pinnatis o ceus. lareralibus. Syft. veg. ed. 14.

Gramen \&c. Pluk. alm. tab. 30I. f. I.

In Virginia, ad cap. b. Spei 24.

Magnitudo Sacchari. Sp $₫$ thæ magnæ, I-phyll. alternæ, deciduæ, racemos floriferos involvunt .

9. alternifo- C. culmo triquetro, nudo, apice alternatim foliks. liofo: pedunc. lateralibus, proliferis. Syft. veg. ed. 14 .

Gramen \&c. Morif. hist. 3. f. 7. tab. 3. f. 17. In Virginia 4.

Culmi pedai. Fol. femipedal. conferta, enfiform. lavia, margine fcabriufc. Bract. parva, fubulata, e fingulis alis. Pedunc, filiform. Spica ovata .

30. denudatus. C. culmo triquetro: involuc, fubnullo. Syft, veg. ed. 14. Lin. fuppl.

Ad cap. b. Spei.

Culm. 2-pedal. vagina unica in medio culmi. Umbel, compofita, non multum expanfa. Spicæ oblong. purpurafc. carina viridi, apice pztentiufc.

1. distens. C. culmo triquetro, nudo ; umbella fupradecompof. foliofa : fpicis alternis, filiformibus, flofcul. diftantibus. Syst, yeg. ed, 14. Lin. Suppl. Rottboel. defe. pl. tab. Io.

In Malabaria.

Culm. 2-ped, ad medium foliofi . 
32. pannoni- C. culno triquetro: fpicis fefflibus: glumis lacus. teralibus, fphacelatis. Syst, yeg. ed. 14. Lin, fuppl. Jacq. H. 3. tab. 6.

In Hungaria.

Planta glabra, \& nitida. Cefpes denfiff. Involuc. foliol. 2-raro 3. inæqu lia. Spicula ovat ${ }^{\circ o b-}$ long. umbellatim feffiles, obtufæ, compreffæ. Sem. late ovata, compreffa .

mucronatus. C. culmo nudo, vaginato, triquetro: involuc. 1-phyll. ftrato: ipicis fubrernis, feffilibus. Rottbuel. defe. pl. l. 1. tab. 8. f. 4 .

Culmi pl, pedal, vagina ferruginea. Spicæ raro folitar. oblong. fed numero variæ, fæapius 2-7 aggregatæ, frequenter ternæ, denfe imbricata, fquamis coriaceis, ovat. obtufis, nitidis .

Simil. C. lavigato; differt teneritudine ma. defeziu involuc, infini : Spicarum longe minore numero.

dubizs, C. culmo triquetro, fetsceo: capitul. terminali : involuc. longiff. 4-phyl. Rottboel. defcr. pl. l. 1. $n .22$.

Culm. pl. palmar. erecti. Fol. linear. ftriata, carinata, mollia. Capitul. folitar, fpicis innumeris glomeratum. Spica parvæ, lineari-lanc. compreffæ, diftichæ, imbricatæ, fquamis comprefis, ovatis, obtufiff.

eruentus. C. culmo triquetro: involuc, polyphyl, longo: umbella fimplici, fpicis conglomeratis: flofc. fulcato-punctatis. Rattboel. defcr. pl, l. 1, n. 2j.

Culm. aggregati, ad b fin bulbofi, inferne vaginis albidis obfiti . Fol. fub 6 longiff. linear. ftriata, carinata, conduplicata. Involuc. folia 5-plura, patentia: partiale nullum. Capitulum centrale, feffile, cinctum radiis paucis, patentibus, glomere (picarum termiratis, Soic $\boldsymbol{x}$ diftichæ, linceol. acutæ, torofæ, 4. circiter lineas longæ, coloris teftacei, imbricatæ, fquamis alternis, membianaceis.

songlomeratis. C. culmis fubtriquetris: fol: fefquipedalibus, fafciculat, ftriatif. canalicul, capitulo terminali, paniculato, 3-phyl. Ratibueb. defcr. pl, l. 1. tab. 13. f. 7 .

Culmi falciculati; torti. Fol, glauca, vaginis I iij 
nigro-purpur. Capituli umbellul, central. feffles; laterales breviter pedicellatæ. Spicæ ovatlanc, diftichæ, denfe imbricatæ, fquamis membranaceis, glaucis, vel gryleis, cum purpura mixta.

effufus. C. culmo tereti, fubligneo: umbella rara: fpicis conglomeratis: involucr. fubulato, 3 -phyll. Rottboel. defcr. pl. l. 1. tab. 12, f. 3 .

Culmi apex pulverulentus, albus. Involuc. univerfale inæquale: partiale foliolo ovato, bafin radiorum obvolvente. Capitulum folitar. feffile, fpicis divaricatis glomeratum; interdum præter hoc, 2-3. lateralia. Spicæ longiores, difichæ, oblon-lanceol. fquamis fubpubefcen. col. grylei, cum purpura mixta.

Jeminicus. C. culmo triquetro, incurvo, bafi bulbofo: fol. fafciculat. fetaceis : umbella fimpliciff. fpicis conglomeratis. Rottboel, defc. pl. l. 1. tab.8. f. $\mathbf{r}$.

Radix bulbofa. Culm. palmar. fuper. parte nudus. Fol. ferruginea. Involuc. univerfale diphyll. umbella paulo longius, parrial. fquama lanceol-acumin. ad ortum fpicarum. Umbel, 3-4 rad., cum umbellula intermedia I-2. Spicæ vix uncial. lineares, difticha, compreffre.

fphecelatus. C. culmo triquetro: umbella fimpliciff. fpicis alternis, linearibus, compreffis : flofcul. margine fphacælatis. Rorthoel. defc. pl, l. I. n. 32.

Radix bulbofa. Fol. radical. splura, linear. glauca. Culm. pedal. Involuc. univerfale foliol. 3. linearibus, patentibus, umbella longioribus, partiale, fquamæ lineari-fetaceæ ad pedicellorum ortum. Umbel. radii pauci, 2-3, fefquiunc. cum umbellula una, alterave intermedia. Spicæ 4. lineas longæ, linear. diftichæ,

tuberofus. C. culmo triquetro, baft foliofo, involuc. 3-phyl. umbella compofita ; fpicis lanceol. teretiufcul. Rottboel. defc. pl. l. 1. tab. 7. f. T.

Radix tuberofa, fulca, vel ferruginea. Culm.2-ped. teftaceus. fufco-maculatus. Fol. 4-5 alterna, longiff. lanceol, glauca, margine, \& carina fcdbra. Involuc, univerfale foliol. 3 inæqualibus, maxino umbella duplo-triplo longiore: partiale, bracter feraceæ ad divifionem panicula, 
\&. ad fl, exortum. Umbel. radii $4-5$ inæquales, fub-2-unc. cum umbellulis centralibus. Spicæ, femiunc. alternæ, lanceul. crafiæ, diftichæ, imbricatæ, fquamis dilute ferrugineis, margiaibus membranac. albidis .

cenziflorus. C. culmo triquetro: fol. linearibus, umbella decompofita: fpicul. linearibus, angultiff. acutis . Rotebuel. defor. pl. l. I. tab. 14. f. 1 .

Culm. tenuis, ad bafin foliofus. Fol. margine re. voluto, flavefcentia. Involuc. univerfale foliol. 3-4. inæqualibus, quorum maximum umbella duplo circiter longius: partiale fol. lanceolacuto, umbellæ divifionibus fubiecto. Umbel. radii 7-pl, I-2. unc. inæqual, cum umbell. centrali. Spicæ 5-7. lineas longæ, alternæ, imbricatæ, nitidæ, obfcure purpur.

Pangorei, C. culmo triquetro: involuc. 3-phyl. umbella univerfali decompofita; partialibus lub 3-fid. fpicis alternis; filiformibus. Rottbcel. defcr. pl. 1. 1. tab. 7. f. 3 .

Culm. fefquiped. \& ultra, fungofus, fufco-macular. Involuc. univeriale foliol. 3 . linearibus, glau cis; tertium dimidio brevius: prriale, fquamula ovat-lanceol. ad pedicellorum , \& f picarum ortum. Umbellulæ central, 1-2. feffil: cæteræ radiis pl. inæqualibus, uncial, patentiffim. apice fub 3-fid. Spicæ fefquiunc, alterta, diftichæ, linear. Squamæ ferrugin. cum. carina, \& margine pallidiore.

faftigiatus. C. culmo triquetro: umbella decompofita ; pedunc. longiff. filiformibus, fexquinquefid. fpicis pl. linearibus, fparfis. Roctbcl. defcr. pl. l. I. n. $4 \mathrm{t}$.

Culm. glaucus . Involuc, univerfale fuliol. 6. margine, \& carina aculeata; maximo umbella 2-3. duplo longiore; partiale foliol. 2. fetaceis ad divifionem peduncul. Umbella univerfalis ex pedunc. 10. inæqualibus, filiformibus (quorum longiff. palmar. \& ultra) minimi, vix uncial. Umbellæ partial. fubfeffil. pedicel. fubquinis, capillaribus. Spicæ C. longi Gmiles.

Surinamenfis, C. culmo triquetro, nudo: umbella decompofita : fpicis obl-ovatis, glomeratis, mucronibus incumbentibus. Retibel. defcr. pl. 1. I. tab. 6. f. 5 , 
Culm. plufquam pedal. flaccidus, ftriatus. Invo. luc. univerfale 3-phyll, lineare; partiale, fquama lanceol. concava, fpicis fubiecta. Umbella pedunc. plurimi, I6. inæquales: umbella partialis brevis, nuda; pedicelli $4-5$. breviff. inæqual. reflexi; finguli glomere fpicarum denfifimo terminati. Capitula I-2. in centro umbellarum, feffilia. Spicæ obl ovatæ, fub 2unc. diftichæ, denfe imbricatæ .

alopecuroides. C. culmo triquetro: umbella fupradecompofita: fpicis digitat. oblon. fpicul. confertifl, erectis, imbricatis. Rottboel. defcr. pl. 1, I. tab. 8. f. 2 .

Culın. craffus, ftriatus, fupra nudus . Involuc. univerfale inæquale, fub 5-phyll. Fol. lanceol. fulcata, revolura, rugofa, margine lævia, extima umbella 2-3. longiora, interioribus eadem multo brevioribus. Partiale fol. lanceol-linearibus, 3-4. acutiff. inæqualibus, ad divifionem peduncul. umbellulis, quibus breviora, fubiectis. Umbellæ radii 8. patentes, extimi palmar. \& ultra, intimi fenfim breviores. Spicæ fere 2-unc. feffiles, ad bafin bractea lineari fuffultæ. Spicæ pauca in centro umbellæ.

polystachios. C. culmo triquetro: involuc. polyphyl: panicula terminali, fubfeff. ramcfiff: fpicis linerari-lınceol. confertiffim. complanatis. Ruttbuel. defor. pl. 1. I. $t a b$. II. f. I.

Culm. 2-ped. \& ultra, friatus, flavefcens. Fol. ad bafin plura, linear. glauca, vaginis purpurafc. Involuc. foliol. 4-6. lanceol-linearibus, quorum 2-3. panicula multo longiora. Panicula fere femicircul. Spicæ alterna, diftichæ, fquamis teftaceis, vel ferrugineis, margine, \& carina albidis.

pariculatus, C. culmo triquetro: involuc. fubaquali, 6-phyl. panicul. terminali, feffili, denfifl: fpicis compreffis, lineari-lanceol. paucifl. Rotbboel. defcr. pl. 1. 1. n. 53.

Gramen Cyperoides \&c. Pluk. phytol, tab. qI. f. 3 .

Culm. fpitham. ftriatus, ad bafin fol. lanceol-linearibus dimidio brevioribus, glabris, flavefcentibus cinctus, fupra nudus. Spicæ 3. circiter lineas longæ, acutæe, complanatæ, fquam. 
alternis, lanceol. teftaceis, carina pallide viridi.

Santonici. C. panicul. feffilibus \& peduncul: fpicis linearibus: flofculis alternis, remotis, obtufiff. Rottboel. defcr. pl. 1. I. $t a b$. 9. f. I.

Cyperus \&c. Scheuckz. gr. tab. 9. f. \&. Pluk. phyt, tab. 4I9. f. 4.

Culm. pedal. \& ultra, triquet., debilis, fupra nudus. Fol. linear. ftriata, mollia, margine fubaculeato, pallide viridia. Involuc. univerfale 3phyl. inæçuale, foliolo maximo pedali. Partiale, fquamæ fetaca ad divifionem paniculæ. Spicæ delicatæ, alternæ, diftichæ, imbrica$t æ$, fquamis diftantibus, obrufiffm. pallide flavis, cum carina fubfufca, 3. ftriis pieta .

In Tranquebaria.

corymbofus. C. involucr, polyphyl: umbella fupradecompos. pedunc. filiformibus, ftrictis, corymbofis . Rottboel. defcr. pl. 1. 1. tab. 7. f. 4.

Culm, triquet, , craffus, glaucus, fufco-maculatus. Involuc. univerfale foliol, 4. lineari-lanc. inæqualibus, margine fcabro: partiale, fquamæ lineari-fetaceæ, ad ramificationes umbellæ. Umbella diffufa. Spicæ tenuiff. teretes, fubulatæ, diftichæ, 4.5. lineas longæ, imbricatæ, fquamis oblong. dorfo teftaceis, margine albido .

fabelliformis. C. culmo triquetro, fulcato, contorto: involuc. alternis ; pedunc. axillar. folitar. terminalibus, umbellatis, corymbiferis. Rottboel. defcr. pl. 1. 1. $t a b, 12, \mathrm{f} .2$.

Ile Arabia.

Color totius Graminis glaucus, vel caffirls; fpicarum albus.

Involuc. polyphyllo, trifariam imbricato, flabellum referente: pedunc, axillar, folitar. continua ferie intra umbellam termisalem exeuntibus, a cæteris fpecitbus differt .

hirfutus, C. culm. tereti, fuliofo: fpicis ovat, lobato-conglomerat. terminalibus: glumis mucronat. ciliatis: foliol. lineari, lobis fpicæ fubiecto. Berg. Fl. cap.

Juncus hirfutus \&c. Buxb, cent. 3, tab. 33 . Ad. cap. b. Spei.

Gramen paludofum. Radix repens. Culm. pl. 
pedal. fimplic. erecti, ftriati, hirfuto-fcabri. Fol. 5-pollic. linear. bafi vaginante, hirfutofcabra, ftriata. Spicæ pl. obtufæ.

gradatus. C. culmo tereti, angulato, ad bafin foliofo; bracteis ad apicem pedunculis duplo longioribus, fpiraliter remotis. Forskal. Ag $q p$.

In Arabia.

Culm. 2-cubital. Spicul. lanceol. compreffie, virides.

globofus. C. culmo triquetro, bafi foliofa: fpicis conglomeratis, fubglobofis; fpiculis convexis, viridibus, nitidis. Forsk. Rsyp.

In Arabia.

Culm. f pitham. Spicæ umbellatæ. Spicul, congeftæ, lanceolat.

globulofus, C. culm. triquetro, nudo: umbel. foliofa: fpicis compactis, fubrotundis, flavicantibus. Aubl. Guian. Sloan. Jan. hift, I. tizb. 79. f, I.

\section{In Caierina.}

faftigiatus . C. culm. triquetro, cubitali, bafi foliofa : umbella foliofa; denuo umbellifera; fpicis cylindricis; fpicul. utrimq. convexis, flavidis. Forsk. IEgyp.

In Arabia.

complanatus. C. culmo triquetro, fefquifpitham. bafi foliofd: fpicis fubrotund: fpicul. compreffis, planffimis, ovat-obl, brunneis, Forsk. Egyp.

In Arabia.

ferrsgineus. C. culmo triquetro, pedali, bafi foliofa: umbella foliofa: fpicul. fafciculat. linearibus compreffo-convexis, ferrugineis, margine viridibus, raro pedicellatis, coacervatis ad apicem pedunculi ; bract. pedicellis longioribus . Forsk. Egyp. In Arabia.

umbellatus. C. culm. triquetro, nudo : umbel. 2-phylla; pedunc. longiff. fpicatis. Burm. Ind. tab. 9. f. 6 .

In India.

Fol. longitudine culmi. Pedunc, inæqual, ad medium vaginantes. Spicæ capitatæ, ublong. fpiculæ linear. flofculis alternis .

pygmeus, C. culmo tereti; umbella compofita, involucrata: fpicis lanceolatis; glumis mucronatis. Ret?. Obf. fafc. 4 .

In Tranquebaria.

Radicula fafciculatæ. Fol, radical, filiform, cul- 
mo duplo longiora. Culm. vix fefquipoll. ftriatus. Umbella pedunculis $5-6$. fpicul, umbellular. 4-6. compreffæe, pallidæ, medio rufo-fufca. Involuc. 4-phyll, umbella triplo longius . arenarius. C. culmo compreffo, nudo: Ipicís capituli glomeratis, feffilibus: involuc, fub $\mathrm{r}$-phyll. Retr. Obf. fafc. 4.

In India Orient.

Radic. repentes, articulatæ. Fol. filiform. nuda, 3-6. pollic. compreffa; flavo-virid. Culm. e fafciculo folior. folitar. foliis non nihil altior. Spicæ 8-12. fpiculæ diftichæ, craffiores; fquamis fufcis, albo marginatis. Involuc. capitulo longius.

capizatus C. culmo fubangulofo, ftriato, medio foliofo: capitu'o 3-phyllo; fpicis feffilibus. Retz. Obf. finf. 4 .

In India.

Culm. 4-pollic. bafi folium unum, vel alterum . Fol, bafi multum latiora, culmo parum longiora. Capitul. globofum, fpicul. lineari-oblong. Glum. imbricatæ, fcariofæ.

ftoloniferis. C. culin. nudo triquetro: umbella compofita, involucrata: fpicul, lanceol. Retz. Obf. fafc. 4. In Tranquebaria.

Rad. bulbufa, ftolones emittens. Fol. palmar. \& femiped, vaginantia, linear. complicata . Culm. fpitham. Umbella depauperata, umbellulam unicam fubfeffil. trefque circiter pedunculatas habet. Involuc. fub 2 -phyll.

cinnamomeus . C. culm. triquetro, foliofo: umbella fpicul, capitaris, pedunculat. feffilibufque : involuc. 5phyll. ferrulato-fcabro. Retz. Obf. fafc. 4 . Habitat.... (.).

Caul. 3-ped, \& ultra, folitar. bafi foliofi, fuperne nudi. Fol. culmo altiora, plicata, polJicem dimidium fere lata. Capirula ovata, compofita, cinnamomea. Spiculz congeftæ, compreffa, diftichæ, lineares.

81. SCIRPUS. Glumze palcacer, undique imbricatæ. Cor. o. Sem. 1. imberbe.

Differt a Cypero fpicis non diftiche imbricatis, \& non complanatis, fed obris ; \& fem. fetulis circumvallato. 


\section{* Spica unica.}

1. trigynus. S. culme tereti, nudo: fpica cylindrica, fqua mis lanceol. bafi laterali membranaceis. Syft. veg. ed. 14 .

In India Orient. 4.

Facies S. paluftris. Fol, radical. copiofa, conferta, palmaria, filiform, interiore latere canaliculata, bafi membrand laterali, lata, alba . Culm. fpitham. enodis, ftriatus. Spica terminal. pollicar.

2. mutatus. S. culmo triquetro, nudo: fpica terminali, cylindrica. Syft. veg. ed. I4.

In Jamaica 24.

Simililf. S. geniculato, fed culm. triquet, , mollinfculus, nec ariculatus.

3. articulatus. S. culmo tereti, nudiufculo, femigeniculato: capitulo laterali, glomerato. Syft. veg. ed. I4. Pluk. phyt, tab. 197. f. 6.

S. filtulofus. Forsk, IEgyp. monente Vahl.

Ifieli, Rheed. mal. I2, tab. 71 .

In Malaburia aquofis arenojis.

Culm. pedal. \& ultra, cavus, geniculis cinctus, at non undique. Capitulum magnum, feffile, femiverticillatum. Spicæ bafi turgidæ, fquamis magnis, teftaceo \& purpur. feu ferrugn. colore variegatis .

4. palufiris. S. culmo tereti, nudo: fpica terminal. fobovat (imbricata). Syft. veg. ed. 14. Fl. Dan. tab. 273. Leerf. herborn. tab. I. f. 3.

b. S. equifeti \&c. Scheucht. gr. tab. 3. f. 17.

In Elrope fo/fis, \& inundatis.

S. aciculuris Fl. Dun, tab. I67, potius Scirpum paluffrem refert Mil. fed Lin. ad S. cafpitofum refert. Culni cæfpitofi, pedal. Fol. compreffa, bafi ferruginea. Spica imbricara, acuminata, fquamis arcte compactis, muticis.

5. genicula- S. culmo tereti, nudo: fpica terminali, oblontus. ga. Syft. veg. ed. I \&.

Juncus \&c. Sloan. Jam. hift. I, tab. 75. f, 2. \& tab. 8r. f. 3 .

In Jamaical .

Culm, vix fpitham. Spica pollic. denfe imbricata, fquamis membrac. testaceis .

6. ocespitofus, S, culmo nudo, ftriato: fpica terminali, 2-valv. 
longitudine calycis; radicibus fquamula interftinctis. Syft. veg. ed. 14. Fl, Dan. tab, 167.

S. montanus \&c. Scheuchtz. gr. tab. 7. f. 18. Pluk, phyt. 40. f. 6.

Juncus \&c. Morif. hiff. 3, tab. 10, f. 35.

In Europa paludibus cafpitofs, fylvaticis 4.

7. cepitatus. S. culmo tereti, nudo, fetiformi: fpica terainali, fubglobofa. Syft. reg. ed. I4.

In Virginia.

8. cisslaris. S. culmo nudo, tereti, fetiformi : fpica ovata, 2-valv. feminibus nudis. Syft. veg. ed. I4. Fl. Dan. tab. 287.

Juncellus \&c. Morif. hift. 3. f. 8. tab. 10. f. 37 . Juncus \&c. Scheucluz. gr. tab. 7. f. 4 .

In Europa $\int_{u b}$ aquis purioribus 24.

Omnium minimus. Cefpitofus, mollis. Spica iunior compacta ; adulta diflicha. F1. 2-5. Glumæ fufcr, non nitentes .

3. Austans. S. culmis alternis, nudis, teretibus : caule foliofo, flaccido. Syft. veg. ed. I4.

S. equifeti \&c. Scheucht. gram. tab. 7, f. 20.

Gramen \&c. Morif. hift. 3. f. 8. tab. Io. f. 3 I, Pluk. alm. tab. 35. f. I.

In Europe udis, \& rivulis 24.

Culm. crebri, ad terram fupini, articulati. Rami fubdivifi. Fol. multa. Capitul. parvum, fquamofum, Pfyllii æmulum.

\section{** Culmo tereti, polyftachio.}

ro. lacuftris. S. culmo nudo, tereti: fpicis ovatis pl. pedunculat, terminalibus, Syft, veg. ed. 14.

Juncus \&c. Lob. ic. 25.

In Europe aquis puris ftagnantib. \& fluviantib. 24. In läcubus altitudo hña. Culm. fæpe folitar. fimpl. fungofus, mollis, ad terram vaginofus. Fol. fimilia. Stipulæ fub panicula, \& fub ramis lanceol. ariftaræ, ficcæ. Spicul, fquamæ 2fidæ. Glumæ, \& locultæ Cinnamæi col. Sem. 3-gon. Nimia aqua copia culmis deftituitur \& fol. producuntur. Datur var. humilior.

1I. holofiha-S. culmo nudo, tereti: fpicis fubglobofis glonus. meratis: involucr. inæequali, 2-phyl. mucronato. Syft. veg. ed. I4. Fl. Dan. tab. 454. Pluk. phyt. tab. 4.

Scirpoides \&c. Scheuch. gram, tab. 8. f, 2. 3. 4. 5, In Europa auftrali 4 . 
Culm, ad bafin alatus. Fol, teretia. Vaginarum margines lacero-ciliati .

12. auftralis, S. culmo nudo, tereti: capitulo laterali, bractea reflexa: fol, canaliculatis. Syft. veg.ed, I4.

Habitut. .....

Simijl. S. romano, fed foliol. feu culmis fterilibus binis, erectis, leviter canaliculatis, nec teretibus, bafi vaginantibus, margine fcariofo . Culmi vix pedal. læves, fupra capitulum apice erecto, fed canaliculato. Capitul. feffile, cois globatum, rotundatum, obtufum, ferrugin. valvulis imbricat. apice fub 3 -lob. obtulis, lobis lateralibus apice fufcis .

13. romanus. S. culmo nudo, tereti: capitulo laterali, conglobato; bract. reflexa. syft. veg.ed. 14. Jacq. Auftr. tah. 448. Barr. rar. tab. 255. f. 3.

b. Juncus \&c. Pluk. alm. tab. 40. f. 5.

Culm. cefpitofi, I-3. ped. fili craffitie: in S. holofchoeno craffi ut in S. lacuftri, \& apice pungentes. Fol. femiteretia. Vagina fufia, nitidæ. Capitul. fubfufcum, inter 2 . involuc. foliola, unum longiff. alterum brevius .

34. feteceus, S. cuimo nudo, fetaceo: fpica terminali, feffili . Syjt, veg. ed, 14. Fl. Dan, tab. 311. Leerf. Herborn, tab, 1. f. 6.

Juncellus \&c. Morif. hiff, 3. f. 8. tab. 10. f. 23. In Europe litoribus maritimis, ad faggna \&c. 4. Culmi cefpitofi, digital. \& ultra, craffitie fol. Fol, fetacea. Spica lentis magnitudine, Iraro 3. oblong. fufco-rubra, fquama infima fubulata, longitudine fpicæ.

Tenuitate, \& magnitudine culmi; longitudine involuc. numtero, \& craffitie, fpicarum; ratione atatis, \& foli admodum variat.

I5. fupinus. S. culmo nudo, tereti : fpicis felfilibus in medio culmo glomeratis. Syft, veg. ed. I4.

Parifits ,

Planta minima, fupina. Fol. rotundo-teretia .

I6. autumna- S. culno ancipiti, nudo: umbella decompolita; lis. rpiculis ovatis. Syft, veg. ed. 14 .

In Virginia ,

Facies Junci pilofi. Fol, radical. laxa, nonnihit feabra, fape culmi longitudine. Culmi palmar. compreffi, altero latere fubcarinati. Involuc, terminal. 2-phyll. fol, fimile, umbella 
TRIANDRIA MONOGYNIA.

fere longius. Unbel, patula, inæqual. $\mathrm{Pe}-$ dunc. fæpins fpicis 3. Spicæ fquamis ovat, ferrugineis, carina viridi, vix mucronatis.

17 capillaris. S, culmo nudo, capillari: fpicis pedunculat. intermedia feffli. Syft. veg. ed. I4.

S. triftachyos, Rottbarl. defcr. pl, 1, I, tab. 13. f. 4 .

Gramen \&c. Burm. Zegl. tab. 47. f. 2.

In Virginia, Fithiopia, Zejlona.

Fol. capillaria, vix digitalia. Culmi vix fol. longiores. Foliol. fetaceum fub umbella, fpicis longius. Spicæ terminal. 3. ovatæ, fquamis ferrugin. carina viridi, obtufis .

I8. triftachyos. S. culmo nudo, fetaceo: fpicis, (fub) ternis, feffilibus; involucr. 2-phylio, fetaceo. Syft. veg. ed. 14. Lin. Suppl. Rottb. gram. tab. 13. f. 4 .

Ad cap. b. Spei.

Fol. \& culmi fetacei, glaberrimi. Capitulum laterale, mox infra apicem culmi, ex fpicis 3 ad 7. Variat magnitudine. Simil. S. capillari, fed fpica non pedunculate; forte illius var.

I9. globiferus.S. culmo nudo, tereti : umbel. terminali, compofita: capitul. globofis ex pl. fpiculis arcte congeftis. Syft, veg. ed. I4. Lin. Suppl.

In $T_{\text {eneriffa. }}$

Culm. glaberrimus, terminatus fpatha breviff. 2phyll; foliol. æqualibus. fubulatis, mucronatis. Hi globuli circa bafin emittunt novos radios globiferos, iterum dividendos.

20. erifpica- S. culmo angulato, feu fulcato, nudo: fpicis tus. terminalibus, ternis, feffilibus, nudis. Syft. veg. ed. 14. Lin. Suppl.

In Africa.

Culm. pl. 1-2. pedal, głaberrimi . Fol, vix ulla, nifi fquamæe radical. ferrugin. Spicul. parvæ, oblong. erectæ, æquales. Involuc. polyphyl. fol. breviff, fubulatis .

*** Culmo triquetro, Panicula nuda.

21. triqueter. S. culmo triquetro, nudo: fpicis fubfeffilibus, pedunculatifqu. mucronem aquantibus. Sy,t. veg. ed. 14.

Juncus \&c. Pl:tk, alm. tab. 40. f, 2. In Europa euftrali, locis paludojis, 
Culnus angulis planis, nec exfcavaris.

2. mucrone-S. culmo triangulo, nudo, acuminato: fpicis tus, fefflibus, conglomeratis, lateralibus. Syft.yeg. ed. I4,

Scirpo-yperus \&c. Fcheuch. gram. tab. 9, f. I4. Juncus \&c. Muris. hift. 3. f. 8. tab. Io, f. 20. Pluk. alm. tab. 40. f. I. 3 .

In Europa, \& Virginia ftagnis, \& locis maritimis 4 .

Culm. I-2. ped. tricarinati, angulis compreffis, glauci. Pedunc. fimplic, aur ramofi, 4-6 f. Stipula brevis, fpathacea, mucronata. Spicx ferrugineæ. Mucro fl. multo longior, ad latus reflexus. Setæ ad bafin feminis .

23. groffus. S. culmo triquetro, nudo: umbella fupradecompofita : fpicis pedicellatis; involuc. Iongiff. fubulato, lanceol. 3-phyll. Syft. veg. ed. I4. Lin. Suppl.

In India.

Similis S. miliaceo, fed magnitudine, \& craffitie valde differt.

Culm. orgyal. erectus, glaberrim. Fol. radicata, lanceol, glaberrima, fubverrucofa. Spicul. ovatæ, ferrugineæ.

24. dichoto- S. culmo triquetro, nudo: umbella decompoltmus.

ta: fpicis dichotomiz feffilibus. Syft. veg. ed. 14. Rottboel. defcr. pl. 1. I, tab. I3. f. I.

S. bifumbellatus Forsk. 压gyp. monente Vahl.

Gramen \&c. Pluk. alm. tab. IIg. f. 3 .

In India.

Culmi digital. Fol. in cefpitem congefta, plana, hirfuta. Involuc. 2-phyll. longitudine umbella. Radii interior. breves. Vitr. culm. 2-ped. Umbel. magna diffufa, ramofilf.

15. echinatus. S. culmo triquetro, nudo: umbella fimplici : fpicis ovatis. Syft. veg. ed. I4.

Gramen \&c. Pluk. almi, tab. 91. f. 4.

In India utraque.

Culm. fpitham. Invol, longum, 4-5. phyll. Spicæ 8. pedunc. propriis, tamquam in umbella, folitaria.

26. retrofrac-S. culmo triquetro, umbel. fimplici; fpicarum tus. flofculis retrofractis. Syft, veg. ed. 14. Cyperi \&c. Pluk, phyt. 455, f. 4 . In Virginia 24. 
27. ferrugi- S. culno triquetro, fubnudo ; involuc, longituneus. dine paniculæ, ciliatis. Syft. yeg. ed. I4.

Schoenus polymorphus. Rottboel. defcr. pl. I. I. P. 67.

Gramen Bac. Sloan. Jam, hift. I. tab, 77, f, 2.

In Jamaica paludibus maritimis.

Culm, 2-ped. Ariatus, flavefcens. Squamæ coriaceæ, concavæ, fufco-maculatæ, bafi culnum ambientes. Umbel, terminalis, decompofita, cum fpica intermedia feffili. Radii 3-4. triquetri, inæqual. Spicæ folitar. oblong. ovatæ, ferrugineæ, magnitudine variæ.

28. Spadiceus.S. culmo triquetro, nudo: umbella fubnuda: fpicis feffilibus, terminalibus, oblongis. Syft. veg-ed. I4.

Gramen \&c., Sloan. Jam. hift. 1. tab. 76. f. 2.

In Jamaica fluviis.

Pedunc. longi, terminal. Panicula pl. fparfa, parvis foliol. infructæ. Nonnuli peciiculi funt floriferi. Spica oblongo- rotunda, fpadicea.

${ }_{* * * *}$ Culmo triquetro, Panicula foliacea.

29. miliaceus.S. culmo triquetro, nudo: umbel. fupradecompofita; fpicis intermediis fefflibus: involuc. fetaceo. Syft. yeg. ed. 14. Burm. Ind. tab. 9. f. 2. Rottboel. defcr. pl. 1. 1. tab. 5. f. 2.

In India.

Culmi plurimi, femiped. fimpl. laeves. Fol. graminea, bafin culmi obveftientia, lævia. Umbel. diffufa, laxa. Spica ovatæ, minutiffinæ, ut fem. Milii .

30. cyperoides. S. culm. triquetro, nudo : umbell. fimpl. fpicul. oblong. flofcul. fubulat. $\bar{\imath}$-fl. reflexis. $S y f t$. veg. ed. 14 .

Kyllinga umbellata. Rottbocl. defer. pl. 1. I. tah. 4. f. 2.

Koll-pullu. H. Mal. 12, :ab, 63.

In India Orient. 4.

Facies Cyperi ftrigoji, feu Scirpi retrofracti, fed flofculi laxi, reflexi. Fol, graminea, carinata. Culmi pedal. laves. Involuc. polyphyl. umbella longius, foliol. gramineis. Umbel, inæqual. Spicz plurima, pedunculat. obtufe ; fquamis calycin. convolutis, imbricatis .

31. maritimus. S. culmo triquetro: panicula conglobata, foliaTom, I. $\mathrm{K}$ 
cea : fpicularum fquamis 3 -fid. intermedia fubulata. Syft, veg. ed. 14. Scheuck, gram. tab. 9. f. 9. 10.

In Europe litoribus maritimis, \& locis arenofis inundatis 4.

Culm. pedal, in aquis 3-4 pedal. Fol. recta, acuta, plana, pulpola. Spića plerumq. peduncul, oblong. ferruginea, oberæ, tubis, \& filamenci, tectæ. Sem. fetis oblitum. In aquis omnia altiora, maiora,

32. luxula. S. culmo triquetro, nudo: umbella foliofa, prolifera, Ipiculis fubrotun. Syit. veg. ed. 14.

Gramen \&c. Pluk. mutnt. tab. 417, f. 3.

In India.

Culm. plafquam pedal. levis. Involuc univerfale poiyphy. f l, enfíormibus, umbelia longioribus. Purnal, vix uliun, nií feta breviff. Unbella intermedia brevifima .

33. Sylvaticus, S, culmo triquetro, foliofo: umbel. foliacea ; peduac, nudis, fupradecompofit. fpicis confertis. Syjz. veg. ed. 14. Fl. Dun, tab. 307. Leirs herborn. tab. I, f. 4.

Cyperus \&c. Mortf. hiff. 3. tab. Ix. f6 15.

Gramen \&c. Loef. pruff. tab. 33.

In Europe fylvis humentibus, fecus lacus, flumina 24.

Culm. 1-2 pedil. Fol, planiufcula, margine, \& carina afperrimd; florale unicum maximum, paniculam fuperans. Stipulæ foliaræ, longæ, mucronaræ. Pedunc, inæqual. Panic. fparla, nigricans. Spica ovata. Semen inter fetas pofitum.

34. corymbofus. S culmo triquetro, foliofo: corymbis lateralibus fimplicibus; terminali prolifero: fpicis fubulat. Syst. veg. ed. I4.

Kadira pullu. H. Mal. 19. tab. 43.

In India.

Culm. 2-ped. Fol, baft vaginant. Involuc. univerfale corymb longius. Spiculæ ferrujineæ.

35. Squarrofus. S. culmo triquetro, nudo, fetaceo: fpicis ternis, feffilibus, ovat. fquarrofis. Sy'f. veg. ed. I4. $R$ utbuel. defer. pl. tab. 17. f. 5. Pluk, phyto tab. 350 . f. $8_{3}$.

In India Orient.

Ful. radicalid, fetacea, canalicul. ereeta, culmis 
breviora. Culm. palm-pedal, Involuc, terminale 2-phyll. foliol. retaceis, inæqualibus .

36. intricalus. S. culmo triquetro, nudo: umbel. folıofa fimplici : fquamis calyc, fubul, recurvis. Syft. veg. ed. I4.

Cyperus ariftatus. Rot $t b o e l, d e f c r . p l$. l. 1. $t a b$. 6. f. 1 .

In India Orient, \& ad cap. b. Spei.

Fol. graminea, erecta, lavia. Involuc. terminale, 3-phyll. foliol. umbella longioribus. Spicæ fæe 3. pedunculat. quarta intermedia féffili ; ovato-cylind. obtuf $\mathfrak{x}, \mathrm{fl}$. confertiff. horizontalibus.

37. michelia- S. culmo triquetro: capitulo globofo: involuc. nus. longo, polyphyl. Syft. veg. ed. I4. Cyperus \&c. Tilli pif. tab. 20. f. 5.

In Italia, Monfpelii, pratis Ec. paludofis $\odot$.

Culm. minimus, quandoque unico fol. praditus, fape rubefcens. Involuc. 2-3. phyl. foliol. uno ma. Capitulum rubefcens.

38. ciliaris, S. culmo triquetro, foliofo: umbel. fparfis: fquamis calyc, ariftis ciliaris. Syft. veg. ed. I4. Pluk. phyt. tah. 192. f. 4. \& tub. 417. f. 6. Rottboel. defc. pl. $t a b$. 17. f. I.

In India Orient. $\odot$.

Culm. palm. erecti, laxi. Fol, caulina 4-5. alterna, late graminea, vaginant. laxa. Pedunc. axill. \& terminal, , fpicis 3-5. fefflibus, in capitulum divaricatis. Spicæ ovatæ, hirtæ pilis raris. Involuc. loco fub capitulo fæpe foliol. I-2. parva, fubulata,

\section{***** Culmo triquetro, Capitulo terminali.}

39. hottentot-S. culmo triquetro, foliofo: capitulo globofo, tus. fquamis calys, linceol. hirtis. Syft, veg. ed. 14. Rottboel. defor, pl. tab. I6. f. 4. Ad cap. b. Spei locis paludo/ss.

Culm, 2-3-ped. Atricti, laves. Fol. caulina 3. alterna, remotiff. vaginant, erecta, acuta, fubcarinata, lævia. Capitul. congeftura e pl. flofculorum acervis: involuc. 3 -phyl. inæquali .

49: antaräi- S. culmo triquetro, nudo: capitulo globofo; cus. involucr. I-phyl. Syft, veg. ed. I4. Ad cap. b. Spei 4 .

Fol, radical. filiform. exrus fermiteret, intus ca$\mathrm{K}$ ij 
nalicul. Culm. fubpedal. filiform. Capitul. e fpicis numerolis, æqualibus, feffi ibus. Involuc. fetaceum, capitulo longius. Spica 3-fariam imbricatæ, ovatæ, triquetræ, fufce, margin pallido.

41. cephalo- S. culaio triquetro, nudo: capitulo ovato, fquartes. rofo: involuc. 3-phyl. longo. Syft. veg. ed. 14. Jacq. H. I. $t a b .97$.

Schoenus cephalotes. Rottb. defor. pl. l, I, tab. 20. In India.

Caul. 2-3-ped. ftriatus, lavis. Fol, pedal, alterna, remota, lineari-lanc. margine, \& carina aculeata. Capitul. ad balin breviffime paniculatum, ovatum . Calyc. imbricati, recurvati . Involuc. univerfale longiff. 3-4-phyl. reflexum, margine fcabro.

enaus. S. culmo triquetro, nudo; involucro 2 -phyllo: pedunculis nudis; fpicis folitariis. All. Fl. Ped. Circa lucus, \& locis humidis $\odot$. Fol. linearia, ftriata, mollia, lavia. Culmi pl. 3-6-unc. ftriati. Spica terminales, umbellatæ. Involucri foliola inæqualia. Spicul. ovato-acumin. quarum una in centro umbelle; reliquæ pedunculatæ, pedunc. inæqualibus, qui aliquando proliferi. Sem. ellipticum, ftriatum. cinereum.

Plameaginoides.S. culmis ventricofis, fulcatis, nudis: fpica terminali, cylindrico-fubulata; flofcui. oblong. carinatis. Rottboel, defer. pl. l. I, tab. 15. f. 2.

Color Graminis glauco-viridis: fquamarum albidus, dorfo virefcens, margine teftaceus. Spica 2-3-pollic.

monander. S. culm. fetaceo: involucr. longo, 3-phyll. capitulo feffili, glomerato; flofcul. munandris. Rottb. defcr. pl. l. I. tab. I4. f. 3 .

Culmi pl. palm. triquetri, glauci. Fol. lineariferacea, mollia, vaginis membranac. albis . Involuc. patens, capitulo triplo longius .

ergenteus, S. culmis triquetris, fetaceis: involuc. longiff. 4-phyl. fpicis pl. cyliadricis, in capitulum glomeratis. Rottb. defcr. pl. l. 1. tab. 17. f. 6. H. Malab. 12, tab. 54 .

Culin. I-4-unc. Fol. plurima, fafciculatim in cefpitera congefta, imbricata, ovar-lanc. pal- 
lide ferruginea, fupra convoluto - fubulata, frriata, glauca. Squamæ argenter, cum ftrïs ferrugineis .

barkatus, S. culmo triquetro, vaginis fuboppofitis, ora fuper. barbatis: capitulo terminalı, fubrot. polyitachio. Rottb. defcr. pl. l. 1. tab. 17. f. 4.

Gramen \&c. Pluk. alm. trab. 299. f. 3.

Culm. p'urimi, palm-dodrant. proftrati, fafciculati, fetacei. Fol. radic 1 . 2-3. fetacea, bafi vaginant. Invol. univertale foliol. 4-5. fetaceis : partiale, fquama minima, ciliata, ad bafin fpicarum: fquama purpur, margine albo.

nodefus.

S. culmo compreffo, nodofo: capitulo glomera. to, mucrortato. Rottb. defcr.pl. l. 1.tab.8.f. 3 . Ad cap. b. Spei.

Culm, intortus. Capitul, magnum. Spicæ ferrugineæ.

prolifer. S. culmo tereti, nudo, compreffo: capitulis glomeratis, nudis, tandem proliferis. Ruttb. defor. pl. l. I. tah. I7. f. 2.

Culm. procumb. Spica terminal. linear-lanc. initio pauciores, dein plurimæ, imbricatæ, fquamis lanceol. ferrugin. punctis coccineis intermixis. Fedunc. vel rami pl. fofciculati, ex apice culmi inter fpicas adultioris capituli prorumpentes: finguli capitulo folitar. terminari, cuius inter fpicas fimili ratione fafciculatim progerminat nova proles.

Dipfaceus. S. culmis feraceis: umbel. fimpl. capitul. oblong. fquamofis: flofcul. fubulat. recurvis, diandris; germine echinato. Rottb. defcr. $p l, l$, I. $t a b$. I2. f. I.

Similis priori. Culm. pl. digital, triquetri, ftriati, fupra nudi, ad bafin vaginis purpurafc. foliol, breviff. termioatis, cincti, \& a fociis diftincti. Involuc, foliol. 3-4. bafi lata, concava, apice fubulata, cum capitulo intermedio feftli. Radii pauci, 2-6. breves, incurvi, triquetri. Capitula denfe imbricata, fquamis bafi membranac. ovatis, apice recurvo.

lateralis. $\quad$ S. fpicis ovatis, lateralibus, pedunculat. \& feffilibus. Forsk. AEgyp.

In Arabia.

Culm. triquet. nudus, pedal-cubital. bafi foliofa. Pedunc, Lareral, pollis, fafciculati, filiformo 
æquales. Spicarum fquama ovatæ, ferrugin. margine membranac.

Kali 3. al- S. culmo tereti, foliofo: fpicul, terminalib. conpini. fertis, feffil bus: involuc. longitudine foliorum. Forska!. 压gyp.

In Arabia.

Radix bulbofa, repens. Culm, inarticulat. Fol. fubulata, fuperne canaliculata, carnofo-coriacea.

Schushqeri. S. minimus; fol, teretibus, lineatis: fpica unica, Io-fl. Hall, Emen. \& AZ. Helv. Scheucht. gr. tab. 7. f. I.

In alpibus Helveticis.

5-florus. S. fol. teretib.: fpica unica, minima, 5-fl. Hall. Emen. Scheuchz. $t a b$, 7. f. 19.

Circa Bernam.

Haller. S. (Marifcus) culm. tereti : fol, gramineo: capitulis lateralibus ternis, ovatis. Hall. Helv.

In folfis.

Culm. cefpitofi. Fol, radicalia plura, unciam Jonga, ad fefquilineam lata. Culm. $1-4-6$. unc. Fol. vaginale, fefcunc. fuper fpicam elatum, convolutum. Spica ovat-conica, etiam 2-3. craffa, femunc. longa, ad 3. lineas late. Gluma ovat-lanc. mucronatæe, fpadiceo-virides. Sem. breve, triquetrum, cortice rugofo: villi nudi.

glomeratus. S. culmo nudo, teretiufcul. umbella glomerata: involuc. 2-phyl. brevi : fl, diandris. Retz. Obf. $f a f c, 4$.

In Zeylona.

Fol. radical. conferta, brevia, curvata, rigida . Culm. folitar. palm. Umbel. compofita. Involucc. fquamæ nennullæ, fcariofæ. Spicul. ovatæe, e fquamis latis, obtufis, concavis, fufcis, albo-marginat .

arvenfis .

S. culmis compreffis, ftriat:s: umbell. fimplicibus: involuc. plerumq. I-phyll. brevi. Reta. Obf. falc. 4.

In Zeylona.

Culm. 2-ped, bafi vagina fufca, 2-pollic. Fol. breve e vagina exiens. Umbel. 5-8. ftachya. Raro pedunc, intermedius fpicas 2. pedicellatas gerit. Spic. ovatæ, fulcæ, peduncul. e fquamis lanceol, a bafi fenfim deciduis. 
polytrichio- S. culm. compreffis, fetaceis: fpicis terminalsides.

nutans, bus, folitar. fubriutantibus, monandris. Retz. Obs. fafe. 4 .

Gramen polytrichum. Rumph, amb. 6. tab. 7. f. $I$.

In Zeylona.

Rad. nigricantes. Culmi cefpitofi, 4-6-pollic. Fol. breviora, filiform. Spica fubovira, brocteata. Squam. ovatæ, carinatæ, obtufæ, fcariofæ, aplce fulcæ. Stam raro 2.

S. culn. compreffo, fub 4-gon. cudo: fipica ovata, folitaria, terminali, nutante. Retz. Obf: fafc. 4 .

Habitat Malacca.

Culm. pl. fpthan, filiform, bafi fquamis brevibus, fufcis. Spica nuda, e fpicis ovatis, fubfufcis.

lateralis. S. culmis triquetris, nudis: fpicis fubternis, laterdibus: involuc. 1-phyll. brevi. Retz. Obf. fucc. 4 :

In Zeylona.

Culin. fpirh-pedal, filiform, befi vaginati. Fol. conformia, fed breviona. Spica una peduncul.

caribeus, S. culmis fafciculatis, fetaceis, fulcaris: fpica minima, terminali, ovata. Retz. Obf. fafc. 4. Friis Rotth. Defcr. tab. 15. f. 3 .

In Zeylona.

Sem. ovato-fubtriquetrum .

aftivalis. S. culmis depreffis, triquetris, nudis: umbellis compofitis, involucratis: fl. monandris. Retz. $\mathrm{Obf}$. fofc. 4 .

In Zeylonee fluviis, fundo limofo exficcato.

Radic, nigricantes. Culm. 3-pollic. filiform. Fol. filiform. canaliculata, hirta. Involuc. filiform. hirta, foliol. 5-8: quorum 3. umbella longiora. Involucc. brevia, capillaria. Spicul. tereti-fubargulatæ - Squamæ fufcæ, carinatæ, acuminibus divaricatis.

82. KYLLIN-Awent, ovar. feu oblongum', imbricatum. Fl. GA . cal. corollaq, 2,valvi .

I. menece- K. culmo filifor. triquetro: capitulo globofo, phala. feffili : involucr, longiff. 3-phyl. Syft, veg. ed. 14. Lin. Suppi, Rotth. d-for, pl. 1. 1. tab. 4. f. 4 .

Schonus coloratus. Sygt. reg. ed. 13. Sloatt. $\mathrm{K}$ iv 
Jam. hift. I, tab. 78. f. 1, - Rumph. Amb. 6. tab. 3. f. 2.

In Indiis.

Rarlix farmentofa. Culm. pl. fefqui-2 pedal. ad radicem foliofi, fupra nudi. Fol. digitalia, linearia, culmo breviora, caniliculata, afpera. Capitulum refert recepraculum Fragaria, magnitudine Pifi.

2. triceps. K. capitulis terminalibus fubternis, feffilibus, glomeratis. Syft. veg. ed. I4. Lin. Suppl.

Schœnus niveus. Syft. yeg. ed, 13. Jacq. hort, 1. tab. 97. Rottb. defcr. pl. 1. 1. tab. 4. f. 6. H. Mal. 2. tab. 53.

In Indiis .

Similis priori, fed differt capitulo trilobo.

Planta cefpitofa, denfa. Radix aromatica. Culm. I-2-ped. erectus, nudus. Fol. culmo breviora, enfiform-linear. Involuc, 4-phyll.

3. paricea. K. umbel, terminali; foicis feffilibus, pedunculatifq. cylindric. imbricat: inv luc. univerfali fub 4-phyl: partiali nullo. Syft. veg. ed. 14. Lin. Supp. Ruttb. defor. pl. tab. 4. f., 1.

In Indiis.

4. umbellata. K. umbel. terminali ; fpicis feffilibus, pedunculatifq. cylindricis, fquarrofis: involucr. univerfali polyphyl. partiali 3-phyl. Sy ft. veg. ed. I4. Lin. Suppl. Rottb. gram, tab. 4. f. 2.

In Indiis.

fumatrenfis , K. umbella terminali; rpicis feffilibus, pedunculatifq: cylindricis, fquarrofis: involuc. univerfali polyphyllo; partiali nullo. Tetz. Obf. fafc. 4 . In Sumatra.

83. FUIRE- Ament. imbricat. fquamis ariftatis. Cal, o. Cor. NA . g!umis 3. petaliformibus, obcordat. cirrho terminatis .

1.paniculata.F. culmo angulato: fol. lanceol. Atriatis, remotis : fl. umbellatis. Syft.vez.ed. 14. Lin. Suppl. Rottb. defcr. pl. 1. I, tab. 19. f. 3 .

Facies Scirpi. Culm. altus, fimplex, angulatus, ftriatus. Fol, alterna, in fummo caule, glati$\mathrm{ca}$, longitudine internodiorum, vaginis urceolatis, laxis, culmum ambientibus, breviter pilofis, membrana oris ciliata, fersuginea. pedunc, 2-3. axillar. apice umbellati, hirfu- 
tiff. Spica oblong. conglomeratæ, nigricantes. 84. ERIO- Spica brevis, pauciflora, imbricata, fquamis obPHORUM. longis. Sem. I. lana longiffima cinctum, ut capitulum reddat tomentofum .

I. vaginatum, E, culmis vaginatis, tereribus: fpica fcariofa. Syjt. veg. ed. 14, Fl, Dan. tab. 236 . Juncus \&c. Scheucht. gr, tah, 7. f. 1. 2. 3.

In Europa frigidis alpiom fterilibus 4.

Culmum pedal. terminat globus bombagyno pappo tectus. Fol. radical. plus, minus triquetra, acuta; caulina mutica; fumma bafi purpur. Spica erecta, ovata, fquamis fufcis. Sem. 3gonum, apice dilatatum.

In alpibus humilizs, mollius; capitulo latiore, rotundiore, glumis fufcis, minus lividis \&c.

2. polyfta- E. culmis teretibus; fol. planis: fpicis plerifq. chiven, pedunculatis. Syft. yeg. ed. 14. Leerf. Herborn. tal. I, f, 5 .

Iinagroftis \&c. Vaill. Paris tab. I6. f. I. \& var. f. 2.

Gramen \&c. Garid. Aix. tab. 44.

In Europa uliginojis turfofis 24.

Culm. ped-cubital. Panicula tomento nivea. Spicæ ufque 7. immaturæ erectæ, per æatem pendulæe, primo rotundæe, dein longiores. Spicul. fquamæ pellucidæ, membranaceæ, per retatem rufefcentes.

3. virginicum.E. culmis foliofis, teretibus : fol. planis. Spica erecta. Syft. veg. ed. 14.

Gramen \&c. Pluk. alm. tab. 299. f. 4. Morif. likf. 3. . . 8. $t a b$. 9. f. 2.

In Virginia .

Cultn. I-fefquiped, ereclus, enodis. Fol. Triticea, funma 3. e geniculo, palmaria. Paniculæ glomerata 6-7. tomentofæe, fubfufcæ .

4. 6) perinum. E. culmis teretibus, foliofis: panicula fupradecomp. prolifera ; fípul. fubternis. Syst. veg. ed. 14 .

Cyperus \&c. Pluk, mant. tab. 4I9. f. 3.

In America Septent.

Statura omnino Cyperi, fed fpiculæ Scirpi, nifi fem. maturefcentia producerent lanam gilvam, feu teftaceam, vix fpiculis longiorem.

5. alpinism. E. culmis nudis, triquerris: fpica pappo breviore. Syft, vag. ed. 14. Fl, Dan, tab. 620. 
Linagroftis \&c. Scheucha. gram. tab.7.f. 4. prodr. tab. 8.

In Europ a alpibus 24.

Culm, femiped. fpica unica, ovat-oblon. Gluma cinnameo-virides. Pappus flutans pedicellum refert . Sem. acuminatum, fufcum .

85. NARDUS, Fl. folitarii, fpicati. Glumæ folliculi binæ, anguftæ, acuminatæ, etiam ariftatæ .

1. thamaa, N. fpica filiformi, recta, utrimque imbricata. Syft. veg. ed. 14. Linn. Suppl.

In Tranquebsria.

Fol. in cefpitem nata, 2-pollic. alterna, fetacea. Culm, 2-pollic. Spicæ term n 1. folitariæ, feffiles, teretes, flavefcentes, flofculis vix confpicuis .

3. friza, N. fpica fetacea, recta, fecunda. Syft, veg. ed. 14. Schreb. gram. 1ab. 7 Leerf. herbora.tab. I. f. 7 .

Gtamen \&c. Morif. hift. 3. f. 8. cab. f. 8. Monti ic. 3I. Scheuchy, agroft. tab. 2. f. IO.

In Europa afperis, ferilibus, montanis 24.

Planta cefpitofa. Culm. palmar. \& ultra. Fol. capillacea. Spica longa, linearis, rara. Glumæ lanceol, in fet s definentes, frepius coloratæ. Locufæx fæpe violac.

3. gangitis N N. fpica recurva. Syft, veg. ed. I4. Lob. ic. 84 ، Morif. lift. 3. f. 8. tab. 13. f. cult.

In Gailia nutbonenfi.

Ob fcura : an N. ariftata var. ? Culm. erecti, nudi. Fol, plura, in cefpitem difpofira, longa. Spi-

4. ariftata. N. calycibus ariftatis. Syft. veg. ed. 14.

Gramen \&c. Bocc. Muf. 2, tab. 57. Barr, rar. tab. II . f, I.

Rome, in agro Nicaenfi, \& Pedemonteno $\odot$.

Culm. pl. femiped-palm. ex quorum geniculis alii exeunt, brachiati, recurvi. Fol. plura, brevia, angufta. Spica 2-3-unc. Lucuftæalterna 。

5. ciliaris. N. fpica incurva, ciliata. Syjt. seg. ed. 14.

In Indir.

Fol. graminea, plana. Culm. fpitham. Spica dimidiata, feu altero latere tantum flofcul. alternis, $12-15$.

6. indica. N. fpica fetacea, fecunda, fubincurvata. Syfto veg. ed. I 4. Lin. Juppl.

In Tranquebaria. 
Gramen longitudine digiti, fubramofum, læve. Fol. culmo breviora, alterna, remota, plana. Spica imbricata, verfus fl. anguftifima.

86. POMME- Cal. turbinatus, 2-valv. valvula .4-fid. dorfo REULLA. ariftatæ.

I. cornucopia. P. Syft. veg. ed, 14. Lin. Suppl.

In India.

Gramen parvum, valde fingulare. Radix fibrofa, repens, alba. Fol. vix digitalia, equitantia, bifariam imbricata, compreffa, lavia. Culm. ramofi, vix fol. longiores. Spica fubracemofa, alba, bafi obvallata fol. fubfpaihæformi. Flos florem Caryophyllaum plenum referens. Sem. rufum.

87. LYGEUM. Sparha i-phyll. Cor. binæ fupra idem germen. Nux 2-locul.

I. fpartelum, L.-Syft. veg. ed. 14. Locfl. it, tab. 2. Cluf. hift. 2. fig. 2 .

In Europe campis argillofis 24 .

Planta color e viridi-paleac. Culm. \& fol. in cefpitem fafciculata. Culmus unico articulo verfus apicem donatur, fpith-2-pedal. Flos unicus, terminalis, inclinatus .

\section{I G Y I I .}

88. BOBARtia. Cal. imbricatus . Cor. gluma 2-valv. fupera . 1. indica. B. fpicis capitatis; involuc. foliofo. Syft. veg. ed. 14.

Gramen \&c. Pluk. tab. 300. f. 7.

In India.

R.fert ita Schoenum mucronatum, we eius fig. pro huius ubique venditari poffit.

Culm. altus, nudus, teres. Spica pl. in capitulum collectæ, feffil. oblong. cylindricæ. Involuc. 2-phyll, altero breviore ex fol. horizontal. ventricofo, acumin. longitudine capituli; altero bafi ventricofo, capitulo quinquies longiore, horizontali.

89. CORNU-Involucr. 1-phyll, infundibulifor. crenatum, mulCOPIE, tifl. Cal. 2-valv, Cor, I-valv, Alopecuro nimis adifine. 
I. cucullatum. C. fpica mutica; cucullo crenato. Syft. veg. ed. I4. Juncus \&c. Pet. guz. tab. 73. f. 5 .

Smyrnx.

Caul. fietulof. gericulatus, ramofus. Fol. bafi fpathæform, inferiora media angufta: reliqua linearia. Pedunc. incurvati, fpica duplo longiores. Involuc. lucidu-lividum. Spica obfcure violacea, cum ftriis lucido-purpur.

2. alopecuro- C. fpica ariftata, cucullo hemifphærico recepta. iles. Syft. veg. ed. 14.

In Italia.

Similis Alopecuro pratenfi. Culmi adfcendent. laxves. Fol. lavia. Spica terminal. ovata, laxa, flofcul. breviffme pedicellatis. Vagina fupremi fol. ventricofa, ut in Phalaride. Singularis nota eft urceolus hemifpharicus, integerr. ( confiftentia fol.) qui inftar cal. communis cingit bafin fpica.

90. SACCHA-Cal. lanugo longa extra calycem, in quo differt RUM

I. Spontaab Arundine. Cor. 2-valv.

neutr .

S. fol. convolutis: panicula effufa; fpicis fimplicibus, capillaribus : fl. remotis, involucratis, geminatis; altero pedunculato. Syft. veg. ed. 14.

S. fl. paniculatis \&c. Syft. veg. ed. 13 .

Kerpa. H. Mal. 12. tab. 46.

In Malabarias equefis 4.

Culn. I2-ped. fed non arborefcent. craffitie pennæ anferina, laves, tecti vaginis fol. inanes. Fol: 2-pedal. lateribus convoluta, lavia, latitudine graminis. Panicula magna, effufa, e fpicis capillaribus, fimpliciff. longiff. erectiufc. Fl, remoti .

2. officinerum. S. fol. planis: Al. paniculatis. Syst. yeg. ed. I4. Arundo faccharifera. Sloant. Jam. hift. I. tab. 66. Rumph. amb. 5. tab. 74, f. I.

In Indiae utriufq. locis inundatis. Colitur in Perfia.

Culm. 8-10. ped. fimpl, articulat. fubincurvus. Fol. ad nodos magna, 4-pedal. 3. digitos lata, ftriata, nervo albo, rugofa, pallide glauca. Panic. arundinacea, albo-lanuginofa.

3. Rayenna. S. panicula laxa, rachi lanata: fl, ariftatis. Syft. veg. ed. 14.

Arundo ac. Zan. hift. 1. tab. 24. Monti in Zann. tab. 19. f, 3. Morif. hitf. 3. f. 8. tab. 8. f. 32 . In Italin. 
Altitudo arborea. Culm. medullofus. Fol, 2. ulnas longa, viridia cum punctis rubentibus, ad bafin argentea lanugine adfperfa. Panicul. albo-purpurafc.

4. Teneriffe. S. fol. fubulat. planis: fl. paniculat. muticis: involucr. pilofo nullo; cal. villofief. $S y f t$. veg. ed. I4. I in. Suppl.

In Teneriffa.

Differt a reliquis Speciebus cal. hirfuto, qui in illis nudus. Caret involwc. flofcul. Glume ovetoe, nec fubulatice, ut in S. fpontaneo.

Culm. pedal. \& ultra, geniculatus, articulis adproximatis, foliatis. Fol. brevia, recta, glaberrima. Panicul. medioc. magnitudinis, fimil. Holeo lanato.

5. fpisatum, S. fol. undatis: fl. fpicatis ( paniculatis ). Syft. veg. ed. I4.

Gramen \&c. Plak. alm. tab. II9. f. I.

Tieria. H. Mal. 12. tab. 62.

In Indix petrofis .

Culm. $1-2-$ ped. rectus, fimpler, geniculat, Fol. uncial. lata, bafi caulem amplectentia, margine pilofo. Panicula palmar. coartata, ovata, vel cylindrica, ariftis fericeis, fufco-purpur.

arundinaceum . S. panicula confertæ peduncul. divifis: flofculis geminis, feffili, pediceliatoque, cor. 3-valv. polygamis. Retz. Obf. fafc. 4.

In Tranquebaria ad fiagnorum margines.

Culmi alti ufq. Io-ped. craff, foliofi, femi-inanes. Fol. verticillata, culmo adproximata, lata. Panicula 2-ped. contracta, rachi 4-gon. Pedunc. verticillati, triquetri, articulati. Cor. valvulis hyalinis, una longiore, acuminata,

fegiltatum, S. Aubl. Guian.

In Guiance locis humidis, \& fabulofis.

Caul. maculati fuccum effundunt duicem, \& faccharatum.

biflorum. S. panicula lanata, fecunda: calycibus I-fl. geminatis, extus lanatis. Forsk. $\bar{E}_{g / p}$.

In Arabic locis aquofis 4.

Culm. plufquam orgyal, quandoq. ramofus. Fol. nervofa, bafi fuperne lanato-hifpida; fubrus obtufe carinata, tota viridia; in medio fuperior. canaliculata linea alba longitudinali. Fl, geminati, alter feffilis, alter pedunculat. 
hirfutum.

S. fpica hirfuta: fpiculis geminis; altera feffi!. altera pedicellat. Forsk. $\mathbb{E}_{\mathrm{g}} \mathrm{p}$.

In Arabia.

Culm. pedal. fimpl. Fol. vaginæ longæ, glabræ, intra fol. barba terminata. Spica 4-pollic. hirfutie alba .

91. PHALA-Cal. 2-valv. carinatus (acuminatus), longitudiRIS. ne æqualis, corollam includens.

I. cunarienfis. P. panicula ovata, fpiciformi; glumis carindtis . Syft, veg. ed. I4. Schereb. gram, tab. IO. f. 2. De Leerf. herborn. tab. 7. f. 3. Ludw. ect. tab. II7. Morif: hift. 3. S. 8. tab. 3. f. I.

In Canariis inter fegetes, \& in Comitatu Nicaxerfi $\odot$.

Caul. 3-4 cubital. geniculati, graciles. Fol. hordacea, fubulata, coefia. Spica I-fefcunc. fquamæ candicantes lineis viridibus. Sem. candidum, nitens .

2. bulbofa, P. panicula cylindrica; glumis carinatis. Syft. veg. ed. I4.

In Orience.

Radix bulbofa. Spica 2-pollic. Glumæ ovatæ, carinatæ, arcte congeitæ. Sem. albuin.

3. nodofa. P, paniculd oblong, fol. ringentibus. Syft. veg. ed. I4.

In Europa aufirali.

Radix ex pl, tuberculis Avellanæ magnitudine conftans. Altitudo humana. Culmi paucis geniculis. Fol, rigida Arundinis, margine fca. bra; fummum leviter ventricofum, Spicæ 4-5unc. digiti craffitie, compactæ, ovat-oblong. muticæ, acerofæ. Culyc. ovat-oblong.

4. aquatica, P. panicula fpiciform. ovat-oblon: glumis lanceol. carinatis. Syft. veg. ed. 14 .

Gramen \&c. Burr. rar, lab. 700, f. 1. Burb. cent. 4. tizb. 53 .

Ad Tyberim, E' in AEgypto 24.

Culm. Arundinaceus . Fol, folidiufcula , Panicul. erecta. Glumæ glabra.

5. phlcoides, P. panicula fpiciformi, cylindrica, glabra, paflim vivipara. Syft. veg. ed. 14. Fl. Dan. tab. 531.

Gramen \&c. Murif. Kift. tab. 4. f. 2. Bar. ic. tab. $21, \mathrm{f}, 2$.

In Europx verfuris, \& ad vias $\odot$. Habitus Phlei, fed fl. alii. Culm. fefquiped. ple- 
rumq. violac. Spica arcuata, pallens, in lobos divifibilis, adfperfa hinc inde glumis viviparis . Spiculæ alternæ, diftichæ, culmo adpreffæe, imbricatie.

6. utriculata. P. panicula fpicata: petalis arifta articulata; vagina fupremi folit fpathifor. Syjt. seg. ed. I4. Scop. Delie. Infub. fafo. I. tab. I2.

In Italis $\odot$.

Culmi folitar-pl, pedal, erecti, fæpe fimplic. Fol. lata, mucronata, bafi membrana albida. Spica 6-9-linear. e viridi-paleaceo-alba, vel spadicea ,

7. paradoxa, P. panicula cylindrica, flofcul, mucronatis; neutris plurimis; infimis præmorfis. Syft. veg. ed. 14. Schreb. gram, tab. 12.

Gramen \&c. Pluk, alm, tab, 33. f. 5. Morif, hift. 3. . . 8. $+a b .3$. f. 6 .

In Oriente, \& Comitatu Nicaensi $\odot$.

Radix fibrofa, minime bulbofa. Culm. pl. perlal. erecti, ante anthefin decumbent. laves, ficuti fol. imilis priori.

8. arundina- P. panicula ampla, oblong. ventricola. Syft. veg. cea . ed. 14. Fl. Dan, tab. 259. Leerf. herb. tab. 7. f. 3 .

Gramen \&xc. Echreb, tab. 3. f. 4, A. B. C. Morif, hijt. 3. f. 8. $t a b$. 6. f. 4 I.

b. Phelaris piäa.

In Europe fubhumidis ad ripas lacuum 24.

Caul. orgyal. craffus. Fol. ad 8, lineas lata, glabra, fubglauca. Panicul. pedal. ramofiffima, fed ramis fafcicul. fl. tectis, confertis, imbricatis, alterne longioribus, col. purpurafc. quandoq. albo. Loco nectarii fub quavis glu. ma corollina penicillum pilorum gerit.

9. erucafor- P. panicula fecunda, lineari: calycibus 2-fl. Syf. mis. veg. ed. 14 .

Dactylis \&c. Gmel. Sibir. I. $t a b .29$.

Gramen \&c. Barr. rar. 1158. tab. 2.

In Europa auftrali.

Pafpalum refert, fed valvula $\lambda$. modo contrario dehifcunt.

Caul. 1-2. ped. Fol. palmaria, pulchre viridia. Panic. erecta .

Io. zižanioi- P. panicula fimpliciff, fl, muricatis; altero feffili a des. Syft. veg. ed. I4, In India Orient. 
Culmi 2-ped. laves. Fol. rariora, breviora, vaiginantia. Fl, ad panicula dentes fingulos 2.

Facies aliqua $P$. oryzoides, fed corolla infuruitur. II, oryzoides. P. panicula effufa : glumarum carinis ciliatis. Syft, veg, ed. I4. Schreb. gram. tab. 22.

Gramini \&c. Slonn. Jam, I. tab. 7r. f. I.

Gramen miliaceum \&c. Mont, prodr. ic, 58.

Afperella. Italis .

In Italix agris Oryzaceis; \& alibi fecus aquas 24. Peialis caret. Culm. 3-ped. \& ultra. Fol. 2-lineas lata, afpera. Fix finu fol. fupremi exit panicula erectd, ramoía, ftricta, pedicellis flexuofis. Flofc. albicant. lineis virentibus ,

12. dentata. P. fpica cylindrica, glunis muticis, carinatis, carina dentata; dentibus apice globofis. Syfe. veg. ed, I4. Lin. Suppl.

In Africa.

Gramen pulchrum, \& diftinçiffrmum $p 0^{\circ}$ intuitu. Statura P. Phleoidis. Culm, geniculati, glabri, fol. brevibus. Spicæ terminal. folitarixe.

33. hifpide. P. fpicis digitatis: glumis fcabris: fol. ovatis . Syft. veg. ed. 14. Thumb. Japon.

In Japoria.

Differre omnino videtur a $P$. Zizanoide. Culmi decumbent. pedal. ramofi, capillar. apice erecti, articulati, glabri. Fol. vix pollic. vaginant. acuta, patula, ciliata, glabra. Spica pl. $3^{-6 .}$ unguicul. Flofcul. alterni, feffil. imbricati .

sepera,

P. panicula ficata, tereti: calycibus obcordatis, mucronatis. Retz. Obf. fafc. 4.

In alpibus Europa merid.

Culm. fpitham. bafi ramofi, vaginati. Fol, brevia, angufta, nuda. Panicul. 1-4-poll. Ionga. Cal. pallide viridis. Sem. ovale, oblong. minime compreffum.

alpinn. P. panic. cylindrica, fpicata: glumis calycin, fubariftat. dorfo ciliatis. Turre Giornale di Venezia. T. $\mathbf{1}$.

Culm. 2-pedal. erect. Panic. variegata, villofa, ex fpicul. compactis fpicam cylindricam efformantibus. Cal. glumæ carinatæ, fubariftatæ, dorfo ciliatæ. Cor. calyce duplo brevior.

femiverticilla- P. paniculæ ranis femiverticillatis, patentibus: ta. fpicul, muticis, ciliatis : fol, glabris. For $\sqrt{k}$. IEg. In Arabia. 
Culm. erect. fefquiped. glaber. Fol. fpitham. linear. plana. Panic, rami iterum paniculati .

difticha. P. panicula ovata, mutica: fol. diftichis, invoIutis : culm. repente, ramofo. $F_{\ominus r} \int k$. $E_{\mathbf{g}}$.

In Arabia.

Culmi pars erecta fpitham. Fol. conferta, fubpungentia, bafi barbata, viridia. Bractea panic. folium magnum, pallidum. Panic. ovata, patens, diffufa.

criftata. P. panicula fpicifor. oblonga; valvula calycina utrimq. aritta, cal. duplo longiore. Forsk. Eg. In Arabia.

Spica ariftis pilofa. Vaginæ, \& fol, glabra. Ad bafin fol. membrana erecta, cauli adpreffa, alba. Fol. plana, valde ftriata. Panic. fefquipollic. varie ramofa.

velutina, .. fpicis alternis, filiformibus: culmo, foliifq. villofitr. Forsk. AEg.

In Arabia.

Culm. pedal. Fol. 3-pollic. lineari-lanc. angufta, velutina. Spicæ multæ, terminal. 3-pólic. fparfæ, erecto-patent.

fetacea. P. folitaria, fpicata; fpiculis folitar: involuc. fetaceis : fl. fefquilongioribus. Forsk. $\mathscr{E}_{g}$.

In Arabia .

Culm. ped. fimpl. Fol. 2. pollic. involuta, plana, glabra. Fol. fupremum latius, ante efflorefcentiam fpicam includit in fpatha. Spica 2-pollic. cylindrica, alba .

vaginiflera, I. culm. repentibus, fpicarum capitulis axillaribus, feffilibus, vagina fol. circumdatis : calyce cor, anguitiore, fere filiform. 2 valv. I-fl. valvis compreffis, anguftis, altera longiore. Forsk, 哐g.

In Arnbia.

Fol, fuprema oppofita.

minor. $\quad P$. panicula fpiciform. cylindrica : calycibus carinatis, nudis; nectar. folitar. Retz. Obf. fafc. 3 .

Nulla habet tubera. Simil, P. canarien. fed miuor, panicul. haud ventricofa, \& anguftior :

92. PASPA-Cal. 2-valv. orbiculatus. Cor. eiufdem magniLUM . tudinis. Stigm. penicilliformia.

dibectum. P. fpicis alternis, rachi membranac, fl. alternis, apice pilofis. Syf. veg, ed. I4.

Tom, $I$. 
Gramen \&c. Plàk, mant, tab. 350. f. 2.

In America calidiore $\odot$.

Gramen proftratum, ful, vaginis fere fpathaceis . Spicæ paucæ rachi membranac. dilatata ad 12titudinem fpicæ ipfius diftichæ, \& fecundæ. Fl, orbiculari. Fol. utrimq. pubefcentia .

2. Serobicula- P. fpicis alternis, rachi membranac. fl. alternis:

tum. calycibus multinerviis, extus fcrobiculatis. Sy/t. yeg. ed, 14 .

In India Orient. 24.

Culı. erecti, peda!!. \& ultra, bafi hirfuti. Vaginæ fol. purpur fc. margine ciliatæ, hirfutæ. F: 1. lavid, fupra linea albida, longitudinali. Soica fepe reflexa.

3. villofum, P. fpicis deernis, fecundis, rachi hirfuta; fl. diplici ordine, alternis, fecundis. SyJi. veg. ca. 14: Thum. Japon. tab. 8.

In Japonia.

Culm 3. pedal. glaber. Fol, brevia, fubfabridd, tiriata, Spica 3-4.

4. virgatum, P, fpicul. paniculatis, lternis, bafi villofis: $f$. geminis. ijft. veg. ed. 14.

Gramen \&c, Sloar. Jam, hift. I, $九 a b .69$. f. 2. In Jamaica.

Valvula cal, exterior breviff. margine hirfuta.

5. penicula- P. f́picis paniculatis, verticillato-aggregatis. Syft. tum. veg. ed. 14 .

Grimen \&c, Slaan. Jam, hif., 1, tab. 72. f. 2. In Jamaica.

Erectius hoc eft. Spicul. linear, fecundæ, filiform. angultiff. Fl. duplici ordine digefti, acutiufculi.

6. diffichum, P. fpicis du bus, altera feffili; fl. acuminatis, Syft, veg. ed. 14 .

In Jamaica.

Gramen pedale. Fol. involuto-fubulata. Spica erectæ, adproximatæ, fecundæ. Cal. \& cor. ovata .

hirfutum, P. fpicis alternis, fubbinis, rachi membranac. calycibus multinerviis, lævilus : fol. pedicellifq. hirfutis, Retz. Obf. fafc. 2.

In China .

Culmi erecti, foliofi, fuperne pilofi. Fol, \& vaginæ und.q. pilofæ, oris barbatis. Spicæ 
erectiufc, fubfeffil. Fl. fecundi, alterni, pedicellati, glabri.

longiflerum. P. fpica gemina: florcul. ovali-oblongis. Retz. $O b \int . f a f c .4$.

In Malabaria,

Culmi adfcendentes, filiform. Fol. brevia, acuta, patentid, ad culmi halin vaginantia. Spicæ terminal. erectæ; lineares. Fl. alterni, pedicellati, adprefir. Facies Panici diftachii.

93. PANI- Cal. 3-valv, valvula teria minima, poft alteram CUM. pofita.

\section{* Spicata.}

I. polyfta- P. fpicis teretibus: involucel. I-fl, fafciculato-fechion. tofis: culmis erect, fuperne ramofis. Syft. veg. ed. 14 .

Gramen \&c. Rumph, amb. 6. $t_{a} b, 7$. f. 2 ,

In India $\sigma$.

Simil. in fpicis $P$. glauco, fed dimidio minoribus: piftill. fanguineis . Culm. inferne radicans, ramofus, I-6. pedal. Fol. pilofa, fuperne fere oppofita. Involuc. purpurafcentia.

2. verticilla- P. fpica verticillata; racemul. quaternis; involuc. turn. I-fl. bifetis: culm, diffufo. Syft. veg. ed. 14.

Gramen \&c, Bauh. Theat. tab. 139.

In Europa Auftr. \& Oriente, ad vias, \& limites agrorum $\odot$.

Simil. P. viridi, fed fpica racemis longioribus, 3-4 deorfum fecundis. Fl. virid. piltil. purpurafcent. Culmi læves, 2-pedal. Fol. nuda.

$V a r$. maior paniculı magis diffufa, longiore, $\varepsilon$ craffiore.

Var. mi. panic. fernidigit. fpicata, cylindrica.

3. helvolum, P. fpica tereti: involucel. I-fl. fafciculato-fetofis: feminibus nervofis. Syft. veg. ed: I4. Lin. Suppl,

In India Or. $\odot$.

Simil. $P$. glauca, fed reapfe diverfum. Culm. 6. ped. ranof, ramis terilibus brevioribus. Fol. ad bafin fupra pilis albis, fere pollicaribus, patentiff. Spica fpitham. fimplex, flofcul. abfque ordine. Involucel. helvola, multifera, fl. multo Iongiora. Gluma ftris longitudinalibus (nec tranfverfis undulatis) diftinctis, viridibus . 
4. glaucum. P. fpica tereti; involucel. 2-floris, fafciculatopilofis : feminibus undulato-rugolis . Syft, vego ed. 14. Leerf. herb. tab.2. f, 2. * ichreb. gram. tab. 25. Lob. ic. 13.

In Indiis, Italia, Germania; frequens in arvis $\odot$. Culmi recti. Fol, lanceol. fubtus tomentofa, vaginis oris pilofis, Pedunc. valde fulcatus. Spica fimplex, magnitudine varia, oblonga, craf$\mathrm{fa}$, ut in $\mathrm{P}$. vulg. Involucel. in fpica matura femper lutea, vel fulva. Fl, cœrul.

$P$. viride, gloucum, E verticillat. ex datis charaçeribus pix diftinguntur. Quarendi funt alii, fi adfint.

5. viride. P. fpica tereti, involucel, 2-ft. fafciculato-pilofis: feminibus nervofis. Syft. veg. ed, 14, Fl. Dan. tab.852. monente Vahl. Leerf. herb. tab. 2. f. 2. * Morif. hift. 3. f. 3 tab. 4. f. 10.

In Europa auftrali, ed limites agrorum $\odot$. Simil. P. vericillato, fed molle, nec afperum. Culm. pedal. \& ultra, erectus. Fol. lata, in origine fua etiam tomentofa. Spica fubovata, flofculis folitar. feffilibus. Involuc. fetaceum, flaven, letis longioribus fl. fuperantibus.

6. itelieum. P. fpica compofita, fpicul, glomeratis, fetis immixtis ; pedunc, hirfutis. Syft. veg. $c d$. I 4 . Rumph. amb. $1 a b, 75$. f. 2.

In Indiis $\odot$.

Culm. 2-pedal. Spica ovata, varians col. \& magnirudine. Sem. Milio exiliora, \& rotundiora.

7. erus corvi, P. fpicis alternis, fecundis; fpicul, fubdivifis; glum. fubarift, hilpidis; rachi trigond. Syft. veg. ed. I4.

In Indiis $\odot$.

Habetur pro varietate sequentis, fed minus, tenerius. Panicula magis nutans; rachi trigona, nec pentagona. Spicæ fecundæ, nec undique rachi incumbentes.

8. crus galli. P. fpicis alternis, coniugatifq. fpicul. fubdivifis; glumis (fæpe) ariftatis, hifpidis, rachi 5-angulari. Syft. veg,ed. 14. Leerf. herb. tab. 2. f. 3. Gramen \&c. Morif. hift. 3. f. 8. tab. 4. f. 15.

b. Morif. l. c. f. 16 .

In Europe, \& Virginie arvis ubique $\odot$.

Culm. 2-pedal. Paniculæ axillar. fpicul, alternæ, paniculatæ, pedunc. ramofis. Cal. non eft 3valy. nec I-fa, rachis gqungue fope 3-gona. 
Variat ariftis longilf. aut brevilf. ficuti var. $b$ " aritis decies glumis longioribus, manifefte a communi planta, cui vix fefquilongiores aris ftæ, differt .

9. colonum. P. fpicul, alternis, fecundis, muticis, ovatis, fcabris; rachi teretiufcula. Syft. veg. ed 14. Gramen \&c. Pluk. alm. tab. I89. f. 5. Slonn. Jam. hift. 1. tab. 64. f. 3. Ehret. piá. tab.3. f. 3. Rumph. amb. 6. $t a b$. 5. f. 3 .

In Indice cultis $\odot$.

Culmi adfcendent. fjitham, teretes. Fol. 1ævia, frepe ferrugineo-maculata, fauce purpurafc. abfq. ligula. Spica fimpl. fecundá. Spicul, plu. rimæ, fubfeffil. abfq. fafcicul. pilofis. Piftill. alba, mox purpurafc.

10. Briz̧oides. P. fpicis alternis, feffilibus, fecundis, adpreffis, oblong. Syft. veg. ed. I4.

Gramen \& c, Pluk, alm, aab, IgI. f. I.

In India.

Cuim. erect, pedal, articulat, lavis . Fol, aiterna, remota, 5-6. Iongitudine culmi, lævia, bafi vaginantia, collo cartilagineo. Rachis terininal. palmar. fimpl. Spicæ fape 5.

12. hirtellum . P. fpica compofita; fpicul. adpreffis, alternis, calycibus geminis; valvul. omnibus ariftatis, extima longiffima. Syft. veg. ed. I4. Burm. Ind. tab. 12. f. 1 .

P. undulatifolizm. Ard. $\int p, 2, t a b .4$.

Gramen \&c. Bocc. muf. 2, tab. 55 .

In Indiis, \& in Itrlia ad radices collium. \& montium locis umbrojis 24 .

Culm. repent, aut erectiufculi . Fol, brevia, ovat-lanceol. undulata, vaginis longis. Spica fecundæ, fubfeffil. Fl. arittæ filiform: obtufæ, fanguineæ, glutinofæ, demum uncinatæ. Stam. piftillaq. alba .

12. eonglome- P. fícd fubovata, Secunda; flofcul obtufis. Syft. ratum. veg. ed. I 4 .

In Indic Orient.

Culmi proftrati, radicant. ramofiff. filiform. Fol. lanceol, lævia, vaginis articuld dimidio brevioribus. Spica parva, frepe 8-fl. abfq pilis . Piltil. plumofa, magnitudine totius $\mathrm{fl}$.

13. fangui- P. fpicis digitatis, b. fi interirire nodofis; flofcul。 nale. geminis muticis; Yaginis fol punctatis. Syft. I iij 
veg. ed. 14. Fl. Dan. tab. 388. Schreb. gram. tab. 16. Burm. Ind. tab. 10. f. I. Leerf. herb. tab. 2. f. 6.

Gramen \&c. Buxb. cent. 5. tab. 65. Scheucht. gram. tab. 2, f. 2. Murif. hift. 3. f. 8. tab. 3. f. 5. Sloan. Jam. hift. 1. tab. 170. f. 2.

In America, Media, \& Europa arvis ubique $\odot$.

Culm. bafi procumb. unc-femiped. Fol. longa, margine obfcure rubro, vaginis pilofis. Spica plurimæ, longa, lineares; primæ verticill. ultimæ alternæ. Fl. pedunculati pédunculo uno longiore.

14. dazylon . P. fpicis digitat. patentibus, bafi interiore villofis: fl. foliar. farmentis repentibus. Syft. veg. ed. I4. Munti ic. 99. buna. Scheucht. gr. $t a b$. 2. f. II.

Gramen \&c. Morif. hift. 3. f. 8. tab. 3. f. 4.

In pafcuis, \& agris paffin 4 .

Stolones repentes, craffi, folidi, fquamofi. Culm. pedal. rigidi. Fol. ima fuperioribus breviora, villofa, fcabra, glauc $a$. Spicæ terminal, linear. rigidæ, fufco-rubræ, Fl. unilateral.

Jure merita $\mathrm{Cl}$. Hall. ex hac planta, ficuti ex confimilib. Spicis digitatis, Digitarie genus conftituit, propt. defeäum tertice glume calycina.

I5. filiforme . P. fpicis fubdigitat. adproximatis, erectis, linearibus, rachi flexuofa, dentibus 2-fl. altero feffili. Syft. veg. ed. 14. Jacq. $\cdot b f .3 . t a b .70$.

In Amer. Septentr.

Culm. pedal. fubaphyl. filiform. fuperne erecti, nudi. Fol. lanceol. Spica rara. Spicæ tenues, primum valde adproximata quafi in unum, quamvis alternæ.

16. linenre. P. fpicis digitat. fubquaternis, linearibus; flofcul. folitar, fecundis, muticis. Syft. veg. ed. 14. Burm, Ind, tab, Io, f, 2 .

Gramen \&c. Sloun, hift. I. tab. 70. f. 3.

In Indiis.

Culmi proftrati, ramofi, laves. Spicul. recta, angufta .

17. difta- P. fpicis geminis, fecundis, lævibus. Syft. veg. chyon. ed. 14.

In India Orient.

Culm. pedal. anguftiores, fubramofi. Fol, brevia, graminea, margine fcabra. Spicæ fuba- 


\section{TRIANDRIA DIGYNIA.}

qual. Fl. genioo ordine long tu tinali ad rachin, fefill. mutici, ovari, laeves. Anth, flava. Piftil. plumofa, purpur. Facies Papaii dijzichi, fed fol. lanceol, plana; nec fetacea, involuta, $\mathrm{Fl}$. acutiufe, nec mucronati.

I8. eampofi- P. foica compofita: fpicul, linearibus, fecundis: tum. flofe, geminis remotis; calycib. ariltatis . $i y /$. veg. ed. 14.

In Zejlona.

Culm. repens, foliof. affurgit filiform. tener, fimpl. Fol. lance l, reliquis latiora, breviora. Spicul 4-5. alterna, remotæ, rachi adprefla.

39. elatius, P. fpica compofita, fpicul. oblong. fparfis, adpreffis: flofcul, confertis; calycibufque mucronato-ariftat. Syft. veg. ed, 14. Lin. fuppl.

In Malabaria $\odot$.

Simile priori. Culm. 6-ped. erectus, rigens . Fol. long1, graminea. Spicd incurva, compofira fpicis pl. 12. \& ultra, renutis, alternis, raro oppofitis, in omril hatere racheos.

\section{* Paniculuta.}

20. dickoto- P. panicul. fimplicibus: culmo ramolo, dichomum . tomo. Syft. veg. ed. 14.

\section{In Virginia.}

Statura refert arbufculam inferne fanplicem, fuperne fafciculatam. Culm. vix pedal, Fol, linear. plana, glabra. Panicula minima.

2I. remofum. P. panicula ramis fimplicibus; fl. fubternis; inferiore fubfeffili : culmo ramofo. Syft, yeg. ed. I4. In Indiis .

Culmi pedal. erecti, laves, articulis bafi craffufcul. geniculat. Fol. vaginis lævibus ftriatis, margine, fauceq. ciliata. Panicula ramis triquetris .

22. colora- P. panicula patente; ftaminib. piftillifq. coloratum . tis: culmo ramofo. Syft. veg. ed. I4.

Cairi 24.

Culm. 2-perlal, valde ramofi, laves, vaginis fol. pilofis, demum fcabris. Panicula laxiufcula, ramis filiformibus. Anth. croceæ \& piftil. fature violac, quibus a P. capillari, retiquifque mox diftinguitur. Fol, brevia, linear, laxa.

23. repens, P. panicula virgata; fol. divaricatis. Sy ft. veg. ed. I4 In Hifpania? 4 . 
Simil.priori. Culmi repentes, adfcendent. pedal. Fol. inferne latiora, vaginantia, patentili. mucronata, vaginis fubpubefcentibus: fuper. fol. longiora, anguftiora, erecta. Panicula coaftans 6-8. racemis erectis, quibus fl, alterni, remotiufc. ovati .

4. miliuceum . P. panicula laxa, flaccida: fol, vayinis hirtis: glumis mucronatis, nervofis. Syft. veg. ed. I4. 6. P. fem. nigro. Morif. hif.. 3. f.8. tab. 5. t. 2. In India.

Culm. radicans, ramofus. Fol. graminea, vaginis pubefcentibus. Panicula nutans. Sem. luteum, album, vel nigrum .

25. capillare. P. panicula capillari, erecta, patente; fol. vaginis hirfutis. Syjt. veg. ed. 14. Sloan. Jam。 hift. 1. tab. 72. f. 3 .

In Virginia, Jamaica $\odot$.

Simil. Pore capillari, fed totum hirfutum. Culm. 3-ped. geniculis barbatis, fed barba furfum verfa. Pili in ipfis foliis, etiam e punctis elevatis proficifcuntur. Parjicula plufquam pedal.

26. groffa- P. panicula ramis fimplicibus: fl. geminis; perium . dicello altero breviff. altero longitudine floris. Syft. veg. ed. I4. Burm, Ind, tab. II. f. I.

In Jamaica.

Culm. 2-pedal. compreffus, quandoque ramofus. Fol. lato-lanceol. Graminibus europais latiora. Racemi erecti, alterni.

27. latifo- P. panicula racemis lateralibus fimplicibus: fol. lium. ovat-lanceol. collo pilofis. Syft. veg. ed. r4.

Gramen \&c. Morif. hift. 3. f. 8. tab. 5. f. 4. Sloan. Jam. hift. 1. tab. 71. f. 3.

In America.

Fol. latitudine Commelina, ad fauces amplexicaulia, bafi pilofa. Panic. valde mediocris. Fl. maiufc mutici.

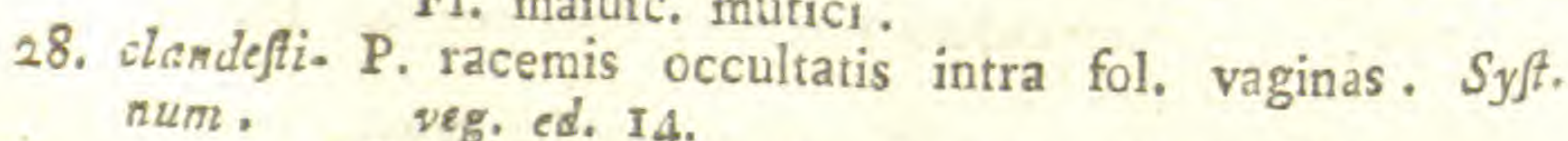
veg. ed. I4.

Gramen \&c. Sloan. Jam. hif.. I. tab. Bo.

In Jamaica, Penfylyania 24.

Culmi dichotomi, ramofi. Fol. ovat-lanc. vaginis punctatis pilofis. Adfine priori.

29. nrbore- P. paniculatum, ramofiff. fol. ovat-obl. acuraifoens, nat. Syfl. veg. ed. I4.

In India 4. 
Altitudine certas cum altiffmis arborib. Culm. vix pensa anferina latior. Panicula laxa, fparfa. Sem. alba.

30. curvatum. P. panicula racemofa, glumis curvatis, obtufis, nervofis. Syfl, veg. ed. I4.

In India Orient.

Culm. filiform. laves. Fol. lanceol. lrevia, fubtus 5-nervia, margine fcabra, vaginis profunde ftriatis. Panic, erecta, angufta. Calyc. frutefcent. triplo ma: purpurafc. Cor. calyce dimidio brevior, membranac.

31. virgatum, 1. panicula virgata; glumis acuminat. lævibus, extima dehifcente. Syft. ${ }^{2}$ eg. ed. I4.

In Virginia.

Gramen altiffim, panicula maxima, difufa, Fol. Arundinacea . Spicul. capillacer, virides. Glumæ ftramineo-fufcæ, acutæ, fed muticæ .

32. patens. P. panicula oblong. flexuofe, capillari, patente; calycibus 2 fl. fol. lineari-ianc. culmo radicante. Syft. veg. ed. I4. Burm. Ind. tab. 10. f. 3 . Hippoyrultis \&c, Rumph. amb. 6. tab. 5. f. 3 .

In India, Lufitania.

Culm. geniculati, glabri. Spica complanata, virides; vetuftiores fufco-purpur.

33. brevifo- P. paniculatum, ful, vaginis longitudinaliter cilium. liatis. Syft. veg. ed. 14. Sloan. Jam, I. tab. 72. f. 3. Pluk. alm. tab. 189. f. 4 .

In India.

Fruäificatio fimil. P. patenti. Var. fol. angufits, \& lanceol. Culmi 1-2-pedal. repentes, inferne fape ramofi. Fol. amplexicaul. ovat acumin. lata, levia. Panicula tenuiff. e peduncul, $\mathrm{ca}-$ pillaribus conflatd.

34. divariea- $P$. paniculis brevibus, muticis: culmo ramofiff. tum . divaticatiff. pedicel. 2 -fl, altero breviore. Syft. veg. ed. I4.

In Jamaica.

Culm, altus, filiform. rigidus. Fol. lineari-lanc. Panicula fubfimpl. depauperata.

Oryzuides. P. fpica compofita nutante: fpicul. fecundis, ariftatis, rachi 3-gona. Arduin. Spec.2. tab. 5. Non eft var. P. crus galli. Radix annua. Culm. fefqui-2. pedal. geniculati, ferruginei, inferne vaginis fol, fpitham, veftiti, Fol, glabra, mar- 
gine afpero, læviffime friata, dilute virid 8 Spica 3-unc. fubpurpur. fpiculæ fubfeffil. uncial, ariftatæ. Sem. cinereum, lacidum .

fulcatum. P. latifolium, fol. lyratis. Aubl. Guian. Plum. MSS. tab. 105.

In Guiank.

maculatum. P. fcandens; caule arundinaceo. Aubl. Guian. Plum. MSS, tab. 82.

In Cuiana.

comprefum . P. fpicis digitatis, fecundis, compreffis; fpicul. folitar. bifariam imbricatis. Forsk. $\mathbb{E}$.

In Arabia.

Culm. diffuf, vix pedal, ramofus, compreffus . Fol. vaginæ compreffæ, glabræ. Fol. linearlanceol. plana, margine ciliato-fcubro, bati pilofa. Spicæ terna, fefquipollic. Spicula lanceol, valde compreffæ .

geminatum. P. fpicis linearibus, alternis adpreffis: fpicul. bifariam imbricatis, muticis. Forsk. AEg.

In Arabia.

Culm. pedal, teres. Spicæ, \& fpicul. feffil: quæ alternæ, remotz. Fol. plana, nuda, ftriatd, barbata ad bafin.

turyidum.

P. Forsk. $\bar{E}$ g.

In Arabia.

Frutex facie Junci. Fol. fefquipollic. plana, involuta: vagina longæ, ad dichotomias ventricofæe, membranz a!bæ. Spicul. obefæ.

tetraftichon. P. Ppicis alternis, fecundis, 4-fariam imbricatis; flofcul. fecundis, hinc planis, inde gibbofis, villofis, muticis. Forsk. IEg $_{\mathbf{g}}$

In Arabia.

Culm, pedal. compreffus, ramofus, friatus. Fol. plana, glabra. Spicæ feffil. dum florent patentes; cæterum alpreffæ, lineares.

adpreffum. P. caul. ramofo; antheris purpurafc. Forsk. 压.

In Arabia.

Culm. longe repens in arenæ fuperficie.

muticum.

$\mathbf{P}$. fpicis alternis, fecundis; fpic ul. remotis, geminatis, muticis, altera pedicellata: rachi 3gona, flexuofa. Forsk, Ag.

In Arabia.

Simil. P. coloni.

udharens, P. Forsk. $A_{g}$.

In Arsbia , 
Involuc. fetacea, retrorfum aculeata. Fl, aculei arcte veftibus adhærent.

Caffrorum, P. panicula verticillatim ramofa: cor, nullis: nectariis villofo-laceris, Retz. Obf. falc, 2.

Facies Holci. Cal. Panici inverfus. Radix annua, fibrofa. Culm. erect. 3-4-ped. farctus, tectus vaginis fol. geniculis tumidis . Folia fefquipedal, patentia, tefqui-pollic. lata, fubfecunda, glabra, margine fcabra. Vaginæ non raro farina alba confperfæ. Panicula ramis patentibus, multifl. Cal. ex albido-hyalinus, cartilagin. hirfutus, rigidus, triglumis.

Asptiackmi. P. Retz. Obf. fafc. 3.

In IEgyto 0 .

Simile $P$. filiformi, at diffinäum a $\mathrm{Cl}$. Jufferu.

Culm. 1-2-ped. vaginis longe, \& denfe pilofis . Ful. 5-7. longa, linearia, utrimq. pilofa. Spicæ fubdigitatæ, longæ, lineares, 4-5. Rachis plana, membranacea, flexuofa: huic ab uno latere alterni adfident flofculi bini, pedicellat. altero pedicello triplo longiore. Flor. lanceol. ftriati, valvula accefforia minuta.

fluitans. P. fpicis alternis, fefflibus, fecundis. Retz. Obs. fafc. 3. Pluk, phyt. $九 a b .417$, f. 7 .

Gramen pulcherrimum, læve, glabrum . Culm. compreffis, foliofus. Fol. linearia. Rachis extus plana, intus, vel. a latere fpicularum carinata, marginata. Spicul. erectiufc. decrefcentes. Fi. alterni, feffil. imbricati, fecundi . Cal. ovat-acutus, valvula accefforia parva, rotundata.

Nifi in P. brizoile monuiffet Lin. Spicas interstitiorum longitudinem habere, \& flofc. triplici ordine feffles effe, effet illud ipfum.

indicum. P. fpica fimpl. nuda; pedicell. geminis: culmo adfcendente, bafi ramofo. Retz. Obf. fafc. 3 . $P$. indicum. Lin. mant. non canglonteratum mant. in noftro nec fpica fecunda, nec flofe. $o b t u f i$.

Gramen femiped. filiform. Spica vix femipoll. involucellis nullis. Valvul, cal. inter or. fubæqual. cymbiform. acuı , levirer hifpidæ ; 2ccefforia obrufa, minuta.

srigonum. P. panicula erecta; pedunc. 2 -fl. calycibus obtufis, hifpidis, I-fl: feminibus, trigonis. Retz. $\mathrm{Obf}, \mathrm{fa} / \mathrm{c}, 3$. 
P. patens (non Linn.) Burm. Ind. tab. 10. f. 2

Culmi proftrati, radicantes, fpitham. foliofi. Fol. angufta, glabra. Panicula parva, ftricta, pedunculis rarius parum flexuofis. Glume calycinæ inæquales.

flexuofum. P. panicula capillari, patente ; peduncul. flexuofis; calicibus ovatis, geniculorum barba refleXa. Retr. Obf. fnfo. 3 .

Cum P. capillari confun fitur. Gramen fubped. Culm. decumbent. ramori, leviter pilofi. Fol. 2-pollic. angufta, pilof, fieuri vaginæ, fed nulla puncta callofa. Panic, vix 3-pollic. ovata. Var. glabra.

fetizerum, P. fpi is remotis: flofculis fecundis; racheos dentibus fetigeris. Retz. Obf. fafc. 4 .

P. repens Burm, Ind. tab. II, f. I。

In China.

Culmi filiform. ramofi, foliofi. Fol. 2-pollic. fubcordata, marginibus vaginarum ciliatis. Spicæ infer. remoræ; fuperior. fæpe verticillatæ, breves. Fl.geminati. Cal. ovatus, acutus, valvula accefforia brevi, lata .

flavidum. P. culmo foliofo: fpiculis remotis, fefflibus, appreffis, fecundis, paucifl. Retz. Obf. fafc. 4 . In Zeylona.

Culm. 2-pollic-femiped. pl. erecti. Rachis elongata. Spicul. 3-7 breves. Fl, globofi, alterni, fecundi, flavi. Cal. gluma omnes apice violac.

fquarrofum. P. fpicis geminis, horizontalibus: involucr. fl, fquarrofis: culm. decumbentibus. Ret\%. Obfo fafc. 4 .

In arenofis Malabaria.

Structura adeo fingulari, ut proprium videatur conffituere genus. Culm. radicaties, ramofi, foliofi. Fol. conferta, brevia, cum vaginis tomentofa. Pedunc. erectus, elongatus, nudus. Spica divergentes, fecundæ, fquarrofa. Ad articulos $\mathrm{fl}$. fafciculati, bracteis difformibus. Fl, terminales fteriles. Facies nonnihil Cenchri.

zmbrofum, P. fpicis fubquaternis, remotis ; flofcul. geminis, inæqualiter pedicellatis: culmo repente, flascido. Retz. Obf. fafc. 4 .

In unbrojis India Orient, 
Caul. pedal. filiform. radicantes, foliof. Fol. brevia, lineari-lanceol. nuda. Flofculi fecundi, fubbinati, ovati, acuti. Cal, viridi-ftriatus, hinc convexus, inde planus, valvul. accefioria brevi, albida. Sem, album, a latere planiori marginatum.

ciliare.

P. fpicis fubdigitatis, adproximatis, erectis, linearibus: rathi flexucla: dentibus 2-fl. calycibus ciliatis. Retz. Obf. fafc. 4 .

In China.

Simillim. P. filiformi, ut facile confundantur. Gramen fefquiped. bafi ramofum. Gramen koc= Panic. Egyptium Fafc. 3. $=$ P. fliforme $=$ P. Sanguinale videntur tot varict.

ifohxomoides, P. panicula erecta, contracta; calycibus 2-fl. polygamis, acutis: culmo fimplici: fol. diftichis, rigidis. Retz. Obf. fafc. 4.

In Malabaria udis ad margines ftagnorum.

Proceritate reliqun Panica excedit. Gramen totum exalbiaum. Culm. erecti, foliofi. Fol, patemria, vaginis tomentofis. Fl. plerumque binati, altero pedicellato. Sem. ovatum, planiufcul.

antidotale, P. panicula nutante; calycibus bifloris, polygamis, acutis: culmo erecto, ramofiff. Retz. Obf, fafe. 4 .

In hortis Malabarorum 24.

Rad. Atolonifera. Culm. 8-ped. \& ultra. Fol. margine, \& nervis maioribus afpera, vaginis barbatis. Panicul. pedal. ramofiff. Flofculi copiofi, virides.

Nigri hoc utuntur pracipue ad ulcern Nafi; etiam ut difcutiens in aliis calibus vel tritum, vel in cataplafinate.

remotum, P. paniculæ ramis triquetris: flofcul, fubgeminatis; altero pedicellato: culmo ramofo, tetragono-comprefío, Retz. Obf. fafc. 4 .

In Tranquebaria.

Culmi 2-ped. \& ultra. Fol, linear. 4-6-pollic. nuda. Paniculæ rami fuboctoni, capillar. remoti, folitar. Flofcul, remori . Cal, albidus . Sem. ovatum, planiufcul, album .

arifatum. P. culmo repente, radicante: panicula ramis indivifis: flofcul. plerumq. binis, feffilibus, ąri* ftatis. Retz, Obf. fufc, 4.

In Chine, 
Culm. ramofus. Fol. brevia, lanceol, nuda, vaginis ciliaris. Panicula ftricta. Involucra fetdcea, alba, numero variantia.

muricatum, P. panicula patente: fl. folitar. muricatis: culmo radicante, adfcendente. Retz. Obf. fafc. 4.

Habitat . . .

Culm, fefquiped. filiformis. Fol. brevia, perfecte lanceol. pilis albis, fparfis. Panicula ranis brevibus. Fl. parvi, obliqui. Cor. obliqua, glaberrima .

notatum. P. panicula patente: axillis notatis: fol. lanceol. ciliatis. Retz. Obf. fafc. 4 .

In Sumatra .

Culm, altus, tenıis, geniculis nigris. Fol. 5 pollic. longa, \& $\frac{3}{4}$ lata, levitime pilora, margine ciliata; vaginis ore barbatis. Panicula fere pedal. in axillis nigro-notasa. Cal. glumæ 2 interior. purpuralçent; accefforia albida.

radicans, P. paniculatum: culm. ramofo, radicante: folior. baft, vaginifq. longitudinaliter ciliatis . Retz. Obf. fafc, 4 .

Ad Canton lectum.

Simil. $P$. trigono Fafc. 3. Vix fub var. angufifolia $P$. brevifolii intellexit Lin.

Gramen pedal. tenue, glabrum. Culm. ufq. ad paniculam foliosus. Fol. lineari-lanceol. fefquipollic, Panicul. 2-pollic. erecta, tenuis. Fl. parvi, pedunculat. obliqui, purpur. nudi.

94. PHLEUM, Calyc, glumæ cufpidatæ, \& intus truncatæ . Cor, inclufa.

T. pratenfe. P, fpica cylindrica, longiff. ciliata: culvo eresto. Syft. yeg. ed. 14. Sitreb. gram, tab. I4. Leerf. herborn, tab. 3. f. I.

Gramen \&c, Morif. hijt. 3. f. 8. tab. 4. f. I. In Europa verfuris, \& pratis 24.

Culm. 1-2-pedal, 4-7 nodis. Radix bulbofx fimilis. Spica dencife. mollis, virefcens; matura albicans. Spiculæ compreffie. P.pratense, nodofum, \& alpinum funt valde fimil.

2. alpinum, P. fpica ovato-cylindracea. Syft. veg. ed. I4. Fl. Dan, tab. 213. Scheuchx. gram, tab. 3.

In alpibus Lapponicis, Helveticis \&c. 24.

Differt a congeneribus fpica nigricante. Culm. pedal. Fol. glabra. Spica I-2-unc, iunior bre- 
viffma; adulta longior. Glumæ villofe, ariftatæ.

3. nodofum, P. fpica cylindrica : culmo adfcendente: fol, obliquis: rad. bulbofa. Syft. veg. ed. 14. Fl. Dan. tab. 380. Leerf. herborn, tab. 3. f 2 .

Grainen \&c. Barr. ic. 53. Morif. hift. 3. 5. 8. tab. 4. f. 3. Petiv. gram. tab. 3. f. I.

In Europa, in pafcuis, \& ad vias in montanis 4. Simil. P. pratenfi, fed radix bulbofa. Culm. non rectus, fed adfcendens. Fol. bifaria, obliqua, lævia, exceptis marginib. fcabris. Spica ylabra, modo brevis, modo longior; antheræe albae.

In folo pingui plantatum fubfequenti anno in $P$. pratenfe tranfiut. Leerf.

4. arenarium, P. fpica ovatd, ciliata: culmo ramofo. Syft. yeg. ed. I4, Pluk. alm. tab. 33. f. 8.

In Europa lacis arenofis $\odot$.

Culm. digital. Spica uncial. turgida, vix e vagina fol. exiens.

5. Schoenoi- P. fpicis ovatis, obvolutis; fol. breviff. ampledes. xicaulibus, mucronatis. Syft. veg. ed. 14.

In Italia, Hifpania, Smyrna $\odot$.

Habitus Schoeni aculeait.

alopectroides, P. Piller. It. Sclavon. tab. I6.

In Sclavonia.

Rad. fibrofa . Culm. pl. conferti, adfcendentes, pedal. Fol, brevia, acumin. tenuia. Spic. cylindricæ, tenues, ccerulefcent. Calyc. glumæ acut. muticæ, fubvillofæe. Cor, 2-valv. Anth. fordide albæ.

Gramen habitu Alopecurum refert, totumque e viridi-purpurafe.

piride.

P. fpica cylindrica, lævi: culmo erecto. All. Fl. Ped.

Ad fepes agrorum locis fterilibus $\odot$.

Differt a P. pratenfe fpica viridi, dimidio breviore, lavi, conftanter non ciliata. A P. nodufo rad. non bulbofa, fol. non obliquis.

Gerardi. P. fpica fubrotunda; glumis ciliatis : caule fimplici : folior. vaginis ventricofis. Ger. Galleprov. All. Fl. Ped.

P. capitatum. Scop. Fl, Carn.

In fummis alpium pretis 24. 
Michelii.

P. fpicis paniculatis, hirfutis; calycibus laneeolat. Hall. helv. n. 1532. All. Fl. Ped,

Gramen \&c. Barr. ic. 2I. f. 2.

In pafcuis montanis, \& locis ficcis 4 .

Spica longa, cylindrica, flavefcens, locuftis pilofis.

genieulatum. P. culmo geniculato; fpica fubovata; glumis ciliatis. Bellardi in liter.

In Pedemontio 4.

Culm. palmar. 3-4-nodis .

capitatum, P. Scop. Fl. Carn.

In montibus.

Cefpitofa planta. Culm. digito vix longior, nudus. Spica fubrotunda, 3 . lineas vix longa.

eutumnale. P. Scop. Fl. Carn.

In Carniola.

Stmil. P, caruleo Scheuchz. fed differt cal. 3-fl. \& folliculorum fabriva diver $\int a$.

95. ALOPECURUS. Gluma corollæ, five folliculi I-valvis . I. indicus, A. fpica tereti; involucel. fetaceis, fafciculatis, 2-fl. peduncul, villofis. $S_{y f t}$. veg. ed. 14 .

Gramen \&c. Pluk, alm. tab. 92. f. S.

In India Orient.

Statura Panici Italici, totus villofur, Fol. latitudine digiti, utrimq. pilora, etiam vaginis. Spica magnitudine digiti, compreffa. Sen. nigro-fulendentia.

2, bulbofiss, A. culmo erecto: fpica cylindrica: rad. bulbofa. Sygt. veg. ed. I 4 .

Gramen \&c. Raii Angl, tab. 20. f. 2. Barr. ic. 699. f. I. \& 680. f. I. 2.

In Gallia, \& Anglia \&c. pratis 24.

Bulbi 3-4. Culm. fefquiped. Fol. anguft, plana. Variat magnitudine culmi, E craffite fpica.

3. pratenfis. A. culmo fpicato, erecto: glumis villofis: cor. muticis. Syft. veg. est. 14. Schreh, gram, tab. 19. f. I. Stillingft. miifc, tab, 2. Leerf. herb. tab. 2. f. 4 .

Gramen \&c. Barr. ic. 123. Morif. hift. 3. f. 8. tab. 4. F. 8.

In Europe pratis 24.

Simil. Sequenti, fed differt fpica breviore; \& arifite cor. valyulis fubaquali. Culm. cubital, totus cum fol. hirfutus, \& mollis. Fol. lata, glauca. Panic, in tenfam ovalem fpicam collecta. 
lecta. Pedunc, breves, ramofi. Cal. glabri. Locuftæ comprefiła, villofæ, ex viridi-albæ; ariftæ recurva.

4. ¿greftis. A. culmo erecto, fpicato: glumis lavibus. Syfr. veg. ed. I4. Fl. Dan. tab. 697. Leerf. herb. tab. 2. f. 5. Schreb. gram. tab. 19. f. 2.

Grainen \&c. Morif. hift. 3. f. 8. tab. 4. f. 12. Barr. ic. 699. f. 2.

Phleum flavum. Scop. Fl. Carn.

In Europa auftrali, ad limites agrorum (๑) .

Differt a priore fpica longiore, tenuiore, fpicul. laxioribus, glabris; fol. anguftioribus, \& radice annua. Culm. erect. cubital. Fol. glabra, retroverfu afpera. Spica 3-unc. laxa, viridis, atro-purpurea, aut incana .

5. geniculatus. A. culmo fpicato, infracto: cor, muticis. Syft. veg. ed. 14. Fl. Dan, tab. 564. Leers, herb. tab. 2. f. 7 .

Gramen \&c. Lob. ic. 13. Morif. hift. 3. tab. 4. f. 15 .

In lacubus natans efl.

In Europa uliginofis, fecus flumina, \& folfas. 4. Structura prioris: an varietas? Culm. I ftfquiped. inferne procumb. geniculatus. Fol. glabra. Spica I-2-unc. cylindrica, denfa, gracilis, glabra. Pedunc. ramofi.

6. hordeifor- A. racemo fimpl. flofcul. ariftis circumvallatis . mis. Syft. veg. ed. I4. Thumb. Jap. tab. 9.

Panicum \&c. Pluk, alm. tab. IIg. f. I.

Spectat al Panici genus. Thumb. Jap.

Habitus omnino Hordei murini. Culm. pedal. Fol, linear. culmo fapius longiora, plano-canalicul. nervofa. Spica longa, fpitham. racemofa, difticha, vel fubfecunda. Fl, numerofi, pedicellis breviff. fimplicibus.

7. monfielien-A. panicula fubfpicata; calyc. fcabris, cor. arifis. ftatis. Syft. veg. ed, 14.

Phleum crinitum. Schreb. gram, sab. 20, f. 3. cum $A$. paniceo coniungit.

Gramen \&c. Barr. ic. II5. f. 2. Morif. hift. 3. f. 8. $t a b .4$. f. 3 .

In locis humentibus $\odot$.

Simil. fequenti, fed triplo ma. Culm. I-2-cubital. geniculat, rigidus, ficuti \& fol. Panic. 5unc. habitior, fpicata, caudata, fericea. SpiTom. $I$. 
cul: arctæ, Sub cal, eft tuberculum. Cor, bre* viffima .

8. paniceus, A. panicula fubfpicata : glumis villofis: cor, ariftat, Syft. veg. ed. 14. Fl. Din. tub. 8uI,

Gramen \&. Barr. ic. iIs. f. I.

In cultis aridis, \& pofouls d ciivibus $\odot$.

Sinil. priuri, fed palmar, mullss.

typhoides, A. r cemo fimpl. flofcul, muticis. Burm. Ind. Gromen \&c. Pluk. alm. tal. 32, f. 4.

In Indis utrifque.

siliatus, A. culmo fpicato, ereeto; glumis ciliatis. Ger. Gullw-piov. Fi. Ped.

In pratis elatioribus $\odot$.

litoreus, A. Fl. F.d.

An Gramen typhinum \&c. Barr. ic. 717 .

Ad litora morls $\odot$.

96. MILIUM. Cal. 2-valv. I.fl, vaivul. fubaqualibus. Cor, breviff. Stigmata penicilliform.

I. capenfe, M. panicula capillari : calycibus acuminatis : cor, anfta terminali curva. Syft. veg. ed. I4. Ad cup. b. Spei.

Culmi palin, teneriores, laves. Fol, angufta, fubrus fparfe pilora, fauce barbata. Panic. undique difperfa.

2. punäatum, M. paniculæ ramis fimpliciff. fl. alternis, geminis, fecundis. Syft. veg. ed. I4.

In Jamaica.

Panicul. rami erecti, fubvillofi, Pedicel. breviff. bafi anulo fulco cincti, altero breviff. Cal. pubefc. Sem. glaberrima.

3. lendigerum, $M$, panicula fubfpicata: $f$, ariftatis, Syft. veg.ed. 14 Schreb. gram. tab. 23. f. 3.

Agroflis \&c. Guuan, hort. tab. I.

Gramen \&c. Morif.3.1.8.tab.3.f, I2. Pluk, alm, tab. 33. f. 6 .

Monfpelii $\xi_{c}$. $\odot$.

Radix hbrofa. Culm. aciculæ ma: craffitiem adæquans, pedal. \& ultra, erectus. Fol. angufta, fubulata. Articuli vix puilic. a fe invicem diftantes, excepto fupremo. Panicul. coarct to, virefcens, vel argentea, vel matura rufefcens, fefquipollic. longa: ca'y inferne ventricofi; vilvula una brevis, alters longior, acuininat. Sem, minimum villofum, in infima porte cal. latens. 
4. eimieinum. M. racemis digitatis; calycum valyula exter. ciliata. Syft, veg. ed. I4.

In Malabaria .

Culm. pedal, erecti, feu adfcendent, læves. Fol. lanceol. ciliata, lævia, vaginis adfperfis raris pilis, culmum inferne includentibus. Pedunc. longus, racemis quaternis, fimplicibus, laxis, fecundis. Fl. alterni.

Flos totus decidit cum femine, quod mediantibus ciliis refert veluti cimicem,

5. effufkm. M. fl. paniculatis, difperfis, muticis. Syft. veg. ed. 14. Leers, herb, tab. 8. f. 7.

Gramen \&c. Morif. hijt. 3. f. 8. tab. 5. f. 10. bene.

In Europa nemoribus umbrefis 24.

Odor foliorum Meliffæ. Culm. 3-pedal. Fol. margine denticulata. Panicula ramofo-diffufa, laxa. Rami verticill. flexuofi, longe nudi. Sem, longiufc, e viridi-albicant, lu ida.

6. confertum. M. fl. paniculatis, confertis. Syjt. veg. ed. I4. In Helvetia fylvis 4.

Prioris varieras.

7. paradoxum. M. fl. paniculat, ariftatis. Syft. veg.ed. r4. Sihreb, gram, tab. 23. f. 2. Scop. Fl. Cirn. tab. 1.

Gramen \&c. Pluk. alm. tab. 32. f. 2.

In Gallia, Carniola, \& agro Nicaenfi, ad rupes mari pruximas $\delta$.

Gramen fefquiped. Fol. femiped. lineas 4-5. lata, bafi rubella, Panic, fpitham. laxa, alba. Cal. laxus. Sem, nudum, ovatum, apice arifta caduca, nigrum, nitidum.

8. globofum. M. panicula diffufa; glumis muticis; pedicellis cingulo luteo, Syft. veg. ed, I4. Thumb. Jap.

In Japonia,

Culm. pedal. \& ultra, erect. fimplex. Fol, vix digital. vaginis, fauce, \& marginibus ciliatis, lanceol. patula, marginata, ftriata, glabra. Panic. fubovata.

97. AGROS-Glumæ calycis, \& folliculi acuminatæ, aut etian TIS. ariftatæ; fed glumæ folliculi calycinis glumis longiores. Flores diftantes.

\section{* Ariftata.}

1. Spice venti A petalo exteriore arifta recta, ftricta, longiff: panicula patula. Syft. veg. ed, $14 . F l$. Dan. 853. Leerf. herb. tab. 4, fo x. M ij 
Gramen \&c. Sheucha. gram. tab. 3. f. ro. Monti gram. tab. 63.

In Eurupa inter fegeres $\odot$.

Culm. cubital. genicul. arro-purpur. Panic. magna , pedal. deflorata patentiff. virefiens, aut rubens.

2. interrupte. A. petalo exter. ariftato, panicula dttenuata, coarctitd, interrupta. Syft. yeg. ed. I4.

Gramen \&a. Vaill, tab. 71. f. 4.

In Eurnpa $\odot$.

Var. Agroftid. Spicce venti. Hall. Culm. 3. pedal. Fol. lata, retroverfa afpera. Panic. maxims, etia!n pedal. multiflora, fre nutans; iunior viridis, matura violac. Cal. fplendens.

3. miliacea. A pet lo exteriore arifta terminali, recta, ftriata, mediocri. Syft. veg. ed. I4.

In Hifpaniu, Monfpelii Ec. 24.

Simil. A. Spica venti, jed arifta flofcul. longitudine tantum aqualis. Culm. pl. 3-ped. Fol. I-fefquiped. 3. lineas lata , Panic. minus ampla, ramis femiverticillaris.

Cultura etiam diverfiffima perfiftit.

4. bromotdes. A. ponicula fimpl. angufara; cor. pubefcente; arifta recta calyce longiore. Syjt. veg. ed. 14. Gouan. Iliuftr. 3. tab, 1. f. 3 .

Monfpelii. 24.

Culm. fefquiped. erecti, rigidi, læves. Fol. anguftiff. fubfiliform. canalicul. lavia. Cor. femen veftiens.

5. ouftralis. A. panicula fubfpicata : feminibus ovat. pubefientibus, arifta longitudine calyc. Syft. veg. ed. 14.

In Lufitania.

Culm. 3-ped. articulati, foliofi, laves. Simil. fequenti, fed panicula magis fpicata; fem non b.fi hirfuta, fed undique pubefcent. Cal. apice fere fetacei. Fol. latiora, planiora. Culm. pl. geniculari.

b.aruindineees. A. panicula oblonga; petalo exter. bafi villofo; ariftaq. torra cal. longiore. Syft. veg. ed. I4. Arundo agroftis. Scop. Fl. Carn. All. Fl. Ped. In Europx montihus falv fis \& 4 . 4.

Culm. 4-ped. Fol. Arundinac. lata, dura . Panic. plerumque f icæarm. contracta, quanduq. laxa, ultra femipedem longa, flavicans. 
Perinez ad Arundinis genus. Scopoli.

7. calamagrof-A. pani ula incraffit; petalo ex er. toco lanato, Jis. apice ariftato: culm. ramofo. Syft. vig.ed. 14. Scheuz. grum. tab. 3 f. If optimz.

In ripibus Helvetia, Verone, \& in Germania 24. Simil. priori, fed cor, tota yalde hurfuld: arifta recta non e $b_{a} \sqrt{i}$, fed apice petali.

Culm. 2-pedal. ramofi. Panicula femiped. denfa, e viridi argentea, fplendens.

8. Serotina. A. panicula flofulis oblong: mucronat. culm. obtecto fol. breviffim. S.jt. veg. ed. 14.

Gramen \&c. Segu. ver. 3. tab. 3. f. 2.

In Verona, Pedemontii pafcais, \& collibus 4.

Culm. ped. adfiendent. Ful. vix articulis longiora, patentia. Paniculæ rami alterni, fubramofi. Fl. pleriq. feffil. Gluma peraloidea lanceol. arundinacea. Piftil. purpur.

9. rubra. A. paniculæ parte florente parentiff. petalo exter. glabro; arifta terminali torrili, recurva. Syft. veg. ed. 14.

In Anglin, Svecia, Pedemontio. 24.

Culm. pl. 6-7. dodrant. raro pedal. Fol. brevia, latiufcula, pdllide virentia, tactu afpera. $\mathrm{Pa}$ nic. 3-4 unc. verticil. nondum florentibus contractis quafi in fpicam: deflorata tora rubefcit.

80. fpiciformis, A. panic. fpiciformi ; flofculis 2 -ariftat: arifta altera receptaculo inferta, geniculata, longiori ; altera infra apicem cor. recta; cor. hirtis. Syft. veg. ed. 14, Lin. Suppl.

In Teneriff, .

Gramen dodrant, erect, glaberrim. culmis fimplicibus. Panicul. coarctata. Calyc. magni, ova$\mathrm{ti}$, compreffi, glaberrimi, margine membranac。 Gluma exterior. ma. Nectarium intra cor. bre. ve, geniralia amplectens.

11, hirfute. A. panicula fubfpicata: caul. foliifq, hirfutis : corollinis glumis dorfo ariltatis, apice 2-fidis. Syff. veg. ed. 14. Lin. Suppl.

In Teneriffa.

Hirfutie fua facile diftinguitur . Panicula refers Alopecurum paniceum.

12. Matrelle. A.fl. racemofis; cal. valvula exteriore incurva, curins aplice tantum dehifcente. Syft. yeg. ad. 14.

In Mulabaris ersnofis, 


\section{TRIANDRIA DIGYRIA:}

Radix repens, fquamufa . Culmi ramofi, inferne decumbent.; dein erecti, palmar. vagiois genicula obtegentibus. Fol. diftantia, fubulata, bifaria, involuta, patentia, vaginis intra proximas receptis. Racemus fimpliciff. fere fpicatus, erectus, flexuofus. Fl. fape 10 fubleffil: erecti, glaberrimi.

33. anina, A. calycibus elongatis, petalorum ariftd dorfali recurva; culm. proftratis, fubramolis. Syjt. $v e g$. ed. 14. Leerf. herb. tab. 4. f. 2. Fl. Dan, tab. I6r.

Gramen \&c. Scheuchz. gram, tab. 3. f. 9.

In Europe pafcuis humidiufculis 24.

Culm. fiqui-2-ped. Foliorum cefpes anguftiflim. \& veluti capillaceorum, e viridi-glaucorum. Panic. frepius elongata, ramulis coardatd, pure purafc. Arifta fetacea, alba, flofculo duplo longiore, recta, medio notata, geniculo fufco.

84. cruciata. A. fpicis quaternis, cruciatis, bafi glabris: valvul. petaloideis, ariftatis. Syft. veg. ed. 14.

Gramen \&c. Sloan. Jam. 1. tab. 69. f. I. In Jamuica.

15. radiata. A. fpicis fabquinis cruciatis, bafi villofis; valvul. petaloideis, ariftatis. Syft. veg. ed. I4.

Gramen \&c, Sloan, Jam. I. $t a b .68$. f. 3.

Simil, priori, fed triplo maior.

** Mutica.

16. ftolonifera. A. panicula ramis patentibus, muticis; culmo repente ; calycibus æqualibus. $S_{y y}$. veg.ed.I4. Fl. Dan. $t i b$. 564 .

In Europa, ad vies locis fterilibus \& fabulofis 24. Culm. cubital primum. proftrati, dein erecti. Fol. glabra. Panic, iunior contracta, dein $e x-$ panfa, plerumq. fpadicea, quandoq. fpadiceoviricl. aut rubens.

17. ecpillaris, A panicula capillari, patente; calycibus fubulatis, æqualibus, hifpidiufc. coloratis; flofcul. muticis. Syft. veg. ed. 14 Stillin. fl. mifc, tab. 3. Fl. Dan. tub. I63. Leerf, herb. tab. 4 f. 3. Gramen \&c. Scheucht. gram, tab. 3. f. 5. B. Monti ic. 64.

In Europa pratis humidis montanis $\odot$.

Culmi 1-3-ped. Fol. linearia. Panicula vere capillaris, pedicellis tenuiffmis, mutica; iunior 


\section{IRIANDRIA DIGYNIA.}

contracta, matura expinfd, pedicellis ramofis? ut in priore, per intervalla verticillatis. Calyc. glunæ per æratem non hifpidæ, fpadiceæ, marginibus albis.

Conv nit cum A. albe. Planta color primuni yiridis, dein purpur. tandem pallens.

38. fylvatics. A panicula coaratata, mutica, calytibus, æqualibus, virgintis cor. breviuribus, foecundaris dulo longioribus. Syft. veg. ed. 14.

In Anglia Sylvis humofis \&c.

Convenit cum A. ftulonifera, capillari, Panicu= la pittens Spadicea.

39. alba. A panicula laxı; calycibus muticis, æequalibus: culmo repence. Syji. yeg. ed, 14.

In Europe nemoribus montanis 4.

$V_{u r}$, prioris maior. Culn, $1-3,-$ ped, quandog, erecti , Panic. modo fpicata, modo divergens, e viridi-purpurafc. Cal. gluma virid. anth. violac.

20. pumila. A. panicula fecunda, mutica: culm. erectis, fafciculat. Syft, veg. ed, $\mathbf{1} 4$.

In Europa 4.

Radix multiplex. Culm. 2-pollic. laves, Fol. vagina fticata, difco fubinvoluta. Panic. per atatem patentiff. Fl, colorari. Sem. maidf.

Differt ab A. Atolonifera, cum qua promifoue crefoit, quod dimidio min., panicul. minus erecte, parumq. Secunda; magis cefpitofa: pedicel. minus undulati, horfum verfum tamen flexi.

21. minima. A. panicula filiformi. Syft. veg. ed. 14. Gramen \&c. Murif, hiff. 3. f. 8. $\operatorname{tnb}$. 2. f. Io. In Germaniz, Gullia, \& ngro Niczenfi $\odot$.

Planta vernalis vix pollic. purpurafe. Culmi in cefpitem filifor. difpofiti. Fol, c nalicul, Spica unilat:ra'. purpur, quandoq. viridis.

22. tenecifrma. A. panicula contractd, filifo m. fl. muticis, linearibus; valvul. paralell. Syjt. veg. ed. 140 Lin. Suppl.

In India Or. 24.

Radix cefpitofa, dura. Culm. pl. femipedal, angultiff. tenaciff. arriculati, glaberr. Fol, graminea. Fl. adpreffi. Cal, 2-valv, valvul, linearibus, diftantibus, longirudine fl. Cor. 2valv, linear. Germ, ovarum, cor. dicendum, fed valde claufums.

\section{$M$ iv}


23. virginies. A. panicula contracta, mutica: fol. involutom fubulat, rigidis exftantibus, $\Delta y / f$. yeg. ed. I4. In Virginia.

Agroficis Virgin. Fursk. Eg. \& A. pungens. Schreb. gram. tab. 28. f. I. qua, monente $\mathrm{Cl}$. Vahl, eft eadem planta, differt panic. ficicata, uzde fpecie differt.

24. mesicane. A. panicula oblong. congefta, calyc. corollifque acuminat. fubæqualib. muticis. Syft. veg. ed. 14. In Amer. calidiore $\delta$.

Habitus Cinna. Difficillime hoc Granen determinatur. Altero anno fluret.

Culm. pl. pedal, erecti, læves; ramis indivifis 。 Fol. leviufc. ligula truncata. Panic. viridis. Fl. fcabri. Stam. alba. Stigmata atro-purpur.

25. indica. A. panicula contracta, mutica; rdcemis lareralibus, erectis, atternis. Eyft. veg. ed. I4.

Gramen. Pluk, alm. tab. 191. f. 5. Sloan. Jam. I. $t a b .73$. f. 1 .

In India.

Culm. erect. Fol, angufta, plana . Panic, oblonga . 26. ciliata. A. panicula mutica; gluma calycina angulata, ciliata. Syft. veg. ed. 14. Thumb. Jap.

In Japonia.

Culm. erect. 2-ped. fimpl. glaber. Fol. culmo breviora, vaginis, fauce, margineque punctatis, ciliatifque; attenuata, ftriata, fcabra. Panic. pedal. congefta, pedunculis filiform. virgatis, angulatis, ciliatis .

vinealis ,

A. calycibus coloratis: petali arifta dorfali longitudine fere calyc. culm. adfcendertibus . Schreb. Fl. Lipf.

Avena monantha \&c. Hall, hift, 1481.

In locis ficcis.

Differt ab A.canina, fpicul, duplo ma. Occurrit etiam flofcul. plerifque muticis. Variat culmi altitudine; fol. latitudine; \& panicula forma. Accedit ad A. copillarem, cum qua non confundatur.

ereserie. A. panicula fpicata, æquali, mutica: fol. fafciculat, radice repente, Gouan. Illuft.

A. Stolonifere. Lin. $b$.

Radix ftolonifera, geniculis crebrioribus. Culm. pl. Fol, uncial, rigida: involuc, acuminat, vde 
ginis latioribus, rubefcentibus. Panic. obfcure viridis.

elpine. A. petalo uno truncato, aut 2-fid. Scop. Fl. Carn. Gramen \&c. Scheuchi. Prodr. tab. 4. f. I.

In pafcuis fummarum alpium $\odot$.

Differt ab A. canina, qua proftrata, crebro geniculata, \& fol. Setaceorum fafciculis inftructa.

Cefpitofa. Culm. vix ferniped. rigidi. Fol. linearia. Panicula contracta, uncial. \& paulo longior, glumis viridib. fpadiceis, aut violac.

ftridä. A. ( $\left.P_{\circ a}\right)$ caul. erecto; panicula ftricta, paucifl. Hall. helv. $n, 1476$.

In Helvetia.

Diverfa ab A.capillari, facie, \& culmo proftrato. Panic. parva, rara, albo-virid.

rupeftris. A. (Avene) monantha, paniculata: fol. fetaceis; gluma calycina exafperata; arifta fl. duplo longiore. Hall, helv. n. 1478. All. Fl. Ped.

In rupibus montanis, apricis $\odot$.

pungens. A. panicula coarctata, mutica; fol. involutis, rigidis, pungentibus : fuperioribus oblique appofitis. Schreb, gram, tab. 27.

A. Virginica , Forsk. $E_{\text {g. }}$.

In locis aridis mari proximis 24 .

linearis. A. fpicis fubquaternis, digitatis: flofcul, unilateralibus, alternis, adpreffis, muticis. Retz. $O b f . f a f c, 4$.

Habitat. . ...

Gramen canefcens, femiped. Sirnile Panico lineari. Culmi, prafertim bafi, foliofi. Fol. brevia, angufta, difticha, patentia. Spica vix pollic. Rachis linearis, flexuofa. Anth. ratione planta grandes,

prosera. A. paniculæ peduncul, racemolis, erectiufcul. fl. lanceol. muticis, hirfutis. Retz. Obf. fafc. 4. In fubhumidis Malabaria.

Caul. 4-ped. \& ultra, adfcendentes, ramofi, foliofi, geniculis fufcis, villo tenui, albo obductis. Fol. femiped, angufta, nuda. Panicula fpitham. Cal. gluma altera fufco purpurafc. altera viridi. Anth. Alava. Stigm. purpuronigricant. Serm. ovatum, planiufe. album .

coromande- A. panicul. ovata, patente: peduncul. fimplicilisne. bus: fl. fecundis, muticis; calycibus aqualibus, acutis, nitidis. Rekt. $O b f$. $f o f c .4$.

In aridis Malsbaria, 
Gramen femised. canefcens, rigidum, a pecoribus non tangitur.

Radic, numerofæ, flexuofæ. Culm. adfcendent. filiform. bafi foliofi, fulc ti, vagina longa demum veftiti. Fol. radical. pollicar. latiuful. lanceol. rigida. Panicula rara, Fl. minuti,

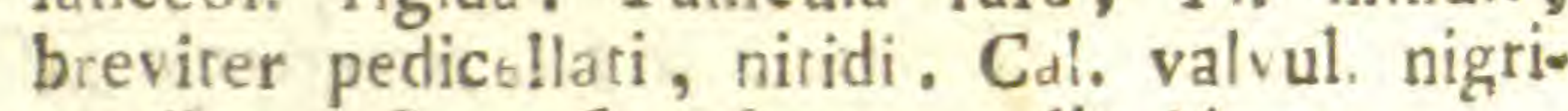
cantibus. Sem. flavefcens, pellucidum .

98. AIRA. Cal. 2-valv. 2-tlorus. Flufc. abfque interiecto rudimento.

\section{* Mutica.}

I. arundine- A. panicula oblong. fecunda, mutica, imbricata: cea.

2. minuta. In Oriente.

fol. plunis. Syjt. veg. ed. 14.

A. panicula fubfaftigiata, ramofiffima, laxa; florc。 muticis. Syft. veg. ed. I4. Schreb. gram, tab. 2I. f. 2 .

Gramen \&c. Buxb. cent, 5. tab. 67. mala.

In Hifpania $\odot$.

Culm. 2-unc--digiral. tribus genicu'is, ultimo longiff. Fol, acura, plana; vagina furlum latior, paulo ventricofa, ibiq. angulofa. Panicula ubic. patentiff. fpadicea .

3. aquatica. A. paniculd patente: fl. muticis, lævibus, calyce longioribus: fol. planis. Syjt. veg. ed. 14. Fl. Dan. tab. 3 s.

Gamen \&c. Vaill. parif. tab. 17. f. 7.

In Europa pafcuis aquofis 4.

Culm. fub ped, bafi repens, binodis. Fol. latiufcula, glabra, vaginis ad b-fin rubris. $\mathrm{Pa}-$ nicul. palmar. verticill ta, laxa. Racemi pl. ex uno puncto capillacei, fæe flexuofi. Spicul. fpadiceo-virid.

$V_{a r}$. in loco ficco, flofc. valde remotis.

4. capenfis. A. culm. ramofo: fl. racemofis: cor. pilofis. Syjt. veg. ed, 14. Lin. Suppl.

Ad cap. b. Spei .

Culm. fefquiped, frepe repentes, laves. Fol. graminea, anguftiora, lavia. Cal. oblong. obtufufe. Cor. oblong. lungitudine cal. obtufæ.

$$
\text { ** Ariftata. }
$$

5. fubfpiceta . A. fol. planis: panicula fubfpicata ; flofcul, medio ariftatis, arilla reflexa, laxiore. Syft. seg. 
ed. 14. Fl. Dan. zab. 228. Hall. app. 10 ad Scheucha. gram. tab. 6.

In Helvetia, Lapponia ơc. alpibus 24.

Bulbilli radical. Culm. trient-femiped-dodrant, fubpaniculat. villofus. Fol. glabra, mollia. Panicula denfa, paucifl.

6. cefpitofa. A. fol. planis: panicula patente; petal. bafi villofis, ariftatifq. ; arifta recta brevi. Syft. veg. ed. I4. Fl. Dan, tab, 240. Leerf. herb, tab. 4. f. 8.

Gramen \&c. Scheuchz. gram. tab. 2. f. 2.3. Mo rif. hift. 3. f. 8. tab. 5. f. 17.

In Europe pratis cultis, \& fertilibus 4.

Culm. 2-ped. \& ultra. Fol. deorfum afpera, lis neari-fubulata : caulina pauca, min. Panic. magna, ramofiff. patula ; florens fpadiceo-alba, aut viridi-alba; fenefcens paleacea: locuftæ minimæ, dianthæ .

7. fexuofa. A. fol, fetaceis : culm. fubnudis: panicula divaricata; pedunc. flexuofis. Syft. veg. ed. $14 . \mathrm{Fl}_{\text {a }}$ Dan. 157. Leerf, tab. 5. f. 1. Halt. hift. $n_{0}^{\circ}$ 1486. var. $b$.

Gramen \&c. Scheucha. gram. tab. 6. f. I. Morif. hift. 3. f. 8. tab. 7. f. 9. Schreb. gram。 tab. 50.

In Europa potris, rupibus \&c. 4.

$V$ ar. certe $A$. montene. Culm. cefpitofi, 2-ped. \& ultra. Fol. 2-3-uncial. fpicul, fufco-argentea.

8. montane. A. fol. fetaceis: panicula anguftata; flofc. bafi pilofis, ariftatis ; arifta tortili, longiore. $5 y \rho t$. veg. ed. 14. Stillingfl. gram. tab. 4. Leerf. herb. tab. 5 .

Gramen. Scheuch, gram, tab. 4. f. I6. Monto ic. 74 .

In Europa alpinis 24.

Differt a priore glumis bafi pilofis. Rami longiores, \& locufta duplo ma: funt. Culn. cubiral. Fol. ad terram plura; caulina pauca. Panic. erects, pedicell. flexuofis; poft efflorefcentiam laxior: loculta fubovata.

9. alpina.

A. fol. fubulatis: panicula denfa; flofcul. bafi pilofis, arilturis, arifta brevi. Syft. veg.ed. I4. In alpibus Lapponicis \&c. 4.

Culmi fubped. ramofi, geniculis fufcis, nigri- 
cantibus. Fol, veluti iuncea, vaginis fubfufcis . Panicul. lub ;-uncial.

I0. villofa. A. fol. fubulatis: panicula elongata, angultara, flofcul: fefqui-aleris, hirtis, ariftutis; arifta brevi, recta. Syft. veg. ed. 14. Lin. Suppl.

Ad cap. b. Spei.

Radix fquamis villofis. Culm. glaber. Fol, remotiora, plana, vaginis frepe villofa. Panic. terminal. pedal, ramificatione Melica. Fl. magni, ferruginei; alter longior, craffior, hermaphroditus; alter anguftior, fubfterilis. Cor. hirfuta .

II.canefiens. A. fol. fetaceis; fummo fpathaceo, paniculam inferne obvolyente. $5 y f t$, veg. ed. 14 .

Gramen \&c. Morif. hift. 3. f. 8. tab. 3. f. 10.

In Europe auftralis arvis arenofis $\odot$.

Dignofcitur colore pallido. Culm. fubpeda': $\mathrm{Pa}-$ nicula erecta, lanceol. contract,, florefcens patens; deflorata longius e vagina exit. Spicul. glauco-virid. albæ, aut rubellæ .

12. precos. A. fol, fetaceis; vaginis angulatis; fl. paniculato-fpicat.; flofe, bafi ariftatis. Syjt. veg. ed 14. Fl. Din. tab. 383 .

Gramen \&c. Ray. Angl. tab. 22. f. 2. Pluk。 alm. $t_{12} b .33$. f. 9.

In Europa auftralis campis montanis arenojis, ins undatis $\odot$.

Adfinis priori, fed pufilla. Culm. 3-pollic-palmar. filiform. Fol. brevia, lineari-fetacea . Panic. 2-3-digital. viridula, dein fubciner. aut purpuro-canefc.

I3. caryophyl-A. fol. fetaceis; panicula divaricata ; fl. diftantilea. bus, ariftatis. Syft. veg. ed. 14. Stillingft. mifcel. tab. 5. Fl. Den. tub. 382. Lecrf. herb. tab. 5. f. 7 .

Gramen. \&c. Morif. hiff. 3. f. 8. tab. 5. f. II. Scheuckr gram. tab. 4. fo I5. Barr. ic. 444. f. $I$.

In locis glareofis $\odot$.

Culm. palm-cubital. fubcefpitofi, filiform. fubnudi, articul. 2. tantum ad radicern. Fol. sonferta, brevia, lineari-fetacea. Panicula expanfa, laxa. Spicul. exiguæ, conicæ, acutæ, graciles. Gluma albido-purpur. Planta vetufac alba. 
mediu.

A. fol. fetaceis: culmis nudis: panicula laxa; flofcul. bafi pilofis; arifta fubterminali, breviore. Gousm. Illufir.

Differt ab $A$. montana, \& capillari, arifta glue mis breviore.

chinenfis. A. fol, fetaceis : panicula erecta, flofe, ariftatis. Retz. Obf. fafe. 3.

In China.

Facies omrino Aira; fed potius Holci Sp. cum is altero fl. vel fole anth., vel plane nihil inveniantur.

Culm. pedal. bafi ramofus. Fol. brevia, gldbra . Panic. parva. Cal, valvul. lanceol. fubæqualibus, ftriatis, glabris. Cor. gluma viltolæ; exterior convexa, ariftata; interior longior, plonior, acuminata, in fundo cucullato genitalia continens.

99. MELICA. Corpufculum pedunculatum inter flofculos (rudimentum floris) characterem effentialem præbet. Cal. 2-valv. 2-fl. glumis ovatis, muticis, æqualibus. Folliculi glumæ mutica, inæquales.

Icones Clufii Melicarum funt mala.

I. ciliate. M. flofcali inferior. petalo exteriore ciliato. Syfr. veg. ed. 14. Gnel. fibir. I, tab. 19. f. I.

b. Gramen \&c. Scheucha. gram. tab. 4. f. II, 12. Barr. ic. 3. n. 2.

In Europa collibus fterilibus, fuxofis 24.

Culm. cefpirofi, cubital. Fol. glabra. Panic. fpicata, denfa. Glumæ candicantes, feu flavefcent. Semen oblong. tenuiffime ftriatum, nitens.

b. Radix arundinacea . Culm. 2.-cubital. Fol. Arundinacea, 2-ped 1 l. Panic. fefquipedal. 1axa, ramis patentibus, glumis corul.

2. nutans, M. petal, imberbibus: panicula nutante, fimpl, Syft. veg. ed. I4. Schreb. grain, tab. 6. f, 2. Leerf. kerb. $t a b$. 3. f. 4 .

Gramen \&c. Scheuch. gram. fig. I6. D, E, F. Monti ic. 73.

In Europe rupibus frigidioribus 4.

Culm. pedal. inferne atro-purpur. Stipula ad oras vaginæ fol. fubulata, colorata. Panic rara, etiam mere fpicata, pedunc. longis. Spicul. 
pendulæ, fecundx, jmberb. Sem. laneeol. compreffa, fulco-ferruginea.

M. I. flura Reti. fufc. I. tab. 10. que pro varietate huius habita fuit, differt panicula, feu racemo ad bafin ramofo, nec cal. fl. binis perfečis.

3. minute. M. culmo ramofo; fol. fetaceis : petal, imberbibus. Syft. veg.ed. r4. Schreb. gram, tab. 20, f. 2. In Italia ad calles 4.

Culmi femiped. filiform. anguftiff. ramofiff, obtecti fol, vaginis. Fol. anguftiff. filiform. involuta, bafi patula. Racemi terminal. fimpl. capillar. paucifl. Flofcul. oblong. mutici, intermedio pedicellato, truncato, fterili .

4. cerulea. M. panicula coarctara; fl. cylindricis. Syft. veg. ed. I4. Fl. Dan. tab. 239. Leer/. herb. tab. 4. f. 7. Gramen \&c. Morif. hift. 3. J. 8. tab. 5. f. 22.

In Europe pajc is aquojis 4.

Culm. fub 2-cubital. articulis orbatus. Fol. fubpilofa. Spiculæ pedicellatæ, acuminatæ, muticæ. Genital. purpur.

5. papiliona- M. calyc. valvula infer. maxima, colorata; petalo exter. fubciliato. Syft. veg. ed. I4.

M. brafiliana Ard. Spec. 2. tab. 6. f. I. 2.

Gramen \&cc. Sloan, hift. I. tab. 64. f. I.

In Brafilia.

Statura Sequentis. Panic, virgata; pedunc. tenuib. flore longioribus, in primis inferne ramofis.

6. altiffima. M. peral. imberbibus : panicula ramofiff. Syft. veg. ed. 14. Gmel. Sib. 1. tab. 20.

Gramen \&c. Morif. hif. 3. f. 8. tab. 7. f. 5I.

In Sibiria, Canada 4.

Culm. 2-3. ped, rectus. Panic. dodrant, pedicul. paucis, diftantibus.

7. falx. M. fpica fecunda, compreffa, imbricata, Syft. veg. ed. 14. Lin, fuppl.

Ad cap. b. SFei b.

Fol. graminea, alterna. Culm. fefquiped. durus, Jævis, geniculis 2. Spica digital. (Cynofuri) ex foliol. lattralibus lanceol. acuminat. trinerviis, fingulis pro fingulo flore, margine albo. Fl. pubefcent. nodosa, M. Piller. It. Sclavon, tab. XIV. 
Adfinis M. carulea: differt culmo denis nodis geniculato. Panic. primum coarctata, dein divaricata. Cal. 4-fl, infimo feffili, reliquis peo dicell tis . Fol, brevia, acumin. rigidiulcula . Gramen torun viridi-purpureum, \& cœrul. 2-ped. \& ulera.

I00. POA. Cal. 2-valv, multiflorus. Spicula ovata, valvul. margine fcariofis, acutiufculis. Sem. folliculo arcte involutum.

I. aquatica . P. panicula diffufa: fpicul. lanceolat. 6-floris . Syft. veg. ed. 14. Leerf. herb. tab. 5. f. 5.

Gramen \&c. Scheuchz. gram. tab. 4. f. 1. Morifs hift. 3. f. 8. tab. 6. f. 25. Monti gram. ic.38. In Europa ad ripas 4.

Culm. 6-ped. Fol. in aquis latiffima; in ficcis anguftiora. Panic. grandis, pedal. erect 1 , rigida, per æratem fpadicea. Pedicelli flexuofi . Spiculæ diftichæ .

2. alpina. P. panicula diffufa, ramofiff. fpicis 6-fl. cordatis . Syjt. veg. ed. 14. Hall. app. I. ad Scheuch. gr。 tab. 3 .

b. P. vivipara.

Gramen \&c. Scheuch, gram. tab. 4, f, 14, Flo Dan. cab. 807.

In alpibus Lapponicis, Helveticis 4.

Culm. vix pedal. torus vaginofus. Fol. lata, mollia, glabra, quandoque longiora, incurva . Panic. denfa, multifl. imbricata. Spicul. magnæ, ex violac-luteo-albo variæ.

3. trivialis. P. panicula diffufa; fpicul. 3-fl. bafi pubefcentibus : culm, ereeto, tereti. Syf. veg. ed. 14. Leerf: herborn. tab, 6. f. 2.

In Europa pafcuis 4.

Differt a P. pratenfi lanæ præfentia, quæ reperitur ad bafin petali exterioris. Panic, e viridi-purpur. Culmi adgregati .

Cum P. angufifolia hanc coniungit Scop. Fl. Carn. 4. anguftifo- P. paniculd diffufa; fpicul. 4-fl. pubefcentibus: lie. culm, erecto, tereti. Syft. veg, ed. 14. Leerfo herb. $t a b .6$. f. 3 .

Gramen \&c. Scheuith. gram. tab. 3. A.l agrorum verfuras 4 .

Hanc a priore diftinguit habitus proprius; panicula valde diffufa; rami pl. e fcapo prodeuntes; fol. longiora; locus natalis quodammodo. 
3. pretenfis. P. panicula diffufa; fpicul. 5-fl. glabris: oulmo erecto, tereti. Syft. veg. ed. I4. Leerf. herb. tab. 6. f. 4 .

Gramen. \&c. Scheuch\%, gram. tab. 3. f. 17. A.

In Europe pratis fertilif/zmis.

Culmi fefqui-2-ped. Fol. vaginantia, 2-3-une. longa.

Differt a priore pracipue Seabritie; Spiculifque mi* nor.: A P. trivial. magnitudine, ramis pl.e fcapo prodeunibus; panicula diffufa; parvitate fpicularum, \& afperitate difcrepat. Defeçu lane flofcul, non vero num. flofcul. a P. triviali differt.

6. annun, P. panicula diffufa, angulis rectis; fpicul. obtufis : culm. obliquo, compreffo. Syft. veg. ed. I4. Stillingf. $\pi_{i} i f c, t a b$. 7. Leerf. herb. tab. 6. f. I. In Europa ad vias $($ ).

Differt a P. triviali panic. diffufa; iulm. decumbentibus, compreffiufcul., maiori molitite, \& teeritate; habitu pre primis. A P. praten $\sqrt{2}$, \& angufifoliu, ramis binis e fcapo prodeuntibus, magnitudine \&c. difcrepat.

7. flave. I P. panicula difrufa; fpicul, ovato-oblong. nitidis. Syft. veg. ed, I4.

In Virginia.

Culm. altus. Fol. pauca. Spica ampla, longa. Gluma pendentes, tremulæ.

9. piloja. P. panicula patente, ftricta; ramificationib. primariis pilofis. Syft. veg. ed. I4.

In Italia.

Culm. pedal. \& ultra. Fol, mucronata, ftriata, glabra, margine afpero. Panic. femi-palm.

9. palufiris. P. panicula diffufa ; fpicul. fub 3-fl. pubefcentibus: fol. fubtus fcabris. Syft. veg. ed. 14. Fl. Dan, tab. 750.

Gramen \&c. Morif. hift. 3. f. 8. tab. 6. f. 27. In Helvetia, Italk Ec.

Culın. 3-pedal. Fol. retroverfu alpera. Panic. femiped. valde multiflora. Spicul, exiguæ, acuminatæ.

ro. amabilis. P. panicula patente; fpicul. octodecim-floris, ovato-linearibus. Syft. veg. ed. 14.

In India.

Maxime adfinis P. Eragrofidi fl. purpur., glumis trinerviis, quarum inferiores fenjim cadunt. 
Fol. Atricta, ad angulum acurum exenntia. Panic. fparfa, undulata.

I1. hirta. P. panicula patula, vaginis fol, punctatomciliat. Syft. veg. ed. 14. Thumb. Jap.

In Japonia.

Culm. erect. 3-ped. fimplex, glaber. Fol. longe vaginantia, ftriata. Panic, pedal, virgata. Pedunc. angulati, angulis ciliato-fcabris .

12. ferrugi- P. panicula patula, capiliari; fpicul. 5-fl. oblong. nea. glumis glabris, Syft. veg. ed, 14. Thumb. Jap. In Japonia.

Culm. erectus, pedal. fimpl. Fol. vaginis fauce barbatis, erecta, convoluta, ftriata, glabra . Panic. fpitham. virgata. Pedunc. \& pedicelli capill, flexuofi.

33. barbata, P. panicula capillari, patula ; fpicul. 6. fl. oblong. glumis carinatis, glabris. y ft. veg. ed. I4. Thumb. Jap. tab. 10 .

In Japonia $\odot$.

Radix fafciculata. Culm, erectus, fpitham. fimpl. glaber, Fol. culmo longiora, angulta, linear. apice attenuata, fetacea, convoluta, glabra. Genicul. barbata .

I4. japonica , P. panicula patula capillari, fpicul, fub 7-fl. foliifque glabris; culmo ramofo, $S_{y j t}$. veg. ed. I4. Thumb. Japon.

In Japonia.

Differt \& $P$. capillari fpicul. 5-9 fl. fol. omnibus glabris, nec bafi pilofis: culm. erecto, altiore. Culm. erect. 2-ped. \& ultra, ftriatus, glaber. Fol, culmo breviora, fpitham. longe vaginantia, angulta, ftriata. Panic. erecto-patens, pedal. ramofift. Pedicelli capillar. ramulofi, flexuofi.

25. abylfinica, P. panicula patula ; fpicul, oblong. fub 5-fl. culm. geniculato, inferne procumb. ramofo, Syft. yeg. ed. I 4. Jacq, ic, rar, tab. 43.

In Abylfinia $\odot$.

Culm, inferne procumb, \& ad nodos inflexus, compreffus, gracilis. Fol. vaginantia, fublinear, acumin. margine fubriliter denticulato . Panic. rerminalis, laxa, rachibus capillaribus, compreffis, \& patulis. Spicul. obtufre. Tota planta glaberrima.

I6. punzata, P. panicula difufa, fpicul, fub I2-fl. fl. diaphaTom, I. 
nis, lævibus, puncto intus fufco. Syft. veg.ed. 14. Lin. Suppl.

In Malabaria.

Culm, refquiped. adfcendentes, læves; genicul, tumidioribus, fæpe 3. Fol. graminea, 1:abriufcula, fubtus lavia, margine fcabra, verfus bafin pilis raris, ereetis. Vaginæ læves. $\mathrm{Pa}$ niculd (Milii effufi). Pedunc. deflorati in racemum coarctati. Glumæ corollina ovatæ, acuriufe, calycinis fimilliuz.

17. Eragro P. panicula patente, pedicèl flexuofis; fpicul. Jis. ferratis, fub 10-fl., glumis trinerviis. yft. veg. ed. 14 .

Gramen \&c. Scheuch. grarn. $t a b .2$. f. 2. Burr. ic. tab. 44. f. 2. Morij, hijt. 3. f. 8, tab.6.f. 47 .

b. Grdmen \&c. Scheuchr. gram. tab. 4, f. I3. planta iunior.

In Helyetia, Italia, Sibiria Esc. $\odot$.

Adfinis Briqa Eragrnfti, \& P. amubili; an folo loco natali diverfu?

Culow, ad radicem bulbof, debiles; in maiori var. cubital. erecti. Fol. glabra. Panic. ramofiffirna, undulata. S icul. erectæ, tenellæa, fubyiolac, el ganter imbricatæ, \& diftiche.

18. capillaris, P. panicula capillari, laxa, patentiffima: fol. pilofis: culm, ramofiff. Syft. veg. ed. 14.

Gramen \&c. Morif. hift. 3. f. 8. tab. 6. f. 33. in Virginia, Canada.

Panicula frictiffima. Fol. ad bafin pilis longis raris. Spicul. ex flofcul. 45-6. minimæ.

I9. afpera, P. panicula ramoliff. pateotiff. pedunc. afperis; fpicul. 10-fl. vaginis fol. antice hirfutis. Sy,t. veg. ed. I4. JuJf. in demonftr. H. R. P. Jacq. H. Vol. 3.tab. 56 .

In India Orient,

Culm. pl. 2.3-pedal, fimpl, erecti, ab exortu adfcendente foliofi, nitidi. Fol, vaginæ apice barbatæ. Fol. longa, acuta, fupra pilofa, fubtus glabra. Panic. pedal. Pedunc. laterales ex primario centrali egreffi. Spicul. parvæ, compreffa, viridi-rubent.

20. malaba P. paniculæ ramis fimpliciff. fl. feffilibus: fem. rica. diftantibus: culmo repente, Syft. veg. ed, 14. Burm. Ind. tab. II, f, 2 .

In India arenofis. 
Fol, ovat-lanceol, Panic, laxa, Fl, alterni. Sem. alba.

2I. chinenfis. P. panicula ramis fimpliciff. fl. feffilibus: feminibus imbricatis: culm, erecto. Syft. veg. ed. 14. Burm. Ind. $t a b$. Ir. f. 3 .

In India.

Culm. pedal. Racemi per intervalla diftantes, fæpius 6-linear. Aricti. Flofc, alterni , 4 .

22. tenella. P. panicula oblonga, capillari, fubverticillata; f. 6-fl. minutiff, nutantibus. Syjt, veg. ed. I4. Gramen \&c. Pluk. alm. tab. 300. f. 2. Burm. Zeyl. tab. 47. f. 3. Rumpl. amb. 6. tab. 4. f. 3. Teph. Zuccagni.

In India.

Culm. proftrati, inferne ramofi, laves. Fol. lavia, margine fcabra, fauce pilola. Panicula patentiff. Fl. oblong. obtufi, purpurafc. linea utrimq. viridi, margine oculo armato ciliati :

33. rigida. P. panicula lanceol. fubramofa, fecunda; ramul. alternis, fecund's. Syff. veg. ed. 14.

Gramen \&c. Morif. hiji. 3. f. 8, tab. 2. f. 9. Barr. ic. 49.

In Europa Jicis $\bigcirc$.

Culn, brevilf rigidus. Panic, rigida. Spicul, linear. acutæ, fub 8-fl. Cal. carinatus.

24. compreffa. P. panicula coarctata, fecunda s, culm, obliquo, compreffo. Syft, veg. ed. 14. Fl. Dan, tab. 742. Leerf. herb, tab. 5. f. 4 .

Gramen \&c, Vaill, parif. tab. 18. f, 5. Mont. ic. 10.

In Europa, \& Amer. eptencr. Jiccis 24.

Culm. femiped. durus, purpurafc. Fol, angufta, glabra, longitudine panicula. Panic. erecta, angulfa, rigida, virid. dein purpur. tandem nigricans. Spicul. Jance 1 . fecundæ, 6-8-fl.

25. amboinen- P. panic, coarctata, fecunda: culno tereti. Syft. fis.

In India, veg. ed, I4,

Similis priori, fed culm. teres. Fl, paniculati, verticillati, 5-fl. Anth. rubræ, Piftil. alba .

26. nemoralis. P. panicula attenuata; fpicul. fub 2 -fl. mucronatis, feabris: culm. incurvo. Sylt. veg. ed. I4. Fl. Dan. tab. 749. Leers. herb. tab. 5. f. 3 .

Gramen \&c. Scheuch, gram. tab. 2.' Monti, gram. io. 12 . 
b. Gramen \&c, Bocc, muf. 2, tab. 59.

In Europa ad rad. montium umbrofas 24.

Gramen procerum, tenerum. Fol. linear. glabra. P nic. palmar. laxa. Spicul, paucifl, acu. min. non fabra.

27. bulbofa. P. panicula fecunda, patentiufe: fpicul, 4-fl, Syfte veg. ed. 14.

b. Gramen \&c. Barr. ic. -03.

y. Gramen \&c. Vuill. parif. $t a b .17$. f. 8.

In Europa ad vios, E. limites agrorum 4.

Culm. \& fol. radicalium bafes tuberofa. Culm. pedal, reretes. Fol. angufta. Panic. ditiula, glauca. Gluma ca!. rriftatæ. Folliculi 3-4. arifteti, ord alba.

28. Spicata, P. panicula fpicatt: fl. fubulatis; flofcul, remo. tis. yft veg. ed. It.

In Lufitania.

Culm. pl e bafi adfeendent. palmar. veft ti undiq. fol. vaginis. Fol. linear. angufta, læu, ia, vag ais craffiufc. Panic. longitudine fere culmi, inæqu ilis.

Habitus Feftuca.

29. diftans. P. panicula ramis fubdivifis; fl. 5-fl. flofcul. diftantibus, obtufis. Syft. veg. ed. 14 .

In Aufiria.

Culm. adficendent. læves, uti fol. Panic. fcabriufc. Flofe. ab apice ad medium cor. albi, diftantes, ut Agroftidis fp. videretur.

30. eriftate. P. panicul + fpicata: calycibus, fubpilofis, fub $=$ 4-fl. pedunc. longioribus: petal ariftatis. Syft. veg. ed. 14. Leerf. herb. tab. 5. f. 6.

Aira criftata. Jacq. Auftr. tab. I4.

Gramen \&c. Morif. hif. 3. f. 8. tab. 4. f. 7a Scheuchy. gram. tab. 3. f. I5.

In Europx ficcioribus 4 .

Culm. cubital. Fol. afpera, plerumq. hirfuta. Panic. e viridi-argentea, digitum longa, pyramidal. anguita, contracta, imbricata, ri4. yidula, efflorefientiæ tempore fefe expandens. Pedicel. fpiculis brevıores.

Per atutem diverfam induit faciem; magnitudine, \& panicula colore varians.

3I. ciliaris. P, panicula contracta; glumarum valsulis inte rioribus pilofo-ciliatis, Syjt. veg. ed, 14, 
Gramen \&c. Pluk. phyt, 190. f. 5. Sloen. Jam, I. $4 a b .73, f ., 1$.

In Jamaica.

Culm. filiform, ramofus. Fol. linearid. Panic。 rubra. Spiculæ ovatæ, glumarum ciliis albis.

32. brizoides, P. panicula racem fa; fpicul, ovatis, compreffis, 8-9-fl. culmo compreffo. Syft. yeg. edo 14. Lin. Suppl.

In Africa.

Fol. ad radicem. Spicul. magnitudine Briza mediæ. Glumæ luteæ, apioibus cœrulefcentibus.

33. difiche. P. fpica terminali, difticha, hinc convexula, inde plana. Syfl. veg. ed. I4. Jacq. mifc. 2. p. 74. ic. rar.

P. Seflerioides. All. Fl. Ped. tab. 9r. f. r.

In pratis elntioribus Icalix \&c. 4.

Culıi pl. palinar. erecti, 3-not. non glabri, ramoli. Fol. linear. erecta, glabra, vagina ftriata, internutii longirudine. Culm. dimidius, \& floriger nudus. Spica frepius paulum inflexa. Locuftæ congeftæ, diftichæ, primo intuitu fesleriam referentes. Pedunc. breves: glumæ calyc. ylabræ, ex argenteo, \& coerul. nitentes, ovat. breviter mucronatæ. Glumæ follic. fimiles. Anth. col, obfcuri.

inotiand.

P. panicula ftricta; locuftis 2-fl: folliculis bafi villofis. Hall, helv, n. 1468. All. Fl. Ped.

Gerardi. P. culmo recto; locuftis 3-fl. glaberrimis, calycibus ariftatis. Hull. helv. n. 1463. Ger。 tub. 2.

In pratis, \& pascuis alpium 4 .

Differt a $P$. praten $\sqrt{2}$, glabritie, panicula diverfa; fl. ma. calyc. ftriato Es. Omnia viridia, mucronibus fpadiceis.

fabauda. P. panicula laxa, locuftis 2-fl. fl. calyce duplo longioribus, glaberrimis. Hall. helv, n. 1470 。 Fl. Ped.

In sabaudin \&o.

Culm. erectus, 3-ped. Fol. ad 3. lin. lata. Panicula pedal. non valde fparfa, valde rara, pedunculis ramofis, longe nudis. Fl. bini, duplo calys, longiores. Locufiz multo, quam 
toti huic generi maiores. Onnia viridia, gla. bra, mutica. Facies Avence, fed abfque omni arifta.

cilienerfis. P. panicula longiffima, ramofa, ramis erectis, flexuofis; fpiculis diftichis, 4-fl. All. Fl. Ped. tab. 91, f. 2.

In agro Ciliani $\odot$.

Culmi pedal. \& ultra, fulcati, glabri, nodo fufco. Fol, 2-3. lin. Jata, lineata, obfcure viridia, glabra, circa vaginam ciliata. Fol. paniculæ fubiectum, longum. Panicula terminalis, ramis ex eodem puncto 3-4. raro folitar. Locuftæ veluti in raram fpicam difpolitæ, ovatoblong.

fylvatica. P. panic. diffufa ; fpicul. fub 5-fl. glumis acutiffim. Pollich, Fl. Pulatin.

In Palatinatu.

Cul. cefpitofi, erecti, 2-3-ped. glabri, glauco-virid. Panic. virit. \& alba, primun contracta, \& denfa, florefcentia tempore $\mathbf{m a -}$ xime divergens. Spicul, parva, ovat-oblon. compreffa, ex albido laete virides.

A. $P$. alpina differt culm. longiore; fol. valde latioribus; Spicul. parvis; glumis folliculat.; $b^{*}$ calycibus, anguffis, aeutiffrmis.

A. Bromo giganteo Spicul. parvis, non arifatis.
divaricata. P. paniculæ ramis geminatis, divaricatis; Spicul. fub 4 ffl. Gouan. Illuft. tab. 2, f. I.

Gramen \&c. Barr. ic, 44. licet Sheuchx. hoc Jynon. Aira caryophylleæ imponat.

In pratis.

Culm, pl. palmar. albi, aut fubrubri. Fol. 2-30 uncial. vaginis amplis. Panic. fubdichotoma. Rami inferior. trichotomi; fummi biftrifidi .

multiflora.P. culmis fimplicibus, erectis; f picul. linearibus, multifloris. Forsk. 座gyp.

\section{In Arabia.}

Communiter gerit fl. 13. verum 15. ufq. 24. in una fpicula. Variat fpicul. fufcefcentibus, 9-fl.

Phenix. P. fpicul. teretibus, compreffis, pendulis, 8-fl. cop. Fl. Carn.

Panicum Loliaceum \&c. I. R. H. \& Scheuchr.

Culm. 2-pedal, \& ultra. Panicul, etiam femiped. laxa, racemis binatis, nutantibus. Spicula ut 
in Bromo pinnato, fed breviores. Variut $p a^{*}$

panicea . nic. ereçiore, magifq. contracza.

P. paniculze ramis fubbinaris, remotis, filiformibus, calyuibus, 2-fI, vaginis punctato-pilo. fis. Retz. Obj: faft. 3.

In China.

Gramen altum, tenue. Fol. 1rvia, nuda. Panic. pedal, rara, fpicul. 3-4-pollic. Fl. alterni, pedicelluti, fecundi.

Paniculie forma refert P. Chinens. Burm. Ind. tab. II. f. 3. Sed multo maior, E teneriur. Calo 4-fl. praterea efle ait Linn.

sontraçe.

P. panicula contracta, flofcul. lanceol. 3-fl. reffilubus, nudis; fol. filiformibus. Retz. $O b \int_{0}$ fafc. 3 .

Gramen 2-pedal. \& ultra, glaberrimum, culm. craffo. Pedunc. longi, ftricti.

P. $\left(F_{e} / 2 u c a\right)$ locuftis 2-fl. fpicetis : calycibus glabris, fl. villofis, Hall. hely. 口. ${ }^{\circ}$ 1445.

Gramen Valefanum \&c, Scheucht.

Ad margines agrorum Valefice.

Simil. P. criftara. Differt ful. vix femilineam lato, convoluto, quafi iunceo; fpica uncial. conica, magis compacta; lucufis multo obeforibus, gluma florali exteriore villofa.

P. caul. recto; panicula rara; locuftis 3-fl. bafi, dorfoq. villofis. Hall. Hift. 1457. Scheuchz. Prodr. tab. 4. It. 6. T. 6. f. 16.

Simil. P. alpina magnitudine locufta, fed differt pancitate florium.

P. panicula fparfa; locuftis 4-fl. follicul. villofis . Hall. Hift. n. 1458.

Non potelt effe $P$. trivialis ob culm. erectum; \& locufta s-fl.

$\mathrm{Poa}$ iuncea, culmo recto; locuftis 4 -fl. floralium durfo fericeo. Hall. Hift, n. 1459.

Simil. P. compreffe, fed difcrimen ex definitionibus. Color violac. in flore.

watans. P. panicula contracta, apice nutante: fpicul.10. f., valvul. reverfis. Retz. Ots. fafc. 4 .

In Tranquebaria.

Culm. 2-3-ped. erecti, fimpl, teretes. Fol, brevia, angufta. Panicul. ramis femiverticill. Spicul. fubrubent. vel viridi-albicant. linear.

cynofuroides, P. panicul, ftricta, pyramidali; peduncul, pater $N$ iY 
tentiff. fpiculis dependentibus, diftichis. Retr. Obf. fafc. 4 .

In India Or.

Culm. folitar. 2-ped. erecti, bafi fol. diftichis, reflexis. Fol, caulina 2-3. convoluta. Panicul. fæpe culmo longior, fub florefientia col. fonguineo. Pedunc. rerno-verticill. horizontal. fpicul. numerofa.

plumofa. P. panicula diffufa; calycibus 6-fl, valvul, corollar. interioribus, linearibus, recurvis, dorfo ciliatis. Retz. Obf. fafi. 4 .

In Tranquebaria.

Culm. pl. cunferti, I-ped. filiform. foliofi. Fol. I-2-polli:. linear. Iævia, vaginis cris longe pilofis. Panicul. peduncul. ramofis, flexuofis. Differt a $P$. ciliari forma panicula ; fl. \& ciliis minoribus.

rifcofa. $\quad$ P. panicula oblonga, patente; fpicul. inferior. 3-fl. fuperioribus 1 2-fl. culmis rigidis, demuna vifcolis. Retz. Obf. fafi. 4.

In Malaburia.

Radic, ftoloniferæ. Culm. fpitham. teretes, rigidi. Fol, brevia, filiform. difticha, convoluta, rigidula. Panicul. peduncul. ramofiffim. fpicul. lineari-lanceol. Color panicula fæpius viridefiens, alias incanus, aut fanguineus. Odor serebinthiniacus.

101. BRIZA . Locufta multiflora, mutica. Calyc. gluma cordato-concavæ, æquales, obtufæ. Fl. in fpicam cordatam, difticham collecti. Folliculi valva inferior ventricofa, major, glumis calycinis fimilis: luperior minor, plana. Sem. ex folliculo fecedens.

I. minor. B. fpicul. triangulis; calyce flofculis longiore. Syft. veg. ed. I4.

Gramen \&c. Scheuchr. gram. tab. 4. f. 9.

In Helvetia, Italia, Germania $\odot$.

Culm. dodrant. Fol. linearia. Panicul. diffufa, trichotoma. Spicul, compreffe, 6-7-Al. fubviolac.

2. virets. B. fpicul. ovatis; calyce flofculis aquali. Syft. yeg. ed, I4.

In Oriente, Hifpania \&c. $\odot$.

Planta vix palmar. Eimil. B. medice, fed fol. duplo latiora, planiora, decurrentis per ligulam 
acutam. Panic. fimillima, copiofior, virid. nec purpurafc. ramulis magis ramness, divaricatif. Fl. paulo min. dum comprimuntur facile decidui .

3. medit. B. fpicul. ovat, calyce flofculis 7-9. breviore. Sy f. veg. ed. 14. Fl. Ditn. tab. 258.

Gramen \&c, Morif. Hift. 3. tab. 6. f. 45. Barr. ic. 16. Sicheuchi. gram. tab. 4. f. 8. Mont. gram. ic. 39.

In Europa pratis ficcioribus 24.

Culm. pedal-cubital. nodis 5-3. ad radicem. $\mathrm{Pa}$ nic. latet in vagina, dein prodit rara, triangul. Flofc imbricati.

4. maxima. B. fpicul. ovatis: flofcul. feptendecim. Syft, veg, ed. 14. Jacq. $a b f$. 3. tab. 60.

Gramen \&c. Scheuchx. gram. tab. 4. f. 7.

In Italia, Luftania $\odot$.

Culm. palm-pedal. Racemus fimpl, magnus. Pea duncul. alterni, fimpl. raro 2-fid. Spicul. candicantes, ftriis virentibus. Glunæ purpur. rufæ, ferrugin.

3. eragroflis. B. fpicul, lanceol-flufcul, plerumque viginti. Syft. veg. ed. 14. Clareb. gram. 2, tab. 39.

Gramen \&c. Morif. hift. 3. f. 8. tab. 6. f. 52. Scheuchz. gram. tab. 4. f. 4. Burr.ic. tab. 4. f. 4 . Ad agrorum verfuras $\odot$.

Culm, decumbent. ramofi, rigidi, geniculis rubris ; ora folio oppofita barbata. Panic. rigida, racemis oppofitis, \& alternis. Spicula fufcre.

Maxime adfinis P. Eragroftidi; an fulo loco diver $\int a$ ?

Cynofuroides. B. fpiculis lanceoldt, multifl, culmo erecto, fimplici, albo ftriato. Scop. Delic. Infub. Fafco 2. tab. II.

Habitat. ... $\odot$.

Culmi rigidi, ultra fupremum fol. rubelli, læves, vix fpitham. Fol. 2. circiter lin. lata, fuperne ftriata, nervo medio albo, vaginis amplexntibus, biauriculatis. Spicæ alternæ, rigidæ, fubfeffil. compreffæ, ut in B. Eragrofide; flofculis imbricatis, diftinctis. Stm. 3. Culmi per æatatem cefpitofi, ramofi. 
monfpedu-

B. fpica nutante, fimplici : fpiculis alternis, pe-

lana. dunculatis, fubfolitariis, ovatis; calyc. 5-fl. Gouan. hort. All. Fl. Ped.

Monfpelii, \& in agro Nicaen $\sqrt{\imath} \odot$.

102. UNIOLA . Cal. multivalv. fpicula ovata, carinata .

I. paniculata. U. paniculata; f́picul. ovatis. Syft. veg. ed. 14.

Gramen \&c. Pluk. alm. tab. 36. f. 6. Catesb car. I. tab. 32.

In Carolina.

Spicul. compreffæ, undiq. acie acuta cinçæ, in paniculam inordinatam difpofitæ.

2. bipinnata. U. panicula fubfficata, racemis pinnatis, fubtus imbricaris. Syjt. veg, ed. I4.

In Aggypto.

Gramen nminium fpeciofiffrmum. Culm. mgnitudine Tritici, fimpl. Racem. peddl. fimpl. e pedunc, alternis, fimplicilf, æqualibus. Fl. feffil. adproximati, compreffi, aqual. complanati more Cyperi. Glum. compreffæ, carinatæ, ovatæ, acutiufculæ.

3. mucronata.U. fpica difticha; fpicul. ovat. calycibus fubariftatis. Syft, veg. ed. I4.

\section{In India.}

Culm. pedal. lavis. Fol, angufta, glabra, vagi nis ftriatis. Fl, II-I2, alterni, fubfeffil, diAtichi, ovati, glabri .

4. Spieate. U. fublpicata: fol. involutis, rigidis. Syft. veg. ed. I4.

In Amer. boreal, maritimis.

Culm. fpitham. Panic. minima, coarctata, ut vix fignum pedicellorum, fecunda. Cal. \& glumæ carinata flofcul. 4.

103. DACTYLIS. Cal.2-ralv. compreffus; altera valvula ma. carinata (Cor, comprelfa).

1. cynefuroi- D. fpicis fparfis, fecundis, fcabris, numerofis . des. Syjt. veg. ed. I4. Lin. fajc. I. tab. 9 .

In Virginia, Canada; nunc in Iufitania, Anglia 4. Culm. 2-ped. arundinaceus, fuperne foliofus. Fol, in culm, 6. lata, culmo longiora, laviff. margine fcabra, incurva, fubtus glauciora. Spicæ divergentes, paleacer. 2. glomeratn. D. panicula glomerata, fecunda. Syft. veg. ed.
I4. Schreb. gram. tab. 8. f.2. Leerf. herb. tab. 3. Fl, Dan. 743 . 
Gramen \&c. Morif. hift. 3, f. 8. tab. 6. f. 38. Loef. ic. 23.

In Europe pratis 4.

Gramen durum. Culm. 3-ped. 5-nodis: in montofis altitudo humana. Fol. glauca, fubhirfuta, vaginis ancipitibus. Panic. fubfpicata, varie diffura, crafla, ábida, vel rubra. Racemi folitar. rigidi, ad angulum acutum diffufi cum culmo. Spicul. 4-fl. glomeratæ, afperæ. $A d$ Feftuca genus pertinet.

3. ciliaris. D. f ica capitata, fecunda; calycibus trifloris: caul. repente. Syft. veg. ed. I4.

Ad cup. b. ipei.

Culm. palm. fimpliciff. articulo unico. Fol. radical. longitudine culm. filifurm. involuta, lævia, caulinum r. læve, longitudine capituli, vagina fubventricofa. Capitul. ovatum. Fl. pl. f.ffil.

4. lagopoides. D. $\mathrm{f}$ icis fubrotund. pubefcentibus, culm. proftato, ramofo. Syft. veg. ed. I4. Burm, Ind. tab. 12. f. 2 .

In Malabaric arvis $\mathcal{U}$.

Culm. pl. p. Im. undque tedi vaginis fol. Fol. patentia, fubslata inilar fpintrum, bafi angufliora. Fl. feffil. multifl. fubfecundi .

5. eapitata D. Ipicis capitatis, levibus: culmo proftrato, ramofo. Syfl, veg. ed. 14. Lin. fuppl.

Ad cap. b. Spei.

Fol. Graminea, lavia, in culm. 3. Culm. fefquiped. laves. Panic. fpiciform. quafi conglomerata, palmar. fuperne anguftior, color. paleacei. Fl. gemisi, depreffi. Cal. fub s-fl. valvul. exter, valde attenuata. Cor, oblon. mutica .

geniculatus. D. culm, geniculato; fpic. ternis, diftichis: fol. linearibus, plicatis, mucronatis. Burm. Ind. tab. I2. f. 3 .

In $J_{\text {ava }}$.

Culm. ramofi, vaginati. Fol. alterna, vaginantia. Spica terminal. erectre; fl. alternis.

104. CYNO. Cal. 2-valv, mulciflorus , Receptac. proprium uSURUS. nilater. foliaceum.

Differt a Phleo folliculis integerrim.

1. criftatus, C. bracteis pinnatifidis, Syft, veg. ed. I4. Echrets. 
gram, tab. 8. f. 2. Stillingf. mifc, tab. 11. Fl。 Dan. tab. 238. Leerf. herb. tab. 7. f. 4.

Gramen \&c. Monti. gram. ic. 23. Barr. ic. 27. Scheuchz. ngr, tab. 2, f. 8. A. C.

In Europe pratis 24 .

Culm. cubital. fubnud. alterne flexuof. Fol, glabra. Spica fefquiunc. \& ultra, gracilis, quaft dilticha. Spicul. unilateral.

2. echinatus. C. bract. pinnato-paleaceis, ariftatis. Syft. veg. ed. I4.

Gramen \&c. Scheuchz. gram. tab. 2. f. 3. D. Barr. rar, tab. 123. f. 2.

In Europa aufirali, \& Oriente, ad agros fecalinos montanos $\odot$.

Culm. 3-ped. \& ultra, 4-nodis. Fol. glaberrima. Bract. una cum fl. fecundæ. Spica uncial. ramis ramofis, fed denfa, ad alterum fxpe latus converfa.

3. Lima. C. fpica fecunda; cal. gluma interiore fpicul. fubiecta. Syft. veg. ed. I4.

In Hifpania $\odot$.

Gramen vix fpitham. Fol. vagina tumidiufcula, fol. ipfo parvo. Spica oblonga, arcte imbricata, ex fl. fecundis, feffilibus, duplici ferie, compreffo-carinatis. Singuli fl. conftant flofcul. 5 .

4. durus. C. fpicul. fecundis, alternis, feffilibus, rigidis, obtufis, adpreffis. Syft. veg. ed. 14. Pollich. pal. tab. I. f. I.

Gramen \&c. Barr. ic. I2I3, tab. 50.

In Europa aufirali $\odot$.

Culm. pauci, vix palm. procumbent. Fol. lævia. Spica fecunda. Spicul. duorum ordinum, abfque involucro. Flofc. compreffi, mutici .

Ad Poc genus pertinet.

5. Spharoce- C. bract. integris: fpicis globof. Syft, veg. ed. phulus.

6. corruleus. I4. Jacq. mife. 2. p. 7 r.

C. bracteis integris. Syft. veg. ed. I4.

Sesleria corrul. Arduin. So. 2. tab. 6. f. 3. 4. 5. Gramen \&c. Scheuchz. gram, tab. 2. f. 9. A. B. In Europa pafcuis, \& pratis montanis, \& fubalpinis 4 .

Habitus Anthoxanti. Culm, dodrant-pedal. inferne vaginofus, durus. Fol. firma, glaucocorrulefcen, radical, lata. Panic. fpicata, o- 
vata, congefta, per æatatem ccrulefc. Var. ficica alba.

Non pertinet ad hoc genus.

7. Uniole. C. ebracteat. fpica fecunda; fpicul. bifariis alternantibus, adpreffis, ovatis, carinatis, obliquis. Syjt. veg. ed. 14. Lin. Suppl.

Ad cap. b. Spei.

Gramen glaberrimum. Facies Uniola, fed cal, 2. valv. non multivalv. Spica linearis.

8. coracanzs. C. fpicis digitatis, incurvatis; culm. erecto, compreffo: fol. fuboppofitis. Syft, reg. ed. I4. Gramen \&c: Pluk, tab. 9I. f. 2.

Panicum \&c. Rumph. Amb. 5. tab. 76. f. 2. Vesl. Egypt. tab. 53.

Tfitti-pullu. H. Mal. I2. tab. 78 .

In India $\odot$.

Culm. 4-ped. fol. petiolis obtecti. Fol. longiora, bifaria, pilis longis, raris villofa ; vaginis amplexicaulibus, compreffis. Spicæ 4-6. terminal. raro unica infer, erectiufe. ftriata, digiti longitudine, maruræ latiores, \& fæpe incurvæ. Spicularum raches depreffr. Sem. magnd, fubglobofa, quadruplici ferie, nuda, tumentia.

9. egyptius. C. fpicis digitatis, quaternis (cruciaris) obtufis, patentiffim. mucronatis; calyc. mucronatis : caul. repente; fol. oppofitis. Syft. yeg. ed. I4.

Gramen \&c. Pluk. alm. tab. 300. f. 8. Morif. hift. 3. 5. 8. tab. 3. f. 7 .

In Africa, Afua, Amer.

Caul. palm. lavis, in genua procumbens. Spicul, 4-5. horizontal. rachi mucronata, ultra fl. protenfa. Fl, alterni, diftichi. Cal. 2-fl. mutici .

๘o. indicus. C. fpicis digitat. linearibus: culmo declinato, compreffo, bafi nodofo; fol. alternis, Syft. veg. ed. 14.

Gramen \&c. Burm. Zeyl. tab. 47. f. r. Rumph. amb. 6. tab. 4. f. 2 . Pluk, phyt, tab. 189 . f. 7 . Kauara-pullu. H. Mal. 12. tab. 69.

In Indiis $\odot$

Culm. fefquifpitham. ftriatus, lævis. Fol, ftriata, lævia, ad marginem fcabra. Spicæ digital. rectæ, vel fubincurvæ, fecundæ; maturæ introrfum convolvuntur. Involuc, integerr. Cal, fub 4 -fl. 
II. virgatus. C. panicula ramis fimplicibus; fl, feffilibus 6-fl. ultimo fterili, inifinis fubaritat. Syft. veg.ed. 14. Gramen \&c. Sloan. Jam. I. tub. 70, f. 2.

In Jamaica.

Panic. longa, fubfaftigiata, verticillata; pedune. fimplicibus .

12. domingen-C. panicula ramis fimplicibus; fpicul. fubfeffilib. fis. 6-fl. fl. omnibus ariftatis. Syji. yeg. ed. 14. Jacq. mifc. 2. p. 363.

Habitat in Domingo.

Culmi pl. herbac. 2-3-ped. teretes, nodofi, folioli, glabri, ramum fæe ex infer. nodo emittentes, caterum fimplic. Fol. enfiformilinear. acuta, plana, margine retrorfum aculeat-afpera, vagina amplexicaul. hirfuta. Panicul. terminal. erecta, fil form. conitat racemofe ex rachibus alternis, vel oppofitis pl. patentiffimilque, ad ortum, fafciculo pilofo munitis; quarum alternanribus denticulis fpiculæe infident exiguæ, bifuriæ, compreffæ. Arilta purpur. \& afpera. Sem. minutu n.

13. aureus. C. panicula fpiculis fterilibus, ternatis, pendulis; fl. arittatis. Syft. veg. ed. I4.

Gramen \&c, Shaw. Afic. tab. 232, Barr, rar. IISo. tab. 4 .

In Europar aufralis faxis, \& rupibus $\odot$.

Lagopoides. C. culmo foliofo: fpicis conicis; pedunc. folitar. villofis . Burm, Ind.

Amaranthoides \&c. Pluk. amalt, tab. 357. f. $A$.

Coromandeli.

Radix alba. Culm, erectiufc. teres, ramis fparfis, fæpe folitariis. Fol. lanceol. magnitudine unguis. Pedunc, terminal. Spica compreffa.

Color totius planta cinereus.

ficulus, C. fpica difticha, compreffo-plana; fpicul. alternis, feffilibus, scutis. Jacq. obf. Bot, tab. 43. Gramen panicul, elegantifi. \&c. Turn. inft.

In Sicilia.

Calyce praprimis a Lima difert.

ternatus, C. ficul. ternatis, quaremifve, lanceol, patentiffin. Forsk. Eg.

In Arabia.

Culm. frepe fimpl, filiform, foliofi, glabri. Fol. 
canalicul. vagina fol. triplo longiore. Spica terminal. horizontal. pollicar, pallide rubentes. Spicul. 4-fl. glumis carinatis, muticis.

flocifolius. C. ipicis linearibus, inferioribus alternis, fuperiorbus geminis: fol. alternis, margine alterne flocciferis. Forsk. IEgyp.

In Arabia.

Culm. ped. frepe fimpl, reticulatus, fol. vaginis tectus, necnifi fuperius nudus. Fol, pedal. linearia, flocculis parvis, denfis, fubglobofis, albis. Spica 3-pollic, erecta, fecundre, bafi pilofæe.

Cynofurus (Sesleria) locuftis 5 -ft. diftichis; $\mathrm{Al}$ 2 dent. Hall. Hift. n. 1447.

An Sesleria Ard, tab. 2, ?

Subrotundus, fed evidenter diftichus.

105. FESTUCA . Locult tenuis, multif. Cal, inæquivalv. 2glumis, glumis acuminatis, muticis. Follicul. 2-valv, valvula infer. maiore, acumia, aut eriam ex dorfo arifłata.

Prima 4-fpec. funt valde adfines.

$$
\text { * Panicula fecunda. }
$$

I. bromoides. F. panic. fecunda: f picul. erectis; calyc. valvula altera integra; altera acumin. Syft. veg. ed. If.

Gramen. \&c. Pluk, alm, tab.33. f. 10. Scheuchz. gram. tab. 6. f. I4.

In Anglia, Gallia.

Differt a F. myuro panic. Subjpicata, glumis non ciliatis. Simil, $F$. nvina, fed fol latioribus.

Culmi femi-I-ped-fpitham. Fol. vaginantia, glabra. Panic. 2-3. unc-angufta .

2. ovine. F. panicula fecunda, coarctata, ariftata: culm. 4-gono, nudiufc. fol. fetaceis. Syft. yeg. ed. 14. Stillingfl, mifc, tab. 8, Leerf. herb, tab. 8. f. $3 \cdot 4$.

Gramen \&c. Loefl. pru】. tab. 24.

b. F, vivipara.

Gramen \&c, Echeuchz. gram, tab. 1, Raii Angl. tab 22. f. I.

In alpibus Lapponiar, Helvetia 24.

Culm. cefpitofi, fed-cubit 1 . erect, tenues, geniculis nigris. Fol, tenula, hirluta. Panicula parum fparfa, raro heteromalla, erecta ( ra- 
cemis folitariis) viridis, glauca, fpadicea. Locultæ violac. per ætatem diftichæ .

Non perimet ad hoc genus. Scop.

3. rubra, F. panicula fecunda, fcabra, fpicul. 6-fl. ariftatis; flofculo ultimo mutico: culmo femirereti. Syft. yeg. ed. I4. Stillingfl. mifc. tab. 9. Leerf. herb. tab. 8. f. I.

In Europee fterilibus ficcis, \& pratis alpium 4. Magnitudine, colore maturitatis rubro; fol. latioribus; culm. Jemitereti, differt a $F$. ovina. A F. duriufcula fol. caulinis latioribus, plinis; fpicul. paulo ma: panic. presterea latiore.

A F. myuro, fol. radicalibus fetacess; ariftis infuper valde brevibus differt.

4. amethy- F.paniculd flexuofa; fpicul. fecundis, inclinatis, fina. fubmuticis: fol, fetaceis. Syft. veg. ed. I4.

In Europa pratis, \& pafcuis montanis 24.

Culm. cubital. \& ultra. Folliculi Amethyftinovirid-argenteo col. varii ; calyc. brevi argenteo.

Variat panic. min. col. ftramineo.

Var. fol. ovina. Hall. Helv. n. 1442. y.

5. reptatrix. F. paniculæ ramis fimplicibus, fpicul. fubfeffilibus. Syft. veg. ed. 14.

In Arabia, Palaftina 4.

Radix longe reptans fub terra, veftita latis fol. rudimentis. Cuim. fere 2-ped. Fol. invulutofiliform. Panic, oblon. ramis alternis, fecundis. Spicul. lanceol. acuminatæ, muticæ, 6-fl.

6. duriufcula . F. panicula oblong. fecunda ; fpicul. oblong, lävibus: fol. fetaceis. Syjt. veg. ed. 14. Leerf. herb. tab. 8. f. 2. Fl. Dan, tub. 848.

Gramen \&c. Raii Angl, 3. tab. 19. 1. 1.

In Europa prutis ficcis 4.

Convenit cum $F$. dumetorum, fol. radicalibus filiformibus, canaliculatis: caulinis planis, gramineis; differt vero glumis lavibus.

A. F. rubra differt fol. radicalibus, \& caulinis setaceis; panicul. contractiore; Spicul. parvis, ovatis. A. F. ovina culm. tereti, \& quod Jpiculce continuo in arifiam breviffiniam terminentur.

7. dumetorum.F. panicula fpiciformi, pubefcente: fol. filiformibus. Syft, yeg. ed. x4. Fl. Dan, tab. 700.

In Hifpania, Dania 24.

Culm. I-fefquiped, filiforin. teretes, genicul, duo. 
bus tumidi. Fol, radical, pedal, teretia, vis ancipitia: caulina breviora, canaliculata. $\mathrm{Pa}-$ nic. parva, fpicul. IO-I2. canefcentes; inferior. geminæ, pedicellata; fuperior. folitariæ, feffil. Adfinis valde $F$. duriufcula.

8. elatior. F. panicula erecta, fecunda, fpicul. fubariftatis; exterioribus teretibus. Syp.veg.ed. I4. Sckreb. gram. tab. 2. Leerf. herb. tab. 8. f. 0.

Gramen \&c. Morif. hift. 3. f. 8. T. 2. f. 15. Barr. ic. II 54, tab. 25. Scheucha. gram, tab. 4. f. 6 .

Phonix \&c. Park. theat. f. II64.

b. Gramen \&c. Buxb. cent. 5. tab. I6.

In Earopa pratis fertilibus, prope foffas aquarum 24.

Culm. 2-4-ped. Fol. fulcata, retroverfu alpera . Panic. magna, laxa, femper viridis, fæpe ad alterum latus flexa. Spicul. teretes, acumin. per ætatem diftichæ, glabræ. Glume florales ex pallido, \& violac. col. variæ, oris albis, ficcis. Var. humilior. Hall. helv. ${ }^{\circ} 1452$.

9. myurus. F. panicula fpicata; calycibus minuriff. muticis: fl. fcabris, ariftis longis. Sy veg. ed. I4. Leers. herb, tab. 3. f. 5 .

Gramen. Barr. tab, 99. f, x. Scheuchy. gram. tab. 6. f. 12. Morif. hift. 3. f. 8. tab. 7. f. 43.

In Europa, Barbaria, locis ferilibus ๑).

Culm. cefpitofi, femiped-cubital. fubnudi, fæpe violac. Fol. linearia, fe convolventıa, \& arefcentia. Panic. longa, etiam femiped, ftrictiff, fubincurva, fecunda, ad angulos per cutos ramofa. Locufta teretes, adultæ difticha. Ariftæ purpurafc.

Io. Spadicea. F. panicula fecunda, calyc. 5-fl, flofcul. ultimo fterilí; fol. laevibus. Syjt. veg. ed. I4. Monspelii, in Helvetia.

Altitudo 4-pedal. Fl, magni F. elatioris, flofcul. magis diftantibus, acutis, bafi fubnodofis, rufefcentibus. Panic. contracta. Stam. violac.

3I. phanicoi- F. racemo indivifo; fpicul. alternis, fubfefflibus, Les. teretibus: fol. hovolutis, mucronato-pungentibus: Syft. veg. ed. 14. Ger. prov, tab. 2. f. 2. Gramen \&c. Pluk, tab. 33. f. 4. In Gallo-provincia Es, maritimis arenofis 24 . Tom. I. 
Culm, ped-cubit. Fol. glauca. Spica 2-unc-pedal; \& ultra. Glumæ mucronatæ.

** Panicula squali.

I2. fufca ; F. panicula erecta, ramofa; fpicul. feffilibus, carinatis, muticis. Syft. veg. ed. I4.

In Palapfina.

Culm. altus, ramofus. Fol. e raginis latiufcul. fubulata, angufta, involuta. Spicul. pollic. erectx, obfuræe, multifl.

13. decumbens. F. panicula erecta; fpicul, fubovatis, muticis; calyce floft. maiore, culm. decumben. is fi. vet, ed. 14. Fl. Dan, tab. 162. Leerf, herborn. tab. 7. f. 5 .

Grdmen \&c Moris. hift. 3. 1. 8, tab. I. f. 6. Pluk. alm. tab. 34. f. I. Monti. prodr. tab. 2. f. I,

In Europe pefcuis fterilibus 24.

Culm. adfcendens, pedal. infarctus, articulis 3. Fol. viginæ pilola. Panic. uncial. timplex. Spicul. 3-4-fl. Locuftæ turgidæ. Stm, ovat. flavefcent.

Ad Melicas pertinet. Hall.

34. paueiflore. F. panicula p tult; f ficul, fub 4-fl. ariftat. Icabris: fol. villofi,. Syft. veg. ed. 14. Thumb. $\boldsymbol{J}_{\text {ap. }}$.

In Japonia.

Culm. ereet. 2-ped. ftriatus. Fol. linearia, Panic. ampla, parentiff. Pedunc. capillar. flexuofi, fcabri. Pedicell. mınus patuli .

I5. fluitans, F. panic. ereetd, (frepus) ratnof, fpicul, fubfeffilibus, tereribus, muticis. Sy/t. veg. ed. 14. Fl. Dan, tab, 237. Stillingfl. mifc, tab. I0. Schreb. gram, tab. 3. Leerf. herb, tab. 8. f. 5 .

Gramen \&c. Loefel, prus, ic. 21. mala. Morif. Hift. 3. f. 8. tab. 3. f. I6. Scheucht. gram, tab. 4. f. 5, Barr. ic. 7.

Vivipura varietas. Leerf. 1. c.

In Europa folfis, \& paludibus 4.

Culin. I-3. ped. bafi repens, \& ramofus. Fol. glabra, mollia, nervo, \& oris afperis : Panic. longa, fparfa, inclinata, quandoque fubfpicata. Spicul. uncial. Fiofc. 9-12. Sem, olivaceum, nitidum. 
16. criftata. F. panicula fpicata, lobata; fpicul. ovat. latis, 6-fl. hirfutis. Syft. veg. ed. 14.

In Lufitanice collibus fterilibus.

Culm. pl. vix digital. Panic. fere ovata. Diverfa ab Aira criftata, flofc. pl. hirfutis, culm. breviore, fed facie accedir.

17. ealycina. F. panicula contracta; fpicul. linearibus, calyce floful. longiore; fol, bafi barbatis. Syft. veg. ed. 14.

In Hifpania.

Fol. radical. in cefpitem collecta. Culm. filiform. digital. Panicul, attenuata. Cal. fpiculæ longitudine.

I8. mifera. F. panıcula contracta; glumis ariftatis, fcabris: culm. geniculato. Syft. veg. ed, 14. Thumb. Jap.

In Japonia.

Culm. decumb. apice erectus, fefquiped 1. Fol. digitalia, glabra. Panic. digital. fubf picata, fubfecunda, glabra. Glumæ paucifl. arittat:e, fcabræ.

9. Spinofa. F. frutefcens, ramis, ramulifq. fpinofis; pedicell. aculeatis. Syft. veg. ed. 14. Lin. Suppl.

Ad cap. b. Spei $\hbar$.

Culm. folidi, proliferi, ramis confertis, ereetis. Fol. vaginis dilatatis. Folium fubulat, breviff. pungens. Rami teretes, aphylli; ramul. alternis, horizontalibus, pollic. fimpliciff. mucronato-fpinof. FI, difichi. Spicæ oblongiufc. 7-10. flofc. minus denfe adproximatis.

dichotoma. F. panicula dichotoma, fpicul. feffilibus, patentibus, linearibus, 3-fl. muticis, Forsk. $Æ$ Eg. In Eg pto.

mucronita. F. panicula glomerata; f picul. multifl. flore glandulifero. Forsk. 平g.

In Arabia.

Culm. repent. ramis rectis, cubitalibus, ramofis. Fol. fubdifticha, patentiff. vagina fiffa, margine ciliata. Panic, terminal. pollic. ovata, fpicul, obl-lanceol.

Lanceolata. F. paniculd æquali: caul. decumb. fpicul. 7-fl. muticis, lanceolat. Forsk. AEg.

In Arabia.

fasciculata. F. panicula fafciculata, fecunda; fpicul. 4-fl. $\mathrm{O}$ ij 
longe ariftitis; calyc. valvula exter. ariftata ; altera minuta, mutica. Forsk. $E \mathrm{Eg}$.

In Arabia.

Feltuca fol. radicalibus, fetaceis; caulinis latio. ribus, loculta 7-fl. Hall. Hift. n. ${ }^{\circ} 438$.

Gramen nemorofum \&c. Scheuchz. gram.

In Helvetia.

Culm. 3-ped. genicul. nigris. Panic. laxa, virid. Calyc. glinæe inæqual: graciles; arilta ex glue ma exrer. lineam longa. Omnid ylabra.

Feftuca panicula itricta; lucultis teretibus, 4-fl. Hall. Hift. n. ${ }^{\circ} 143 \%$.

In Helvetia.

Simil. F. rubræ b. fed locuftx non difticha, magis parvifl, violac. cum fplendore aureo mixto. Fol. slauca, dura. Panic. rara.

Halleri. F, ful. perangultis; panicul. Atrictd; locuft. teretibus, hirfutis, longius ariftatis. All. Fl. Ped. Hall. Hiß $144 \mathrm{~T}$.

In Helvetix Sc. montibus 24.

Fol. glauca, retrorfum afpera. Panic. minima, fecunda. Locuftæ 6-6. longiores quam in $F$. rubra; ariltæ triplo longiores. In loculta vil. lus manifeltus.

indica.

F. panicula contracta, erecta: fpicul. compreffis, fubarifatis, fubfuariofis. Retz. Obf. fafc. 4 .

Tilama pullu. H. Mal. T. XII. tab. 45 .

In Tranquebaria.

Facies omnino Pow. Culm. 3-ped. \& ultra, ftriati, fuliofi. Fol. linearid, vaginis bafi tumidis. Panicula femiped. Spicul. parvæ, alternæ, breviter pedicellatæ.

Dignufcitur col, corulefcenti-viridi. Panicul. dimidia pars fimul floret, \& patet; dein contrahitur florente altera parte.

106. BRO- Cal. glumæ acuminatæ, muticæ, infer. minore. MUS, Folliculi gluma infer. maior, concava, apice 2-fido, ariftam rectam infra apicem emitrens. Super. minor eft, \& mutica. Sem. folliculo arcte inclufum.

7. Secallinus. B. pasicula parente, (ereza ); fpicul. compreffo-ovats, aritis erectis: feminibus diftinctis. $S_{y}$ f. veg. ed. I4. Leerf. herb. tab. I1. f. 2 .

B. vitiofus. Weigel. obf bot. tab. 1 f. 2.

B. multiflorus. Weigel, 1, c, tab. 7. f. I. 
Feftuca \&c. Scheuchz. gram. tab. 3. f. 9.

Gramen \&c. Morif. Hift. 3 f. 3. tab. 7. f. 17.

In Europe agris fecalinis arenofis $\odot$.

Culm. 3-ped. Fol. levia, oris, a nervo afpen ris. Spicul. coloratæ, prius hirfutæe, dein gla bræ. Locufta per maturitatem nut ntes, \& diftichæ.

3. japunicus. B. panicula patente, ramofa: \{picul. oblong. glabris; aritis divaricatis. Syft. yeg. ed. 14. Thumb. Japon. tab. Il.

In Japonida (1).

Culm. erect. fubdecumb. fpitham-pedal. fimpl. bafi geniculat. Fol. culmo breviora, linear. Atriata, villofa. Pedunc. \& pedicel. capillar: apice incraffati, flexuofi, inæqual. glabri. Spicul. 5-6-7-fl. unguicul. Glume imbric. margine parum membranac. ftriatæ, infra apicem ariltata.

Differt a $B$. arvenfi, Spicul. oblong. \& ariftis divaricutis. A B. Fecalino fpicul. oblong. glumis imbricatis, nec diftantibus, \& ariftis divaricatis, A B. Squarrofo, Spicul. duplo anguftioribus, \& glab is, nec non paric. ramofa.

3. mollis. B. panicula erectiulc. fpicis ovat. puber entibus, ariltis rectis: fol. molliffime villofis, Syfe. veg. ed. 14. Echreb. gram. tab. 6. f. 1. Leerf, herb. tab. I1. f. I. Weig. $a b /$. $t a b$. T. f. 4 .

Gramen \&c. Morif. Hift. 3. f. 8. $a a b$. 7. f. 18. Scheueht. gram, tab. 5. f. Io.

In Europe aufralioris ficcis $\sigma^{\pi}$.

Simil. B. Secalino. Fed albido-pubefcens. Genicula craffiora, cylindrica, fubtus in primis valde hirfuta. Fol. utrimq. molliffrna, vaginis ftriatis . Panic. brevius pedicellata.

I'lanta vulgatiff. Culm. I-3-ped. Panicula ovata, angultata .

4. Squarrofus.B. panicula (patula) nutante; fpicul. ovatis; ariftis divaricatis. $S_{y j t}$. veg. ed. I4.

Feftuca \&c. Scheuch. gram. tab. 5. f. II.

Gramen \&c. Barr. ic. 24, f. 1. 2. mant. ic. \$2.

b. Gramen \&tc. Buxb. cent. 5. tab. 38. f. I.

In Gallia, Helvetia, Sibiria, Pedemontio $\odot$.

Culm. pedal-cubital. inferne cum mollibus fol. hirfutus. Spicæ glabræ.

5. purgans. B. panicula nutante, crifp2: fol. utrimq. nus 
dis, vaginis pilofis; glumis villofis. Syft. veg. ed. 14 .

Gramen \&c. Few, peruv. T. I. ?

In Canada 4.

Culm. fefquiped. firmus. Fol. latitudine Arundinis, carinata, viridia. Panic, flexuofa. Spi= cul. oblong.

Differt nofira a Few, radicibus fibrofis, nec fquamofis ; fpicul. anguftioribus.

6. inermis. B. panic, erecta; fpicul. fubteretibus, fubulat. nudis, fubmuticis. Syjt. yeg. ed. 14. Schreb. gram. tab. 13.

Gramen \&c. Barr. ic. 25.

In Germania, Helvetia Es. 4.

Rad. maxime reptans. Culm. erectus, I-3-ped. geniculat. purperafe. Fol, plana, mucronata, fublus nervo albicante. Ligula brevifi, obtufa,

- alba. Panic. pedal. fubnutans ad apicem, primum contracta, dein patens. Spicul. reliquis longior, flofculis fub 9 .

7. bifidus. B. panic. erecta, ramof; ; ficul, ovatis, fub 3-fl. glunis bifido-fetaceis, arifta divaricata. \$yft, veg, ed. 14. Thumb. Jap.

In Japonia.

Differt a B. fquarrofo, panic. ramofa, fpicul. multoties min, paucifl, glabris, gluma 2-fid. 2 feta, nec tantum emarginata.

Culm. erect. 2-ped. fimpl. Itriatus. Fol. brevia, digital. \& pollic. linear. ftriata, pubefcent. Panic. palmar. \& ultra, parun patens. Pedunc, \& pedicel. capillar, flexuofi. Spicul, vix lineam longæ, alternæe, glumis patulis .

8. asper.

Habitus potius Avenc, quam Bromi .

B. panicula nutante, fcabra; fpicul, ariftat. villofis: fol. fcabris. Syft. veg. ed. 14.

Feftuca \&c. Morif, 3. 1. 8. tab, 7. f. 27.

In Germania, Helvetia, Anglia 4.

Differt a B. Secalino panic. pedali; ramis femiped. Spicul. funt anguftæ, teretes, glabræ, ex viridi, alboq. col. purpurafc. Fol. utrimq. hirfuta. Vaginæ villofæ, ac molles.

9. ciliatus, B. panicula nutante: fol utrimq. vaginifq. fubpilof. glumis ciliatis. Syft. veg. ed. I4.

In Crnada.

Culm. tenues. Spicul. ublon. compreffa, peta- 
lorum marginibus valle pilofis; qua notä facile diftinguitur.

10. fterilis. B. panic. patula; fpicul. oblong. diftichis; glumis fubulato-arittatis. Syft. veg, ed. I4. Leerf. herb. tab. II, f. 4 .

B. grandifl. Weig. obf. $t a b$, i. f. I. fub qua denominatione $B$. Sterilem, \& teforum coniungit. Gramen \&c. Mont. ic, I. Scheuchi. gram, tab. 5. f. 14 .

Feftuca, Morif, hift. 3. f. 8. $t a b .7$. f. II.

In Europa auftralis agris \&c, $\delta$.

Differt a $B$. tectorum, magnitudine; pedunc. fiabris, non pilofis.

Culm, cubital. Fol. longa, fuperne villofula. Panic. magna, fol, caulinis longior, fere unilateral, multifariam divifa, poft eftorefcentiarn nutans. Pedunc. longi. Spicul. 2-unc. fubcompreflæ , apice divergentes.

Var. hirfuta. Hall. Hift. n. 1507.

II. arvenfis, B. panicula nutante: fpicul, ovat-oblong. Syfto veg. ed. 14. Fl. Dan. tab. 243. Leerf. herb. tab. II. f. 3. Weig, obf, $t a b$, i. f. 3.

Gramen \&c. Vaill. tub. 18. f. 3.

Feftuca \&c. Scheuchi. grum. tab. 5. f. 15. Rudb. elyf. f. 7. optima.

In Europa ad verfuras agrorum $\odot$.

Culm, 4-ped. Fol. magna, iuniord hirfuta, adulta glabra. Panicul. longa, femiped. diffufa, pedunc. Jongis, fparfis; ramolis. Locultæ denlæ .

12. genicula- B. panic, erecta; flotcul, ditantibüs; pedunc: antus.

gular. culmo genu procumbent. $S_{y j t}$. veg. ed, I4. In Lufitania.

Culm. vix palm. Fol. graminea, lævia, vaginis culmum veftientibus. F1. oblong. 4-fl.

13. tezorum. B. panic. nutante: f picul. linearibus. Syft. veg. ed. I4. Leerf. herb, tab. I0. f. 2.

Feftuca, Pluk. alm, $t_{t} b$, 299. f. 2, Morif. Hift. 3. . . 8. tab. 7. f. 13 .

In Europa tectis terrefribus \& callibus ficcis $\%$.

Tota planta rape purpurafc, Culm. fpitham. gracilis. Fol. margine cili ta. Panic, fecunda. Arittæ breves, vel !ongæ.

14. giganteus . B. panic. nutante; fpicul, $4 \mathrm{fl}$, arifis breviorib. Syft, yeg. ed, 14. Schreb. gram, tab. II. Leerfo 
herborn. tab. 10. f. I. Weig. obf. tab. I; f. 5 .

Gramen \&c. Vaill, Parif. tab. 11. f. 3. Scheucht. gram. tab. 5. f. I4.

b. B. glaber \&c. Hal. Hift. n. 1 506. Gramen \&c。 Scheuch. agroft. tab. 5. f. 16.

In Europa humidis, umbrofis collibus, fylvis 24.

Culm. 3-4-pedal. Fol. fpitham. lata, glabra. Panic. palm. ampla, ad florefcentiam fparfa,

15. rubers. B. panic, fatciculara; foicul. fubfeffilibus, villofis,
, ariltis erectis. Syft. veg. ed. 14.

In Hispania, \& agro Nicaenfi $\odot$.

Spicul. multæ, oblong. longe ariftatæ, in fa= fciculum ovatum congett $a$.

26. foparius. B. panic. fafciculata; fuicul. fubfeffilibus, glabris; ariftis patulis. S S ft. veg. ed. 14 .

In Hifpania.

Panicula ovata ex fpicis fubfeffilibus, ovat-obl. Ariftæ extrorfum verfæ.

57. rigens, B. panic. fpicata; fpicul. erectis, fubfeffilib. pubefcent. fub 4-fl, Syjt. veg. ed. I4 .

In Lufitania.

Culm. fpitham. fol. veftiti. Fol. nervofa, fupra leviter pilofa, vaginis totum culmum veftientibus. Spica erecta, breviter peduncul. fpicul. fparfis, fubfeffilibus, erectis. Arifta longitudine fpiculæ.

18. racemofus. B. racemo fimpliciff. pedunc. I-fl, fl, 6-fl, lavibus, ariltatis. Syft. veg. el. 14.

In Anglia.

Racemus nutans. Fol. fubtus villofa. F1. ovati, acuminati .

19. triflorus. B. panicula patente; fl. fub. 3-fl. Syft. yeg. edo I4. Fl. Dan. tab, 440.?

In nemoribus Germanine Ec.

Culm. digit-palm. geniculi purpurafc. Ligula obtufiufc. alba. Panic. digit-palm. Spicul, parva, lanceol. e glauco-viridi-albicantes.

20. madriten-B. panic, rariore, patulo-erecta; fpicul. lineafis. ribus, intermediis geminis, pedicellatis, fuperne incraffatis. Syft, veg. ed. I4. Barr. ic. $7^{6}$, f. $\mathrm{r}$.

In Hifpania, Anglia, Comitatu Nicaenfi $\odot$ :

Culm. 2-pedal. genicul, turgidis. Fol, latiufc. mollia. Arifta longæ, erectr. 
2I. ramofus, B. culm, ramofiff. fol, involuto-fubulatis: f́picul. feffilibus. Syft. veg. ed. I4.

In Oriente 4.

Culm. procumbent. filiform. Fol, fetacea. Spica fæpe 3. alternæ, facie omnino B. pinnati.

22. pinnatus. B. culm. indivifo; fpicul, alternis, fubfeffilibus, teretibus, fubariftatis. Syft. veg. ed. 14. Flo Dan. tab. 164. Leerf, herb. tab. 10. f. 3. Weig. obf. tab. 1. f. 10.

Gramen \&c. Petiv. gram, tab. 3. f. I. Mons。 tab. 16. Scheuchz. gram, tab, 1, f. 7.

In Europa fylvis montofis afperis 4.

Culm. r-2-ped. una cum fol. \& vaginis villofus. Fol. plana. Spica ftrict, dilicha. Spicul. oblong. Cal. \& fl. glum pi'is lo gis, lutefcentibus, \& p befcentibus prædi æ. Cr. fubariftata. Spicularum latus planum cul no obveritur. Du in fluret, fpicæ a cul no ho izontaiter difcedunt : poft efforcfentiam culmo adproximantur.

33. criftatus. B. fpicul diffiche imbricatis, fefflibus, depreffis . Syft. veg. ed. I4.

Triticum \&c. Schreb. gram. tab. 23. f. 2.

Feftuca \&c. Cmel. Sib. 1. tab. 23.

Gramen \&c. Buxb. certs. 1, tab. 50. f. 3. mala:

In Sibiria, Tartaria 4.

Culı. ped-cubital. Fol. glauco-vi idia . Spica unc-fefquiunc, plerumq. fubihrfuta . Spicul. longæ, teretes.

24. diftachyos. B. fpicis fub du bus erectis, alternis. Syft. veg. ed. 14. Ger. prov. tab. 3. f. I. Weit. obf. tab̆. I. f. 8.

Gramen \&c. Barr. ic. 99. f.2. Pluk. alm. tab. 33. f. ro In Europa auftrali, Oriente $\odot$.

Differt a reliquis precipue $\int$ picis $f$ pe duabus, quarum inferior fefflis, nam in culto 3. fpica arifizto.

Culm. I-z-ped. indivifus, erectus, glaber. Spicæ fub io-fl. (picul. feifli. planæ, obverfæ fcapo, ut in Tricicis .

35. flipoides. B. panicula erectiufc, , pedunc, enfiformib. Syfto Y.g. ed. 14.

In Maioria $\odot$.

Gramen fpitham. Culm. pl. ereeti, lavos, fol. culmo breviorib. Panic. oblonga, fufefcens. 
Pedunculi ad dentes terni, intermedio I-fl, lateralibus 2-3-fl.

Diverfus a ftipa membranacea \& genere, E habitu, pedunc. licet conveniat; curn ftipo arifte femine quc.lruplo longiores; huic vix feminis longitudine.

fylvaticus, B. fpicul. feffilibus: culm. indivifo; ariftis folliculi glumas longitudine æquantibus. Pollich. Palat, Fl. Dan, tab. I64.

In Palatinatu.

Differt revera a $B$. pinnato, cui fimilis. Culm. 2-ped. \& ultra, villofus. Fol, utrimq. pilis mollibus villofa. Spicul. villufæ, ac leviter Atriatæe .

gracilis.

B. fpica terminali, debili: fpicul, alternis, remotis, teretibus fubulatis, glabris; ariftis longioribus. Weig. obf. Bot.

In Palatinatu.

Differt a B. pinnato, culmo graciliore; fol. longioribus; fpica e vagina fummi folii; of Spicul. remotis, angufioribus, longius ariftatis.

montanus. B. panicula nurante; fpicul. fub 6-fl. ariftis longioribus. Pollich. Palat.

In Palatinatu .

Culm. 4-j-pedal. erectus, teres. Fol. plana: ligula brevis, alba; vaginæ, præcipue infer. fcabra, \& villofa. Spicul, lanceol. ariftis un-

friąus. cial, tereti-compreffulc.

B. Scop. Fl. Carn.

In Carniola.

Culm. 2-pedal, diffufi. Fol, vix 2 -unc, refracta. Panic. 2-3-unc. laxa, rigida. Racemi plerumq. fimpl. paucifl. Spicul. 2-3-fl. axi adprefla. Petalum exterius 2-fid. e medio ariftatum; interius muticum, 2-part.

villofus.

B. Scop. Fl. Carn.

Triticum rad, repente vaginof. Hall. Hift. $\mathbf{n}$. I 423 .

In Carniola, Helvetia.

Statura Tritici, nodis 6. Fol. femipedal. Spica 4-unc. Flofc. ariftati. Cdl, muticus. Receptac. villofum. Variat culm. nodis, vaginifq. pilofis. villofus. B. panicula fáficulata ; fpicul. linearibus, 6-1., pedicell. glabris. Forsk, $\mathbb{E g}$. In Agypto. 
Culm, pedal. villofus, \& rachis paniculæe. Fol. 2-pollic. lanceol. villofa. Vaginæ longiff. glabræ, ad apicem villofæ, terminatæ intra fo. lium membrana amplexic. hyalina. Spicul, pollic. erectæ ,

polyftachios . B. piniculis patentibus, ramis fpicatis; fpicul. alternis, adpreffis, linearibus, ariltis breviff. Forsk. IEg. $^{2}$.

In Egypti-fofis .

Culm. cubitalis .

Poiformis . B. panicula fpicata, ovato-oblon. fpicul, horizontalibus, compreflis, 5-fl. Forsk. IEg.

In Agypo.

Broniss ( Triticum) locuftis remotis, hirfutis, teretibus, exiguis: culmis floriteris gracilioribus. Hall. Hijt. n. 1432.

In Helvetia.

Simile B. pinnato.

ligufficus. B. All. Fl. Pid.

Gramen \&c. Barr. ic. 76. f. 2. Scheuch. gram. tab. 6. f. 13 .

In Liguria ad litnra maris ().

egreftis. B. hirfutus, angufufolius; locuftis 5-fl. ariftis folliculo brevioribus. Hall, helv. n. 1507. All. Fl. Ped.

Gramen \&c. Scheuchi. gram. tab. 5. f. 13.

Feituca \&c. Vaill. tab. 18. f. 2.

In pafcuis fterilibus 4 .

Dertonenfis. B. All. Fl. Ped.

Gramen \&c. icheuchz. gram, tab. 6, f. Io.

Ad agrorum margines ().

Plukenetii. B. fol, convolutis, pungentibus: locuftis binis terminalibus. All. Fl. Ped.

Gramen \&c. Pluk, ph,t, tab, 33. f. I. In lucis uridis faxofis, calidioribus 4 .

Rad. repens . Culmi pl. ad bafin ramofi, rigidi : Fol. linearia, glauca. Culn. fpithama longior, fubnudus, excepta parte inferiori. In culmo erecto ad bafin nodus fufcus, ex quo vagina fol. caulini erumpit. Loculta diftichæ, teretes, fed ramen utrimque compreffæ, glabræ.

ramofus. Allion.

B. panicula ramof, nutante, fcabra; fpicul. linearibus, IO-fl, arifta longioribus, fol. fcabris . Hudf. Fl. Angl. All. Fl, Ped,

In fylyis collium 4. 
107. STIPA. Cal, 2-valv. I-fl. Cor, valvula exteriore arifta terminali; bafi articulata. Dignofcitur glume corollina arifta longi/fima.

1. pennata. S, ariftis lanatis. Syjt. veg. ed. I4. Cluf. hifto 2. P. 221.

In Europa, e rupium fifuris folet prodire 4.

Radices cefpitofæ. Fol, in iunceam tenuitatem convolura. Panic. pedal, latior, \& difiecta eX vagina fol. latiufc. Arifta quandoque femiped, undique emittens pilos albos, tenuiffimos, patulos.

2. iuncea, S, ariftis nudis, rectis: calycibus femine longioribus, fol. intus lævibus. Syft. veg. ed. I4.

In Helvetia, Gallia ơ .

Culm. 3-ped. Panic. longa, pedal. anguftiff. e= xiens e fol. convoluto, tamquam ex fpatha. Aritta non pilofa.

Haller. cum fequenti coniungit, a qua tamen certe difinzza.

3. capillata. S. ariftis nudis, curvatis; calyc. femine longioribus: fol. intus pubefcentib. Syft. veg, ed. 14.

In Germanix, Gallixe, Pedemontii vallibus \& montibus 24.

Simil. priori, fed fol, non teretia, fu'co longitudinali; fed breviora, rigidiora, minus fcabra, latere fuper. magis explanata, \& fubpubefcent. Cal, non albus, fed fpadiceus. Arifts breviores, \& adultiores varie curvatæ .

4. Ariftella. S. ariftis nudis, rectis, calyce vix duplo longioribus. Syft, yeg. ed. 14 .

Monfpelii 24.

Culm. 2-ped. Fol. angufta. Panic. fublpicata, pedunc. 2-3-fl. Cal, longitudine feminis. Sem. teres, raris villis pubefcens.

5. tenaciffma.S. ariftis bafi pilofis: panicul. (picata: fol. fili= formibus ( tenaciff.). Syft. veg. ed. 14 .

Spartum \&c. Cluf. 2. p. 220.

In Hifpaniac collibus arenofis 4.

Culm. pl. 2-3-ped. erecti, rigidi. Fol. radical. multa, glabra; caulina breviord; vaginæ longa. Panic. fpithama longior, erecta, contracta.

6. avenacea. S. ariftis nudis; calycibus femen aquantibus. Syft. veg. ed, I4.

In Virginia.

Culmi tenues, Fol, fummum ventricofum, lase 

gitudine panicul. Panicula pedunc. coniugatis, I-fl.

Gramen hoc Avena fativa minus eft .

7. membra- S, pedicell, dilatatis membranac. Syft. veg. ed. nacea. I4.

In Hifpania, ad cap. b. Spei.

Culm. lavis. Racenus pedunc. I-fl. Arifta fema flexuofa, femine paulo longior. Flos penultimus feffilis.

8. arguens. S. ariftis n dis; bracteis bafi barbatis, flofcul. fefhli-fufciculatis. Syft. veg. ed. 14. Rumph. Amb. 6. tab. 6. f. I.

In India.

Culm. 6-7-pedal. ex purpur-fufci. Fl, in fafcicul. congefti, ut glumæ vix a bracteis diftinguantur. Bract. longiores. Sem. bafi hirfuta, arnitis terminalibus nigris, contortis .

9. Spicata, S. fl. fpicat, ariltis feminudis. Syjt. veg. ed. I4. lin. fuppl.

Ad cap. 6. Spei 24.

Radix repens. Culm. pl. fefquiped. læves. Fol. graminea, lævia, in fummo culm. brevia. Spica vix digiti longitudine, angulta. Fl. feffiles, vix pubefcent. bafi villofi. Arifta terminal. vix digitalis, torta, pilofiufcula .

108. AVENA. Cal. 2-glumis, multifl. glumis ventricofis, non ariftatis. Arilta e dorfo cor. articulata, contorta. Germina pappus fericeus fæpe circumdat.

I. fibirica, A. paniculata; calyc. I-fl. feminibus hirfutis; ariftis cal. triplo longiorib. Syft. veg. ed. I4.

Feftuca \&c. Gmel. Sibir. I. tab. 22.

In Sifiria.

Culm. I-2-cubital. Fol. fere iuncea, pedal. \&ultra, in fe quafi convoluta. Panic, dodrant. fpicata, fæpe beteromalla, viridis, purpuroviolac, aut verficolor.

2. elatior. A. paniculata; calyc. 2-fl. flofcul. hermaphrodito fubmutico, mafculo ariftato. Syft. veg. ed. I4. Fl. Dan, tab. I65. Sithreb. gram, tab. I. Leerf. leerb. $t_{a} b$, Io. f. 4 .

Gramen \&c. Morif. Hift. 3. f. 8. tab. 7. f. 37. b. f. 38 . Scheuchr. gram, tab. 4. f. 7. Ment。 gram tab. 76. Lob. ic. 23.

Holcus avenacius. Scop. Fl, Carn. All. Fl. Ped. In Europe montanis, \& apricis 24. Radix ex tuberibus compreflis . Culm, 2-3-pedal 
Fol. etidin fubhirfuta. Panicula longa, angufta, multifl. conitans ex locuftis Avenacearum $\mathfrak{z}-$ mulis. Aifite incurvæ, purpurafcent.

Ad Holci genus perinet cum hac dofinitione = H. fl. mafculo arifito; arifa dorfali, tortili, refratic.

3. fitipiformis. A. paniculata; calycibus 2-fl. ariftis fem. duplo longioribus: cuim, ramofo. Syjt. veg. ed. I4. Ad cap. b. Spei.

Culm. pedal, frepe reclinati, lreves, geniculis fufcis. Ramus brevis, etiam florifer, ex fingulis fol. alis. Punic. parva, avendcea.

4. penfylya- A. panicul. attenudtd; calyc, 2-fl. tem, villofis; nica. ariftis calyce duplo longioribus. Syft. veg. ed. I4. In Penfylunia.

Fol, pollic. rigida, bafi barbata .

5. loeflingiana. A. panicula contracta; flofcul. binis hirfuris; altero peduncul. apice biariltato; arifta intermedia longiore. Syft. veg, ed. 14.

In Hilpania, ad cap. b. Spei.

Gramen vix digiti longitudine. Culm. pl, ex radice. Fol. planufc. fummum ventricolum, latius. Panicul. craffa. Cal. flofcul. longior. Arifæe terminales, fetaceæ, longitudine corol. dorfalis duplo longior, torta.

6. Sativa, A. paniculata, calycibus difpermis; fem. lavibus; altero ariftato. Syft. veg. ed. 14. Black. inb. 422. Hall, in nov, comm. Gottin. VI. tab. 4.

b. A. alba.

In Iizula Ivan Fernandez verfus Chilli $\odot$.

Caul. 2-pedal, articulatus. Fol. Tritico anguftiora. Panicul, varia, femper laxa. Locufta longæ, peduncul, pendulæ.

7. nuda.

A. paniculata, cal. 3-fl. receptaculo calyc. excedente; peralis dorfo ariftatis; tertio flofculo murico. S'yft. veg. ed. 14. Hall. comm. nov. Gotzing. V1. tab. 2. 4. Lob. zc. 32. Morifo Hifl. 3. S. 8. tab. 7. f. 4.

Adfunis Sative, fed fem. decorticata decidunt.

8. fatua. A. paniculata; calycibus 3-fl. flofcul. omnibus ariftatis, bafiq. pilofis. Syft. veg.ed. 14. Schreb. gram. tab. 15. Leerf. herb. tab. 9. f. 4 .

Gramen \&xc. Barr. ic, 75. tab. 5. f. I. Scheuch. grami. tab. 5.7.

If Europe agris montanis inter fegetes $\mathrm{O}$. 
Culm. 4-pedal. Fol. glabra, retroverfu afpera. panicul. ampla, palmar. pyramidal. patens; matura valde nutans. Locuftæ flavefcentes.

9. fefquiter- A. paniculata; calyc, fub 3-fl. flofcul, omnibus tia. arittatis; receptacul, barbaris. Sy/t. veg.ed, I4. Gramen \&c. Scheuchy. gram. tab. 4. f. 17. A. B. in Helvetice, Auftria, Pedemontii pratis montanis . Panicul. oblonga, Var. A. flavefientis Hall. Hift. n. 1497.

10. pubefeens. A. fubficata, calycibus fub 3-fl. bafi pilofis: fol. planis, pubefcentibus. Syft. veg. ed. 14. Leerf. herb. tab. 9. f. 2.

Gramen \&c. Raii. Angl.3.tab.21. f. 2. Scheuchz: gram. tab. 4. f. 20. Mont. ic. 65.

In Europa pratis 24.

Nimis adfinis $A$. pratenfi, fed fol. non involuta. Culm. 2-3-pedal. erectus, geniculis 3. purpurafe. Ligula mucronata, alba. Panicul. 4-6pollic. laxa, molliufcula, in florefcentia folum patens. Spicul. maiufcul. fpeciofa, ex viridialbo-purpureo fplendentes.

I1. fterilis. A. paniculata; calyc. 5-fl. exterioribus flofcul. ariftifq. bafi pilofis; interioribus muticis. Syjt. veg. ed. 14.

Figylops \&c. Pet. gax. tab. 38. f. 7 .

In Hilpania.

Similis A, fatur, ut forte fola var. fed triplo ommibus partibus ma. Culmi 2-cubital. Fol. angufta. Utriculi longe peduncul. Ariftæ longifi. fefquipalmar. ficcæ, in modum fpiræ convolutx.

12. flavefcers, A. panicula laxa; calyc, 3-fl, brevibus flofcul. omnibus ariftatis. Syft. veg. ed. 14. Schreb. gram. tab. 9. Leerf. herborn, tab. 10. f. 5.

b. Gramen \&c. Monti. gram, tab. 79. Morif. Hift. 3. f. 8. tab. 7. f. 42.

In Europa pratis, \& pafcuis montanis 4.

Culm. 2-3-pedal, vaginis fubvillofis. Fol, glabra, vel hirfuta. Panicul. femipedal. anguita, pallide viridis, ad deflorationem pitula. Spicul, compreffæ, molles; maturæ diftichæ, nitentes.

13. hifpida, A. paniculata; calycibus 3-fl. pilofis. Syf. veg. ed. I4. Lin. Suppl.

Ad cap. b. Spei. 
Fol. gramined, vaginis pilofis. Culm. pedal. erecti, laves. Panic.' feu racemus pedicell. indivifis, 3-4. Glumæ pollic. oblong. acumin. erectæ, pilufa. Cur fubulata. Arifla tortæ.

14. capenfis. A. panicul coarctatd; calyc. 3 fl. fubulats ; cor. pubefiente, arifta intermedia tortili, curva. Syft. veg. ed. 14. Lin. Suppl.

Ad cap. b. Spei.

Rddix repens. Fol, graminea, pauciora, levia, margine fcabra. Culm, pedal. lævis. Panicul. quali f́picata, ovat-oblong. purpurafc. Cor. 2valv, valv, interiore brevi .

I5. purpurea. A. panicul. coarctuta; calyc. 2-fl. ovatis; cor. villofis; glumd exteriore 2 -fids; arifta terminali inflexa. Eyft. yeg. ed. 14. Lin. Suppl.

In Martinica.

Gramen parvum, geniculat. glaberrimum. Fol. brevia ui in Feftuca ovina, cefpitofa, fetacea, glabra. Panicul, parva. Glunæ calyc. purpur. Fl. omnes ariftati, lanugine alba ubliti .

r6. lutea, A. panicul. patente; calyc. 2-fl. fubulat. cor. nudis triariftatis; arifta intermedia flexuofa. Syft. veg. ed. 14. Lin. Suppl.

In Murtinicil.

Habitus, \& color Airæ flexuof .

17. lupulina. A. panicul. ovata, coaretata; calyc. 3-fl. lanceol. cor. villofis, gluma exter. bifubulata; aritza intermedia reflexa. Syf. veg. ed. 14. Lin. Suppl.

Ad cap. b. Spei.

Difficilime diftinguitur cum fufficienti difcrimine ab $A$. purpures, etfi differens. Hacc maior, vaginis fol. tomertofis, albis. Panicul. huius lutea, nec purpur, arçe coarctata in fig. coni Lupalini. Fl. longiores; cor. hirfutioribus 2fid, , laciniis fubulato-uriftat. nec obtifis, ut in $A$. purpurea.

I8. fragilis. A. fpicata; calycibus 4-fl. flofculo longioribus. Syft. veg. ed. 14. Schreb. gram, tab. 24. f. 3. Culm. pl. fpitham. 3-articul. laves, flurentes adfcendentes. Fol. pollic. plana, nudiufc. margine ciliata, vaginis pilofis. Spica longitud. çulmi, difticha: rachis compreffa. Fl. adpreffi, alterni.

Dignofcitur a Spica, quod fingulare in Avena genere.

I9. pra- 
I9. preten/2s. A. fpicata, calycibus 5-floris. Syff. veg. ed. I4. Leerf. kerb. tab. 9. f. I.

Gramen \&c. Morif. Hift. 3. S. 8. tab. 7. f. 1. Voill. parif, tab. 18. f. I. Raj. Syn, 3, $\imath_{1} b .2$ I. f. I.

In Europa pratis, \& pafiuis collinis, \& montanis 24 .

Culm. ped-cubir. \& ultra, fere nudus. Radix inftar bulbi albidi. Fol, angufta, glabra, retroverfu afpera. Panic, 2-unc. \& ultra, angufta, purpuro-argentea. Ariftæ longæ, nigræ .

20. fpicata . A. Ipicata, calyc. 6-fl. longioribus; petilo exter. apice ariftato, furcatoq. Syft. yeg. ed. I4.

In Penfylvaniz.

Gramen anguftum. Fol. linearia. Spicul. 3-4. remotæ, erectæ fubpedunc. Facies Fefiuca decumbentis.

2I. bromoides. A. fublpicata; fpicul. binatis; altera peduncul. ariltis divaricatis, calyc. 8-fl. Sy/t. yeg.ed, 14. Gramen \&c. Scheuchz. gram, tab. 4. f. 21, 22. In Helvetia, Monfpelii .

Habitus Bromi fquarrofi, Hallero Var. eft A.pratenfis. Culm. 2-pedal. Spicul. erecta, teretes, veluti argentea.

ftrigofa.

A. panicul. oblong. fecunda, fubnutante; flofcul. geminis, apice 2 -ariftat., dorfo arifta geniculata. Schreb. Spicil.

Inter Avenam fativam, \& Hordeum, raro Secali immixta.

Culm. \& fol, nuda. Gluma corollina maturo fem. nigra. Sem. mediæ magnitudinis, altero apice barbatum.

pupeftris. A. Allion. Fl. Ped. Hall. helv. n. 1478.

In alpium apricis.

Facies hirta, inconcinna.

Fol, angufta, caulina etiam femilin. lata, Locuftæ ma. lividæ, arifta recurva.

aureta.

A. Allion. Fl. Pedem, Hall. hely, n. I488.

In alpibus.

Pulchra planta. Culmi dodrant. Fol. fetacea, tenuiffina. Panicula fparfa, erecta, ftricta. Loculta longæ, mucronatz , Fl. elliptici, aurati, bafi villofi. Sem. oblongum, acutum. Planta adulta tota col, aureo. Tom, I. 
A. diantha, fol. planis, patulis : periol. floralibus vilJofis. Hall. helv, n. 1489 .

In alpibus.

Rad. reptans, multicaul. Caul. femi-r. ped. ad terram foliofi, fuperne nudi. Fol. glauca, lineam lata. Panic. angulta, pene firata, fub 20-fl. e viridi-purpur. \& albo varia. Adulia planta diflicha eft, tuncque fl. ex argenteo, \& violac, varii .

Scheyehzeri. A. petiolis ramolis; locuftis teretibus, 5-fl. baft pubefcentibus. Hall. helv. n, 1500. All. Fl, Ped.

Feftuca \&c. Sckeuchy. it. 6. tab. 19.

Giamen \&c. Scheucht. gram, tab. 3.

In pafcuis editioritus 24.

Culm. fubpedal. Fol, 2-lineas lata, carinata. glabra. Panicul. longa, angufta, fpicata, pedunc. 3-5-fl. Cal. fplendens, purpur. apice curvo. Folliculi gluma exterior ex viridi-fpddiceo-aureo varia, mucronata; interior membranacea, ex aureo, \& argenteo col. varia . Arifta long, tortilis, fufca; pedunc. brevibus villofis.

yog. ANTHISIIRIA, Cal. æqualiter ad bafin fiffus in lacis. 4. æquales .

1. ciliata, A. Syft, veg. ed. 14. Lin. Suppl.

In Indin.

imberbis, A. fol, involucrifque nudis, Retq. $O b \int$. fafc. 3. Ad cap. b, Spei.

Omnia teneriora A. ciliatæ. Culm. compreffus . Cal, fimil. prioris Pedunc. fclitar. capillar. 2-fl. e vaginis 2. fupremis.

I10. LAGURUS. Calycis glunæ ariftatæ, arifta villofa. Folliculus biglumis, valvuld maiori, terminata duplici arifta, cuin tertia dorfali retorta, valo vula altera minori acuminata. Sem, oblongum, folliculo arcte inclufum, ariftatum .

I, oyatus, I. fpicd ovata, ariftata, Syft, veg. ed. 14. Schreb. gram. tab. 19. f. 3. Barr, ic. tab. IIb. f. 1.2. In Italia, Gallia, Sicilia, Lufitania $\odot$.

Culm. femi-1. ped. Fol, flexilia, lanugine quadam obfita, vaginis membrana alba. Spica mollis, incana. Ariltæ lutefcent, , aut dilutofufcæ.

2, cylindricus, I. fpica cylindrica, mutica. Syft. veg. ed. 14。 
Gramen \&c. Barr. ic. II.

Monfpelii, in Creta, Smyrna, agro Nicaenfi 4.

Culm. pl. 2-pedal. recti, fimpl. glabri. Fol. radical. longiora, nervo eminente, glabra: caulina internodiis breviora; quo fuperiora magis vaginancia. Spica dodrant. nuda.

III. ARUNDO. Cal, 2-valv. Flofc, vagi, congefti, lana cincti. Sern. Januginofo folliculo arcte inclufum.

r. Bambos. A. calycibus multifl. (picis ternis, feffilibus. Syft. veg. ed. I4.

Ily, H. Mal. r. $t a b$. I6.

Alritudo 2-3. hña. CuIm. articulat. Fol. fpitham. digitum lata, fenlim anguitiora, breviter petiol. venis in longum ftriata. Palmæ inftar $e$ fummitate ramos undiq. dfpergit. Spicæ fl. fquamofæ nodulis caulium proveniunt . Panicul. laxæa, purpurofc. vel nigra.

Elicitur Saccharum. Chinenfes ex hac conficiunt Papyrum .

2. Denax. A. calye. plerumq. 5-fl. panicula diffufa: culm. fruticofo. Syft, veg. ed. I4. Monti. ic, I.

b. Arundo \&c. Morij. Hift. 3. .. 8. tab. 8. f. 9. In Europa collibus \& c. 24.

Culm. 6-pedal. \& ultra, articulatus, durus, fiftulofus. Fol. 2-pedal, vaginantia, lata, fubulata, integerr. patula. Panic, fefquiped. erecta, lanuginofa.

3. phragmites. A. calyc. (fub) 5-fl, panicul, laxa. Syft, veg. ed. 14. Leerf. herb. tab. 7. f. I. Morif. Hijt. 3. S. 8. tab. 8. f. 2. Scheuchz. gram, tab. 3. f. 14 .

In Europie lacubus, fluviis 24.

Culm. 6-pedal. fimpl. Fol. unc. lata, lineata, oris fecantibus, Panicul. pedal. per atatem nutans. Pappus copiofiff. fericeus.

4. epigejos, A. calyc. I-fl. panicul. erecta: fol. fubtus glabris. Syft. veg. ed. 14.

In Europa collibus aridis, fubulofis 4.

Radix geniculata. Culm, cubital, \& ultra, fimpl. ad terram vaginofi. Panicul. 2-unc. fubfpicata, angufta, fpadicea. Petal. 1. convolutum, calyce longius. Cor. ariftata. Hac fpec. of yalde confufa.

5. Calamagro- A. calycibus I-f., lavibus: cor. Januginof. culm. ftis, ramofo. Syjt, veg. ed, I4. Fl. Dan, tab. 280. 
Gramen \&c. Scheuchz. gram. tab. 5. e 3. F. B. C. D. In Europa paludibus grominafis 24.

Culm. cefpitofi, 2-cubitai. Ful cubital. fubulata, lita, oris, nervilque afperis. Panic. pedal. denfa, alterne laxior, \& contracta.

6. arencrie. A. calyc. I-fl. fol. involutis, mucronato-pungentibus. Jyft. veg. ed. 14 ,

In Europa, Planta glaberrima . Culm. fefquiped. erectus, geniculat. atro-purpur. Fol. 3-4. pollic. $\mathrm{Pa}=$ nicul. 3-pullic, in fpicam coarctata, oblicure violac.

frataีe.

Plizii. A. calyc. I-fl. fol, utrimq. glabris, margine in-

maxime.

A. teruis, altiffmeq. fcandens. Aubl. Guiam. Plum. MSS. $t a b .92$.

In Guiana. trorfum fabris. Turre. Aninıad. Bot. Zann. Hif. $t a b .19$. f. 2.

In Bononia fluviis 24 .

Non confundenda cum Andropogone Ravenna.

Alritudo hña. Calami graciles, viminum inftar fl.xibiles, geniculati, medullufi. Fol, anguftiora, 2. dodrantas longa, afpera. Panicul. ex fpicul. plumatis, viridi-cœrul-purpur, varia.

A. f l. margine ciliatis, b. $\mathrm{fl}_{\mathrm{l}}$ albis, hirfutie ciliatis, ftriatis, planis, totis viridibus. Forsk. IEg.

In Arabia .

Giferis. Fol. marginis fcabrities atate evanefcit.

A. culmo er cto, foliofo: fol. bifariis: panicula coarctata; calycibus 3-fl. Retz. Obf. fafc. 4 .

In India Orient.

Fol. conferta, fpitham. pollicem lata, patentiffima, plana. Pa ic. erecta. Cor. gluma exterior longa, fubariftat, ventricofd, exfus lanata: interior duplo brevior, hyalina, emarginata. Anth. flavæ. Stigm, barbata, viridi-cœrul.

Eerke.

A. culycibus I-fl. nudis, flore fubulato, intus lanato multo brevioribus: panicula fecunda, nutante. Retz. Obf. fafc. 4.

Habitat in In ia Orient.

Culmus altus, priori anguftior, inanis. Fol, 


\section{TRIANDRIA DIGYNIA.}

longa, digitum tranverfurn lata, fcabra. $\mathrm{Pa}$ nic. 2-fpitham. contracta. Pedunc. longi, femiverticill. inæqualiter divifi. Fl. fparfi, longe pedicellati, folitar. fubulati.

12. ARISTIDA. Cal. 2-valv. Cor. I-valv, ariftis 3. terminalibus.

\$. adfasmbonis. A. panicul. ramofa, fpicis fparfis. Syfo, yeg. ed. 14.

Gramen \&c. Sloan. Jam. I. tab. 2. f. 56. Pluk, alm. $t a b$. 191. f. 3. ?

In Infula Adfcenfionis $\mathbf{4}$.

Habitus Feftuce ovina, fed paulo ma. Radix cefpitem conftituens. Culm inferne ramofi. Fol. e bafi latiore fenfim anguftatd, plano-canaliculata, fubulata. Panicul. oblonga .

2. americane. A. paniculæ ramis fimpliciff: fpicis alternis. Sy $f$ 。 veg. ed. 14.

In America.

Differt a priore, quod radii puntcula fant itudivifi: Jpicul. alkernce e tlofcul. feffilibus, quorums valvula calycina purpurafit .

3. lumofa. A. paniculata ; arifta intermedia longiore, lanata : culm. villofo, Syft. veg. ed. I4.

A. lanata. Forsk. Eg. monente Vahl.

In America.

Panicula ariftis lanatis refert Stipam pinnnen, fed panic, magis compofita, \& omnes partes mi. \& culın, villofus. Arifta fem. itidem lanata, fed dd bafin nuda.

4. artadinu- A. paniculatd, arifta intermedia longiore, lavi. sea. Syft. veg. ed. I4.

In India Orient.

Facies Graminis communis. Culm. 4-ped. angufti, læves, farcti. Fol. angufta, involuta, ftriata, lavia. Panicul. oblong. erecta, pedicell. capillaribus. Fl, oblong. canefcent. pilis albis immixtis .

S. giganiea. A. panicul. elongata, effúa, fecunda; calycibus I-fl: ariftis corollinis fubæqualibus, re= ctis. S.ft. veg. ed. 14. Lin. Suppl.

In Teneriffa.

Gramen altiff. ramofum, glaberrim. Panicul, terminal. dodrantal. non coarctara, ut in A. adfcenflonis: calyc, glaberr. inæqual. corulefcentes, 
6. Hyfrise A panicul, divaricata, patentiff. flofcul, fimpliciff. glabris; ariftis rectis, divaricatis. S, fis. veg. ed. 14. Lin. Suppl.

In Malabaria.

Gramen repens, ftoloniferum, glaberr. Culm. breves, tenaciff. foliati. Fol. graminea, convoluta. Panicul, terminal. magna, pedunculis, pedicellifq. binatis. Flofc. longi, filiform.

paniculata. A. fpicul. linearibus, oblong, arifta cuiulvis flofculi triplici, giabra. Eorsk. AEg.

In Arabia.

fesacea. A. culmo erecto; ariftis fcabriufculis. Retz. Obfo $f a / c .4$.

In Malabaria.

Culmi ftricti. Panicula contracka. Cor. bafi lanata. Inter utiliffnia Indorum gramina.

depreffa. A. culmis trifido-ramofis, decumbentibus, ariftis fabriufculis, Retz. Obf. fofs. 4.

In Malaburia.

Culmi fefquiped, filiform. Fol. anguftifima, vix convoluta. Panicula fubfecunda. Cal, I-fl. valvulis albis, dorfo viridi. Cor. bafi tantum lanata.

Similis priori : differt culmo; glumarum calycinarum longitudine relativa, \& forna. Fl. ut etiam ar ftue mirt. breviores, minus divaricate.

113. LOLIUM. Fl. fpicati, diftichi, locuftis multifl. ad flexuofum fcapum feffilibus. Fovea nimirum in fcapo eft loco valvæ calycinæ, arque ex altera parte gluma una, longa, calycina, five foliolum, in cuius ala fedet fpicula. Follicul. quilibet 2-glumis, ex valvis inæqualibus. Sem. nudum .

1. perenne. L. fpica mutica ; fpicul, compreffis, multifl. (contiguis). Sy.t. veg. ed. 14. Leerf. herb. tai. 12. f. 1. Schreb. gr. $t a b .37$.

b. Var. ariftata. Vaill. ab, 17, f. 3 .

y. Gramen \&c. Scheucht. gram. tab. 2.

Var. ficica ratrofa.

Var. fol, radicalibus, anguftis; \& fpica tota diflicha, lata. Scheuchz. gram. tab. I. f. 7. Mom rif. Hiff. 3. f. 8. tab. 2. f. 2.

Vor. Spicis anguftioribus. Mons. ic, I9. 
Var. fpicis teretibus, \& langioribus quambine vulgari.

In Eutope ad agrorum verfuras folo fertili 4.

Culm. cefpitofi, pedal. focile detumbent. Fol. retroverfu afpera. Spica longiff. fæe pedal. rara, \& interrupta, virid. albr, \& tubputpur.

2. tenue, I. fpica matica, levi; fpicul. 3-fl. Syjt. veg.ed. 14.

In Gallia, Germania, \& Pedemontio $\odot$.

An vin. prioris? Diverfum a Tritico tenello :? 3. temulentum, L. annuum, lucultis diftichis. Hall. helv. $\mathrm{n}$. 1420.

I. fica ariftata \&c. Syft. veg. I4. Sctreb. gram. tab. 36. Fl. Dan. tab. 160. Leerf. herb. tab. 12. f. 2 .

In Europe agris inter Hotdeum, Linum \&c. $\odot$.

Culm. cubital. Fol. graminea, glabra. Fl. fpicati. Spica pedal. locultis raris, I8. Sem. 0 le, utrimq. conpreffum minus quam in genuinis Cerealibus. Vur. Spicis muticis, fed differt a L. perenni fpicul. teretioribus.

4. difachion. L. frica binata; calycibus 1-fl. cor. lanatis . Syft. veg. ed. 14.

In Malabaria.

Culm. decumbent, bafi ramofi ; floriferi adfurgent. pedal. filiform. laves. Fol graminea. Spica terminal, aqual. feffil. lineares, extrorfum fecundre, fl. alternis, albo-hirfuris.

114. ROTTBOELLA. Rachis articulata, tereriufcula, in pluribus filiformis.. Cal. ovat-lanceol. planus, fimpl, feu 2-part. Flofcul. alterni in rachi flexuofa.

I. incurvata . R. fpica tereti, fubulata; gluma calyc. fubulata, adpreffa, 2-part. Sift. veg. ed. 14. Lin. Suppl.

-Egylops incurvata. Syft, veg, ed, 13. Bocc, muf. tab. 59.

In Europa maritimis $\odot$.

Culm. ramofus. Articuli fub 14, fingulo articulo adfider fpicula filiform. Cal. 2-valv, exterus. Cor. valvul. calyci contraria.

2. compreffa. R. Ipica com reffa, fubalata; gluma calycina lanceoliplana, indivifasi Syjt, veg. ed. 14. Lin。 Suppl.

In India. 
3. dimidiata. R. fpica dimidiata, compreffa, lineari; laters exteriori aggregato flofculofo; interiori lavi, nudo. Syft. veg. ed. 14. Lin. Suppl.

Panicum dimidiarum. yft. veg ed, 13. Burm, Ind. tab. 8. f. 3. Pluk, phytol. f. 6.

In India.

Rachis membranacea, dilatata, alternatim ad fpiculas dente excifa, ac fi folium effet adglutinaturn. Spicul. flócul, 5 .

4. exaltate. K. fpica tereti-filform. undiq. flofculofa, ylumis ovat., obtufis, vaginis punctato-hirfutis: Syft. veg. ed. 14, Lin. suppl.

\section{In Indiis.}

Gramen altum, culmo folido, farcto. Spicæ folitar. laterales, palmar. \& ultra.

5. corymbofa, R, fpicis adgregatis, lateralibus, filiformibus : floful. bifaris patentibus, fol. bafi ciliatis. Syft. veg. ed. 14 .

zicisura ngilops exaltata. Syft. veg. ed. I3.

65 ints In Malabaria ad füfas agrorum .

Culm. orgyal, erecti, fimpl, ftriati, glabri, tenaces, geniculati, inanes, fol. $2-3$. obfiti. Fol. fubped. angufta, lævia. Spicæ fubulatæ R. incurvata fimiles, longitudine fere digiti, rectre, angultr.

lavis.

R. pedunc, longiff: fpica flofcul, binatis, lateralibus: calycibus ovatis, inpunctatis, lævibus. Retz. Obf. fafi. 3 .

In Tranquebaria.

idtat Culmi adfcendent, vaginantes, foliofi. Pedunc. e vagina 3-4. plufquam pedal. monoftachii. Fol. brevia, carinata, oris barbatis. Spica ftriatiff.

fanguinea. R. panicula fpicis ariftatis, fimplicibus, alternis pedunculat. fl. bractea laterali ciliata. Retz. Obf. fafc. 3 .

In China.

olusist

Facies omnino Andropogonis. Culm. femiteres, articulat. foliofus. Superiores articulos vagina veftiunt fuperne dilatatæ, \& fere cucullatæ. F qualibet harum fpica exit filiformis, pedunculo intra vaginam latente. Fl. feffil. alrerni in rachi exfcavata. Cal. 2-valv. oblique latesalis, gluma exteriore fenitereti, fubulata, 
cartilaginea ; interiore aquali, tenuiffma, al$\mathrm{ba}$, ftriis fanguineis . Cor. gluma exterior fanguinea; interior ad bafin ufque fifla. Ad huius bafin arifta torta .

15. ELYMUS. F1. dentibus flexuofi fcapi infidentes. Locufta geminæ, multifl:: qualibet fpicula duabus non glumis, fed rigidis fetis excipitur. Follicul. ศuilibet 2-valv. valvula exter. ariftata; inter. plana .

I. arenarius. E. fpica erecta, arctı; calycibus tomentofis, flofculo longioribus. Syft. veg. ed. I4.

Triticum \&c. Gmel. Sib. I. $t_{n} b .25$.

Ad Europe litora 24.

Culm. fub 2-cubital. Fol. Arundinacea, modice lata, glauca. Spica longa, tomentofa. Spicul. 2. rectre, 2-fl, mutica.

2. fibiricus. E. fpica pendula, arcta; fpicul. binatis, ical. longioribus. Sift. yeg. ed. 14. Schreb, gram. tab. 2I, f, I.

Triticum \&c. Gmel. Sib. 1, tab. 28.

In Sibiria 24.

Planta glabra, aut hirfuta . Culm. 2-ped. admodum fragiles. Fol. glauca. Spica palmar-femiped. viridis, amethyftina, fpadicea, aut his coloribus variegata. Sem oblong. fufca.

3. philadelphi. F. fpica pendula, patula ; f́picul. 6-fl. inferioricus. bus ternatis. Syif. veg. ed. 14.

In Philadelphin 4 .

Simil. fequenti, fed fpica nutans ulrra bafin. Spicul. \& præcipue intermedium latus planum, ut Triticum, culmo obvertit. Ariftæ flexuofæe

4. cansdenfis. E. fpica nutante, patula; fpicul. inferioribus ternatis; fuperior. binatis. Syft. veg. ed. I 4. Gramen \&c. Morif. Hift. 3. f. 8. tab. 10. f. 2. In Canadn 24.

Convenit in pl. cum E. Sibirico. Differt fpicul. villofis, nec nudis; involuc. arifta m gis fubulata; fpicis inferne 3 \&c.

3. caninus. E. fpica nurante, area: fpicul rectis, involuc. deftitutis; infimis geminis. S ft. veg. ed. I4. Leerf. herb. tub. I2, f. 4 .

Triticum \&c. Gmel. ib. 1. tab. 27.

Gramen \&c. Morif. Hijt. 3. f. 8, tab. 1, f, 2. Buxb. cent. 4. $t a b$. 50.

In Euroga dumletis, \& Jylvis 24. 
Sinill. Tritico repenti, fed rudia fibrofa, nec res pens vaginofa, ut in illo. Planta viridis, non glauca. Culm. 2-ped. \& ultra. Fol, breviter pilofa, retroverfu afpera. Spica brevis, 3-unc. rara. Arilta fpica fua multo longiores.

Ad Tritici genus fpezatat.

6. tener. E. fpica pendula; flofculis geminis. Syft. yeg. el. 14. Lin. Suppl.

In Sibiriu .

Culm. 2-pedal: lavis, geniculis rubris. Fol. fubfcabra, vaginis lævifl. Spica E. Sibir. fimil. fed multo tenuior. Involuc. alterna, 4phyll. flofculis (præter ariftam) breviora, fubuldta, 3-fl. Flofcul. feffil. intermedio pedicellato. Arifta terminal. flofculi fere longiores, fape flexuof .

7. virginicus. E. f pica erecta; fpicul. 3-fl: involuc. ftriato. Syft. veg. ed. 14.

In Virginia 4.

Spiua 9. pollic. longa. Involuc. 4-phyll. Arifta fpicula longiores.

8. europeus. E. fpica erect ; fpicul. 2-fl. involucro xqualibus. Syft, reg. ed. 14.

Gramen \&a: Scheuchz prodr. tab. I. f. I. Hall. app. ad Scheuchx. agroft. tab. I.

In Germania, Helvetia Ec. Sylvis 4.

Ad Hordei genus fpęut.

9. caput me- E. f icul. 2 -fl: involuc. fetac. patentiff. Syft. veg. dufa. ed. 14. Schreb. gr. tab. 23. f. 2.

In Lufitan. \& Hifpan. maritimis .

Culm. ped. fpica oblong. Videtur novum gerus polfe confticui.

10. Hy frix. E. fpica erecta; f picul. involucro deftirutis, patentibus. Syjt. veg. ed I4.

Altitudo humana. Spica longiffima, conftans ex fpiculis 2. Spicul. 4-fl. ariftis longis .

fubulatus. E. fpicul. uniflor. diftichis, alternis, adpreffis, fpicam fubulatam formantibus. Forsk. $\mathbb{E} g$. In Egypto. $_{\text {gato }}$

Cal. corolla maior, unilateralis.

116.SECALE.Cal. oppofitus, 2-valv. 2-fl. folitarius .

1. cereale. S. glumarum ciliis fcabris. Syft. veg. ed. 14.

S. hybernum. Black, tab. 424.

In Creta $\odot$. 
Cerealium noftrarum alciffimum. Fol. retroverfu afpera. Spica Tritico longior, \& compreffior; conferta, fubdivifa. Glumæ inferior. arifta. longiffima. Var. fpicis ramofis .

2. villofum. S. slumarum ciliis villofis; fquamis calycinis cuneiformibus. Syl. yeg. ed. 14 .

b. Gramen \&c. Buxb. cent. 5. tab. 4I.

In Europa auftrati, \& in Orience.

Glumæ villofæ in aritas longiff, definentes .

3. rientale. S. glumis hiffutis; fquamis calycinis fubulatis . Syft. veg. ed, 14,

Ad Arcipelagum.

Spica brevis, \& lata .

4. creticum, S. glumis extrorfum ciliatis, Syft. veg. ed. I4. In Creta.

Cum. 2-cubiral. Fol. linearia, vaginis hirfutis. Spica 3-unc. ufque pimır. 3-4. lineas lata. Lotulta 5-6. lin are .

117. HOR - Scajus altetne flexuofus, \& forcbibus excifus . DEUM. Loculta $3 \mathrm{fl}$. five ex tribus ifiti ctis fl. compofita. Cal, comm. 6. nguftis fo iol, conftat, duobus nempe glum rum inftar fingulo folliculo fubictis, \& arift tis. Folli.ul. 2-valv. valvula exteriore ventricofa, in ariftain loagam; definente; interiore pluna. Sem. folliculo arcte involutum.

1. vulgare. H. flofcui. omnibus hermaphrodit. ariftaris: ordinibus duobus erectioribus. Syf. veg. ed. I4. Black. $t a b .423$.

H. polyftichon. Hall, in nov. Comm. Guttin. VI. tab. 2. Morif. Hift. 3. f. 8. tab. 6. f. 3.

b. H. caelefte. Sem. decorticatum.

In S icilia, \& $R$ I $/$ ia $\odot$.

Fol. Ttitico anguftiora. Spica quafi difticha, etfi plurium ordinum, ad bafin turgida, ariftis longis afperis.

2, hexaffichon. H. flofcul. omnibus hermaphroditis, ariftatis: feminibus 6-feriam aqualier pofitis. Syft, veg. ed. I4.

Spica craffior, \& torcfior.

3. diftichon. H. flofcul, literalibus m-feulis, muticis: femin. imbricatis, angularibus. Syft. veg. ed. 14. Morif. Hif., 3. f. 8. tab, 6. f. 1. Lob. ic. 29.

b. H. nudum. Sem. decorticnta.

Ad Samaram Tartarie fluvium (.). 
Culm. pleruinq. fefquicubit. Spica diftiche imbrie cata, compreffufc. ariftis longis, \& afperis.

4. Zeocriton. H. flofcul. lateralibus mafculis muticis: femin. angularibus patentibus, curticatis. Syft. veg. ed. I4. Schreb. gram, tab. 17.

H. diäum Oryza germanica. Bauh. Hift. 2. p. 429. cum ic. bona.

Culm. priore brevior. Spica brevior, \& latior, granis magis confertis; ariftis nonnihil brevioribus.

5. bulbofum. H. flofcul. omnibus ternis, fertilibus ariftatis; involucris fetaceis, ciliatis. $S_{y} f$. veg. ed. I4. Gramen \&c. Barr. ic, 112, f. 2. Morif. Hijt. 3. S. 8. tab. 6. f. 7 .

In Italia, Oriente 4.

Radix bulbofa, globofa. Culm. 3-pedal. vagina fummi fol. ventricufa. Spica H. murini .

6. nodofum. H. floficul. lateralibus mafcul. muticis; involuc. fetaceis, lævibus. Syft. veg. ed. 14.

Gramen 3x. Raii Sinop. Stirp. Brit. tab. 20. f. 2 , In Inuia, Anglia.

Radix bulbofa, copiofa. Fol. angufta, glabra. Spica uncial. gracilis .

7. murinum . H. flofcul, lateralibus, mafcul, ariftatis; involuc, intermediis ciliatis. Syft, yeg. ed. 14. Fl. Dens tab. 629.

Gramen \&c. Morif. Hift. 3. f. 8. tab. 6. f. 4. In Eurupa locis ficcis ad vias, \& limites agrorum $\odot$.

Culm. ped-cubital. Spica ovata, craffa, polyfti-

8. iubatum. H. ariftis, involucrifq. fetaceis, longiff. Syft. vega ed. I4.

Elymus crinitus. Schreb. gram. tab. 24. f. I.

Gramen \&zc. Buxb. cent. I. tab. 52. fo I.

Smyrne.

Habitus H. murini, fed involucra, \& arifte fetacea quadruplo longiores quan tota fpica; thtde fingularis facies Graminis.

secalinum. H. flofcul. lateralibus, mafculis, ariftatis; involuc. fetaceis, fcabris. Schreb. Spicil. Fl. Lip. fiens, All. Fl. Ped.

H. murinum. Lin. $b$ 。

In locis ficcis $\odot$. 
Altius, duplo anguftius, \& magis fufcum $\mathrm{H}_{\text {. }}$ murino. Fol. mollia, pilofa. Spica min. \& tenerior quam in $\mathrm{H}$. murino. Involuc. min. nullibi ciliata. Var. Spica amone purpur.

geniculatum. H. culno decumbente, fol. obtecto; fummo fpathaceo fpicæ fubiecto, fupremo nodo incure vato. All. Fl. Ped. tab. 91. f. 3.

Gramen \&c. Pluk. pliyt. tab. 33. t. 2.

Ad litora maris $\odot$.

Non eft H. iubatum. Culm, pl. palmar, nodofi . Fol. molliter pubefcentia: radical. linearia; caulina culmum involvunt ufque ad nodum, inde larefcunt gradacion; ut ovato-lanceol. fut. Spica fubunc. fubovata, obfure difticha. Pedunc. 3-fl. oppofite nafcuntur. Sem. oblong. fufcum, intus fulcatum. Planta culta tota maior evadit.

I18. TRITI-Cal. 2-valv. folitar. fub 3-fl. Flos obtufiufc, acuCUM . tus. Scapus alterne flexuofus, \& fcrobibus excifus. Solus fitus fpicularum diffinguit Triticum a Bromis.

* Anrus.

I. arifatum. T. calyc. 4-fl. ventricofis, glabris, imbricatis, ariftatis. Syft. veg. ed. 14. Nov. com. Gottin. V. $a b$. 1. f. 1. Black. tab. 40. f. 4. 5.

Apud Bafchiros in campis $\odot$.

Fl. fleriles fape fubhirfuti corpufculo terminantur, quale Melica of pro charactere.

Culm. 3-ped. celpitofus. Fol. glabra, 3. lineas lata. Spica denfa, ponderofa, aliquot unc. locuftis imbricatis.

2. muticum - T. calycibus 4 -fl. ventricofis, lævibus, imbricatis, fubmuticis. Syft, veg. ed. I4. Nov. comm. Gottin. V. tab. 1. f, 2. Blak, tab, 40. f. 1. 2. 3. o.

Culm. cefpitofi, 3-pedal. geniculati . Fol. glabra . Spica denfa, ponderofa, imberb. locultis imbricatis. Sem. congenerum maximum, villo tectum.

3. compofi- T. fpicula compofita; fpicul. confertis, ariftatis. tum. Syft. veg. ed. I4. Lin. Suppl. Morif. Hift. 3. f. 8. $2 a b, 1, f, 7$.

In Agypto. Seritur Neapoli.

Simil, T. arifate, fed fpica palm, quadruplo ma. 
ex fpicul. bifariis, alternis, adproximatis, $q=$ 12. funma folitaria.

4. turgidum. T. calyc. 4-fl. venrric of. villofis, imbricatis, obtuis. Sy/t. veg. ed. 14 Nov. comm. Gottin. V. tab. I, Morif. Hift. 3. f. 8. tab. I. f. 14. $\sigma^{\pi}$.

Var. calycibus ariftatis, \& muticis. Maius, \& elatius T. mutico. Spicæ ma. cinereæ, ariftis longis. Glumæ cinereæ, hirfutæ.

5. polonicum. T. calyc. bifloris, nudis, flofcul. longiff. ariftatis; racheos dentibus burbatis. Syft. veg. ed. 14. Nov. comm. Gotting. V. tab. 1, I6. Pluk. phyt. 231. f. 6. Morif. Hift.3. $\int 8$. tab. I. f. 8. Simil. prioribus fed fpica maior, cinerea : gluma duplo longiores, bifloræ \&c.

6. Speltu. T. calyc, 4-fl. truncatis: flofiul, ariftat. hermaphroditis; intermedio neutro. Syft. veg. ed. I4.

Zea \&c. Morif. Hift, 3. f. 8. tab. 6. f, 1. 3.

o.

Flores magis conici; \& femen villo tectum, magis quam $T$. vulg.

7. monococ- T. calyc. sub 3-fl. primo ariftato, intermedio cum. fterili. Syft. veg. ed. I4. Nov. comm. Goutzm. V. $t a b$. I. f. 17 .

Zed \&c. Mortf. Hift. 3. f. 8. tab. 6. 6. 2.

Briza. Lob. ic. 31 .

○.

Culm. \& fpica breviores, anguftiores, ac depreffe quam in priore. Spica difticha, longd. Ariftæ fubafperæ. Sem. min. Secale corniculntum Halleri ob morbum, cui fubiacet.

8. proftratum, T. calyc. multifl, fpica ovata, difticha; flofcul. imbricatis, ariftato-mucronatis. Syft. veg. ed. I4. Lin. uppl.

Secale proftratum Pallaf. It. Vol, I. Jacq. Hort. 3. $t a b .44$.

In Dauurin.

Culm. pl. fubped. procumbent. fimpl. geniculati . Fol. fublinear. acuta, integerrima, læviter pubefcentia: caulina longe vaginantia : fumma fatiora. Spica ovat-fubrot, denfe difticha, compreffo-plana: fpicul, lanceol, imbricata. Matura fpica integra cadit, \& germinat tot caulibus quot fpicula. Ipfa fpica radicis vices getit. 
9. pumilum. T. fpica ovata, glumis fubariftat, calycinis bifulcatis. Syft. veg. ed, I4. Lin. Suppl.

In Sibiria.

Gramen digiti longitudine; vagina fuprema ven. tricola. Spica dura, compreffa.

** Perennia.

10. iunceum, T. calycibus 5-f. truncatis : fol, involutis . Syjt. veg. ed. 14 .

Gramen \&c. Baut. Prod. tab. 17. Morif. Hift. 3. f. 8, tab. I. f. 5 .

In Europa auftrali, Oriente, ad vias, \& loca ficca 24 .

Gramen glaberrimum . Radix geniculata, Ionga . Culm. cum tora planta glaucus, 3-ped. \& ultra. Vaginæ fol. tomentofæe. Fol, angutiff. fupra glauca. Spicul. culno adpreffe; calycibus, corollifq. ariftatis, aut muticis .

11. repens. T. calyc. 4-fl. fubulatis, acuminat. fol. planis. Sylt. veg.ed. 14. Fl. Dan. 743. Leerf. herb. tab. 12. f. 3. Schreb. gram. tab. 26.

Gramen \&c. Morif. Hifı. 3. f. 8. tab. I. f. 8. Monti, ic: 25 .

b. Gramen \&c. Vaill, paris, tab, 17. f, \&.

In Europa cultis 4.

Radix longe repens, flavefcens. Culm. fpitham. fefquiped. erecti. Fol. vaginant. angufta, acumin. obfcure virid. fubtus nervo albicante; liguia minima, alba. Spica lanceol-ubtufa , contracta, compreffa, difticha, 4-polic.

12. mariti- T. fpica ramofa; calyc. 6-fl. flofcul. fecundis, mum . apice arittatis.

T. calycibus \&c. Syft. veg. ed. I4.

Gramen \&c. Pluk, phyt. 32, f. 7. Bocc. muf. 2. tab. 95. Morif. Hift. 3. f. 8. tab. 2. f. 6.

In Gallae, Anglia marisimis.

Culm. fpitham. Fol. longitudine culmi, vaginis purpurafc. Spica fere paniculata, ramis angulatis.

3. tenellum. T. calyc. fub 4 -fl, flofcul, acutis, muticis: fol, fetaceis. Syjt. veg. ed. I4.

Gramen \&cc. Mrif. Hlft. 3. f. 8. tab. 2. f. 3. In Helvetia, Pedemontio, ad pafcua declivia $\odot$. Culm. fpitham. filiform. tener. Fol. involuta. Pl. omniao fpicati. Spica tenuiffima. 
I4. unilaterale. T. calyc. unilateralibus, alternis, muticis. Syft. veg. ed. 14 .

Gramen \&c. Pluk. playt. 32. f. 7. Boce, muf. 2. tab. 57.

In maritimis Italia, Gallia $\odot$.

Culm. refqui-2 ped. Fol. angufta. Fl, facie Poa, in fpica unilaterali, 2-unc.

bicorne.

T. calyc. ftriatis, bicornibus, 3-fl. flofcul. la= teralibus, fertilibus, ariftatis; medio fterili. Forsk. Eg. $_{\text {g. }}$

In Arabia.

Tricicum laviff. glaucum, locuftis $4-\mathrm{fl}$. duobus fl. ariftatis, 2. mucronatis. Hall. Hift. n. 1423. Colitur in Thuringia, \& Helvetia.

Spica irregular. non difticha, lungiff. Granum maximum, dimidio vulg. Tritici femine longius,

\section{T R I G Y N I A.}

I19. ERIO- UAl. communis, capitulum imbricatum. Pe-

CAULON . tal. 3. æqualia. Stam. fupra germen .

3. triangulare. E. culm. triangul, fol, enfiformibus: capitulo ovato. Syft. veg. ed. 14 .

Plantaginella Ec. Brevn. cent. tab. 50. Morifs Hift. 3. f, 8. tab. I6. f, 17.

In Brafilia.

Cauliculi pl. 3-unc. Fol. in orbem pofita, pate va, angufta, glabra. Capitul. lanuginofum, col. leucoph. Flof. flavi .

2. quinquean-E. culm. 5-angul. fol. enfiformibus, Syft. veg. gulare. ed. I4.

Scabiofa \&c. Pluk, alm. tab. 221, f. 7 .

In India 24.

Non confundatur cum E. decemangul. Caul. nudus. Capitul. argentea. Cal. comm. 5-pyll.

3. Sexangulare. E. culm. fexangul: fol, enfiformibus. Syfl. veg. ed. I4. Burm. Ind. tiab. 9. f. 4 .

In India 24.

Caul, pedal. Fol, Jatiora. Capitul, rotundum, tomell= 
TRIANDRIA TRIGYNIA.

tomentofum. Foliola capiculum, loco calyc. univerfalis, cingentia, orbiculata funt, nec angufta, ut in priore.

4. fetaceum. E. culm. fexangul, fol, fetaceis. Syft. yeg, ed. I4.

Randalia \&c. Petiv. gaz. tah. 33. f. IO. H. Mal. I2. $t a b, 63$.

In India.

Radices in aquis difperfa funt. Vagina membranac. initar fpathæ, ad bafin culmum includit.

5. decangula- E. culm. decangul, fol, enfiformibus. Syft, veg. re. ed. I4. Pluk. emalt. tab. 40g. f. 5 .

Randalia \&c. Petiy. gaz. tab. 6. f. 2.

In Amer. Septent. paludibus.

Fol. 2. humifufa, fubulata, canalicul, articulata, Capitul. parva, globofa, albicantia . Petala puncto nigra intra apicem.

120. MON- Cal. 2-3. phyll. Cor. I-petal. irregular. parva, TIA. I. fontana. M. Syjt. yeg. ed. 14. Fl. Dan, tab. I31. Mich. 5-part. laciniis 3. alternis minoribus. Caps. gen. tol. 13. f. 2.

Alfineformis \&c. Pluk. alm, tab. 7. f. 5.

Alfine \& \&c. Pet. herb, tab, ro. f. I2.

b. Montia \&c. Mich. gen. tab. 13. f. I.

Alfinoides \&c. Veill. purif. เab. 3. f. 4.

Ad Europe foaturigines $\odot$.

Caul. procumb. ramofus, articulatus, in pratis riguis femiped, in glareofis fubunc. Fol, petioldt. ovata, vel oblonga, aut obverfe-ovata. Fl. racemofi, penduli, exigui, albi, raro fefe aperientes.

I2I. PROSER-Cal, 3-part, fuperus. Cor. o. Sem. I. triPINACA. locul.

I. paluftris. P. Syft. yeg. ed. I4.

In Virginia paludibus.

322. TRIPLARIS. Cal, maximus, 3-part. Cor. o. Antheræ lineares . Nux triquetra, intra calyc. bafin ovatam--Cal. in fructu non patet, fed femen arcte ambit, \& includit, dein in tria foliol. longiff. \& erectiufe. abit: potius ergo caly,x foliacens, longiff. dicendus.

I. nmericane. T. [picis erectis, terminalibus, $S_{y f} t_{2}$ veg. ed. I4. Jacq. Am. tab. 173. f. 5. Aubl, Guian. tab. 347. In Amer. meridionali $\$$. Tom, $I$. 
Arb. altudin. hñæ. Coma e paucis ramis horizontalibus in pyramidem efformata. Fol. fpitham. ovata, acumin. integra, petiolat. Spicæ pilofæ, bracteis ovatis, acuminat, parvis, pilofis. Cdl. fufcus. Nux nitidiffima.

Ad Diaciam dodecandram fpezat. Aubl. Ad Triandriam trigynum. Jacq.

2. remiflora. T. ractmis lateralibus, ddgregatis. Syft. veg.ed. 14. Jacq. Amer. ed. 2. piâta tab. 259. f. 3. quoad frufum.

In Amer. meridion. $\hbar$.

Arbor ramola, diffufa. Fol. ovata, vel fubrotundo $\rightarrow$ vata. Racemi denfi, fubpollic. multifl. villofi. Nux fufca.

I23. HOLOSTEUM. Cal. 5.phyll. Pet. 5. æqualia, emarcida. Capf. fubcylindrac. I-locul. apice dehifcens, poly?per.

7. cordatum, H. fol. fubcordatis, Syft. veg. ed I4.

Alfine \&c. Herm. parad. tub. I1.

In Jamaica, Surinama.

Caul, decumbent. repent. inferne rigiduli. Fol. oppofita, fabfeffil, orbiculato-cordata, lavia . Stipul. utrimq. 4. membranac. Pedunc, lateral. elong ti, adfcendent. 7-fl. primo intermedio, reliquis utring. 3. e pedunc, ulterius ramofo. Cal. oblong. acutus, concavus. Petal, erecta, lanceol, calyc. min. alba .

2. Juceulentum . H. fol. elliptic. carnofis. Syft. veg. ed. I4.

In Noveboraco.

Caul, repens. Fol, integra, glabra, fucculenta. Pet, fubtrifida, calyce min, alba .

3. hirfutum. H. fol orbiculatis, hirfutis. iyft. veg. ed. I4. In Mulubaria.

4. umbellatum. H. fl. umbellatis. Syft. veg. ed. I4. Lychnis \&c. Morif. 3. f. 5. $t a b .22$. f. 46. In Europe aufiralis arvis $\odot$.

Caul. fuberect. ufque fpithamæus, ad radicem rdmulofus. Fol. radical. multa; caulina bafi connatd, omuia glauca; ima ovata, dein amplexicaul. ovato-lanceol. fuper. elliptica . Bract. fubumbellatæ. Fl. 4-8. Petal. fere conniventia, extus fubrubra, intus alba.

124. Kब्EIGIA. Cal, 3 phyll. Cor, o. Sem. 1. ovatum, nue duim.

I. islandica. K. Syft. veg. ed. 14. Fl. Dan, tab. $4^{18}$. In Isiandia. 
Facies Polycarpi. Caul. digital. fucculentus, ramis pauciff. oppofitifoliis, patentiff. Fol. alterna, fubpetiol, obovata, obtufa, integerr. fubfucculenca, longitudine internodiorum caulis. Stipul, folitar, vaginal. (more Perficariæ) intrafoliac. campantl. perfiftentes. Fol, terminalia, quaterna. Fl. terminal, plurimi, fubfafciculati, fubpeduncul, bracteis membranaceis diftincti. Variat ftaminibus $2-3$.

525. POLYCARPON. Cal. 3-5-phyll. Petala s. minima, perfiftentia, ovata (emarginata). Capf, 1-locul. 3-valv.

I. tetraphyl- P, eaul, proftrato, ramofo: fol. quaternis. Syft. lum . veg. ed. I4. Pluk, phyt. เab, 259. f, I,

Anthyllis \&c. Barr. rar. tab. 534 .

In Italia, Gallia Ec. $\odot$.

Caul. femipalm. glaber. Fol. elliptica, obtufa, integerr. bina in caule, ad originem ramorum quaterna. Flofcul. albi .

2. magellani- P. calulibus fimplicifi: fol, fparfis, imbricat, licum . nearijus. Syft. veg. ed. 14. Lin. Suppl. Donatid fafcicularis. Forft. Gen, tab. 5. In terra del Fuego. Planta digital. finpl. tecta fol. glaberrimis .

126. MOLLUGO. Cal, 5-phyll. Cor. o. Capf. 3 locul. 3-valv. I. oppofittfu- M. fol. oppofitis, lanceol. ramis alternis ; pedunc. lia. lateralibus, confertis, I-fl. Syft. yeg. ed, I4. Alfine \&cc. Pluk. ulm, tab. 75. f, 6. In Zeylona.

Fol. petiol. glabra. Rami longi, diffuli, glabri . 2. Atriza. M. fol. fubquaternis, lanceol. fl. paniculat, nutantibus: caul. angulato. Syft. veg. ed. 14. Alfine \&c, Pluk. phyt.tab.256.f, 2. Burm. Zeyl. tab. 5. f. 3 . In Africa $\odot$.

Radix fibrofa . Caul. 3-4-palmar. dichotomi, læves, erecti, vel interdum diffufi, ramis erectis, divaricatis. Fol, verticillata, inæqual. 2. plerumq. ma. feffil. unguicul. ftricta, acuminara. Panic. axill. fol. longiores, primo, fecundoq. dichotoma, dein racemofæ. Pedunc. \& pedicel. capillar, Fl, nutantes, albi, fimiles M. verticillase.

3. pentaphyl- M. fol. quinis, obovat. aqualibus fl. paniculat. la. Syft. veg. ed. 14. 
Alfine \&c. Burm. Zeyl. tab. 8. f. 12.

In Zeylona.

Caul. pl. fubdiffufi. Fol. angufta, obtufa; none nulla radical. ad ramos quinata, mın. Pedunc. axillar. Iongiff. Cor. alba .

4. verticil- M. fol. verticillatis, cuneiformibus, acutis: caule lat2. decumben. fubdivifo: pedunc. 1-fl. Dyft. veg. ed. 14 .

Alfine \&c. Ehret. piat. tah. 6. f. 3. Pluk, mant. tab. 332 . f. 5 .

In Virginia $\odot$.

stiphylle. M. fol, ternis, obovatis, inæqualibus, intermedio maximo; perlutucul. verticill. I-fl. Burm. Ind. Pluk. amalc. tab. 257. f. I.

In India.

Cdul. fpitham. Icaber. Fol, fubpetiol. Fl. fub 20. ad divifuram caulis .

panieulata. M. fol. quinis, obovatis: peduncul, terminalibus . Burm Zeyl. tab. 6. 6. 2.

I27. MINUARTIA . Gil. 5-phyll. Cor. ov Capf. I-loc. 3-valv. Sem. nonnulla.

I. dichotoma. M. fl. confertis, dichotomis. Syft. veg. ed. I4. A7. Stok, 1758. tub. 1. f. 4. Lafl, it. tab. I. f. 5 .

In $H_{i}$ spania $\odot$.

Plantula risida, dura, tenax, fapius fimpl. Caul. fæpe ungue non maior. Fol. oppofita, fetacea. Fl. cymofi, in capitulum quadratum, arcte dichotomum, feffil. Bract. fetacea, fl. longiores. Sem. 5-8. Color planta fubfufcus.

2. campeftris. M. กी. terminalibus, alternis, bractea longioribus. Syft. peg. ed. I4. AZ. Stok. 1. c. f. 3.

In Hispanice collibus, planis $\odot$.

Caul. vix uncial. fimpl. teres, fol. tectus. Fol. multa, oppofi:a, cauli adpreffa, angufta, pla no-fubulata, 7-friata. Fl. capitulum compactum, irsequale, fed non totum dichotomuin .

3. montana. M. Al, lateralibus, alternis, bractea brevioribus. Syft. veg. rd. 14. Loefl. it. tab. 1. f. 4. In Hifpania collibus alits $\odot$.

Caul. pl. diffufi, digital. fubpubefcent. fubcanefc, Rami laterales, brevifl. alterni, fimpl. 
Fol. oppofita, fubuldta, pubefient, bafi connata, longirudine ramorum. Fl. glomeres laterales, leffil. inter fol. longiora.

128. QUE- Cal. 5-phyll, Cor. o. Cips. I-locul. 3-valv. RIA. Sem. r. Sinilis Minuartiz, fed differt fem. numero.

I. hifpanica. Q. fl, confertis, Syft, veg. ed. I4. In Hifpania $\odot$.

Planta unguem vix excedens. Capitulum fl. obfoletius tetragonum, fdillime a caule difcedens. Bract. erect, feraceæ, hinaræ. Color planta albidus. Habitus Minuartia montana.

2. canadenfis. Q. fl. folitar: caule dichotomo. Syft. yeg. ed. I4. In Canada, Virginia 24.

Rad. tibrofa . Caul. f picham. erectus, filifor. Fol. oppofita, lanceol-ovata, integerr. adfperfa utrimq. punctis fufcis. Stipul. 2. membranac. Fl. parvi, virid: ex fingula dichotomia.

329. LECHEA . Cal. 3-phyll. Petdl. 3. linearia. Caps. 3locul. 3-valv. valvul. totidem interioribus. Sem. I.

3. minor. L. fol. lineari-lanceol. fl. paniculatls. Sy/. veg. ed. 14. Amoen. Acad. 3, tab. I. f. 4.

In Canada Sylvis glarenfis 4.

Caul. erectus, vix femiped, teres, firapl, fuperne paniculat. Fol. fparfa, breviter petiol. erecta, acuta, integerr. fupra glabri, nitida, fubrus fubpubefcent. margine reflexo. Panic. pedunculita. Ad radicem rami oppofiti, vel terni. Fol. fæpe quaterna, ovata.

2. meior. L. fol. ovat-linceolat. fl. lateralibus, vagis . Syft. veg. ed. 14. Amcen. Acad. 3. tab. I. f. 4 .

In Canadx aridis.

Caul. teretes, purpurafc. Rami fimpl, alterni, remori. Fol. alrerna, fubpetiol. fupra fcabra, fubtus tomentofa, margine reflexo. Stam, 4 . kurum 2. Super, adproximata. 


\section{NOVA GENERA}

\section{MONOGY I A \\ VOU A P A.}

Cal. Perian. I-phyll. fubrotun. concavum, 4dent: bract. 2. oppofita, oblong. lata, ad bdfin calyc.

Cor. Petal. I. erectunt, expanfum, unguicul. margine fuper, undulato, calyc. fundo infertum.

Stam. Filam. 3. calyc. inferta, petalo oppofita. Anth. exigua, 2-locul.

Piffil. Germ. fubrotun. pedicell. Siyl, longus . Stigmd obtufum .

Peric. Legum. coriaceum, oblong. obtufum, lâtum, I-locul. 2-valv.

Sern. I. amplum, fubrotud. compreffum.

bifolia.

V. Aubl. Grian. tab. 7 .

In Cä̈nna, \& Giana $\hbar$.

Arb. 6o-ped. fuperne ramofiff. ramis, \& ramulis fparfis. Fol. alterna, pinnata. Foliol. 2. eidem petiol. alnexa, ovat-obl. acuta, uno latere latiora, integer. glabra. Stipul. 2. uninimæ, decidur, ad bafin petiol. comm. Fl. axill-terminal. corymbofi, violac. Legum, fubluteum .

Simira.

V. Aubl. Guian. tab. 8.

In Curibais $\$$.

Arb. 80-ped. craffiffim. fuperne ramofiff. ; ramis, \& ramul. fparfis. Lignum violaceum. Fol. alterna; foliol. 2. petiolat. \& eidem petiol. adnexa, in egerr. Stipul. 2. oblong. decilua, ad bafin petiol. comm. Fl, axill-terminal. racemofi. Legum. craffum, ferrugineum.

\section{O U T E A.}

Cal. Perian. I-phyll, turbinat. 5-dent, involucr. 2-phyll. cinctum .

Cor. Pet. 5. fuper. erect. oblong. obtufum, undulatum, magnum: 4. infer. parva, fubrot. patula, calyc. fauci inferta. 
Scam. Filam. 4. unum Aterile, breve, fub petal. infer. ipfius bafi fuppofitum: 3. longifl. tenuia, calyci fub petal. min. inferta. Anth. oblong. 4-gonæ, 2-locul. nutantes.

Pijt. Germ. oblong. ovat. petiolo longo, e fundo calyc. emergente, fubitentatum. Siyl.longus . Stigm. fubrolun. concavum.

Guianenfis. O. Aubl. Guian. tab. 9.

In Guiana \$.

Arb. 50-ped. fuperne ramofiff. ramis fuper. erectis; infer, reflexis. Ful. alterna, pinnafa : foliol. oppofita, biiugata, ovata: ftipulze 2. parvæ, acutæ, deciduæ, ad bafin petioli . Fl. axillar. fpicati, bracteati. Petal. violac.

\section{TON T A I E A.}

Cul. Perian. I-phyll. 5-dentat. laciniis acutis . Pet. 5. ovata, difco urceol ad bafin inferta. Stam. Filam. 3. extus reflexa, difci parieti interno inferta. Anth. fubrot. 2-locul.

Pift. Germ. fubrot. difco circumdatum. Styl. oblong. Stigma obtufum.

Peric, Bacca fphrerica, I-locul.

Sern. 4 .

feandens. T. Aubl. Guian. tab. ro.

In Sylvis Sinemarienfibus.

Caul. farmentofi, fiandentes, longiff. ramofi. Fol. oppofita, fubfeffil, ovat-obl. acuta, insegerr. glabra. Fl. axill. \& terminal. racemofi, pedunc, oppofitis, ad bafin fquamatis . Cor. parva, viridis.

\section{$\mathrm{X} I \mathrm{P} H I \mathrm{DI} U \mathrm{M}$.}

Cal, nullus.

Cor. Pet. 6, tria exter. ovata, acuta; 3 . inter. min. tenuiora.

Stam. Filam. 3. receptac. germin. inferta. Anth, oblong, fulcata, 2-locul.

Pift. Germ. fubrot. trifulcatum. Styl, longus , triangul, Stigma craffiufs, trigonum . 
Peric. Capf, ovata, trifulcara, hirfuta, 3-ilo cul.

Sem. numerofa, fubrot. nigra .

1. eceruleum. X. fl. paniculat, fol. \& fl. pilofis. Aubl. Guiun. tab. II.

In Guiana 4 .

Radix obliqua, geniculata, fibrofa, Caul. pedal. \& ultra, fimp : cylindric. hirfutus. Fol. remota, alterna, amplexicaul. longd, acuta, plana, ftriata, ferrulara. Fl. terminal. paniculati . Pet. 3. exter. inferne viridia, fuperne cœrul. 3, inter. ccerul.

\section{I P U R A.}

Cal. Perian. fpatha membranac. oblong. acuta, concava, fl. involvens.

Cor. Pet. 6: tria exter, erecta, ovata; inter. minima, concava; omnia bafi in tubulum connata.

Stam. Filam. 3. breviff. tubo cor, inferta. Antls. oblong. 2-locul.

Pifril. Germ. inferum. Styl. craffus, 3-gonus. Stigm. 3-lob. lobis ovat. acutis.

Peric. Caps. oblong. angulata, 3-locul.

Sem. plura, angulata.

paludofs. C. Aubl. Guian. tab. 13.

In pratis humidis Guiana 4 .

Rad. tuberofa, orbiculata, tunicata. Fol. radical. fæpe 4. pedal. \& ultra, angufta, acuininata, ftriata. Scap. femiped. fubnudus, rigidus, fuperne 2. fol. longis, \& aliis minoribus terminatus. Intra hæc folia fl. pl. peduncul, Cor. alba, vel cœrul.

\section{A Y A C A.}

Cal. Perian. 3-phyll. fol. oblong. acutis, perfiftentibus .

Cor. Pet. 3. fubret. concava, receptaculo piftilli inferta.

Strm. Filam. 3. Anth. oblong. 2-locul.

Piftil. Germ. fubrotun. Styl. oblong. Stigma 3-fid.

Peric. Caps. fubglobofa, fylo coronata, I-loc. 3-valy. 
Sem. 6. ovata, Ariata, nigra: duo fingula valvæ placentæ adfixa; fuperne unum, inferne alterum.

fluviatilis. M, Aubl. Guian, tab, 15.

In Guiana.

Herba ramulis decumbentibus, mufco fimilibus, Fol. capillacea, crebıa, minuta, acuta. Fl. axill. folitar. peduncul, albi .

Cal. Glum. 2-valv. valuul, acutis, concavis, altera min.

Cor. 2-valv. calyce min. valvul. tenuioribus, oblong. acutis, concavis, inæequalibus,

Stam. Filam, 3. longiff. receptac. germinis inferta, \& ipfi oppofita. Anth. oblong. acuræ, 2-Jocul.

Piflil Germ. oblong. 3-gonum. Styl, longus. Stigm. 3. filiform. acuta.

Peric. Cor. fem. obveftiens.

Sern. 1. 3-gonum, cor. inclufum.

maritime. R. Aubl. Guian, tab. I6.

In arenofis Caüennx, \& Guiana 4.

Rad. longa, nodofa, aromatica. Culm. femiped, apice ramofi, inferne fquamis caulem amplexantibus. Fol. ramorum oblong. angufta , acuta, friata, rigida, margine afpero, bafi vaginante . Fl. panicula terminal. brevis, fubfefill. denfa.

\section{A P A N I A.}

Involuc, I-phyll, trifoliatum, foliol, ampliff, ovat: acut. glabris, integerr. ftriatis, nervis longitudinalibus .

Cul. Perian. 6-phyll. fol, oblong. ovat. acutis; dentatis, concavis, imbricaris.

Cor. nulla.

Stam, Filam. 3. receptaculo germinis inferta. Anth. oblong. 4-gon. 2-locul.

Pift. Germ, ovatum. Styl. Jongus. Stigm. 3. filiform.

Peric.

Semb 
Jylvatice. M. Aubl. Guian, tab. 17.

In Guiane 4 .

Radix liguofa. Scap. pl. 2-ped, triangul, ad ba fin fquamulis, feu foliol. oblong. acutis, imbricat. rufefcentibus præditi. Fl. terminal, numerofi, congefti, feffil, in fundo involuc. amplifimi.

\section{I G Y N I A.}

\section{T R I S T A R I A.}

cal. Gluma 2-valy. 2-flora, valvul. lineariacuminat. muticis, glabris, cor. longioribus, altera breviore.

Cor. 2-valv. lineari-acuta; valvul. interior planiufc. hyalina, brevior, mutica: exter. convexo-compreffa, margine membranac, arifta $\mathrm{ex}$ apice 2-part. duplo longiore: alia ex dorfo intrd apicem fimpl. triplo longiore.

Stam. Filam. 3. filiform. Anth. incumbentes.

$\boldsymbol{P}_{\text {ift. Germ. parvum. Styli 2, nudi. Stigm. fime }}$ plicia.

Peric. nullum.

Forskal.

Sem. 1.

T. Forsk. Ag.

In Agypto $\odot$.

Culm. erect. pedal, bafi ramofus, teres. Fol. 3pollic. linear. plana, villofa, ficuti vagina. Panic. fpitham. contracta .

\section{VIEUSSE U X I A.}

Cal. fpath. 2-vaik fl, diftinguentes, perfiftentes. Cor. 6-pet. Petal. 3. exter. patentia, ovata, unguibus latiufcul. erectis, bafi femicylindricis . Petal. 3. inter. multo min, patentiufc.

Stam. Filam. 3. bafi coalita in cylindrum, ftylum includentem. Anth, oblong.

Pifl. Germ. inferum, clavatum. Styl. fimpl. Iongitudine filamen. Stigm. 3-part. lacin. petaloid. erectis, apicibus 2 -fid. inflexis. 
Peric. Capí, oblong. triquetra, 3-locul, 3-valv. fpiralis, $\quad$ Serm. fol. radicali unico, caulis longitudine. De la Roche nov. pl. tab. 5.

Bulbus fub ylindric. incurvus. Scap, rectus, pedal. divifus, articulatus. Fol. radicale enfifor. me, flaccidum: caulina vaginant. ftricta. Fl. terminal, peduncul. Cor. luteola, cum maculis purpur. Petal. 3. exter. ma.

fugax.

V. fol. radicali unico, caule duplo longiore. De la Roche nov. pl.

Simil. priori, ed duplo maior. Scap. fefquiped. \& ultra, fimpl. articulatus. Fol. radicale Gramineum, molle, ftriatum, carinofum : caulina ad fingulos articulos vaginantia, ftricta. Cor. candida .

ariftate.

V. fol, fingulari, fcapum vaginante, longiff. $D e$ la Rochs nov. pl.

Buibus fpharico-compreffus. Scap. erect. 4-5pollic. Fol. lineare. Spadix a fol. caulino. tamquam e fpatha proveniens, ramofus. Fl. lutei, fugaces. Pet. 3. exter. ovata, deflexa; interior. lanceol. cbtufa, patentia.

\section{O M E N I A.}

Media inter Ixiam, \& Gladiolum.

Cor. monopet. tubulora, tubo fubincurvo, limba campanul. 6-fid. aquali. Stam. emarginata.

3. Borbonica . L. fcapo altifimo, ranofo: fol, enfiformibus, nervolis, duris, margine cartilagineis: fl. fer filibus: peral. mucronatis. Pourret. Mem, de l" Acad. de Touloufe. T. 3. t:b. 5.

In Infula Borbonica 4 .

R d. bulbofa. Fol radicalia, nervis paralellis, \& adproximatis. Scapus 3-4-ped. bracteatus, fl. alternis ex fpatha fquamofa, \& pellucida exeuntibus. Petala fere Lilii, violaceo-purpur. albo col. mixta. Stam. \& ftylus fature purpur. anth. flavis.

\section{A P E I R O US I A.}

Cor. monopet, infundibulif. tubo long:ffrmo; limbo 6-fid. aquali. Ixia genus proximum, fed 
cor. lacin. alternatim inæquales in noftra; anth. non fimpl. led 2-fid. Stigm. non filiform. fed emarginata: ovarium non glabrum, fed tomentofum .

comprela.

L. fcapis ramofis, compreffis, margine ftrigofis: fol. enfiformibus, nervofis, fubfalcatis, dorfo ferrulatis: fpathis exterioribus plicatis, crifpis: fi. alternis, folitariis, Pourret. Mem. de l'Acad. de Touloufe. T. 3. tab. 6.

In Infula Gallia 4.

Rad. bulbofa. Fol, radicalia 2-3.2. pollic. longa, 4-5. lin. lata. Scap. 6-7-pollic. a bafi ramofus, ramis alternis, alatis: fol. caulina fimilia, fere margine fpinofd, alterna: rami axillares, diftıntes, alterni. Fl. fpatha duplex: exterior 3-4-longior interiore, $\mathrm{f} \in \mathrm{ffilis}$, horizontal. ovali-obrufa, margine rubra, dorfo fubfpinofo : interior lanceol. membranacea. Fl. albo, \& purpur. variegati ; tubo longitudine fpathæ exterioris. 


\section{L A S S I S IV. \\ TETRA N D R I A.}

\section{MONOGYNIA.}

Fl. monopetali, monofpermi, inferi.

I30. Protea. Cor. 4-pet. 4-fid. feu 4-part, petal. fubinde vel bafi, vel apice coharentibus, Anth. linear. vel oblongæ, infertæ petalis infra apicem. Cal. proprius o. Sem. 1, fuperum, nudum. Caul, arborefcens, vel frutefc, Rami fæpius verticillati, proliferi. Fol. alterna, fempervirent.

I3r. Globula-Cal. comm. imloricat, planus: proprius tubulat. ria. inferus . Corollulæ lab. fuperius 2-part. infer. 3-part. Receptacul. paleac.

$\mathrm{Fl}$. monopeb. monofpermi, fuperi. Aggregatæ .

I32. Cepha- Cal. comm. o. proprius infundibuliform. fupelanthus, rus. Receptac. globofum, nudum. Sem. I. lanuginofum .

132. Dipfacus, Cal. comm. polyphyll. fol. anguftis, fpinofis: proprius fuperus. Receptac. conicum, paleaceum. Sem. columnaria.

133. Scabiofa. Cal. comm, polyphill: proprius dupl. fuperus. Receptac, elevatum, paleac. feu nudum. Sem. ovato-oblong. coronata, involuta .

134. Knautic. Cal. comm. oblong. fimplex, 5 -fl. proprius fimpl. fuperus. Corollul. irregul. Receptac, planum, nudum. Sem. apice villofa. Differt a Scabiofa cal. tubulofo; \& fimplici flofculorum orbita.

135. Alliunia. Cal. comm. fimpl. oblong, 3-phyll. 3-fl: proprius obfoletus, fuperus . Corollui. irregul. Receptac. nudum.

* Valeriana fibirica.

Fl. mопореt. monocarpi, inferi.

154. Aquartie, Cal. campanul. fub 4-fid. Cor. rotata, lacin. linearibus. Bacca globofa, polyfper. 
153. Callicar-Cal, campanul. 4-fid. Cor. tubulora, 4-fid. Bacpa. ca globola, 4-fper.

173. EEgiphi- Cal. breviffm. cainpanif. 4-Jent. Cor. tubulola. $\quad$ ra, 4-fid. Styl. femibifid. Bacca fubrotun. 4fperm.

361. Scoparie. Cal. 4-part. Cor. rotata, 4-part. concava. Caps. oblong. I-locul. 2.valv, polyfperin.

366. Centun-Cal. patens, 4-fid. Cor, rolara, 4-fid. Stam. culus. brevia. Capf. rotunda, r-locul. circunfciffa. 360. Plantago. Cal. 4-fid. Cor, 4 fid, limbo reflexo. Stam. longiff. Capf. ovata, 2-locul. circumfciffa. Appendices parvæ, membranacea, ovato-lanceol. in apice pleruinq. 2-fid, unicuiq. anth. fubiectæ .

155. Polypre- Cal. 4-phyll. Cor. rotata, 4-fid lobis obcorddmum. tis. Capf. compreffa, emarginata, 2-locul.

158. Buddle- Cal. 4-fid. Cor. campanulata, 4-fid. Stam. ex ja. incifuris. Capf. oblonga, bifulca, 2-locul. polyfiperm.

159. Exacum. Cal. 4-phyll. Cor. fubcampanulata, 4-fid. Capf. fubrotan. compreffa, bifulca, 2-locul, apice dehifcens, polyfper.

156. Penca. Cal. 2-phyll. Cor. campanulata, 4-fid. Styl. 4angular. Capf. 4-gon. 4-locul. 8-fperm.

157. Blaria. Cal. patens. 4-part. Cor. fub.ampanul. Stam. receptac. inferta. Capf, 4-gon. 4-locul, polyfper.

* Swertia corniculata; dichotoma.

* Gentiana 4-fida.

Fl. monopet. monocarpi, fuperi.

350. Pavetta. Cal. 4-dent. Cor. monopet. infundibulif. fupera. Stigma curvum. Bacca 2 -fper.

349. Ixora. Cal. 4-part. Cor. I-per, infundibulif. tubo tenui, longiffimo, fupera. Stam. intra faucem. Bacca fubrotun. 2-locul. 4-fperm.

I5I. Petefia. Cal. 4 dent. Cor, monopet, infundibulif. Stigm. 2-fid. Bacca globofa, 2-locul. polyfper.

I48. Cntef- Cal. 4-dent. Cor, monopet. infundibulif. longiff. baa. Supera. Stam. intrà fuucem. Bacca oval. polyfper.

I52. Mitchel-Cal.4-dent. Cor. binæe eidem germini, monopet. la. tubulofa, fupera. Stigmat. 4. Bacca biflora, bifid. 4-fper. 
175. Hydro- Cál. 4-part. Cor. infundibul. Fruct. anceps, Iphylax. rper.

136. Hedyo- Cal. 4-part. Cor. monopet. infundibulif. Capf. tis. didyma, polyfper. apice dehifcens,

179. Olden- Cal. 4-part. fuperus . Cor. 4-pet. tubulofa. Capf. landia. fubglobora, coriacea, didyma, polyfper. dehifiens inter deutes.

190. Manet- Cal. 8-phyll. Cor. rubulofa, 4-fid. Gapf. infera, tia. 2.valv, I-locul. turbinata, compreffa. Sem. imbricata, orbiculata; feminulo centrali .

167. Sangui-Cal. brevis, 2-phyll. Cor. 4-part. plana. Germi. forba. inter calyc. \& cor, Fruct. 2-locul. Fol, imparipinn. Fl. fpicati .

\section{* Coffea occidentalis.}

* Peplis tetrandra.

Fl. monopet, dicocci, inferi .

143. Houfto- Cal. 4-dent. Cor. moaopet, infundibulif. Capf. nita. 2-locul. 2-valv. 2-fper.

137. Scabrita. Cal, tubulof. truncatus. Cor monopet. hypocraterif. Sem. 2, compreffa, emarginata .

Fl, monopet. dicocci, fuperi. Stellata.

I46. Rubia. Cor, monopet, campanulata. Baccæ 2, coalitæ, monofper. glabræ.

344. Galium . Cor. monopet. plana, 4-fid. Fruct. bini, fubglobofi.

I4. 0 . Afperu-Cor. monopet. infundibulif. Sem. 2 , fubrotunda . ln. Differt a Galio tubo cor. longiore.

139. Scherar-Cor. monopet. infundibulif. Sem 2 , trident. obdia. longa.

138. Spermacoce. Cor, monopet. infundibulif. Sem. 2 , bident. 142. Knoxia. Cor. monopet. infundibulif. Fruet. bipartibilis, fulcatus. Calyc. unicum fulium ma. Habitus Plumbaginis.

I4I. Diodia. Cor, monopet, infundibulif. Fruet. 4-gon. coro= natus, 2-valv, 2-locul. 2-fperm.

145. Crucia- Cor, monoper. iufundibulif. tubo filifor. limbo nella. unguicul. 4-fid. Cal. 2-phyll. Sem. 2, Hinearia.

$\mathrm{Fl}$. monopet. tetracocci, inferi.

147. Sipho- Cal. 5-part. Cor. monopet. infundibulif. tubo renthus. longiff. infera. Baccæ 4 , fubrotun. I-fperm. Fl. tetrapetali, inferi.

169. Epime- Cal. 4-phyll. caducus. Nect. 4. cyathiform. pedium. talis incumbentia. Cor. 4-pet. Capf, acumin. I-locul, 2-valv, polyfperm. 


\section{TETRANDRIA MONOGYNIA.}

I62. Skimmia . Cal. 4-part. pet. 4, concava. Bacca 4-fperm.

163. Rhaco- Cal. 4-part. Cor. 4-part. fimbriata. Capl. fubroma. tun. I-locul. I-fperm.

164. Othera. Cal. 4-part. Pet. 4, ovata, plana. Stigm. feffile. Capfula?

165. Oriqua. Cal. 4-part. Pet. 4, lanceol. plana. Stigin. cdpitatum. Capfula?

174. Rtelea. Cal. parvus, 4-part, inferus. Pet. fæepe 4, raro 5 , plana, coriacea. Fruct. compreffus, membrana fubrotunda, centro monofpermos.

I7r. Samara. Cal. minimus, 4-part. Pet. 4, ovata, bafi lacuna longitudinali Stam. bafi petali immerfa. Stigm, infundibulif. Drupa fubrot.

172. Fagara. Cal. parvus, 4-fid. Petal. 4, oblong. patentia. Stan. petalis longiora. Capf. 2-valv. 1-fperm.

180. Amman-Cal. I-phyll, tubulofus, pli atus, 4-8. dent. nia. inferus. Cor. 0 , vel 4-pet. calyci inferta. Capf. fubrotun. 4-locul.

178. Bankfra. Amentum fquamatum. Cor. 4 pet. Anth. in cavitate laminarum feffiles. Caps. 2-valv, Sem. 2-partibile.

192. Hartogia. Cal, 5-fid. Cor. 4-petala, patens. Drupa ovata, 2-fper.

\section{* Cardamine hirfuta. \\ * Evonymus europaus.}

Fl. tetrapetali, fuperi.

182. Trapa. Cal. 4-part. Cor. 4-pet. Nux ovata . cincta fpinis 4 , oppofitis, quæ calyc. fol. fuere.

I68. Ciffus. Bacca rotund. I-fperm, cincta calyce, corollaq. 4-part. Sem. offeum.

170. Cornus. Involuc, 4-phyll. frepius. Cal, minimus, 4-dent. deciduus. Petal. 4. Drupa umbilicata, nucleo 2-loc.

177. Ludwi- Cal. 4-part. fuperus . Cor. 4-pet. Caps. 4-gon. gia. $\quad 4$-locul. infera, polyfper.

I88. Santa- Cal. 4-dent. Cor. 4-pet. calyci innata, prater lum. glandulas 4. Bacca infera, I-fperm. $F l$. incompleti, inferi.

189. Struthio-Cal. 2-phyll, tubulofus, lacin, acutis, comprefla. fis, carinatis. Nectar. 8, antheriform. fingulo bafi corona ferarum circumdato, fauc. margini impofita. Cor. 4 -fid. Bacca exfucca, I-fperm. 
IgI. Krane- Cal. o. Cör. 4. pet. Pet. oblonga, patentia. riz. Nectar. fuper. 3-part. inferius 2-phyll. Bacca globufa, echinata, ficca, I-fperm.

194. Rivina. Cal. o. Cor. 4-per. perfittens. Bacca globofa, I-fperm. Sem. lentiforme, fcabrum .

195. Embboth-Cor. 4-pet. Anth. feffiles, apicibus petalorum ri $<m$. infidentes. Folliculus teres.

186. Nigrine. Cal. O. Cor. 4-pet. Capfula?

Iy6. Sulvadu-Cal. 4-fid, lacminis revolutis. Cor. o, Bacca Ira. fperm. Sern. rotundum, arillatum.

197. Camplo- Cal. urceolat. 4-dent. dentibus 2. oppofitis, rofma. alternifque minimis, reflexis. Cor. o. Capf. 1-fperm. calyce obvoluta.

198. Alchernilla. Cal, 8-fid. Cor. o. Sem. I. calyc. tectum.

183. Dorfte- Receptac. comm. I-phyilum, carnofum, in quo wi nia. fem. folitaria nidulantur. Fl. aggregati. Involuc, magnum, angulatum. Flos monopetal, anomalus, carnofus, pedem anferinum referens. Fruct, eiufdem formæ.

184. Cometes. Involuc. 4-phyl. 3-fl. Cal, 4-phyll. Capf. 3$\operatorname{cosc} d$.

\section{* Corchorus coreta. * Ammannia. \\ Convallaria bifolia.}

Fl. incompleti, fuperi.

176. Sirium. Cal. campanulat. femi 4-fid. Cor. o. Nectar. 4phyllum, claudens calycem. Germ. inferum. Stigm. 3-fid. Bacca 3-locul.

193. Acana. Cal. 4-phyll, Cor, 4-pet. Bacca obovata, ficca, infera, $\mathbf{I}$-fperm. retrorfum echinata.

I8r. Ifnardia . Cal. campanuldt. 4-fid. perfiftens. Cor, o. Capf, ciacta calyce, 4-locul, polyfper.

186. Elxagnus. Cal. campanulat. 4-fid. interne coloratus, deciduus. Cor. o. Drupa intra calycem, ovata, glabra, I-locul. I-fperm.

187. Gonocar-Cal. o. Cor. 4-fid. Drupa fuloglobofa, 8-gon, pus. I- perm. 


\section{I G Y N I A.}

202. Bufonia , Cal, 4-phyll. perfittens, foliul. alternis minoria bus. Petal. 4. calyce breviora, angufta. Caps. I-locul. 2-valv. 2-per.

205. Hype- Cal. 2-phyll. Pet. 4 ; exterioribus 2 latioribus,

c $u$ um . 3 -fid. Siliqua .

203. Hamame- Involuc. 3-phyll. Cal. proprius 4-phyll. Peral. lis. $\quad 4$, longitt, linearia. Nux 2-cornis, 2-locul.

204. Cufcute, Cdl, \& cor. 4-5-fid. Squamæ nectdriferæ fl, fegmentis interpofira. Stam, 4-5. Capf. fubrotund. carnofd, 2-locul. 3-4-1per.

206. Gomozia. Cal. o. Cor. campanul. 4-nd. Bacca 2-locul. I99. Galopina, Cal. o. Cor. 4fid, Sem. 2, nuda. 200. Aptanes, Cal, 8-fid. Cor. 0. Sem, 2, calyce tecta. 201, Cružtu, Cal. 4-phyll, exter, 3-phyll. Cor, 0. Sem. I in calyce conniventi.

* Herniaria fruticosa.

* Gentiana.

* Swercia .

\section{T E T R A G Y N I A.}

207. Ilex, Cal, 4-dent. Cor. monopet, rotata, 4-fid. Styl. o. Stıgm. 4. Bacca 4-fperm.

208. Coldenia, Cal. 4-phyll. Cor. I-per. infundibulif. 4-fid. lacin, obtufis. Styl. 4, Sem. 2, bilocular. angulato-fcabra, flylis roftrata.

21r. Sagina. Cal. 4-pyll. Pet. 4, patentia, calyce breviora. Capf. ovata, 4-valv, 4-locul, polyfper.

212. Tillea. Cal. 3-4 part. Pet. 3-4, æqualia, acuta, plana, culyce fere minora. Capf. 3-4, oblong-acu. min. polyfper.

2r3. Myginda, Cal. minımus, 4-part. Pet. 4, fubrotunda, patentiff. Drupa globofa, I-fper.

209. Potamo- Cdl, o. Pet, 4, ovata, decidua. Styl, o. Germ. geton. 4. Sem. 4 , nuda, feffilia.

Ruppia.

In fummis ramulis prodeunt fpicæ ferentes anth. 8 , reniform. feffil. Inter has nafcuntur pedunc. 8 , tenues, finguli fubltinentes germen parvo ftigm te inftructum. Capf, acumin, afpera, I-fperina, 


\section{$M O N O G Y N I A$.}

130. PRO- COr. 4-pet. 4-fida, feu 4-part. petalis fubinTEA. de vel bati, vel apice cohærentibus. Anth. linear. vel oblong. infertæ petal. infra apicem. Cal. propr. O. Sem. I. fuperum, nuduin.

Caul. arborefc. vel frutefc. Rami fapius verticill. proliferi. Fol, alterna, fempervirentia. * Pinnata ; fol. pinnatis, fliformibus.

I. decumbens, P, fol, trifid, filiform, caul. decumbente. Syft. veg. ed. 14. Thumb. diff. de Protea tab. I. Aż. Medic. Svec, T. I. tab. I. Al cap. b. Spei $\$$.

Caul. pedal. filifor. parum ramofus, fanguineus . Rami in apice caul. Fol. digital. remora, erecta, fecuuda, glabra. Pinne in medio fol. oppofitæ. Cipitul. terminal. magnitudine Pif ma: Cor. fericea.

2. flurida, P. fol. trifid. filiform. caul, erecto: capitulo fo. litar. bract. obvallatis. Syft. veg. ed. 14. Thumb. l. c. tab. I. Aa. Medic, Svec, T, I. tab. I. Al cap. b. Spei 5 .

Tota planta, excepto cal. glabra. Caul. ped. \& ultra, erectus, teres, purpur. Fol. palmar. fparfa, erecta; infer. pinnata, fuper. 3-fid. pinnæ oppolitæ, fub 3-iugæ, pollic. fenfim breviores. Capitul. terminal. peduncularum. Pedunc. palm. inæqual. I. fl. Bract. inferne $\mathrm{fp}_{\mathrm{p}}+\mathrm{r} \mathfrak{2}$, fuperne adgregatæ. Cal, fquamæ ciliis flavefcentibus.

3. cyanoides. P. fol. trifido-pinnat. filiformibus, caul, erecto: capitul, folitar. nuis. Syft.veg.ed. 14. Thumb. l. c. n. ${ }^{\circ}$ 3. Pluk, mant. $t a b$. 345 . f. 6. Ad cap. b. Spei $\hbar$.

Caul. fimpl, vel ramofus, erectus, teres, glaber: rami fubverticill, inæqual. Fol. frequentia, pollic. \& ultra, erecta, rarius 2-trifida, acuta, glabra. Pinnæe oppofira, confimil. $\mathrm{Ca}$ pitul. terminale, folitar. magnitudine Nucis Avellanæ. Calyc. Iquamæ ciliis albis. Cor. intus purpurafc. extus tota lanata, pilis longis, albis.

$R$ ii 
4. patula. P. fol. trifido-pinnat. filiform. caul. erecto: $\mathrm{ca}$ pitul. adgregatis. Syft. veg. ed. 14. Thumb. l. c. $\mathrm{n} 0^{\circ} 4$.

Ad cap. b. Spei $\hbar$.

Caul. pedal. ramofus, glaber, ruber. Rami um* bellati, patent. inæqual. Fol. frequentia, pollic. raro 2-pinn. glabra. Capitul. terminale, fubfeffile, magnitudine Pili. Calyc. fquama glabræ. Cor. niveo-tomentofa.

3. Spharoce- P. fol, 2-pinnat. filiformibus; pedunculis capituphala. lis brevioribus; fquamis calycin. evatis, bafi villofis. Syfi. veg. ed. I4. Thumb. l. c. 10. 5. Ad cap. b. Spei b.

Caul. pedal. proliferus, flexuofus, glaber, fufcopurpur. Fol. frequentia, pollic. erecta, flexuofa, glabra: pinnæe circiter 4. oppofitæ: pinnu$1 æ$ alternæ, fubfaltigiatæ, apice acutæ, rufefcent. glandulofæ. Capitula termindia, peduncul, adgregata, magnitudine fere Nucis Avellanæ. Calyc. fquamæe rufefcent. Cor, argentea, pilis longis, imbricatis .

6. ferraria, P, fol, bipinnat, filiform. hirtis: pedunc. eapitulis longioribus; fquamis calyc. ovar-lanceol. hirtis. Syft. veg, ed. 14. Thumb. l. c. n. ${ }^{\circ} 6$. Pluk. mant. tab. 329. f. I, Burm. Afric. tab. 99. f. $\mathrm{I}$.

b. Seb. Thes. 2. tab. 69. f. 6 .

Ad cap. b. Spei 方.

Caul. 2-ped. \& ultra, ramofus, flexuofus, proliferus, ramis pubefcentibus pilis helvolis . Fol. frequentia, pollic. erecto-patula: pinna circiter 3. oppofita, pinnulæ alternæ. Capitula faftigiata, adgregara, pedunculata, magnitudiue Pifi. Cor. extus hirta. Var. fol. hirtis, \& hirfutifirm:

7. triternate. P. fol. 2 pinnar. filiform. glabris: pedunc. capitulis longioribus: fquamis calyc, lanceol, hirtis . Syft. veg, ed. I4, Thumb, l. c, n, 7 .

Ad cap. b. Spei \$.

Caul. fefquiped. \& ultra, fimpl. fuperne flexuofus. Fol. fpirham. verfus caulis apicem frequentia, erecta: pinnæ oppofitæ, acutæ; pinnulæ alternæ. Capitula terminalia, adgregata, magnitudine Pifi ma. Cor, lanata, pilis argenteis. 
8. glomerata. P. fol. 2-pinnat, filiform, pedunc, comm, elongato, nudo; pedicellis capitulis longioribus. Syft. veg. ed. 14. Thumb، l. c. n. 8. Butrt. Afric. tab. 99 . f. 2.

Ad cap. b. Spei b.

Caul. erectus, fubprolif. glaber, purpur: rami nudi. Fol. fefquidigit. glabra. Pinnæ circiter 4. alternæ, confimil. pinnul. circiter binæ, alternæ. Corymb. terminal. e fpica factus; bracteis diftinguentibus, lanceal, ferrugineis. Cor. extus hirfuta.

9. phylicoides. P. fol. 2-pinnat. filiform. capitul, terminal. folitar. lanatis. Syft, veg, ed, 14. Thumb.l.c. n. ${ }^{\circ}$. Al cap. b. Spei b.

Caul. pedal. \& ultra, erectus, fuperne ramofus, fofcus: rami fubumbellati. Fol. frequentia, pollic. erecta: pinnæ circiter 3. oppoitæa ; pinnulæ alternæ, fubulatæ, apice rufefcent. $\mathrm{Ca}-$ pitul. ovatum, Nuce Avellanæe maius. Cor. lanata, pilis denfis, grifeis.

30. lagepus. P. fol, 2-pinnat. filiformibus: capitul. fpicat, adgregatis. Syft. veg. ed. I4. Thumb. l.c. n. ${ }^{\circ}$ IO. Ad cap. b. Spei $\hbar$.

Caul. erectus, fuperne ramofus, glaber, cinereus : rami fubverticill. erecti. Fol. pollic. pinnæ tres, oppofitæ; pinnul. alternæ, acutæ, faftigiata, apice rufefcent. Spicæ digital. villofæ, albæ.

Diverfa a feq. capitul. adgregatis; \& Spica conica, feffil , hirfutid.

Ir. Spiota, P. fol. 2-pinnat. filiform. capitul. fpicatis, difinctis. Syft. veg. ed. I4. Thumb, l. c. n. ${ }^{\circ}$ I Ad cap. b. Spei b.

Caul. erectus, 2-ped. \& ultra, prolif. purpur. Rami verticill. quaterni ; iuniores incani. Fol. frequentia, 2-pollic. glabra ; fuprema fericea : pinnul. alternæ, acutæ. Capitula remota, fparfa, 4-fl. peduncul. Spicæ fparfæ, pollic. tomentofæ. Cor. extus hirfuta, limbo breviff. ovato.

22. feptrum, P. fol. inferioribus 2-pinnat. fuperioribus 3-fid. integrifq. Syft. veg. ed. 14. Thumb. l.c. n. ${ }^{12}$ AE. Stock. 1777. tab. I.

Ad cap. b. Spei D.

Caul. erectus, 2-ped, \& ultra, glaber: rami $R$ iij 
fubverticill, erecti. Fol, 3-pollic. infer. filiforma media obovat-oblong. 3-fida, 2-pollic: fumma pollic. petiolat. obovat-oblong. Capitula fpicata. Spicæe tres, poliic. argenteo-albæ. Cal. tomentofus. Cor. fere pollic. argentea.

\section{** Dentatx: fol. dentatis, callnois.}

13. crinita. $\mathbf{P}$. fol, plerumq 5-dent. glabris: caul, erecto: capitul, terminalibus fubternis. Syjt. veg, ed. 14. Thumb. l. c. n. ${ }^{\circ} 13$.

Ad cup. b. Spei $\$$.

Caul. 2-ped. \& u!tra, villofus. Fol. pollic. vel paulo ulira, feffil. ovata, obrufiff., rarius indivifa, \& 3-dent, bafi villofa. Capitula adgregata, magnitudine fere Juglandis. Cal. fqudmæ apice barbatæ. Cor. cylind. villofa, unguicul. purpurafc. Differt a feq. fl. capitul. pl. Es min. cor. breviore.

14. conocarpa, P. fol. fape 5-dent. glabris: caul, erecto: cdpitul. terminali. Syjt. veg. ed. I4. Thumb. l. c. n. ${ }^{\circ}$ 4. Boer. Lugd. 2. tab. Ig6. Pluk. alm. tab. 200. f. 2 .

In Athiopia 方.

Caul. 3-ped. \& ultra : rami pauci, alterni. Fol. 2-pollic. erecto-parent. feffil. oblong. obtufa, integra, apice dentata, bafi villofa. Capitul. folitar. magnitudine Pyri . Calyc. fquamæ ciliatæ. Cor. pollic. filiform. hirfuta, pilis longis, flavis .

15. elliptica, P. fol. elliptic, fæe 3-dent. glabris : caul, erecto: capitul, terminal. Syft. veg. ed. I4. Thumb. l. c. n. ${ }^{\circ} 15$.

Ad cap. b. Epei b.

Caul. flexuofus, villofus. Fol. digital. erectpatula . Capitul. folitar, magnitudine Pyri. Cal. tomentofus. Cor. lenga, hirfuta .

16. hypophyl- P. fol. tridentat. glabris, fecundis : caul. decumla. bente: capitul. terminali. Syft. yeg. ed. I4. Thumb. l. c. n. ${ }^{\circ}$ 16. Boer. Lugd. 2. tab. 198. Ad cap. b. Spei 万.

Caul. ped. \& ultra, glaber, purpur. Fol. palmar. erecta, elliprico-lanc. obtufa cum acumine, callofo-3. dent, rarius 5-dent, inferne integra; recentiora fubpubefcent. Capitul. folitar. magnitudine Juglandis, pedunc, tomentofo. Cal. 
imbricat. fquamis ovat. tomentofis. Cor. pollic. filifor. femi-2-fid. extus villofa. Differt a cazeris caul. decumbente; \& jol. fecundis.

17. cucullata. P. fol. 3-dent, glabris: capitul, lateralibus. S fto veg. ed. I4. Thumb. l. c, n. 17. Boer. Lugd. 2. tab. 206. Pluk, alm. tab. 304. f. 6.

Ad cap. b. S Sei $\hbar$.

Caul. prolif. nodulofus, tomentofus. Fol. frequentia, fefquipollic. fparfa, imbri atd, feffil. infra medium latiora, ovara. Capirula feffil. s-fl. Cal. paucifol. imbricat. fubviliofus. Cor. pollic, filiform. inferne pubefcens, fupra denfe villofa. Facile dignofcitur capitul. lateralibus anguftis.

18. tumentofa.P. fol. fxpe 3-dent, tomentofis. Syft. veg. ed. I4. Thumb. l. c. n. ${ }^{\circ} 18$.

Ad cap. b. Spei b.

Tota planta incano-tomentofa. Caul. erect. 2ped. \& ultra, fimol. Fol. frequent. pollic \& ultra, linearia. Captul. terminal. folitar. vel duo, magnitudine fere Juglandis. Cor. unguicul, tenuifime pubefcens.

19. heterophyl-P. fol. 3-dent, integrifque: caul, decumbente. la. Syft. veg. ed. 14. Thumb, l. c. n. ${ }^{\circ} 19$. Ad cap. b. Spei b.

Caul. ped. apice ramofus, glaber, fufcus: rami divaricati. Fol. frequent. unguicul. incumbentia, oblong. acuta, inferne atrenuata . Capitul. terminalia, magnitudine $\mathbf{N}$ cis Avellanæ ma. Cul. tomentofus. Cor. unguicul villofa . ${ }^{* * *}$ Acerofa ; fol. filiformibus, fubulatis .

20. pinifolin. P. fol, filiformibus : fl. racemofis, ecalycul, glabris. Syft. veg. ed. 14. Thumb. l. c, n. 20 . Burm. Afric. tab. 70. f. 3.

Ad cap. b. Spei 下.

Tota planta glabra. Caul. erectus, z-ped. \& ultra, ramolus. Rami verticillati, flexuofi, fubdichot apice foliofi, floriferi, rubro-fufci . Fol. conferta, 2-pollic. fparfa, erecto-incurva, longa, fubcanalicul. Racemi terminal, erecti, fafcicul, feffil. ovati. Bract, fubulata. Pet, 4. lineari-lanc. cruciatim patentia.

21. racenofa , P. fol. fi fformibus: fl. racemofis, calyculat. tomentofis. Syft. veg. ed. 14, Thumb.l.c. n, $2 \mathrm{I}$ 。 Ad cap. b. Spei b. 
Caul. erectus, 3-ped. ramofus, ferrugineus. Fol. frequen. pollic. infer. glabra, fuprema fericea. Fl. in ramis termiaal. Racemi digital. Cal 4phyll. villofus. Cor, tota hirfuta, lana denfa. Simil. 2. feq. fed habet unicum fl. intra calyc.

22. incurva. P. fol. fihform. incurvis, glabris: capitul. racemofo-fpicatis, tomentofis. Sy/l. veg. ed. It, Thumb. l. c, n, ${ }^{\circ}$ 22, a $a b, 3$. AZ. Medic. Syec. T. 1. tab. 3 .

Ad cap. b. Spei b.

Caul, erectus, 2-ped. \& ultra, fuperne ramofus, rufefcens: rami verticill. Fol. fparfa, pollic. glabra .

23. caudata, P. fol. filiform, hirtis : capirulis fubf ffil. fpicatis. Sy, z. veg. ed. 14. Thumb. l. c. n. 23, tub. 2, Al. Medic. Svec. T. 1. tab. 2.

Ad cup. b. Spei $\hbar$.

Caul. erct. fub 3-ped. fuperne ramofus, rufefcens. Fol. unguicul. erecta, infer. hirta, fuper. hirfuta. Spica digital, cylindrica. Cal. fape 2-fl. Cor, hirfuta.

24. braqeata. P. fol, filiformi-canalicul. capitulo terminali; bracteis multifid. Syft. veg. ed. 14. Thumb. l. $c$, n. ${ }^{\circ}$ 24. tab. 1. Boer. Lugd. 2, tab. 193. Az. Medic. Svec. T. 1. tab. I.

Ad cap. b. Spei b.

Tota glabra. Caul. erectus, pedal. fimpl, raro 2-fid. rugofus, fufcus. Fol. frequent. 3-pollic. fubfecunda. Capitul. folitar. magnitudine Juglandis. Cor. fub 4-gona, apice 4 -fid, , limbo intus pappo denfo. Convenit cum P. Pinifolia, E aulacea calyc. nullo: cum umbellata brá. multifid.

25. comofa. P. fol, infer. filiformibus: fuper. lanceol. capitulo terminali. Syft, veg. ed, 14. Thumb. L.c. n. 25 . Ad cap. b. Spei 方.

Tota glabra. Caul. erectus, pedal. \& ultra, ramofus, fufcus. Rami faftigiati, verticillatoquaterni. Fol. frequentia, fefquipollic. fuper. comofa. Conus fl. folitar. magnitudine Jnglandis .

26. gurpurea, 1. fol. linearibus, recurvis: capitul. linearibus, cernuis: caul, decumbent, Syft, yeg. ed. IA. Thumb. l. c. n. ${ }^{\circ} 26$. Ad cap. b. Spei b. 
Caul, 2-ped. fubfiliform. prolif. ramofiff, purpur. ramuli fubvillofi. Fol. frequentia, fparfa, fesniungui ul. imbricata, mutica, integra, patentirecurva. Capitula magnitudine Pifi. Cal. tomentofus, foltol. filiformibus. Cor. minuta, villofa, limbo glabro, purpur.

27. prolifera. P. fol. adpreffis, Tubulatis: caul. prolifero. Sy.fo veg. ed. 14. Thumb. l. c. $\mathrm{n}^{\circ} 27$. tab. 4. AC. Medic. Svec, T. I. tab. 4 .

Ad cap. b. Spei 万.

Caul. ereçus, 2-ped. glaber: rami erecti. Fol. frequentia, fubimbricata, unguicul. glabra . Capitula in divaricatione ramorum, magnitudine Pifi.

28. corymbo- P. fol. lineari-fubulat. adpreffis: ramulis fubfaSa. ftigiat. vericillat. Syf. veg. ed. 14. Thunb. $l$. c. n. ${ }^{\circ}$ 28, tub. 2. Aat. Medic. Svec. T. 1. tab. 2. Ad cap. b. Spei b.

'Tota glabra'. Caul. erectus, 4-ped. \& ultra, ra* mofus: rami plurimi, digital. Fol. frequent. imbricata, unguicul. Capitula terminalia, magnitudine Pifi min. Cal, corolla brevior. Cor. minuta, lutea. Var. cal. tomentofo.

29. nane. P. fol. lineari-fubulat. capitul. terminali; cal. co. lorato. Syft. veg. ed. I4. Thumb. l. c. n. ${ }^{\circ} 2 \%$ Pet. gaz. tab. 27. f. 7 .

Ad cap. b. Spei 5 .

Caul. erectus, 2-ped. ramofus, cicatricibus fcaber. rami fubterni, cernui. Fol. frequentia, fubimbricata ( Pini fylv.) femipolic, patentis, patula. Capitulum cernuum, magnitudine Pruni. Cal. fquamis laxis, fenfim ma. Cor. unguicul. lana aurea extus tecta. Calycin. radius purpur. difcus flavus. Dignofcitur fl. Rofam referentibus. Tota planta, excepta cor. glabra.

3o. lanatr. P. fol. adpreffis, triquetris: capirulo terminal. lanato. S/ft. veg. ed. 14. Thumb. l. c. no. 30. tab. 3. Aaz. Medic. Svec. T. I. tab. 3. Ad cap. b. Spei b.

Caul. erectus, 2-ped. filiform. debilis, samofus, fol. tectus: rami bini. Fol. imbricata, unguicul. linear. Capitul. fericeum, magnitudine f re Juglandis. Cor, unguicul, extus pilis argenteis. 
**** Lineares: fol. linearibus.

31. torta. P. fol. linearibus, obliquis, callofis. Syft. veg. ed. 14. Thumh. l. c. n. 3 r. Ad cap. b. Spei b. Tota planta, excepta cor. glabra. Caul. fuberect. 2-ped. \& ultra, ramofus. Rami, verticillatoquaterni, incutvati: ramuli in apice breviff. verticillati. Fol frequentia, femipollic. integra. Capitula terminal. magnitudine Pifi . Cal. breviff. tomentofus. Cor. argentea.

32. $a l b a$. P. fol. linearibus fericeo-tamentofis. Syft. veg. ed. I4. Thumb. l. c. n. 32 .

Ad cap. b. Spei 方.

Tota argenteo-tomentofa. Caul. erectus, ramofus : rami fub 6-umbellati. Fol. erecto-imbricata, pollic. Cepitula in divaricatione ramoruin, fol. obvallata, magnitudine Pifi.

***** Lanceolata; fol. ellipticis, \& lanceol.

33. aulacea. P. fol. ellipticis: fl. racemofis, ecalyculat. Syft. veg. ed. 14. Thumb. l. c. n० 33. เnb. 2. Ac. Medic. Svec, T, 1, tab. 2.

Ad cap. b. Spei $\hbar$.

Tota glabra. Caul. erectus, 3-4-ped., prolif. parum ramofus: rami fubversicillati, erectopatentes. Fol. adproximata, feffil. 'erecta, digital. caulem tegentia. Racemi terminal. fubumbellati, pollic. oblong. cernui . Bract. fub fingulo pedunc, lanceol. albæ. Cal. o, Pet. unguic. erecta, linear. alba.

34. umbella- P. fol. elliptic. capitul. terminalibus; bracteis multa. i tifid. Syft. veg. ed. 14. Thumb. l. c. n. $0^{\circ} 34$. Ad cap. b. Spei b.

Planta glabra. Caul. erectus, 2-ped. \& ultra, ramofus. Fol, ut in priore, Capitul. folitarium, magnitudine Nucis Avellanæ ma. Cal. o. Cor. ut in P. brachiata.

35. linerris. P. fol. ellipticis: capitul, terminali, tomentofo. Syf. veg. ed. 14. Thumb. l. c. n. ${ }^{\circ} 35$, tab. 4, Aa. Medic. Svec. T. I. tab. 4. Ad cap. b. Spei $\$$.

Caul. erectus, 4-ped. ramolus, purpur. rami longi. Fol, frequentia, digital. \& ultra, felfil. linear, fubtus concava. Capitul, conicum, 
magnitudine Pomi mediocris . Cal. fquamæ exrus tomentofa.

36. Scolymus. P. fol. lanceol, acutis, capituloq. terminali rotundo, glabris. Syft. veg. ed. 14. Thumb. l.c. n. 36. Boer, Lugd. tab. 192.

Ad cap. b. Spei $\hbar$.

Frutex totus glaber. Caul. erectus, 3-ped. ramofus : rami erecti, fubverticill. Fol. frequentia, digital, erecto-patula, integra. Capitul. folitar, ovat. fol, obvallatum, magnitudine Pruni . Cor. purpurafc. Receptac. ferr ugineo-tomentofum .

37. mellifera. P. fol. lanceol-elliptic. capituloq. terminali oblongo, glabris. Syft. veg. ed. I4. Thumb. l.c. n. 37.

Ad cap. b. Spei Ђ.

Arbufc, tota glabra. Caul. erectus, orgyal. \& ultra, ramofus. Rami fparfi, erecti, ramulofi. Fol. frequent. digital. integra, patula, avenia. Capit. vilcofum, frrugineum, magnitudine Ovi Anferini. Differt a fequenti caul. arbor. ramufo, multifloro: fol. planis; cono oblong. bituminofo, plano, nitido.

38. repens, P. fol. lanceol-elliptic. capiruloq. ovato, gla bris : caul. decumb. breviff. Syft. veg. ed. I4. Thumb. l. c. n. ${ }^{\circ} 8$.

Leucadendron repens $b . \int p \cdot p l$.

Ad cap. b. Spei Ђ.

Tota glabra, excepta cor. Caul, vix palm, flexuefus, fubramofus. Fol. in apice caul. \& ramorum conferta, fpitham. feffil. erecta, margine cartilagineo. Capitul. termindl. fulitar. fol. obvallarum, magnitudine Pruni. Cor. villo albo .

39. obliqua. P. fol. elliptic. glabris, callofis, obliquis : capitulo caulino terminali. Syft. veg.ed. 14. Thumb. l. c. n. 39 .

Ad cap. b. Spei b.

Caul. erectus, 2-ped. \& ultra, g'aber. Rami fparfi, erecti, fil form. Fol. frequent. femipollic. reffil. erecto-parula. Capirul. magnitutudine Pruni.

40. parviflora. P. fol. elliptic. obtufis, obliquis, callofis: capitulis terminalibus, ramulorum glabris. Syft. 
veg. ed. I4. Thamb. l. c. n..$^{\circ}$ 40, tab. 4. AZ. Medic. Svec, T. I. tab. 4.

Ad cap. b. Spei h.

Caul erectus, 3-8. ped. ramofiff. fufco-cinereus: rami fparfi, flexuofi, ramulofi. Fol. fparfa, unguicul. magnitudine fere Vitis idea, erecta, obtufa. Capitula fub 4-gona: fl, paniculati, copiofi, lutei, magnitudine Piperis. Cal. ovatus, imbricatus, fcariofus. Var. caul. \& fol. glabris, vel incano-fubtoment.

4. pallens. P. fol. elliptic, acutis, glabris, callofis : capitul. terminali, involucrato; invòluc. longo, acuto, pallido. Syft. veg. ed. 14. Thumb. l. c. n. 4i, P. conifera b. y. fp. pl. Boer. Lugd. tab. 97. Ail cap. b. Spei $\mathbf{b}$.

Caul. fructic of, erectiufc, pedal. ramofus, fubangulat, glaber: rami fparfi, divaricati. Fol. pollic. \& ultra; caulina, \& ramea fparfa, feffil. fubdecurent. inflexa. Bract. conum obvallantes, concavæ, albidæ, cono triplo longiores. Conus feffil, ovatus. Pet. linear. obtufa: ungues albæ, villofæ; lamina patens, flavefcens.

42. conifera. P. fol elliptic. acutis, glabris, callofis: capitul. terminal. involucrato; involuc. longo, acuto, concol. Syft. veg. ed. I4. Thumb. l. c. n. 42. Breyn. cent, tab. 9.

Ad cap. b. Spei $\hbar$.

Adfinis priori. Caul. erectus, 3-ped. \& ultra: rami verticillati, foliofi, ramulofi. Fol. frequent. pollic. erecta, integra, concava. Conus ovatus, tomentofus, magnitudine Pifi.

43. Levifanus. P. fol. elliptic. obtufis, glabris: capitul terminal. involucrato; involuc. brevi, obtufo. Syft. veg. ed. I4. Thumb. l. c. n. 43. Burm. Afric. trb. xo0. f. 2. Boer. Lugd. tab. 202. Pet. Gaz. tab. 5. f. 7.

Ad cap. b. Spei $\hbar$.

Tota planta, excepta cor. glabra. Caul. erectus, ped. prolifer, lævis: ramulis fubpubefcent. Fol, fparfa, parva, unguicul, fpatulata, obtufa cum acumine, erecto-patula. Capitul. axill. \& terminal. lanata, magnitudine Pifi. Cal. comm. tomentofus.

44. frebilina . P. fol, elliptico-oblong, retufo-callofis : capitu- 
loq. terminal, glabris. Syft.veg.ed. I4. Thumb. l. i. n. 44 .

Ad. cap. b. Spei b.

Caul. erectus, prolif. ferrugineus, pubefcens. Fol. fparfa, fefquipollic. feffil. fpathuldtd, patent. reflexa, integra, concaviufc. Conus mdgnitudine Pruni.

45. imbricata . P. fol. imbricat. lanceul. friatis, glabris: capitulo terminali. Syft. yeg. ed. I4. Thumb. $l$. c. n. 45,tab. 5. Az. Medic. Syec. T. 1. tab.5. Ad cap. 6. Spei $\hbar$.

Tora planta, exceptis ramis, \& cor. glabra. Caul. erect. 3-ped. \& ultra, ramofus: rami bini-terni, erecti. Fol. ramos tegentia, femiunguicul. teffil integra, rugofa. Capitul. raro 2. oblong. magnitudine Juglandis min. Cor. extus lana flaveic. tecta.

46. Sericea, P. fol, lanceol, fericeis : ramis filiformibus: caul. decumb. Syft. veg. ed. 14. Thumb. l. c, n. 46. Ad cup. b. Spei $\hbar$.

Caul. ramofus, glaber. Fol. unguicul. erecta . Capitul. in ramis terminalibus, folitar. raro adgregata, fubcernua, magnitudine Pifi min. Cor. vix unguicul. luteo-tomentofa.

47. faligna. P. fol, lanceol. fericeis: caul, fruticofo: capitul. oblong. involucrat, Syjt. veg. ed, 14. Thumb. l. c. n. 47. Pluk. mant, tab. 229. f. 4 .

Ad cip. b. Spei $\hbar$.

Caul. erectus, 4-ped. fuperne ramofus, inferne nudus, ftriatus, purpurafc: rami conferti, breves, virgati. Fol. vix pollic. erecta. $\mathrm{Ca}-$ pitul. in ramis terminal. oblong. fol. obvallata, magnitudine Pifi.

48. argentea, P. fol. lanceol, argenteo-tomentofis, ciliatis: caul. arbor. capitulis globolis. Syft. veg. ed. 14. Thumb. l. c. n. 48. Com. H. 2, tab. 26. Boer. Lugd. tab. 195. Zanon. Hijt. 24.

Ad cap. b. Spei 万.

Fol. omnium nitidiff, argentea. Arb. orgyal. \& ultra, ramofiff, rami, \& ramuli erecto-patentes, tuberculofi. Fol, frequent. digital. feffil. in regra, nitentia. Conus rotundus, magnirudine Pruni, dein Pomi ma. Cal. fquamæ tomenrofa. Cor. vix unguicul, argenteo-tomentofa, 
****** Oblonge: fol. oblong. ovatis.

49. acaulis. P. fol. oblong. capituloq. globofo glabris: caul. decumbent. breviff. Svft. veg. ed. 14. Thumb. l. c. 11. 49. Boer. Iugd. 2. tab. 119.

Ad cap. b. pei $\hbar$.

Tota planta glabra. Caul. 2-poll. raro ramofus, fufcus. Fol. fparfa, pollic-palmaria, terilinalia, inæqualia, integra, marginata, venola, decidua. Capitul. termioale, folitar. magnitudine Juglandis. Cur. hirfuta.

50, myrtifolia. P. fol. oblorg. glabris: capitul. terminalibus, adgregatis. Syjt. veg. ed. 14. Thumb. l. co n. 50.

Al cap. b. Spei $\hbar$.

Tota planta, excepta cor. glabra. Caul, erectus, 3-ped. ramofus, purpur. Rami alterni, filiformes, ramofi, purpurafc. Fol, unguicul. feffil. obtula, bafi cbliqua, integra, patula. Capitul. in ramis, \& ramul. terminalia, folitaria, magnitudine Pifi. Cor. exrus albo-hirfuta.

51. grandiflo- P. fol. ublong. venofis, capitaloq. hemifphri$r a$. $\quad c o$, glab is: caul. arboreo. Syjt. veg. ed. I4. Thumb. l. c, n. 51. Boer. Lugd, 2, tab, 183. Ad cap. b. Spei 古.

Tota arbor glabra, Caul, orgyal. \& ultra, ramofus. Fol. digital. feffil, obrufa, integra, venofa, patentid. Capitul. faitigiatum, folitar. magnitud ne pugni. Cor. albo-tomentofa. Hac, \& P. Cyanoides Jpeciofa funt capitul, maximis.

52. glabra. P. fol. oblong. aveniis, capituloq. hemifphærico, glabris: caul. frutic. Syft. veg, ed. 14. Thumb. l. c. n. 52.

Ad cap. b. Spei 万.

Caul. glaber. Fol. pollic. erecta, feffil. craffa, Capitul. terminal: folitar. magnitudine Pomi.

53. Jpeciofa. P. fol, oblong. glabris: capitul. oblong. fquamis calycin. apice barbatis. Syft. veg. ed. I4. Thumb. l. c. n. 53. Bocr. Lugd. 2. tab. 145 . Ad cop. b. Spei b.

Caul, arbor. orgyal, ramofus, villofus. Fol. palmar. fubpetiolar. marginata, coriacea, nervofa, patula, apice fuíco. Capitul, terminal. 


\section{TETRANDRIA MONOGYNIA.}

ovat. magnitudine Ovi Anferini. Cor. filifor. hirfuta. Var. fol. anguftior. \& latioribus : calyc. apice barba ferruginea, \& nigra .

54. totta ? P. fol, ovatis, glabris, callofis: capitul. ovat: cor, cylindric. hirtis. Syft. veg.ed, I4. Thumb. l. c. n. $\$ 4$.

Ad cap. b. Spei b.

Caul villofus, purpurafc. Fol. pollic. feffil, obtula, raro 3-dentara, glabra, Capitul. terminal. folitar. magnitudine Pyri. Cor. pollicar. filifor. villofa.

55. hirta. P. fol. ovat. glabris: fl. laterylibus. Syft. veg. ed. 14. Thumb. l.c. n. 55. Boer, Lugd. 2, tab.

I94. 205.

Ad cap. b. Spei b.

Caul. erectus, pedal. \& ultra, villofus. Fol. pollic. feffil. imbricata, raro ciliata . Capitul. folitar. fub-8-fl. Calyc. fquimæ luteo-fanguin. fplendentes. Cor. filiform. villofa. Piltil cor. duplo longiora, curva. Simil. P. cucullata, fed differt fol. Jubloubefc. villofitate fl. helvola, nec ulba Ec.

56. pubera, P. fol. ovatis : capitulifq. terminalibus, tomentof. Syft. veg. ed. 14. Thumb. l. c. n. 56. Boer. Lugd. 2, $t a b$. 201.?

Ad cap. b. Spei $\hbar$.

Caul. fruric. 3-6-ped, ramofus, villofus . Rami verfus apicem fubverticill. Fol, unguicul, imbricata, feffil. elliprica, pubefcent, iniana . Capitul. raro folitar. fæe plura, magnitudine Cerafi, Cal, hirfutus. Cor. unguicul. villis lanata. Variat ful. ovat. \& oblongis .

57. divaricata. P. fol. ovat, hirtis: capitul, terminalibus, ramis divaricatis. $S_{y, f}$, veg. ed. I4. Thumb.l.c. n. 57 . Ad colp. b. Spei $\hbar$.

Caul, diffufus, fruticulofus, procumb. pedal. \& ultra, prolifer, purpurafc. fubpilof, rami divaricati. Fol. fparfa, imbricata, feffil. lineam longa, ovat-fubrot, integra, villofa, rugofa. Capitul. in ramis terminalibus folitar. iaxum, cernuum, magnitudine Pifi. Cor, extus tomentofa.

******* Rotundate: fol, fubrotund.

58. Spathulata. P. fol, fpathulat, fubcucullat, glabris. Syjt, veg. 
ed. I4. Thumb. l. c. n. 58 . tab.5. Ad. Medic. Svec. T. 1. tab. 5.

Ad cap. b. Spei b.

Caul. erectus, 2-ped. \& ultra, ramofus, glaber. Rami bini, terni, purpurafe. Fol, unguicul. petiolat. imbricata, integra, marginara. Capirul, in apice ramorum adgregata. Cal. com. fub 4-phyll. 4-fl, tomentofus. Cor. vix unguicul. lanata.

59. cynaroides. P. fol, fubrotun. petiolatis, glabris. Syft. veg. ed. I4. Thumb. l. c. n, sq. Boer. Lugd. 2. tab. 184 .

Ad cap. b. Spei b.

Caul, vix ped. fumpl. rugofus. Fol, digital, integra, marginata, patentia. Capitul. faftigiatum, ovatum, magnitudine calyc, Cynarce. Cal. imbricat. fquamis extus cinereis. Cor. albo-toment.

60. cordata. P. fol. cordatis. Sy]. yeg. ed. 14. Thumb. l. c. tab. 5. Aa. Medic. Svec. T. I. tab. 5.

Ad cap. b. Spei Ђ.

Tota planta glabra. Caul. decumb. fpitham.

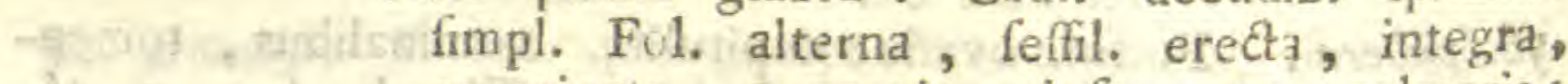
4 . 2 . d marginata, 9-nervia ; infer. ma: palmaria; fuper. fenfim breviora. Capitul. fubradical. ovat. truncatum. Pappus femen obvallans, purpurafe.

61. bruniades. P. fol. tubulatis: capitul. terminalibus, globo* fis. Sy/f. veg. ed. 14. Lin. SuFpl.

Ad cap. b. Spei b.

An P. lanata? Frutex determinate ramofus, fufces fcens. Fol. conferta, glabra ; recentia pilofa. Capitul. folitar. magnitudine nuclei Coryli . Flofculi pilofi, apicibus flavis.

13T, GLOBU-Cal, corn. imbricat, (planus): proprius tubulaLARIA. tus, inferus , Corollulæ lab. fuper. 2-part. infer. 3. part: Receptac. paleac.

I. Alypum G. caul, fructic: fol. lanceol, 3-dent. integrifq. Syft. veg. ed. I4.

Alypum Niff. Aa. 1712, tab. 18. Garid. Aix. $t a b, 43$.

In Sylvis Italia \&c. and rupes, \& faxofa b. Caul, 2-ped. Fol. feffil, dura, fempervirent, Fl. ccerul-purpurafc. 
2. bifnagarica. G. caul, frutic: fol. radicalibus cuneiformíbus, retufis: caulinis lanceol. Sy/z. veg. ed. I4.

Scabiofa \&c. Pluk. alm. tab. 53. f. s.

In Bifnagaria fylvis 24.

3. vulgaris. G. caul, herbac, fol. radicalibus 3-dentat, caulinis lanceol. Syft. yeg. ed. I4.

Aphyllanthes. Camb. hort, 18, t«b, 7, Lob. ic. p. 478.

In Europx apricis 4.

Caul. 6-uncial. ramofus, foliofus, rubefcens. Fol. nervofa, glabra: radical. petiolat. ovata, frepe emarginata; caulina oblongo-lanceol. Cor. ccerul, vel alba. Var. non foliofa.

4. Spinofa. G. fol. radical. crenato-aculeat, ; caulinis mucronat, integerr. Syft. veg. ed, I4.

In Granada montibus 4.

Flos globofus, corul. Reliqua ex definitione.

5. cordifolia. G. caul. fubnudo: fol. cuneiformibus, tricufpidat: intermedio minimo. Syft. yeg. ed. I4. Jacq. Aufir. tab. 245.

Scabiofa \&c. Morif, Hift. 3. f. 6. tab. I5. f. ultim.

In Aujtria, Helvetia \&c. 4 .

planta cefpitofa, fuffrutefiens. Caulic. pl. fufci. Scap. 2-5-unc, purpur. nitidus. Fol. adgrega. ta, petiolat. hucida. Capitul. fubrotun. Cor. 3-4. firl. coerul.

6. nudicaulis, G. caul, nudo: fol. ovat-oblong. integerr. Syft. veg. ed. 14. Jacq. Auffr. 3. tab. 230.

Scabiof́a \&c. Morif. 3. . . 6. tab. I5. f. 4.

In Auftrie, Helvetice \&c. montibus 4.

Caul. fub-ped. fuperne purpurafc: fructifer uno, alterove foliolo. Fol. plura, obtufa, craffiufc. glabra, nitida, fupra fature, fubtus pallidius virent. Sripul. lanceol-acum. Capitul, fubrotun. Coroll. ex purpur-cerulefc: 3 . fuper, longior: 2. infer. breviores.

7. orientalis. G. caul. fubnudo: capitul. alternis, feffilibus: fol. lanceol-ovatis, integris. Syft. veg. ed. I4.

In Natolia 4.

Fol. obverfe ovata, in petiol. definentia, plurima, integra, nuda. Caul. ped. herbac. fimpl. fol, remotis, minimis, alternis, lanceol. $\mathrm{Ca}-$ pirul. in apice caul, 7-10, alterna, feffil. Tom, I, 
132. CEPHA-Cal, comm, c. proprius fuperus, infundibul. Re-

LANTHUS . cept. globofum, nudum. Sem. I. lanuginofum.

1. occidenta- C, fol, oppofitis, ternifque. Sift. veg. ed. 14. lis.

Duham. $a r b$, I. tab. 54 .

Scabiola \&c, Pluk, alm. tab. 77. f. 4.

In Amer. Septentr, $\hbar$.

Squamæ capitulum efformantes. Capf. nullæ. Sen. longa, pyramidata, bafi attenuata, angulata, I-locul.

I32. DIPSA-Cal. comin. polyphyll. (foliis anguftis, fpinofis): CUS. proprius fuperus, Receptac. paleaceum.

I. fullonum. D. fol. fefflibus, fersatis: paleis recurvatis, Syft. veg. ed. 14.

In Europa ठ

Squamæ mulro duriores, \& apice reflexæ. Cal. foliola capitulo duplo longiora.

2. fylveftris. D. fol. integris; paleis rectis. Syft. veg. ed. 14. Jacq. Auftr. 5. tab, 402, Black. tab. 50.

Dipfaco, o labbro di Venere altro. Matth. In Europa o .

Fol. omnino connata. Cal. foliola capitulo breviora, fubinermia.

3. laciniatus, D. fol. connatis, finuatis. Sy/t, veg. ed. I4. Jacq. Aujtr. 5.tab. 403. Morif. Hift. 3.5.7. $2 a b .36$. f. 4. In Europa б".

Laciniæ lateral. obtufæ, dentatæ; terminal. acuminatæ.

4. pilofus, D. fol. petiolat, appendiculat. Syft. veg. ed. 14. Jacq. Auftr. tab. 248. Blak. tab. I24.

Virga di paftore. Matth.

In Europa б".

Cdul, orgyal. ramofus. Fol, pallide virent. fcabriufc. ad bafin caulis connata, ovar-lanceolferrata; fuprema lanceol. integerr. Capitul. ro• tundarum, fubvirefc. Cor. albida .

133. SCABIOSA. Cal. comm. polyphyll. proprius duplex, fuperus. Receptac, paleac. feu nudum. Sem. ovato-oblonga .

\section{Corollul. 4-fidis.}

x. alpina S. cor. quadrifid. æqualibus calyc. imbricat. Al. cernuis : fol. pininat, foliol. lanceol, ferratis. Syft. veg. ed. 14. Besl. Eyft. aft. 122. Lob. adv. ic. p. 537.

In alpibus helveticis, italicis 4. 
Inter congeneres omnium ampla, valde hirfuta. Caul. 4-ped. ramofus, fiftulofus. Fol. ad terram elliptica, ferrata; caulina pinnata, nervo foliac, lato: foliola utrimq. 6-7. impari maximo. Fol. terminal, ad balin uniuntur. Capitula congefta, pene fpharica. Cal. fquama extus villofæ, fubfufca. Cor, ochroleuc.

2. rigida. S. cor. quadrifid. fubradiantibus: calyc. imbricat. obtufis: fol. (fuperior.) lanceol. ferratis, auriculat. Syjt. veg. ed. 14, Comm. hort. 1. tab. 93.

In Ertiopia $\hbar$.

Caul. fuffrutic. fcaber. Fol, ad bafin 2-dent. infer. ovata, in petiolum definentia ; reliqua feffilia. Pedunc. terminal. longiff. Cor, albicans.

3. $\operatorname{tranfylva-S.~cor.~quadrifid.~aqualibus,~cal,~paleifque~ari-~}$ nica. flatis; fol. radical. lyratis; caulin. pinnatifid. Sjft. veg. ed. 14. Jacq. H. 2, tab. III. All. Fl. Ped. tab. 48. Morif. Hijz. 3. א. 6. tab. 13. f. I3.

In Tranfylvania, Pedemontii collibus (-).

Planta tota pilis hifpida, fed magis inferius. Caul. 3-cubital, ab imo ad funmun ramofus, brachiatus, obfcure 4 gonus, fuperius evidentius, fulc tus, \& ftriatus. Fol. oppoitra, amplexicaulia, coalita, pinnata, pinnis per nervun decurrentibus 5-6. Pinnæe plerumque refecta, \& veluti corniculatæ, extremum atem par exhibet duo foliola lanceol to-linearia, quorum interior pars amplior eft. Impar foliorum longe ellipticu-lanceolat, eft, \& toto folio longius. Folior, lacinize variant modo parcius refectæ, modo integræ. Prinæ $\&$ profundius, \& pluries refectre effe folent. Pinnarum numerus in fuperioribus minor eft . Rami oppofiti, paruli, divifi. Pedunc. floriferi terminales, fubpalm. nudi, fere glabri. Extremi rami 2-3-fl. Cal, ex 5-foliol. viridibus, ovatis, pilofis, dein longe ariftatis, qua parte non virent, pellucidis, \& albicantibus. Capitul, ovatum. Cor. difure purpuro-cœrulea.

4. fcabra, S, cor, 4-fid, aqualibus: calyc, imbricat, obtufis: fol. fub 2 -pinnat. fcabris, rigidiufc. syft. veg. ed. I4. Lin. Suppl. 
Planta herbacea, ftatura, caul. floribufque $S$. rigidula. Caul. finpl. teretes, fcabri. Fol. feffil. linear. acuta, cum rudimentis ramorum foliof, axillar. Fl. terminal, folitar. longe peduncul. Flofc. albi .

5. Syriaca. S, cor. quadrifid. aqualibus, calyc. imbricat. paleifq. ariftat. caul, dichot. fol. lanceol. Syft. veg. ed. 14. Morif. hift. 3. f. 6. tab. 14. f. 14 .

In Siria.

Caul. pilofus. Fol, ferrata. Fl, in dichotom. fubfeffil. Cal. vix ullus, fed palere in conum, ovatum imbricatæ. Cor, alba.

6. leueenthe. S. cor. quadrifid. fubæqual. fquam. calyc. imbricat. ovatis: fol. pinnatif. Syft. veg. ed. I4. Bauk. hift. 3. part. 2. p. 8.

In Narbona, Carniola Ec. 24.

Caul, fruticofus. Fol. villofa, linear. uno, aliove dente fuperne inftructa; foliol. decurrent. infima fcabra. Fl. fubglobofi, albi. Cal, hemifph. Corollula lacinia inferior deflexa, paulo longior. Sem. 3-gona.

7. fuecife. S. cor. 4-fid. æqual. caul. fimpl, ramis adproximaris: fol. lanceol-ovat. Syft. veg. ed. 14. Fl. Dan. tab. 279. Black, tab. 142. Ludw. ezt. tab. I9). Knor. hort. 1. $20 b .7$.

Succifa Matih.

In Europe pafcuis humidiufculis 24.

Radix truncata, feu in centro demorfa. Caul. apice ramofus, fub 3-fl. Fol. firma, glabra, fubvifcida, fubdent. obfcure virent. margine purpuro-nigra ; infer. petiolat. fuper. feffil. radical. ovalia, fubintegra ; caulina pauea, longa, lanceol. Cor. carul. purpur. alba. Var. proliferia: fol. incifis : cor. 5-fidis : coroll, albis: hirfuta.

8. integrifolia.S. cor. 4-fid. radiantibus: fol. plerumq. divifis; radicalibus ovatis, ( plerumque) ferratis; rameis lanceol. caul, herbac. Syft. veg. ed. I4.

Monfpelii, in Helvetia \&c. $\odot$.

Caul. fubhirfur. aut glaber; ramis patulis. Fol. radical. Bellidis, petiol. ovata, obtufiufc. fcdbra, acutius ferrata: caulina pauca: ramea amplexicaul. bafi ciliata, Iongiff. culta dentata, feu pinnatifida. Cal. ro-phyll. flore brevior. Cor. cœrul-purpurafc. Sem. fericea, denticulata. 
9. amplexi- S. cor. 4-fid. radiantibus: fol. amplexicaul. lancaulis. ceol. integerr. radical. 3-fid. crenatis. Syft. veg. ed. I4.

Habitat..... $\odot$.

Caul. ped. brachiatus, fcaber. Fol. radical. oblong. fabriufcula . Panicula dichotoma. Pedunc, lon giff. Cor. cœrulefc.

Differt a priore fol. redicalibus non indivifis: causlinis bafi latiuribus: calyce non cor. dimidio breviure.

I0, attenua- S. cor. 4-fid, aqualibus: fol. linearibus, integris, ta. 3-fidifque. Syjt. reg. ed. 14. Lim. Suppl. Ad cap. b. Spei.

Planta lævis.

II, tetarica. S. cor. 4-fid, radiantibus: fol, lanceol, pinnatif, lobis fubimbric. caul, hifpido. Syjt, veg. ed. I4. Az. Upf. 1744. tab. I.

In Tataria ơ.

Caul. altus, 12-perl. brachiatus, fiftulofus . Ramĩ oppofiti, e geniculis a radice ufq. ad apicem fæpe bis dichotomi. Pili rari, parvi, albidi . Fol. amplexic. oppofita, pinnis ovat-lanceol. floralia indivifa. Fl, pallide lutei. Paleæ lineares, feminibus longiores, decidua.

I2. uralenfis. S, cor. 4-fid, radiantibus: fol. radical. fimplicibus: caulinis decurfive pinnat, paleis aridis, apice reflexis. Syft. veg. ed. 14. Comm. Gutting. 1782. $t a b, 4$.

13. arvenfis. S. cor. 4-fid, radiantibus : fol. (fuperioribus) pinnatif. incifis, (lobis diftantibus) caul. hifpido.

S. \&c. Syß.veg.ed, I4, Fl. Dan, tab. 447. Ludw. ec., tab.21. Black, tab. I85. Bauh. hift. 3. part. I. $\mathrm{p}, 2$.

In Europe pratis 24.

Caul, erectus, cubital, brachiatus, maculatus. Fol. pallidiufc, hirfuta, firma, fcabra : radicdl. petiolat. ovat-lanc. fubferrata. Cap. oblong. Corollul. rubella, cœrul. Fructus fimil. S. tatarica, fed abfque paleis. Var. fol. omnibus integris: fl. alba. Lob. ic. p. 53. Altera yar. glabra.

I4. Sylvatice. S. cor. 4 -fid, radiantibus: fol. omnibus indivifis, ovat-oblong. ferrat. caul. hifpido. Syft. veg. ed. I4. Jacq. Auftr. 4. tab. 362, Obf. I. tab. 72 . In Europa fylvaticis 24 . 
Caul. fuperne adfperfus punctis purpur. inferne glaber, r-4-ped. Fol. magna ; infer. petiolat. profunde ferrata, ut finuata videantur: proxima feffil. furma anguita, integerr. Pedunc. longiff. Flos pro plantæe porione parvus. Cor. purpur.

Priore viror ubforior: facies hifpidior: fol. fernper indivifa: bafes cordate, \& amplexicau?. bulbilli rubelli ad bafin caul. corollul. obfsure radiantes: ansh. carul.

\section{** Corollul. quinquefidis.}

15. gramuntia .S. cor. 5 fid. calyc, breviff: fol. caulin, 2-pinnat. filitormibus. Syjt. veg. ed. I4.

Monfpelii \&c. Jecus vias $\sigma^{\top}$.

Capitulum globofum .

I6. columba- S. cor. 5-fid radiantibus: fol, radicalibus ovat. ria. crenat: caulinis pinoat. fetaceis. Sy/t. veg. ed. I4. Fl. Dan. tab. 3i4. Herm. par. tab. 221. Knorr. del, hort. 2, tab. $\int 13$.

b. prolifera. Bauh. 3. part. I, pag. 5.

In Europa montafis, ficcioribus.

Caul, pedal-cubital. brachiat. in zxima ex parte nudus. Fol. pallide virent, radical in orbem pofita, petiolat. caulina connato-feffil, 2-pinn. apice rubello. Rani longi. Involuc. laxum membranac. inverfe conicum. Capitul. globufum. Cor. purpuro-corul vel dilute rubella, raro alba. Variat glabritie, \& kirfutie.

Planta polymorpha. Mire variat fol. figura; quidem

P. fol. imis oblong. undique dentat: fuperior. pirnatif. lacin. linearibus, \& plerifq. indivifis : qux communior eft.

2. fol. imis oblong. undiq. dentat: fuperior, pinnatif. lacinits lanceol. incifis.

Planta alpina, fpitham. Caul. firspl. 3. fol. paribus: horum primum indivifum, cætera pinnatif. Arifta e cal. proprio nigra.

3. fol. imis oblong. apice dentat: fupremis pinnatifid; lacinia terminal. oblong. dentata; cateris linearibus, \& indivifis. Simil. var. Jecundee.

4. fol. omnibus, oblong. \& undique dentat: fupe rior. baji pinnatifid. 
Effentia fpecifica fira eft in cor, radiante: germine villofo, coronato : receptaculi paleis brevibus, foliac. lanceol.

17. ficula. S. cor. 5-fid, æqualibus, calyc. brevioribus : fol. lyrato-pinnatifid. Syft. veg. ed. 14.

S. divaricata. Jacq. hort. I. tab. 15.

In Sicilia $\odot$.

Caul. herbac. ped. dichot. divaricatus, debilis, ruber. Fol. petiolata, nudiufc, fubpilofa; infer. lyrata; fuper. fubpinn. linear. Pedunc. longi, dichotomi, vix pubefe. purpur. Cal.8phyll. Cor. rubicunda. Differt pracipue a $S$. maritima fl. non radiutis.

18. maritime. S. cor. 5-fid. radiantibus, calyc. brevioribus : fol. caulinis pinnat, ; fummis linearibus, ( fæpe) integerr. Syft, veg. ed. I4. Bauh. Hift. 3. p. 7 .

In Sicilia, Monfoelii $\odot$.

Habitus S. pappofa. Caul. 2-ped. ramofus, villofus. Fol. dentata, venofa; radical. palmaria, lanceol. obtufa, tandem pinnatif. Scrophularice canina fimilia. Pedunc. longiff. Cal. imbricat, hemifphær. fquamis ovatis, obrufis; infimis foliol. lanceol. cor. longioribus. Cor. albo-purpurafc. Fruct. S. atro-purpür.

19. fiellata, S. cor. 5-fid. radiantibus: fol. diflectis: receptac. A. fubrotundis. Syjt. veg. ed, s4, Clus, hift. 2. p. I.

In Hispania Ec. (.).

Fol. infer. obovat-oblong. incifo-ferrata ; fuper. lyrata. Cor. albido-cœrulefc. Fructus capitul. globofum. Var. fl. vix radiatis. fol. linearibus, pinnatis,

20. proliferu. S. cor. 5-fid. radiantibus: fl, fubfeffilibus: fol. indivifis: caul, prolifero. Syft, yeg, ed, 14. Herm. parad. tab. 125.

In 压gypto $\odot$.

Caul. herbac, dichotomus. Fol, lanceol. fubpubefc. bafi connata; infer. fubferrata. Fl. axill. Cal. laxus, longitudine cor. Cor. flava.

2I. atropurpu-S. cor. 5-fid, radiantibus: fol, diffectis : receprea. tac. fl. fubulatis. Syjt. veg. ed, 14, Clus, hift. 2. Pag. 3 .

In India? $\odot$.

Cal. 12-phyll, linearis, recurvatus, longitudine $S$ iv 
cor. Flos atro-purp. anth. albis. Fruct, ovatus : Receptac. fubulatum, paleis fetaceis. Sem, 4gona.

2. argenses. S. cor. 5-fid, radiantibus: fol. pinnatifid.; lacin. linearibus : peduncul. longiff: caul. tereti. Syft. veg. ed. 14.

In Oriente 2.

Caul. pilis albis, raris. Fol, radical. fubdent: caulina indivifa, verfus bafin ciliata. Cal. 8phyll. recurvatus, bafi valde ramofus, cor. Jongitudine. Cor. albida, limbo cœrulef. Stam. alba.

33. indurata. S. cor. 5-fid, radiantibus: fol, ovat-lanc, erofis, bafi dentat: caul, rigente. Syjt. veg. ed. 14.

In Africa 古.

Adfinis S. africanz, ut fere varietas? Caul. ped. pubefc. Fol. feffil. fpitham. fubtoment. viridia. Panicul, dichot, prima dichotomia pedunculifera, reliquis apice proliferis. Pedunc. longiff. Cal. brevis, patens, 10-phyll: fubxqual. non imbricatus. Cor. pallide coerul. calyce longior. Pdlez fetaceæ. Sem. oblong. 8 -fulcata.

24. africane. S, cor. 5-fid, æqualibus: fol. fimplicibus, incis fis: caul. fruticofo. Syft. veg. ed. I4,

S. altifima Jacq. hort, tab. 185. huius yar. 1idetur. Herm. parad, tab. 219.

b. S. minor \&c. Breyn. ic. tab. 26.

In Africa, Oriente 2.

Altitudo humana. Caul. villofus. Fol, euneiform. fubpinnatif. incifo-ferrata, utrimq. villofa; fumma lanceol. bafi pinnatif. Capitu?. convexum. Corollul. ma: purpuro-pallide coerulefc.

25. monfpeli- S. cor. 5-fid. rqualibus, calyce brevioribus: enfis. fol. omnibus pinnat. ciliatis. Syft. veg. ed. 14. Jacq. rar. tab. 23.

Monspelii.

Planta tota hirfuta. Caul. fefquiper. teres, inferne purpur. Fol. oppofita, periolat. pinnis diftantibus, oblong. acutis, aliis integerr. aliis apice rariter incifis, Peduncul. terminalis. Cor. purpur, extus pilofula, lacin-obrufis .

26. purnila. S. cor. 5-fid, radiantibus; fubacaul: fol. pilo- 
fiff. radicalibus lyratis; caulin. pinnat. incifis. Syjt. veg. ed. 14.

Ad cap. b. Spei 24.

Planta fuitham. tora hirfuriffima.

27. cretica. S. cor. 5 -fid: fol. lanceol. fubintegerr. caul, fruticofo. Syft. veg, ed, 14. Morif. hif.. 3. 1, 6. tab. I5. f. 3 I.

In Creta, \& ndiacentibus $\hbar$.

Caul. 2-cubital. ramofus. Fol, in caule confertiff. ut fere imbricata, 2, unc. longa, latoelliptica, incand. Fl. ampli. Cal. obtufus . Cor. fubcorul.

28. graminifo-S. cor. 5-fid. radiantibus: fol. lineari-lanceol. lia. integerr, caule herbac. Syf, veg. ed. I4. Bauho prodr. tab. 127.

In alpibus Helverie, Baldi, Pedemontii, Tridentini 2 .

Tota planta albida. Caul. cubital. I-fl. Fol. graminea, bafi connata, aut amplexicaul. longa, nudiufc. Involuc, in cavum infundibul. abit . Cor, argentea. Sem. argenteo-nitida . Var. glabra.

29. palaftina. S. cor. 5-fid. radiantibus: lacin. omnibus $3^{4}$ fid: fol. indivifis, fubferratis; fummis bafi pinnatifid, Syf. veg. ed. I4. Jaiq, hort. I. tab. 96.

In Palafina 4.

Caul. pedal. teres. Fol, latius lanceol. aliquot incifuris donata, pubefcent. Pedunc. longiff, Fl. albi, aut citrini, longitudine cal. Truct. omnino S. Stellata.

30. ifetenfs. S, cor. 5-fid. radiantibus, calyce longioribus: fol. 2-pinnat, linearibus. Syft. veg. ed. 14. Gmel. Sib, 2, $t a b .88$, f. I.

In Sibirice Ifetenfis rupibus.

Caul. adfendent. pedal. fubromentofi. Fol. pilis rigidulis adlperfa; fumma fimpliciter pinnata. Rami fre nulli. Flos albus, calyce non brevior. Cal. polyphyll. patens. Sem. ut in S. fellata.

31. wcranica. S. cor. 5-fid. radiant bus: fol. radicalibus pinnatifid: caulinis linearibus, bafi fape ciliatis. Syft. veg. ed. I4. Gmel. Sib. 2. tab. 87.

In Ucrania, Pedemantio 4.

Caul. fefquicubit. ramofi, quandoque hirfuti, fuperne rubent, Fol, carnefa. Involuc. capituio 
valde longius. Cor. ochroleuca. Var. fatura; fol. \& glabritie.

32, ochroleuca. S. cor. 5-fid. radiantibus: fol. radical. 2-pinnat. linearibus. Syft. veg. ed. 14. Jacg. Auftr. tab. 439. Obf. 3. tab. 73. 74. Morif. hift. 3. f. 9. tab. 13. f. 23. Barr. ic. 770. f. 2.

In Sibiria, \& Germania pratis ficcis $\delta^{\circ}$.

Adfinis S. columbaria. Fol. caulina pinnata, pinnis linearibus. Periol, bafes lata. Pedunc. longi. Cor, flavercenti-albida. Fructus ovatus. Caul. genicula purpurafc.

33. pappofa. S. cor. 5-fid. inzqualibus : caul erecto, herbac. fol. pinnatifid: feminibus ariltat. plumofoqpappofis. Syft. veg. ed. I4.

In Creta $\odot$.

Caul. I-2-ped. filiform. brachiatus, paniculat. fubdichotom. Fol, petiol. mollia, albefcent. hirfutula. Pinnæ paucæ, longæ, anguftæ. Pedunc, axill, longi, filiform. Cal. polyphyll. foliol. ovatis, longe acuminat. Cor. ex violacalbefcens. Peduacul. \& calyc. fubtomentofi.

34. Fteroce- S. cor. 5-fid. caule fructicolo, procumbente: phala. fol. laciniat, hirfutis: pappo plumofo. Syft. veg. ed. 14.

In Gracia? b

Planta incana. Caul, vix e terra prominens. Scap. breviff. I-fl.

Lyrata.

S. fol. radicalibus ovatis; caulin. pinnatis. Forsk. Suppl. IEg.

Ad Dardanellos.

Habitus S. argentea. Caul. fubtomentofus. Pedunc. longi, glabri. Dichotomia fimpl. Cor. 5-fid. radiant. violac.

Trenta. S. Hacquet, pl. alp. Carn, tab. 4. f. I.

In Carniol ex fcopulurum fifuris.

Simil. S. Tranfylvanica. Caul. 6-pollic. fimpl. teres, fubftriat. Fol, infer. amplexicaul. pinnatifida: lobi infer. liberi, valde crenati, \& runcinati; exier. maiores. Ex ultimo loborum pari alter lobus perpendiculariter exurgit. Superior. fol. linear. integerr. Flos unicus, globofus, Calyc. fquama membranac. mucronato-ariftatæ, albidae. Cor, 4-fid, radiant, albæ . 
tomentofa. S. caul. I-fl. fol, tomentofis, imis pinnatis, pinnis dematis, \& femipinnat: caulnis pinnat. Haller. Hift, n. 207. All. Ped. tab. 25. f. 2. Bocc. Muf. tab. 6.

In Helvetia Ec.

Caul. prater par fol, pinnatorum, nudus, femiped-dodrant. Fol, omnia tomentofa, prima Bellidis, ovata, habitu ab omnibus noftratibus diverfo. Flos unicus, radiatus, purpur. An differt a $S$. columbaria?

grendiflore. S. corollul, 5-fid. radiantibus: fol. radicalibus oblong: crenatis: caulinis pinnatis ; pinnis lanceolat-linearibus, patulis. scop. Delic. Infub. $t a b, 14$.

In regno Tunetano 24 .

Caul, fub 3-ped. tenax, villofulus, in fenio rubefcens, tamofus, in adulta planta furculos e bufi proferens. Fol. furulor. longe petiolata: caulina pinna terminali longiore, \& latiore. Perlunc. terminal. longi, nudi. Capitula magna, Cal. comm. 8-10-fid. 1 gmentis inæquaJibus, linearibus. Fl. limbis albis; tubis rubellis. Capitul. fructiferum magnum, oblongum. Habitus fl. ut in S. atropirpur.

albe. $\quad S$. corollul. 5 - fid. radiantibus: fol. rameis fim= plicibus, linearibus, albo punctulatis: caul. fuffruticofo. Scop. Delic. Infub. fafc. 3. $t a b$. 16.

Circa Ticinum 24.

Rad. craffa. Caul. erecti, 3-ped. \& ultra, teretes, læves, ramofi, albi, in fenio bafi rubentes. Fol, inferiora pinnata, pinnis linearibus. Pedunc. axillar. longi, nudi, tenues. Cal, comm, ex foliol. 7-8, linear:bus, patulis, inæqu libus. Cor. alba. Capitula feminifera rotunda, folicl. calycinis, iifque reflexis, minora. Differt a S. maritima, rad. perenni; caul. fuffruticofo; fatura multo maiore; fl. ulbo, \& non rubro \&c.

134. KNAU-CaI. comm. oblongus, fimpl. 5-fl. proprius fimTIA. pl. fuperus, Corollul. irregul. Receptac. nudum. Differt a fcabiofa cal. tubulofo; \& fimplici flofcul. orbita.

T. orientalis. $\mathrm{K}$. fol. incifis: cor. 5. calyce longioribus. Syft. veg. ed. 14.

In Oriente $\odot$. 
Gaul. pedal. Fol. oppofita, feffilia, villofa, in medio caule pinnatifida; reliqua tantum ferrata. Pedunc. axill. longi. Cal. foliol. linearibus. Sem. compreffa, pilofa, apice multident.

2. propontica. K. ful. fuperior. lanceol: integerr: corollul, denis cal. æqualibus. Syft.yeg. ed, I4. Tilli Pif. tab. 48.

In Oriente $\sigma$.

Caul. 2-ped, villofus . Fol. fubpilofo-fcabra, ferrata, fpitham. Cal. fol. apice fubulatis . Cor. 4-fid. purpurafc. Filam. \& pittil. alba. Anth. purpur. Differt a priore fol. indivifis: corollul, decern, nec quinis \&c.

3. palaftina. K, fol. integris: calyc. 6-phyll, feminibus pappofis. Syft. veg. ed. I4.

In Palefina $\odot$.

Caul. erectus, vix ped. teres, brachiatus, fubpilofus. Fol. oppofita. fubpetiol. lanceol. pilofa. Pedunc, folitar. longiff. erecti, aphylli .

4. plumo $\sqrt{a}$. K. fol. fuper. pinnatis: calyc. Io-phyll: fem. pappofis. Syft. veg. ed. 14 .

In Oriente $\odot$.

Caul. erectus, fefquiped. teres, brachiatus, pubefc. Fol. oppofita, fublanc. fubtomentofa, venofa, patentia; infer. lato-lanc. indivifa, profunde ferrata, bafi tomentofa. Pedunc. folitar, longiff, recti, aphylli. Cal. foliol. Io. lineari-lanc. Flofc. 15. Cor. pallide coerulefc.

135. ALLIO- Cal, comm. fimpl, oblong. triflor: proprius obNIA. foletus, fuperus . Corollul. irregular. Receptac. nudum .

1. violacea, A. fol, cordatis: calycibus 5-fid. Syft. veg. ed. 14. Lafl. it. IOI.

In Cumuna Americes.

Caul, erectus, herbac. ramofus, debilis. Fol. oppofita, acuta, integerrima, glabra ; infer. Jonge petiolat. Panic. terminal. ramofa, bracteolis brevibus. Calyx comm, laxus. Corollul. maiufc. purpuro-coerul.

2.incarnata. A. fol. oblique cordatis: calycibus triphyll. Syft. veg. ed. 14. Herit. Stirp. nov. fafc. 4. tab. $3 \mathrm{I}$.

Wedelia, Ioff. it. I80.

In Cumance arenofis, $\varepsilon$ in Perua, rupibus arenofis $\odot$. 
Planta glauca, habitu Boerhasvice hirfute. Rad, ramofa, fubfibrofa. Cotyled, petioldt. fubrotundx. Caul, proftratus, bafi fæpe 3-part. fubramofus, teres, villofus, fubvifcidus. Ramuli alterni e folior. altero minore, axillar. villofiores. Fol. oppofita, altero minore, primordialia terna, periolata, ovalia, bafi inæqual. obtufiufcula, feu vix acumin. repanda, lasiffime nervofa, craffiufcula, villora, vix fcabriufcula, pallida, fubtus glauca, margine purpurefc. patentia, concava, $18-20$. lin. Ionga, I0-12. lin. lata. Pedunc. folitarii e latere fupino coniugationis foliorum, filiformes, villofi, 2-fl. primun breves; floriferi longi, fructiferi triplo longiores, apice nutantes. Fl. terminales, folitarii, incarnati, 3. lin. longi, \& lati.

536. HEDYO-Cor. 1. pet. infundibul. Capf. 2-locul. polyfperTIS. ma, infera .

1. maritima. H. fol. ovalibus, obtufis: fl. oppofitis, reffili= bus. Syft. veg. ed. 14. Lin. \{uppl.

In India Orient. $\odot$.

Caul. proftrati, herbacei, palmar. læves. Fol. oppofita, fubpetiol. patentia, fubcarnofa . Fl. lateral. feffiles. Fruct. magnitudine Coriandri.

2. pumila. H, fol. ovat, acutis: fl. alternis, pedunculat. Sylt, veg. ed. 14. Lin. Suppl.

In Tranquebaria $\odot$.

Facies Anagallidis arvenfis. Caul. palm. parum ramofi, laves. Fol, vix petiol. lavia. Fl, axill. Capf. fubrotunda.

3. fruticofe. H. fol. lanceol. petiolat. corymbis terminalibus involucratis. Syft. yeg. ed. 14.

Valerianella \&rc. Burm. Zeyl. tab. 107.

In $Z_{\text {ej }} \operatorname{lon} a$ 古.

Habitus Phyllitidis. Caul. 4-gon. Fol. oppofita, integerr. nervofa, glabra. Srip. breves, Jatæ, ovato-rhombea. Corymbi 3-fidi.

4. Auricula- H. fol, lanceol-ovat. fl. verricillat. Syft. veg.ed. I4. ria. Valerianella \&c. Burm. Zeyl. tab. I08. f. r.

In Zeylona 24.

Caul. longi, glabri. Fol. oppofita, fubfeffil. pendula, integerr. nervofa, glabra. Stipul, dentat. Rami longi, alterni, articulat. Fl, multi. 
3. herbacea, H. fol. lineari-lanceol. caul. herbac. dichotomo: pedunc. geminis. Syf. veg. ed. 14 .

In Zeylona.

Caul. femiped. Fol. oppofita, fubpetiol, avenia, raro repanda. Peduac. ad fingula!n caulis ramificarionem, I-fl.

6. graminifo- H. caul. decumbente: fol. linearibus : panicul. ralia. cemofa, fecunda; pedunc. folifequiis. Syft. veg. ed. I4. Lin. Suppl.

In India Orient. 4.

Caul. ped. filifurm. debiles, ut Stellarice graminea. Fol. remote oppofita. Cor. coerul. limbo 4-fido; laciniis ante meridiem patentiff. temp. vefpertino 2. erectis, 2. reflexis. Capf. compreffa, retula.

mericana. H. fol. linearibus: fl. axillar, folitariis , Jacq. Amer. ed. 2. piça tab. 18.

In lituribus rupeftribus Havane D.

Frutex raro 3. ped. excedens. Rami diffufi, bafi procumb. cæeterum erecti, Fol. numerofa, 4linear. oppofita, petiol. lineari-acumin. integerr. craffa, carnofa, nitida, fubtus fulcata, lateribus convexis, fupra planiufc. Petioli utrimq. oriuntur, membrana ramulos a nplexante, \& cum acumine obtufa. Fl, feffil. lutei, inodori.

hifpida. H. fol. lineari-lanceolat, fl. verticillatis. Retz. Obf, fafc. 4 .

In China.

Caul, decumbent. femiped. 4-goni, hifpidi, ramo uno, alterove . Fol. petiolat. integra, utrimq. hifpida. Petiol, valde hifpidi, cum flipul. filiformi-laceris connati, vaginam brevem conftitunt. Styl. clayatus. Stigm. incraffatum. Capf. femibilocul.

137. SCABRITA.S. cor. I-pet. hypocrater. Cal, truneatus . Sem. 2. emarginata, fupera.

I. Scabra. S. trifiora. Syft. veg. ed. 14.

In India $\hbar$,

Frutex ramis tetragonis, foabris. Foll: oppofita, petiolat. ovata, oblong, integerr. articulis rameis longiora, utrimq. fcabra. Pedunc. axill. oppofiti, folitar. 4-gon. fol, dimidio breviores, apice 2-phylli. Involuc, partial, 4-phyll, foliol. obovat. obtufis . 
138. SPERMACOCE. Cor. I-pet. infundib. (4-fida). Sem. 2. bident.

I. tenuior. S. glabra: fol. linearibus: fl. verticillat. Ataminib. inclufis. Syft. veg. ed. 14. Dill. elth. tab. 277. f. 359. Sabb. hort. Rom, 2. tab. 99.

Anonymos \&c. Pluk, alm, tab. 136, f. 4. In Carulina $\odot$.

Caul. 2-3--ped, acute 4-gon. Fl. minimi, feffil. purpuro-albi. Sem. hirta .

2, verticilla- S. glabra: fol, lanceol, verticill. globofis. Syjt. ta. veg. ed. 14. Dill, elth, tab. 277 . f. 358.

Scabiola \&c. Pluk. alm. tab. 58.f. 6. In Jamaica, Africa.

Caulic. dodran-ped. 4-goni . Fol. oppofita, Hyffupifor. 9-nervia, fcabra; axillaribus min. fafciculat. Caul. \& fol. hirfuta . Fl. parvi. Cor. revoluta, alba. Variat verticill. glebofis, amplexicaulibus \& pedunculat.

3. kirta. S. fcabra; fol. oblong. fummis quaternis: fl. verticillat. Syft. veg. ed, 14. Burm. Zeyl. tab. 20. f. 3 .

In Jamaica $\odot$.

Caul.4-gon. angul, acutiff. deorfum pilofis; cæterum glaber, ramofiff. rigidus. Fol. elliptica, lineata, utrimq. fcabra, non villofa, fubpetiol. petiolis connexis membrana multifeta. Fl. lateral. tubulofi, albi. Stam. fauce longiora. Anth. violac.

4. articularis, S. fol. elliptic. obtufuff. fubfcabris. Syft. veg. ed. 14. Lin. Suppl. Rumph. Amb. 6. tab. I0.

In India Orient. $\odot$.

Caul. herbac. ramofus, teres, utrimque canaliculat. ruber, Rami procumb, virgati. Genicula craffa. Fol. oppofita, fubpetiolat. alternatim, in primis fubtus, lineata. Membrana tranfverfa ftipulæ loco, multi-ariftata, fol. combinans. Fl. anguft, albi .

5. ftriza. S. fol. lineari-lanceol, lineatis. Syft. yeg. ed. I4. Linn. Suppl.

In India Orient. $\odot$.

Planta femiped. erecta, ftricta, angulis fcabra. Rami breviores, alterni. Fol. oppofita, fubpetiolat. fcabriufc. connata membrana ciliata. Verticilli angufti. Cor. alba. 
6. hifpide. ed. 14. Comm. Gott. 1772, $t a b$, 5.

In Zeylona $\odot$.

Caul. erectus, herbac. obfolete 4-gonus, pilofohifpidus. Rami inferi oppofiti. Fol. oppofita, fubpetiolat, craffufc. utrimq fcabra, flexuofa, mucrone minuto, reflexo. Stipula connectens utrimq. fol. paria, fcariofa, truncara, fetis 5. diftantibus. Fl, axill. feffil. 2-3. Cor. turbinato-campanul. cateris fpec. ma. erecta, femi4-fid. violac. Statm. longitudine cor. purpurafc.

7. procum- S. procumb. fol. linearibus: corymbis lateralibus, bens. pedunculat. Syft. veg. ed. I4.

In India.

Caul. diffufi, herbac. debiles, angulati, Fol. reflexa. Fl. faicicul. involucro polyphyl, umbella longiore. Stam. cor. longiora .

8. frinofa. S. fuffrutic. fol. linearibus; fpinul, ciliatis. Syfto veg. ed. I4. Loefl. it. 20I.

In America.

Caul. 2-5. ped. diffuli, ad bafin ramofi. Fol. Rofmarini. Verticil, paucifl. Cor. alba.

ocymoides .

S. glabra: fol. ovatis, acumin. Burm. Ind, tab. I3. F. I.

In India.

Media inter S. tenuior. \& hífpidam : differt pracipue caul. glabro, 4-gon. fol, ovat-acum. tomentofof, verticill. confertis, feffilibus.

latifolin. S. caul. erecto, 4-gon. fl. axillar. Aubl. Guisn, tab. 19. f. 1 .

In Cä̈enna, \& Guiana.

Planta herbacea. Caul. pl. 2-3-ped. ramofi, nodofi. Fol. oppofita, petiolis ftipulæ amplexic. ciliaiæ adnexis, ovata, acut.integerr. afpera, inferne pallide virentia. Fl, axillar. cefpitof, feffil. albi .

cerulefcens. S. fol. ovat. acutis: fl. axillaribus numerofis, verticillatis: caul, erecto, fimpl. Aubl. Guiart. tab. I9. f. 2 .

Iifdem in lucis.

Difert a priore caulibus humilioribus, fimplicibus: fol. minor, virefcentibus ; Atipul. breviore, minus ciliata: fl, parvis, coerul. \& fructu exigulo. 
groftratc. S. fol. parvis, ovatis, lavibus. Aubl. Guian, $t a b$. 20. f. 3 .

Ad ripas fluviorum in Guiana.

Differt a prioribus caulibus decumbent. ramis oppofitis: fol. minor, viridibus, mollibus, fubfeffilibus, integerr.

redieans. S. fol. lanceol. acutis: fl. parvis, Aubl. Guian. tab. 20. f. 4 .

Ad ripam fluvii Orapu 4.

Caul. pl. ramofi, nodiferi. Fol. oblon-angufta, integerr. glabra. Fl. cefpitofi, axillar.

longifolia. S. caul. flexuoto: fol, ovat-obl, acuris: fl. minimis. Aubl. Guian, tab, 21.

\section{In Guinna.}

Caul. pl. farmentofi, ramofi, nodofi, 4-goni. Fol. fubpetiol. lata, integerr. glabra. Fl, axill. congefti, numerofi, feffil. albi .

aspera. S. fol. oblong, anguftis: fl. verticillatis. Aubl. Guian. $t a b$. 22. f. 6 .

In Guiana, \& Cä̈enna.

Caul. pl. 1-2-ped. nodofi, 4-goni, afperi. Fol. feffil. acuta, afpera. Fl. axillar. multi, feffil. albi .

alata. S, caulibus, \& ramulis radicantibus: fol. fubfeffilibus, ovatis: fl. terminalibus, cœrul. Aubl. Guian. tab. 22. f. 7 .

In Guiana.

hexangularis. S. caul. flexuofo: fol, petiolat. ovat-acut: fl. terminalibus. Aubl. Guian, tab. 22. f. 8.

Iifdem in locis.

Differt a priore caul. 6-gon. fupra vicinas plantas fparfis: fol. min. petiolat. ovatis .

feandens. S. fol. fubrotun-acumin. Phyllitidi fcandenti affinibus, minoribus oppofitis. Sloan. Jam, hift. I. $t a b, 28$, f. 4 .

In Guiana.

Super Arbores fcandit. Omnes ha species $a b$ Aublet relate yalent in gonorrhau.

hayanenfis. S. fruticofa, ranis fpinofis. Jacq. Amer. ed. 2. piaze.

In Havana $\hbar$.

Frutex nanus, diffufus, ramofff. rigidus, nitidus. Spinze axillar, in foliis: terminal, in ramufcul, junioribus, brachiatis, fubulate. Fol. femipollic. oppofita, petiolata, obverfe ovaTom. I. 
ta, integerr. nirida . Panicul, terminal, Fl, nu= merofi, exigui, candidi, inodori, germinibus rubellis.

fumatrenfis, S. hifpida ; fol. Janceol. corymbis terminalibus, dichotomis. Ret\%. Obf. fafc. 4.

In Sumatra.

Caul. herbaceus, 4-yon. tomentofus, articulis longis. Rami oppofiti. Fol. petiolat. integerr. hifpida, nervis fubtus tomentofis. Cal. minutus, 4-dent, F1. 2-fperm. 4-dentat.

I39. SCHE- Cor. I-petal, infundibul. Sem. 2, trident, oblonRARDIA. ga. Fol. vericillata.

1. arvenfis, S. fol. fenis, lanceol-linearibus: fl. terminalibus, feffibus, umbellatis. Hall. helv.

S. fol. ommibus, verticill. \&c. Syft. veg. ed. I4. Fl. Dan. tab. 439. Hort, rom. I, tab. 80.

In Europar arvis $\odot$.

Caul. cefpitoi, humiles, decumbent. triental. ramof. Fol. elliprico-lanceol. argute mucronata, afpera, diluce virentia; infer. 4-6. margine ciliato. Fl. inter fol. in fumma planta congefti. Petala purpur. non coeruled.

2. muralis, S. fol. floralibus, binis, oppofitis: binis fl. Syjt. veg. ed. 14.

Afperula \&c. Colum. ecphr. tab. 300.

Galium \&c, Buxb. cent. 2, tab. 30, f. 2. All. Fl. Ped, tab. 77. f. I.

In Italia, \& Confantin, muris vetuftis (a).

Caul. decumbenr. Fol. ovat-lanceol. infer. fena; media quaterna; fumma bina. Flores peduncul. plani, pallidi. Fruct. oblong. hifpidi. Sem. fubarcuata.

3. fruticosa, S. fol. quaternis, aqualibus: caul. fruticofo. Syft. veg. ed. I4,

In infula Adfcenfionis $\hbar$.

Frutex inæqual. torofus, fcaber, Rami obtule 4-goni. Fol. angufto lanceol. integerr. glabra, margine revoluta. Stipul. breviff. fubularæ. Fl. axillar. oppofiti, feffiles. Cor. alba.

fatidiffma, S. caulibus lignofis, procumbentibus: fl. corymbos. 4-fid. Cyrill.: app. ad plant, charat. T. 3. f. 7 .

In Calabria.

Odor ftercoraceus. Caul, cefpit, fpitham, Fol. 
fafciculata, fere verticillata, lineari-lanceol. fubhirfuta, 2. femper in fingulo verticillo, reliquis duplo longioribus. Fl. terminal, uf plurimum 8. purpur. Cor. laciniis acuminat. incurvis. Videtur Afperula calabrica.

I40. ASPE. Cur. 1-petal, infundibulif. Sem. 2. fubrorunda. RULA. Differt a Galio tubo cor. longiore. Fol. verticillata,

I. odorata. A, fol, octonis, elliptico-lanceol: fl. fafciculat. pedunculat. Syft. veg. ed. I4. Fl. Dan, tab. 562. Black. tab. 60. Kniph. cent. I, tab. 9. Ladw. ea. $i a b .146$.

In Europa umbrofis 24

Caul, erectus, peda!, fimpl, vix ramofus. Fol, glabra, atro-virent, nervo, orifq. fubhirfutis; ima oblonga, fuper, ma: acuminata: Fl. magii, albi, odori. Fruct. reniform. villis uncinatis hirti. Var. anguftior, \& humilior.

2. arvenfis. A. fol. fenif-octonis: fl. terminalibus, adgregatis, feffilibus. Syft. veg. ed. I4

Rubeola \&c. Bauh. hift. 3. p, 719.

In Europu $\odot$.

Caul. erectus, pedal. ramofus . Fol, glabra, lanceol-linear. obtufiufc. floralia fæpe ad bafin ciliata, fupra hifpidd. Cor. crerul. Fruetus glabri.

3. tourina. A. fol. quaternis, ovat-lanseol: fl. terminalibus, fafciculatis. Syft. veg. ed. I4.

Rubia \&c, Morif. hift. 3. f. 9. tab. 21. f. I.

In alpibus Helvetia, \& collibus: fylvis umbrofis Italia 4 ,

Caul, erecti, pedal. ramofi, 4-gon. Fol, villofula . Rami alterni. Pedunc, alterni, I-2, Bract. ciliatæ. Cor. alba, Fol. Latiora, \& cor. multo longiores, quam in priore.

4. crafsfolie. A. fol. quaternis, oblong. lateralibus, revolutis, obtufiufc. pubefcentibus. Syft. veg. ed. I4.

In $C_{\text {resa, }}$ Oriente $\hbar$.

Caul. diffufus, alterne ramofus, fubpubefcens. Fol, ovalia, fupra gibba, uti Sedum; ramea remotiora, angufto-lanceol. inæqualia. Rami floriferi erecti, alterne ramofi. Fol. ultima bina. Fl, terminal, fafcicul, pauci, Cor, extus pubefe. 
5. calabrica. A. fol. quaternis, oblong. obtulis, lavibus: (caule fruticofo). Syft. veg. ed. 14. Lin. Sup. pl. Herit. Stirp. nov. fafc. 4. tab. 32.

Leandro di Candià \&c. Zan, hift. tab. 47. Thymeliea \&c. Zan. hift. tab. I66.

Sherardia foetidiffina . Cyr. Chur. tab. 3. f. 7.? In Calabria, \& Syrice montibus $\hbar$.

Similis priori, fed lavis, proftrata, odore ftercoraceo. Caules teres, duriufc, vix pubefc. Fol. fubpetiol. nuda, craffiufcula, fubfeffil. I2-15. lin. long. 3-4. Jata.

Rami floriferi terminal, terni, fol, oppofitis. Fafcicul $\mathrm{fl}$ : florefq. feffil: rubri . Bractea 2-phyll. acutd, patula, fub germinibus.

6. tinctoria. A. fol. linearibus: infer. fenis; intermediis quaternis: caul. flaccido: fl. plerifq. 3-fid. Sy/to veg. ed. I4.

Galium \&c. Tabern, hift, tab. 733. f. I. bona. In Europe aridis faxofis 24.

Planta, nifi fubftentetur, procumbens. Caul. 3.ped. ramofi, fub vertice tumentes. Fol. tenuiter, $\&$ acure dentata, etiam quina; fumma oppofita; fub fl. ovat-lanceol. Fl. umbellati, albi, triandri.

7. pyrenaica. A fol. quaternis, lanceol-linearibus: caul. erecto: fl. Trpius trifid. Syft. veg. ed. 13.

In Pyrenceis, \& Helvetia 24.

Caul. fpitham. 4-goni, valde ramofi, ramis umbellatis. Fol. acuta, carinata, lævia; infer. breviora, lanceol. obtufiora: fol. fumma, \& floral. oppofica, latiora, lanceol. acuta, Fl. rubri. Statura Sherardice arvenfis.

8. eymanchice. A. fol. quaternis, linearibus; fuper. fæpe binis: caul, erecto: fl. 4-fid: Syft. veg. ed. I4.

Galium \&c. Tabern. hift. 433. fo 2. Col. ecphr. 1. $t a b .297$. f. 1 .

In prutis aridis, faxojis, cretaceis collium, \& alpium 24.

Caul. palı. fcaber. Fl. extus fubrugofo-fcabri, rubri. Germina rubra .

9. ariftata. A. fol. linearibus, fubcarnofis; infer. quaternis: fl. fubrernis, ariftatis. $S_{y j}$. veg. ed. 14. Lin. Suppl.

In Europa auftrali.

Caul. erectus. Fl. paralelle pofiti, pallide flavefc, lacin. obtufe ariftatis. 
I0, lavigata. A. fol. quaternis, elliptic. enerviis, Javiufc: peduncul. divaricatis, trichotomis: fem. fubris . Syjt. veg. ed. I4. Jacq. Aujtr. I. tab. 94.

Rubia \&c. Morif, hift. 3. f. 8. tab. 21. f. 4-5. Bocc. Sicul. tab. II. f. 5 .

In alpibus Helvetice Ec.

Caul. fimpl, læyes, patuli, 4-goni: Fol. fubpetiol. obtufa, patentia, vix ciliata. Rami florentes horizontal. 2-fidi; bract. 2. parvis, lanceol. F1. frepius terni, peduncul. albi . Anth. flavæ.

Kexaplyylla, A. fol. fenis, linearibus: Al. terminalibus, umbellatis, fubfeffilibus. All. Fl. Ped, tab. 77. f. 3 .

Ad rupes 24.

E rupium fiffuris prodit, caulicul. femipalm. 4gonis, ad bafin interdum ramofis, cæterum fimplicibus. Fol. erecta, plana, internodis folio paulo longioribus. Unibella foliaced. Fl. tubo longo, 4-fidi, fegmentis fubrevolutis, purpur. intus albi. Sem. compreffa. Tota planta glabra.

141. DIODIA. Cor. I-petal. infundibul. Capf. 2-locul. 2-fperma.

1. virginica. D. Syft, veg, ed. 14 .

In Virginix aquofis.

Caul. procumb. pedal, rubent. tamis alternis . Fol. oppofica, feffil. lanceol. acumin. erecta, glabra, integerr. ad bafin fæpe denticul. ciliata, longitudine internodiorum caulis. Fl. axill. oppoliti, feffil. folitarii, albi .

142. KNO- Cor. 1-petal. infundibul. Sem. 2. fulcata. Caly-

XIA. cis unicum fol. maius. Habitus Plumbaginis .

I. zeylanica. K. Syjt. veg, ed. 14. Burm. Ind. tab. 14. f. 2.

Veronicæ \&c. Pluk, alms, tab. 1s4, f. 2.

In Zeylona fupra truncos arborum putridarum.

Caul, erectus, pedal, articular. glaber. Fol. oppofita, fubseffil. lanceol, avenia, glabra. Spicre longæ, angufta. Fl. fparfi, minimi, feffil. nivei.

143. HOUSTONIA. Cor. 1-petal, infundibul. Capf,-2-locul, 2-fperma.

I. carula. H. fol, radicalibus, ovatis: caul compofito: pedunc, primis 2-fl, Syft, veg. ed. I4. 
Paronychiæ \&c. Morif. hilf. 3. F. 15. tab. 4. f. Io b. Chamaeiafme \&c. Pluk, alm. 6ab. 97. f. 9.

In Virginia.

Plente verna. Caul. palmar, ramufus. Fol, radical. in orbem pofita, exiyua, Paronychice yulg. fimilia : caulina 2-3. Cor. corul.

2. purpurea. H. fol. ovat-lanceol corymbis terminalibus: $\mathrm{fl}$, fuperis. Syft, veg. ed. 14.

In Virginia.

Fol. pauca, parva, oppofita. Fl. purpuro-rubent.

An diverfi generis?

I44. GAIIUM . Cor. I-pet. plana, 4-fida. Sem. 2. fubrotunda. Fol. verticillata.

\section{* Fruáu glabro.}

I. rubioides. G. fol. quaternis, lanceol-ovat, æqualibus, fubtus fcabris: caul, erecto: fruchbus glabris. Syft. veg. ed. 14.

In Europa auftrali.

Habitus G. borealis, fed fol. duplo latiora. Caul. erectus, pedal. \& ultra, firmus. Fol. marginibus reflexis, nervo fpinulis adfperfo.

2. paluftre. G. fol. (fape) quaternis, obovatis, inæqualibus: caul. diffufis. Syft. veg. ed. i4. Fl. Dato. tab. 423 .

In Europa rivulis limofis 24.

Caul. 2-ped. reclinati, ramofi, fragiles, afperi, augulofi, ramis longis. Fol. margine rarius dentata, glabra, late virent. fuper. afpera. Pedunc. florigeri, breves, ramofi, divaricati . Fl. multi, parvuli, aibi . Dar.-ftatura.

3. trifidum $\mathrm{G}$. fol. quaternis, linearibus caul. procumb. fcabro; cor. 3-fid. Syft. veg. ed. 14. Fl. Dart. zab: 48 .

In Dania, Canada.

Caul. ramofiff. ramis ternis-quaternis, divaricatis. Fol. obtufa, latiufc. glabra, fubtus pa rum fcabra. Pedunc. fæe terni, tenuiff. I-fl. Fl, minimi, albi. Stam. 3 .

4. montanum. G. fol. (6-8.) linearibus, lavibus : caul. debili, fcabro: fem. glabris. Syft. veg. ed. I4. In Germania, Helvatia 4. Statkra inter G. Molluginem, \& glaucum medis. 


\section{TETRANDRIA MONOGYNIAZ}

Fol. caulina quina, reflexa ; ramea quaterna . Corymb. 3 -fid. Cor, reliquis ma: alba, ante

explicationem extus purpurafc. Anth. fufca.
5. tinctorum. G. fol. linearibus : caulinis fenis; ramorum quaternis : caul, flaccido; pedunc. fub 2-fl. fructibus glabris. Syft. veg. ed. 14 .

In Amer. Septentr.

6. uliginofum , G. fol. fæpe fenis, (plerumq.) lanceol. retrorfum ferrato-aculeat. mucronar, rigidis : cor. fructu maioribus. Syft. veg. ed, 14. Pet, herb. f. 6. Barr. ic. 82 .

In Europa pafouis aquofis, ferilibus 4.

Caul. fefquiped, ramofus, flaccidus, ftriatus . Fol, unguicul fubtus glauco-virid. Corymb. 3-fid. Fl. maiufc. albi. Var. ramis longtoribus; foliifq. lanceol: ramis breviortbus : folufque ovatis.

7. fpurium. G. fol, fenis, lanceol. carinatis, fcabris, retrorfum aculeat. genicul. fimplicibus, fructibus (fæpe) glabris. Syft. veg, ed. I4.

Aparine \&c. Vaill, parif. tab. 4. f. 4. etfi ferto hirfut, pingat.

In Eurape cultis $\odot$.

Adfine G.Aparines, fed minus. Caul. fefquiped. debilis, diffufus, ramofus. Fol. late virentia. Pedunc. divaricati, 2-fidi - Fl. maiufculi , albi.

8. fazatile. G. fol. fenis, elliptic. petiol, breviff. I-fl. Hall. helv, n. 718 .

ato is Galium \&c. Syft, veg. ed, I4. Juff. AZ. Parif. 1714. $t a b$, I5.

In Hifkanial, Helvetia alpinis.

Habitus valde foliofus. Caul. angulati, 6-unc. Fol. longiora, cis originem latefcentia, abfque fpinulis .

b. G. Harcynium. Hall, helv, n. 717 .

Vix pedal. multicaul. \& ramofum. Caul, 4-gon. Fol. peculiaris figuræ, rotunda, \& argute lanceola terminata. Pedunc. axill. $\mathbf{I}-2$-fl. fafcicul. umbellatis. Sem. pro plantæ parvitate

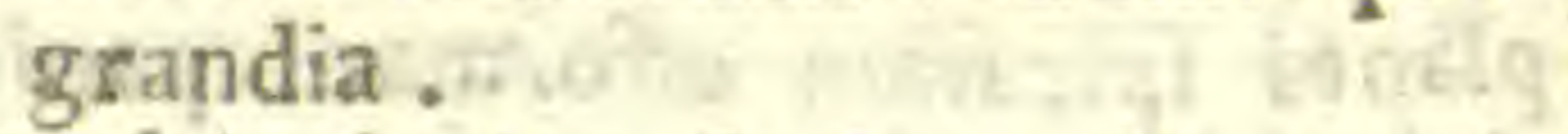

9. pyrenaicum, G. fol. fenis: fl. Iateralibus, oppofitis, folitar.

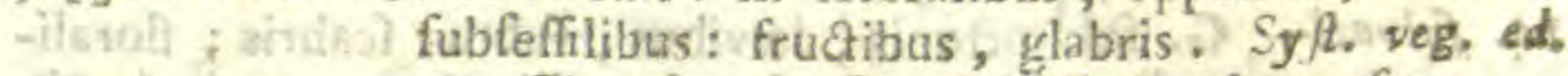
I4. Lin. Suppl, Couan. Illuf. tab. I. f. 4. In Pyrenais. 
Caul. exigui, vix uncial. ramofiff. debiles, giaberrimi ; geniculis tumidiufc. Fol. glaberrima, nitida, mucrone infirmo. Fl. oppoliti, albi, aut citrini: quandoq. flos unus, aut alter.

10, mixusum. G. fol. octonis, lanceol. mucronat, ferrato-aculeat. glabris, incurvis: fructibus reflexis. Syft, veg. ed. 14.

In Imperio Ruthenico 4.

Sirnile G. vero, fed palmo brevius, decumbens . Caul. lævis, nec margine fcaber. Fol. utrimq. parum convexa, nec margine reflexa. Frustus magni, carnofi, pedunc. reflexis, unde conglomerati .

11. pufllum. G. fol. (fæpe) octonis, linesribus acuminat. fubimbricat. hifpidis; peduncul. dichotom. Syjt. veg. ed. 14.

Rubeola \&c. Burf. XIX. 17.

In montibus Gallo-provincia 24.

Caul. numerofi, digital. angulati. Foliol, 8-6. lanc-linear. Rami rariores, alterni. Fl. verticilli conferti. Panicula rarior.

12. verum - G.fol. (frep) octonis, linearibus, fulcatis: ramis florifer. brevibus. Syft. veg. ed, 14. Black. tab. 435. Hort, rom. I, tab. I, 81, Ludw. ea. tab. 39 .

In Europa frequens 4.

Caul, anceps. Fol, fragilia, nigro-virent. florente planta reflexa. Rami floriferi foliofi. Fl, numerofi, flavicant. Anth. defloratæ fiunt fufcæ. Var. 1, monftrofa, =2. fol. Jena; \& Sem. hirfuta.

13. Mollugo. G. fol. octonis, ovat-linearibus, mucronar, fubferrat. patentiff. caul. flaccido; ramis patentibus. Syfl, yeg. ed. I4. Fl. Dan. sab. 455. Black. tnb. 168 .

Mollugo \&c. Lob. ic. 802.

In Europa mediterranea 24.

Ctuger. 3-ped. 4-gonus, fubverticillis tumefcens. Fol. duriufcula, fordide virefc. glabra, fuper-

ne acutiora. Rami axill. florigeri in fumma planta fpicatarn efformant paniculam. Fl. multi, parvi, albidi.

34. fylvati- G. fol. octonis, lævibus, fubtus fcabris; floralicum . bus binis : pedunc. capillaribus: caule lævi. Eyft. veg. ed. 14.

Ir Europa nuftral. montibus fylvojis. 
Planta fubglauca. Caul. alti, ramofiff. debiles. Fol. lato-lanceol. Pedunc. elongati . Fl. parvi, albi, odori, ante flurefcent. nutantes.

I5. arifiatum, G. fol, (fæe) octonis, lanceol. lavibus: panicul. capillari ; petal. ariltatis: feminibus glabris . Syjt. veg. ed. 14 .

Rubia \&c. Bucc, Muf. sab.75. Barr. ic. 356.583 .

In Baldo \&c.

Planta lavis. Caul. decumbent. pedal. 4-goni, hifpidi, pracipue ad balin. Panicul. divaricata ex ramis axillar. aiternis, internodia plerumque fuperantibus . Rami panicul. geminati ; ramufi. ter-quater ternati. Cor. purpurafi. apice feta alba. Anth. flavæ.

16. fesbrum. G. fol. fuboctonis, fcabris, mucronatis : ramis florifer fubrrichot. Syjt. veg. ed. 14. Jacq. Auftr. 5. $t a b .422$.

In locis fy? $y^{\text {vaticis. }}$

Caulic erecti, inferne pilis brevibus albis obfiti, fuperne glabri, nitidi, \& per ramos paniculati. Fol. 7-8. in ramis pauciora, linear. patentiff. villofa, fuper. minus. Pedunc. fub 2fl. Cor. alba, patentiff. odora. Aath. flavæ. Fruct. parvi, glabri .

17. hyerofoli- G. fol, denis, lanceol-linearibus: umbellis faftimitanum. giatis : fractibus glabris. Syfi. yeg. ed. I4.

In Palaeffina.

Statura proxime accedit ad G. rubrum .

18. glaucum. G. fol, verticillat-linearibus: pedunc. dichotom. caul. lavi. Syft. veg. ed. I4. Jacq. Auftr. tab. 81. Fl. Dan, tab. 609. Bocc. Muf. 2. tab. 116.

In Auftria, Helvetia \&c. 24.

Caul, debil. proftrati. Fol. fena, fed ad ramorum ortum etiam feptena, ferrata, glauca; infer. reflexa. Umbella parva. Cor. alba. Anth. Iuteo-virentes .

19. purpu- G. fol, verticillat, lineari-fetac. peduncul. capilreum. laribus fol. longioribus. Syft. veg. ed. 14.

In Italia, Helyetia.

Caul. erectus, ramofiff. totus foliofus. Fol. plerumq. octona.. Caul. \& fl. atro-purpur, quî terminales, potius paniculati, purpurei, non fufco-rubri, ut in G. rubro.

20. rubrum. G. fol, verticillatis, linearibus, patulis: peduncul. breviff. Syft.yeg, al, I4, Cluf, bift. 2, pug. 175. In Italia or. 
Planta pallide virefcens. Caul. decumbent. palmar, ramofi, angulis fubalatis, fcabri. Fol. margine fpinulofa ; caulina octona ; ramea 5-6. Pedunc. 2-11. F1. minimi, fufco-rubri. Differt a G. purpureo fol. non ellipticis, neque expanfis; brevitate pedunoul. ac modo florendi.

\section{** Fruçu hifpido.}

21. boreale. G. fol. quaternis, lanceol. trinerviis, glabris: caul. erecto: feminibus hifpidis. Syft. veg. ed.

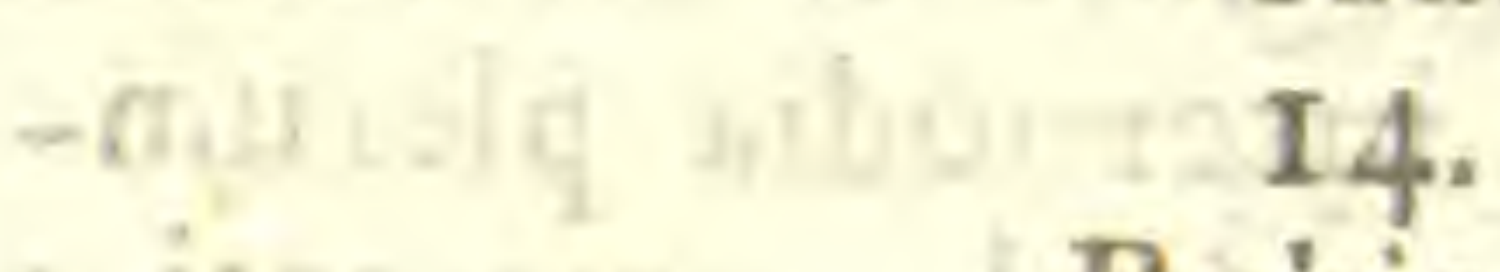

: is in . Rubia \&c. Burf. XIX. I5.

In Europe protis 4.

Planta fubafpera. Caul. pedal. vix ramofus, tuzilinfy : nor mefcens. Fol, margine reflexó, atro-virent. nitida. Panicula rami 2-phylli. Fl. parvuli, albi .

22. mariti- G. fol. (inferior. fape octonis) hifpidis : pedunc.

mum. s plerunaq. I-fl. fructibus villofis. Syft. veg. ed. I4.

Aparine. Tourn. ic. 4.

In Oriente, Monfpelii \&c.
Caul. brachiat, ramofiff, h

- Caul. brachiat, ramoliff, hirfus : rami ultimi di- s rili whi. chotomi. Fol, in medio caul. 4-raro-5. floral. fæpius 2. omnia lanceol-ovata, fumma fubpe-

23. bermudia-G. fol. quaternis, linearibus obtufis : ramis ranum .

\section{tot $\boldsymbol{I}_{\boldsymbol{n}}$ Virginia.} mofiff. Syf. veg. ed. I4.

Cor. \& fem. atropurp, quæ hifpida

24. gracum . G. hirtum, fol, fubfenis, linearibus, ianceol. cau... libus lignofis. Syf.veg. ed. I4. Alp. exot, tab. I66.

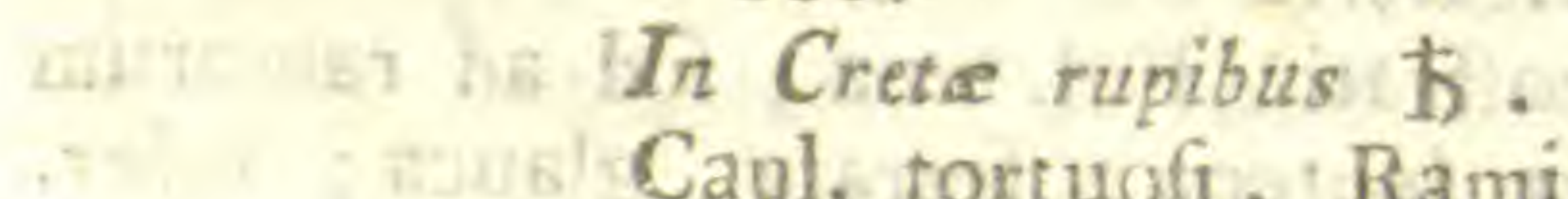

Caul. tortuofr. Rami recti, herbac. villis albis tuirti, vuti fol. perlunculi, \& germina. Fol. feffil. erecta, ftricta, parcius villofa. Pedunc.

25. Aparine G. fol. Cuboctonis, lanceol. carinis fcabris, retrorfum aculeat. genicul villofis: fructibus hifuidis. Syjt. veg. ed. I4. Fl. Dan. tab. 495. Black tab. 39. hort. rom, 1. tab. 78 .

In Europa $\odot$.

Caul. ramofiff 4 . angulis retrorfum aculeatis . Fol. fupra f:abra, fubtus glabra . Rami oppofiti. Fl, paryuli, albi, vel purpur. 
26. parifienfe, G. fol. verticillatis, linearibus: pedunc, 2-3-fle fructibus hifpidis. Syft. veg. ed. I4.

Aparine \&c. Raii Angl. tab. 9. f. I.

In Anglia, Gallia $\odot$.

Caul. debiles, pedal: 4-goni, retrorfum fcabri. Fol. feptena, mucrondt, flavida, fcabra, præfertim margine. Rami floriferi oppofiti, breviores. Pedunc. nudi. Cor. parva, flavæ, aut atro-purpurafc. Sem. hifpida .

euftriacum, . G. Jucq. Auftr, tab. 80.

In Austria.

Differt a G, slauco ftatura min. \& caulibus 4gonis. A Gruligin $\int s$ potiffumum fol. neutiquam retrorfum Jerrat-aculeat. Simil. G. Halleri n. $75 \mathrm{r}$.

Caul. bafi procumb. glaberr. nititi. Fol. num. varia 5-ro. lihear, aus pulormagis latefcent. cum brevi arifta; plana, nitida, glabra. Fl. ultimis ramis infident, exigui, nivei. Fruct. parvi, glabri, nigricant.

4perum sa G. fol. fubfeptenis, cauleq: inferne pubefcentibus : panicula ramis ftrictis, dichotomis . Schreb. Lipf. Hull. Helv. 2715.

In locis aridis

Caul, debiles, bafi tantum ramofi, angulati . Fol. 6-9. plerumq-7. linear. apice paulo la-

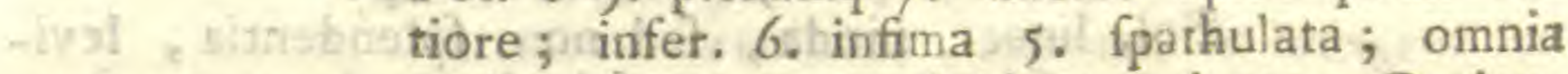
gquat iche he carinata, mucrone rigido terminata. Panicu* intongu naz 81 la rami elongati, divergentes . Fl. parvi, albi.

Pafchale. G. fol. lineari-lanceol. mucronat. glabris. Farsk. Suppl. AEg.

Ad Confantinopolim .

Fol. 4-8na, margine retrorfum fcabro. Caul。 4-gon. Pedunc. dichotom. Fruct. glabri .

Ova pafchalia Graci radic, decodzo, rubro tingunt col.

Aparinoides, G. fol. fubfenis, cuneiformibus, obtufis cum eilacumine retrorfum aculeati; genicul, aqualibus. Forsk, Ag.

In Arabia.

Facies G. Aparines. Fol. 4-6. non octona, glaifuryl bra. Genicula non villofa. Anth, propendentes. Fruct, hifpidi. 
lucidum. G. fol. fenis, rigidis, obfcure virentibus: fl. $e$ fummo caule prodeuntibus. All. Mifc. Taur. Fl. Ped. T. 77. f. 2.

In cullibits ficcis.

Tota planta fplendide viret. Ad radicem valde ramofum, fed rami eriguntur, plerunque fimplices. Fol. fena, dein quina-quaterna, $\mathrm{fe}-$ miteretia. fubulata, furfum incurva . Caul. herbacei, acute 4 -goni. Panicula ternsinalis. Flos quandoque albus, fructu maior. Fructus oblongo-ovati, incurvi, rugofi, nigri.

sinereum. G. caul, fublignofo: fol. fenis, longe ellipticis, rigidis, ferrato-aculeatis : fructibus ovatis, lavibus, albefcentibus. All. Mifc. Taur. \& Fl. Pedem. tab. 77. f. 4 .

In vineis 4 .

Planta, rore glauco obducta, quo deterfo lucide viret. Caul. obfcure 4-goni. Fol. in fine ampliora, alba fpina prædita. Rami ad angulum rectum ex caule difcedunt. Panicula terminalis, ultimis pedunculis fæpe 3-fl. Sem. magna, matura rugofa. Differt revera a $G$. glauco Lin.

tenuifolium. G, fol, fenis, fubrigidis; diffufe ramofum: $f$. albis e fummo caule prodeuntibus. All. Mifc. Taur. Fl. Ped.

In collium Nicaenfum dumetis $\mathbf{4}$.

Fol. linear. nitida, fed non fplendentia, leviter ferrulata, cum fpinula, ad ramos fæpe octona. Caul. acute 4-goni. Rami oppofiti, quorum unus longior. Pedunc. 2-3-fl. Petal. magna, ariftata. Sein. fubrugofa, nec hifpida, nigra.

Boccone. G, caul. angulofo: fol. fenis, fubafjeris, ariftatis. Hall. helv. Fl. Pedem. Barr. ic. 57. bene.

Rubeola Bocc. mul. tab. 107.

In Alpium apricis faxofis 4 .

megalofper- Gevanum, cauliculis erectis, ramofis: fol. quimum, nis, ellipticis: fructibus rugofis, flore maioribus. All. Fl. Ped. T. 39. f. 4.

In mante Cenifio 4.

Cefpes caulicorum, etiam digital. longitudinis, alterne ramoforum. Fol. acuminata, ferrulata, viridia. Rami ex altimo verticillo, pe- 
duncul. 2-fl. Cor. pallide lutea. Fruct. magni fordide albicantes.

faccharatum. G. All. Fl. Ped.

Aparine fem. coriandri \&c. Park. Theas. 567.

In cullibus $\odot$.

Variet. Valantix Aparines Lin.

145. CRUCIA.Cor. I-petal. infundib, tubo filifor. limb. un-

NELLA. guicul. ( 4 fid.) Cal. 2-phyll, Sem. 2. linear. Fol. verticillata.

1. angufififolia. C. erecta, fol. fubfenis, linearibus: fl. fpicatis. Syf. veg. ed. 14. Sabb. hort. 2. tab. 12. Monfpelii \&c. in collibus (-).

Planta e viridi-ciner. Caul. erectus, dodrant. 4-gon. Fol. acuta, erecta. Spica erecta, bracteis lanceol. brevior, fed craffior fequenti.

2. letifolia. C. procumb. fol. (fæe) quaternis, lanceol. fl. fpicatis. Syft. veg. ed. I 4 .

In Cretn, Monfpelii Ec. locis areno/is $\odot$.

Caul. pl. afperiufc. obfolete 4 goni. Fol. brevia, patentia, obtufa, afpera, cinerea, quandoq. 5-6. Spica longa, fernipalm. fubnutans. Cor. "fubvirefcens .

3. Ifgyptiace.C. fol, quaternis; fuper. fublinearibus: fl. fpicatis, 5-fid. Syft. veg. ed. 14.

C. herbacea. Fursk. Agg. monente Vahl.

In Egypto $\odot$.

Caul. erecto-patuli, ad radicem diffuin. Fol. lateribus revoluta, fuperne, \& margine $\mathrm{fca}$ bra: infima ovata; infer: lanceol. reliqua linearia. Spicæ latiores. Bract. lanceol. non carinatæ. Fl. parvili, flavefc-albidi, ariftati, ut in C. maritima.

4. patula, C. diffula ; fol. fenis: fl. fparfis. Syf. veg. ed. 14. Lafl. it. 68.

In Hifpania $\odot$.

Rami, \& fol. patentiff. Fol. linear. fcabra. Fl. axill. Cor. lurea .

5. maritima. C. procumb. fuffruticofa: fol. quaternis, mucronat: fl. oppofitis, 5-fid. Syft. veg. ed. 14. Sabb. hort. 2. tab. I3.

In Creta, \& Monspelii b. .

Caul. provoluti . Fol. lanceol. rigida . Braft. ovatæ. Cor. ariftatæ, triftes, lutefcent. Antheræ nigræ. Fl. die claufi, nocte patentes, ambrofiaci, 
6. monspelia- C. procumb: fol. acutis; caulinis quaternis, $c a$. ovatis; rameis fubquinar. linearibus: fl. fpica. tis. Syft. veg. ed. I4.

Monfpelii, \& in Palaftina \&c. fecus urra collium . Caul. craffufc. Rami alterni, recti, fimplicior. Fol, rigida. Pedunc, audi. Spicæ finil. C. angufifioliae.

I46. RUBIA. Cor. I-petal. campanul. Baccæ 2. coalitæ, Ifperm, glabræ. Fol. verticillata .

I. tinzorum, $R$, caul. aculeato: fol. annuis. Syft. yeg, ed. I4. Sabb. hort. 1. tab. 77. Black. tab. 26.

In Italia, Helyetia \&c. 24 ,

Radix magna, rubra. Caul. 2-cubital, ramofff: angulis aculeol. recurvis; adultus fubtomentof. etian foliis. Fol. 4-5-6. lanceol. ciliata, margine, \& carina aculeol. recurvis. F1. 45-6-fid. luteo-virid. apice unguiculati. Bacia nigra. Ver. folior, magnitudine.

2. peregrina. R. fol, perennantibus, linearibus, fupra lavibus. Syft. veg. ed. I4.

In Europa 24.

Fol. quaterna, ex nigro-virore lucentia. Cor. alba. Bacca nigra.

3. lucida. R. fol. perennantibus, fenis, ellipticis, lucidis: caul. lavi. Syft. veg. ed, 14.

In Maiorca 24.

Simil. priori, fed fol, margine tantum retrorfum fcabra, non vero carina. Fl. paniculati, mucronati, 5-fid. albi.

4. anguftifolia. R. fol. perennantibus, linearibus, fupra fcabris . Syft. veg. ed. I4.

In Minorca 24.

Caul. diffufi, 4-goni, faberr. Fol. 4-6. carina, \& margine ciliata. Fl. plani, s-fid. lutei.

5. cordifolia. R. fol. perennantibus, (plerumque) quaternis, cordatis. Syfl. veg. ed. 14. Anm. Ruth. 19. Pallar. it. 3. $t a b$. L. f. I.

Iu Moiorea, Sibiria, Chtna 4.

Planta diffura, feandens, tota glabra. Caul. laxi, 4-goni, angulis retrorfum fabris. Fol. unguicul, petiolar. s-nerv. patentia, margine reflexo, fupra fcabra. Panicula patentiff. verticillato-fubtrichotoma. Fl. fubcampanul. apice unguic. pauci, patuli, albo-pallidi. Bacca rubra. 
747. SIPHO-Cor. I-petal. infundibul. tubo lon giff. infera . NANTHUS, Baccæ 4. monofperm. (fubrot,).

I. undicu. S. folicis foll tl. flavefcente. Syjt. veg. ed. I4. Act. Petrop. 1736. tab. Is.

In Amer. meridion.

Caul. herbac. fimpl. Fol, terna, feffil slanceol. Raceinus terminal. erectus.

I48. CATFS-C. I-petal. infundibul. longiff. fupera . Stam.

BAA. intra faucem. Bacca (oval.) polyfperma.

I. fpinofa. C. Syft. veg. ed. I4. Catesb. carol, 2. tab. 100.

In Provincia to.

Arb, 12-14-ped. Fol. fafciculata, Buxi min. Spina axill. Fl, 6-pollic. penduli, lutei, 4fid. Bacca ovi Gallinac. magnitudine, lutea'

I49. IXORA. Cor. 1-petal, infundibulif. (tubo renui, longif,) fupera. Stam. intra faucem. Bacca (fubrot.) 4-iper.

I. coccinea, I. fol. femiamplexicaul. ovalibus: fl. fafciculat. Syff. veg. ed. 14. Pluk. alm. tab. 59. f. 2, mant. tab. 364. f. 1. Hort. mal. 2. tab. 13.

Jalminum \&c. Burm. Zeyl. tab. 57.

In India $\hbar$.

Altitudo humana . Frutex parum ramofus, caul, rubro. Fol. oppofita, glabra, integerr. fupra intenfe virid. fubtus dilutiora. Stipul. inter fol. folitaria, acumin. ut in Coffea. Fl. Jonge peduncul. holofericei, coccinei , Baccz Cerafis proxima.

2. alba... I. fol. ovat-lanceol. fl. fafciculatis. Syf. veg. ed. 14. Pluk. alm. tab. Iog. f, 2. Hort. mal. 2. tas. I 4 .

In India $\hbar$.

Differt fol. latioribus obtulis, \& acuminat. F1. albidi.

3. americana. I. fol. ternis, lanceol-ovat. fl. thyrfoideis. Sy $f_{0}$ veg. ed. I4.

Pavetra \&c. Brown. Jam, tab. 6. f. 2.

In Jamaica $\hbar$.

Planta fruticofa, ramis fubnodofis. Fol. longe petiol. integerr. venofa. Stipul axill. folitar. Fl. laxi, patent, Cor. 4-fida.

alternifolia, I. fol. alternis. Jacq. Amer. tab. 177. f. 8. ed, piza tab, 16. Plum. Sp. ic, 157. f. I.

In Martinica fylvaticis $\$$. 
Arbufc. 12-20-ped. erecta, ramofa. Fol. petiol. ovat-lanc. acuta, integerr. nitida. Pedunc. axill. breviff. multifl. Cor. alba.

150. PAVET- Cor. I-petal, infundibul. fupera. Stigm. cur-

TA.

3. indiea. vum. Bacca 2-fperma.

P. fol. elliptic. umbell. terminalibus, fafciculatis; cal. brevi, acuto. Syft. veg. ed. I4. Burm. Ind. $t a b$. I3. f. 3. Pluk. $a l m . t_{a} b, 147$. f. I. Rumph, amb, 4. tab. 47. Hort. mal. 5, tab. 10. In India $\hbar$.

Frutex 3-8-ped. ramulis in orbem diffufis. Fol. oppofita, petiolat. craffa, mollia, viridia, fupra nitida, odore gravi. Corymb. faftigiati, trichotomi, peduncul. longo, filiform. infidentes. Fl. parvi, candidi, 4-fidi, odori. Stigm. oblongum, 2-fid. Baccæe e viridi-fufca.

2. cuffre. P. fol. ovat. integerr. capitul. terminalibus, feffilibus: calycibus fetaceis, longitudine tubi. Syjt. veg. ed. 14.

Ad cap. b. Spei ந.

Arb. glabra, ramis teretibus. Fol. oppofita, petiolat. venofa. Receptac. pilofum. Cor. limbo regul. laciniis lanceol. Fl. in planta ficca nigri.

151. PETE-Cor. I-petal. infundibul, Stigma 2-fid. Bacca SIA .

3. fipularis . (globosa), polyíperma .

P. fol. lanceol-ovat. fubtus tomentofis: thyrfis lateralibus. Syft. veg. ed. I4. Brown. Jam, tab. 2. f. 2 ,

In Jamaica $\hbar$.

Frutex. Fol. oppofita, integerr. Stipul. rigidæ. Racemi axill. brachiati, fol. breviores .

2. Lygiftum . P. fol, ovat. nudis, lineatis: caul. flexuofo. Syft. veg, ed. 14. Brown. Jam. tizb. 3. f. 2. In Jamaica $b$.

Frutex caul. lævi. Fol. petiolat. oppofita, acuta. Pedunc, axill. frepius gemini, $1-f l$.

152. MIT-Cor, I-petalæ, binæ eidem germini, fuperæ . CHELLA. Stigm. 4. Bacca 2-fid. 4-fperma .

J. repens. M. Syft. veg. ed. I4.

Syringa \&zc. Pluk. amalt. tab. 444. f. 2. Catesb. carol. I. tab. 20.

Baccifera \&c. Per. gaz. tab. I. f. 13.

In Carolina, Virginia \&o. ந). 
Fol. fubovata. Fl. gemelli, albi. Cor. tubus longus, anguftus, limbo expanfo, laciniis acutis, intus villofis. Bacca globofa, mollis .

Is3. CALliCARPA. Cal. (campanul.) 4-fid. Cor. (tubulofa) 4-fid. Pacca (globofa) 4-fperma.

I. americana. C. fol. ferratis, fubtus tomentofis. Syft, veg. ed. I4.

Burchardia. Du-Hamel. Arb. I. tab. 44.

Anonymus \&c. Pluk. alm. tab. 136. f. 3.

Frutex \&cc, Catesb, carol, 2. tab. 47.

In Java ந.

Altitudo humana. Frutex ramis compreffufc. albido-tomentofis. Fol. oppofita, petiolar. ovatlanc. fupra nervofa. Panicul, axill. dichotome, tomentofæ; brą. minutis, fubulatis, ad fingulam dichotomiam oppofitis. Baccxe rubra.

2. tomentafit. C. fol. integerr. lanatis. Syjt, reg. ed. I4.

In India $\hbar$.

Arb. fingularis, \& fine pari tota tomentofa. Fol. oppofita, petiol. ovata, acuminata, coriacea, rugofa, nuda, magnitudine manus. Pedunc, axill. folirarii, dichotomi, divaricati.

3. jeponica. C. fol. ferratis, glabris. Syft, veg. ed, 14. Thumb. Jap.

In Japonia b.

Caul. erect, fruticor. glaber. Rami oppofiti, divaricati, purpur. Fol. 2-pollic. oppofita, breviter petiol. oblonga, acuminata, bdfi, \& apice integra, nervofa, fupra virid. fubtus pallida . Fl. axillar. paniculati, minimi . Panicula trichotoma - Bract, linear. Pedunc, femipollic. pedicellis breviff. Cor. alba .

integrifolia. C. fol. integerrim. fubtus læviffime tomentolis. Jacq. amer, :ab. 173. f. 7. ed. 2. piała tab. 259. f. 6 ,

In fylvaticis Cartagence $\hbar$.

Arb. 12-ped. inordinatim ramofa. Fol, 2-3-pollic. oppofita, petiolat. oblongo-ovata, odore fubaromatico. Racemi axiil. \& terminal. compofiti, denfi, incani. Fl, numerofi, albi, odori. Baccæ nitidæ, virides, ad bafin flavæe, Pifiform.

154. AQUARTIA. Cal. campanul. Cor, rotata, laciniis linearibus. Bacca globofa, polyfperma.

Tom. I. 
1. aculeata. A, Syft. veg. ed. 14. Jacq. Amer. tab. 12, ed. S. piaza tab. 15.

In Amer. Merid. b.

Frutex 4-ped. ramofus, habitu accedens ad Solanum incanum. Rami feniores aculeati, aculeis brevibus, fubulatis. Fol. pollic. alterna, petiolat. fubovata, integerr. vel repanda, tomentofa, incana. Pedunc. lateral, breviff. Ifl. Cor. candida. Bacca Pifi magnitudine, fla$\mathrm{Va}$, nitens .

155. POLYPREMUM. Cal. 4-phyll. Cor. 4-fida, rotata, lobis obcordatis. Capf. comprelfa, emargin. 2locul.

z. procumbens, P. Syjt. yeg. ed. I4.

Linum \&c. Pet. gat. tal. 5. f. 6.

In Caroline, Virginia $\odot$.

Caul. procumb. dichorom. Fl. folitarii, feffil. in ramificationibus. Calyx intus coloratus. Capf. oyata.

356. PENFA, Cal. 2-phyll. Cor. campanul. (4-fida). Styl. 4-angul, Capf, 4-gona, 4-locul, 8-fperma .

I. Sarcocolla. P. fol. ovatis, planis: calycibus ciliatis, folio maioribus. Syft. veg. ed. I4.

Tithymali \&c. Pluk, mant. tab. 44.

In Ethiopia $\hbar$.

Arbufcula. Caul. dichotom, Fol. oppofita, craffa, obrufiufc. Fl. 4-5. Cal. intermedio flori nullus. Cor. obrufa, limbo rubicundo. Sryl. magis fubulatus quam in reliquis.

2. mucronate, P. fol, cordatis, acuminat. Syft. veg. ed. I4.

In 压thiopia $\hbar$.

Caul, fruticofus, ped. Fol. oppofita, feffilia, paIentia. Fl. congelti, rubri .

3. marginata. P. fol. cordatis, marginatis: $\mathrm{fl}$. lateralibus. Syft. veg. ed. I4.

Ad capitis b. Spei fluvios $\hbar$.

Frutex ftrictus, ramis fepius ternis. Fol. oppofita, feu terna, fubfeffil. obtufiufc. nitida, magnitudine Buxi. Fl. inter folia, fubfeffil. folis non longiores, $a l b i$.

4. furcata. P. fol. rhombeo-ovat. brac. cuneatis, acutis, coloratis. Syft. veg. ed. I4.

In cap. b. Sfei montibus $\hbar$.

Frutex ramofiff, ramis teretibus; ramulis angulatis. Fol. oppofita, patula, acuta, Iævia. Fle terminal. fafciculati, purpur. Bract. purpur. 
5. Squamofa. P. fol. rhombeo--suneiformibus, carnofis. Syft. veg. ed. I4.

In Fthiopia D.

Bractea f́pica fol, duplo latiores, ciliatæ, refinofo-unctuofa. Cor. maiufc.

6. fruticulofa . P. fol. oblongiufc. obtufis: bract. orbiculat, acutis. Syft. yeg. ed. I4. Lin. Suppl.

Ad cap. b. Spei ந.

Fruticul, ramis decorticandis teretibus. Fol. oppofita, fubpetiolat. craffufc. avenia, remota : Fl. in apice ramorum fubfolitarii, breviffime pedunculati, acutiufculi .

7. Myrtoides. P. fol, lanceolat. Syft. veg. ed. I4, Lin. Suppl. Ad cap. b. Spei D.

Rami erecti, teretes, rubri . Fol. conferta, oppofita, feffil., lævia, Myrti Tarentinæ, fubtus vix nervola. Fl, terminal. fubfolitar. cincti bracteis viridibus, acutis, fub quibus folicla 2. parva. Cal, acutus, virid. non coloratus.

8. laceriflora, P. fol ovatis: fl, lateralibus, feffilibus. Syft. veg. ed. I4. Linn. Suppl.

Ad cap. b. Spei b.

Caul. rubent, ramis elongatis. Fol. oppofita, feffil, acutiufc. integerr. lævia, fub bafi fere carinata, interftitiis longiora. Fl. feffil. Jutei, longitudine fol. Cor. laciniis lanceol, triquetris, feu introrfum carinatis, carina bafi excifa,

Letregone. P. fol, rhombeis, quadrifariam imbricat, patentibus: tubis fl, longis; foliol, calycin. obovat. ciliatis. Berg. Fl. cap.

Ad cap. b. Spei b.

Caul. fruticof. vix ped, 4-gon. fuperne ramofus. Rami fimpl, umbellati, foliofi. Fol, feffil. firma, craffa. Fl, adgregati, Cor. purpur .

157. BLARIA, Cal. 4-part. ( patens). Cor, 4-fida. Stam. receptac. inferta. Capf. (4-gona) 4-locul. polyfperma, Differt ab Erica folum antheris bicornibus.

I. ericvides, B. fl. capitatis; cor. campanulat. Syf.,veg. ed. 14.

Frica \&c. Pet. gaz. tab. 2. f. I0.

Ad cap. b. Spei $\hbar$.

Planta fruticofa, ramofiff. ftatura Erica $\mathrm{yulg}$. Fol. quaterna, ovat-oblon. adpreffa, gibba, 
pilofo-fabra, longirudine internodiorum caulis. Fl. terminal. albo-purpurafc. Cor. erecta . 2, ciliaris. B. fl. capitatis; calycibus ciliatis. Syft. yeg. ed. I4. Lin. Suppl. Ad cap. b. Spei 万.

Similis priori tota fua ftatura. Dignofcitur calycibus albis, diftincte ciliatis; ftaminibus inclufis.

3. articulata . B. Aaminibus exfertis, 2-part. cor, cylindricis. Syft. veg. ed. I4.

Penæa Sarcocolla. Berg. cap.

Ad cup. b. Spei $\hbar$.

Differt a $B$. ericoide, qua cor. campenulat. ftaminibus aqualibus, fol. magis imbricatis: a B. pufilla, qua calyc. glabrls; cor. injundibulif.

Fruticul. diftortus, flatura Erice vulg. Fol. quaterna, ovata, adprella, ramis longitudine internudior um, ovata , fcabra. Capitula termicual. calyc. albo-villofis . Cor. incarnatæ. Anth, exferiæ, anguftiff. 2-part. nigræ.

4. purpurea. B. ftaminibus inclufis, 2-part, cor. oblong. rectis: fl. terminalibus, adgregat. peduncul, erect. $S, f t$. veg. ed. I4. Lin. Suppl.

Ad cap. b. Spei ந.

Símil. B. arriculatæ; at in illa capitula cernua .

3. pufille. B. fl. fparfis: cor. infundibulif. Syft. veg. ed. I4. Ad cap. b. Spei $\hbar$.

Statura Erica min. Rami pubefcent. Fol, quaternd, petiolat. linear. fcabra, fubtus linea exarata. Fl. minuti, fol. breviores. Caute $a b$ Ericis diftinguenda.

158. BUDDLEJA . Cal. 4-fid. Cor. 4-fid, Stam. ex incifuris . Capf. (oblong.) 2-fulca, 2-locul. polyfperina.

I. americana. B. fol. ovat. ferratis, oppofit. fl. racemofo-fpicatis : caul. fruticoto.

B. fol. ovatis. Syft. veg. ed. I4.

Verbafci \&c. Sloan. Jam. I. hift. 2. tab, 173. f. I.

In Caribais ad ripas, \& torrentes $\hbar$.

Caul. fruticof. tomentofus. Fol. Verbafci amula. Racemi terminal. oppofiti, recti. Cor. lutea .

2. occidenta- B. fol, lanceol. acuminat, oppolitis, integerr. lis. fpicis interruptis.

B. ful. lanceol. Syft, veg. ed. I4.

Ophioxylum \&c. Pluk, alm, tab. 2IO. f. I.

In Anerica $\hbar$.

Fol. fubtus lanuginofa. 
3. virgats B. fol, lineari-oblong. obtufis, integris: racemis rerminalibus, ramis virgatis, erectis. Syf. veg. ed. I4. Lin. Suppl.

Ad cap. b. Spei 方.

Habitus Hy Jopi . Rami, \& fol, fubtiliore tomento cana.

4. incompta. B. fol. fafciculat. ovatis, canis; ramis flexuofis, rigidis: racemis terminalibus. Syft. veg. ed. 14. Lin. Suppl,

Ad cap. b. Spei b.

159. EXA- Cal. 4-phyll. Cor. 4-fid. tubo globofo. Capfo

CUM. (fubrorunda) 2-fulca, 2.locul, polyiperm. apice dehifcens.

1. albens. E. fol. fubdecurrentibus: ftaminibus exfertis. Syft. veg. ed. I4. Burm. Afr. tab. 74. f. 4 . Pluk. aln. $t a b$. 343. f. 3 .

In India $\odot$.

Cal. palm. herbac. dichotomus, 4-gon. lævis. Fol. oleracea, cordata, lævia. Cor. albd. Adfine Gentianis.

2. aureum. E. fol. feffilibus: ftaminibus exfertis. Syft. vegn ed. 14. Lin. Suppl. Pluk, «lm. tab, 275. f. 3 . bona.

Ad cap. b. Spei $\odot$.

Habitus Gentianæ Cent. Caul. palm. brachiat. dichoromus, fub 4-gon. lavis. Fol. oppofita, infer. \& fuper. lanceol.

3. cordatum. E. fl. 5-fid. calyc foliol. cordatis, ftriatis. $S_{y} /$. veg ed. 14. Burm. Aj. tab. 74. f. 5. Seb. muf. 1. $t a b .22$, f. 7.

Centaurium \&c. Pluk. alm. tab. 275. fo 4.

In Afia, \& Africa $\odot$.

Caul. erectus, fpitham. fimpl, dichotom, 4-gon. lavis. Fol. oppofita, feffil. ovata, integerr. F]. ex divaricat. caulis, folitarii, fol. maiores. Cor. lutea .

4. punfatum. E. fol, breviff. petiolat, oblong. trinerviis, pun. ctatis: ftaminibus exfertis. Syf. veg. ed. I4. Lin. Suppl.

In India.

Maior prioribus. Fol. glandulofa, ut in $\mathrm{H}_{3}$ perico, punctata. Cor, ccrul. Stam, lutea.

Guinnenge. E. fol, connatis, oblong. acutis: fl. purpurafcent. Aubl. Guian, 3ab, 26, f. I.

In Guiana $\odot$. V ij 
Caul. ped. ramis, \& ramulis oppofitis. Fol. oppofita, integerr. glauca. Fl, axill. folitar. Cor. lacin. fubrotun. undulatis .

snxifolium. E. fol, linearibus: f. violaceis . Aubl. Guian。 tab. 26. f. 2 .

In Caienna, \& Guiana $\odot$.

Differt a priore caul. tenuiare: fol. minimis, anguftifl: fl. min: cor. violac. laciniis acutis.

Ad hoc genus fpectat Coutoubea ramofa, \& spicata Aublet Guian. T. 27. 28.

160. PLAN-Cal. 4-fid, Cor. 4-fid. limbo reflexo, Stam. lonTAGO. giff. Capf. ovat. 2-Iocul, circumfciffa.

Appendices parva, membranacea, ovat-lanceol. in apice, utplurimum laviter, 2-fid. unicuique anth. Subiecta.

\section{* Scapo rudo.}

¿. maior. P. fol. ovat. glabris : fcap. tereti : fpica flofcul. imbricatis. Syft. veg. ed. I4. Fl. Dan. tab. 461. Gmel. Sib. I. tab. 35. 36. Black. tab. 35.

In Europa, \& Japonia ad vias 2 .

Fol. fpitham. 7-nervia, integerr. late virent. Spica cylindrica. Bract. lanceoi. Fl. parvuli, herbidi, anth. albis .

I. var. fol. dentat.

2.... minor.

3.... Spica 2-multifida.

4.... rofea, fl. quafi in fpicam difpoftitis.

3..... refea, fl. expanfo.

2. Afratica. P. fol. ovat. glabris : fcap. angulato: fica flofcul, diftinctis. Syft. veg. ed. 14. Gmel. Sib. tab. 37 .

In China, Sibiria.

Simillima priori; at differt fpica longiore: $\mathrm{fl}$. diftantibus; fol. fapius bafi fubdenrat: fcap. angulato .

3. media. P. fol. ovat-lanceol. pubefc: fpica cylindrica: fcap-tereti. Syft. weg. ed. 14. Fl. Dan. tab. 581.

In Europa pafcuis apricis, argillofis 24.

Fol. in rofulam fparfa, integerr. pallida. Calyc. glabri. Filam. purpurafc. Var. Spicis multis. Morif. hift. 3. f. 8. tab. 15. f. 7.

4. virginica, P. fol. lanceol-ovat, pubefc. fubdenticul, fpicis 


\section{TETRANDRIA MONOGYNIA.}

floribus remotis: fcap. tereti. Syft. veg. ed. 14. Morif. hift. 3. S. 8. tab. I5. f. 8. Pet, gaz. I. $t a b$, I. f. IO.

In Virginia $\odot$.

Fol. 3-4-unc, obtufa, femitrinervia, Spica palmar. Fliss in Amer. cor. explicat, E Stam. exerit, in Europa vero vix.

9. altifima. P. fol, lanceol. 5-nerviis, dentat. glabris : fpica oblong. cylindrica : fcap. angulato. Syft. ves. ed. 14. Jacq. obf: 4. $t_{12}, 83$.

In Italia 4.

Scap. 2-3-ped. fcaber. Fol. 1-fefquiped: obtufe. dentata, dentibus remotis, craffa, glabra. Spica cylindr. vix fefquipollic. glabra.

6. lanceolata, P. fol. lanceol: fpica fubovata, nuda: fcapo angulato. Syjt. veg. ed. 14. Fl. Dart. tab. 487. Black, $t a \bar{b}, 14$.

In Europa campis faterilibus 24.

Planta mulriformis. Fol, petiolat, rariter dentata, nervola, duriora, glabrt, obfcure virent. Cor. fufcomalbida. Siam, albida .

1. Var. minar, \& humilior .

2.... trinervia, fol. anguftilf. Ger. Prov. tak. I2.

3.... hirfuta.

4.... alpina, fiap. lanugin. capitulo nigro.

\%.... Spica 2-3-multifida.

6.. . . caulis fummitace faliofa.

7. Lagopus . P. fol. lanceol. fubdenticul: fpica ovat. hirfuta: fcapo tereti. Syft. veg. ed. 14. Moris. hift. 3 . f. 8. $t a b .16$. f. 13. Rauw. it. 4. tab. 6.

In Gallia Narbon, Hifpania \&́c. $\odot$.

Fol. fubtus pubefc. apice, denticulifq. obfoletis, fufca.

8, Iufitanica. P. fol. lato-lanc, trinerviis, fubdent. fubpilofis: fpica oblong. hirfuka: fcapo angulato. Syft. yeg. ed. 14. Butr, rar, tab. 745.

In Hifpania 24.

Fol. palmar. erecta, latiora quam in P. medid. Scap, foliis longior. fubhífpidi, 5-fulcat. Spica P. Lagopi, fed oblong. bract, breviter hirfutis . Cor. alba, fria flavefcente. Stam. alba. Styl. elongatus, pubefcens, albus .

9. albicans. P. fol. lanceol. obliquis, villofis: fpica erecta, cylindr: fcap, tereti. Syft, veg ed. 14, Cluf, hift. 2. p. 110. 
P. cylindrica. Forsk. Ag. monente Vahl.

In Hifprnia, \& Narbona aridis \&c. $\odot$.

Caul. Falmar. Fol. tomentola. Spica conferta.

10. alpine. P. fol. linearibus, planis: fcep. tereti, hirfuto: fpica (florente ovata; fructif. cylindrica, erecta ). Syft. veg. ed. I4. Jacq, hort. 2, tab. 125. Hort. rom. 2. tab. 7 .

In Helvetia, Auftrix alpibus 24.

Fol, fapius integerr. fubtus convexa, nitida. Spica ante efflorefcentiam cernua. Cor. la.in. nigra. Var. fpicis ramojis. Zann. tab. I 4 o.

11. cretica. P. fol. linearibus : fcap. brevilf. tereti, lanato: fpica fubrot. nutante. Syft. veg. ed. 14. Cluf。 hift. 2. p. 1 I,

In Creta.

Fol. pedal, villofa. Pedunc. lignofi, recurvi, villofi .

12. maritima . P. fol. femicylindr. (fapius) integerr. bafi lanatis: fcapo tereti. Syft. veg. ed. 14. Fi. Dan, tab. 243 .

In litoribus maritimis Europ. Amer. boreal. 24.

Scap. 6-unc. Fol. cefpitofa, linearia, glauca, fubtus trinervia. Spica cylíndr. Cor, herbida. Atrth. lutea .

13. incurvata. P. fol. lineari-fubulat. canaliculat. recurvatis, deriticulat. punctatis: fcapo tereti. Syft. veg. ed. I4. Comm. Gott. 1780. tab. 6.

I4. fubulata. P. fol. fubulat. triquetris, ftriatis, fcabris: fcap. tereti. Syft. veg. ed. I4.

Serpentina \&c. Lob. ic. 439.

In maritimis arenofis Mediterranei 24.

Scap. fol: longior, non glaber. Fol. conferta. Spica ovat-cblonga, non villofa .

15. Serrarie. P. foll lanceol. 5-nerviis, dentato ferratis: Scap. tereti. Syft, veg. ed. 14. Barr. ic. 749. Col. epkr. 1. tab. 259. Morif. hiji. 3. .. 8. tab. I6. f. 19.

In Apulia, Mauritania 4.

Fol. fubpetiol. ftriata, fubpubefcentia. Scap. pubefc.

16. coronopus, 1 . fol, linearibus, dentatis: fcap. tereti. Syfo. veg. ed. 14. Fl. Dan. tab. 272. Dod. pempt. 109.

b. Black. tab. 460.

In Europx glareofis (-). 
Scap. dodrant. fubhirfut. Fol. longa, ex petiol. latefcente femipinn. vel folum dentata, fubhirfuta. Spica cylindric. Squamæe ovatæ, albæ.

b. in montibus faxofis. Scap. erectus, 3-unc. Fol. uncial, integra, vel fubdent, pilofifi. Spica cylindrica, hirra, canæfcens, femiunc.

17. Iaflingii. P. fol. linearibus, fubdent. fcap. tereti: fpica ovata: bract. carinatis, membranaceis. Syjt. yeg. ed, 14. Jitcq. hort. 2, tibb. 126. Pet. herb. 3. tab. 9 .

In Hifpania collibus \&c. $\odot$.

Differt a priore, quod fit minor, \& ut in definitione.

18. Cornuti. P, fol. pinnatis, pinnis inæqualibus, \& diftantibus: fcapo rereti; fylis longiff. filament. breviff, S, ft. veg ed, I4. Jacq. Mifc. 2. Ic. rar.

Habitat

Fol. r dical, multa, humifufa, acuta, pilis mollibus ciliata, lemipedal, cofta canaliculara. Pinỉæ feffil. inordinato fitu egreffæ, linear. acura, integerr. vel rariter incifa. Scap. pl. adfcendentes, denfe villofi, longitudine fol. Spica 3-unc. linear. aphylla, erteta, teres, gracilis, bracteatd. Petal. albida.

** Caule ramujo.

39. Pfyllium . P. caul. ramofo, herbaceo: fol. fubdent, recurvatis: capitulis aphy!lis. Syft. veg. ed. I4. Black. tab. 412. Ludw. ea. tab. 44. Sabb. hort. 2. tab. 10. Pfillio Matth.

Inter fegetes Europa auftralis $\odot$.

Caul. erecti, villofi. Fol. infer. oppofita, fuper. terna-quaterna, linear. villofo-vifcida, latiora P. Cynops. Pedunc. fol. longiores. Capitul. bract. \& calycin. foliol. prædita.

20. Squarrofa. P. herbacea, caulibus diffufis, decumbentibus, ramofis: fol. linearibus, integetr. capitatis, qquarrofis. Syft. yeg, ed. 14. Com. Gotting. I781. $t a b .3$.

P. Fgypriaca. Jacq. Mifc. 3.

In ÁEpto.

21 , indica. P. caul. ramofo, herbac. fol. integerr. reflexis, ciliatis: capitul. foliofis. syft. veg. ed, I4.

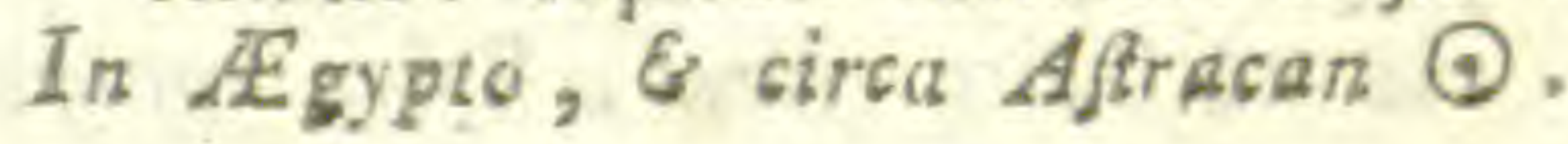


Caul, erectus, pilis albis. Fol. fuperior, terna . Pedunc, axill. Spica fubovata, bafi cincta foliol. 4, inæqualibus, fpica longioribus. Calyc. foliol. 2. infer, fpatulata, obtufiff, valde gibba, intus concava .

22. pumila. P. cau!. ramofo, herbac. fol. integerr. fubulat. carnofis: ramis lavibus. Syft. veg. ed. I4.

P. exigua. Comm. Gott. 1778. tab. 5.

In India Orient.

Similis P. indice. Caul. fpitham. varie flexus. Fol. oppofita, fuper. terna-quaterna, patentiff. apice reflexo, pubefc. yel ciliata .

23. Cynops. P. caul. fuffrutic. ramofo: fol. filiformibus, ftritis, integerr: capitul. fubfoliatis . Syft. veg. ed. 14 .

PfyHium \&c. Morif. hift. 3. f. 8. tab. 17. f. 1. In Italia, Gallo-provincia Ec. collibus ficcis $\hbar$. Caul, repens, palmar. purpurafc. durus. Fol. oppofita, canalicul-trigona, erecta, fubvillofa. Pedunc. axillar. Bract. inter flofcul. ovatæ, concavæ.

24. afra. P. caul. fructic. ramofo: fol. lanceol. dentatis: capitul. aphyllis. Syft. veg. ed. I4.

Pfyllium \& 2 . Morif. hift. 3. 5. 8. tab. 19. f. 4. Bocc. fic. 8. $2 a b$. 7. f. B.

In Sicilia, Barbaria $\hbar$.

Caul. erect. pedal. pubefcens. Fol. fubvillofa, ftriata. Spicæ pl, ad apices ramorum .

Columne. P. fol. 2-pinnat. bafi lanatis; foliol. confluentibus, fummis auricular: fcap. tereti. Govan. Illuft.

In montibus.

Scapi pl. fub 2 -unc. alii erecti, alii deflexi . Fol. hirta, variabilia, quandoq. pinnata more Scabiofarum; in iunioribus tantum pinnata, pinnula terminal. 3-fid. Spica femunc. cylindr. canefcens, fubqlabra.

Cornuti Go- P. fol. ovat. integerr. carnofis, puftulatis, bafi uan. lanatis. Govan. Illuft.

24.

Proxima P. maiori, fed triplo ma: falf, carnofa, glauca. Fol. petiol. longis, bafi villofis, 7-nervia, glaberrima. Scapi 2-ped. rubentes, vix ad bafin villofi. Spica longiufs, glaberr. 
owata.

P. fol. linearibus, utrimq. hirfutis: fcapis erectis, hirfutis: fpicis ovat-oblong: cor. ovatis. Forsk. Eg.

In Egypio.

Spica vix pollic. Fl. conferti. Cor. latiffima, cordato-acuta .

crafffolia. P. fol, carnofis, femiteretibus, lineatibus, ciliatis, bafi nudis. Forsk. 正g.

Alexandria.

Vix differt a P. maritima, nifi fol. bafi nudis . Scapi teretes, villis adpreflis. Spica 2-pollic. cylindricæ.

Bellardi. P. pubefcens, fol. fublinearibus, planis, petiolat: fcapo tereti, folicrum longitudine: fpicis cylindricis. All. Fl. Ped. tab. 85, f. 3.

In locis flerilibus $\odot$.

Fol. radicalia, petiolata, fubrus tribus nervis percurfa. Scapi 3-4. ereeti 2-4-inc. Spica primum ovatæ, \& compactæ, dein cylindricæ. Bractex lanceol. Cor. flavefcens.

Serpentina. P. All. Fl. Ped.

P. gramineo fol. Tourn. inft.

Ad montium radices, locis fabulofis, \& aridis 4.

161. SCOPA-Cal. 4-part. Cor. 4-part, rotata, ( concava). RIA. Capf. oblong. r-locul. 2-valv. polyfperma .

3. dulcis.

S. fol. (fummis ) ternis : fl. pedunculat. $S_{y} \beta_{0}$ veg. ed. 14 .

Veronica \&c. Herm, Par. tab, 241. Sloan, Jam, 1. $t a b, 108$. f. 2 .

Phytenoides \&c. Pluk, alm. tab. 2r5. f. x.

Scoparia ternata. Forsk. Fg. monente Vahl.

In Jamaica, Curafjao $\odot$.

Caul. erect, 3-ped. ramofiff. angulatus. Fol. in petiolum attenuata, oblonga, acuta, ferrata ; inferiora oppofita. Pedunc, axill. I-fl. Cor. alba .

2. procumbens. S. fol, quaternis: fl. feffilibus. Sy f, veg. ed. I4. In Amer, calidiore $\odot$.

Vix femiped. Habitus prioris, fed caul. procumberecti, dichoromí. Fol, parva, fubulata, acuminat. Fl. parvi, albi .

3. arbores. S. fol, alternis, lanceol, integerr. corymbo fupradecompofito, trichotomo. Syft. veg. ed. 14. Lin. Suppl.

Ad cap. b. Spei t. 
Habitus facie Olea, feu Phyllirer. Inflorefcentia maxima, \& fumme compofita. Fl. parvi. 162. SKIMMIA. Cal. 4-part. Pet, 4. concava. Bacca 4-fperma. I. japonica. S. Syft. veg. ed. I4. Thumb. Fl. Jap.

Mijama skimmi. Kamph, am. exot. p. 779.

In Japaria b.

Caul. erectus, fruticol. glaber. Rami alterni, fub 4-goni. Fol. in apice ramorum digitalia, aiterna, petiolat. frequentia, oblonga, undulara, integerr. fed apicem verfus obfolete crenata, erecta, margine reflexo, fupra víridia, rugofa, fubtus pallida, punctata, fempervirentia, fapore aromatico. Fl, terminal. paniculati. Cor. alba. Bacca magniturline Pifi, rubra, intus farinacea, pulpofa, alba.

163. RHACOMA. Cal. 4-part. Cor. 4-part. Capf. ( fubrotunda) 1-locul. I-fperma.

1. Croflopetalum. R. Syft. veg. ed. I4.

Croffopetalum. Brown. Jam. tab. 17, f. I.

In Jamaica $\hbar$.

Suffrutex ramis dichotom, pubefcentibus. Fol. oppofita, fubpeticl. ovata, mucronata, tenuiffime acute ferrata, fubpubefc. Pedunc. axillar. filiform. pilofi. Umbella compofita, 2-4-

164. OTHE- Cal, 4-part. Petala capillar. Involuc. minima. RA. feffile. Capfula?

1, japonica, O. Syft, yeg. ed, I4. Thumb. Jap.

In Japonia $\hbar$.

Caul. fruticofus . Rami teretes, ftriati, purpur. Fol. fefquipollic. alterna, petiolat. ovata, obtufa, patentia, coriacea, integra, glabra. Fl. axillar. adgregatí, pedunculat. Cor. alba.

165. ORIXA. Cal. 4-part. Petala 4. lanceol. plana. Stigma capitatum. Capfula?

I, japenica. O. Syft. veg. ed. I4. Thumb. Jap.

In Japonia $b$.

Caul. erectus, orgyal. frutefcens, flexuofus, ramofus. Rami alterni, glabri, ultimi villof . Fol. Cemipollic. alterna, petiolat. ovata, integra, fupra viridia, fubtus pallida, villofa, præcipue iuniora. Fl. racernofi, rłcemis pollicar. alternis. Cor. virefcens. Bract. fub pedicellis concava. Pedunc, \& pedicelli villofi , 
I66. CEN- Cal. 4-fid. (patens). Cor. rotatd, 4-fid. Stam. TUNCULUS. brevia. Capf. rotund. I-locul. circumfciffa. I, mintmils, C. Syft, veg. ed. 14. Fl. Dan, tab. 177. optime. Ephem. cur. Cent. VI, tab. 10. f. 3 I. Anagallidialtrum \&c. Mich. gen. tab. 18. Anagallis \&c. Vaill. parif. tab. 4. f, 2. Alfine \&c. Mentz. tab. 4. f. 5.

In halia \&c. arenofis fubudis $\odot$.

Caul. procumb.uncial. herbaceus, ramofus. Fol. alterna, parva, fimplicia, lanceol. caulina inferiora oppofita, feffilia, ferpyllifulia. Flos axill. fefflis, albus, fugax, vix conspicuus .

167. SANGUISORBA. Cal. (brevis) 2-phyll. (Cor. 4-part. plana). Germen inter cal. \& cor. Fruct. 2locul. Fol. impari-pinn. Fl. fpicari .

I. officinalis. S. fpicis ovatis. Syft. veg. ed. I4. Fl. Dan. tab. 97. Ludw. eat, tab. 94. Sabb. hort, rom. 2, tab.70. In Europe pratis ficeis 24.

Planta glabra. Caul. 3-pedal, herbac. fubramofus. Fol. periolar. Foliol, ad 6-inga, cordato-ovatd, acute ferrata, firma, ficca. Pet. iuniora alba; adulta col, fanguinei obfcuri .

2. media. So fpicis cylindricis. Syjt, veg. ed, I4, Zan, tab. 138.? Morif. hijt. 3. f. 8. tab. 18. f. 2.

In Canida 24.

Spicæ, \& ftam. longiora quam in priore.

3. camadenfis. S, fpicis longiffimis. Syft veg. ed. I4. Zann, tab. 137. Knorr. del. hort. 1, tab. P. 5. Morif. hift. 3. f. 8. $t a b$, I8, f. 12, Burr, rar. tab. 739.

In Canada, Sibiria 4.

Caul. 4-ped, Fol. lata bafi amplexicaul, glabra. Fl. pulli .

auriculate. S. Scop. Fl. Carn. ed. 2.

Pimpinella \&c. Bocc. Muf. tab. 7.

In Carniola Ec. 24.

Ad Poterii genus fpectat.

Caul.2-ped. ramofus, glaber. Fol, oblong. dentata, glabra, fupra nitida, fubtus pallidiora. Ad bafin petioli fol. feffile, ovatum, denticulat. Spicæ cylindricæ, rubræ.

168. CISSUS, Bacca (rotunda) I-fperm, cincta calyc. corollaq. 4-part. (Sem. ofleum).

Sp. omnes Salanthi Forsk, huc pertinent, monente Vahl. 
I. vitiginea. C. fol. cordatis, fub 5-lobis, tomentofis. Syft. veg. ed. 14.

Arbufcula \&c. Pluk. mant. tab. 337. f. 2.

In India $\hbar$.

Arbufc. habitu Vitis. Fol. alterna, petiolat. Caul. tomentofus. Umbel. axillar. prolifera. Bacca nitens, argentea.

2. cordifolia. C. fol. cordatis, integerr. Syft. yeg. ed. I4.

Sahelanthus rotundifol. Forsk. ic. rerum natural. tab. 4 .

Vitis \&c. Plum. Amer. ic. 159. f. 3.

In America 24.

Fol, cordato-orbiculata . Racerni corymbofi .

3. Sicyoides. C, fol, fubcordat, nudis, fetaceo-ferratis : ramulis teretibus. Syft. veg, ed. I4. Jacq. Amer. tab. 15. ed. 2. piata tab. 20.

Vitis \&c. Plun, ic, 259, f. 2.

Funis crepitans. Rumph, amb. 5, tab. I64. f. I. Schunumpi-valli. Hort. Mal. 7. tab. II. Irfiola \&c. Brow. Jam. tab. 4. f. I. 2. Bryonia \&c. Sloan. Jam, tab. I44. f. I. In Jamaica 4 ,

Habitus fingularis, fcandens. Caul. lignofi. Fol. 3-4-pollic-femiped. alterna, petiol. fubdifticha, nitida. Umbellæ lateral, compofitæ, alternæ . Involuc. minimum, multidentat. F1. multi, parvi, inodori, rubri, flavi, virides. Baccæ Pifi magnitudine, fucculentæ, nigræ, nitidæ.

4. quadrangu-C. fol. (cordatis) carnofis, ferrato-dentat. caul. laris. 4-gono, tumidiufc. Syft, veg. ed. I4.

Salanthus tetragonus. Forsk, ic. rerum \&c. tab. 3 . Funis quadrangular, Rumph. amb, 5. tab. 44, f. 2. In Arabia, India 4.

Radix tuberofa. Caul, fcandens, longiff. carnofus, lævis, perennis. Fol. alterna, petiolat. fubhaftata, argute, remoteq. ferrata, utrimque glabra. Cirrhi oppofitifolii .

3. aeida. C. fol. ternatis, obovatis, incifis, carnofis, glabris. Syft. veg. ed. I4.

Bryonia \&c. Rumpl. amb. 5. tab.66. f.2. Sloan. Jam. I. tab. I42. f. 6.

Bryonioides \&c. Pluk. alm. tab. 152, f. 2. Vitis \&c. Plum. Sp. tab. 259 . f. 5.

In America 24.

Caul. fcandens, lignofus, ramofiff. cirrhifer. Fol, 
alterna. Foliol. acuta, glabra. Umbellula ut in C. Sycioide.

6. trifoliata. C. fol ternatis, fubrotundis, fubdent. hirfutis: ramis membranaceo-angulatis. Syft. veg. ed. I4. Jacq. Amer, tab. 182. f. 10. ed. 2. piąa tab. 259. f. 8.

Bryonia \&c. Sluan. Jam. hift. I. tab. I44. f. 2. In Jamaica 4.

Scandit, fuperatque altif., arbores. Caul. lignofi . cirrhiferi. Fol. alterna : foliol, acuta ; medium ovatum; lateral. femicordata, latere interno ad bafin obliterato. Umbell. \& $\mathrm{fl}$. ut in C. Sycioide, fed omnia paulo maiora. Flos ruber. Fruct. maturus niger.

arburea. C. fol. oblongis, integris, craffis, Forsk. AEg. In Arabia $\mathrm{b}$.

Arbor ramis debilibus recurvis. Fol. oppofita, petiol. oblong-acuta, glabra. Pedunc. terminal. brachiatim paniculati. FI. feffil. Cor. revoluta, viridis, laciniis ovalibus, femimarcidis . Bacca Pifo maior, feffil. flava, vel nigra, bafi cincta cal. \& cor. marcida ; edulis .

169. EPIME- Nectaria 4. cyathiform. petalis incumbentia. Cal. DIUM . caducus, 4-phyll. Cor. 4-pet. Capfula acuminata, I-locul. 2-valv. polyfper.

I. alpinum. E. Syft, veg. ed. 14. Lob. Hift. 176.

In alpium, \& collium umbrofis. 24.

Caul. cubital. in teroos furculos divifus, fufcus, pallidus. Fol, longe petiolat. faftigiata, triternata. Foliol. cordiform, dentata, fature virent. glabra, venofa, rigida. Fl. purpuroflavi, variegati, emarginati .

170. CORNUS. Involuc. 4-phyll. frepius ( Cal. minim. 4dencat.) . Petal. 4. fupera. Drupa (umbilic.) nucleo 2 -locul.

I. florida. C. arborea; involucr. maximo, foliol, obcordat. Syft. veg. ed. 14. Catesb. carol. tab. 27. Pluk. $a l m, t a b, 20$. f. 3 . phyt. $t a b .26$, f. 3 .

In Virginice fylvis $\hbar$.

Arb. medioc. magnitudinis. Fol. maiora C. mare . Bacca ovata, rubra. Var. involuc. fanguinei col.

2. mafcula. C, arborea; umbellis involucrum æquantibus. Syft. veg, ed. 14. Ludw. eđt. $t_{a} b .3^{8}$. Knorr. del. hort. I. tab. Z, Black, tab. I2I, Kniph, cent. I. tab. 18. 
Corniolo. Matth.

In Sepibus Europe $\hbar$.

Arbor. Fol. láa, mucronata, integerr. venora. Fl. flavi. Bacca oblong. magna, coccin. vel luted. Var. fol. eleganter variegatis.

3. japonica. C. arborea; umbellis involucrum fuperantibus: fol. fersatis. Syft. yeg, ed. 14. Thumb. Japon. Jamma fimira. Kamph. am. exot. Fafc. V. p. 747. In Japonia b.

Frutex erectus, orgyal. Rami oppofiti, ftriati, cinerei, glabri. Fol. in epice ramorum oppofita, 3-pollic., 2-pollic. lata, petiolat. ovatacumin. ferrata, bafi integra, nervofa, fubtus pallida, glabra. Unb lla decompofita, patentiff. 3-4-5-radiata. Cor. alba. Drupa magnitudine Pifi min. comprefia, rubra. Nex lentiform. dura. Nucleus durus, albus .

4. Janguinea. C. arborea; cymis nudis: ramis rectis. Syft. veg. ed. 14. Fl. Dan, tab. 481. Lob. 2. p. I69. Virga fanguinea, Matth,

In Europa, Afix \&c. dumetis 24.

Cortex fanguineus fraticis, \& ramorum. Fol. ovat-lanceol. fubtus nervofa. Fl. parvi, albi, odori. Bascæ parvæ, fubrotundæe, fature violac.

5. alba. C. arborea ; cymis nudis, ramis recurvatis, Syft. veg. ed. 14. Amm, rutk, tub. 32. Mill. tab. 104.

In Sibiria, Canada $\hbar$.

Simil. omnino priori: differt ramis recurvatis, \& baccis albis. Stolones muli ad radicem enati procumbunt. Cor, alba, receptacul. atro-purpur.

6. fericea. C. arborea; cymis nudis; fol. fubtus fericeis . Syft. veg. ed. I4.

In Amer. Septen. b.

Frutex. Rami fanguinei, punctis fubyerrucofis, cinereis adfperfi, quibus prior orbatur. Fol. oppofita, nec bifaria, ovata, plicato-lineata, fubtus alba, non pallide virid, fericeo-nitent. Petala patentia, alba. Stam. alba, cor. duplo longiora. Receptac. plirpurafc. Baccæ atropurpur, maturæ alba.

7. alcernifulia. C. arborea; fol, alternis. Syft. veg. ed, 14. Lin. Suppl.

In Amer. Septentr. $\hbar$. 
Rami atro-purpurafc. punctis albidis. Fol. petiol. ovata, acuta, integerr. lavia, lineata, fubtus pallida. Stipula nulla. Panicula corymbofa, fupra piana, alba. Petala revoluca, alba .

8. freciea. C. herbacea, ramis binis. Syft. veg. ed. I4. Fl. Lapp. tab. s. f. 3. Fl. Dan, tab.5. Dill, elth. tab. 91 .

In Svecia, Norvegia, Ruffia 24.

Caul, 4-unc. lignofus, fufco-virens. Fol. Androfæmifolia, fature viridia. El, albo-virent. Baccæ flavo-rubræ.

9. canadenfis, C. herbacea, rawis nullis. Syfi. veg. ed, I4. Burf. X. 106.

In Canada 4.

Caul, vix 9-pollic. Fol. 2. in medio caulis, oppofita, ovalia. Pedunc. terminal. 2-pollic. Involucr. quam in priore longius.

77I. SAMARA. Cal, minim. 4-part. Pet. 4. ovata, bafi lacuna longitudinali. Stam. bali petali immerfa. Stigm. infundibul. Drupa fubrot, Fol, alterna :

I. late. S. Syft. yeg. ed. I4.

Memecylon \&c. Burm. Zejl, tab. 31 .

In India Orient. $\hbar$.

Arbor. Rami purpurafc. læves. Fol. alterna, petiolat, interupte-piunata, 5 -iuga . Foliol. oppofita, breviter petiol. lanceo-ellipt. obtufa, integerr, utrimq. lavia. Corymb. lateral-axill? vix petiolis longiores. Fl. copiofi, lutei.

I72. FAGARA. Cal. (parvús) 4-fid. Pet. 4. (oblonga, patent.). Capf. z-valv. (Sem. T. rotundum).

7. Evodia. F. fol. fimplicibus, oppofitis, lanceol. elongaris : racemis axillaribus, folitariis, ramolis. Syft. veg. ed. 14. Lin. Suppl.

Evodia hortenfis, Forft, gen.

In Tonga tubu.

Planta bene odorata. Stigma 4-fid. Capf. 4,

2. Pterots. F. foliol. emarginatis. Sy ft. veg. ed, I4.

Pterota \&c. Brotwn. Jam. tah. 5. f, 1 .

Iauro \&c. Sloan, Jam, 2. tab. I62. f. I.

In Jamaica b.

Odor hircofus. Arb. 20-ped. ligno duriff. ramis alternis, hamatis. Fol. 3-4-iuga. Foliola 0vata, ferrulata, impari longiore. Petioli alati, articulati, inter binos aculeos reflexos. Spic. axill. Fruct. ovat.

$$
\text { Tom, I. }
$$


3. Piperita, F. foliol. crenatis. Syft. veg. ed. 14.

Piper \&c. Kamph. am. tab. 893.

In Japonia b. .

Arbufc, fapore Piperis, 2-orgyal. ramofa. Rami purpur, aculeis fparfis, horizontalibus. Fol. pluis, in opice ramulorum, Fraxiniform. fub 6-iuga. Folrol, unguicul, alterna, \& oppofita, fubreffil. ovata, emarginata, gidbra. Fl. inter fol. paniculati, parvi. Cor. herbido-livida. Capf, rugofa. Sem. atrum, nitidum.

4. tragodes. F. articulis pinnarum fubrus aculeatis. Syft veg. ed. I4. Jacq. amer. tab. I4. edit. pila tab. I9. In America b.

F. Pterota valde adfinis. Frutex fuberect. 5-ped. ramofus. Aculei gemin, recurvi, fufci, nitidi . Fol. alterna, feffil. pinnatu-articulata. Foliol. 5-6-iuga, feffil. obl-obtufa, bati attenuata, integerr. nirida, Fl. axillar. adgregati, parvi. Capi. globofa.

5. octandra. F foliol. fape tumentofis. Syft. veg. ed. I4.

Elaphrium \& i. Jacq. amer, tab. 7I. f. I. 3. edite piąa tab. 106.

Ir. Curaido duris 5 .

I73. FGIPHILA. Cal. breviff, campaniform. 4-dent. Cor. tubul. 4 fid. Siylus femi-2-fid. Bacca (fubrotunda) 4-fper.

1. martini- E. Syft. veg. ed. 14. Jacq. obf.2. tab.. 27. Amer. cenfis. piat. $t a b .16$.

In Martinica ad fylvarum margines $\hbar$.

Frutex orgyal. ramis oppofitis, 4-gon. glabris. Fol. oppofita, petiolat. fimplicia, lanceol-o. vata, acuminata, integerr. gluberr. Panicul. terminal, \& axillar. compofitæ, foliof $\mathfrak{a}$, ftricte, Cor. alba, Bacce Pifo ma: luteo-purpur.

174. PTELEA, Cal. (parvus) 4-part, inferus. Pet. fape 4raro 5. coriacea, pland. Frut. membrana fub-

I. trifoliata, P. fol. ternatis. Syft. veg. ed, i4. Trew. rar. tab. 9. Miller. ic. tab. 211 . Du-Hanuel. arbr. tab. 43. Frutex \&c, Dill. elth, $t a b, 122$. f. 148. In Virginia $b$.

Frutex oryyal, ramis patulis. Foliol, ovat-lanc. medio ma: Fl. cymofi. Petala parva, dilute viridia. Var. fol. quinis.

2. pinnata, P. fol. abrupte-pinnat. $S_{y} f_{2}$, veg.ed. 14. Lin. Supplo 
Blackburnia pinnata. Furft. gen.

In infula Norfolk.

Fol. alterna, 2-3-iuga; follol. oppofitis, ovatis , obliquis, glaberrmis. Panicul. axill. parvæ .

175. HYDROPHYLAX. Cal, 4-part, Cor, infundibulif. Fruct. anceps, I-fpermuss .

I. maritima, H. Syjt. veg. ed. 14.

Ad litora maris, prope Giduluhr. 24.

Facies Arendice maritima, at maior . Radix longa, filiform. carnofa, dulcis, fanguinea. Caul. repens, filiform. articulat. vaginatus, glaber, coloratus, longiff. Foll oppotira, petiolat. patentia, adproximata, ovata, acuta, integerr. carnofa, nitida, exafperata, callis minimis, albicantibus, pellucidis. Petioli breves, membranac. Fl. axitl fubfellil. erecti, plerumq. binati, non oppofiti . Cor. pallide coerul. Anth. coerul.

r76. SIRIUM, Cal. femi-4-fid. Cor. o. Nectario 5-phyll. claudente calycen. Germ, inferum. Stigma 3-fid. Bacca 3 -locul.

I. myrtifolium. S. Syjt. veg. ed. I4.

In India Orient. b.

Arb. facie Myrti; ramis Atrictis, brachictis, paffin articulatis. Fol. oppofita, petiolat. nimplicia, 2-pollic. lato-lanceol, integerr. teaera, glabra, fubsus glatuca. Stipulæ nullæ. Fl. in thyrfum collecti, Cal. coloratus. Bacca obovat, coronata.

377. LUD- Cal. 4-part. fuperus, Cor, 4-pet, Capf, 4-gon. WIGIA. 4-locul: infera, polyfperma.

I. alternifolia. L. caul, erecto: 'fol. alternis, Ianceol. Syft. veg. ed. 14. Trew. ehr. 2, tab. 2.

Lyfimachia \&c. Pluk, aln. tab. 203. f. 2.

Frurex \&c. Pluk, amalt. tab. 412. f, I.

In Virginia $\odot$.

Caul. herbac. fæpe declinatus, teres, glaber. Fol. petiolat. integerr. glabra. Fl. lateral. axill. pedunculat, folitarii, Pet. flava, Capf, cubica, calyce minores.

2. oppofitifolia. L. caul. diffufa: fol. oppofit. lanceolat. Syjt. veg. ed. 14 .

In India 4.

Habitus Lychri hyffopifolii, Caul, fpitham. Fol. petiol, integerr. ftriata, lavia. Flos axill, fo- 
litarius, Caryophylli Offic. figura. Cor.flava, calyce brevior. Capf. fol. dimidio brevior.

3. erigata. L. caul, erecto: fol. oppofitis, lanceol, iyft. veg. ed. 14.

In India $\odot$.

Caul, herbac. pedal. brachiatus, lævis. Fol. petiolat. integerr. læuia. Pedunc. terminal, fubterni, I-fl. raro axilldr. Germina 4-gono-alata. Cal. minutı. Cor. vix confpicua. Capl. fubcubica .

trifolia.

L. fol. ternis, ovat-lanceol: fl, terminalibus, pedunculat. Burm. Ind.

In Jaya.

Radix fibrofa. Caul, erectus, fpitham. herbaceus, ftriatus, lævis. Fol. oppotita, petiolat. Pedunc. pollic. Bract. ovaræ. Fl. gemini, pedicellati .

178. RANK-Ament. fquamat. Cor. 4-pet. Anth. in cavitate SIA. Iaminarum feffiles. Capf. 2-valv. Sem. bipartibile.

I. ferrata. B. fol. linearibus, in petiol. attenuatis, æqualiter, ferratis, apice truncatis cum mucrone. Syft. veg. ed. 14. Lin. Suppl.

In nova Hollandia.

Speciofiff. fpecies huius generis, Pol, in apice ramorum coufluentia, fparfa, fpitham. patentiff. coriacea, plana, glabra, amentum cingentia. Amentum maximum, craffum, erectum, teres, obtufum. Fl. adfcendent. patentiff. laminis extus pubefcentibus, canis .

2. integrifalia. B. fol. cuneiformibus, integerr. fubrus tomentalbis. Syft. veg. ed. 14. Lin. Suppl.

In nova Hollandia.

Fol. in apice ramulorum fubverticillata.

3. Ericafulia. B. fol. adproximat, acerolis, truncato-emarginat. glabris. Syft. veg. ed. I4. Lin. Suppl.

In nova Hollandia.

Fol. huius minima, fed copiofiora.

4. dentata. B. fol. oblong. in petiolum attenuatis, curvis, flexuofis, dentatis, dentibus fpinula terminatis; fubtus albis. Syft. veg. ed, 14. Lin. Suppl.

In nova Hollandia.

Fl, huius minores. 
179. OLDEN-Cal. 4-part, fuperus. Cor. 4-pet. Capf. (fubLANDIA. globofa, coriacea) 2-locul. infera, polyfperma.

2. verticillata. O. fl. verticillat. feffilibus : ftipul, fetigeris. Syff. veg. ed. I4.

Crateogonum. Rumph. amb. 6. tab. 10.

In Amboina, Jamaica collibus apricis.

Caul. fub-ped. fimpl. articulati, teretes, læves, utrimq. fulco exarati. Fol. oppofita, feffil. angufto-lanc. acuminaca, cofta exarata, fcabra. Fl. congefti.

2. repens. O. capful, feffilibus, hifpidis: fol, lanceol. Syft. veg. ed. I4. Burm. Ind. tab. I5. f. 2.

Crufta \&c. Rumph. amb. 6. tab. 170. f. 4. Pluk. phyt. 356. f. 5 .

In India.

Caul. repens, filiform. ramofus, articulatus, ad fingula genicul. radicatus, lavis. Fol. oppofita, fubpetiol. integerr. lavia, parva. Fl. axill. folitarii, alterni, fubfeffii.

3. eapenfis. O. pedunc. axillaribus, I-fl. fol. linearibus, acutis. Syjt. veg. ed. 14. Lin. Suppl.

Ad. cap. b. Spei .

Simillima $O$. repenti, at capf. glabra.

4. unifere, O. pedunc. fimpliciff. lateralibus: fructibus hirtis : fol. fubovatis, acutis. Syft, veg. ed. I4. Alfine \&rc. Pluk. alm. tab. 74. f. 5. mala.

In Virginia, Jamaice aquofis.

Caul. repentes, ramofi, fubdivifi. Fol. oppofita, fubpetiol, integerr. Fl. pauci. Germ. hifpida.

5. biflora, O. pedunc. bifloris, petiolo longioribus; fol. lanceol. Syft. veg. ed. 14 .

Antirrhinum \&c. Burn. Zeyl. tab. II. In India $\odot$.

Caul. erectus, herbac. dichotomus, articulatus . Fol. oppofita, petiolat. bafi angufta, integerr. Fl. axill.

6. umbellate. O. umbellis nudis, lateralibus, alternis: fol. (lanceol-linearibus). Syft. veg. ed. I4. Iyfimachiæ \&c. Pluk. alm. tab. I19. f. 4. In India 24.

Habitus Ciffi Helianthemi. Radix extus alba, intus ruberrima. Caul. procumb. palmar. dichotomi. Fol. fubquaterna . Pedunc. axill, \& ter$\mathrm{X}$ iij 
minales, alterni, umbellati. Pedicell. ex fingula umbelld 2-5-6-fl.

7. hirfute. 0 . umbellis axillar. caul. calycibufa, hifpidis: fol. oyatis, acutis. Syft, veg. ed. 14. Lin. Suppl.

In Java,

Planta diffufa. Fol, oppofita, petiol, integerr. nervofa, venofa. Umbell. peduncul. paucifl.

8. corymbofa. 0 . pedunc. multill. fol. lineari lancer 1 . syjt, veg. ed. 14. Plum. ic. 212. f. 1. Ehret. piz. tab. 2. f. I.

In. Amer. merid. $\odot$.

Caul, fubproftrati, adfcendent. 4-goni, laves, ramis oppofitis. Fol. oppofira, longttudine internodiorum, lavia, linea longitudinali exarata. Stipul. oppofitz, connectentes folia, obtuffer. apice ariftis tribus. Pedunc. laterales, alterni, folit rii, filiform. audi, longitudine folii . Umbellula fub-4-fl. abfq. involuc, Cor. alba .

9.piniculata. O. pedunc. terminalibus, paniculat. fol. ovalilanceolat. Syft. veg. ed. I4.

Mollugo \&c. Burm, Zeyl, tab. 71, f. 2. Ind. tub. 15. f. 1 .

In India Orient.

Caul. erectiufc. pedal. dichotomus, lavis. Fol'. oppofita, fubpetiolat, integerr. laevia. Panicula aphylla. Fruct. læves.

10. Ariża. O. pedunc, terminulibus, racemolis: fol. linearibus: caul. erecto, brachiato. Syjt. veg. ed. I4.

Alfine \&c. Pluk. mant, tab. 332. f. 2.

In Malabaria 24.

Caul. fruticof. teres, articulatus, friatus, pedal. trichotomus. Fol. oppofita, articulis breviora; radicalia fere lanceol. Pedunc. ftricti. Capl. obovata, truncata.

pentundra. 0 . fl. pentandris, monogynis: fol, linearibus: perluncul, 2-fl. Retz. Obf. fafc. 4 .

In Tranquebaria.

Simil. O. biflore, fed maior, femiped. Caul. erectus, pibefcens. Fol. oppofira, feffil. inregerr. pubefcent. Pedunc. axill folitar. fimplic. Peral. parva, albida, cum levi rubedine. Cal. pubefc. 
digyna. O. fl. pentandris, digyuis, fefflibus: fol, lanceo1at. Reiz, Obf. fafc. 4 .

In Tranquebaria.

Facies ab Old nlandia aliena. Caul. decumbent. ramofi, Fol, fefil, integra. Fl, axillar. quandoq. breviffime peduncul. Cal, tubo globofo . Peral. minuta, alba.

trinervia. O. caul. decumben. fol. ovat, trinerviis: fl. axillar. verticillatis : capful, bifpidis, Retz. Obf. fafc: 4 .

In Tranquebaria.

Caul. depreffi, angulati, ramofi. Fol. oppofita, petiol. lato-ovata, integerr. fubpilofa. Fl.bre" viter pedicellati. Frica, didymus, 4-dentat.

tenuifolia. 0 . pedunc. $I$ fl alternis: fol. linearibus, pedunc。 longioribus, Burm, Ind. $t a b$, 14. f. 1 .

In Java .

Caul. procumb. fistham. Fol, oppofita, Pedunc. axill, breviff. Fl, albicantes.

180. AMMANNIA. Cal. i-phyll. tubulefus, plicatus, 4-8dent. inferus. Cor. 4-petala, calyci inferta, vel nulla. Capf. (fubrot.) 4-lucul.

1. Latifolia. A, fol. femiamplexic. caul.4-gono, ramis erectis . Syft. veg. ed. I4.

Aparines \&c. Slonn. hiff. 1. tab. 7. f. 4.

In Caribais, locis humidis $\odot$.

Caul. angulis obtufis, lateribus alternis, convexis. Fl, verticillat, utrimq. 3. feffil. Calyc. dentes alterni, conniventes. Cor. alba . Stylus germine brevior.

2. ramofior. A. fol. femiamplexic. caul. 4-gono: ramis patentiff. Syjt. veg. ed. I4. Bocc, Muf. tab, 104. In Virginia $\odot$.

Caul. angulis acutis, lateribus planis. Fol. lanceol-linear، bafi dilatata, rufefcentia. Fl. lateral, axillar. utrimq. 3. fubpeduncul, Cal, dentibus 8. parulis. Pet. fubror. patentia, purpur. Filam. purpur. Styl. germine longior.

3. bascifera. A. fol, fubpetiolat. capfulis calyce maioribus, coJoratis. Syft, veg, ed, 14. Burm, Ind. tab. 15. f. 3 .

Cornelia \&c. Arduin, 2.tab, t. AZ. Bonon. tab.7. Anonymos \& e., Pluk. alm, tab. 136, f. 2.?

In China, \& in Italia $\odot$.

planta erecta, digiti longirudine, tenera, ablque $\mathrm{X}$ is 
ramis. Caul. teres, rufefcens. Fol, oppofita lanceol. integerr. Cal. 4-dent. Fl. axill. verticillati, plurimi, peduncul. minimi . Capf, ru= bra, calyce maior.

4. vatandrs. A. fl. petaloideis, octandris. Syft. yeg. ed. I4. Lin. Suppl.

Ammannia coccinea. Rottb. Progr. I775.

In India Orient.

Caul. giganteus, erectus, brachiatus, lavis. Fol. oppofita, feffil-amplexicaul. lineari-lanceol. integerr, lævia. Pedunc, axill. breviff. 1-3-f. Petal. fanguinea.

4. pirratifida. A. caulibus procumbentibus, radicantibus, compreffis: fol. linearibus, pianatifid. Syft. veg. ed. 14. Lin. Suppl.

In $J_{\text {ava }}$.

Ammenniis reliquis faile fimil. Fol. fparfa, magis adproximata, pinnis minimis, quafi filiformibas. Fl. axill. parvi, folitar. vel pl. Cor, incarnata.

181. ISNARDIA . Cal. campanulat. 4-fid. Cor. o. Capful, 4locul. cincta calyce, polyfper.

X. paluftris, I. Syft. veg. ed, I4. Zann. tab. 67.

Dantia \&c. Petit. ger. tab. 49.

Glaux \&c. Boce. Muf. tab. 84. fo 2.

Alfine \&x. Lind. alfat. tab. 2.

In Italia, Gallia, America Ec. ad lacus, fod as 24.

Simil. Pepli portulizer; repens, natans. Caul. procumb. palmar. ex viridi ruber. Fol. oppofita, ovalia, integerr. quandoq. rubentia. Fl, axill. oppofiti, fefil. virides .

182. TRAPA. Cal, 4-part. Cor. 4-pet. Nux ovata, fpinis 4. oppofitis cincta; qua calyc. fol, fuere.

I. bieornis. T. nucibus bicornibus. Syjt. veg. ed. 14. Iin, Suppl. Plum. ic. $t a b, 67$. fol. infina.

In Chine aquis.

2. natans. T. nucibus quadricornibus : fpinis patentibus . Syft. veg. ed. 14.

panover \&c. Hort. Mal. I1. tab. 33.

Tribulus aquaticus. Cam. eqit. 715. Matiho

In Europe, Afire fagnis $\odot$.

Radix longa, fibrofa. Caul. fubmerfus longe per aquas repens. Fol. immerfa multifido-capillacea, Myriophylli; natantia rhombara, crenata, 
fupra glabra, fubtus rugofa. Petala alba, exigua. Germen cinguni calyc. fol. 4. duobus ad laterd, duobus ad angulos germinis, unde cornua fructus, qui primum cinereus, dein niger.

783. DORSTENIA. Receptacul. commune I-phyll. carnofum, in quo fem. folitaria nidulantur.

Fl. adgregati . Invulucr. mngnum, angulatum . Flos 1-petal. anomal. carnofus, pedem anjerinum referens. Fruat. eiufdem forma.

7. Houfon? D. fcapis radicatis: fol. cordatis, angulatis, acutis: receptacul. quadrangulis. Syft. veg. ed. 14. Houft. AZ. Angl.

In Campechia 24.

2. Contrajer-D. fcapis radicatis : fol, pinnatif-palmat. ferratis: va. receptacul. quadrangul. Syft. veg.ed. 14. Black. tab. 579. Houft. Act. angl. f. 1. Plum. ic. IIg.

Drakena radix. Cluf. exot. 83.

In mova Hifpania, Mexico \&c. 44.

Radx infar Cyperi tuberculofa, \& nodora. Fol. radival. petiolat, in 7 . lobos acuminatos, \& ferratos divifa.

3. Drakene. D. fcapis radicatis: fol. pinnatif-palm, integerra recepraculis ovalibus. Syft. yeg. ed. 14 .

In vera cruce 24.

4. eculefcens. D. pedunc. caulinis. Syft. veg. ed. 14.

Parietaria \&c. Plum. ic. 120. f. 1.

In Amer. meric. 24.

Planta humilis. Caul. fimpl. Fol. oppofita, lon. ge petiolat. finuata, denticul. Fl. pedunculati, in placentam colle eti.

184. COMETES. Invol. 4-phyll. 3-fl. Cal, 4-phyll. Capf. 3cocca.

1. elterniflora, C. Syft. veg. ed. I4. Burm. Ind. tab. Is. f. 5. Clinopodium \&c. Pluk, alm, tab.,380. f. $4 . ?$ quod fl. feffilibus differt.

In Surette $\odot$.

Caul. ped. herbac. Fol. oppofita, feffil. obovata, acumin. integerr. glabra. Pedunc. axill. alterni, (alterius alæ) folitarii, I-fl, patuli, longitudine fol. Involuc. foliola hifpida. Petal, 4 oblonga , obtufa, erectiufc.

185. NIGRINA. Cal o. Cor. 4 pet. Capfula.

I. Spicata. N. Syft, veg. ed. I4. Thumb. Jap. In Jeponia. 
Caul. erectiufc. herbac. palmar. \& ultra, teres, fubfucculentus, glaber. Fol. fefquipollic. oppofita, breviter petiol. ovat-oblong. obtufa, ferrata, glabra, fupra viridia, fubtus pallida. FI. fpica axillar. compofita fpiculis alternis, floful. oppofitis. Bractea fub fingulo flore ovata, acuta.

Planta ficcatione nigrefoit.

186. ELFAGNUS. Cal, 4-fid, campanul. fuperus, interne coloratus. Cor. nulla. Drupa intra calyc. (ovata, glabra) I-locul. I-fperm.

I. anguftifo- E. inermis; fol. lanceol. Syft. veg. ed. I4. Dulia. Ham. arbr. I. tab. 39. Hort. Angl. tah. 19. In Bohemia, Hifprnia, Augufte Pretcrix sc. $\hbar$. Arbor mediocris magnitud. cortice albicante. Rami patuli. Fol. alterna, fefcuncem longa, unciam fere lata, \& anguítiora, breviter petiol. modice obrufa, albentia, præcipue fubtus. Fl. axill. parvi, lutei, argenteo col. nitentes, odori. Bacuæ parvæ, oblong.

2. orientalis. E. inermis; fol. ovatis, oblong. opacis. Syft. veg. ed. I4.

In Oriente $\hbar$.

Facies prioris, fed fol. duplo latiora, utrimq. tactu mollia, fubtus pallida, fed neutra pdgina nitentia, aut argentea.

3. Latifolia. E. inermis; fol, ovatis. Syft. veg. ed. 14. Burm. Zeyl. tab. 39. f. 2 .

In Zeylona $b^{5}$.

Fol. ovato-fubrotunda .

4. crifpa. E. inermis; fol. lanceol-oblong. obtufis, undulatis: fl. folitariis. Syft. veg. ed. 14. Thumb. Jap.

In Japonia 5 .

Arb. ramis, \& ramulis erectis, alternis, divaricatis, teretibus; punctato-fcabris, cinereis. Ramuli ultimi angulari, albidi. Fol. fefquipollic. alterna, petiolat. erecto-patula, integerr. fupra nuda, fufcentia, punctata, fulco medio longirudinali, fubtus argentea. Fl. in ultimis ramulis fparfi, peduncul.

5.multiflora, E, inermis; fol. obovat. obtufis: fl, axillaribus, adgregatis: peduncul. flore longioribus. Syft. veg. ed. 14. Thumb. Jap.

In Japonia b. 
Caul, fruticofus, parum ramofus. Rami, \& ramuli alterni, rari, patentes, teretes, punctato-fcabri, fulco-ferrugin. Fol. e fingula gemma plura, inæçual. fubpollic. alterna, petiol. erect?, integerr. fupra punctis fquamofis, argenteis, fubrus tora fquamofo-argented. Fl. inter fol. pl. peduncul. Pedunc. fubpollic. laxi, argentei. Calyx cldvatus, oblong.

6. umbelluta. E. inermis; fol. obovatis, obrufis: fl. axillar. adgreg tis: peduncul. flore brevioribus. $S, f$. veg. ed. 14. Thumb. Jup, tab. I4.

In Japonia $\overline{\mathrm{D}}$.

Adfinis priori. Caul. fruticofus. Rami, \& ramuli erecti, alterni, teretes, punctaro fabii, ferrugineo-fufcefc. Fol. e gemmis alternis plura, unguicul. periol. parala, fupra nudiufe. punctis argenteis, fubrus tota argentea. Fl. inter fol. pl. fubumbellati, cernui .

7. glabra. E. inermis; fol, ovat-ublong. acuminat. fl. axillaribus, fubfolitar. Syfi. veg. ed. 14, Thumb. Jap.

In Japunia $\hbar$.

Arbor. Rani fubteretes, nudiufc. fufci . Ramuli er cto-patuli, alterni, angulati, punctaro-fcabri, cinereo-rufefcent. Fol. fefquipollic. alterna, petiolat, putenti-erecta, integerr. fupra virid. glabra, fubtus rufefcenti-fquamofa, interfparfis punctis ferrugin. Fl, ereeti, peduncul.

8. Spinofa. E. fol, ellipticis: bafi ramulorum fpinola. Syft. veg. ed. 14. Med. abf. Soc, cecort. Lutr. 177ta p. 196.

In A gypto $\hbar$.

Fol. dimidio breviora, fed non anguftiora $E$. angu ifol. $F$ l. quadruplo min.

9. pungens, E. ramulis fpinefcentibus: fol. oblong. undulat. fl. axill, fubbiais. Syfi, veg. ed, i4. Thumb. Jap.

Akin-gomi . Kampf. am. ex. Fafc. V. p. $7^{89}$. In Japoria b.

Arbon orgyal. erectus, ramofus, fcaber, fufcus . Rami patent. teretes, flexuofi, aphylli. Fol. pollic. alterna, periolat. reflexo-patentid, obtufiufc: integerr. rigida, fupra viridia, g/abra, fubtus fquamofo-argentea, interfparfis punstis ferrugineis. Fl, diflincti, erecti. Dif- 
fert ab $E$. Spinofa-ramul, fpinefcentibus: fol. oblong: latioribus : fl. ma:

mecrophylla . E. inermis; fol, rotundato-ovat. argenteis . Thumb. Jap.

Fon-Gomi. Kamf. am. exot. Fafc. V. p. 789 . In Japonia $\mathrm{b}$.

Arb. erecta . Rami erecti, teretes, friati, ruberculati, ramulis deciduis, punctato-fcabri, cinerei. Ramuli alterni, angulati. Fol. pollic. alterna, petiolat. integerr. erecto-patula, fupra glabra, virid. fubtus argentea. Fl, axill. adgregati, fuberecti, pedunculati .

Differt ab E. orientali cui fol. ovat-oblong.-fol. rotund ito-ovat. fubtus argenteis. $\mathrm{Ab} \mathrm{E}$. latifolia-fol. magis rotundatis; ramulis inermibus, nec fpinefcentibus.

187. GONO-Cor. 4-fida. Drupa fubglobora, 8-gona, ICARPUS. fperm.

I. micranthus. G. Syft, veg. ed. I4. Thumb. Jap. tab. I5.

In Japonia $\odot$.

Radix fibrofa. Caul. folitar. vel pl, vix fpitham. 4-gonus, bafi decumbens, apice erectiufcul. fuperne ramofus. Fol. lineam longa, oppofita, breviffime petiol. patentia, ovata, acuta, ferrata, glabra. Fl. ramei, fpicati, remoti, minuti, fubfecundi, cernui .

I88. SANTA-Cal. 4-dent. Cor. 4-petala; petalis calyci innatis,

LUM .

r. album, præter glandulas 4, Bacca infera, I-fperma .

S. Syft. veg. ed. I4. Breyn. ic, tab. 5. f. I. Rumph, amb. 2. tab. II.

In India $\hbar$.

Arb. altitudinis Juglandis, Rami ramofi. Fol. impari-pinnata. Foliol. oppofita, petiolat. 0vat-obl. integerr: iuniora viridia; adulta fublutea. Cor. ccerul-nigricans . Bacca Lauriform. matura e coerul-nigra.

I89. STRU- (Cai. 2-phyll. tubulofus, lacin. acutis, comTHIOLA. preffis, carinatis. Nect. 8. antheriform. fingulo bafi corona fetarum circumdato, faucis margini impofita. Bacca exfucca, I-fper.)

I. virgate, S. pubefcens. Syft. veg. ed. I4.

Thymelæa \&c. Burm. Afric, tab. 47, f. I. Jed fol. breviora.

Ad cap. b. Spei b. 
Frutex ramis longis, fimplicibus, virgatis, fubvillofis, ramul. 4-gonis. Fol. oppoita, lanceol. acumin. ftriata, canaliçulata, margine ciliato-barbata. Fl, axill. folitar. feffll longigitudine folii, rubri, extus tomentofo-fericei. Var. fl. flavefcen.

2. ereส̄a, S. glabra. Syft. veg. ed. I4.

Pafferina \&c. Burm. Afric. tab. 47.

Ad cap. b. Spei $b$.

Planta glabra. Caul. ped. \& ultra, fruticof. erectiufc. ramofus, cinereus. Rami fimpl. adgregati, corymbofi. Fol. fparfa, feffil. imbricata, lanceol-fubulata, obtufiufc. 2. circiter lineas longa. Fl. lateral. axill, folitarii, feffiles. Cor. alba .

3. nane. S. fol. linearibus, obtufis, pilofis: fl. terminalibus, fafciculatis, tomentofis. Sy ft. veg. ed. 14. Lin. Suppl.

Ad cap. b. Spei b.

Bracteæ cœrulefcent.

lanceolata. S. fol, ovato-lanc. corollifq. nudis: calycibus pubefcent. Retz. Obf. fafc. 3 .

Rami ftricti, teretes, nudi; ramulis 4 -gon. Fol. integerr. coriacea, patula. Fl. in apice ramorum oppofite congefti, bracteati . Cor, tubo - longo; limbo lineari-rufefcente .

juniperina. S. fol. linearibus, acutis, patentibus: cor. calycibufq. nudis. Retr. Obf. fafc. 3 .

Fruticulus totus glaber. Rami tenues, teretes, ramulis 4-gon. Fol. patentia. Fl. a media ramulorum parte ad apicem fere intra bracteas foliis fimiles, oppofitas, feffil. Cal. glaber. Cor. glabra, alba, laciniis acutis.

I9o. MA- Cal. 8-phyll. Cor. 4-fid. Capf. infera, 2-valv. NETTIA. I-locul. Sem. imbricata, orbiculata, feminulo centrali.

I. reclinate. M. Syft. veg. ed. I4.

In Mexico $\odot$.

Caul, reclinatus, herbac. debilis, ramofus. Fol. adproximata, oppofita, petiol. ovata, acuta, fubciliata, fubtus pubefcent. femipollicar. Petioli breviff. hirfuti. Stipul. oppofitæ, petiolis adnatæ, adpreffæ, femicurcul. brevifí. Pedunc, axill, folitar, foliis breviores, multift. 
pedicell. oppofitis, teretibus, hirfutis. Bracted ad lingulum pedicellum minura, acuta. Cor. alba.

Ad hoc genus fpeczat Naciber. Aubl. Guian. T. 37.

19r. KRA- Cal. o. Cor. 4-pet. (Peial. oblong. patentia). MERIA. Nectario fuper. 3-part. infer, 2-phyllo. Bdc. ca (globofa) ficca, echinata, I-fperm.

1. ixina. K. Syft. veg. ed, 14. Loefl. it. 195. In Cumana America $\hbar$.

Planta fufco-cana. Caul. fruticofi, inferne procumbentes, undique fparfi. Fol. alterna, fubfeffil, Janceol., fuperiora linearia, acuta . Racemus terminalis fl. alternis, cuin binis bracteolis. Cor. rofea-purpur. Nectar. fuperius apice pallidum; inferius nigro-purpur.

192. HARTO-Cal. 5-fid. Cor. 4-pet. pateus. Drupa ovata, GIA . 2-fperma

1. capenfis. Syyt. veg. ed. 14. Lin. Suppl, Ad cap. b. Spei b.

Arbor. Fol. oblonga, obtufa, ferrața, glabra . Fl, axill. minuri, pedunculati.

193. ACFANA. Cal. 4-phyll. Cor. 4-petala. Bacca (obovara), ficca, infera, I-fperma, retrorfum echinata. I. elongata. A. Sy f., veg. ed. 14.

In Mexico b.

Kramerix adjinis. Caul. pl, lignofi, erectiufc. 2-ped. ramofiff. ramis longiff. Fol. pinuata, fparfa, vaginant. foliola adproximata, feffil. fubtus pubefcentia; paribus primum minimis, linearibus, acutis, integerrimis; paribus 48 . ma: oblongis, ferratis, ferraturis apice barbaris. Spicæa axilar, ancipites, erecte, rigidulæ, fpithameæ. Bract. propriæ ovat-oblon. concava. Fl. fubfeffil. alterni.

194. RIVINA. Cal. o. Cor. 4-pet. periftens. Baçca (globofa) I-fperma. Sem. Jentiforme, fcabrum.

I. humilis.

$R$. racemis frmplicibus: $\mathrm{fl}$. tetrandris: fol, pubefcentibus. Syft. veg. ed. 14.

Amaranthus \&c. Comm. hart. I, tab. 66.

Solanum \&c. Pluk, almz, tab. 112. f, 2.

In Caribais \&c. 4.

Caul. pedal. Fol, alterna, brevibus petiol. purpurafc. innixa, ovata, acumin. Jæte virentia . Racemi infer, nudi, axillar. Pet, alba. Baccæ 
puniceæ, magnitudine baccarum Sumbuci, dulces. Sem. fubnigricant.

2. lavis, R. racemis fimplicibus: fl, tetrandris: fol, glabris. Syjr. veg. ed, I4. Pluk. phyt. tab. I5I. f. 3 .

In Ainerica $b$.

Priori nimis adfinis, fed tota glabra. Fol. margine purpurafe. Fl. extus rubicundi .

3. oftundra. R. racemis fimplicihus, fl. ottandris, dodecandrifve. Sylt. veg. ed. I4. Jacq. obf. Is tab. z. edit. 2. picis tab.21. Plum, ic. tab.241. Brown. Jam. tab. 23. f. 2 .

In Amer. calidiore $\hbar$.

Arb. 20-ped. ramofiff. farmentofa, ramis longiff, Fol. multa, alterna, petiolat. lanceol-ovata, acuminata, integerr. glabra, quandoq. fermipedal. Racemi terminal. laxi, raro axillar. Cal, in $\mathrm{fl}$. albus; in fructu ex purpuro-faturate rubens. Baccd, atro-purpur. Sem, nigricans .

4. paniculata. R. panicula racemis compofitis, oppofitifq. $S_{y f t .}$ veg. ed. 14.

Salvadora perfica. Syft. veg.ed.14. monente Vahl. 195. EMBO-Cor. 4-pet, Anth. feffil, apicibus petalorum inftTHRIUM. dentes, Follicul. teres.

I. umbellatum. E, umbellis axillar. fimpliciff. pedunculatis: fol. oblong: aveniis; anth. feffilibus. Syjt. veg. ed, 14. Korft. gen.

In nova Caledonia $\hbar$.

Frutex pulcher. Fl, min, rubicundi.

2. coccineum, E. thyrfis terminalibus, feffilibus: fol. obopatis, venofis: antheris pedicellatis. $S_{y j} L_{0}$ veg. ed. I4. Forft. gen.

In terra del Fuego $\hbar$.

Fl. maior. purpurei .

196. SALVA-Cal. 4-fid: laciniis revolutis. Cor. o. Bacca I-

DORA. fperm. Sem. rotundum, arillo veftitum.

1. perfica, S. Sylt. veg. ed. 14. AC. Angl. 1749. n. 49r. Ad finum Perjicum, in India Or. 5 .

Frutex fol. oppofitis. Racemus terminalis, compofitus.

Videtur eadem planta ac Rivina paniculata. Vahl.

197. CAM- Cal. urceolat. dentibus 2. oppofitis; alternifq. PHOROSMA. minimis, reflexis. Cor. o. Capf. I-fperm. (calyce obvoluta).

I. monfpeliaca, C. fol. linearibus, hirfutis. Syft. veg, ed. I4. 
Buxb. cant. I, tab. 28. f. I. Gmel. Sib. 3. tab. 22. Bauh. hift. 3. p. 379.

In Hifpanice, Tartarix Ec. arenofis 4.

Caul. pedal, fruticof. fubvillofus, albefcens . Fol. alterna, feftlia, odore Camphora.

2. ceuts. C. fol, fubulatis, rigidis, glabis. Syft. veg. ed. 14.

Anthyllis \&c. Lab. ic. 404. Dalech. hift. IIso.

In Italia, Tartaria 4.

3. glabra. C. fol. fubtriquetris, glabris, inermibus. Syft. veg. ed. 14. Dalech. hilt. 1179.

In Helvetia 4.

Caul. humifufi, cubital, ramofi, Fl, axill. feffiles.

4. Pteranthus. C. ramofiff. pedunculis enfiformibus, dilatatis: bract. criftatis. Syft. veg. ed. I4.

Pteranthus. Forsk. Ag. monente. Vahl.

In Arabia $\odot$.

Radix fibrofa. Caul, palm. herbac, articulatus, 2-3-chotomus. Fol. linear. fubramofa, rerefiufc. verticillata; 2 . inferioribus paulo maioribus. Fl. parvi, lubfeffl. virides, cinci membrana 2-fid. breviff.

5. paleacee. C. fruticofa ; ramis fpicaformibus, paleaceis, pilofis. Syft. veg. ed. 14. Lin, Suppl.

Ad cup. b. Spei 5 .

Frutex vix pedal. determinate ramofus. Rami foliis, floribufque imbticatim mixti. Paleæ membranac. minutæ, albæ. Fol. minuta, feffil. elliptica, lrevia. Pet l. breviff obtufa, ciliara.

398. ALCHEMILLA. Cal, 8-fid. Cor. O. Sem. 1. (calyce tectum ).

3. vulgaris. A. fol. lobatis. Syft. veg. ed. 14. Black. tab.72, Ludw. eą, tab. 176. Knorr. del. hort, tab. A. 9. Fl. Dan. tab. 693. Garid. Aix, tab. 4. In Europa pafcuis 24.

Fol. feptemlobata, ferrata ; infer. longe petiol., fuperiora breviter \& fubreniform. Stipul, foliacea. Var. birfutie, cujus fol. ultra mediun in lobos feara.

2. alpine. A. fol, digitat. ferratis, fericeis. Syft. veg. ed. I4. Fl. Dan. tab. 49. Marif. hif. 2. f. 2, tab. 20. f. 3. Barr. ic. 27 . n. II. Pluk. phyt, tab. 240 . f. 2, hybrida.

In alpibus Europa 4.

Fol. ovata, lobis 5-7-9. Stipul, membranac. integerr. 
3. aphanoides. A. caul, erecto: fol. multipart. Syft. veg. ed. I4. Lin. Suppl.

In nova Granata $\odot$.

Caul. fpitham. fubramofi, teretes, pubefc. Fol. Aphanis fimillima, nuda; radical. petiol., reliqua amplexicaulia. Racemi terminal. fubverticill.

4. pentaphyl-A. fol. quinatis, multifid, glabis. Syfo, veg. ed. leR. 14. Bocc. muf. I. $t a b$. I. In Helvetia E"c. montibus 24. Habitus humilior, vix femiped. totus glaber. Lobi in pl, minores divifi.

\section{I G Y N I A.}

199. GALOPINA. CAl. o, Cor. 4-fid. Sem. 2. nuda. a. circasides. G. Syft. veg. ed. 14. Thumb. dif. nov. gen. 200. APHANES. Cal. 8-fid. Cor. o. Sem. 2. calyce inclufa. Ab Alchemilla differt fl. axillar. feffilibus; caterum habitu convenit.

x. arvenfis, A. Syft. veg. ed. I4.

Alchemilla \&c. Morif. hift. 2. tab. 20. f. 4. Petiv. tab. 9. Col. ecphr. tab. 146.

In Europa, \& Orientis arvis, inter fegetes 9 .

Caul. palm. Fol. parva, alterna, fæep 3-fida, laciniis 3-fid. Stipul. ferratæ, magnitudine fol. Fl. fafcicul. herbacei. Var. pift. \& fem. I.

201. CRUZITA. 'Cal. 4-phyll. exterior 3-phyll, Cor, D. Sem. I.

I. hifpanica. C. Syft. veg. ed. 14. Loefl, it. 203.

In Cumana America $\odot$.

Caul. erectus, 4-pedal. fuperne brachiatus, ramis erectis, cppofitis. Fol. oppofita, lanceol. integerr, fufca. Fl. in paniculam collecti, minimi.

202. BUFONIA. Cal. 4-phyll. perfiltens, foliol. alternis minoribus. Petal. 4. calyce breviora, anguita. Capi. I-los. 2-fperma.

I. tenuifolia. B. Syft. veg. ed. I4. Magn, monfpel. tab.97. hort. tab. I5.

Alfine \&c. Pluk, alm. tab. 7j, f. 3. In Anglia, Gallie, Hifpenia, Italia $\odot_{\dot{Y}}$
Tom, I. 
Caul. erectus, fubped. bafi plerumq. ramofus; ramis diffufis, procumbentibus ; genicul. tumentibus, inferne crebrioribus, tandem rarioribus.

Fol. lineari-fetacea, fenfim anguftiora, integerr. glabra: inferior. internodiis aqualia, vel longiora, bafi connata, fubvaginant, vagina bre. vi, fubventricofa. Fl. axillar. \& lateral. fefil. terminal. peduncul. recti, ramis adpreffi, fpicas filifor. raras formuntes. Pet, anguita, calyce min. membranac. diaphana. Capf, ovata plana.

203. HAMAMELIS. Involuc. 3-phyll. Cal, proprius 4-phyll, Per. 4. longilf. inear. Nux 2-corn, 2-lowul.

3. virginica, H. Sylt.veg. eat. I4. Catesb, Car.3, tab.2. Duham. $a r b r$. I. $t a b$, 114 .

In Virginia $\mathrm{b}$.

Frutex furcuils, \& folonibus Corylo fimilibus . Fol. alterna, petiol. ovata, crenata. Pedunc. 3-fl. Nect. ex 4 foliol. trunsatis, ad ungues petalorum, minimis. Nux globularis, fuperne cum 2. fulcis cruciarim, \& in 4. cufpides ob. tufos fecta. Nucleus ovet-obl. nitidus. Floret Autumno, inf quente vere fem. perficit.

204. CUSCUTA. Cal. \& Cor. 4-5-fida. Squanæ nectariferæ fi. fegmentis incerpofira. Stam, 4-5. "Capf. ( fubrotunda, cornofa) 2-locul. (3-4. fperma). Planra parafitica, aphylla. Fl. in glomeres congelti.

I. europea. C. fl, feffilibus, Syft. veg. ed, 14, Fl. Dan, tab. 199. Black. tab. 554 .

Epitumo Matth.

In Eutopa pratis collium ().

Caul. volubil. ruber. Fol, albo-rubefcent. Fruet. rubri .

2. epithymum, C. fl. fefflibus, 5-fid. bracteis obvallatis. Syft.veg. ed. 14. Loefl. it. 216. Fl. Dan, tab, 427.

Habitat in iifiem locis.

Minor priore.

3. americana. C. fl. pedunculat. Sygt. veg. ed. I4. Sloan. Jamt, I. $t_{2} b .128, \mathrm{f}, 4$.

In Virginia fruticibus.

Planta ramolif. tenera, fubflavefcens, nitida. Pedunc: comm. breviff. Fl. parvi, flavefc, vel virentes. Sem. I-2-3. 
furinamenfis , C. Schilling. de Lepra tab. 2.

In Surinam.

Planta parafitica, aptylla. Caulicul. lusuriat, \& molnplicatis in immenfum filamentis fuis involvit plurimas arbores, frutices, herbas. Flosculorum fafciculos undiq. pandit; mire prolifera.

205. HXPECOUM . Cal, 2-phyll. Per. 4. exterioribus 2, latioribus, 3-fid. Erust, Siliqua.

I. procum- H. filiquis arcuatis, comprellis, articulat. Syft. bens.

veg. ed. 14. Dout. peme. 499.

Mnemofilla. Forsk. AEg. manerite Vahl.

Inter Narbona ơc. fegetes $\odot$.

Caul, fpithain. fimpl. Fol, radieal. compofita ex foliol. alternis, laciniatis, laciniis alternis, acuminat, terminali 3 -fida. Fl. terminal. breviffmi, pedunculati. Cor. citrina: petal. 2. interiora, in lobis externis, nigris brevibus friis maculata.

2. pendulum. H. filiquis cernuis, teretibus, cylindric. Syft. veg. ed. 14 .

Cuminum \&c. Daleck, hift. 698.

In Gallo provincis, Sibiria 0 .

Caul. ramofi. Fol, longiora, anguftiora, tenuius divifa, glauca. Fl. axill. flavi.

3. creâtum. H. filiquis ereclis, teretibus, torulofis, $S y /$, veg. ed. 14. Amm, rush, tab, 9 .

In Danuria.

Stam, videntur tetradynama.

206. GOMOZIA. Cal. o. Cor. camparul, 4-fid. fupera. Bacca 2-locul.

I. grariatenfis. G. Syft. veg. ed. I4. Lin. Suppl.

In Amer. merid.

Caul, diffufi, herbac. Ipitham, ramis brevioribus oppofitis. Fol. oppofita, petiol. orbicul-cordata, obtufiufc. integerr. lavia. F1, terminal. minuti, folitar, feffit. pallidi.

\section{TE TR A G Y I A.}

207. ILEX. CAl. 4-dent. Cor. rotata, 4fida . Styl. o. Stigm. 4. Baccs 4-fperma. 
I. Aquifo- I. fol. ovatis, acutis, fpinofis. Syft. veg. ed. Is, lium, Fl. Dan. tab. 508. Black. tab. 305. Matth.

In Europa, Japonis, Virginia b.

Frutex fempervirens. Fol. alterna, petiol. Lauriform. viridiff. plerumque undulata, nitida. Fl ax ll. glomerati, abi. Bacca rubra, quandoq. lutea. Var. foltor. pagina Super. echinata: \& altere fol. inferioribus tantum aculeatis.

2. Calfine, I. fol. ovat-lanceol. ferratis. Sy/t. veg. ed. I4.

Aquifolium \&c. Catesb. car. 1. tab. 31.

In Curolina $b$.

Planta 16-ped ramis erectis. Fol, longiora, diluriora, ine mia. Baciæ rubræ.

3. afiatica. I. fol. Lato-lancecl. obtulis, integerr. Syft. veg. ed. 14.

In India Ajia $\hbar$.

4. integre. 1. fol. obl-abiufis, integris: peduncul. I-fl. Syft. veg. ed. I4. Thumb. Jap.

In Japonia $\hbar$.

Caul. fruticofus, erectus. Rami, \& ramuli alterni, patentes, angulati, fufci. Fol. pollic. alterna, petiol. margine parum reflexo, fupra virid. fubtus pallida. Fl. axill. umbellati, umbel. feffli. Pedunc. femiunguic. fubquaterni, erecti, angulati, $\mathbf{I}-\mathrm{fl}$.

3. rotunda. I. fol. rotundato-ovat-acutis, integris: pedunc. umbelliferis. Syft. veg. ed. 14. Thumb. Jap.

In Japonia b.

Caul. fruticofus. Rami fubumbellati, nodulofi . Fol. verfus apicem ramulorum fparfa, frequentia, fefquipoll. petiolat. glabra, fubrus pallidiora. F1. axillar.

6. erenata, I. fol. ovatis, crenatis: pedunc. rameis fparfis, fub 3-fl. Syft. veg. ed, 14. Thumb. Jap.

In Japonia $\hbar$.

Cdul. erectus, fruticofus. Rami, \& ramuli patuli, fubteretes, nodulofi. Fol. fparfa, unguicul. breviter petiol, obtufa, margine reflexo, fupra viridia, fubtus pallida.

7. emargina- I. fol. obovatis, emarginatis: fl. axill, binis. ta. Syft. veg. ed. 14. Thumb. Jap.

In Juponia $\hbar$.

Caul. fruticofus . Rami flexuofi, ramulofi, reretes, glabri, cinerei. Ful. alrerna, breviff. petiol. obtufa, crenata, margine revoluto, fem- 
pervirent. fupra virid. fulco longitudinali, fubtus pallida, carina media elevata. Fl. axill. peduncul. bini, raro folitar.

8. ferrata. I, fol. ovatis, acutis, ciliato-ferratis: fl. axill. folitariis. Syjt. veg. ed. I4. Thumb. Jap.

In Japonia $\mathrm{E}$.

Caul. erectus, fruticofus, ramofifin. Rami teretes, læves, glabri, cinerei . Ramuli patuli, filifurm. Fol, femipollic. alterna, petiolat. patentia, tenuia, fupra virid, fubrus pallida. Fl. pedunculati.

9. japonica. I. fol. oppofitis, feffilibus: fl. terminalibus, racemoiss. Sy/t, veg. ed. I4. Thumb. Jap.

In Japonia $\mathrm{b}$.

Caul. humilis, fruticofus, glaber. Fol. fefquipolíc. dentato-fpinofa, globra. Racemi digital. bracteati. Pet. obovara, integra, alba .

50, latifolia. I. fol. ovatis, ferratis: fl. dxill, adgregatis. Syft. veg. ed. 14. Thumb. Jap.

In Japoria $\$$.

Caul, arborefc. Rami angulati, rigidi, fufci . Fol. 3. pollic. longa, 2. lata, alterna, petiolata, obrufiufc. margine reflexo, patentia, fupra nitida, fubtus pallida. Petioli fufci. Fl. fupraxill. pedunculati.

auneifolia. I. fol. cuneiformibus, tricufpidat. Syft. veg. ed. I4. Plum, ic, n18. f. 2.

In Amer. meridion. $\hbar$.

Fol. alterna, feffil, tribus angulis acutis, fpinulofis rigida.

308. COLDENIA. Cal, 4 phyll. Cor. infundibulif. (4-fid. laciniis obtufis). Styli 4. Sem. 2, bilocul. (angulato-fcabra, ftylis roftrata ).

3. procumbens. C. Syjt. veg. ed. 14.

Teucrii \&c. Pluk, alm, tab. 64. fo 6。

In India $\odot$.

Planta depreffa, ramis alternis, diffufis, confertis, fpitham. pilofis. Caul. lignofi, tomentofi. Fol. unciam longa, femuncem lata, alterna, petiolat. obovata, latere fuperiore fublunata, plicata fecundum ferraturas profundas, tomentofa. Fl. lateral. feffiles.

209. POTAMOGETON. Cal. o. Pet. 4 . ovat, decidua. Styl. nullus. Germ, 4. Sem, 4, nuda. 
S. natens. P. fol, oblongo-oyat, petiolat, natantibus. Syfe. reg. ed, 14. Fuchs. p. 651.

In Europe lacubus \& fluvils 24.

Cauli ramofas, articulatus. Fol. firma, integerr. nervis ellipticis: vagina maxinæ. Fol, fubmería graminea. Spica floralis axillar. longa, denfa, gracilis. Var. fol, lunceol-oblang.

2. perfolia- 2. fol. amplexic ulibus, cordatis. Sy/t, veg. ed. sum. 14. Fl. Dan. tab. 196. Loef. pruff. tab. 65. In Europe lacubus, flaviifg. argillojis 4.

Fol. tenuia, pellucisda, apice ten iter denticun lato, nervola, undulata. Vaginæe nulla, dut breves. Spica brevis, craffa .

3. denfum. P. ful. oppolitis, confertis, fovatis, acuminatis: caulibus dichotomis: filia 4-fl, Syft. weg. ed. 14.

Fontinalis \&rc. Buth, hi.j. 3. p. 769 .

Tribulus aquaticus \&c, Cluf, bift. 252.

In Gallia, Italia 24.

Fol. latiufcula, iuxrd nervum plicata, ut anguftiora videantur : in fumma planta congefta, imbricata. Spica exigua, rotunda, 4 -f. $\mathrm{Pe}-$ dunc. e dichotomia caul. breviff.

4. Iueans. P. fol, lanceol, planis, in petiolos definentibus, Syft. veg, ed. 14. Fl. Dan. tab. 195.

Fontinalis \&c. Bauh. hift. 3. p. 769 .

In Europe lacubus, ftagnis, fluviis argillefis 24 . Habitus natabilis. Fol, pralonga, undulata, pellucida, raro ovata ; fuper. longe petiolat. Vagina magna, virides. Spica axill. longe peduncul.

5. crifpum. P. fol. alternis, oppofitifq. lanceol. undulatis, ferratis. Syft. veg. ed. 14 .

Fontilapathum \&cc. Lob. ic, 286.

In Europe foffis, \& rivulis 24.

Caul. comprefí, ramofi. Fol. feffil. contracta, apice fpinuloro. Vagina breves, alba. Spica paucifl.

6. Serratum. P. fol, oppofitis, lanceolat. fubundulatis. Syft. veg. ed. 14. Fl. Dan, tab. 195.

In Europx rivulis 24.

An var. prioris ? Fol. feffil, nitida. Vaginx maxima, ciliata. Pedun, curvi, laxıff. Spica cylindrica, denfæ.

7. compreffum. P. caul, compreffo : fol, linearibus, obtufis, 
Syft. veg. ed. 14. Fl. Dan。 tab. 203. Loef. pruff. tab. 66.

In Europa foffis paludofis 24.

Caul. palleis. Fol. graminea, plana, vel undulata, acute lanceol. ariftata. Vaginæ albæ. Stipul. breviff. albre. Spica paucifl. Var. fol. alternis, \& oppofitis.

8. peçinatum. P. fol. fetaceis, paralell, adproximatis, difichis. Syft. veg. ed. I4.

In Europx folfs, \& paludibus 24.

Caul. ramotiff, dichorom. fubruber. Fol. 2-unc. Pedunc. fub-Io-fl. (effil. adproximati.

4. felaceith. P. fol. oppofitis, lanceol. acuminatis. Syff. yeg. ed. 14.

In Europa foffis paludofis 24.

Fol. adproximata, plana.

Io. grami- P. fol. lineari-lanceol. alternis, fefflibus, ftipula neum. latioribus. Syft. veg. ed. 14. Fl. Dan, tab. 222. Raii. Angl. 3. tnb. 4. t. 3.

In Europe folfis, \& paliadibus 4 .

Habitus Graminis. Caul. longus, planus, Fol. longe linear. lente decrefcentia. Vagina pl. magne. Pedunc. axill. breves, rect, 6-fl.

b. Fontinalis media lucens. Bauh. hift. 3. ps 777.

21. marinum, P. fol. linearibus, alternis, diftinctis, inferne vaginantibus. Syft.weg. ed. 14 . Fl. Dan. tab. 186. Vaill. parif. tab. 32. f. 5. Boce. Sic.teb. 20. f. 5. Pluk, alm. tab. 216. f. 1 .

In Europa, ad maris litore $\odot$.

Fol, 2-unc. plana, angufta. Vaginæ ftrictre, breviter 2-fid. in orru albefcentes. Stipul. fine capillaceo. Fl. primum congefti in Spicas; dein longis, \&t nudis intervallis diffincti .

32. pufillutz. P. fol. linearibus, oppofitis, alternifq. diftinctis, bafi patentibus, caul. tereti. Syft. veg. ed. 14. Fl. Den. tab. 186. Zoef. pruf. tab. 67. Vaill. perif. tab. 32 , f. 4.

In Furop paludious (5).

Fol. multa, uncial. Caul. gracilis. Vaginæ ovatæ, \& oblongæe. Vagina ramorun longa. $\mathrm{Pe}$ dunc. axill. 3-4-fl,

haterophyllum, P. fol. fubmerfis linearibus, fefflibus; natantibus petiolat, lanceol, Schreb. Fl. Lipf. 
Differt a $P$. natante, quod longe minus, \& tenerius fit. Accedit ad P. gramineum fil. latiufe. \& rumificationibus denfe ftipatis. Ruii. Sinop. 3. tab. 4. f. 3. pro cuius varietate forte haberh potefz.

Caul. ramofiff. teres, internodiis brevibus. Fol. linear. acuta, bafi anguftota, tenera, fubdiaphana; natantia latiufcula, breviter petiolat. Stipul, intrafoliaceæ, folitarize, fol, anguftiores.

2IO. RUPPIA. In fummis ramulis prodeunt fpica, ferentes anth. 8 reniformes, feffiles. Inter has nafcuntur pedunculi 8 , tenues; finguli fubftinentes germen parvo ftigmate inftructum. Capf, acumin. alpera, 1-fperm.

1. maritima, R. Syft. veg. ed. 14. Fl. Dan. tab. 364.

Buccaferrea. Mich. gen. tab. 35.

Potamogeton. Raii Angl, tab. 6. f. ra

Fucus \&c. Lob. ic. 255.

In Europe maritimis $\odot$.

Caul. demerfus, herbac. articulatus. Fol. fimplicia, alterna, feffil. linear. Fl. 2xill. folitar. pedunculati .

2xI. SAGI- Cal. 4 phyll. Petal. 4. (patentia, calyce bre-

NA. viord). Capf. ovata, 4-locul. 4-valv. polyfperma.

Num. Fartium aliquando quinarius.

1. procumbers. S. ramis procumbentibus. Syft. veg. ed. 14. Ard. fp. 2. $t a b$. 8, f. 2 .

Alfine, Pluk. tab. 74. Seguier. ver, tab. 5. f. 3. Lind. hort, alf. tab. 8.

b. Saxifraga \&c. Vaill. parif. f. 2.

In Eurape pafcuis fterilibus, uliginofis, aridis .

Caul. 2-unc, ramofus. Fol. ima in cefpitem congefta: caulina breviora. Fol. lineari-lanceol, rigida, glabra, late virentia. Pedunc. axill, folitar. $\mathrm{I}-\mathrm{fl}$. fol. triplo longiores, erecti; fructiferi recurvi. Pet. parva, albido-virefcent: in fylvis maiora quam in agris; vel nulla.

2. apetala. S. caul. erectiufcul. pubefcente; fl. alternis, apetal. Syft. veg. ed. I4. Ard. fp. 2. tab. 8. f. I. In Italia $\odot$.

Caul fub 3-unc. filiform. dichotom. Fol. amplexicaul. lineari-lanceol. fubrus convexa, fubhirfuta, obfcure viridia. Fl, axill, Cor, 0. 
3. ereża. S. caul, erecto, fub I-fl. Syft. veg. ed. I4. Fl. Dan. $z a b .845$.

Alline \&c. Rnii Angl. 3. tab. I5. f. 4. Vaill. parif. tab. 3. f. 2 .

In Europa fterilibus, glareofis $\odot$.

Caul. 3-unc. Fol. lineari-lanc. duriora, glabra, fature virent. oppofitionibus 4-7. Pedunc. longi, nudi. Calyc. foliol. lanceol, acuminata. Cor, alba .

4. virginica. S. caul. erecto: fl. oppofitis. Syft. veg. ed. I4.

In Virginia, inter Mufcos ad margines fontium.

Caul, digital, filifor. Fol, remota, minima, fubulata, oppofira. Flos terminalis. Capf. roftrata. An huius generis?

212. TILL ÆAA. Cal. 3-4-part. Pet. 3-4. æqual. ( acuta, plana, calyce fere minora) Capf. 3-4. (oblon-acumir.), polyfperm.

I. aquatice. T. erecta, dichotoma: fol, acutis: fl. 4 -fid. $S_{y f t}$ veg. ed. 14.

Sedum \&c. Vaill. parif. tab. ro. f. 2.

In Europa inundatis $\odot$.

Planta minima, fub-pollic. Fol. oppofita, amplexicaul. 2. lin. longa, obfcure virent. Petald rofea.

2. perfulieta. T. fol. perfoliat. ovat. corymbis terminalibus . Syft. veg. ed. 14. Lin. Suppl.

Ad cap. b. Spei, in aquis.

3. eapenfis. T. fol. oblongiufcul, fl, 4-fid. Syft. veg. ed. I4 Lin. Suppl.

Ad cap. b. Spei.

Videtur var. T. aquatica. Radices copiofæ, capillar. Caul, herbac, pollic. dichotom. Fol. oppofita, fubcarnofa. Fl. folitarii, pedunculati. Petala alba.

4. mufsofa. T. procumb. fl, 3-fid. (fæpius) Syft. veg. ed, 14. Mich. gen, tab, 20.

Polygonum \&c. Bocc. Sic. tab. 29.

Sempervivum \&c. Bacc, $M u f$. tab. 22.

In Italia \&6. mufcofis.

Frudificalionis purtes terna. Caul. pl. uncial.

Fol. breviffima, verticillata, capillar. Fl. herbacei.

213. MYGIN-Cal. 4-part. (minimus). Pet. 4. (fubrot, paDA. tentif.) Drupa globofa. (Nux oyata). 
5. uragoga, M. Syf. veg. ed. I4. Jacq: am. tub. I6. ed. 2. picta tab. 22.

In Amer calidiore $\hbar$.

Frutex in litoribus arenofis 3-ped. in fylvaticis 8-ped. Eol. oyata, vel lanceol-acuta, petiol. breviff, rubentibus innixa, oppolita, interclum alterna, dimidium, vel fefquipoll. longa, tenuiffiae ferrata. Pedunc. comm. axill. oppofiti, filiform. 2-fidi, lacinia utraque 3-fid. \& 3 -Al. Fl. exigui, nitidi, atro-rubent. Fruclus Pili magnitudine, rubri.

\section{O NOG Y N I A.}

T O M EX

\section{Genus proximun Callicarpa.}

Cal. P Erian. I-phyll, 4-dent, fubventric, ur - zatilicinas zeolatum, dentibus patentibus.

Cor. Pet, 4. lineari-1anc, bafi erecta, limbo patente, cal. duplo longiore.

Nect. fquamæ 4 erectæ, fuborbicul. carnofe, retufæ, extus unifulcatæ; fingula inter petalum, \& fam. triplo brevior. filamentis .

Stam. Filam. 4. erecta, fubulata, bali connata, in tubum quadrangul. quod. Monadelphize proprium elt. Anth. eresta, lanceol, longitudine fildment,

Pift. Germ. fuperum, cylindrico-ventricolum . Styl. germine anguftior, \& triplo brevior. Stigma 1-lobum, \& capitatum.

Peric, ovale, fucco vifcido, violac. infipido; edule.

Sem. unicum, ovatum, oblong. carnofum.

glabra. T. Tol, ovatis, glabris: ftaminibus bafi conna= tis. Forsk. AEg.

In Arabia $\hbar$.

Arbor maxima, ramis teretibus. Fol. oppofita, petiol, verfus bafin craffiora, fape 2-pollic. 


\section{TETRANDRIA MONOGYNIA.}

coricea, acumin. plana, integerr. flavefcent. Pedunc. ex ultimis axillis prodeuntes, conferti, brachiati, paniculati, nudi. Fl. fpicati Cal, viridi-albefc. Rer. alba. Fructus pollic. tuberculofus .

dubia. 2 T. Jacq. lort tab. I9z.

In Africa b.

Arbufcula, Fol, inordinatim alterna, breviter petiol. oblon-acuta, utrimq: atienuata, fubdenticul. firma, glabra, inodora, faporis fubadftringent. Pedunc. I-fl. Fl. parvi, inodori. Cor. minima, 4-dent, virid. Pet. fubovar, obtufiff. plana. Fructus ghaber.

An kuius generis? idcirco dubia diąa fuit.

\section{PETASIOIDES.}

Cal. Per, I-phy'l. 4-part. licin. fubrot. obtulis, concayis, conniventibus, color tis.

Cor. 1-pet. erecta, conica, lengitudine calyo. margine 4-p r truncato, \& connivente.

Stam. Fil m 4 breviff, erecta, longitudine tubi cor. cui inferta.

Anth. er cta, acumin. 3-angul.

Piff. G.rm. fubrutun. intra calyc. corollamq. Styl. erequs, sy'indrac. longitudine cor. S:igma fimpl. cbtufum.

\section{Per.}

Sem.

Zaurifolium, P. Jacq. Amer. $p$ g. 17.

Ad cacumina montium in Domingo b.

Arbufcula inelegans. Rami pauci, teretes. Fol. s-pollic. alterna, petiol. ovat-ablong. obtufa, craffa, integerr. nitida, ad tactum pinguia, gracilia. Racemi compofiti, thyrfiform. terminal. 2-pollic. Fl. muiti, exigui, Cal. fubrubens. Cor. alba.

\section{H O M E I I A.}

Cal. Per. panvum, t-phyll. germini infidens. Tubus erectus, cylindrac. Limbus 4-fid. lacin. lanceol, acumin. planis, revoluris, tubo brevioribus.

Cor. I-pet. Tubus cylindric. Longiflum, tenuis, 
erectus. Limb. 4 -fid. lacin. lanceol. planis, in acumen fetaceum abeuntibus, patentiffimis, tubo brevioribus .

Stam. Filam. 4. breviff. erecta, fubulata, in fuper. parte tubi cor.

Anth. magna, linear. incumbentes, longitud. tubi .

Pift. Germ. parvum, oblong. 4-fid. inferum . Styl. filiform. longirud. ftaminum . Stigm. 2fid. lacin, oblong. craffuufc. patentibus .

Peric. Drupa oval. calyc. coronata .

Sem. Nux oblong. 4-fulca, 2-locul, Nuclei folitar. teretes.

Spinofi, C. Jacq. Amer. tab. 13. edit. 2. piäa tab. 17. In Cartagena fylvaticis $\hbar$.

Arb. 12-ped. tota ramofiff. \& fpinofiff. Rami horizontal. glabri. Fo! in apice ramulorum conferta, oppofita, in brevem petiolum attenuata, fubpoilic. fubovat. acura, integ rr. nitida, per venas fubrugofa. Pedunc. axill. fulitar. plerumq. 3-fl. Fl. fefquipollic. feffil, tenues, interdiu inodori, nocte fuavifimi. Cor. levi cum virore albefcens. Drupa cortex nigricat; pulpa mollis, \& albida. Nux dura .

\section{S I DEROXY L O I D E .}

Cal. Perian. minimum, I-phyll. acutum, 4-dent. germini infidens.

Cor. I-per. Tubus longus, cylindr. incurvus . limb. 4-fid. lacin. oblong. obtufis, planis, reflexis, tubo duplo brevioribus.

Stam. Filam. 4-breviff. orta infra divifuras limbi . Anth. erecta, oblonga.

Piftil. Germ, fubrot. inferum. Styl. filiform. longitudine tubi cor. Stigm. oblong. obtufum, craffiufc.

Peric.

Sem.

ferreum.

S. Jacq. Amer. tab. 75 . f. 9 . ed. 2 piäa sab. $2590^{\circ}$ f. 7. Pluk. alm. tab. 224. f. 2 .

In Sylvis mont ofis Martinica $\hbar$.

Arbor procera, ramofa. Fol. femiped. oppofita, petiolat. ovat-lanc. acuta, integerr. nitida. Pedunc. axill. breviff. faepe 3-fl. Fl. parvi, extus rofei, intus candidi. 


\section{P E T I T I A.}

Cal. Perian. I-phyll. parvum, erect. 4-dent. inferum, perfit.

Cor. I-pet. Tubus erect. cylindrac-longus . Limb. 4-fid. lacin. ovatis, acut. planis, reflexis.

Stam. Filam. 4. breviff. fubulata, in fuper. parte tubi. Anth. erectæ.

Pijt. Germ. parvum, fubrot. Styl. erect, fubulat. longitud. ftaminum. Stigma fimpl.

Peric. Drupa fubrot.

Sem. Nux ovat. obtufa 2-locul. Nuclei folitar. oblongi .

Domingenfis. P. Jacq. Am, tab. 182. f. 6, ed. 2. piza tab. 259. f. 5 .

In Sylvaticis Domingo $\hbar$.

Arbufc. erecta . Rami iunior. 4-gon, fulcati . Fol. femiped. oppofita, petiolis fuperne ad angul. obrufum inflexis, ovat-oblon. acumin. integerr. glabra, fubtus venofa. Panicula axill. 3-pollic. Fl. plurimi, exigui, albi, fape triandri; calyce, corollaq. 3-part.

\section{P E R A M A.}

Cal. Perian. 4-phyll. laciniis ovat. acut. villofis . Cor. I-pet. Tubus longus, receptac. piltilli infertus. Limb. 4-fid. lacin. fubrotund.

Stam. Filam, 4. intra divifuras cor. Anth. fubrot, 2-locul.

Pift. Germ. ovat, utrimq. fulcatum. Styl, long. Stigm. acutum. Peric.

Birfute. P. Aubl. Guian, tab. 18.

In Guiana locis humidis $\hbar$.

Planta herbacea, tota cooperta pilis rufefcentibus. Caul. 1-2-ped. ramofus. Fol, oppofita, feffil. ovata, nervis longitudinalibus. Fl. $t \in r-$ minal, capitati. Receptacul. paleaceum, paleis fumbriatis intra fingulos $\mathrm{Al}$. Cor, lutea. 


\section{MONETIA.}

Cal. Perian. I-phy'l. ventricof, obfolete femi4-fid. nunc 2-3-fid. pubefc. lacin. lanceol. acuris, reflexis.

Cor. Pet. 4. receprac. inferta, linear. acuta, revoluta.

Stam. Filam, 4. erecta, receptac. inferta, fere Iongitud. cor. Antb. oblon. 2-locul, peltata, lureæ.

Pift. Germ. fuperum, fub 4-gon. Styl. craffufc. conicus. Sigm. acutum .

Peric. Bacca? ylobría, exfucca, calyculata ; capitulo mammolo apici impofito; 2-locul, 3lin. longi, \& lata.

Sem. 2. adpreffa, orbicular. compreffa, intus plana, extus lubunvexa. A

Character effentialis.

Cal. 4-fid. Pet, 4. Germ. fuperum. Bacca? 2locul. Sem. folitaria.

barlerioides. M. Herit. Surp. nov, cas. I.

Iycium Ind. \&c. Seb. thef. I. tab. r3. f. I.

Synun. Barleria hyj ricis in Lin. ic. S:b. fl, viduaua utrifq. convenit.

In India $\pitchfork$. Sonnerat.

Frutex mediocris, aculeatus, habitu Barlerice hyftricis. Rad, cinerea, odore Glycyrrhiza. Caul, erectus, rimofior, cinereus. Rani oppofiti, diffufi, ramulofi. Turiones ramulis conformes, in folo natali pubefient, in hortis nudi. Acul, 4 verticillati, decuffari, horizontal. axillar. e fingula ala binati, fubulati, pungent, apice Sph celati, tongitudine dimidii fol. Fol. oppofra, breviter petiol. patentia. ovat-lanceol. acuinine fpinufo, arguto, fphacelato, reflexo, $\mathbf{x}$-nervia, integra, perfitent. I. $\frac{3}{2}$ poll, long, 8. lin. latd. FI. axillar. nonnikil conferti, àd apicem terni, quandoq. folitar. feffl. herbac, autumal. 2. lineas lati. Bract. ( feu nafcentes aculei ) oppofira, 2phyll. Petal. lineav, revoluta. Fruct. globofus, exfuccus, ca yculatus; capitul. mammofo apice impolito; 3 . lin. longo, \& lato.

Hofpltatur in Tepidario. 


\section{A N A B E A.}

Cal. Perian. I-phyll, furbinat. villofum, 4-dent. denticul. acuris.

Cor. I-pet. tubulofa : tubus calyce longior, receptaco piltil, infertus: limb. 4 -fid.

Stam. Filam, 4, oblong. tubo inferta, infra divifuras.

Piff. Germ. minim, fubrot. Styl. longus, 2-part. Stigm, obtufum.

Peric. Bacca ovata, calyc. obvoluta, 2-locul.

Sem, I-2.

sillof $a$, M. fol. ovat. fubtus incanis: fl. glomeratis, virefcentibus. Aubl, Guian, $t_{0} b, 23$.

In Cü̈enra ђ.

Frutex 8-ped. Caul. pl. erecti, ramofi 4-goni, incani. Fol. oppofita, breviter petiol, inæqualia, uno ma: altero min. acuta, integerr. Fl. fubaxill. corymbofi, corymb. oppofitis, pedunc, comm. 3-part, Cor. fubviridis. Bacca lutea.

arborefcens, M. fol. ovatis, acumin. fl. glomeratis, albis . Aubl..Guian, tab. 24.

In Cä̈enna, \& Guiana \$.

Frutex ro-pedal. fuperne ramofus, ramis, \& ramulis 4-gonis, nodofis, fparfis. Fol. oppofita, petiol. integerr. glabra, fupra viridia, fubtus pallidiora. Fl, axill, corymb. oppofitis, 3-part. Cor. alba. Drupa compreffa, lutea .

lavis. M. fol. oblon-ovat, acuminat. Aubl. Guian, tab.25. In Guiana b.

Frutes 8-ped. Caul. pl. reeti, ramofi, 4-goni . Fol. oppofita . Fl. fubaxill. corymbis oppofitis, pedicell. 3-part. Braet. 2. ad bafin ramorum. Fl. in capitulum collecti. Cor. flava, lacin. obtufis .

\section{T A C H I A.}

Cal. Perian. I-phyll. oblong. tubulos. 5-dent. denticul, erect. acutis.

Cor. I-pet. tubulofa, receptac. piftil. inferta ; fauce inflata: limb, s-fid, lacin. ovat. acut, reflexis , 
Stam. Filam. 4. infimæ p.rti cor, adfixa. Anth. oblong. 2-loull. extrd tubua prominentes.

Pift: Germ. oblong. difco 5-glandulari ad bufin circumdatum. Styl, longiff. Stigm. bildmellatum .

Peric. Capf. oblong. calyce tecta, 2-locul.

Sem. numerofa, minutiff.

Guianenfis. T. Aubl. Guian, tab. 29.

In Jylvis Sinemarienfibus b.

Frutex 5-6-ped. Rami plurimi, oppofiti, farmentofi, nodofi, 4-goni. Fol. oppofita, amplexicaul. ovata, acuta, integerr. glabra. $\mathrm{Fl}$. axill. utrimq. folitar. Cor. lutea .

Fagara pentandra non videtur pertinere ad hoc genus.

\section{R O U P A L A.}

Cal. Perian. o.

Cor. Pet. 4. oblong. obrufa bafi angufta, fubtus convexa, fupra concava.

Stam. Filam. 4. breviff, verfus medium petali inferta.

Anth, oblong. obtufæ, 2-locul. in cavitate petali reconditæ.

Pift. Germ. fubrot, villofum . Styl, longus .

Stigm. craffiufc. fubovatum.

Peric. I-locul.

Sern. I.

montene.

R. Aubl. Guian, tab. 32.

In Guiana b.

Frutex ramis 3-4-pollic. Fol. alterna, petiol. ovata, acta, integerr. rigida, limbis furfum revolutis, quafi canaliculatis. Fl. axill. \& terminal. fpicati, bini, femper feffil. alterni. Pet. viliofa, fupra candicant. fubtus lutea .

\section{P O U T R I A.}

Cal. Per. I-phyll, 4-part. lacin. ovat. acutis, non deciduis.

Cor. I-pet. tubulofa. Tubus brevis, calyc. fundo infertus: limb. 4-dent. denticul. acutis, intra quos feta oblonga erigitur.

Stam. Filam, 4 tubo cor, ad bafin inferta .

Anth. oblong. 2-locul, 
Pift. Germ. fuperum, ovatum, villofum. Styl. 4-gon. Stigm. 4-cufpidat.

Peric. Capf. ovat, pilis brevibus, rigidis tecta, 4-locul. 4-valv. valvis intus purpurafcent.

Sem. folitar, oblonga, extus convexa, intus an-

gulata, membrana tenui, purpur. involuta.

P. Aubl. Guian. tab. 33.

In Sylvis finemarienfibus b.

Arb. 40-ped. fuperne ramofa, ramis rectis, fparfis. Fol. congefta, alterna, longe petiolat. ovat-oblong. acura, integerr. rigida, glabra. Fl. axill. \& fupra ramulos, binati, ternati, breviter peduncul. Cor. fubvirid.

\section{A C O U C O U A.}

Cal. Perian. I-phyll. 4-part, lacin. brevibus, acutis .

Cor, 2-pet, receptac. pifilili inferta: rubus breviff, limb. 4-fid. lacin. fubrotun.

Stam. Filam. 4. intra divifuras cor.

Anth. fubrot. 2-locul.

Pift. Germ. minimum, fubrotun. Styl, nullus, Stigm. obtufum.

Peric.

Sem.

Euinenfis.

M. Aubl. Guian, tab. 34 .

In Cä̈enna, \& Guiana b.

Arb. 30-40-ped. fuperne ramofa. Fl, axill. corymbofi, peduncul. Cor. alba .

\section{O T O M I T A.}

Cal, Perian. I-phyll, turbinat, 4-dent.

Cor. Pet. 4. oblong. acuta, reclinata, difco inferta.

Stam. Filam. 4 breviff.

Anth. oblong. membrana tenui terminatæ, \& in cylindrum tubulofum quafi connatæ, introrfum dehifcenres.

Piff. Germ. calyce inclufum, difco coronatum. Styl. longus, tubum, faminibus formatum, perforans. Stigm. 4. oblong. acuta .

Peric. Drupa infera, cal, adnata, \& coronata, I-locul.

Sem. I, Atriatum. 
Guianenfis, V. Aubl. Guian, tab. 35.

In Guiana Ђ.

Frutex 5-6-ped, fuperne ramofus; ramis fparfis, nodofis ; ramuf., 4-angul. Fol. oppofita, fubfeffil. ovata, acuta, integerr. rigida, glabra. Stipula brevis, acuta, ad bafin petioli, decidua . Fl. axill. corymbofi . Corymb. oppofiti, 3-4-fl. Cor. alba.

\section{R O U H A M O N.}

Cal. Perian. I-phyll. 4-part. lacin. acutis; fquamulis 2, ad bafin munitum .

Cor. I-pet. tubulofa. Tubus brevis, receptaculo piftil. infertus : himbus 4-fid. laciniis acut. villofis .

Strm. Filam. 4. tubo cor. inferta.

Anth. oblong. 2-lòcul.

Pift. Germ. ovatum. Styl. longirudine cor. Stigtha obtufum.

Perie. Capful. orbicul. I-locul,

Sem. 2. ovata, hinc plana, inde convexa .

Guidnenfe, R. Aubl. Guian. $4 a b$. 36 .

Ad ripas fluvii Sinemarien fis 5 .

Frutex 78-ped. Rami longifl. fupra arbores fparfi. Fol, oppofita, fubfeffil. fubrotun-acuta, integerr. fupra pallide virent. fubtus fubcinerea, trinervia. Fl. corymbofi : corymbi axill. oppofiti, fubfeffil. Cor. alba. Capf, flavefcens . Quandoq. cirrhus axill, oblong. rectus, ad apice $m$ incurvus, \& incraffatus.

Var eirrhis orbata: fol. glabrioribus: $f$. \& frucibus min.

\section{O U S A R EA.}

Cal. Perian. I-phyll, turbinat. 5-dent.

Cor. I-pet. Tubus brevis, difco fupra germen infertus: lumb, 4-fid, lacin. oblong. acutis .

Stam. Filam. 4. tuho inferta, infra divifuras limbi . Anth. oblong. 2-locul.

Pift. Germ. fubrotun. cal. adnatum, difco coronatum. S yl. longus. Stigm. 4-5-cufpidat.

Peric. Bacca ovat. umbilic. I-locul.

Sem. I. coriac. fubrotund. 
violaced. C. Aubl. Guian, tab. 38.

In Guiana b.

Frutex 8-ped. ramofus, ramis, \& ramulis oppolitis. Fol. ampla, oppofita, petiolat. ovata, acuta, infegerf. glabra. Stipul. ad bafin utrimq. petiol. laræ, actira. Fl, terminal. eos rymbof, corymb. fubfeffilibus. Cor. alba. Bacca cortice extus vielac. intus fubcarnof, lutéa.

\section{E V E A.}

Cal. Periahi, I-phyll. turbinat, patens, 4-dent. denticul, minimis.

Cor. I-pet. infundibulif. Tubus longus, difco fupra germen infertus; limb. 4 -fid. lacin. acutis . Stam. Filam. 4t breviff. tubo ad bafin inferta. Anth, oblong. linear. 2-locul.

Pift. Germ, inferum, ovat. calycis fundo adnatum, difco coronatum. Sfyl, brevis. Stigma 2-lobum .

Peric.

Sem.

Fl. capitati. Invol 4-phyll foliol. 2 inferior. latioribus, oppofitis, fabrotun. acutis .

Guianenfis, E. Aubl, Guign, tab. $3 \%$.

In Guiana b.

Frutex 6-8-ped. Rami oppofiti, nodofi, 4-gon̂i Fol. oppofira, petiolat. ovata, oblongd, integerr. rigida, glabra. Stipul. 2. utrimq. ad bafin petioli, breves, acutæ. Capitula axillar. pedunculata. Receptaeul. fl. paleaceum .

\section{F A M A R E A .}

Cnl. Perian. I-phyll, turbinat, 4-dent.

Cor. 1-pèt. tubulofa. Tubus difco fupra germen infertus: limb. 4 - fid. lacin. bblong, acutis .

Stam. Filam. 4. brevia, tubo verfus bafin inferta . Anth. oblong. linear, 2-loc.

Piffil. Germ, calyci adnatum, inferum. Styl. longus. Stigma fubrotun, $z-l o b$.

Peric, 2-locul.

Sein;

corymbofa. F. fol ovat, acutis : pedunc, terbatis, corymbofis. Aubl. Guian, tab. 40. f. $x$.

In Guiane b. 
Frutex 7-8-ped. Rami fparfi, oppofiti. Fol, fubfeffil. integerr. glabra. Stipul. 2, utrimq. ad bafin petioli, acutæ. Fl, in 3. corymbos terminal, , pedunculati : corymbi compreffi, quafi flabelli, I0-15-A. Cor. alba.

Seffilfora. F. fol ovatis, acutis: fl. feffilibus, terminatricibus. Aubl. Guian. $2 a b$. 40. f. 2.

Jifdem in locis $b$.

Differt a priure fl. Jeffilibus, carymb. 3-4=fio Cor. tubo longiore.

\section{A L A N E A.}

Cal. Perian, I-phyll. 4-dent.

Cor. I-pet. Tubus breviff. difco fupra germen infertus: limb. 4-fid. lacin. acut, villofis.

Stam. Filam. 4. tubo inferta, intra divifuras cor.

Anth. fubrotun 2-locul.

Pijt. Germ. fubrotun. calycis fundo adnatum, difco coronatum. Styl, 2-fid. Stigm, obtufum.

Peric. Bacca ovat. calyc, denticul. coronata, I-locul.

Sem. Officul. 2-locul. Sem. I. oblong, in quolibet loculo.

farmentofa. M. Aubl. Guian. tab. 4r.

Supra arbores in Guiana b.

Frutex 5-6-ped. Rami longiff. oppofiti, fupra proceras arbores expanfi. Fol. oppofita, petiolat. ovata, obtufa, integers. fupra viridia, fubtus tomentofa, lanugine rufefcente. Stipul. utrinq. ad bafin petiolor. oblong. acuta, villola, decidua. Fl. glomerulis oppofitis in fpicam digefti; fpicis oppofitis, axillar. villofis. Cal. tomentolus, Cor. fubcoerul, Bacca viridis .

\section{T O N T A N E A.}

Cal. Perian. I-phyll. turbinat. 4-dent.

Cor. I-pet. infundibulif. Tubus longus, difco fupra ovarium infertus. Limb. 4-fid. lacin, acutis.

Stum. Filam. 4. oblong. fauci cor, inferta, 
Anth. fubrot. 2-locul.

Pift. Germ. fubrotun. fundo calyc. adnatum, difco coronatum. Styl. longus, 2-part. Stigm. obtufa .

Peric. Bacca ovata, calyc. denticul. coronata, 2-partibil. 2-locul.

Sem. plurima, fubrotun. convexa, marginata, diffepimento adfixa, nigricant.

Guianensis, T. Aubl. Guian, tab. 42 .

In $\int y$ lvis Caz̈enna \& Guiance 24.

Caules decumbent. radicant. carnofi, femiped. erecti, tomentofi. Fol. oppofita, petiolat. ovata, carnofa, integerr. fubtoment. Stipul. utrimq. 2, ad bafin petioli. Fl. axill. capitati, longe peduncul. Capitula 3-5-fl. Cor. alba, vel coerul, Bacca carnofa, vifcofa, ccerul.

\section{P A T A B E A.}

Cal. Perian. I-phyll, turbinat. 4-dent, denticul. acur.

Cor. I-pet. Tubus oblong. difco fupra germen infertus. Limb. 4-fid. lacin. oblong, acutis .

Stam. Filam. 4. brevia, tubo ad taucem inferta.

Anth. oblong. 2-locul.

Pifl. Germ. inferum, calyc. fundo adnatum, difco coronatum. Styl. oblong. 2-fid. Stigm. 2. obtufa.

Peric.

Sem.

coccinea.

P. Aubl. Guinn, tab. 43.

In Guiana b.

Frutex 4-5-ped. fuperne ramofus. Fol. oppofita, petiolat, fubtus pallide virent. Stipul. utrimq, all bafin petioli, oblong, acutæ. Fl. terminal, capitati. Capitulum fquamofum . Receptac. paleis oblong. acutis, intra fingulos fl. Cor. rubra .

\section{Embelia Burmanni.}

De churatere huius generis effentiali nihil certi pronunciare audeo, non vifa fpecie Burmanniana; fide uutem König. bine huius funs Spec, 

In India.

Groffuleria. Ev fol, ovat-lanceol. oppofitis: fl, tetrandris o Retr. Obf: fafc. 4 .

\section{In Tranquebaria.}

Arb. ramis oppofitis. Fol. petiolat. integerr. nervofa, pallide virid. R cemi compofiti, terminal. ramorum, e folior. axillis prodeunt. Fl. parvi, albefcentes. Cal. inferus, cavus, 4-fid. laciniis rotundatis. Stam. 4. Piftil. Stigm. capitatum. Stylus nullus, Germ. fuperum, globofum. Bacca.

Huilus gen. videtur Ribefioides Lin. Fl. Zeylo etfit pentandra fit, \& pentapetala.

\section{I G Y N I A.}

\section{P E G A M E. A.}

Cal. PErian. I-phyll, turbinat. 4-dent.

Cor. I-pet. Tubus brevis, difco fupra germen infertus: limb. 4-fid. lacin. fubrotun, villofis . Stam. Filam. 4. breviff. fauci tubi inferta . Anth. fubrot, 2-locul.

Pift. Germ. fundo calyc. adnatum, fubrot. difco coronatum. Styli 2. Stigmata acuta .

Peric. Bacca calyc. funcio immerfa, 2-locul.

Semz. Officul. 2. hinc convexa, inde plana, 2locul. unicum in quolibet loculo; quandoq. unum abortitur.

Guianenjis, P. Aubl. Guian, tab. 44.

In Guiana b.

Frutex 7-8-ped. ramulis inclinatis. Fol. oppofita, lanceol. integerr. glabra. Stipul. amplexic. 2-loba. Fl. axill. terminal. oppofiti, feffil. laxe fpicati. Cor. alba. Bacca viridis. 


\section{$36 c_{2}$ \\ CLASSIS V. \\ PENTANDRIA. \\ MONOGYNIA.}

Fi. monopet. inferi, monofpermi.

189. Mirabi- CAl. inferus. Cor. infundibulif. fupera - Ne= lis. ctar. globofum, germen includens. Nucula infra corollam.

756. Weige- Cor. infundibulif. Styl, e bafi germinis. Stigm. lia. peltat. Sem. I.

258. Plumba-Cal. 6-dent. Cor. infundibulif. s-fid. Stam. fquago. mis bafin cor. claulentibus, inferta. Stigm. 5fid. Sem. I, oblong. tunicatum.

Fl, inonopet. inferi, 2-fpermi. Afperifolize.

221. Cerinthe. Cor. limbus tubulofo-ventricofus, ore 5-dent. fauce nuda: Anth. pone hamulis coharentes. Capf. 2-locul. ex feminibus binis, offeis coalitis.

227. Meffer- Cor. infundibulif. fauce nuda. Bacca fuberofa, fchimidia. 2-partibilis; fingulo 2-1permo.

$\mathrm{Fl}$. monopet. inferi, 4 - fperm. Afperifolize.

226. Echium . Cor, tubulofo-campanifor, irregular. fauce nuda . Stam, inæqualia.

214. Heliotro-Cor. bypocraterif. 5-fida, dentibus interiectis; pium. centro fl. plicato, fine glandulis .

219. Pulmo- Cal, prifmatico-5-gon. 5-dent, Cor. infundibulif. naria. limbo 5-fid. concavo, lacin. rotundis, fauce pervia.

216. Lithosper-Cal, 5-part. Cor. infundibulif. limbo 5-fid. fauce mum. perforata, nuda. Sem. 4, dura. Differt a Myofotide fauce pervia, \& ftigmatibus binis .

222. Onofma. Cor. tubulofo-ventricofa, 5-fid. fauce pervia. Sern. 4 , diftincta .

220. Symphy-Cor. tubulolo-ventricofa, limb. 5-fid. fegmentis tum. erectis; fauce claufa radiis fubulatis.

223. Borago. Cor. rotata, 5-part. fegment. cufpidatis; fauce rad. claufa duorum ordinum. Filam. breviffe- 
ma, fulcro ad bafin adfixa. Anth. oblong. acuta, conniventes.

223. Iycopfis. Cor. infundibulif. tubo incurvo; limbo 5-fid. fauce fornicata.

224. Afperu-Cal. 5-fid, polt efflorefcentiam comprellus, forgo. ma 2-valv. Cor, infusdibulif. tubo recto, breviffimo; limbo femi-s-fid. fquamulæ 5 , in fauce pofita.

218. Cynoglof-Cor. infundibulif. tubo brevi, fegment. orbicular. fum. fauce claufa fornicibus. Sem. 4 , depreffa, interiore tantum latere ftylo adfixa.

217. Anchs- Cor. infundibulif. tubo longo, recto, limbi fegSa. ment. orbicularibus: fauce claufa 5 fquamul.

215. Myofo- Cor. hypocraterif. 5-fid. emarginatd: faux glantis. dulofa, interiectis plicis albidis.

Fl. monopet. inferi, 5-fperm.

229. Nolana . Cor. monopet. campanulata . Styl. inter germina. Sem. 5, baccata, 2-4 locul.

Fl. monopet. inferi, angiofpermi .

290. Coris. Cal. Jo-dent. Cor. fubringens, 5-fid. Stigm. capiratum. Capf. 5-valv. 1-locul.

24I. Hydro- Cor. campanul. intus ftriis 5 , melliferis, longiphyllum. tudinalibus exarata. Stigm, 2-fid. Capf. globofa, 2-valv. 1-locul.

329. Gulax. Cal. Io-phyll. Cor. hypocraterif. Stigm. fubrotun. Capf. 2-valv. I-locul, elaftica.

234. Cortufa. Cal. 5-fid. Cor. rotata, femi-s-fid. fauce anulo elevato. Capf. ovalis, 1-locul, apice 5-valv.

244. Anagal-Cal. profunde 5-fid. Cor. rotata, ;-fid. Capfo lis. circumfciffa, I-locul.

243. Lyfima-Cal. 5-fid. Cor. rotata, s-part. Stigm. obtulum , chia. Capf globofa, mucronata, 5-10-valv. $t$-locul.

237. Cycle- Cor, rotata, 5-part. reflexa, fauce prominente. men. Stigm. acutum. Capf. globofa, pulpofa, 5valv. I-locul, polyfperm.

236. Dodeca-Cor. rotata, reflexa. Stam. tubo infidentia. theon. Stigna. obtufum. Capf. oblong. I-locul.

235. Solda- Cal. 5-fid. Cor. campanulata, lacero-multifida. nelle. Stigm. fimpl. Capf. cylindracea, I-locul, apice multident.

233. Primula. Involuc. umbella. Cal. 5-fid. Cur. infundibulif. ore patulo, fauce pervia. Stigm. globofum. Capf. I-locul. 5-10-valv.

232. Andro- Involuc. umbellæ. Cor. hypocraterif, tubo brevi, sece. ventricofo, ore 5-fid, glandulofo; fauce co 
arctata. Capf. globofa, I-locul. s-valv, polyfperm.

231. Aretia - Cor. hypocraterif, tubo ovato, limbo s-fid. Stigm. depreffo-capitatum - Capf. globola, I-locul. fub 5-fperm.

340. Hotto- Cal, 5-fid. Cor, hypocraterif. tubo infra ftam. nia. limbo 5 -fid. plano, plicis binis ad bafin finguli fegrmenti. Stigm. globofum. Capf. acumin. 1-locul.

838. Menyan-Cal. 5-fid. Cor. campanul. femi-5-fid. laciniis thes. ciliatis. Stigm. 2-fid. Capf, oblonga, 1-locul. 2-valv. polyfperm.

239. Dorana . Cor. 5-fid. Stigm, emarginatum . Capf. I-locul. 361. Alla- Contorta. Capf, lentiform. echinata, erecta, 2manda. valv. valvulis cymbiformibus polyfper. Sem. imbricata .

245. Theo- Cor. campanulata, laciniis, \& divifuris obtufis. pkrafta. Stigm. acutum. Capf. maxima, globofa, Ilocul. polyfiper.

253. Shesfel- Cor. campanulata. Filam. 10, alterna fterilia. dia. Capf. I-locul, 5-valv.

246. Retzia . Cor. cylindrica, extus villora . Stigm. 2-fid. Capf. 2-locul.

247. Spigelie. Cor. infundibulif. Stigma fimplex. Capf. globofa, didyma, 2-locul. polyfper.

248. Ophior- Cor. infundibulif. Stigma 2-fid. Capr. 2-loba, 2rhizi. locul.

26r. Convol- Cor. campanulata, plicata. Stigm, 2-fid. Capfo vulus. 2-locul, loculis 2-fperm.

250. Lifinn- Cor. infundibulif. tubo ventricofo, laciniis rethus. curvatis . Cal. carinatus. Stigm. 2-lamellatum. Styl. perfiftens. Capf. oblonga, 3-locul. 2valv. valvuldrum marginibus intortis, polyfperma .

308. Patago- Cal. frudiferus maximus. Cor. rotata. Stylus nula. dichotonus, declinatus. Capf. 2-locul.

293. Detura. Cal, tubulofo-angulatus, deciduus. Cor. infundibulif. 5-angulato-plicata. Capf. 4-valv. 2locul. polyfper. plerumq. echinata .

294. Hyofcya-Cor. infundibulif. inæqual. obtufa, 5-fid. Stam. mus. declinata. Stigm. capitatum. Capf. operculata, 2-locul.

295. Nicotis- Cor, infundibulif. limbo plicato. Stam. inclinata . nn. Scigm. emarkinatum. Capl, 2-valv, 2-locul.

292. Verbufcum. Cor. rotata, fubinæqualis, limbo 5-6id. Stam. 
inæqual. declinata. Stigm. obtufum . Capf. $2-5$ valv. 2-locul.

306. Chiro- Cor, rotata. Stam, tubo cor. infidentia. Anth. nia. defloratæ fpirales. Capf. 2-locul.

230. Diapen- Cal. 8-phyll. imbricatus. Cor. hypocraterif. Capf. fia. 3-locul.

259. Phlox. Cal. prifmaticus. Cor. hypocraterif. tubo curvo. Stam. inæequal. Stigm. 3-fid. Capf. 3-locul. Ifperm.

263. Polemo. Cor. 5-part. fundo claufo valvis ftaminiferis. nium. Stigm. 3-fid. Capf. ovata, 3-locul. fupera.

262. Ipomea. Cor. infundibulif. Stigm. capitato-globofum. Capf. 291. Broßaa . Cal. carnofus. Cor. truncata . Capf. 5-locul. polyfper.

254. Azalea . Cal. campanif. 5-fid. repandus. Cor. campanulata. Stam. receptac. inferta. Stigm. obtufum . Capf. 5-valv. 5-locul, fubrotunda. Staminum num. differt ab Erica, \& Andromeda.

255. Epacris. Cor. infundibulif, villofa. Squama nectarifera germini adnatæ (in quo effentia generis). Capf, 5-valv. 5-locul.

368. Cerope- Contorta. Cor. limbus connivens. Folliculi 2, gia. erecti. Sem. plumofa.

363. Nerium . Contorta. Cal. parvus, 5-fid. Cor. tubus terminatus corona lacera villofa; laciniis magnis, profundis. Folliculi 2 , erecti. Sem, plumofa.

364. Echites. Contorta. Cor. infundibulif, fauce nuda. Folliculi 2 , erecti. Sem. pappofa.

269. Pergula-Contorta. Cor, bypocraterif. Nectar. ambiens ria. genitalia cufpidibus 5. fagittatis . Folliculi 2.

365. Plume- Contorta. Cor, infundibulif, Follic. 2 , reflexi . ria. Sem, alata, membranæ propriæ inferta.

366. Camera- Contorta. Cor. hypocraterif. Follicul. 2, horia. rizontales, lobati, Sem. alata.

367. Taberna-Contorta . Cor. hypocraterif. Follic. 2, pulpofi . moniuna. Sem. nuda.

362. Viaca. Contorta. Cor, hypocraterif, s-fid, lacin. extrorfum latioribus. Follic. 2, erecti. Sem. nuda, remota.

302. Igratia. Cał. 5-dent. Cor. infundibulif. Iongifimia. Drupa I-locul. polyfper.

358. Cariffa. Contorta. Bacca 2, polyfperm.

305. Jacqui- Cor. IO-fida. Stam. receptac, inferta, Bacca 1nia.

fperm. 
3IT. Laugie- Cor. 5-fid. Stigm. capitarum. Drupa nucleo 5ria. locul.

357. Yaderis. Contorta. Styl. 2-fid. Bacea inflata, fragilis, 2-Sperm.

310. Varronia. Cor. 5-fid. Stigm. 4-duplex. Nux 4-locul.

307. Cordia. Cal, baccze accretus, Cor. infundibulif. Styl. dichotomus. Drupa nucleis 2-locul. 3e9. Ehretia. Stigm, emarginaturn. Drupa 4-fperm. Nux 2-
locul.

228. Tourne-Bacca 2-locul. 2-fperma, fupera, apice 2 poris forti, perforata.

356. Rauwol Contorta. Bacca fucculenta, 2-fperm. Sem. corfia. data.

359. Cerbera. Contorta. Drupa I-fperm. Nux compreffa, retufa.

4I8. Ardui- Cor. monopet. curvata. Stigm. 2-fid. Bacca 2nia. locul. 2-iper. Sem. oblong.

320. Myr/ine , Cor. femi-s-fid, connivens . Stigm, villofum . Germ, corollam replens. Bacca nudeo 5-locul. Effentia generis fita eft in ftigmate maximo, fimbriato-plumofo, extra fl. exporrecto.

321. Bladhia . Cor, rotata, decidua. Bacca 1-fper, Sem. arillatum.

303. Ceftrum . Cor. infundibulif. Stam. denticulo in medio notara. Bacca 1-locul. polyfper. Differt a Lycio bacca I-lucul.

312. Brunsfel-Cor, infundibulif. longiffima, Bacca I-locul, pos fia. Jyfper.

25r. Randia. Cal. I-phyll. truncatus . Cor. hypocraterif. Bacca I-locul. cortice capfulari,

252. Fagraa. Cal. campanulat. Cor. infundibulif. Stigm. peltatum. Bucca carnofa, 2-locul. Sem. globofa .

300. Strych- Cor. 5 -fid. Stigm. capitatum. Bacca cortice linos. gnofo, I-locul.

299. Capfi- Cor, rotara. Anth. conniventes. Bacca exfucca, cum. 2-locul.

2y8. Sola- Cor. rotata. Anth. fubcoalitz, apice biperforatz . num. Bacca 2-locul. calyce patulo tecta.

297. Phyfalis . Cor, rotata. Anth, adproximatx. Bacca 2-locul. intra kalyc. inflatum claufa.

296. Atropa. Cor, campanul, Stam. diftantia, incurva. Bacca globofa, 2-logul.

242. Ellifis . Cor. infundibulif. angufta. Bacca fubrotunda, exfucca, 2-locul. 2-valv. Sem. 2, punctara, altero fupka altarum. 
304. Lycium. Cal. s-dent. Cor. tubulufa, fouce claufa filamentorum villo. Bacca 2-locul. polyfperm.

206. Menais. Cal, 3-phyll, Cor. hypocraterif. Stigm, 2. Bacca 4-locul. 4-fperm.

314. Sidero- Cor. 8-10-fid. laciniis interioribus incurvis . xylon. Stigm. fimpl. Bacca 4-5-fper.

313. Chryfo- Cor. companul. Io-fid. lacin. exterioribus paphyllums. tentiffimis. Bacca Io-fper.

\section{* Achras.}

Fl. monopet. fuperi .

268. Samolus. Cal. 5-fid. Cor. hypocraterif. 5-fid. Stam. munita fquamulis cor. Stigm. capitatum. Capf, I-locul. infera, 5 -valv, polyfperm.

272. Bellonia. Cor, rotata. Stigm, acutum. Capf. infera, Ilocul. polylper: umbilico roftrato.

249. Virecta. Cal. 5-phyll, dentibus interiectis . Cor. infundibulif. Stigm. 2-part. Capf. I-locul.

27r. Macrocne-Cor. campanul. Stigm. 2-lob. Capf. infera, turmun. binata, 2-locul. Sern. imbricara.

270. Rondele- Cor. infundibulif. Stigm. obtufum. Capf. infera, tia. fubglobofa, coronata, 3-locul. poly\{per.

275. Cinchona. Cor. infundibulif. apice lanata. Stigm, fimpl. Capf. infera, 2-locul: diffepimento paralello. Sem. imbricata .

273. Portlan-Cor. ventricofa. Anth. longitudinal. Stigm. fimdia. plex. Capf. 5-gona, retufa, 2-locul. polyfper. coronata calyc. 5-phyll. Sem. imbricata.

265. Roëlla . Cor. infundibulif. fundo claufo valvulis ftaminiferis . Stigm, 2-fid. Capf. cylindrica, 2-3locul. coronata, infera .

256. Phyteu- Cor. tubulofo-corniculata, 5-fid. lacin. linearie ma. bus, bafi coalitis . Stigm. 2-3-fid. Capf. infera, 2-3-locul. Sem. exigua. Fl. in capitulum, aut fpicam collecti.

254. Campa- Cal. 5-fid. Cor. frepius campanul. 5-fid. fundo nula. claufo valvulis ftaminiferis. Stigm. 3-fid. Capf. infera, poris lateralibus, dehifcens.

274. Scavola. Cor. monopet. irregularis, tubo longitudinaliter fiffo; limbo 5 -fid. laterali, flabellifor. Drupa infera, I-fper. Nux 2-locul.

267. Trache- Cor. infundibulif. Stigma capitatum . Capf. infelium, ra, 3-locul. perforata. 
288. Matthio. Cor. infundibulif. longiff. indivifa, fupera. Cal. la. integer. Stigm, obtuf. Drupa nucleo globofo.

282. Morinda. Fl. adgregati, infundibulif. Stigm, 2-fid. Drupa adgregatæ, I-fper.

276. Pfycuth-Cal. 5-dent, coronatus. Cor, infundibulif. Stigmria. emarginatum. Bacca globofa. Sem. 2, hemifphærica, fulcata .

277. Coffea. Cor, hypocraterif. Stam. fupra tubum. Stigm. 2-part. Bacca infera. Sem, arillat.

278. Chiococ- Cor. infundibulif. Stigm. fimpl. Bacca infera, ca. 1-locul, 2-fperm.

360. Gardenia. Contorta . Cor. monopet. Anth. tubo cor. abfque filamentis, infertæ. Bacca infera, 2-4-10cul. polyfper.

30r, Genipa . Cor. rotata. Stigm. clavatum. Bacca fubrotun. 2-locul. Sem, nidulantia, cordata .

280. Lonicera. Cal. 5-dent. Cor. monopet. irregul. varia; tubulofa, vel campanul. limbo s-fid. lab. fuper. 2-4-fid: infer. 3-fid, vel integro. Bacca infera, fubrotund. 2-loc. polyfper.

281. Triofte- Cal. longitudine cor. Cor. monopet. fubrquaum. lis. Bacca infera, coriacea, 3-locul. 3-fper.

287. Muffan-Cor. infundibulif. Stigm, 2, craffiufcula. Bacca da. infera, oblonga, 4-locul.

279. Hamellia. Cor. tubo longo, limbo 5-fid. Skigm. linear. Bacca inferd, 5-locul. polyfper.

285. Erithalis. Cal. urceolat. Cor. rotata, 5-raro 6-part. lacin. linearibus, recurvis. Stigm. acutum. Bacca in. fera, fubglobofa, 10-loc.

\section{* Rubia. \\ * Crucianella. \\ * Prinos,}

Fl. pentapet. inferi .

337. Hirtelle. Petal. 5. Filam. longiffma, fpiralia, perfiftentia. Styl, lateralis. Bacca I-fperm.

315. Rram-Cal. tubulofus, 4fid. intus coloratus, fequamis nus. Ptam. munientibus. Petal. 4-5. Bacca rotund. 2-3-locul. Dantur etiam fi. fexu diftincti .

317. Ceano- Cal. tubulofus. Petal, 5, fornicata, faccata . thus. Bacca ficca, 3-locul, 3-fper. 
322, Celaftrus. Cal, planus. Cor. 5-per, patens. Capf. 3-gon. 3-locul. Sem. arillats.

323. Evony-Cal. patens. Cor. 5-pet. Capf. ovata, 5-gon. mus. 5-locul, 5.valv, colorata. Sem, baccato-arillata,

341. Aquilicia, Eft Leea aquata.

343. Vitis. Cal. 5-dent. Petal. Fxpe emarcido connata. Styl. nullus. Bacca fupera, 4-5-fper. Fl. racemofi.

331. Eleodendrum. Cor, 5-pet. Drupa ovata, nuce 2-locul. 334. Coryno- Nectar. 5, petaliform. cum petalis alternantia, carpus. bofi glandulifera. Nux clavata .

336. Mangife- Petal, 5, lanceo!. Drupa reniform. Nucleus la$r a$ nuginofus,

330. Cedrele, Cal. marcefcens, Cor. 5-pet. infundibulif, bafi seceptac. adnata. Capf. lignofa, 5-valv. 5locul, bafi dehifcens. Sem. deorfum imbric, ajara ,

332. Calodendrum. Petal, 5, explicata . Nectar. 5.phyll, Capf. s-locul,

319. Biittne- Petal. 5, auriculata, Stam, apice petalis connaria. ta. Capf. 5-cocca, muticata.

324. Diofma, Cor. 5-pet. Neet. 5, fupra germen. Capf. 3-5. coaliræ. Sern. arillata.

325. Hovenia, Petal. 5, convoluta . Stigm, 3-fid, Capf. 3-valv, 3-locul.

348. Claytonia. Cal, 2-valv, Cor. 5-pet. Stigm, 3-fid. Capf. Ilocul.

345. Roridu- Cal, 5-phyll. Cor, 5-petal, Anth. bafi fcrotiform. la. Capl. 3.valv, I-locul.

328. Itea. Petal, longa, calyci inferta, Stigm, obtufum. Capf, 2-valv, I-locul.

346. Sauvage. Cal, 5-phyll. Cor. 5-pet, fimbriata. Nectar. 5-

faa. phyll. cum petalis alternans. Capf. I-locul,
347. Caroxy-Cor. 5-pet. Nectar, 5-phyll. connivens, cor, inlon. fertum, Sem, tunicata.

326. Brunia , Fl, adgregati . Receptac. comm. villofum. Stam. unguibus petalor, inferta. Stigm. 2 fid. Sem. 1 , villofum.

284. Kuhnia . Flos compofitus, flofculofus, Recéptac, cómtn. nudum. Sem. I, pappofum.

269. Nauclea. Cor-infundibulif, Receptac. comm, globofum, nudurn. Sem, 1, 2-locul.

* Cafalpinia pentandra. * Bumbar pentandrum. 
* Caffia nichtitans.

* Vivla.

Fl. pentupet. fuperi.

339. Ribes, Petal. 5., \& Stam. calyc, 5-fid. inferta, Styl, 2-fid. Bacca infera, globofa, umbilicata, polyfperm.

333. Efcallonic. Petal. 5, diftantia, lingulata. Stigm. capitatum. Bacca 2-locul. polyfper.

342. Hedera. Petal, 5, oblong. patentia, apice non coalita. Sigm, fimpl. Blacca globofa, 5-fperm. calyce cincta. Fl, in umbella fimplici. Frutex volubilis.

338. Plectro-Pet. 5, calycis fauci inferta. Anch. inclufa, nia. geminatæ. Bacca infera, 2-fperm.

316. Phylica. Cal. turbinat, 5-part. Cor, o. Squama 5. ftam. munientes. Capf. infera, 3-cocca. Fl, pluzi$\mathrm{mi}$ in difcum, vel capitulum collecti.

340. Gronovia. Cal. coloratus. Pet. minuta, cum ftaminibus calyc, incifuris inferta. Capf. infera, colorata , I-fperm.

349. Heliconia. Spathæe utraque. Cal. o. Cor. 3-pet. irregular. Nectar. 2-phyll, Capf. 3-cocca.

327. Cyrilla. Pet. acuta, receptac. inferta. Styl. 2-fid. perfiftens. Capf. 2-locul. polyfper.

335.Argophyl-Pet, 5. Nectar. pyramidale, 5-angul. longitudine lum. cor. Cafp. 3-locul.

344. Lagacia. Involucra utraque. Petal. bicornia. Sem. 2., nuda .

283. Conucar-Cal, campanul, Pet. S. conniventia, aut nulpus. la. Sem. I. inferum, nudum. Fl. adregati, excepta C. racemofa.

Fl. incompleti, inferi.

350. Achyran-Cal. exter, 3-phyll. Cor, 0, Stigm, 2-fid. Sem. thes. I. oblang.

351. Celefia. Cal. exter, 3-phyll, coloratus. Stam. bafi nectario plicato coniuncta. Capf. horizontaliter dehifcens, 3-fper.

352. Chenolea. Cal. globofus, I-phyll, 5-fid. Capf. I-valv. Ifperm.

353. Illece- Cal. cartilagineus, 5-phyll. Cor. o. Stigm. fimpl, brum. Capf. 5-valv. 1-fper.

354. Glaux. Cal. campanul. 5-fid. coloratus. Capf. s-valv. 5-fperm.

*Polygonum amphibium: Lapathifolium. 


\section{* Caratonia.}

Fl. incompleti, fuperi .

355. Thefium. Sem. I. calyci adnafitur itaut fegmenta cal, ex fummo temine nafci videantur. Segmenta cal. triangularia, $5-4$, intus colorata. Stam. tot, quot fegmenta fl. Tuba fimpl, apice globofo.

* Loranthus. Trianthema monogyna.

D I G Y N I A.

Fl. monopet, inferi.

375. Stapelia. Contorta . Cor. rotata. Nectar. duplici ftellula tegente genitalia. Planta carnufa, fuccofa. Follic. 2.

372. Cynan- Contorta. Differt ab Afclepiade nectario cylinchum. drico, 5-dent.

371. Periploce. Cor. rotata. Nectar. 5, filiformia. Follic. 2. 373. Apocy- Cor. campanul. femi 5-fid. Nect. glandulofa, num. 5, fetis 5. Follic. 2.

374. Afcle- Contorta. Cor. plana, vel reflexa, 5-fid. Nectar. pias. 5, auriformia, unguicular. Follic. 2. Sem. pappofa.

270. Melodi- Contorta. Faux cor. coronata. (Nectar. in menus. dio tubi ftellatum). Bacca 2-locul, polyfper.

392. Swertia. Cor. rotata. Pori 5, nectariferi ad bafin cor. Capf, 2-valv, I-locul.

393. Gentia- Cor. monopet. varia. Capf. oblong. conica, 2na. valv. 1-locul. receptacul. 2 , longitudinalibus.

382. Creffa. Cal. 5-phyll. Cor. hypocraterif. 5-fid. limbo reflexo. Filam, tubo infidentia. Capr, 2-valv. I-fper.

388. Hydro- Cal. 5-phyll. Cor. rotata. Filasn, bafi cordata . lea. Capf. 2-valv. 2-locul.

260. Porana, Cal. 5-fit. in fructu maior. Cor. campanul. Styl. elongatus, femibifid. perfiftens. Stigm. globofa. Fruct, 2-valv.

389. Schrebe. Cal, 5-part. Cor. infundibulif. Filam, in fauce cor. ra. fquamis totidem bafeos.

383. Sieris, Cal. S-part. Cor. rotata. Bacca I-locul, polyfper.

395. Rugelia . Cal. 5-phyll, Petal. 5, fupera . Capf. 1-locul. polylper.

$\mathrm{Fl}$. pentilpet, inferi.

39I. Veleziu. Cal. filiform, cylindric, 5-dent. Cor, 5-pet. par- 
va. Stam, etiam 6. Capf. cylindrica, I-locul. polyfper. Sem. ferie fimpl.

376.Lineonia . Cal. 4-phyll. Pet. 5, foveola nectar. bafi infculpta. Capf, feminiferd, 2-locul.

387. Nama. Cal. 5-phyll. Cor. 5-part. minor. Capf, 2-valv. I--locul.

390, Heuchera. Cor. 5-pet. calyci inferra - Capf, 2-roftris, 2-locul.

396.Bumalda . Cor. 5-pet. Styli villofi. Capf, 2-roftris, 2-locul. 381. Anabafis. Cal. 3-phyll. Cor. 5-pet, minima. Bacca I-fperm. calyce cincta.

\section{* Staphylasa pinzata.}

Fl. incompleti.

380. Sulfola . Cal. 5-phyll. fubcoloratus . Cor. o. Capf. globofa, 1-fperm. Sem. I. cochleatum.

378. Chenopo- Cal. 5-phyll. 5-gon. Cor. 0. Sem. I, lenticuladium. re, fuperum, calyc. ficco involurum. Fl, glomerato-racemofi.

379. Beta. Cal, 5-phyll, bafi femen fovens. Cor. o, Sem. I, reniform.

377. Hernia- Cal. 5-part. Cor. 0. Filam. 5, fterilia. Tuba ria. 2-fid. Capf. I-fper. Sem. ovatum.

384. Gompkre-Cal. coloratus, exterior 3-phyll. compreffus, Pet. na. 5, rudia, villofa. Nectar, cylindric. 5-dent. Styl. femi 2-fid. Capf. circumfciffa, 1-fper.

385. Bofea. Ad polygamas eft relata.

386. Ulmus. Cal. monophyll. 5 -fid. emarcidus. Bacca ovalis, compreffo-membranac. exfucca. Sem, I.

$$
\begin{aligned}
& \text { * Rhamnus Zixiphus. } \\
& \text { * Polygonum Virginicum. } \\
& \text { * Trianthema Fentandra. }
\end{aligned}
$$

Fl. pentapet. fuperi, difpermi .

\section{U M B E L L A T 压.}

Involucro utroque.

394. Vahlia. Ad RuJfelliam eft relata.

397. Phyllis. Fructificariones fparfie. Stigmata hifpida .

404. Coprof- Flos hermaphroditus. Cal, 5-part. Cor. 5-7-fid. ma. Stam. 5 ad 7. Styl. 2, longi. Bacea 2-1per. Sem. planiufcula. Fl, fem. \& mafcul. ut in hermapbr.

$$
\text { Tom. I. }
$$


398, Eryn- Fl, capitati . Cal. comm. 5-phyll, foliol, longifgium, fimis, acutis, rigidis. Petal, introrfum flexa. Thaldm, poleaceus. Sem. 2 , latere plano contigua .

399. Hydroco- Umbella parva, fimpl, irregular. Involuc. 4tite. phyll. Pet. integra . Sem. femi-orbiculatocompreffa.

400. Sanicula. Umbella fubcapitata, conferta. Involuc. univerfale fere 5-phyll. 3-lobat. aur certe dentatum. Partiale ex 5 foliol, lanceolat. Sem. oblong. muricata, cal. proprio coronata.

40r. Afiran-Involuc, univerfale magnum, polyphyll. coloratia. run. Cal. S-dent, perfiftens. Fl. mafculi, \& hermaphroditi. Sem, non dlata, 5-coftata, fed membrana tranfverfim plicata tecta. Sem. fi hac membrana, quæ facile feparabilis eft, exuantur, ad Ligufici fem. accedust .

42r. Hera- Involuc caducuin. Cor. radiata, inflexo-emarcleum. gin ta. Fruet. ellipticus, compreffus, ftriatus, vix emargin。tus, membranaceus.

428. ⿷匚 nanthe. Involuc, fimpl. Fl. radiati, difco fterili . Pet, inæqual. Fruct. ovatus, cal. infigni, 5-dent. coronatus. Sem, ovatum, non acuminatum, ftriatum, intus planum.

403. Echino- Involuc. univerfale paucorum fol. partiale I-phyll. phora, multifid, Fl. radíti, peral, inequalibus. Sem. feffil. Coronata involuc. indurato.

407. Caucalis . Involuc. fimpl, Cor, radiatæ, difci máfulæ. Pet. inflexo-emarginata. Fructus muricarus .

408. Artedia. Involuc. pinnatifida. Fl. radiati, difci mafculi . Sem. margine crenis foliaceis.

409. Daucus, Involuç. univerfale fol, profunde pinnatifidis. Umbella in fenio connivens, concava. Cor. fubradiaræ, omnes hermapbrod. Fruct. pilis hif pidus. Sem. ovalia, coftara, aut ftriata.

406. Tordy- Involuc, fimpl. Cor, radiatæ, omnes hermaphrolium. ditæe. Fruct. fuborbiculat. margine crenatus.

420. Laferpi- Fl. flolculofi, abortivi. Per, inflexo-emarginata, tium. patentia. Sem. plerumque 4-alata.

416. Peuceda-Iavoluc. fimpl. breviffina. FI. flofculofi, abornum. tivi. Fructus ovatus, utrimque ftriatus, ala cinctus non pellucida.

410. Ammi, Involuc. pinnatifida. Cor. radiatæ, omnes hermaphroditæ. Fruct. exiguus, fubrotund. lavis . Sem, intus planum, dorfo tenuius ftriato. 
405. Hofjel- Pet, cordata. Fl. laterales mafculi, centrali herquiftia. maphrodito. Sem, ambitus geminata, margine crenata, ovalia, pland, medio convexa; difci folitar, urceolata, hemifpharica.

412. Conium . Involuc. dimidiata, fub 3-phyll. Pet, inflexo-emarginata. Fruct. fubglobofus, s-ftriatus, utrimque crenatus.

411. Bunium . Umbella conferta. Involucc, fetacea. Fl, flofculofi, fertiles. Pet. cordata, reflexa. Fruct. ovali-Iongior, fere cylindric, Sem. fubtiliter ftriata. Rad. carnofo-tuberofa.

41q. Atha- Pet, inflexa, emarginata. Fl. flofculofi, fertiles. manta. Fruct. ovat-oblong. ftriatus. Plures Spec. SpeCant ad Selini genus,

402, Bupleu- Involucra umbellul, maiora ( $\mathrm{fi}$ adfint) 5-phyll. rum. Fl. flofculofi, flavi. Petal. involuta. Sem. in variis fpeciebus varia, oblonga, ovat. ovatacumin, coftata, aut fimpliciter ftriata. Fol, in noftris, fimplic. integerr.

424. Sium. Involuc polyphyll. Fl. flofculofi, fertiles, Petal. cordata. Fruct. oblong-ovat. Sem. ovata, leviter ftriata, intus plana, calyce minimo coronata .

413. Selinum. Involuc, reflexum. Fl, flofculofi, Pet. cordata. Fruct, ovali-oblong. compreflo-planus, in medio ftriatus, ftriis eminentibus, \& fubalatis, margine alato, ala m gna, membranac.

427. Cumi- Umbella 4-fid. involuc, longiffin. fetaceis. Fl. num. flofculofi, fertiles. Pet. cordata. Fruct. ovatus, friatus.

4I9. Ferula. Fl. flofculofi, fertiles. Pet. cordata. Fruret. magnus, ovalis, compreffo-planus, 5-ftriat. cinctus ala magna, folida, non membranaced.

417. Crith- Involuc. horizontalia. Fl. flofculofi, fertiles. Pet. mum, planiufcula. Sem. ovale, intus planum, tota fuperficie cohærens; dorfo 3 obfcuris coltis percurfo .

426. Bubon. Involuc. 5-phylla. Fl, flofculofi, fertiles, Pes. planiufcula. Fruct. ovatus, ftriatus, villofus. 418. Cachrys. Fl. flofculofi, fertiles. Pet, planiufcula. Fruct. magnus, fubovatus, angulatus, cortice fuberofo.

422. Ligufti- Involuc. membranacea. Fl, flofculofi, fertiles. cum. Pet. involuta. Fruct, ovato-acuminat. 5-coftatus, coftis fubalatis, non roftratus . 
423. Angelica. Fl. flofculofi, fertiles. Umbellul. globofa. Pet. incurva. Fruct. fubrotund, angulatus, folidus, alis 2 , membranaceis .

425. Sifon. Involucra paucifol. fub 4-phyll. F1. flofculofi, fertil. Pet. cordata . Fruct. parvus, ovali-oblon. Sem. fubtiliter ftriata. Carum, Bunium, \& Sifon adfinia funt genera, ut agre diftingui peffint .

Invclucris tantum partialibus.

431. AEthufa. Involucc. dimidiata, 3-phyll. pendula. Fl. fubrad. fertil. Fruct. fubrotund. Sem. ovatum, intus planum, maxime gibbum, 5-coftarum.

432. Corian- Fl, fubglobofi. Involuc. univerfale I-phyll. Indrum. volucc. dimidiata. Fl, radiati. Pet. inflexoemargindta. Fruct. fphæricus, aut didymus.

433. Scandix. Cor. radiata. Pet. emarginata. Flofc. difci fæpius mafculi Fruct. fubulati.

434. Chero- Involucc. 5-phill. reflexa, concava. Fl. flofcul, bhyllum. Pet. infle $x$-cordata. Fruct. oblong. lævis,

429. Phellan-Cor. radiata. Pet. cordiform. Fruct. ovatus, driam. lavis, obirer 5 -ftriatus, coronatus cal. \& piltil.

435. Impera- Uinbella expanfo-plana . Fl. flofcul. fertil. Pet. toria. inflexo-emarginata. Fruet, fubrotund, compreffus, medio gibbus, margine cinctus.

436. Sefeli. Uinbellæ globofæ, rigidulæ. Involuc. univerfale foliol. uno, alrerove. Partiale polyphyll. Fl. flofcul. fertil. Pet. cordata, reflexa. Früct. fubrotund. aut ovatus. Sem. ovatum, acuminat. intus planum, gibbun, 5 -coftatum .

430. Cicuta. F1. flofcul. fertil. Pet. planiufcula Fruct. fubovatus, fulcatus .

\section{* Bupleurum rotundifol. \\ * Apium.}

\section{Petrofelinum, \& Anifum.}

Involucro nullo.

439. Smyr - Involuc, nulla. Fl, flofcul, abortivi. Pet, acunium. minata. Fruct. magnus, fubrotund. Sem. carinata, dorfo fubrotunda, \& tribus coftis obtufis, \& veluci funiculis percurlo; interiore facie veluti triangulari; neque idcirco tota plana, \& contigua.

441. Carum, Fl, flofcul, abortivi. Pet. carinata, inflexoemargin. Fruct, ovat-oblong, friatus. Sem. intus plana. 
437. Thapfia . Fl. flofcul. fertil, Pet. lanceol, integra. Fruct. oblong. membrana cinctus, qua fupra, \& infra ampliter truncata eft, \& emarginata.

438. Paftina- Fl. flofcul. fertil. Pet. involuta, integra. Fruct. ca . elliptic. compreffo-planus, ftriacus, vix emarginatus.

440. Anethum. Fl. flofcul. fertil. Pet. involura, integra . Fruct. fubovat. compreffus, ftriatus,

445. IEgopo- FI. exter. inæqual. inter. æqual. Pet. profunde dium. cordata. Sem. magna, oblong. convexa, profunde ftriata, nuda.

444. Apium. Involuc, I-phyll, vel o. Fl. flofcul. fertil. Pet. inflexa, integra. Fruct. minimus, fubrot. Sem. ovatum, intus planum, dorfo tenuiffime ftriato.

442. Pimpinel-Fl. fubradiati, fertil. Umbel. ante efflorefcenla. tian nutantes. Pet. cordata. Fruct fubrotund. aut fubovatus. Sem. intus plana, paulifper acumin. dorfo gibbo, tricoflato.

443. CuJonia. Pet. trigona. Margo receptac. dilatatus in calyc. s-dent.

\section{T R I G Y N I A.}

Fl. fuperi.

448. Vibur- Cal. 5-dent. fuperus. Cor. campanul. 5-fid. Bacca num. T-fper.

450. Sambu-Cal. 5-fid. Cor. rotata, concava, 5-fid. Baccus. $\quad$ ca 2-3-fper. Fol, pinnata. Fl, in noftris cymofi .

$\mathrm{Fl}$. inferi .

446. Sernecarpus. Cor. 5-pet. Drupa cordata, cellulofa, I-fper. 447. Rhus. Cal. 5-part. Pet. 5. Bacca coriacea, I-fper. 449. Caffine. Cal. 5-part. Cor, 5-pet, Bacea 3-fperm. 45I. Spathelin. Cal. 5-phyll. Cor. 5-pet. Filam. bifi dent. Capf. 3-gona, 3-locul. Sem, folitar.

452. Staphy-Cal. concavus, 5 -fid. marcefcens. Pet. 5 , elliplea. tica. Styli 2-3. Capf. veficæeform. membranacea, 3-locul. Sem, globofa, cicatrizata, offea.

453. Tamarix. Cal. campanul. 5-part. Pet. 5. Stam. etiam 10. Capf, 3-valv. I-locul. Sem, pappofa.

460. Drypis. Cal. 5-dent. Pet. 5, coronata. Capf. circumfcifla, I-1per.

455. Turnere, Cal, infundibulif, 5-fid. exter, 2-phyll. Pet, 5, A a iij 
calyci inferca. Stigmat. multifid. Capf. 3-valv. I-locul.

462. Sarot/ura. Cal. I-phyll. 5-part. Cor. 5-pet. Capf. 3-valv. 1-locul. colorata .

459. Alfine. Cal. 5-phyll. Pet. 5, bifid. aqualia. Capf. 3valv. r-locul. polyfper.

456. Telephi-Cal. 5 phyll. Pet. 5, aqual. receptac. inferta . um . Capf, triquetra, 3-valv. I-locul. polyfper.

457. Currigio-Cal. 5-phyll. Cor. 5-pet. Sem. 1, triquetrum, la. sudum, cal, contentum.

458. Pharaaceum. Cal. 5-phyll. Sor. o. Capf. 3-locul. polyfper.

454. Xylo- Cal. 5-part. coloratus, Cor. o. Stign. lacera . phylla. Capf, 3-cocc. Sem, 2. Fl, hermaphr, \& fea. in eodem caule.

461. Bafella. Cil. o. Cor. 7-fid. lacinî́s 2 oppofitis, latioribus. Sem. I, globofum, calyc. baccato.

* Rhamnus Paliurits. * Celaftrus.

\section{T E T R A G Y N I A.}

463. Parnaffa. Cal. 5-part. Cor. 5-pet. Nectar. 5, cordata, ciliata, apicibus globolis, ( in quibus effentia generis). Capf. 4-valv. 4-locul, locul. polyfper.

464. Evolvu-Cal. 5-phyll. Cor. rotata, fub-5-fid. Sem. folus. litar.

\section{P E N T A G Y N I A.}

\section{Fl. fuperi.}

465. Aralia. Involuc. umbellulæ. Cal. 5-dent. fuperus. Cor. 5-pet. Bacca 5-fper.

Fl. inferi.

472. Crafula. Cal. 5-phyll. Cor. 5-pet. Squamæ 5 nectarifera ad bafin germinis. Capf. 5. Staminibus 5 a Sedo differt. Fol. carnola, fuccola.

471. Gifekia. Cal. 5-phyll. Cor, o. Capf. 5, adproximatæ, fubrotun. Sem. folitar.

468. Linum, Cal. 5-phyll, Pet. 5, æqualia. Filam.5. bafi membranofa communi inter fe connexa. Capf, 5-valv, Io-locul, Sem, folitar. 
469. Aldro- Cil. campanul, 5-part. Cor, 5-pet. Capf, 5-valv. vanda. 1-lowl. Io-fper.

470. Drofera. Cal. tubulofus, 5-fid. Cor, 5-pet, Capf. apice dehifcens, 5-valv. t-lozul, polyfper.

473. Mahernia. Cal. 5-dent. Cor. 5-pet. Nect. 5, obcordata, filamentis fuppofita. Capf. s-locul.

466. Commer-Cal. 1-phyll. corollifer. Cor. 5-pet. Nect. s-part. fonia. Capf. echinata; 5-locul.

474. Sibbaldia. Cal. 10-fid. Pet. 5, calyci inferta. Styli e latere germinis. Sem. 5.

467. Statice. Involuc, univerfale varium. Cal, proprius infundibulif. limbo integro, plicato. Per, 5, fenfim dilatata, \& iuxta fe pofita, infundibulum referentia. Fruct. ftellatus, I-fperm. ex calyc. perfiltente.

* Cerafium pentendrum.

* Spergula pentandra.

* Gerania pentandra.

P O I Y I N I A.

475. Myofu- Cal. 5-phyll, bafi adnatus. Nectar, 5, fubulata, rus. petalifor. Sem. numerofa.

* Ranunculus hederaceus.

214. HELIO- UOr. hypocraterif. 5-fida, interiectis dentibus: TROPIUM, centro floris plicato, fine glandulis .

1. peruvia- H. caul, frutefcente: fol.lanceol-ovat. fpicis nunum.

\section{$\mathrm{MON} O \mathrm{G}$ Y N I A.} merofis, aggregato-corymbofis. Syft, veg. ed. 14. Mill. ic. tab. 243.

In Peru $\hbar$.

Caul. 2-ped. hirti, inferius longe ramofi.. Fol. lineata, rugofa, pubefcent-fcabra, utrimq. viridia, breviter petiol. Padunc. verfus extremitates hirti, 2-fidi, feu dichotomi. Spicz 3-4. fecundæ, recurvatæ. Cor. cœrul. fimil. H. indico, odore debili Vanilla.

A a iv 
2. indicum. H. fol. cordato-ovat. acutis, fcabriufcul. fpicis (fæe ) folirar. fructibus 2-fid. Syjt. yeg. ed. 14. Pluk. pht. $t$. 245. f 4

b. H. americ. \&c. Sabb, hort, rom. 2, tab. 34 . In India utraque.

Caul, herbaceus, ped. Fol. petiolat, integerrima. Spicæ longiffima, palmar. apice revolutæ. Cor. cœrul. Sem. unilocul. per parid adproximata.

3. parviflo- H. fol, ovat, rugofis, fcabris, oppofitis, alterrmm, nifque: fpicis coniugatis. Syft. veg. ed. 14, Dill. elth. tab. 146. f, 175. Pluk. phyt. tub. 404. f. 3.

In India $\odot$.

Adfine admodum priori. Caul. erectus, pedal. pubefc. Fol. petiol, acuta, lucida. Pedunc. oppofitifol. aut e dichotonid caul. erecti. Spicæ imbricatæ, recurvatæ. Cor. parva, alba, fundo flayo.

4. europeum. H, fol. ovat, integerr, tomentofis, rugofis: fpicis (fupremis) coniugatis. Syft. yeg. ed. I4. Jacq. Auftr. 3. tab. 207. Subb. hort. 2. tab. 33. Bocc. Sic. $t a b .49$.

In Europa auftrali $\odot$.

Caul. cubital. fere diffufus. Fol. alterna, petiol. nervofa, albida. Spicæ longæ, , intortæ, fecunda. Cor, albefcens. Var. $f$. ma: odore Jafmini .

5. Supinum, H. fol. ovat. integerr. tomentofis, plicatis: fpicis folitariis. Syjf. veg. ed. 14. Gouan. Monfp. cum fig. Cluf. hift. 2. p. 47. fig. bonat.

In Salmantice agris, \& Monfpelii in litore $\odot$.

Planta procumbens. Fol, parva.

6. frutieofum, H. fol. lineari-lanceol. (hifpidis): fpicis folitar. feffilibus. Syft. yeg. ed. 14. Sloan. Jam. 1. tubs. 132, f. 4.

In Jamaica $\hbar$.

Frutex parvus, vix fpithamaus.

7. curaJavi- H. fol. lanceol-linearibus, glabris, aveniis: fpicis oun . coniugatis. Syft. veg. ed. 14. Burm. Ind. tab. 16. f. 2. Pluk. alm. $a a b .36$, f. 3. Sloan. Jam. 1. tab. 132. f, 3. Morif. Hift. 3. S. Is. tab. 31. f. 12. Herm. Par. tab. 183 .

In America caludioris maritimis $\odot$.

Caul, palmar, teres, glaberrimus, rore glauco. 
Fol. fubpetiol., pafim alterna, \& oppofita, obtufiufc, oleracea, erecta, integerr. Spicæ recurvæ, Cor. alba, fundo flavo, fauce patula.

8. orientale. H. fol. linearibus, glabris, aveniis: fl, lateralibus, fparfis. Syft, veg. ed. I4.

In Afra $\odot$.

Planta parva, procumb. repens. Fol, alterna : Fl. folitar. alterni, fubfeffil.

9. gnaphalo- H. caul. frutefc. fol. linear. obtnfis, tomentofis; des. pedunculis dichotomis, fpicatun fliquternis. Syft. veg. ed. 14. Jacq Atne-. tab. 173. f. IT. ed.2. pida sab.259. f 9. quard folium Morif. hift. 3. f. II. tab. 28, f.6. Pluk. alm. tab. 193. f. 5 .

In Barbados, Jamaica maritimis $\hbar$.

Cdul. plerumque 2-raro 6-pedal. Rami formantes comam convexam, candicantem. Fol. numerofi, feffil. fparfa, cuneiformi-lineas. cruffa, glauca, conferta in fummis ramis. Pedunc. termiual. tomentofi . Spica fecunda, fapius 2-fida. Cor. alba .

bacciferum. H. caul. frutefcen. proftrato: fol. oblongis, hifpidis, margine reflexis. Forsk. I g $_{\mathrm{g}}$.

In Arabia.

Cor. tubus flavus, calyce duplo longior; limbus albus; faux nuda. Stylus medio incraffatus, \& anuln Jato circumdatus fub ftigmate, quod 2-fid, eft. Sem. intra baccam 4-angular. umbonatam .

ovalifolium. H. caulibus decumbentibus : fol. petiolat. oblongovalibus, integris. Forsk. $\overline{A g}$.

In Arabia.

Stylus anulatus. Dentes nulli in fauce.

fabrum. H. caul. diffufo, ramofo: fol. lanceol. Arigofis : fl. congeftis. Retr. Obf. fafc. 2.

Radix fimpl. fufiform. Fol, alterna, in fummis ramulis quandoq. oppofita, plerumq. obliqua, integerr. Fl. terminal. parvi, albi, fol. obvallati .

Marifolium . H. caulibus procumbentibus, fruticulofis: fol. lanceol. hifpidis: fpicis fimplicibus, alternis. Ret?. Obf. fafi. 2.

Radix lignofa. Caul, ramofi, hilpidi, Fol, alter- 
na, \& fparfa ( $T_{\text {eucrii }}$ Mari, led minora). Spicæ copiofæ: bracteæ forma fol. Cor. alba, exrus, ficuti calyx, hirfuta .

Coromande- H. fol. obovat, integris, villofis: fpicis fimplilianum. cibus, coniugatilque: feminibus punctatis ? Rerz. Obf. fafc. 2.

Radix fimpl. fufiform. Caul. erecti, ac prokrati, hifpidi. Fol. oppofita, \& alterna. Spica lateral. \& terminal. Cal. inæqualiter hifpidus. Cor. parva, alba.

malnbaricum. H. fol. ovatis, plicatis, integerrim. Atrigofis: fpicis fubfolitar. Retz. Obf. fafc. 4. Burm. Ind. tab. I6. f. I.

In. Mntabaria.

Differt ab H. europeco ftrigofitate totius plante: folior. plicis, Eparvitate: petiol, brevibus: fpicis fape geminis, fed non coniugatis: calycibus minime imbricatis.

215. MYOSOTIS. Flos Heliotropii, fed faux glandulofa, interiectis plicis albidis.

1. fcorpioides, M. feminibus lævibus : fol. apicibus callofis. Syft. veg. ed. 14.

arvenfis.

Fl. Dan, tab. 583 .

In Europe campis aridis $\odot$.

Planta bifpida, Caul. ramofus, 4-unc. Fol. ovato-lanceol, tubercolo terminata: ima petiolat. fuperiora feffil. fordide virentia, ficca. Spicæ fcorpioideæ, aphylla, incurvæ. Cor. corul. vel carnea, umbilico flavo, val albo;

raro alba. In alpibus adnata villofior eft.

paluftris. Species diftincta a priore. Zan, tab. ISI. In aquofis fcaturiginofis $\mathbf{4}$.

Planta glabra. Caul, pedal. Fol. craffufe. late virent. Cor. cœrul. vel alba .

2. fruticofa. M. fémin. lævibus : caul. fruticofo, lævi. Syft. yeg. ed, I4.

Ad cap. 6. Spei b.

Caul, pedal, ramofus. Rami multi floriferi ad fummitatem caul. Fol. alterna, linear. fere Javia, pilis raris adfperfa. Spicæ feffil, fecundæ. Fl. \& fruct. parvi.

3. virginiana. M. feminibus aculeato-glochidibus: fol, ovat-obl. ramis divaricatis. Sy.f. veg. ed. I4.

Cynogloffum \&c. Morif. Hift, 3. f. I1, tab. 30, f. 9. In Virginia $\odot$. 
Fol. magna, acumin. utrimque viridia. Flos minimus, albus. Fructus nutans. Sem. interiore latere nuda, angulata, erecta, bafi adfixa, ut in fequenti.

4. Lappula. M, feminibus aculeis glochidibus: fol. lanceol. pilofis. Syft. veg. ed. 14. Fl. Dan, tab. 692.

In Europa argillofis, muris \&c. $\odot$.

Caul, ped, ramofus. Fol. angufta. Fl. axill. fubfeffil. Spica fcorpioidea, incurva. Cor. parva, corul, vel alba. Capf. echinata, aculeorum apicibus ftellatim fimbriatis.

5. apula . M. feminibus nudis: fol. hifpidis: racemis foliofis. Syft. veg. ed. 14. Pluk. phyt. 16. f. 5.

Echioides \&c. Col. ecphr. 1. tab. 185.

Anchufa \&c. Lob, ic. 312.

In Italia, Hifpania \&c. $\odot$.

Differt a M. fcorpioide, cor. tubo longiore; ftaminibus altius cor. parietibus adfixis; cur. Lutea.

(pauciflora.) Myofotis (Scorpiurus) fol. ovatis : Ppica pauciAlora; calyuibus tementofis. Hall. Hijt. n. 592. Bocc. Muf. 2, tab. 107.

In alpibus Helvetia.

Plantula humillima, nequidem trientalis, cefpite foliorum denfiffimo. Fol. Serpylli, fubrotunda, fubhirfuta. Spica parva, 3-fl. aut paulo ultra, ut unicus flos totam occupet; grandes enim funt, \& late coerul. Cal. longo villo fericeo barbatus. Flos maior ex tota familin. rupeftris. M. Pall. It. $3 . t, i$, E. f. 3 .

In Dauurice mantibus 24 .

Caul. pl, digital. diffufi, adfcendent. fimpl. pilofí Fol. radical. conferta, obovato-lanceol. obrufa, dura, hifpida : caulina alterna, oblongo-linear. Fl. racemofi, ante efflorefcentian revoluti, breviff. dein elongati. Cal, hifpidus. Cor. nunc mediocris, nunc magnitudine M. feorpioidis, fpeciola, fature cyanæa, fauce flava. Pedunc. fructiferi elongati.

peäinata." M. Pall. 1t. 3. tab. E. f. 4. Semen.

In Daunia.

Priori crefcendi modo fimilis. Fol. omnia ovatlanceol. acutiufc. tenuiora, pilis longis birfuta : radical. conferta; caulina fparfiora, alterna, fefil. Caules pauciores, dodrant. \& ultra, fub- 
hirfuti. Racemi floriferi pl. fubdivifi; poft efflorefcentiam elongati, foliolis min. adfperfi . Cal. ur in priore. Cor. min. cyanæa, fauce pallida.

echinophora. M. Pall. It. 3. tab. I. I. f. I. A.

In Dauuria ○.

Planta fubdigital. pilis albis hifpida, M. Lappula

fucculentior. Caul. rectus, initio fubfimpl. fructificando fenfim elongatus, in paucos ramos dichotomus. Fol. duo feminal. ovata, bafi attenuata, glabra; cærera alterna, linearia, a. pice latiufculo, fubrus, margineq. pilofa. Cor. minuta, limbo azurreo, fauce albida, coarctata . Terglouenfis, Myofotis. Hacquet pl, alpin. Carniol.tab.2. f. 6. In Carniole 24.

Plantæ col. tritis, vel viridi-fufcus, excepto fl. Odlor Syringa. Caul. 1-pl, recti, vel procumbentes, foliofi, imbricati, hirfuti. Fol. ima fubnigrefcent. cæetera fufco-virent. feffil, oblonga, ovata, aut fpathulata, 2-3. lineas longa, integerr. plana, pilis albis rigidis oblita; caulem circundantia: in medio $2-3$. fl. nafcuntur . Cor. tubus ventricofus anulum cilyndricum etformat, flavum, fulphureum, Cor, limb, planus, eleganter coeruleus, fegmentis fubrotund. ovatis, integris.

fquarrofa. M. feminum angulis fetofo-uncin. fol, lanceol, pilofis, apice callofis. Retr. $O b f$. fafi. 2.

Radix anrua, ramofa. Caul. in culta planta 2ped, pilofus, denfe ramofus, ramis inferior. brevioribus, Fol. alterna, obtufa, integerr. Racemi alterni, longi, laxi. Fl. parvi, cœerul. fauce flaya, bracteati. Cal. pilofus .

An M. echinophora, Pall. It, 3. tab. I. f. I. A?

$n a n \pi$,

M. fol. tomentofis, feminum marginibus ferratomarginatis, invicem coniunctis. Vill. prosp. tab. 23. f. 3. Fl. Ped.

Echium \&c. Bocc. Muf. trb. 129.

In monte Ceniflo \&c. 24.

216. LITHOSPERMUM . Cal. 5-part. Cor. infundibul. limbo 5-fido, fauce perforata, nuda. Sem. 4, dura . (Differt a Myofotide fauce pervia, \& figmatibus binis. )

I. officinale, L. feminibus lavibus : cor, vix calycem fuperantibus : fol, lanceol, Syft, veg. ed. 14, Black. tab. 
426. Sabb. horc. \&. tab. 29. Ludw. ea. $t a b$. I 47.

In Europe ruderatis 24.

Caul. erectus, teres, fupra medium ramofus. Fol. alterna, feffil. elliptica, hirta, cinereovirent, integerr. Fl, axill. parvi, albidi. Sem. candida. Canadenfe totum hirtusz.

2. arvenfe. I. feminibus rugofis: cor. vix calycem fuperantibus. Syft. yeg. ed. 14. Fl. Dan, tab. 456.

In Europe agris, \& arvis $\odot$.

Radix rubra. Caul diffufi, pedal. ramofi. Fol. elliptica, afpera, ficca, cinereo-virent. Fl. congefti. Cal. peduncul. Cor, parva, cœrul. vel allua.

3. virginicum. L. fol. fubovalibus, nervofis: cor. acuminat. Syfi. veg. cd. 14. Morif. hift. 3. f. II. tab.28. f. 3 .

In Virginia .

Caulicul. dosrant. Fol. fefquiunciam longa, inordinata, obtufa, afpera. Puncta adfperfa foliis funt exfcavata, horum latiora feta egrediente norata. Cor. ex albida.

4. orientale. L. ramis floriferis lateralibus: bracteis cordatis, amplexicaulibus. Syft. veg. ed. I4.

Buglolfum \&c. Dill, elch, tab. 52, f. 60, Buxb. cent. 3. tab. 29.

In Oriente $\odot$.

Caul. fterilis erectus, pilis rarioribus. Fol. lanceol. bafi anguftiora, obtufa, integerr. utrimq. pilis roriferis. Rami floriferi ex alis fol. inferiorum. Bract. pilofæ, roridæ. Fl. fubpedunc. lutei . Stam. tubo breviora . Anth. nigra.

5. purpuru-ca. L. feminibus Iævibus: cor. calycem multoties furuleum. perantibus. Syft. veg. ed. I4. Jacq. Auftr. I4. Bocc. Sic, tab. 40-41. Dod. pempt. 83.

Anchufa \&c. Pluk. tab. 76. f. 2.

In Europe nemoribus \&ic. 4.

Caul. fteriles repentes, radicantes; floriferi erecti, villofi, fubnigri. Fol. lanceol. nervo medio norata, hifpida, dura, integerr. pallide virent. Fl, multi cœerulei, \& purpur.

6. fruticofum . L. fruticofum; fol. linearibus, hifpidis : ftaminibus cor. æquantibus. Syft. veg. ed. I4.

Anchufa \&c. Barr. ic. I168.

Bugloffum \&xc, Garid, aix, tab. Is. 
b. Anchufa \&c. Alp. exot, tsb. 68.

In Gallia, Samo, \& Europa auftrnli $\hbar$.

Caul. parsus, ramofus, hifpidus. Fl. in apice ramorum. Cal. feffil. Cor. violac.

7. tenuiflorum. L. fol. lineari-lanceol. ftrigofis: cor. filiformibus. Syft. veg. ed. 14. Lin. Suppl.

Bugloffum chium, arvenfe \&c. T. Cor.

In Egypto $\odot$.

Planta palm-fpitham, facie ninoris L, arven/sis. Caul. erect. fubramof, filifor, fubpubefiens . Fol. alterna, feffil. obtufiufc. Calyces ramorum fecundi, alterni, fubpedicell. laterifolii, oblongi . Cor, minutiffimæ, cœrul.

8. difpermum. L. feminibus duobus: calycibus patentibus, Syft. veg. ed. I4. Lin. dec. I. tab. 7.

In Hifpania $($ ).

Caul. erectus, palmar, herbac. ramofus, teres, hirtus. Fol. alterna, feffil. lingulata, pollicem longa, obtufa, hirta: ramea lanceol. acuta . Fl. ramei, oppofitifol. alterni, pedunculat. Cal. quafi inflacus. Cor. dilute purpur. Sem. tantum 2, nec tamen bilocular.

retortum. L. Pall, It. 3. $2 a b$, I, I, f. 2. B.

In Douuria $\odot$.

Simile L. difpermo, fed conftanter I-fpermum. Plantula dodrantal. ficca, rigida. Fol. feminalia pro radicalibus, vel fola, vel rariıs adhuc altero pare duplicata, feffit, ovalia, nuda: caulina alterna, oblongo-linearia, cauli adpreffa, pilofa, Racemi circinnati. Fl. fecundi, minuti, pallide cyanæi, fauce pallida .

hifpidum, I. caul. procumb. fol. lanceol-linearibus, feffilibus, undato-dentatis : f picis termindhous, fecundis. Forsk. $\mathbb{E}_{\mathrm{g}}$.

In Arabia 4.

Caul. pedal, ad bafin ramulofi, dichotomi, hirpidi. Fol. pollic. alterna, rigida. Pedunc. fpicati, ante efflorefcentiam revoluti. Fl. conferti. Cal. hifpidus. Cor. calyce longior, plicata, obtufa, alba .

Heliotropioi- L. caul. procumb. fol, breviter petiolat, ovalides. bus, fubrepandis: fpicis lateralibus, \& terminalibus. Forsk. $\Phi_{g}$. In Arabia $\mathbf{4}$. 
Simile priori, Rami alterni, binis propiorihus, Fol. obrufa, utrimq, villofa, venis fimplicibus, remotis. Pedunc. 2-pollic. Cal. hifpidus, non s-part. fed 3.dent. Cor. vix calyce longior, acumin. alba, fauce pervia. Sem. oblong. lævid.

oiliatum. L. fol. ovato-lanceol. tomentofis, aculeato-ciliatis. Forsk. Eg.

In Arabia.

Cdul. aculeis hifpidus. Fol, brevifima , Cor. calyce longior, violac, fauce pervia. Sem. parva, nigra.

anguftifolium. I. feminibus levibus: cor. calyce triplo tongiore : caul. diffufo: fol. lanceol. Forsk. AEg. 8

\section{In Arabia.}

Habitus L. purpuro-carul. fed nec repens, nec latifolium. Caul. p!. dimidiam fpithamam longi, apice parum ramofi, albo-rufefc. hifpidi . Fol. erecta, patentia ; fuperiora pollic. feffil. alterna, hifpida, potiflimum fubtus. Spicæ rerminal. pedunculat. fecundz, ante florefcentiam revolutæ; fl. alternis, bracteatis. Cor. incarnata, limbo violac. laciniis ovat. medio albis ; deflorata coerul.

digynum. L. fol. ovatis, margine reflexis: feminibus villofis. Forsk, 死g.

In Arabia b.

Fruticul. diffufus, ovalis, ramofus. Fol. alterna, feffil, nutantia, villofa, fcabra, fupra profunde venofa, fubrus iifdem venis valde elatis. Stipula 2. lanceol. patentes, foliola aliquot fafeiculata in qualibet axilla foventes. Pedunc. ramorum terminales, oppofiti, fecunde fpicati, aphylli. Cal, hifpidus. Cor. viridis, apice albido-flavo .

217. ANCHU-Cor. infundibul, tubo longo, reto, limbi fegSA. mentis orbicularibus: fauce claufa 5 fquamulis .

1. officinalis. A. fol. Ianceol: fpicis imbricatis, fecundis. Syft. veg. ed. I4. Fl. Dan, tab. 572 .

Ad Europe ruderata 4.

Confundebatur a Botanicis cum A. Italica Retz. Obf. fafc. I. A qua differt magnitudine; $A_{1}$. cequalibus, multo magis imbricatis; limbi lacin. ovatis; faucis fquamis leviter tantum tomentofis, \& quafi cucullatis; calycis laciniis brevio, ribus, latioribus. 
2. angufifo- A. racemis fubnudis, coniugatis. Syft. veg. ed. lia.

3. italica. A. fol. lanceol. undulat. fummis acumin. fqua-

14. Mill. Diä. tab. 82.

Borago \&c. Zan. tab. 39 .

Bugloffum \&c. Morif, Hif..3.f. 11, tab.26. f. 4. Echii \&c. Lob. ic. 576.

In Italia, Germania, ad vias, \& fecus arva 24. Radix crafía, fulva. Caul. cubiral. \& ultra. Fol. humifufa, \& erecta, craffa, hirfura, afpera, e viridi-pallefcentia: caulina feffil. breviora, anguftiora, bafi artenuata, fubdent. fpinulis afperd. Fl. terminal, initio capitati, dein fpicati, fpicis incurvis. Cor. parva, violac. corrul. fanguinea, rero alba, ftaminibus candidis. mulis faucis penicilliformibus. Syft. veg. ed. I4. Trew. pl. rar. dec. 2, tab. 28.

4. undulata. A. ftrigofa; fol. linearihus, dentat. pedicellis bractea minoribus; calycibus fructifer. inflatis. Syjt. veg. ed. 14. Mill. diä. tab. 29. Gmel. it. I. $t a b .37$. Bacc, Muf. tab. 77. Barr. ic. 578 . In Hifpania, Lufitania, Sibiria pratis. Planta pilofa. Fol. undulata.

5. tinctoria. A. tomentofa; fol. lanceolatis, obtufis: ftaminibus corolla brevioribus. Syjt. veg. ed. I4. Beuh. hift. 3. p. 584 .

Monfpelii, in Sicilia, Pedemontio, locis aridis 4. Similis A. Lanuta, \& tota albo villo tefa. Pali ftaminum longitudine cor. Radix rubra, fucco fanguineo prædita . Caul. hifpidus. Fol. pleraq. radical. crera alterna, pilis albis obfita. Fl. terminal. purpurafc.

6. virginica. A. caul. glabro: fl. fparfis. Syft. veg. ed. I4.

Lithofpermum \&c. Morif. Hift. 3. f. Ir. tab. 28. f. 4 .

In Virginia 24.

Fol. oblong. angufta, obtufa, fubhirfuta. Fl. axill. Paraly $f i$ timiles, lutei.

7. lanata. A. fol. villofis; calycibus hirfutis: faminibus cor. longioribus. Syjt. veg. ed. 14 .

Halgiria .

Caul. pedal. fimpl. Fol. alterna, lanceol. obtufiufe. Racemi ex, alis fuperior. foliofi, recurvati, valde villofi, Cal, albido-flavefc. Cor. cœrul. Nect, unguibus 5. breviff, Anth, incumbent. Styl, longior.

8. Jem= 
8. Sempervi- A. peduneul, diphyllis, capitatis. Syjt. yeg. ed. I4. rens. Sabb. hort. 2. $a a b .23$.

Bugloffum \&c. Morif. Hift. 3. S. II. tab. 26. f. 2. In Anglia, Hifpania 24.

Caul. ad latera capitis rad. erecti, hifpidi. Fol. ovata, lineata, albo-maculata, periolar, remo. ta. Pedunc. axill. multif. Brast. 2, oppofitæe, feffil, lanceol-ovatæ. Cor. coerul. tubo brevi, uti Omphalodis.

lucida.

(italica.)

A. tul. Iucidis ftrigofis: racemis 2-part. 2-phyll. fl. fubinaqualibus, fauce barbatis. Retz. Obf. fafc. I,

Bugloffum Italicum, fl, cœerul. Eyft. AEft. Ord. 8. fol. 5 .

Buglofrum vulg. maius. J. B. Hifk. 3 .

In Itulia.

Confufa cum A. officinali, \& anguftifolia. Caul. erect. 4-ped. \& ultra, ramofus, angulatus, ftrigofus. Fol. infer. 2-ped. in petiolum definentia, lanceolata; media pedalia, lanceolata ; fuper, feniped. feffil. cordata, acumin. Pedunc. axill. \& terminal. 2-phyllı, foliol. cordatis, feffilibus terminati ; fpica coniugata, fecunda, reflexa. Pedicel, erecti. Cal. hifpidus. Cor, nonnihil inequal. longitudine calycis. Erģo A. officinalis e e $\int_{e}$ nequiz. Differt ab A. angufiffolia, magnitudine, \& fol. integerr. convenit vero cum hac racemis, coniugatis, 2-phyllis .

Saxatilis .

A. Pall. It. 3. tab. F. f, I.

In Dauuria 4.

Radix extus fufco-rubra. Caul. I-pl. quandoq. ramofi, erecti, vel patuli, uti tota planta, maxime fetofi, Fol, radical, ante efflorefcentiam marcefcentia; caulina alterna, oblongolinearia, urrimq. pilofa; floralía lanceol. Fl. e medio caule alterne fparfi, axill. breviter pedunculati, fecundi. Cor. purpuro-cœrul.

hifpida.

A. peduncul, axillar. brevibus: caule retrorfum hifpito; fol. inferioribus petiolat. Forsk. $\mathbb{E}_{\mathrm{g}}$.

In Arabia $\odot$.

Caul. diffufus, fpitham, ramofus. Fol. hifpida. Bract. feffil, ovat-lanceol. hirfuto-hifpidæ. Cal. extus hirfutus, Cor. violac. vis calyce longior, fauce claufa,
B b 
finocarpos, A. fl, paucis, albis: fornicibus 5. fupra antheras. Forsk, IEg.

In Agypto.

Caul. diffuf, fcabri. Fol. vix pollic. linearia, villofa, mollia. Cor. non emarginata. Sem. muricato.fpinofa.

tuberculath, A. feminibus tuberculatis. Forsk. AEg.

In Agypto.

Caul. proftratus . Fol. lanceol, hifpida. Spica foliola. Cor. lacin. obtufiffim. non emarginatis, cœrul. Fornices faucis 5.

Barrelieri. A. (Buglolfum) fol, ovato-lanceol: caule erecto: axillis folior. florigeris: racemis florum udilareraibus. All. Ped. Barr. ic. 333.

Secus vias, \& in vallibus 24 .

Rad. fufca, intus dilute rubens, lignofa. Fol. ad radicem plura, elliptico-lanceol. fubdecurrentia, petiolo lato, canaliculato, bafi ampliore, ambitu obfolete denticulata. Caulina femiamplexicaul. inordinata, conferta, magis lanceolata. Caul, angulatus, ftriatus. Rami florigeri, arque, fi folia floralia exceperis, nudi funt, Pedunc. bracteati. Bracteæ in oppolitos latus reflectuntur. Cor. azurrea, vix calyce maior. Fol. radicalia hifpido-verrucofa, ferfrm pili molliores in caule, \& fol. Pedunculi, \& fummi rami hirfutie fubincani.

2r8. CYNO-Cor. infundibul. tubo brevi, fegment, orbicular. GLOSSUM , fauze claula fornicibus. Sem. 4. depreffa, interiore tantum latere ftylo adfixa.

I. officinale. C. At uinibus corolla ibrevioribus: fol. latolanceol. (undulatis, fericeis.) Syft. veg. ed. 14. Bluck. tab. 249. Ludw, ea. tab, 81.

In Eurupa ruderutis $\delta$.

Caul. cubiral. erectus, $a b$ imo ad fummum ramofus, angulatus, villofus. Fol. magna, obfcure virentia, mollia, integerrima, alterna ; ima petiol. caulina reffili-amplexicaul, Fl. axill. Spicæ nudæ. Cor. fanguinis emortui col. vel alba, Capf. echinata.

2. virginicum, C. fol, fparulato-lanceol. lucidis, bafi trinerviis : bractea pedunculorum amplexicauli. Sy/t. veg, ed. I4. Morif. hift. 3. f. 11, tab. 30. f. 9.

In Virginia $\odot$.

Adfine priori: differt fol, fupra lucidis . 
3. eheirifolium.C. cor. calyce duplo longioribus; fol. lanceol Syft. veg. ed. 14. Cluf. hilt. 2. p. 612.

In Cretr, Hispania, Carnigla, Oriente, Pedemontio 0 .

Fol. fericeo-argentea. Cor, alba, venis fane guineis.

4. npenninum. C. ftaminibus corollam æquantibus. Syjt. veg. ed. I4. Sabb. Jorz. 2. tab. 36. Cul. ecphr. I. tab. 170.

In Apennino \&c.

Caul. erectus, 2-cubital. hirfutus, minus folio. fus. Folo maiora, feffilia, elliptico-lanceol. afpera, non fericea. Cor, brevior.

5. lavigatum. C. fol. lanceolato-ovat, glabriufculis: calycibus tomentofis: feminibus lavibas. Syfto veg. ect.

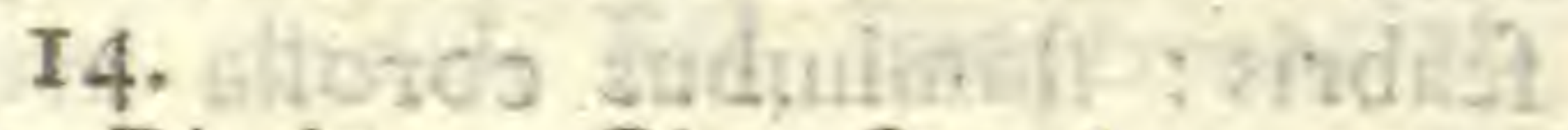

C. Rindera, Lin. Suppl.

Rindera tetrafpis. Pall, it. 1, tab, F. f. 1. 2.

In Sibirin, Oroburgi, \& ad Jaccum 24.

Caul, pedal, erect. fuperne paniculat, ftriatus. Fol, radical, petiol: caulina parva, feffilia .

Cal. 5-phyll, Cor. s-fid. alba. Filam, nulla. Anth. in ipfor finu inter lacinias cor, feffil. Styl. fetaceus. Stigm. globofum, vix confpicuum. Sem. deprefla, fuperius acuta, undique alata, margine lato, ftriato, rigide membranac, qua confertion adhaerent medio receptaculo craffo, conico, flylo perfiftente terminato. Sem. unurn, alterumq. raro marcefcit .

6. lufutanicum, C. fol, lineari-lanceol, glabris, $S_{y f t}$ veg. ed. I4. In Lufitania $\odot$.

Adfine fequenti, fed maius, \& afperius.

7. linifolium, C. fol, lineari-lanceol. (fupra) fcabris, Syft. veg. ed. 14. Morif. hijt. 3. f. I I. tab. 30. fo II.

In Iufitania $\odot$

Caul, fpitham. Pedunc. axill, multif, fubnudi. Cor. alba.

8. Omphalo- C. repens, fol. radicalibus cordatis. Syf. veg. des. ed. 14 Kniph, cent. 1, tab. 22. Knorr. del. 2. tab. C. 7. Fl, Carn, ed. 2. tab, 3.

Borago \&c, Morif. hift. 3. f. 11. tab, 26. f. 3 . In Lufitunia, Carniola, Pedemontil nemuribus, ad radices montium 4.

B b ij 
Radix obliqua, fufca, fibrofa . Caul. florifee fimpl. femipedal. e baft ftolones longos emittens. Racemi axill, paucifl, Cor. pulchre coerul. fauce albida, plicis 5. cordiformibus.

9. japonicum , C. caulibus proftratis : fol. oblung. villofis, $\$ y j t$. vig. ed. 14. Thumb. Jap.

In Japonia $\odot$.

4. Radic fibrufa Caul. 4-5. palmar. flexuofierecti, teretes, inæqual. villof. Fol, radical. fubdigitalia, ramea fenfm min. unguicularia: amplexicaulia , acuta, tenuifime ferrulata, potentia. Fl. terminal. racemofi. Cal. totus villofus, Cor. purpur.

- Ianceolatum. C. fol. lanceolat bafi attenuatis, pubefcentibus, fabris : ftaminibus corolla brevioribus. Forsk. Ag .

In Arabia.

219. PULMO-Cal. prifmarico-5-gonus, 5-dent. Cor. infundi-201 NAR1A bulif. limbo 5 -fid. concavo, lacinis rotundis, fauce pervia.

Wilfet suos $*$ Perianth longitudine tubi cor.

1. anguftifolia. P. fol. radicalibus lanceolat. Syft. veg. ed. I4. Fl. Den. $t_{t} b, 483$, Boce. muf. tab. 86. Cluf。 hift. p. 170.

In Helvetie, Pannonia, Italia, Germania, Svecia 4 .

Sequenti valde adfinis; differt folum fol. anguftis. Caul. fequenti altior, 3-ped. \& ultra. Fol. hifpida, fordide virentia: ima elliptica, obrufa ; fuperiora feffil. cordiformia. Fl. terminal. congefti, corul. rubri, albi .

2. officinalis. P, fol, radicalibus ovato-cordatis, fcabris . Sy ft. veg. ed. I4. Fl. Dan. tab. 482. Blak. tab. 376. Sabb. hort. 2, tab. 26. Ludw. ect. teb. 45 .

In Europa nemoribus 24.

Planra fubhirfuta : Caul. ramofus, brachiatus: Fol. dilute virent, frepe cum maculis albis: ima in petiolum definentia; fuperiora feffil. Fl. fpicæ incurva. Cor. coerul. rubra, alba. 3. fuffruticofa, P. fol. linearibus, fuabris: calycibus fubulat, 5-part. Syft. veg. ed. I4. 
Lithofpermum \&c. Pluk. phyt. 42. f. 7. Bock。 jic. 77.

In alpibus Italia $\$$.

2utu: Caul. radicales lignofi, perennantes cum foliis: florenres caules palmar. fimpliciff. fubpilofi . Fol. fere filiform. fparfa, longa, hifpida. Fl. terminal. fafciculati.

** Calyces tubo cor. dimidio breviores.

4. virginica. P. calycibus abbreviatis: fol, lanceol. obtufiufcul. Syft. veg. ed. 14. Mill. ic. tab. 212. Trew. Ehret. 10 b. 12.

Symphytum \&c. Pluk, alm. tab. 227. f. 6. In Virginia 4.

Caul. pedal. Fol, ima triuncial. petiolat, ovalia, carnofa, glabra, glauca; caulina anguftiora. Fl. corymbofi, longiores, coerul.

8. fibirica. P. calycibus abbreviatis: fol radicalibus cordatis. Syft. veg. ed. 14. Gmel. Sib. 4. tab. 390 In Sibiria 4 .

Caul. etiam cubital. Atriati. Fol. variæ magnitudinis, farure viridia, glabra, glauca, venofa : radical. petiol. cordata; saulina feffil. ova. ta. Corymbi ramoli, nutantes. Cor. purpur. vel cœerul.

6. maritima. P. calycibus abbreviat: fol. ovatis: caule procumb. ramofo. Syft. veg. ed. 14. Fl. Dan. tab. 25 .

Cerinthe \&zc. Dill. elth. tab. 65. f. 75.

Cynogloffum \&c. Pluk. alm. tab. 172. f. 3. Morif. hif. 3. S. I1. tab. 28 . f. 12 .

In Anglia, Norvegia, Islandice litoribus, filiceis $\odot .24$.

Caul. dein. erectus, pedal. pallidus. Fol. craffiufcula, glabra : glauca, venofa. Fl. corulefcent. immaturi coccinei .

Tres ultima nimis ndfines: 4. caul. erealo; cor. tubo longiore quam limbus: 5. fol, radicalibus cordatis: 6. caul. ramofif. qui eafdem fro varietate habet, vix errat.

220. SYM- Cor. Jimbus rubulato-ventricofus: ore 5-fid. fegPHYTUM mentis erectis: fauce claufa radiis fubulatis. x. officinale, S. fol. ovat-lanceol, decurrentibus, (alternis). Syft, veg. ed. I4, Fl. Dan, tab. 664. Blask. B b iij 
tab. 252, Sabb, hart. 2, tab. 30. Ludw. ect. tab. 80 .

In Europe umbrafis fubhumidis 24.

Planta afpera. Ciul, erectus, brachiatus. Fol. magna, pallide virentia, rugofa. Spica longa, fecunda, fl. cernuis. Cor. albido-flavefcens, vel purpur.

a. tuberofum . S. fol. femidecurrentibus; fummis oppofitis. Syft. veg. ed. 14. Jacq. obf. 3. tab. 13. Fl. Auftr. 3. tab. 225. Sabb, hort, 2, tab. $3 \mathrm{I}$.

In Germania, Monfpelii, Italia, Hifpania, ad ugrorum mergines, in pratis montanis 4 .

Prioris forte varietas. Tota planta hirfuta. Radix tuberofa, alba, nec exrus nigra, ut in priore. Caul, pedal, 5-gonus. Fol. elliptica ; inferiora rariora, alterna, minora, anguftiora priore. Cor. ochroleuca, vel magis flava.

3. orientale. S. fol. ovat. fubpetiolat. Syft. yeg. ed. 14. Buxb, cent. 5. tab. 68.

Juxta Conftantinopolis rivulos, primo vere 4 .

Planta afpera. Fol. Boraginis, fature virentia. Cor. alba, vel corul.

221. CERIN-Cor. límbus tubulata-ventricofofus, ore s-dent. THE. fauce pervia. Anth. pone hamulis cohærentes. Capf. 2. biloculares, ex feminibus coalitis :

r. maior C. fol, amplexicaulibus : cor, obtufiufe, patulis . Syft. veg. ed. 14. Sabb. hort. 1. tab. I2.

In Helvetia, Italia \&c. $\odot$.

Caul. cubital. ramofi. Fol. alterna, oblonga, bafi latiore, mucrone obtufo, glauca, verrucofa, maculis albis adfperfa. Fl. pedunculati, penduli, Cor. lutea, vel rubro-purpurafc.

Var. fol. afperis, \& fl. flavo.

2. minor. $\ddot{C}$ fol. amplexicaulibus, integris: cor. acutis, claufis. Syft, veg. ed. 14. Jacq. Auftr. 2. a ab. 124.

In Isalia, Aufirin Ec. 24.

Priori valde adfinis.

222. ONO- Cor. tubulofo-ventricofa, 5-fida, fauce pervia. SMA. Sem. 4. diftincta.

2. fimpliciffime. $\mathrm{O}$. fol. confertis, lanceo-linearibus, pilofis. Syft. yeg. ed. 14. Gmel. Sib. 4, tab. 40 . 
Echium \&c. Alp. exot, tab. 129.

In Sibiria,

Caulic. vix polm. Fol, digiti fere longitudine. Racemi fæepius 2. terminales, vix peduncul. Cor. Symphyti, vix 5-fida. Apex floriferus nutans, flavelceni-albus.

2. orientalis. O. fol. lanceol, hifpidis : fructibus pendulis . Syft. veg. ed. 14.

In Orience $\mathbf{5}$.

Huius plunte, verfus mare Cafpium crèfcentis, icom nerm dediffe credit cl. Pallas in itin. fui vol. 2. $t a b . L$.

Caul. teretes. Fol. alterna, feffil, integerr. Racemus terminalis, duplex. Bract, lanceol. anguftæ. Fl, pedunculaĩi .

3. echioides. 0 , fol. lanceol. hifpidis: fructibus erectis. Syft. veg. ed. I4. Jacq. Auftr, 3. tab, 295.

Anchufd \&c. Sabl, hart. 2, tab, 32. Col. ecplsr. tab. 183.

In Italia, Auftria, Helvetia Ec. rupibus 4.

Tota planta hifpida. Folia primo anno prodit fola radicalia, 2-5-unc. longa : altero anno, caulem femi-fefquiped. fuberectum, purpur. vel magis pallidum; qui peracto fructu perit. Fol. alterna, feffilia. Rami axillar. peduncul. breves, ex alis fuperioribus folitarii , r-fl. nutantes. Poft focundationem calyx fructiger erigitur. Cor. primum nivea, dein ochroleu$\mathrm{ca}$, extus parum villofa. Sem. cinerea.

223. BORAGO. Cor, rotata, profunde 5 -fid, fegmentis cufpidatis: fauce radiis claufa.

I. officinalis. B. fol. omnibus alternis: calycibus patentibus. Syft. yeg. ed. 14. Black. tab.36. Sabb. hort. 2. tab. 20. 21. Ludw. eâ. tab. 3. Knorr. del. I. tab. B. I.

In Europa: venit olim ex Aleppo $\odot$.

Caul. humilis, ramofus. Fol. ovato-lanceol. lata, rugofa, hilpida, integerr. e viridi-nigricantia; inferiora petiolat, fuper. feffil. Pedunc. terminal. multifl. Cor. magna, corul. carnea, alba.

2. indica B. foliis ramificationum oppofitis, amplexicaulibus: pedunc, I-fl. Sy/t. veg. ed. I4.

Cynogloffoides \&c. Ifrard. Aa. I718. tab. 10.

Anchufr \&c. Pluk. alm, tab. 76. f. 3 .

In India Oriens. $\odot$.

$\mathrm{Bb}$ iv 
Caul. ramofus . Fol. lanceol. minus hirfuta, $\mathrm{fca}$ bra; infer. oppofita, fuper. alterna. $R$ ma axill. alterni, patentes. Peduns cernui . Fol. Calycina cordato-Cagittata. Cor. alba.

3. africana. B. fol, oppofitis, petiolat. ovatis: pedunc. multifl. Syft. veg. ed, I4.

Cynoglolfoides \&c. Ifnard. Aa. I7r8, eab. II. In Athiopia $\odot$.

Similis priori, fed altior, \& robuftior. Caul. magis divifus. Fol. longe latiora, \& ovata, magifque hifoida. Planta flimulis adfperfa. Fol. floralia alterna. Pedunc, e fummis alıs, \& ramulis, pilof. Fl. parvi, cernui, fordide cœrul. medio flavo, punctis 5. purpur.

4. zeslanica. B. fol, rameis alternis, feffilibus: pedunc. I-f. calycibus inauritis. Syjt. veg. ed. r4. Burm. Ind. $t a b .14, \mathrm{f} .2$.

Anchufa \&c. Pluk. munt. tab. 335. f. 4 .

In India Orient. $\odot$.

Differt ab Europeza, \& Afric. pedunc. I- $f$. a B. Indica fol. non amplexuntibus; calycibus nor calcaratis. Caul, ramofus, hilpidus. Fol, caulina oppofira, feffil. lanceol. hifpida; ramea plura, alterna, minora, acutiora. Pedunc. ad fingula fol. ramea folitar. filiform. fol. longiores, pilofi. Cal. erectus, longitud. cor. pilofus, canefcens. Sem. glabra, quafi offea $C_{e-}$ rinthes.

5. orientalis. B. calycibus tubo cor. brevioribus: fol. (radicalibus) cordatis. Syjt. veg.ed. I4. Sabb. hort. 2. tab. 22, Tourn, it. tab. 523. Buxb. cent. 5. tab. 30.

Circa Conftantinopolin . 24.

Caul. fefquiped, rubens. Fol, radical. petiol. amplexicaul. bipalmar, cordara : caulina fubfeffil. ovata. Pedunc. axill. multifl. Cor. revoluta, hifpida, coerulefcens.

verrucofa. B. fol. verrucofis : verrucarum fetis rigidis, pumgentibus. Forsk. $\mathbb{A}_{5}$.

In Arrbia.

Cal. prifmaticus. Anthera longis fetis terminatæe. Sem. extus plana, emarginata, ferrata.

24. ASPERUGO. Cal. ;- fid. poft. efflorefcentian compreffus, forma 2-valvi. Cor. infundibulif. tubo recto, 
breviffimo; limbu femi $s$-fid. Squamula $s$ in fauce potita.

I. procum- A. calycibus fructus compreffis. Sy f. veg. ed. 14. bens.

Bugloffum \&c. Murif, hift. 3. .. I1. tab.26. f. I3. In Europez ruderatis pinguibus (-).

Caul. decumbens. Fol, alterna, periolat. oblongoovata, hifpida, cinereo-virent. fuperiora fuboppofita. Fl, parvi, prius subicundi, dein violac. Vir. fl. ulbis.

2. Egyptia- A. calycibus fruchus ventricolis, Syft.veg. ed. 34 . ca. ailet Jacq. hort. 3. tab. 2I.

Anchufa flava, Forsk. $E_{5}$. monente Vahl.

In Egypto $\odot$.

Caul. femiped. \& ultra, divaricatus, pallido-maculatus, hifpidus. Fol. alterna, fubpetiol. lanceol. craffula, venofa, adfperfa maculis albis, fubconicis; infina obtufa, fumra acuta. Fl. unilaterales. Cal. hifpidus, longitud. fere cor. Cor. ochroleuca'.

divaricate.

A. calycibus fructus ventricolis: fol, feffilibus . Murray. Comm. Gottin. 1776, tab. 2.

Habitat ... .

Habitus totius plantæe hifpidus, \& fuccofus. Rad, ramofa, exrus fufca. Cefpes radicalis denfus folior. \& caulium. Caul, ped. obliquus, angulat. in 2. ramos plerumq. fuperne divifus, quorum inferior fimplex; alter 2 fid. uterque divaricatus. Fol. lanceol. fetis irregularibus, ciliis remotis, feffil. venofa, obfolete repanda, cofta craffa: radical pedulia, bafi linear. canaliculata; caulina breviora, bafi latiore, fubdecurrentia. Fl. ramei, folitar. alterni, infimi aphylli, fuperior. axill. peduncul. Pedunc. dein cernui. Cal, ovat-oblong. lacin. acuminat. 2. fuperior. latioribus; fructu maturefcente inflexus, connivens, dein patens. Cor. alba, limbo patente, fauce fubclaufa fquamis 5. pilofis. Sem. nigra.

225. IYCOPSIS. Cor, tubo incurvato; limbo 5-fido.

1. veficaria. I. caul. proftrato: fol, integerrimis: calycibus fructefcentibus inflatis, pendulis. Syft. veg. ed. 14. Zann. tab. 38.

Bugloffum \&cc. Morif. hiff. 3. ., I1, tab. 26. f, II. In Exropa auftrabi $\odot$. 
Caul. pedal. hifpidus, in tres ramulos divifus . Fol. alterna, feffil. angufta, hirfuta, afpera. Pedunc. axillar. Cor. exigua, pulla, atra.

2. pulla. L. caul. erecto: fol, integerr. calycibus fructefcentibus inflatis, pendulis. Syft. veg. ed. I4. Jacq. Auftr. 2 tab. 188.

In Germania, Tartaria 4.

Differs a priore radice repente; caule erecto. Planta tota hirfuta. Rad. repens. Caul. fubped. fuperne ramofus. Fol, alterna, feffil. lanceol. acuta, craffula, mollia, pallide virentia. Fl. folitar, nunc axillar. nunc inter folia. Petala fuperne fufca, inferne atro-purpur.

3. crgyptis. L. caulibus adfcendentibus: fol. integerr. fcabris : caulibus fructefcentibus inflatis, pendulis. Syft. veg. ed. 14. Jacq. Mifc. vol. 3. ic. rar.

In Egypto.

4. variegata. L. caul decumbent, fol, repandis, dentatis, callofis : cor. cernuis. Syft. veg. ed. I4. Fl. Dan. tab. 435. Zann, tab. 37. ?

Bugloffum \&c. Stiff. Bot. tab. 57. Morif. hift. 3 . f. II. tab. 26 . f. 10.

In Creta, Dania, Pedemontio $\odot$.

Caul. dodran-pedal. Fol. radical. virid. bullis albis adfperfa. Fl. terminal. parvi, cœrul. vel rubri, friis albis.

5. arvenfis. L. fol. lanceol. hifpirlis: calycibus florefcentibus erectis. Syft. veg. ed. 14. Fl. Dar, tab. 435 .

Bugloffum \&c. Black. tab. 234.

In Europa arvis ficcis $\odot$.

Planta hifpida. Caul. fefqui-fpitham. ramis fparfis. Fol. late virent, tenera, fuccofa, quandoq. decurrentia, finuato-dentata, vel integerr. Fl. fpicati, multi, parvi, pallide ccerul. vel albi.

6. orientalis. L. fol. (cordato-ovat.) integerr. fcabris; calycibus erectis. Syjt. veg. ed. I4.

In Oriente $\odot$.

Caul. pedal. Fol. inferior. longe petiol. femipedal: caulina anguftiora. Fl, parvi, cœerul.

7. yirginice. L. fol. lineari-lanceol. confertis, tomentofis, mollibus: caul, erecto. Syft. veg. ed. 14. In Virginia ad vias $\mathbf{4}$. 
226. ECHIUM . Cor, irregularis, tubulofo-campanifor. fauce nuda. Stain. inæqualia.

I. fruticofum. E. caul, fruticofo: ramis, faliifq. pilofis. Syjto veg. ed. 14. Comm, kort. 2, tab. 54 .

Bugloffum \&cc, Pluk, mant, tab. 341. f. 7 .

In Athiopia $\$$.

Caul, 3-ped. fufcus. Fol. fefcunc. longa, mee diam lata, feffil. lanceol. inferne attenuata, viridia. Bract. lineari-lanceol. obtufæ. Rami fuperne breviter corymbofi. Cor. cœerul. fundo purpur. lacit, rotundatis. Stam, cor. non longiora.

2. candicans . E. caul. fruticofo ; hirfutum, albicans : fol. lanceol, urrìmq. acuminat, venofo-nervofis : panicul. terminal, pedicell. fpicatis. iyfito veg. ed. 14. Lin. Suppl.

In Madera rupibus altis

Frutex pulcher. Tota planta albicans, quafi argentea hirfutie albida. Fol. adproximata, fpithamæa, bafi attenuita ufque ad infertionem, ubi dilatata, fupra lineata, fubtus venofa. Panicula conica. Spicæ fecundæ, incurvatæ. Cor, ex minoribus huius generis, fubhirfuta, cœrul.

3. giganteum. D. fruticofum; ramis canis, glabris : fol. feffilibus, lineari-lanceolat. fcabriufcul. thyrfo terminali; fpicis fimpliciff. Syft. veg. ed. 14. Lin。 Suppl.

In rupibus Teneriffe $\hbar$.

Altiffimum. Fol. fpitham. longa, latitudine digiri, venofa. Thyrfus maximus, pyramidal. Fl. fecundi, Cor. fubæqual: obtufæ, albæ. Differt ab E. altiffimo Jacq. App.

4. fricizum. E. fruticofum: fol. petiolat. ellipticis, hilpidis, fcabris: caul. reverfe-hifpido: pedunc, axillarilus, fpicato-capitatis. Syjt. veg. ed. 14. Lin. Suppl.

In rupibus Teneriffa 5 .

Dignofcitur caule ftriato; fol. petiolat. oblong: pilis caulis deorfum verfis. Peduncul. in apice caulis, folitar. nudl, apice fpicul. 3-part. Fl. parvi, cœrul. Stam. exferra.

5. Spicatum - E. caulibus atfendentibus, fimpliciff. fl. fpicatis. Syft. reg. ed. 14, Lin. Suppl.

Ad cap, b, Spsi. 
Fol. radicalia plurima, palmar. lanceol-linear. valde pilofa. Caul. fol. duplo longiores; foliis aliquot minoribus, alternis, pilofis. Spica terminal. fere digital: compacta. Calyc. cani . Stam. cor, longiora .

6. argenteum. E. fol. linearibus, albido-hirfutis, apice patulis . Syft. veg. ed. I4.

In cap. b. Spei muntibus nigris.

Caul. determinate ramofus. Fol, vix pollicar. 1parfa, acuta, apice extrorfum curva . FI。 axillar. feffil. folitar, alterni . Cor. cœrul.

7. capitatum. E. caul, pilofo: fol, hifpidis : fl, capitato-corymbofis, æqualibus; ftaminibus cor, longioribus. Syft, yeg. ed. I4.

Ad cap. b. Spei b.

Caul. fruticofus, ramofus, pilofus. Fol. lanceol. adiperfa fetis patulis, pellucidis, bafi bultbofis . Capitula terminalia . Cor. infundibulif. vix $L y-$ copfidis ma. Sram. corollis; \& ftyl. ftaminibus duplo longior.

8. plantagine- E. fol. radicalibus ovatis, lineatis, petiolat. um. Syft. veg. ed. 14.

E. lato \& Barr. rar. f. 1026.

E. plantaginei varietas; fol. radicalibus lanceol. longe petiol. Jacq. Auftr. I. tab. 4 \%.

In Italin, ubique ad vias, \& loca ficca 8 .

Fol. fupra pilofa, mollia, hifpida . Radical. magna (Plantayinis): caulina $\mathrm{f} \in \mathrm{ffrl}$, lanceol. Caul. pilofi, punctis fufcis fub pilis, ut in reliquis, fed minutis. Cor, violac. (non corul, E. vuly. nec calyce breviores E. cretici) . Bract. inter. $\mathrm{fl}$, , femicordatæ, longitudine calyc. (non fubulata E. vulg. nec calyce longiores E. cretici).

9. lxvigatum, Ex caul. lavi : fol, lanceol. nudis, margine, apiceq. fcabris : cor. fubrequalibus. Syft, veg. ed. 14.

b. E. pyrenaicumz. E. maius, \& afperius, fl. dilute purpur. Tourn. inft, 135 .

Ad cap. b. Spei : b. Monfpelii 24.

Caul, fuffrutic. pedal, laves. Fol, glabra. Racemi ex alis fol, fupremorum, fecundi, laves. Cal. lavis, Stam. declinata, Sem. muricata .

b. Simil, E, italico, hifpidum, th fere urens fti- 
wiszag vigs mulis albis . Cor, calyce non latior, fubincarnara (nec alba), infundibulif. fere regular. calyce duplo longior, extus pubefcens, pallidiorque. Filam. duplo longiora, fature rubra. Ant, coerul. Sem. lavia, apice fubtrigona, quafi denticulo intermedio, feu interiore productiore.

10. italioum . E. caul, erecto, pilolo: fpicis hirfutis: cor. fubaqualibus: ftaminibus longiflim. Syft. veg. ed. 14. Cam. epic, p. 738 .

An E. altiffimum. Jacq. Auftr. 5, $a p p . t a b, \mathbf{I} 6$. mera huiks var.?

In locis ficcis Pedemontii Ec. $\sigma^{x}$.

Caul. pedal. erectus, vix ramofus, afper. Fol. glauca, pilis longioribus. Fl. parvi. Cor. vix calyce longior, violac, vel alba.

1r. rubrum. E. caul, ex racemulis brevibus longe fpicato: fol. hifpidis: cor. fubrequalibus. Syft. veg. ed. 14. Jucq. Auftr. 5. app. tab. 3. Aloviunh of

In prasis 24 .

Differt potiffmum a vulgari, fol. minor, anguftioribus: \& fl. rubro.

12. vulgare. E. caul, tuberculato, hifpido: fol. caulinis lanceol. hifpidis: fl. lateralibus, fpicatis. $S_{y} f$. veg. ed. 14. Fl. Dan, tab. 445. Black. tab. 229. Knorr. del. vol. 2. tab. E.

In Europa ad vias, \& agros $\gamma$.

Caul. cubital. erectus, fimpl. maculatus. Fol. inferiora lingulata, pilis bulbofis, petiolat. fuper. feffilia. Cor. violac. immatura rubra. Stam. corollam aquantia. Var. fl. albo, \& rubro; \& panicula crifpa.

I3. violaceum. E. cor. ftamina requantibus: tubo calyce breviore Syft. veg. ed. I4.

In Aufiria, Germania $\odot$.

Simil. priori, fed cor. violai, Caul. magis diffur fus. Cor. tuhus longitudine fore calyc. Stam. non langiora, purpur. tamen fillo albo, pilofo. Facies diftincia.

24. creticum. E. caul. procumbente: calicibus fructefcentilaus diftantibus. Sj t. veg. ed. I4. Chuf. hift. 2. P. 165.

In Creta, Oriente $\odot$.

Caul. afperi. Fol. radical. humifufa, maculis pallidioribus adfperfa. Cor, fature rubra, th: 


\section{PENTANDRIA MONOGYNIA.}

bo calycibus breviore. Filam. apice parum villofa ,

I5. orientele. E. caul, ramolo: fol, caulinis ovat, fl, lateralibus, folitar. Syft. veg. ed. I4. Tourn, it. 2. f. 107. ed. all. it. 3. pag. 94.

In Oriente.

Caul, 3-pedal, dilute virid. Fol. infer, Wub 15. pollic. longa, 4-5. lata, dilute virid. mollia, tomentofa : caulina femipedal. mollia, acutiora, minus tomentofa. Pedunc. axill. Fl, ma gni, campanulati, dilute purpur.

16. Iufitanicum. E. cor. ftamine longioribus. Syft. veg. ed. I4. In Europa auftrali 24.

Caul. fimpl. Fol. ampla; caulina lanceol. fericea, Fl. laterales, fpicati.

227. MESSERSCHMIDIA . Cor. infundibulif. fauce nuda . Bacca fuberofa, 2-partibilis; fingulo difpermo.

I. fruticofa, M. caul. fruticofo: fol. petiolat: cor. hyprocateriformibus. Syft, veg. ed. 14. Lin. Suppl.

In Septentrionalibus plogis Teneriffe $\hbar$.

Simil. Jequenti; diforimen ex definitione. Frutex altus, hirtus, fcaber, ramis apice panicular. Fol. alterna, longe petiol: lanceol, integra, hirta, venofa. Spica terminal. compofita, dichotom. fecundæ. Cal. breviff. Cor. parva, verfus limbum inflata, globofa. Bacca rotundata, ficia,

Cor. Tournefortia, fed frua. Me Jerfchmidia.

2. Arguzia, M. call. herbac. fol, feffilibus: cor. infundibujifor. Sy.li. veg. ed, 14. Ad. Petrop. 1763. tab. 11. Gmel. it, 2, tab, 27.

In Dauurix apricis glareafis, aridis 24.

Radix repens. Caul. erectus, fpitham-palm. rami alterni, fteriles. Fol. alterna, ovatooblon. venofa, tomentofa. Fl. fafciculi fæpe bini. Calyx tubo cor. brevior. Cor. alba . 228. TOUR-Bacca 2-locul. difperma, fupera, apice 2. poris NEFORTIA , perforata.

x. ferrata, T. fol. ovatis (acuminat.), ferratis ; petiolis fpinefcentibus: foicis terminalibus, recurvis. Syff. veg. ed. 14

Pittonia \&c. Plum, gen, ic. 228. f. T, b. 2. In America calidiore $b$.

Planta arborefcens. Fol, alterna, petiolis a cau- 


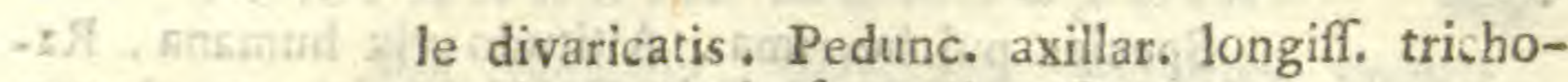
notrafin or tomi, racemis fecundis. Cor, magna.

2. hirfutifina, T. fol. ovat. (acuminat.), petiolat: caul. hirfuto: fpicis terminalibus, ramofiffmis. Syft.veg. ed. 14 .

Pittonia \&c. Plum. gen, ic. 209.

In America calidiore $\hbar$.

Planta arborefcens. Fol, alterna, fupra glabra, fubtus hirfuta. Racemi fecundi. Baccæ albae.

3. volubilis. T. fol. ovat. acuminat. glabris, petiol. reflexis: caul. volubili o. Syft. veg. ed, i 4 .

Bryonia \&c. Sloan, hift. 1. tab. I43. f. 2. Virga aurea \&c. Pluk. alm. tab. 235. f. 6. In Jamaica, Mexico, arbares fcandens $\hbar$. Planta 7-8-pedal. Fol, alterna, uisciam longa, parum reflexa, col. leucophizo. Racemi terminal. Fl. plurimi, herbacei.

4. fatidifima . T. fol. ovar-lanceol. hirtis; peduncul, ramofis: fpicis pendulis. Sy ft. veg. ed. 14 .

Pittonia \&ec. Plum, gen. ic. 230.

Heliotropii flore \&c. Sloan. Jam, 2. tab. 2 I2. f. $I$.

In Mexico, Jamiaica b.

Frutex 3-4-pedal. valde ramofus. Fol. magna, 9. unc. longa, 3. lata, petiolat. rugola, fubtus lanuginofa, obfcure virid. foetida. Racemi terminal. magni, ramofiff \& penduli, quibus a cæteris fpeciebus differt. Fl. \& baccæ albæ .

5. humilis. T. fol, lanced, feffilibus: fpicis lareralibus, feffilibus, recurvis. Syft. veg. ed. 14.

Pittonia \&c. Plum. gen, ic. tab. 227, f. 2.

In America calida $\hbar$.

Simil. T. volubili. Planta humilis, diffufa. Fol. alterna, integerr. fubtus hirfura.

6. cymofa. T. fol, oblon-ovat, integerr. nudis: fpicis cymofis. Sylt. veg. ed. I4.

Heliotropii flore \&c. Sloan. hift.2, $t a b .212$. f. 2.

In Jamaica b.

Priori nimis adfinis.

Fol. magna, glabra. Cor. albicans. Bacca niveæ, cum maculis nigris.

7. argentea. T. fol, ovat. obtufis, tomentofo-fericeis: fpicis terminalibus, compofitis. Syft. veg.ed. 14. Lin. Suppl. Rumph. Amb. 4. tab. 55 .

Ad litora maris Zeylanici b. 
Species pulcherrima. Altitudo vix humana. Rami patentiff. hirfuii. Fol, in apice ramulorum adproximata in rofam, alterna, feffil. linguiform. Panicula terminalis, magna, divifa in fpicul s fecundas, revolutas. Fl. nivei, recurvati . Baccæ impeiforatæ.

8. Suffrutico- T. caul. fuffrutic: fol. fublanceol. incanis. Syft. fa. veg ed. 14.

Thymelæd \&c. Sloan. Jam. 2, tab. I62, f, 4 . In Jamaica b.

Caul. 7-pedal. cortice fufco-rubente, fuperne divifus. Ful. multa, unciam longa, feffil. crafo fa, fucculenta. Pedunc incurvi . Fl. 4-pet. flavi.

maculatu, T. fol. ovatis, utrimg. glabris: fpicis ramofifim. pendulis. Jacq. Amer.

In Carthagena tepibus b.

Frutex raunis debilibus. Fol, petiolat, acumin. inregerr. inodora; fructibus duteis, bafi 4. maculis atris notatis.

glabra. T, ramofiffima, baccis niveis. Aubl. Guian. Plum. MSS. tab. 6. f. 53 .

In Guiana.

229. NOLANA Cor. campanulata. Stylus inter germina. Sem. 5. baccata, 2-4-locul.

I. proftruta. N. Syjt. veg. ed, I4. Lin. fil. dec. 1. tab.2. Sabb. hort. I. tal. 4.

Atropa \&c, Gouan. hort. 82.

Walkeria. Ehret. Aa. Angl. 1764. tab. 10.

Zwingera, $A a$. helv. 5. tab. I.

In, Peru 9 .

(10I ala Planta humifura, ramofa. Fol. geminata, altero breviore, decurrent. integerr. ciliata, carnofa. Cor. \& fructus fig. Convolvuli. Cor. cinerea, venis cœrulefcentibus. Stam. cœerulefcent. vil. lofiff.

230. DIAPENSIA. Cor. hypocraterifor. Cal. s-phyll. imbricat. foliol. 3. Stam tubo cor. impolita. Capf. 3-locul.

I. Inpponica, D. A. pedunculatis. Syft. veg. ed, 14. Fl. Dan. tab. 47. Fl. Lapp. tab. I. f. I.

Androface alp. perenn. \&c. Tourn. I. R. H.

In alpibus Lapponicis $\mathbf{4}$.

Habitus Sedi. Caul, digital, ramofus, foliofus. 
Fol. radicalia, imbricata, longitud. unguis, linear. obtufa, fere membranac. fuperne patentia. Pedunc. longitud. pollicis tranfverli, in apice ramul. I-fl, Cor. albs .

23I. ARETIA . Cor. hypocraterif, s-fid. tubo ovato. Stigma depreffo-cavitatum. Capf. globofa, I-locul. fub 5-fperm.

I. helvetica. A. fol, imbricat. fi. fubfefflibus. Syft. veg. ed. 14. Hall. helv, tab. 8. Jacq. Vind. 303.

In alpibus occidentalibus Helvetio \&c. 4. Ad Androfacen fpectat. Planta cefpitofa, cauliculi mufcofi, Sedi facie, tecti fol. pubefcentibus. Fol. breviff, ovata, conniventia, hirfutie albida. Scapus I-fl. Cal. magnus. Cor. fegmenta planiffima, rotunda, alba .

2. alpine. A. fol, linearibus patentibus: fl. pedunculat. Syft. veg. ed. 14. Jacq. Auftr. app. zab. 18. Hall. Helv, n. 618, tab. 11 .

In Vellefia 4.

Ad Androfacen fpeazat. Scapus 2-linear. Fol. pene glabra, ciliata. Flos maior. Cal, hirfutus, cylindric. femi-5-fid. Cor. tubus brevis, limbi fegmentis emarginatis, ferratis; albæ. Var. fol. villofis, of cor. rafea: vel fol. tomentofovillofis, \& cor. purpur. Cap\}. S-valv.

3. Vitaliana. A. fol. linearibus, recurvatis: fl. fubfefflibus . Syfl. veg. ed. 14 .

Vitaliana Sesl. epif, talb. Io. f. I.

Sanicula \&cc. Pluk, $a l m, t a b$. 108. f. 6.

Sedum \&c. Colum. ecplir. tab. 65. f. I.

In alpibus Pyrenacis, Helveticis, \& Italicis 4. Planta cefpitofa. Scap. breviff. I-fl. Fol. fubriliter villofa, per oras ciliata, inferne latiora. Cal, ultra medium 5-fid, villofus . Cor. longe de calyce eminet, flava, tubo longo, fegmentis ovatis. Sem. 5.

232. ANDRO-Involuc. umbellæ . Cor. tubus brevis, ventriSACE. cofus; ore glandulofo, 5-fido. Capf. globofa, I-locul, 5-valv. polyfper.

I. maxima. A. perianthiis fructuum maximis, Syft. veg. ed. I4. Jaeq. Auftr. 4, tab. 33I. Sabb. hort. 2. tab. 1 .

Inter Germania, Helvetix \&c. Segetes $\odot$.

Scap. 2-6-unc. rubellus, fuperne incraffatus. Fol. radical. petiolat. ovalia, denticulata . Tom, I. 
Umbella 5-8-fl. Cor. mirima, alba, intra calyc. maximum .

7. elongata, A. fol, fubdentat, pedicellis longiff. cor. calyce brevioribus. Syjt. veg. ed. 14. Jacq. obf. I. tab. 19. Fl. Aujtr. 4. sab. 330. Gmel. Sib. 4. tub. 44. f. 4 .

In Sibiria, Germania.

Simil. priori, fed calyc. maiores non evaduns abjoluto fl. Verum pedunc. proprii elongantur, longitudine ipfius fcapt. Planta 2-unc. \& ultra. Scap. medius erectus, reliqui patentilf. Fol. plura, radical. lanceol. vel oblonga, craffula, quandoq. integerr. Cor. alba .

3. Septentrio- A. fol. lanceolat. dentat, glabris: perianth, annalis. gulat, cor, brevioribus. Syft. veg. ed. I4. Fl. Dan, tab. 7. Gmel, :ib. 4. tab. 43 . b. f. 2, f. I. A. B, Buxb, act, 2. tab. 23, f. 2 .

In alpibus Lapponia, Ruffia, Germania $\odot$.

4. villofia, A. fol. pilofis: perianth. hirfutis. Syjt. veg. ed. 14. Jacq. Aujir. 4. tab. 332. Cluf. hift. 2. p. 62 .

In alpibus Rheticis, Caraiolicis, Pyrenais Ec. 24.

Scap. 2-unc, rubellus: Fol. lanceol. Cor. alba, ad faucem rofed, lutea, vel carnea. Variet. I- $f$.

5. leater, A. fol. lanceol. (plerumq ) glabris; umbella involucris multoties longiore. $S y f t$. veg. ed. I4. Jacq. Auftr. 4. tab. 333 .

In Aufiria, Helvetia Ec. alpibus 4.

Odor gratus Primula. Scap. I-7-fl. Fol. angufta, nitida, margine fcabro. Cal. e viridi-luteus. Cor. nivea, raro rofea, fegment. emarginatis. In fcap. I-fl. involucri fol. 2. aut nulla,

Ad Areilix genus pertinet.

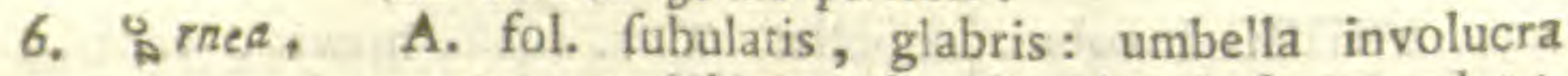
æquante (demum longiore). Syft. veg.ed I4.

S dum \&c. Colum. ecphr. 2. tab. 65. f. 2.

Sanicula \&cc. Plak. alm. tab. 108. f. 5 .

b. Aretia \&c. Hall. Helv, 486, tab. 7. ed. 2. D. 619. $t a b, 17$.

In alpibus Pyrenais, Helveticis 24.

Simil. Aretia Vitalianx, fed differt umbella, fl. parvitate, colore \&\%. Scap. triental. hirfutus, 
3-fl. Fol. Graminea, ciliata, rugofa, plana, margine fcabro. Cor. tubus brevis, limbo ovato, roleo.

odoratifuna. A. fol. triquetris, ciliatis: perianthis hirfutis. Schreb. dec. 1, tab. 4 .

A. oriental. \&c. Tourn, Cor.

In Cappadocia alpinis.

obtufifolia. A. All. Fl. Ped. tab. 46. f. I.

Aretia \&c. Spec. Ped. tab. 4. f. 2.

In herbidis nivofis iugis 24.

Fol. elliptica, lingulata, obtufe acuminata. FI. fegmenta ovata, integerrima: color plerumque purpur. aliquando albus. Vor. I-fl.

233. PRIMU-Involuc. umbelle, Cal. s-fidus. Cor. tubus cyLA. lindric. longus, ore patulo. Capf. I-locul. 5-10-valvis.

Vur. num. ftaminum in toto Genere.

5. yeris. P. fol. dentatis, rugofis. Syft. veg. ed. I4.

a. officinalis P. limbo cor. concavo. Fl. Dan. tub. 433 .

b. elatior. P. limbo cor. plano. Fl. Dan, tab. 434 .

y. acaulis. P. fcapo nullo. Fl. Dan. tab. 194. Var. fl. viridi, pleno.

In Europe pratis 4.

Fol. radical. feffil. oblonga, obtufa, pallide, aut luteo-virentia. Scap. brevis. Fl. cernuiv Cal. fublureus. Cor. 2-fid. lutea, cum macula crocea, odora .

2. farinofa. P. fol. crenatis, glabris: fl. limbo plano. Syft. veg. ed. 14. Fl. Dan, tab. 125. Gmei. Sib, 4. tab. 44. f. 3. Claf. hift. p. 300.

In alpinis, frigidifque Europa pratis, uliginofis 4. Fol. lato-lanceol, dentata, læete virent. farina fubtus adfperfa. Caul. 5-unc. fimpl. Fl. umbellati, erecti : cor. limbus cordat, anguftus, purpuro-carul. aut. albus. Var. fol. utrimque vi. ridibus.

3. Auricula . P. fol. ferratis, glabris (inverfe ovatis). Syjt. veg. ed. 14, Jacq. Auflr. tab. 415. Sabb. horb. I. $t a b .98$.

In Italize alpibus Helveticis \&c. 4.

Juniora fol. integra; adulta fupra medium ferrata , craffa, quandoq. pulvere albido veluti adfperC c ij 
fa Fl. interdum umbellati, quandoq. folitarii . Involucri foliol. ovata. Pedunc. farinofi. Cor. varians col.

4. longiflora. P. fot. ferratis, glabris: umbella nutanre: cor, tubo longiff. Syft.veg. ed. r 4 . Jacq. Auftr. App. tab. 46. All. Ped. tab. 39. f. 3 .

In Auftria \&c. 24.

Diverfa a P. farinofa. Fol. multa, radical, obtufe fublanceol. cilute virent. fubtus pallidiora, ferrora. Scapus lpitham. Fl. umbellati, 2-6. roro $\mathrm{pl}$, in fouelcenta lecundi. Cor, tubus extus palide ruliers, intus albus: limbus 5-part. lacin. obverfe cordaris, pallide rubellus, per atatem siolac.

5. villefa. P. fol. ferrular. pianis, hirfutis. Syft.veg. ed. I4. Fl. Anjtr. App, tab. 27.

Auricula \&c. 3. cluf. Hift. p. 303.

b. pubefiens. Jacq. Mifc, tab. 18, f. 2.

In alpium rupibus 24 .

Fol. racical, in orbe $m$ fparfa, oblong-ovata, obtufiufs. crafiula, undiq. villofula, uris anterioribus obrufe ferrans. Scap, ab uno pollice ad dimidiam fpitbam. altus, teres, villofulus. Involuc. foliol. 3-7.parva, ovata, oblonga, vilJofa. Fl, umbellati 2-12. Cor. elegans, dilute corul. vel violac, fauce alba. Odor fuavis. Farina nulla in planta. Var. I-fl.

6. glutinofa. P. fol. lanceol. ferrulat, glutinofis : involuc. longitud fl. Fefflium. Syft.yeg. ed, r4. Lin. Suppl. Jacq. Auftr. App. tab. 26.

Auri,ula \&c. Pluk. alm. tab. 1496. In alpibus Tirolenfibus 24.

Statura P. farinule. Fol. \& fl.odore Orchitis Conoplea, uut odoratiffime. Fol. plura, radical. lineari-lanc: obtufiufc. ferratd, nuda, fere pulpofa, vifcida. Scap. 1-2-poilic. erectus, rudus. Fl. 5-7. umbellati, fubfecundi. Involuc. foliol. 4-5. inæqual. oblon-ovat. viridi-atropurpur. Cor. limb. 5-fid. fature violac.

7. minima. P. fol. cuneiformibus, dentat. nitidis, hirfutis: fcap. fub I-fl. Syft. veg. ed. 14. Jacq. Obf. I。 tab. 14. Fl. Auftr. tab. 273.

Sinicula \&c. Lob. ic. 871.

Auricula VIII. Cluf. hift. 1. p. 305. In alpibus Helvetia, Auftria, Silefice. 
Planta fubcefpitofa. Scap. brevis, quandoq. nullus. Fol. in rofulas collecta, feffil. craffula, femper glaberrima. Bractea I-2. Involuc, 2phyll. Cal. tubo longior, quandoq. rubens. Cur. intus hirfutd, lutea, carnea, vel purpur. raro alba .

\&. cortufoides. P. fol. petiolat. cordatis, fublebat. crenatis. Sy/f. veg. ed. 14. Gmel, Sib. 4. tab. 45. f. I. In Stbiria.

Herba fol. Cortufa; fl. Aretia Vitaliana. Planta hybrida ex utrifque. Caul. femiped. pilofi. Fol. radical. mulra, profunde laciniata, P. Auricula fimilia: caulina oblonga, angulta. Fl. terminal, purpur. umbilico flavefcente.

9. integrifo- P. fol. integerr. oblong. glabris: calycibus tulia. bulofis, obtufis. yft. veg. ed. 14. Jacq. Obf: 1. tab, 15. Aufir, tab. 327. Fl. Dan, tab, 188. Auricula \&c. IV. Cluf. Hift. 1. tab. 304.

In alpibus 24.

Habitu, \& ftatura convenit cum P. Auricula. Scap. fefquiunc. fubbiflorus. Fol. plura, feffil. craffa, nitida, ciliata. Involuc. foliola teradquaterna, inæqual. linearia. Fl. magni, cernui. Cor. violac, vel purpur. odore melleo, laciniis femibifid. tubo fimpl. ablque collo coarctato .

10. carnivica. P. fol. integerr. elliptic. umbella erecta : calycibus breviff. acutis. Syft, veg. ed. I4. Jacq. Auftr. App. tab. 4.

In Carniole Ec. alpibus 24.

Differt a P.integrifolia folo $\mathrm{fl}$. Cal.in noftra plufquam duplo brevior eft tubo cor. Lacinize cor. non valde fecantur. Fol. oblong-ovata, fubacuta, parum craffa.

nivalis. P. Patl, It. 3. tab. G. f. 2 .

In Dauuria 4.

Scapi fpitham. \& ultra, recti. Fol, radicl. erecta, oblonga, argure dentata, glabra, digitalia. F1. umbellati. Involuc. I-phyll, profunde 5-fid. lacioiis fubulatis. Stipul. linear. ad peduncul. partial. Cal. parvus, fubcolorarus. Cor. maiufcula, purpurafc. Capf. magna, grifea'.

verticillata. P. fl. verticiliat, fol. linceol-ovat. ferratis, petiolat. fubtus farinofis. Forsk. $\bar{E}_{g}$.

In Arabia 4 . C c iij 
Fol. pedal. petiolo ad bafin latiore, utrimq. at lato, fol. continuato. Fol. bafi integra, fuperne inæqualiter ferrato-dent. Scap $2-p \in d$. farinofus. Bract: farinofa. Cor.flava, apice are ctato . Odor Primula veris.

vifcofe. R. fol, vifcofis, odoratis, linguiformibus, finuatis, integerrimis. All. Fl. Ped. tab. 5. f. x.

Ad rupes 4.

Rad. craffa. Fol. radical, palmaria, petiolo una cial, bitumen olenti, fubtiliter villofa, fubtus pallid, figura $C_{y}$ glnffz vulgaris. Scapus palmar. Fl. umbell ti, 6-7. cœeruleo-pallidi .

234. CORTUSA. Cal. 5-fidus. Cor, rotata, femi s-fira; fauce anulo elevato. C pf, oval. I-locul. apice 5-valv.

1, Mathioli. C. calycibus cor. brevioribus. Syf. veg. ed. I4. Cam. epit. 278. Cluf. hift. 1. p. 307. Mnth.

In alpibus Auftria, Silefice, Sibiric Ec. $\delta$.

Fol, radical. 6-7. longe petiolat, petiol. villofis. Fol. diametro 3-unc. rotanda, Iobata, lobis 3-fid. odora. Scap. quandoq. cubiral, pilofus . Involucrum ex 3. foliol. fublinearibus, inæqualibus, pinnata-dentat. quandoq. laciniatis. Radii umbellæ I. 2-unc. I-fl. Fl, longe pedunculati, primum quandoq. penduli, dein erecti. Cor. patens, femi-\& ultra s-fida, fegment. 0-

2. Gmelini. C. crlycibus cor. excedentibus. Syft. veg. ed. 14. Gmel. Sib. 4. tab. 43. f. I.

In Sibirin 4 .

Fol, radical, in orbem fparfa, longe petiol. Irte viridia, utrimq. hirfuta, reniformi-cordata, lobis rotundatis. Scap. toliis altiores, ad fummum 4-unc. hirfuti. Umbella fub 3 -fl. involuc. foliol. ovat. Cal. magnus, hirfutus. Cor, alba.

235. SOLDANELLA. Cal. 5-fidus. Cor. cimpanulata, laceromultifida. Capf. (cylindracea) I-locul, apice multidentata.

1. alpina. S. Syft, veg. ed, 14. Jacq. Auftr. tab. 13. Sabb. hort. 1. tab. 16. Morif. hift. 2. f. 3. tab. 15. f. 8.

In alpibus Helvetic, Auftria, Pyrencorum 4. Fol. inferiora longe petiol. fubrotunda, integerr. quandoq. obfolete crenata, craffa, lzevia, nitida, fupra fature virentia, fubtus dilutiora. 
Scap. 2. 6-unc, 2-rar()-3-fl. Flos nutans, Cor. fature cœrul. raro alba. Capf, erectd.

236. DODECATHEON. Cor rotata, reflexa. Stam. tubo infidentia. Capf. oblong. I-locul.

I. Meadia . D. Syjt. yeg. ed. 14.

Meadia . Cutes. Car, 3, tab, 1, Trew. Ehret, tab, I2. Auricula \&c. Pluk, alm, tab, 79, f. 6.

In Virginia 24.

Plunta habitus Primule. Flos Cyclamini. Involuc. parvulum, multıfolium. Fol. radical, obverfe ovata, ferrata, involuta, glabra. Umbella fimpl. fl. peduncul, dilute purpur.

237. CYCLA-Cor. rotara, profunde 5-fida, reflexa; tubo MEN . breviff: fuce prominente. Capf. globofa, 5vilv. I-locul, polyfperma.

I. europaum. C. cor. retroflexa, Syf. veg. ed. I4. Jacq. Anftr. tab. 401, Knorr. del. V. 1. tab. S, 16. Sabb. hort. 2, tab. 68. Black. tab. 147.

In Europo, Tartarice fictis, umbrolis, nemorofis 4. Radix tuberofa, orbiculata, foris nigricans, intus alba. Ful. bina radical. denticulata, craf$\mathrm{fa}$, fature virent. cum maculis albis. Petioli multi, unifolii, aut I-fl. Variat fol. cordatis, orbiculatis, reniformibus, immaculacis : $f l$, pur-

2. indicum. C. cor. limbo nutante. Syf. veg. ed. 14v In Zeylona.

238. MENY-Cal. 5-fid. Cor. campanulata, femi 5-fida, la-

ANTHES. ciniis ciliatis. Stigm. 2-fid. Capf. oblon. $1-$ locul. 2-valv. polyfperma .

I. Nymphoides. M. fol. cordato-orbicul, integerr. cor. ciliatis. Syfl, veg. ed. 14. Fl. Dan, tab. 339. Sabb. hort. 2. $t a b .67$.

Nymphæa \&c. Dalech. hift. p. Ioro, f. r.

Limnanthemum. Gmel. Aa. Petrop. 1769. Vol. 14. $t a b .17$. f. 2 .

Ir. Belgii, Anglix, Germanice foffs maioribus $\mathcal{4}$. Fol. maiora, oppofita, petiolat. vagin ntia, laete virentia, venola, glabra. Scap. pedal. erectus, finplex, teres, punctirus. Pedunc. e latere petioli. FI. fimbriati, aucei .

2. indica, $M$. fol, cordatis, fubcrenitis; petiolis $f$ iriferis: cor. interne pilofis. Syft, veg. ed, 14. Rumph. Artb. 6. tab. 72 f. 3 .

Nedel-ambel. H. Mal. ir. tab. 28.

In Malnbarie, Zeylona folts. $\mathrm{C} c$ iv 
Caul. rotundi, filtulofi, in quorum apice fol. cæteris rotundiora. Pedunc. e latere petioli, ut in priore. Fl. candidi .

3. ovata. M. caul. paniculato: fol. petiolat. ovat. Syft. yeg. ed. 14. Lin. Suppl.

Ad cap. b. Spei.

Facies Alifme; at flos Menzanthis.

4. trifoliata, M. fol. ternatis. Syft, veg. ed, I4. Fl. Dan, tab. 541. Gmel. Sib. 4. tab. 97. Sabb. kort. I. tab. 48. Black. tab. 474 .

In Europa paludofis 24.

Fol. longe petiol. oblongd, fubferrata, craffufc. nitida, Jate virentia. Scapus pedal-cubital. vaginis tectus, racemofus. Cal. 6-7.fid. Fl. albi, rubro variegati.

239. DOR ENA. Cor. 5-fida. Stigm. emarginatum. Capf. Ilocul.

I. japonica. D. Syjt, veg. ed. I4. Thumb. Jap.

In Japonia b.

Caul. arboreus, orgyal. Rami alterni, divaricati, teretes, glabri, cinerei. Fol. digital. alterna, petiolat. oblon-acumin. patentia, remote, \& obfolete ferrata, nervofa, glabra. Fl. racemofi, minuti, albi.

240. HOTTO. Cal. 5-fidus. Cor. hypocraterif. 5-fid. plana, NiA. is plicis binis ad bafin finguli fegmenti. Stam. tubo cor. impofica. Capf, acu nis. I-locul,

I. paluftris. H, pedunc, verticillato-multifl. Syft. veg. ed, 14, Fl, Dan. tab. 437.

Myriophyllum alterum. Matth. in 68.

In folfs, \& paludibus Europa borenlioris 24.

Scap. pedal. erectus, filtulofus. Fol. alterna, impari-pinnatifida, pinnis linearibus, tenera, late virentia. Pedunc. bractea fuffulti . Cor. pallide purpur. fauce fublutea ; lacin. emarginatis, planis.

2, indica, H. pedunc. axillar. I-f. Syft, veg. ed. I4, Burm, Zeyl. tab. 55. f. 1 .

Erica \&cc. Seb. muf. 2. tab. 37. f. 5.

Tfiunda Tfiera. Hort. Mal. I2, tab. 36.

In India.

Genus etiam num dubium, Caul, digital. fimpl. Fol. verticillata, fæpe 8-tona, linear. 3-fidatertrifid. Pedunc, folitar. fisl. longiores.

241. HYDROPHYLLUM. Cor, campanul, interne ftriis $5 . \mathrm{mel}$ - 
liferis, longitudinalibus: Atigm. 2-fid. Capf. globola, 2-valv.

I. virginicum. H, fol, pinnatifid. Syft. veg. ed. I4. Sabb. kort, I. tab. 15 .

Dentaria adfinis \&c. Dodart. mem, tab. 77.

Dentaria facie \&c. Morif. hift. 3. S. 15. tab. To f. $I$.

In Virginia 24.

Radix nodofa. Caul. fubped. Fol, longe petiol. dentata. Pedunc. multifl. Fl. oblongi, albi . Capf. hirfuta .

2. canadenfe. H. fol. lobato-angulatis. Syft. yeg. ed. $\mathbf{3} 4$. In Canada 24.

Differt a priore folis foliis Aceriformibus.

242. ELLISIA. Cor. infundibulif, angufta . Bacca fubrotunda, ficca, 2-locul. 2-valv. Sem, 2. punctata, altero fupra alterum .

r. Nyzelea. E. Syft. veg. ed. 14. Nov. Az. Upf. Vol. r。 tab. 5. f. 5 .

Planta \&c. E. N. C. I76r. tab. 7, f. I.

Scorpiurus \&c. Morif. hiff. 3. f. II. $t a b .28$. f. 3 . In Virginia $\odot$.

Adfinis Hydrophyllo. Caul. diffufus, proftratus, herbac. ramofiff. dichotom. Fol. alterna, petiol. pinnatifida, foliatione retrorfum imbricata, laciniis acutis, utrimq. dente notatis. Pedunc. oppofitifol. patentes, elongati, pubefcen. I-fl. Fl. cernui. CaJ, cor, muior. Cor. tubo filifor. curvo, limbo 5 -fid. alb 3 , laciniis intus punctis minutis purpur. Capf. fcrotiform. coriac. calyculata. Sem. globofa, nitida.

243. LYSIMA-Cal. 5-fid. Cor. rotata, profunde 5-fid. Capf. CHIA. globola, mucronata, 5-10-valv.

$$
\text { * Pedunc. multifl. }
$$

x, yulgaris, I. paniculata; racemis terminalibus. Syft. veg. ed. 14. Fl. Dan. tab. 689. Black, tab. 278. Sabb. hort. 2, tab. 41. 42. Math. 349.

In Europa ad ripas, \& paludes 24.

Caul. 2-3-cubital. erectus, ramofus, angulatus, hirfutus. Fol. oppofita, terna, quaterna, ovat-lanceol. acumin. glabra, integerr. fupra atro-virent. fubtus albefcent, Racemi coniugati. Fl, multi, fature flavi. Filam. bafi coalita. 
2. Ephemerum . L. racemis terminalibus, fimplicibus: petalis obtufis: ftaminibus cor, brevioribus. Sy/t. veg. ed. I4. Comm. Gott, 1782, tab. 2. Sabb, hort. 2. tab. 43. Buxb. cent. 1. tab. 33. Tilli Pif. tab. 40. f. 2 .

In Media, Sibiria $\odot$.

Convenit cum L. atropurpurea habitu, fruçura, col. glauco. Differt fol. plerumque fubtus fufcopunctatis, quod non fequentis: petalis obtufis, patulis : ftaminibus cor. brevioribus, fl. pedicello infidentibus .

3. atropurpu- L. fpicis terminalibus: petalis lanceol. ftaminibus rea. cor. Iongioribus. Syjt. veg.ed. 14. Comm. Gutt. 1782. tab. I. Com, rar. tab. 33. In Oriente $\odot$.

Adfinitas nimia cum priore, fed revera diffincta. Caul, erectus. Fol. lanceol-linear. glauca, fubtus inpunctata. Petal, acumin. calyc. paul. lon. giora, conniventia, faturate rubra, vel fanguinea :

4. thyrfiflore. L. racemis lateralibus, pedunculat. Syft. veg. ed. 14. Fl. Dan, tub. 517. Cluf. hift.2. 53, f, 12. In Europe padulibus 24.

Caul. fub 2-ped. erectus, fimpl. Fol. oppofita, longe ovat-lanceol, punctis nigris adlperfa, pallide virent. glabra. Stipul. longæ, anguftæ. Racemi parvi, ovati, denfi. Pet. lutea, ajice fulvo punctata.

$$
\text { ** Pedunc. I-fl. }
$$

5. quadrifo- L. fol. quaternis, petiolo ciliatis: pedunc. qualia.

ternis, I-fl. Syft. veg. ed. I4.

Anagallis \&c. Pet, guz. 5.tab.2. f. 5. Pluk, mant. tab. 333. f. 1 .

b. ciliata. $S_{p}$. pl. Walth, hort. tab. 12.

In Virginia, Canada.

Fol. fubfeffil. ovat-acuta . Cor. lutea .

b. Fol. in fummis ramulis quaterna. Pedunc. gemini, r-fl, fub calyce turbinati. Fl. cernui . Petal. mucronata, ferrata.

6. puntata. L. fol. fubquaternis, fubfeffilibus: pedunc. verticillat, 1-fl. Syjt. vey. ed. I4. Jacq. Auftr. 4. tab. 366. L. I1. Claf. hift. 2, p. 52. f. 2 . Blattaria \&c. Morif. hijt. 2, $\int$. 5. tab. 10, f, 15. In Hollandia, Helvetia \&c. 
Caul. 3-ped. incani, toti foliofi. Fol. ovat-lane ceol. fubtus nigro-punctata. Ex qualibet ala pedunc, 2. fimpl. Cal. pubefc. Cor, lutea, intus maculis fulvis punctata.

7. Linum ftel- L. calycibus cor. fuperantibus : caul. erecto, ralatum. mofiff. $S, f t$. veg. ed. 14 .

Linum \&c. Magn. Monfp tab. 162.

In Gullia, Italia collibus $\odot$.

Caul. vix fefquiunc. Fol. fubulata. Pedunc. fol. breviores. Cor. Centunculi, Srfid. Fructus 5valv.

8. nemorum . I. fol ovat, acutis : fl folitar. caul, procumbente. Syft. veg. ed. 14. FL. Dan. tab. 174.

Anaysllis \&c. Morif. hilt. 2. S. 5. tab. 26. f. 5. In Germania, Gallia \&c. nernoribus glareofis roridis 4 .

9. Nummula-L. fol. fubcordat. Al. folitariis: caul, procumb. ria. Syft. veg. ed. 14. Fl. Dan. tab. 493. Black。 tab. 542 . Ludw. ea. $t a b, 149$, Sabb. hor. 2 . t...b. 44 .

In Europa, iuxte agros, \& rivulos 4.

Fol. oppofita, breviter petiol. craffufcula, nitida, glibra. Pedunc. axill. oppofini, longi, nudi, $\mathrm{r}$-f. Cor. magra, flava .

3o, japonica, L. fol. fubcordat. Al axillar bus; peduncul. fol. brevioribus. Syft. veg. ed. 14. Thumb. Jap.

In Japoria.

Radix fibrofa. Caul, decumbens, apice flexuofoerectus, palmar. simpl. filiform, viliofus, Fol. unguicul. patentia, oppofita, petiolat. fubrotunda, obtufa, integerr. tenuiff. villofa. Fl. taro folirar. fape bini .

244. ANA- Cal. profunde s-fid. Cor, rotata, s-fida. Capfo GALLIS , circumfciffa .

Differt a Lyfimachia filament. hirfutis.

1. aryenfis. A. caul. procumb. fol. indivifis. Syft.veg. ed.14. Sabb. hort. 2. $t a b .46$, Black. sab. 274.

a. A. fl. caruleo.

b. A. placuiceo fl. Fl. Dan. tab. 88, Black, tab. 43. $a b b$. toort. 2. $t a b .45$.

In Europa arvis $\odot$.

Caulic. tene i, ramofi. Fol. parva, oupofita, integerr craffufc. glabra, glauca. Pedunc. axill. longi, aphylli, r fl. Cor. nutans, crenulata. Var a. fo'. ternis, quaternis. Var. b. sar, fh. a.bo, kmbiliso purpur. 
2, munelli. A. fol, indivifis: caul, erecto. Syft, vez.ed. I4. Verona $\odot$.

Caul, brevis, ramofus, angulatus. Fol. oppofita, feffil. ovat-lanc, acumin. Cor. intenfe corrul.

3. latifolia. A. fol, cordat. amplexicaulibus: caul, compreffo. Syft. veg. ed. I4.

Cruciata \&c. Barr. ic. 584 .

In Hifpania $\odot$.

Caul, erecto patens, brachiatus, ramofus, 4gon. Fol. bafi deorfum fpectantia, obtufiufe. nervofa, glabra, fubtus pallide punctata. Pe-

" dunc. axill. folitar. r-fl. nudi, teretes. Cor. corrul. fundo purpurafc. Filam. purpur. Anth. oblong. flavæ. Dignofcitur caul. compre $\sqrt{0}$ : fol. magnis, \& latis.

4. linifolia. A. fol. linearibus: caul. erecto. Syf. veg. ed. 14.

In Lufitania, Hifpania \&ic. $\odot$.

Caul. palmar. 4-gon, rigidulus, ramis alternis, erectis. Fol. oppofita, feffil. lævia, internodiis longiora. Pedunc. filiform. fuliis duplo longiores. Cor. cœerul. Frut. cernui, calyce breviores.

5. tenella. A. fol. ovatis, acutiufc. caul. repente. Syft. veg. ed, 14 .

Nummularia \&c. Morif. hift. 2, f. 5, tab. 26. f. 2 .

In Italix, Gallia, Anglix Ericetis humidis 24. Fl. longe peduncul. folitar. purpurafc.

verticillata, A. ereeta, fol, caulinis verticillatis: axillis foliorum in caule, \& ramis florigeris. All. Fl. Ped. $t a b$. 85. f. 4 .

An Cruciata \&c. Barr. ic. 584 ?

In Comitatu Nicaenfi $\odot$.

Caul. erectus, pedal. 4 gonus, ramofus. Fol. caulina quaterna-quina; ramea oppofita, elliptico-lanceol. glabra, fæepius deorfum reflexa, fubtus fufce, \& minutim punctata. Rami inæquales. Pedunc. nudi. Fl. erecti, dein nutantes. Cal, margine albo. Cor. læte cortul.

245. THEO-Cor. campanulata, laziniis, \& divifuris obtufis . PHRASTA. Capf, maxima, globofa, I-locul. polyfperma. 
I. emericuna. I. Syft. seg. ed. 14.

Erefia \&cc, Plum, gen, 8. ic, I26.

In Amer. aquinact. $\hbar$.

Caudex fimpliciff, nudus, apice frondofus, ut in Palmis. Fol. longiff. undique diffura, lanceol. dentat, nervis undulatis. Fructificat. diffula, ramofx, inter folia.

246. RETZIA. Cor. cylindrica, extus villofa. Stigma 2-fidum, Capr. 2-locul.

I. Spicati, R. Syjt. veg. ed. 14. Lin. Suppl.

R. capenfis. Thumb, Aat. Lund. P. 1. tab. 1, f. 2. pulchra.

Ad cap. b. Spei b.

Maximam adfinitatem cum Convolvulis hebet. Quadriped. erecta, fubramofa. Rami breves, inæqual. pilofi. Fol, quaterno-verticillata, conferta, adproximata, feflil, lanceol-linear. erecta, punctis impreffis, fubtus bifulca. Fl: laterales, verfus apicem conferti, erecti, leffil, inter fol. fere abfconditi. Bract. lanceol. hirfuta. Cor. rufefcens, extus verfus apicem hirfuta.

247. SPIGE-Cor. infundibulif. Capf. globofa, didyma, 2-loLIA . cul. polyfperma.

I. Anthelmia.S. caul, herbac: fol, fummis quaternis. Syjt. veg. ed. 14. Lin, ancen. Acad. 5. tab. 2, Brow. Jam. tab. 37. f. 3. Plenk. fajc. 4. tab. 88. Brazeel-partis. Pet, gay. tab. 59. f. 10.

In Cä̈enna, Brafilia $\odot$.

Caul, erectus, fpitham. fimpl. brachiat. glaberrimus, fuperne parum craffior. Fol. lanceol: caulina alia 2. Oppofita. Ramus ex ala fingula fol. caulini folitarius, terminatus fol. 4 . cruciarim pofitis, ut in caule. Racemi terminal. breves, bracteati. Fl. parvi, unilateral. purpurafc.

2. mnrilandica.S. caul, tetragono: fol. omnibus oppofitis. Syf, veg. ed. 14. Aa. Edin. 3. an. 1771. tab.

1. Plenk. fa/c. 4. tab. 89.

Peryclimeni \&c. Catefb. carol, tab. $7^{8}$.

In Virginia, Marilandia, Carolina 5.24.

Caul. erecti, fimpl. rigidi, fcabri, annui. Fol. feffil. ovat-lanceol. integerr. patentia, glabra. Spica folitar. fecunda; bract. parvulis, oppofiris. Cor, coccinea, fuperne 5-angulata, 
fauce gibba, bafi dilatata. Limb. 5-part. la= cin. lanceol revolutis .

248. OPHI- Cor, infundibulit. Stigm, 2-fidum. Fructus 2-loORRHIZA. bus.

I. Mungos. O. fol. lanceol-ovatis . Syft. yeg. ed. I4. Lin。 med. tab. I. Flenk. fafc. 4. $2 a b, 90$.

In India orient. 4.

Caul. fimpl. Fol. oppofita, petiolat. Adhatodz fimilia, integerr. glabra, nervis oblique tranf. verfis. Curymb. terminal. ex fpicis fimplici= bus, feu 2-fid. unbellatis. Fl feffil. Capfo ovata, compreffa, 2 -locul. 2-valv.

3. Mitreola. O. fol. ovatis. Syft. veg. ed. 14.

Mitra. Horft. MSS. T, bona.

In Amer, meridion.

Caul. erectus. Fol. oppofita, petiolat, utrimq: integerr. glabra. Romi oppofiti. Racemus terminalis, ex racemulis dicho:oms, patentibus, Fl, alterni, feffil.

249. VIRE- Cal. 5-phyll, dentibus interiectis. Cor, infun-

CTA. dib. Stigm, 2 part. Capf. J-locul.

1. biflora, V. Syft, veg. ed. 14. Lin. Suppl.

In Surinami fubhumidis $\odot$.

Herba tenera, Mercurialis annuc. Caul, fpitham. \& ultra, fimpl. interdum radicans, teres, pubefcens. Fol. oppofita, in petiolum decurrentia, parva, ovata, obtufa, integerr. venofa. Stipul. interfoliaceæ, parva, erecta, fubulatæ. Pedunc. terminal, inter ramos duos teneros, foliis fapius brevior, 2-fl. Fl. inferior. feffil. Cor. rubefc, ore albo.

250. IISIAN-Cor. tubo ventricofo, laciniis recurvatis. Cal. THUS. carinatus. Stigm. 2-lamell tum. Capf. oblong. 2-locul. 2-valv. valvularum marginibus intortis.

1. longifolius, L. fol. lanceolat, Syf. veg. ed. I4. Brow. Jam. tab. 9. f. $\mathrm{r}$.

Rapunculus \&c. Sloan, Jam, hift. I. tab. I0I. f. 1 .

In Jamaica fylvis $\$$.

Frutex. Fol. oppofita. Fl. terminal, folitarii, fpeciofi, lutei.

2. cordifolius. L. fol. cordatis.. Syfl, veg. ed, 14.

In Jamaica b.

Valde adfinis priori. 


\section{PENTANDRIA MONOGYNIA.}

3. Chelonoides. L. glaber ; fol. oppofitis, fubconnatis, oblong. panic. terminali, dichotoma, racemofa. Syjt. veg. ed. 14.

L. alatus. Aubl. Guian, tab. 80.

In Surinamo, Cayena, in altis arenofis.

Canl. 2-3-ped, herbac. fimpI. teres. Fol. ellip tico-oblong. obtufufc. feffil, integerr. glauca, glabra. Fl, remoti, alterni, fecundi, penduli, lutei. Cal. globofus. Cor, tubo fubrecurvo, fentim ampliato. Capi. decumbens, cum ftylo.

Hetba yalde amara, \& ut validum purgans adhibetur.

4. glaber. I. glaber; fol. petiolat. ovatis; corymb. terminalibus. Syft, veg. ed. I4. Lin. Suppl. Icon. Mutis Amer. 2, tab. 1.

In Amer. meridion.

Glaberrimus, nec pubefcens, \& canus, ut I. cordifolius. Cor, lutea.

purpurafcens, L. fol, ovat, acuris, integerr. Aubl. Gujan. teb. 79 .

In filfuris humidis Guian. $\odot$.

Caul. pl. 2-pedal, erecti, 4-goni, nodofi. Fol. oppofita, feffil. fubcarnofa, glabra, glauca. Fl. terminal. dichotomi. Cor. purpurafc.

Tota planta guffui amara.

grandiflorus. L. fol, connaris, ovat-oblong. acutis: fl. virefcentibus. Aubl. Guinn, tab. 8I.

In lacis humidis Caienna \& c c. $\odot$.

Caul. erectus, fimpl, nodofus. Fol. integerr. glabra, glauca. Fl. terminales, ramufculo ad apicem dichotomo; \& iterum in dichotomia defineate, Fl. intra dichotomiam axillar, folitar. pedunc. incurvo. Cal. carnofus, Cor. ampla, introrfum flexa.

coerulefcens. I. caul. 4-gono, marginato: fol. angufto-lanceol. Cor. laciniis acut. Aubl. Guian, tab.82.

In pratis humidis Guianx $\odot$.

Caul. pedal. membranac. Fol. feffil. integerr. glabra, glauca. Fl, terminal, dichotom. Cor. fubcorul.

251. RAN- Cal. I-phyll. Cor, hypocrat. Bacca I-locul, DIA. cortice capfulari.

I. mitis.

R. fubinermis. Syft, vez. ed, I4.

In America b. 
Frutex 10-12-ped, ramis oppofitis. Fol, unc. longa, dimidiam lata, oppofita, in medio lata, apice fenfim anguftato, gldbra, luteo-viridia, nitentia. Fl. axill. parvi, ftellati, albi. Fruct. femunc. pyramidal. umbilicati, virides .

2. aculeata. R. ramis bifpinofis. $\$ y f$. veg. ed. I4. Brow. Jatn. $t a b$. 8. f. 1 .

Lycium \&c. Pluk. alm. tab. 97, f, 6.

In Jamaica $\mathrm{t}$.

An var. prioris ?

252. FA- Cal. campanulat. Cor. infundibul. Bacca 2-locul. GRFA . carnofa. Sem. globofa.

I. zeylanica. F. Syjt. yeg. ed. 14. Thumb. AZ. Stock. 1782. tab. 4 .

Habitat.

233. SHEF- Cor. campanulata. Filam. Io, alterna fterilia , FIELDIA. Capi. I-locul. 5-valv.

x. repens. S. Syft. veg. ed. 14. Lin. Suppl. Forft. gent.

In nova Zeelandia.

Simil. Peplidi Portula, excepta fructificat.

254. AZA- Cal. campanifor. 5-fidus, repandus. Cor. camLEA. panulata. Stam, receptaculo inferta. Capf. 5valv. 5-locul, fubrotun. Stam. num. differt $a b$ Ericu, \& Andromeda.

I. pontica. A. fol. nitidis, ellipticis, utrimq. glabris : racemis terminalibus. Syft. veg. ed. I4.

Chamærhododendron \&c. Buxb. cent. tab. 69. In Ponto, Trapequnte b.

Simil. Rhododendro pontico, fed huic stam. 5 . cor. later, nec violac. Fol. min. ovata, ciliata: Altitudo Rhododendri pontici, quandog. altior. Fol. in apice ramorum 4-poll. Ionga, fefquipoll. lata, petiolat, integerr. nervofa, pulchre virent. Fl. conferti in apice ramorum, breviter peduncul. lutei, odore Caprifolii, fed vehementiore.

2. indica. A. fl. fubfolitariis; calycibus pilofis. Syft. veg. ed. 14 .

Ciftus \&rc. Herm. Iugd. tab. I53.

Tfutfufi, Kamf. $a m, t a b, 846$.

In India b.

Frutex 2-cubital. ramis brevibus, contortis. Fol. faftigiata, villofa. Fl. ampli, dilute coccinei .

3. nudiflora. A. fol. ovatis: cor. pilofis; ftaminibus longiff. 


\section{PENTANDRIA MONOGYNIA.}

Syft. veg. ed. I4. Duham, arb. I. tab. 3. Trew. Ehret. 48 .

In Virginue ficcis $\mathrm{b}$.

Fol. alterna, integerr. Rami nudi. Fl. terminal. conferti. Cor, lutea.

Floret ante jol, vel $\int u b$ ip $\int a$ vernatione; \& fam.

4. vifcofa. gerze duplo cor. longiora.

A. fol. margine fcabris: cor. pilofo-glutinofis. Syft. veg. ed. 14.

Ciftus \&c. Comm, Car. I, sab. 57. Pluk, alm. tab. I6I, f. 4 .

In Virgina $b$.

Adfinis priori. Caul. erect. ramofus. Fol. alterna, petiolat. ovalia. Fl. corymbofi. Cor. alba.

Floret poftquam omnia adulta funt.

5. lapponica. A. fol. (fuperne) adfperfis punctis excavatis . Syjt. veg. ed. 14. Fl. Lapp. tab. 6, f. I.

In alpibis Lapponix $\mathbf{b}$.

Fruticul. fpirham. divaricatus, Fol. perennantia, elliptica, rigida, petiol. conferta, margine reflexo, fubtus ferruginea.

6. procumbens. A. ramis diffufo-procumbentibus. Syft. veg. ed. 14. Fl. Dan. tab. 9. Fl. Lapp. tab. 6. f. 2.

Chamærhododendros. Bucc. muf. 2. tab. 53.

In alpibus Europa $\hbar$.

Caul. femiped. \& ultra, ramofiff. lignofus, fufcus. Fol. Thymi, oppolita, fubfeffil. ovatlanc. convexa, dura, nervo eminente, fordide virent, fubtus ferruginea. Fl, terni-quaterni, amæni, folitar. ex fummis alis, \& breviter pedunculati. Cal, purpurafc. Cor. carnea.

Rofmarinifolia. A. fol. quaternis, \& ultra, lanceol. fl. folitariis. Burm. Ind, tab. 3. f. 3 .

In Japonia, \& Java $\$$.

Frutex ramis fimplicibus, fcabris. Fol, Rorifinarini, marginibus reflexis, fupra villofa, linea longitudinali prædita, fubtus ex grifeo-tomentola, caulem terminantia, ad exortum pilis ferrugineo-rubris. Pedunc, terminal. pollicar. folitar. I-fl, pilis ferrugineis lanati. Flos magnus, Cal. e ferrugineo-ruber, Cor, flava .

255. EPACRIS. Cor. infundibulif, villofa. Squama nectarifera $\mathrm{D} d$ 
germini adnatæ. Capf. 5-loc. 5-valv. Efentia Gen. in Nectario.

3. longifolia. E. arborea; fol. fubulat. vaginantibus: racemis erectis; tl. oppoiitis. Syjt. veg. ed. 14. Lin。 Suppl. Foril, gen.

In nova Zeclandia $\hbar$.

2. iuniperina, E. arborea; fol. fparfis, linearibus, acutis, patentibus, feffilibus: racemis cernuis ; fl. alternis. Syjt. veg. ed. 14. Lin. Suppl. Forft. gen.

In nova Zeelandia $b$.

3. pumila, E. herbacea; fol. ovat. imbricatis, Syft. veg. ed. 14. Lin. Suppl. Forft. gen.

In nova Zeelandia.

256. WEIGE-Cor, infundibulif. Stigma peltatum. Styl, e bafi LA.

I. japonica, W. Syft. veg. ed. 14. Thumb. af. Stock. 1780. tab. 5. Jap. 16.

In Japonia $\hbar$.

Caul, fruticofus, Rami oppofiti, teretes, ciner. glabri. Ramul. erecti, fub 4-goni. Fol. 2pollic. oppofita, petiolat. ovatd, acumin. ferrata, glabra, venis utrimq. hirtis, patentia, fubtus pallida. Petiol. lineam longi. Fl. in ramis, \& axill. fol. Pedunc. comm. folitar. e fingula ala, unguicular. 3-fl. Cor. purpur.

257. TECTO: Cor. infundibulif. ftigm. dentatum. Drupa ficca, NA. fpongiofa, intra calycem inflatum. Nucleus 3-locul.

I. grandis. T. Syft, veg. ed. 14. Lin. Suppl. Rheed. Mal. 4. tab. 27.

In Zeylona $\hbar$.

Arb. procera, trunco alto, cortice Alni. Fol, maiora, oppofita, petiol, parabolica, acuta, plerumq. bafi obliqua, pendula, patentiff. fupra glabra, punctis minutiff. albis, fubtus argentea. Pedunc. comm. erectus, 4-gonus, divifus in paniculdm. Bracteæ ad omnes ramificationes 2. oppofitæ, ovatæ. Cal. tomentofus, albus. Cor. alba, extus pubefc. punctis atris interfparfis. Nectar. rubro-aurantiacum . Drupa magnitudine nucis Avellanæ, grifea, fridbilis.

258. PLUM-Cal, 5-dentatus. Cor. infundibulif. 5-fida. Stam. BAGO. fquamis bafin cor. claudentibus inferta. Stigm. 5-fid. Sem, 1, oblong, tunicatum. 
צ. europas. P. fol. amplexicautibus, lanceol. fcabris. Syft. veg. ed. 14. Sabb. hort. 2. tab. 39. 40. Cluf. hift. 2. 123 .

Tripolium \&c. Col. ecphr. I. tah, 16r.

In Europe auftrali 4.

Caul. 2-cubital, purpurafc. Fol, quandoq. obverfe ovata, atro-virent. Fl. congefti. Cal. exrus tuberculis bateos 5, præter glandulas petiolatas. Cor purpurafc.

2. zeylanica. P. fol. petiolat. ovatis, glabris: caulibus filiformibus. Syft, yeg. ed. 14.

Lychnis \&c. Comm. hort. 2. tab. 85.

Tumba codivelli $\boldsymbol{H}$. Mal. 10. $t a b .8$.

In India b.

Caul. 2-3-ped. nodofi. Fol. oppofita, fubtus albida. FI. fpicati. Cor, alba.

3. rofea, P. fol. petiolat, ovat, glabris, fubdenticul: caul. geniculis gibbofis. Syft, veg. ed, I4.

Radix veficatoria. Rumph. Am,b. 5. tab. 168.

Schetti-codivelli, H. Mal. Io, tab. 9.

In India b.

Cortex niger. Caul 4-5-ped. Geniculi quandō. non adparent. Fol. breviter petiol, cufpide angufto, fubtus dilutiora, quandoq. undulata . Cal, fubruber, Cor. miniato-rubra.

4. fandens, P. fol, petiolat. oblong-ovat. glabris: caul, flexuofo-fcandente. Syft. veg. ed. I4. Jacq. amer. piä. $t a b .23$.

Dentellaria \&c. Sloan. Jam, I. tab. I33. f. I.

In Amer. calidiore $\hbar$.

Caul. viticulofus, 3-8--ped. ramofus, debilis . Fol. alterna, acuta, integerr. Racemi terminal. femi-2-pedal. Fl. fere feffil. Cor, alba.

259. PHLOX . Cal, prifnaticus. Cor. hypocraterif. Filam, inæqualia. Stigma 3-fid. Capf. 3-locul. I-fperma.

3. paniculata, P. fol, lato-lanceol. margine fcabris; corymbis paniculat. Syft, yeg. ed, 14. Millo diâ. tab̆, 205. f. 2.

Lychnidea \&c. Dill. elth, tab. 166, f. 203.

In Amer. Septentr. 4.

planta magna, alta. Caul, obtufus, levis. Corymbi conferti in umbellam, fl. numerofis. Cor. dilutiff. violac. tubo pubef ente.

2. maculata, P. fol, cordato-lanceol, lavibus: racemo oppofi- 
te corymbofo. Syft. veg. ed. I4. Jaeq. hort, 2 , tab. 127 .

In Virginia 24.

Caul. erect. ped. teres, fcabriufc. purpurafc. punctis virentibus. Fol, altern. (infimis oppofitis ) feffil. acumin. margine fcabro. Racem. terminal, corymb. alternis, interftinctis foliol. Cal. 5-gon. Cor. violac.

3. pilose. P. fol. angufto-lanceol. villofis: caul, erecto: corymbo terminali. Syft. veg. ed. 14. Lychindea \&c. Fluk, alm, tub. 98. f, I. in Virginia 4.

Caul, teres, hirfurus. Fol. oppofita . Cal, hiro futus, \& lanuginofus.

4. caroline. P. fol. ovat-lanceol. lavibus: caul. fcabro: corymbis fubfaitigiat, Syft. veg. ed. I4.

Lychnidea \&c. Mart. cent. IO. tab. IO. In Caroline 4.

Simil. P. glaberrime, fed caul. triplo altior, nonnihil fcaber. Fl. numerofi. Cor. tubus lævis .

5. glaberrime. P. fol. lineari-lanceol. glabris: caul. erecto: corymb. terminali. $S, f$. yeg. ed. I4.

Lychnidea \&c. Dill, elth. tab. I66. f. 202.

In Virginia 4.

Cul. pl. fefquiped. fimpl. Fol. oppofita. Cor.

6. divaricata. P. lito-lanceolat. fuperioribus alternis : caul. bifido, peduncul. geminis. Syft. veg. ed. I4. Mill. dią, ic. f. 1.

In Virginia.

Caul. erectiuf. fimplic. dein divifi in dnos ramos. Fol. in caul. fimpl. oppofita per 5. oppofitiones, molliufcula, fcabra ; fuper. alterna. Cal. s-part. Cor. pallide cœrulefc. tubo curvato.

7. oveta. P. fol. ovatis: fl. folitariis. Sy/t. veg. ed, 14.

Iychnidea \&c. Pluk, mant. tab. 348. f. 4. In Virginia 4.

Flos amplus.

8. Subulata, P. fol, fubulatis, hirfutis: fl. oppofitis. Syf. veg, ed, 14.

Lychnidea \&c. Pluk. alm, tab. 89, f. 2, In Virginle. 
9. fibirica. P. fol. linearibus, villofis: peduncul. ternis . Syjt. veg. ed. 14. Gmel. Sib. 4. tab. 46, f. 2. In $A$ fia boreali 4 .

Caulic. ufque pedal, Fol, ex eodem centro prodeunia, fubtus pilora, fuccofa, late viridia . Pedunc, axillar, hirfuti. Cal. Jongirudine rubi Cor. lacinis rotundatss, integris. Petala purpur. vel alba, Atriis purpureis.

10. Setacea. P. fol. fetaceis, glabris: 1. Lolitariis. Syft. yeg. ed. 14.

Lychnidea \&cc. Pluk. alm. $2 a b .98$. f. 3. In Virginia.

260. PORA-Cal. 5-fid, in fructu maior. Cor. campanulata . NA. Styl. longior, femibifid. periftens. Stigm. globofa. Peric. $2-\mathrm{valve}$.

3. volubilis. P. Syft. veg. ed. 14. Burm. Ind. tab. 21. f. I. In India Orient. $\bar{b}$.

Frutex caule glabro. Fol. diltantia, alterna, periolat. ovata, vix acumin. plicata, lavia. Panicula terminalis, magnd, patula. Cor. femi-5-fid. Lacin. ovatis .

26r. CON- Cor. campanulata, plicata. Stigm, 2-fid, Capf. VOLVULUS. 2-locul. loculis difpermis.

\section{* caul. volubili.}

P. arvenjis. C. fol. fagittatis, utrimq. acutis: pedunc, fub I-fl. Syft. veg. ed. I4. Fl. Dan. tab. 459. Knorr. del. 1. $t a b$. W. 6.

Elxine Ciffampelos. Matth.

b. Bocc. muf. tab. 33.

In Europa agris 24.

Caul. repens. Fol. oppofita, breviter petiolat.

2. fepium Glabra, venola, pallide virefcent. Cor, rolea. C. fol. fagittatis, poftice truncatis: pedunc, 4-
gonis, I-fl. Syft. veg. ed. 14. Fl. Dan, sab. 458. Black. tab. $3^{8}$.

In Europe fepibus 4.

planta lactefcens. Caul. orgyal. Fol. alterna, petiolat, glabra, læete viridia, margine fufco. Calyc. foliol, 2. exteriora cordata. Cor. magna, lactea .

3. fcammonia.C. fol. fagitratis, poftice truncatis: pedunc. teretibus, fub. 3-fl. Syft. veg. ed. 14. Mill. Dia. tab. 102. Morif, hif. 3. f. 1. tab. 3. f. 5. In Syrit, Myjis, Cappadocia 24. 
Simil. priori, fed fol, non margine fufca. Involuc, minimum, patulum, remotum. Cal, Lateribus dilatatus, emarginatus.

4. fibiricus. C. fol cordatis, acuminatis, lævibus: pedunc。 2-flor, Syft. veg, ed. 14. Pall. it. 3. tub. K.

In Sibiria $\odot$.

Caul, argyal, lævis, biangulatus, (a ftipulis decurrentibus non tamen anceps ) volubil. Fol. vix repanda, acumine longitudine fol. fubtus pallidiora, venofa. Petioli fupra canaliculati . Stipul, parvæ, vertical fubdecurrentes. Cal. ovatus, arctus, ebracteat. Cor, albida, feu fubincarnato-albida, fundo flavefc. campanul, (Convolv. arvenfis, $\mathrm{f}$ d dimidio minor) plicata. Stam. cor. disidio breviora. Anth. flava .

3. farinofus. C. fol. cordatis, acuminat. repandis: pedunc. fub-3-fl. caul, farinofo. Syft. yeg. ed. 14. Jacq. hort. $t a b, 35$.

Habitat .... ๑.

Caul, volubil, orgyal, teres, Fol, poftice obtuffiff. emarginata, nuda, fupra rugof, fubtus venofa, valde acuminata, duplo longiora quam Iata. Petioli farinofi. Cal. teres, aretus , Cor. calyce triplo ma: acula, 5-fida, fubincarnata .

6. Mediumb C. fol. linearibus, hatitato-acuminat. auriculis dentat. pedunc. ( fæpe) I-fl. calycibus fagittat. caul. volub. Syft. veg. ed, 14 .

Tala-neli. H. Mal. Ir. tab. 55 .

Adfinis C, reptanti. Caul, volub. non radicans . Fol, auriculæ recurva. Bract. in medio pedunc. 2. Oppofitæ, lanceol. acumin. Calycis foliol. fagittata .

7. japonicus. C. caul. volub. fol, haftatis, lanceol. lobis lateralibus I-dent. pedunc. I-fl. Syft, veg. ed. 14. Thumb. Jap.

Firagawo. Kamf. am. exot. Fafc, V. p. 856.

In Japonia.

Caul. filifor, fimple glaber, Fol, femipollic, alterna, petiolat. fubfecunda, glabra : lobus intermedius pollic. lanceol. acutus, integerr. laterales parum reflexi. Fl. axill. folitarii.

8. pendura- C. fol. cordatis; ( inferioribus integris; fupetus. rioribus) panduriformibus: calycibus lavibus. Syjz. veg. ed. 14. Dill. eltk. ssb, 85. fo 99. In Virginie arenofis. 
Caul, volubil, Fl, axill. I-2-3. ampli, lactei, fundo eleganter purpur.

9. carolinus, C. fol. cordatis, integris, trilobifque, villofis: Calycibus lævibus: Capful, hirfutis: pedunc. fub 2-fl. Syjt. veg, ed. 14. Dill. elat, tab. 84. f. 98 .

In Carolina 4 .

Caul. rufefiens. Fl. C. arvenfis magnitudine, \& figura, dilute purpur.

10. hedera- C. fol. cordatis, integris, trilobifque; cor. indiceus, vifis: fructibus erectis. Syft. veg.ed, 14. Knorr. del. 1. $t a b$. W. 5. Dill, elth, sab, 83. f. 96 . infer. \& $t, 26,8 \mathrm{r}, \mathrm{f} .93$.

In India $\odot$.

Caul. oblcure purpur. Fol, varia, fubhirfuta, fubtus pallidiora. Fl. 4-5. Cal, hirfutus, punctis nigris adfperfus. Cor, primo fature purpur, fundo albido; dein pallide purpurafcens.

11. Nil.

12. purpuC. fol. cordatis, trilobis: pedunc. petiolo brevioribus, cor. femi-5-fid. Syft. veg.ed. 14. Dill. elth, $t a b, 80$. f, 91-92, Baul, kift. 2. p. :64. In America $\odot$.

Fol. dilute virentia. Pedunc. breviff. Fruct. erecti . Cor, cyanæa.

reus. craffatis: fruatibus cernuis. Syft, veg. ed. I4. Knorr. del, I. $6 a b$. W. 2. \&W. 4. Ehret. pia. f. 2.

b. Dill. elth. $t a b$. 82 . f. 94 .

y. Dill, elth, tab. 84, f. 97 .

In America $\odot$.

Pedunc. erecti . Cal, tuberculis pilorus - Cor.

33. angularis . C. Purpur. vel. cordatis, quinqueangularibus, integerr. villofis: pedunc. (frepe) mulrifl. Syft. veg. ed. 14. Burm. Ind. $t a b$. 19. f. 2.

In Java.

Caul. volubil. lignofus, pubefcens. Fol. fubfeffil. angulis obtulis, villofo-fcabra. Pedunc. 3raro I-fl. Cor, aurentiaca .

34. Batates. C. fol cordat. haltatis, 5 -nerviis : caul, repente, tuberifero, hifpido. Syft. veg. ed. 14. Catef. Carol. tab. 6o. Morif, hijs. 2. f. 1. tab. 3. f. 4 . Rumph, amb. 5. tab. 130.

Kappa Kelengu. Hort. Mal. 7. tab. 50. In India utraque $b$. 
Radix grandis, dodrantal. tuberculata, odore virofo, fed cocta edulis, rubra evadens. Cortex purpurafc. pallidus, vel albus. Caul. procumbent. Fol. longe petiolat. carnofa, ex viridi-canefcentia. Cor. pallide purpur. oris albicantibus .

An huius $p l$. fpecies diftinza?

55. biflarus. C. fol. cordat. pubefcentibus : pedunc. geminis : cor. lobis trifidis. Syft. veg. ed. 14.

In Chine (a).

Caul. volubil. magnitudine C. arvenfis, bafi ramofus, teres, pilofus. Fol. oblong. petiolis pilofis. Cal. 5-phyll. foliolis 2. exterioribus cordato-oblong. 2. intimis lineari-lanceol, quinto femicordato. Cor. parva, s-fida, plicata, alba .

16. verticilla-C. fol. cordat. oblongis, nudis : pedunc. umbeltus. latis, 2-fid. multifl. Syft. veg. ed. I4.

Quamoclit \&c. Plum. ic. 92, f. 2. Sed cor. non jeca.

In America.

Fol. quandog. ovata, margine fubrepando, fcabriufculo. Fl. parvi, coerulefc.

17. umbella- C. fol. cordat. caul. volubili : pedunc. umbellasks. tis. Syjt. veg. ed. 14. Plum. Amer, tab. I02. Pluck, alm, $t_{a} b .167$. f. I.

In Martinica, Domingo, Jamaica 4.

Fol. petiolat. Pedunc. axill. longi. Cor. lutea.

18. malabari- C. caul, perenni, villofo: fol. cordatis ( fubpicus. lofis). Syft. veg. ed. I4.

Kattu-Kelengu. H. Mal. II, tab. 5 I.

In Malabarice arenofis 5 .

Caul, fublignofi. Petioli oblongi, pilofi . Cor. albo-viridi-flavefcens, fauce fufco-purpurea

9. canarien- C. fol. cordatis, pubefientibus, caul. perenni o fis . villofo: pedunc, (fæpe) multiff. Syft. yeg. ed. I4. Comm, hort. 2. tab. 5I. Pluk, alm. tab. 325. f. I. Phyt. tab. 30r. f. 3.

In Canarienfibus infulis $\hbar$.

Caul. fruticofus, 20-ped. fubruber. Petioli tomentofi. Fol. mollia, \& incana. Cor, ex albido-purpur.

20. murica- C. ciul. muricato: fol. cordatis: peduncul, inzus. craffatis, calycibufque lavibus. Syft. veg, ed. 14. Ia Surate. 
Similis C. purpureo, fed caul. lævis, adfperfus aculeis inermibus. Fol. indivifa. Pedunc. (æpius 2-fl. Cor, purpur, infundibul, magis quam C. purpurei, Diverfus ab Ipomea bona nocte.

2I. anceps. C. fol. cordatis: caul. volubili, utrimq. carinato. Syft. veg. ed. I4.

In Zeylona, Java.

Cdul. anceps. Fol. oblonga, lævia . Cor. parva, 5-fida, rubra.

22. Turpe- C. fol. cordatis, (frepe) angulatis; caule memsthum. branac. ( plerumq.) 4-gono: peduncul, multifl. Syjt. veg. ed. 14. Black, tub. 397, Zan. tab. 57. Herm, Lugd. tab. 178. 179.

In Zeylone 4.

Radix craffa, 3-4-cubital. fufca, fucco lacteo, flavefcente. Caul. 6-7-uln. Fol, periol, fubmucronata, mollia, incana, fubvillofa. Fl. magnitudine C. vulgaris, albi .

23. standiflo- C. fol. cordat, ovatis, obtufiufc. integerr. pedunc. rits. fub-2-fl. calycibus coriaceis : caul, petiolifque pubefcentibus. Syft, veg, ed. I4, Lin. Suppl. Jacq. app. $t a b .69$.

In infula Martiniea.

Caul. volub. I2-ped. inferne lignofus, ramofus, cinereus. Fol. ampla, alterna, longe petiolat. Cor. grandis, nivea, fuaveolens .

24. maximus . C. fol, cordat. ovatis, acuminat, integerr. glaberrim. caule, petiolifque glaberrimis. $S y j z$. veg. ed. 14. Lin. Suppl.

Tiru-Tali. H. Mal. II, tab. 53 .

In Zeylona $\hbar$.

Caul. inferne ligneus, dein volubil. altiflime fcandens .

25. Speciofus. C. fol. cordatis, ovatis, acutis, fupra hirtis; fubtus argenteo-fericeis; petiol. teretibus . Syft. veg. ed. 14. Lin. Suppl.

In Brafilia 4.

Caudex arboreus, erectus, dein volubil. teres, pubefcens. Fol. maxima, fupra viridia .

26. trinervius, C. caul, volubil, tereti : fol. cordat. oblong, glabris, trinerviis: pedunc. I-fl. Syft. yeg. ed. I4. Thumb. Jap.

In Japonia.

Caul. frmpl. filiform. glaber, Fol. pollic. \& paulo ultra, oppofita, petiolat, acumin., fubtus pâl- 
lidiora. Fl, axill. fubfeffil. folitar. vel bini . Cor. purpur.

27. peltatus . C. fol. peltatis : peduncul. multifloris. Syft. veg. ed. 14. Rumph, amb. 5. $2 a b ., 157$.

In Amboina.

28. Jalapa. C. fol difformibus; cordat, angulatis, oblong. lanceolatifque: caul, volub. pedunc. I-fl. $S_{y} f$. veg. ed. 14. Plenk. fafc. 4. rab. 94.

In Mexico, vera Cruce 4.

Radix tuberofa, extus nigra, intus rufa. Sem. hirfuta .

29. Sericeus. C. caul, volubil. fol, lanceol-ellipticis, fubtus tomentofo-fericeis; pedunc. fubumbellat. calycibus pilolis. Syft, yeg. ed. 14. Burm. Ind, tab. I7. $f, 1$.

In India $\mathrm{b}$.

Fol. alterna, petiolat. lato-lanceol. fupra nuda . Pedunc, axillar. involuc, ovato, fericeo. Cor. patens, purpur. extus albo-pilofa .

30. tomento- C. caul. lanuginofo: fol. trilobis, tomentofis . Sus. Syft. veg. ed. 14. Sloan. Jam, 1, tab. 98. f. 2. Pluk, alm. tab. I67. f. 4 .

In Jamaica.

Flos oblongus, purpureus .

3r. althroi- C. fol. cordatis, finuatis, fericeis; lobis repandos. dis: pedune. fub 2-fl. Syft, veg. ed. 14. Barr. rar. tab. 312. Mont. in Zan. tab. 54.

b. C. fericeus. Forsk. $\mathbb{E}_{g}$-Arab. monente Vahl. In Europa meridion. Orientis, Africe collibus 4. Fol, tenuia, non craffa, primordial. non laciniata, dentata, hirfuta. Cor, rofea .

32. cairicus. C. fol, pinnato-palmat. ferratis : peduncul, filiforınibus, paniculatis: calycibus læevibus. Syjt. veg. ed. 14 Vesl. Eg. tab. 74.

Ipomea palmata. Forsk, monente Vahl.

In AE I gyto.

Fol. magis pinnatifida, \& ferrata fequent. Cor. duplo maior, purpur.

33. copticus, C. fol. pedatis, ferratis: pedunc. enfiformibus, 2-fl. calycibus muricatis. Syjt. yeg. ed, I4.

C. quinquefolius, B. prod. $\mathbf{1 3 4}$.

In Oriente.

Caul. fpitham. vel brevior, proftratus, herbac. angulatus, lævis. Fol. petiolat. potius palmata, vel ad bafin fere s-loba, unguicul, lavia; 
foliol. lanceolat. ferratis; lateralibus fenfim brevioribus. Stipul. parva, fol, fimil, Pedunc. axill, compreffi Bract. 2, minutæ. Cal, muricatus . Cor. 5-fida, acuta, alba. Stigma fanguin. Capf, ratione plantæ magna.

34. vitifolius, C. fol, pa!mat, quinquelubis, dentatis, glabris: caul. pilofo: pedunc. multifloris. Syjt. veg. ed. 14. Burm. Ind. tab. 18. f. 1, Pluk, alm. tab. 25. f. 3 .

In India orientali.

Fol, ad dimidium divifa, laciniis acumin. Racemi 2-part. Cal, villofus, Cor, aurantiaca .

35. diffeczus, C. fol. palmatis, feptempart. dentato-finuat. gla. bris: caul. pilofo: pedunc. rxpe I-fl. Syft. veg. ed. 14. Jacq. Obf, 2. tab, 28, Hurt. 2 tab. 159 .

In America $\odot$.

Caul, alte fcandentes. Fol, petiolis longis, pilo. fis innixa, lobis lanceol, acutis, \& varie diffectis. Pedunc, axill, folitar. Cal. membranac. fubpellucidus. Cor. albida, fundo purpur.

36. macrocar- C. fol. palmato-pedatis, 5-part. pedusc. (alatis) pus. I-fl. Syft. veg. ed. I4. Plum, ic. gI, f. I.

In America.

Foliorum lobi lanceol. integerr. medii maiores. Fl. axill. magni, peduncul, purpur. Capf, magna, torofa, purpur.

37. panicula- C. fol, palmatis: Iobis 3-5-7. ovatis, acutis, intus. tegerrimis : pedunc. paniculatis. Syft. veg. ed. 14. Pal-modecca. Hort, Mal, ir, tab. 49.

b. Modecca. Hort, Mal, 8, tub, 20.

In Malabarice arenofis.

Radix craffa, tuberofa, cubital. Caul. vetuftiotes cinerei. Fol. rupra fufca, \& nitentia, fubtus dilute viridia: petioli rufefcent. Pedunc. fpitham. rainofi, incurvi, fubrubefc. Cor. purpuro-rubia.

38. macrorkizos, C. fol. digital. feptenis, integerr: caul. glabro: pedunc. 3-fl. Syjt. veg. ed. r4. Plum. Sp. I. ic. go. f. 1 .

In America.

Radix craffa, bracbiata. Fol. lobi lanceol-acumin. Fl, magni, coccinei.

39. quinequefo. C. fol. digirat, denrat. glabris: pedunc. levibus.

liuss. Syft, vog. ed. x4, Pluk, alm, 6ab, 167. f, 6.

In Americe $\odot$. 
Flos magnus, purpur.

40. pentaphyl- C. fol. digitat. quinis, pilofis: caul. pilofo. Syft. lus. veg. ed. I4. Herm. Lugd. tab. 185.

b. Plum. Amer. 1. ic. 91. f. 2.

In America $\odot$.

Foliorum laciniæ lanceol, fubtiliter denticulatæ, intermedii mai. Pedunc. axillar. longi, ramofi. Bract. 2. magna. Fl. terni, vulgaris forma, albi. Capf. obtufa .

41. martinicen-C. caul, repente, fubvolub: fol. elliptic. Syft. fis. veg. ed, 14. Jacq. Amer. pict. tıb. 24.

In Martinicu umbrojis, inundatis.

Caul. longi. Fol. obtufa, cum ftipula in acumine, petiol. 2-pollicar. Pedunc. axillar. fuperne ftipulis 2. oppofit. Cor. alba .

\section{** Caul. non volubili.}

42. Spinofus. C. erectus, fruticofus: fol. lanceol. fericeis : ra mulis floriferis, 1pinofis. Syft. veg. ed. I4. Lin. Suppl.

C. fruticofus. Pall, It, 2, tab. M.

In Dauuria $\hbar$.

Frutex humilis, fubflexuofus, ramofus, furculis tomentofis. Fol. alterna, feffil. oblongo-lanceol. Fl. terminal. furfum verfi, I-lateral. Cal. tomentofus. Cor. plicato-5-dent. tubo extus tomentofo, limbo rubicundo.

43. Jiculus. C, fol, cordato-ovat, pedunc. I-fl. bract. lanceol. Syft. veg. ed. 14. Bocc. Sic, tab. 48. Morif. hift. 2. $\int .1 . t a b .7$. f. 5 .

In Sicilia.

Caul. fubvolubil. 2-ped. Fol. parva, humifufa, longe petiolat. mucronata. Fl. axill. minimi, coerul.

44. pentapeta-C. fol. lanceol. obtufis, nudis, lineatis; ramis loides. declinatis: fl. folitar. femi-5--fid. Sy $f$. veg. ed. 14 .

In Maiurce $\odot$.

Simil. C. tricolori, fed minor. Fol. fubpetiol. F1. axill. folitar. breviffime peduncul. Cor. corulefc. fauce lurea, femi-5-fid. lacin. acuminat.

45. liheatus, C. fol. lanceol. fericeis, linearis, petiolat. pedunc. 2-fl. calyc. fericeis, fubfoliac. Syft. veg. ed. 14. Morif. hift. 2. S. 1, tab. 4. f. 2. mala. Barr. rar, $t a b$, II 32 . Triumf, obf. $t a b$. 9r. f. 2 .

In Hifpania, Sicilic \& G maritimis 4. 
Caul. proftrati, flexuofi, femiped. incani. Fol. remota, bafi anguftiora, acuta, ad angulum acutum lineata. Bract. 2. calyc. longiores. Cor. dilute purpur. extus hirta .

46. Crieorum. C. fol, lanceolat, tomentofis: fl. umbellatis: calyc. hirfutis: caul. erecto. Sylt. veg. ed. 14. Morif. hift. 2. f. I. $t a b$. 3. f. I. Bocc. rar. 4 , tab. 470 . Bocc. mul. 2. tab. 70. Burr. rar. tab. 470.

In Hifpania, Crota, Syria Ec. 44.

Fol. fericea. Umbella 4-phylla, S-radiata; pedunc. centrali i $-\mathrm{fl}$, aphyllo, lateralibus. 4-5fl. Bract. 2, fubbifurcatura \& 2, fuls altero $\mathrm{fl}$. Calyc. obtufi, hirfuti uti bract. Cor. alba.

47. Cantabri- C. fol lineari-lanceol, acutis : caul, erectiufc, raca. mofo: pedunc, fub 2-fl, calycibus pilofis. Syft. veg. ed. 14. Jacq. Aujir. tab. 296. Morif. hift. 2. . 1. tab. 4. f, 3. Cluf. hift. 2. p. 49.

b. C. terreftris. Bauh. hift. 2. p. 160 .

In Europa auftrali, Sibiria, Africa 4.

Tota planta villofa. Caul. fefquiped. Fol. alterna, integerrima: radical. petiolat. obtufiora; caulina feffil. Pedunc. axillar. Cor. carnea, cum lineis rubris .

48. Dorychni- C. fol. fublinearibus, fericeis: caul. fruticul. paum. niculato: calycibus obtufis, nudiufcul. Syft. veg. ed. 14 .

In Oriente $\mathrm{b}$.

Rami rigidi, raro dichotomi. Fl. folitar.

49. fcoparius. C. erectus, fruticofus, glaber, ramis virgatis: fol. feffilibus, linearibus: racemo terminal. peduncul. fub 3-fl. Syft. veg. ed. 14. Lin. Suppl. In Barancas oppidum s. Crucis $\mathbf{b}$.

Facies Spartii, feu Genifte, \& non Convolvuli.

Caul. teres. Rami erecti, fimpliciff. foliofi. Fol. remota, brevia, erecta, alterna, fubpilofa. Racemus fubfecundus. Cor. alba, extus hirfuta.

Rafura huius ligni fpargit odorem rofaceum; \& faporem ncriufcialum habet. An vero Lignum Rhodium Off:?

so. Wothe- C. erectus, fruticofus: fol. linearibus, canefcenroides. tibus: peduncul. axill. folitar, erectis, I-fl. bractearis: calyc. lanceol. glabris. Syjt. veg. ed, 14 . Lin, Suppl.

Ad sap, b. Spei. 
Habitus Enothera molitfima. Caul. rubicundi, glaucitate quadam tecti. Fol. longitudine digiri, laxa, plana. Pedunc. breves. Cor. magna, fulva.

51. floridus. C. fruicofus, proftratus, canus: fol. lineari-lanceol, glabis: thyrio terminali, pyramidato, compofito. Syjt, veg. ed. 14. Lin. Suppt. In rupibus circa Barrancas $\hbar$.

Similis C. cneuro. Fol, digital, petiolat, undulata, integerr. venofa, glibra. Fl. min. Cor. dilute rubra, extus hirfuta. Copia fl. omanium pulcherrimus,

52. corymbo- C. caul, repente (flexuofo): fol. cordatis: pedunfus. cul. umbellatis. Syft. veg. ed. I4. Plum, Sp. I, ic. 89 . f. 2.

In America.

Fol. petiol. acumin. integerr, Pedunc, axill, longiff. Fl. vulgaris forma, ac magnitudine. Cor. alba .

53. Spithama-C. fol. cordatis, pubefcentibus: caul, erecto: cus. pedunc. 1-fl, S,ft, veg. ed. 14.

In Virginia.

Fol, pauca, Flos pro planta modo magnus, albus.

34. perficus. C. fol. ovalibus, tomentofis: pedunc. I-fl. $S_{j}$ f. veg. ed. 14. Gmel. it. 3. tab. 7.

In Perfia, ad maris Cafpici littus 24.

Tota planta Verbafci infiar tomentofa. Fol. magnirudine extimi articuli pollicis, breviter petiolat. obrufa, integerr. Pedunc, axillar. Involuc. 2-phyllum, ovatum. Cor, alba .

35. tricolor, C. fol, lanceol-ovat. glabris: caule declinato: fl, folitar, Syf, veg. ed. I4. Morif. hift. 2. f, I. $t a b, 4$. f. 4 .

In Africa, Hifpania, Sicilia $\odot$.

Caul. fefquiped. flexilis. Fol. infer. 3-4-unc. fuperiora min. Fl. axillar. Cor. magna, azur= rea, umbilicainiveo, fundo luteo.

56. repens, C. fol. 1agittatis, poftice obtufis: caul, repente: pedunc. I-fl. Syft. veg. ed. I4, Plume Amer. tab. I05.

Ballel, Hort, mal, ir. tab. 52 ,

In Americe maritimis $\mathbf{4}$.

Radix longa. Cor. magna, patens, plicata, fuba

Io crenata, alba, margine dilute rubente. 
37. reptans. C. fol, haltato-lanceol, auriculis rotundatis : caule repente: peduac. I-2-fl. Syft. veg. ed. 14. Olus vagum. Rumph, amb. 5. tab. I55. f. I. Ipomea aquat, Forsk. Eg-Arab. Vahl. In india.

Planta ex minoribus, Caul, filiform, lavis . Fo!. gldbra, interdum dentata. Pedunc. breves. Cal. rotund tus. Cor. tubo purpuro-rubente, limbo albicante.

38. edulis, C. caule repente, angulato: fol. cordatis, integris, trilobifve, glabris. Syft. veg. ed.-I4. Thumb. Jap.

In Japonia.

Differt a C. Batata fol, in medio non anguftatis, ut fagittata evadant. Ipomea triloba non poteft elle.

Radices magnitudine fæpe pugni, tuberculata, carnofæ, uti Batatas, efculentæ, molliffinæ, \& fapidiffimæ.

59. hirsus. C. fol. cordutis, fubhaftatifq. villofis: caul. pe. tiolifq. pilofis: pedunc. multifl, Syjt. $v_{c g}, e d$. I4.

In India.

Planta non magna, minus volubilis. Fol. parum villofa: primaria cordato-fubrotun: fecundaria proprie cordata: fl. proxima fæpe haftata. Pedunc. nudi, fl. alternis, pedicellat. involucris ad fingulum pedicellum minimis, lanceol.

60. foldanella, C. fol, reniformibus : pedunc, I-fl. Syft. veg. ed. 、 I4.

Braffica \&c. Bauh. Hift. 2. p. 166.

In Anglice, Frifice litoribus maris; in Carniola, Pedemontio Ec. 24.

Caul. repens, farmentofus, rubefcens . Fol. longe petiol. craffa, obfcure viridia, glabra. Bract. 2. corvaræ, calyce ma. Cor. rofea.

6r. Pes capra. C. fol, bilobis : pedunc. I-fl. Syft. veg. ed. I4. Rumph. S. amb. tab. 159. f. I.

Schovanna-adamboe. H. Mal. I1, tab. 57. Herm. Lugd. tab, 175. Pluk. phyt, tab. 167. f. 3. In India.

Radix obliqua. Caul, repens, herbac. 3-4-uln. Fol. alterna, fubrotunda, cor referentia, carnofa, lucida, glabra. Cor, ampla, rofea, umbone atro-purpur. 


\section{PENTANDRIA MONOGYNIA:}

62. brafilienfis. C. fol, emarginatis, bdfi biglandulofis: pedunc. 3-fl. Syft. veg. ed. 14. Plum. Anzer, tab. 104.

In Brafilia, Dorningo maritimis.

Fol. fubrotunda, nitida. Cor. purpur.

63. Sublobatus, C. procumb. fol, fuperior. apice dentato-repandis: fl. capitatis. Syft, veg. ed. I4, Lin. Suppl. In India $\odot$.

Fol. fubpilofa; infer. cordata, fuper. obtufa. Fl. terni, feffil. paralelli. Involuc. 6-phyll. Cor. mazna.

64. litoralis . C. fol. oblong, lobato-palmat. pedunc. I-fl. caul. repente. Syft. veg. ed, 14. Plum. Sp. I. ic。 90. f. 2.

In America.

Fol. ad nodos petiolat. laciniis irregularibus, obtufis. Fol. min. 3-lobata. Pedunc. longi. Fl. vulgaris forma.

Guianenfis. C. fol, oblong. hirfutis, e viridi-cinereis: fl. parvis in capitulum collectis. Aubl. Guian. tab. 52.

In Guiana 4 .

Tota planta ladeo ficco fcatet. Caul. pl. volubil. tomentofo-cinerei. Fol. alterna, petioldt. ovata, integerr. tomentofo-cinerea. Fl. longo perdunculo axill. innixi. Cor. alba, dut corrul. calyce paulo maior. Capf. villofa. Sem. angulata , nigra .

glaber. C. pentaphyllos: fl. magno, albo. Aubl. Guian.

In Cä̈enna 24.

Tota planta lacieo fucco fcazet. Rad. craffa, tortuofa. Caul. pl. volubil, fupra arbores fparfi . Fol. alterna, digitata. Foliol, inæqual. Ionge petiol. lanceol. acuta, integerr. glabra. Fl. axill. racemofi, longe peduncul. albi .

minimus. C. villofus, Heliathemi fol. Aubl. Guian. Plums cat. p. MSS, tab, 6. f. 47.

In Giuna.

Mechoacan. Convolvulus Jetiaucu. Pif. In, cum fig.

In Brafilia, \& in Mechoace nove Hifpania $\hbar$.

Proxime accedit ad C. Sepium. Radix 2-fida, extus fufca. Caul. farmentofi, longe fcandentes, multiangul, Fol. alterna, petiolata, cordiformi-aurita, fature virid. fubtus nervofa. Cor. alba, vel dilute incarnata, intus purpur. Sem. fufca . 
havanenfss. C. fol. oblong. nitidis: pedunc. I-fl, caul, volubil. Jacq. $O b f, 2, t a b, 45, \mathrm{f}, 3$. Amer, ed. 2. picta tab. 264. f. 97.

In Havana.

Alritudo humana . Caul. herbaceus, ramofiff. glaber. Fol. multa, alterna, obtufiff. integerr. femipoll. Pedunc, axill. I-fl. Fl. parvi, albidi .

gemellus. C. caul, volub: fol. cordatis, glabris: peduac. 2-fl. Burm. Ind. tab. 21, f. I.

In Java.

Cául, fimpl. glaber. Fol. integerr. Pedunc, axill. folitar. Cor, albicans, vel lutea.

uniflorus. C. caul, volubil. fol. lineari-lanceol: pedunc, Ifl. bracteis binis, ovatis. Burm. Ind. tab. 21. f. 2 .

In Java.

Fol. fubpetiolat. Pedunc. breves.

nervofus. C. fol. cordatis, nervofis, fubtus tomentofis: pedunc. umbellatis, multifl. Burm. Ind. sab. 2o. f. I.

Habitat Coromandeli.

Planta tomento albo obfita. Fol. palmar. acumin, integerr. fupra nigra, fubtus fericeo-albicantia, nervis cum cofta protuberantibus. Fl. capitati . Cor. magna, purpur. extus fericea.

proftresus. C. caul. plerumque proftrato: fol. feffilibus, Iineari-cuneatis, pilofis: pedunc, axill. r-fl, bibracteatis. Forsk. Suppl. AEg.

In Arabia.

Eaftatus. C. caul. volub. 2-cubit, fcandente: fol. haftatis, 2-pollic: bafi infra unident: pedunc. geminis, femel dichotomis. Forsk. Suppl. AEg,

In Arabia.

Fl. forma, \& col. C. arvenfis.

Hermannia. C. fol. fubhaftatis, poftice obtufis: peduncul. 2-fl. cor, apice pilofis. Herit. Stirp. nov. fafc. 4. tab. 33 .

In Perue \&s. aridis 4.

Planta volubil, tota cana, Rad. fufiform. carnofa, ramofa, grifea, intus alba. Caul. teres, ramofus, fufcefcens. Rami volubiles, alterni, villofiffimi. Fol. alterna, petiolata, fublanceol. feu oblonga, apice obtufiufculo cum acumine minuto, reflexo; integerrima, quanT.m, I. 
doq. fubundulata, fupra lineata, fubrus fubnervofa, villofa, vel fubtomentofa, patentia, $2-2 \frac{1}{2}$ poll. longa, I poll. lata. Petioli tortiles, foliis tercies breviores, hinc teretes, inde unifulci, villofi. Pedunc. axill. folitar. obfolete contorti, 2 -fl bracteati, villofiffimi, longitudine fol. Fl. bini, altero ferotino, pedisellati, albi, 6 lin. Iongi, \& lati, Bracteæ parvæ, lineares, acutæ, fub pedicellis .

262. IPO- Cor. iufundibulif. Stigm. capitato-globofum . MEA , Capf. 3-locul.

\section{* $\mathrm{Fl}$, diftinäis .}

I. Quamoclit, I. fol, pinnatifld, linearibus: fl. fubfolitar, Syjt. veg. ed, 14. Mill, ic. tab. 214. Sabb. hort. I. $t .3,85$.

Convolvulus \&c. Col, aquat. tab. 72.

Flos Cardinalis. Rumph amb. 5. tab. I55. f. 2. Tiurid-cranti . Hort, mal, 11, tab. 60 .

In India $\odot$.

Caul, volubil. fcandens. Fol, fature viridia, FI. 2. rubra axill, inrenfe rubri, feu fanguinei.

I. fol, pinnatifid. lin aribus: $\mathrm{fl}$, racemofis, pendulis. Syft, veg. ed. I4.

Quamo-lit \&c, Dill, elth, tab. 24 T, f. 3 T2,

In Curvilina citerioris arenofis,

Plania non lactefcens. Caul, fuffrutic ofus, fefquiped. \& ultra, fuperne ramofus, totus foliofus, rectus. Fol, primi anni in orbem dirpofita, Coronopi inftar laciniata. Cal. tubo brevi, dentibus fubulat. Cor. armæne purpur. extus faturatior, intus maculis albicantibus, ftrïs purpur. variegara.

3. umbellata, I. fol. digitatis, feprenis: pedunc. umbellatis, breviffin. Syft. veg. ed. 14.

Quamoclit \&c, Plum, fp. 3, ic. 92, f, 2.

In America.

Fol. petiolat. lacin. lanceol, fubæqualibus, integerr. Cor, cúccinea. Capf. oblonga, acuminara.

4. carolina, I. fol. digitat: foliol, petiolat: pedunc, I-fl. Syft. yig. ed. I4.

Convolvulus \&c. Catef. Car. 2. tab. 9I.

In Curolina.

Cor. parva, extus dilute viridis, intus violac. 
5. coceinee. I. fol. cordatis, acuminnar, bafi angulatis: pedunc. multifl. Syft, veg. ed. I4.

Quaroclit. Comm, rar. $t a b, 21$.

Convolvulus \&c, Plam, amer. iab. 103. Pluk. phyt. tab. 385 . f. 2 ,

In Dorningo $\odot$.

Caul, debilis, fubcinereus. Fol. longe petiol, cordiform. 4-5. digitos longa, tenella. Pedunc, axill, longi, ramofi. Cứr. dilute coc= cinea.

6. lacunofa. I. fol, cordatis, acuminat. fcrobiculatis, baft angulatis; pedunc. fub-1-fl. flore brevioribus. Syjt. reg. ed. I4.

Cenvolvulus \&c. Dill, elth, tab, 87. f. 102. In Virginia, Carolina $\odot$.

Simulis I. coccines, fed pedunc. I-2-fl. Fl. tubo craffore, albo, ore purpurafe. nec coccineo.

7. folanifolin. I. fol. cordat, acutis, integerr: fl. folizar. Syft. veg. ed, 14 .

Quamoclit \&c., Plum, Sp. 3. ic. 94. f. I. In America.

Caul, angulatus. Fol, petiolat, venofa. Pedunc. axill, longi, Cör. paren's, 's-fid. rofea.

8. tuberofa. I. fol, palmatis; lobis feptenis, fanceol acutis, integerr. pedunc. 3 -fi. Syft. veg. ed. 14.

Convolvulus \&ce. Sloah. Jam. 1, tab. 96. f. 2. Pluk, alm. tal, 276. f. 5 .

In Jamiaica 44.

Tota planta lactefcens; florems pulchra vifui . Caul. fruticofus. Fol. palman humanam $x-$ quant. Pedunc axill. Fl. 2-polinc, farure fulphur. odori. Capf. membranac. ex quadratofubrotunda, fub-pellucida. Sem. 4. atra, villola.

9. digitcta. I. fort palmatis; lobis feptenis, Jancèol. obtats fis: pedunc. $3-$ Al. Sy/t, veg, ed. 14.

Quainoclit \&c. Ptum, sp. 3. taxb. 92, f. I. In America.

Radix ingens, tuberculata, brachiata. Caul. flexuofus. Fol. lobi integerr, exter, mín. Fl. longi. Cor. coccinea. Capf, oblong. Sem. conica.

ro. bona nox.I. fol. cordat, acutis, integerr. eaut aculeato; f. binis-ternis; cor. indivifis. Sy/t. veg. ed. 14. Ee ij 
Convolv, Slonn. Jam. kift. 1. teb. 96. f, I. Pluk。 alm. $t a b, 276$. f. 3 .

Munda-valli . H. Mal. II, tab. 50.

In India arenofis, arbores fiandens.

Caul, orgyal. Fol. magna, longe petiolat. moilia, fubtus dilute virid. trita odoris gravis. Fl. axillar. pedunculat, tortuofi . Cor. ampla, violac.

II. campenu-I. fol. cordatis: pedunc. multifl. periant. exter. late. orbiculari: cor. campanul, lobatis. Syft. veg. ed. 14.

Adamboe. H. Mal. II. tab. 56.

In India.

Caul. repentes, pilofi. Fol. magna, mollia, tenuia, petiolis pilofis innixa. Cor. præ reliquis craffior. 4-part. laciniis inæqualibus, inferne purpuro-rubra, fuperne purpuro-albefiens.

12. violacea , I. fol. cordat. integerr: $\mathrm{fl}$. confertis ; cor. indiviuss. $S_{\text {jt }}$. veg. ed. 14.

Convolvulus \&c. ¿lonn. Jam. hijt. I. $t a b .98$. f. $\mathbf{r}$.

Quamoclit \&c. Plum. Sp. 3.tab. 93. f. I.

In America merid.

Fol. ampla, longe petiol. acuta . Pedunc, axill. longiff. Fl. longiff. purpur. Capf. fubrotunda.

13. carnes. I. fol. cordar. glabris: pedunc. multifl. cor. marginatis. Sy ft. veg. ed. I4. Jucq. Am, tab. 28. ed. 2. pizta tab. 25 .

In Americe $\hbar$.

Caul. orgyal-20. ped. fruticofus. Fol. alterna, petiol. fubrotundo-cordata, integerr. venofa. Pedunc. terminal. Fl. 3-pollic. carnei. Capf. fufca, nitida.

34. repanda. I. fol. cordat, oblong. repandis: pedunc. ramofis, cymofis. Syft. veg. ed. 14. Jacq. am. tab. 20. ed. 2. pia. tabb. 27 .

In America.

Caul. volubil. Planta glaberrima . Fol, petiolat. fupra virid. fubtus viridi-glauca, cum venis violac. Cor. plicata, 2-pollic. elegans, coccin. nitidiff. Capf. coccinea .

15. filiformis. I. fol. cordat obtufis cum acumine, integerr: pedunc, ramofis, filiformibus. Syft. veg. ed. I4. Jacq. am. ed. piąa $2 a b, 26$.

In Murtinica Jylveticis . 
Planta glaberrima. Caul. volubil. ro-ped. Fol. magnitudine varia, breviter petiolat. Racemi axillar. longiff. Fl. numerofi, purpur. inodori.

16. haftate. 1. fol. fagittato-haftatis: pedunc. 2-fl. Syft, veg. ed. 14. Burm. Ind. $t a b$. 18. f. 2.

In Java.

Fol. glaberrima, lucida, lobo fuper. Iongiff. lanceol. Cor. lutea, limbo breviff.

17. glaucifolia. I. fol, fagittat, poftice truncatis: pedunc. I-th. Syft. veg. e.t. 14.

Convolvulus \&c. Dill. elth. tab. 87. f. IOr.

In Mexica arvis.

Caul. cubital. \& ultra. Fol. alterna, C. arverfis fimilia, glauca. Fl. axill. carnei, fig. \& magnitudine Speculi Veneris.

18. triloba. 1. fol. cordatis, trilobis: pedunc. fub-3-fl. Syft. veg. ed. 14.

Convolvulus \&rc. ? Sloan. Jam. Hift. I. tab. 97. f. 1 .

In America $\odot$.

Caul, volubil, angulatus. Fol. intermed. ovato, lateralibus femicordar. integerrima, glabra. Cor. violac. Capf. pilofa.

19. kederifolie. 1. fol. cordatis, trilobis: pedunc. racemofis, multifl. Syft. veg. ed. I4.

Quamoclit \&c. Plum. SP. 3. tab. 93. f. 2.

In America .

Fol. petiol. glabra, venofa. Pedunc. axill. longiff. Cor. magna, indivifa. Sram. longiff. huic fpeciei tantum propria. Capf. fubrot. obtufa. ** Fl. aggregatis.

20, hepaticifo- I. fol. trilobis: fl. adgregatis. Sy.ft. veg. ed. I4. lia. Burm. Ind. tab. 20. f. 2.

In Zeylona.

Caul. volubil. longi, pilofi. Fol. pilofa, fubtus pallidiora. Cor. s-angul. pallide cœrul.

2r. tamnifolia, I. fol. cordat. acuminat. pilofis: fl, adgregatis . Syft. veg. ed. 14 .

Volubilis \&c. Dill. elth, tab. 318. f. 4 I4.

In Carolina.

Fl. denfe capitati, perpufilli, fol, pilofis cincti .

Cor. plerumq. plicata, cœrulea, per ætatem fufca. 
32. Pes Tigri-I. fol. palmatis: fl. aggregatis. Syft. veg.ed. I4. dis. Kniph. cent. tab. 53.

Convolvulus \&c. Herm. Lugd, tab. I87. AZ. Bonon. 11. tab. 23. f. 2. Pluk, phyt. tab. 166. f. 6 .

Volubilis \&c. Dill. elth. tab. 318, f. $41 \mathrm{I}$.

Pulli-Schouadi. H. Mal. I1. tab. 59.

In India.

Planta pilofa. Fl. parvi, maioribus immixtis, albi, vel dilure purpurafc.

paniculata. I. caul. volubil: fol ovatis, acumin: pedunc. paniculatis. Burm. Ind. tab. 2I. f. 3 .

In Jaya.

Folior. acumen ariftatum : pedunc. incraffati. Caul, verfus fines: fol, tenujora: pedunc. \& cal. toment.

Euftuchiana. I, fol. cordat. 3-lobis: pedunc. 2-fl. Jacq. Obf. 2. $t a b, 36$.

In America.

Non fatis diftincta ab. I. triloba.

verticillata. I. Forsk. AEg.

In Arabia.

Planta tota villofa. Fl, axillar. terni, bon conferti. Capf. 4-locul.

biloba. 1. fol. fubrotun. 2-lobis, integris. Forsk. Eg. In Arabia.

Caul. fcandens. Pedunc. fub-I-fl.

scabra. I. caul. volubil: fol. 5-lobis, utrimq. fcabris: fl, axillaribus, folitar. cœrul, Forsk. Eg.

In Arabia.

Habitus Convolvuli hederacei. Bract. 2. oppofitæ, Fineares. Calyc. fcabro-hirfuti.

triftora. I. fol, cordat. acuminat: glabris: pedunc. 3-ff. Forsk. Eg.

In Arabia.

Fol. fefquipollic: integerr. petiolo vix fefquipollic. Pedunc. axill. Cor. pallide flava.

Leueantha. I. fol. cordatis, fubangulatis; peduacul. plerifque 2-fl. Scop. Delic. Infub. Fafc, 2. tab. 4.

Habitat . . $\odot$.

Caul. volubil. ramofus, glaber, rubellus, 4-5pedal. Fol. petiolat, acuminata, glabra, fubtus rubore fuffula. Pedunc. axillar, bracteati. Cor. alba, calyce vix duplo longior. Capf. 
fufca, rarioribus pilis pubelcens. Differt $a b$ I. coicinea.

263. POLE- Cor. fundo diufo valvis ftaminiferis. Stigm. 3MONIJ a fidum Capf. ovat. 3-lucul, fupera .

I. coruleam, P. fol, pinnat: fl. erectis: calycibus tubo cor. longioribus. Syft, veg. ed. I4. Fl. Dan, tab, 255. Sabb. hort. 2. tab. 52.

b. P. calycibus lanatis. Gmel. Sib. 4. tab. 50.

In Europia, Afia 24.

Caul. cubital, \& ulcra, erectus, ramofus. Fol. elegantiff. læte virent. impari extremo: pranulæe el'iptico-lanc. integræ. Fl. terminal. fubumbel ati. Cor. cœrul. vel alba .

2. reptans. P. fol. pinnatis, feptenis: fl. terminalibus, nutantibus. Sy/t. yeg. ed. I4. Mill. diä.tab. 209.

In Virginia $\mathbf{2}$.

Differt a priore rad. repente: fol. 7. nec 17:

3. dubium - P. fol. inferior. haftatis; fuperior. lanceol. Syft. veg. ed. I4.

In Virginia.

Dubii generis. Facies aliena a Polemoniis, fed Veronica Teucrii. Sty\}. \{emibifid. Cor. dilute coerul.

4. Relloides. P. erectum; caul. filiform. fol. lanceol. ciliatis: panicula peduncul. paucifl. nuda. Syft. veg. ed. I4. Lin. Suppl.

Ad cap. b. Spei .

5. Campanulo-P. erectum, glabrum ; fol. erectis, lineari-lanides. ceol. integris : fl. terminalibus, folitar. Syft. veg. ed. 14. Lin. Suppl.

Ad cap. b. Spei.

Simil. Campanule Perizcofol. at Atigma fimpl.

264. CAM- Cal. 5-fidus . Cor. fæepius campanulat. 5-fida

PANULA. fundo claufo valv, ftaminiferis. Stigm. 3-fid. Capf. infera, poris lateralibus dehifcens.

* Fol. lavioribus, anguftioribus.

I. cenifia, C. caulibus I-fl. fol, ovar, glabris, integerrim. fubciliatis. Syft, veg. ed. i4. Allion, Spec. Pedem, $t a b, 5$. f. I. Fl. Ped, tab, 6. f. 2.

In Atpibus montis Cenifü, \& Helvetix 24.

Radix repens, altertatin etwittens ramos termisatas fot, radicalibus. Caul. pollic. filiform. fump!. Fol. radical, confertas caulina 4-5, obo= 
vata, obtufa, lavia. Pedunc. terminal. Flos ratione planta magnus. Cal. hirtus. Cor. femi-5-fid. corul.

2. taiflore. C. caul. calyc. corol. xquante, Syft, yeg.ed. I4. Fl. Lapp. tab. 9. f. 5. 6.

In alpibas Lapponicis 24.

Caul. fimpl. digital. oblique erectus, teres. Fol. caulina 6-7. alterna, infima ovata, media lanceol. fumma linear. Flos terminal, nutans . Cor. cœrul. Capf, pyriform.

3. pulla. C. caulicul. I-fl. fol. caulinis ovatis, crenatis: fl. cernuis. Sy.f. veg. ed. 14. Jacq. Obf. 1. tab. I8, Auftr. 3. tab. 273.

b. C. fol. fubrotun. Bauh. prodr. tab. 35.

In Auftria.

Kadix repens, filiform. Caul. fpitham. erecti, flexuofi, filiform. raro ramo uno, alterove, eoq. florifero. Fol. petiol. nuda, crenis diftantibus. Flos magnitudine C. rotundifolix, calyc. lavi .

6. Fl. pl. in apice caulis variat.

4, rotundifolia. C. fol. radicalibus reniformibus; caulinis linearibus. Syft, veg. ed. I4. All. Fl. Ped. tab. 47. f. 2. Dod. pempt. 167.

b. C. minor. \&c. Bauh. prodr, tab. 34 .

y. C. alpina \&c. Fl. Dan. tab. 189. Bocc. muf. tab. 103. Barr. ic. 457.

In Europa, ad rupes, E loca ficca 24.

Caul. pedal. \& ultra, filiform. I-multifl. Fol. radical. ferrata, obfcure virent. caulina plerumq. integra. Cor, magna, cœrul.

b. Differt fol. furmioribus nitidioribus: caulinis latioribus, ferratis; primis rhomboildais, reliquis elliptic. acutis, radicalibus ctiam anguftius dentatis.

5. patula.

y. Differt fol. omnibus linearibus, femper integerr. C. fol. frictis; radicalibus lanceol-ovalibus: panicula patula. Syft. veg. ed, I4. Fl. Dan. tab. 373. Dill. elthe tab. 58. f. 68.

In Anglie, Svecie, Pedemontii, Helvetia arvis 24.

Radix obliqua . Caul. diffuf, cubital. afperi. Fol. flavo-virentia, flaccida: caulina linearia, ferrata. Rami fparfi, paucifl. Fl, parvi. Cor. cerulea. 
6. Rupuncu- C. fol. undulatis; radicalibus lanceol-ovalibus: lus.

panicul. coarctata. Syft, yeg. ed. I4. Fl. Dan. 855. Rapunculus \&c. Fuclif. 214 .

In Helvetia, Italia Ec. $\sigma$.

Caul. 1-2-cubital. fuperne pene nudus, angulatus, afper. Fol, obfcure virent. molli lanugine obfita ; caulina acutiora. Racem. terminal. Rami fimiles, breviores, erecti. Pedunc. fæpius terni, intermedio longiore. Cor. dilute purpur. vel alba.

7. Perficifo- C. fol. radicalibus obovatis: caulinis lanceol-lilia. nearibus, fubferrat. feffilibus remotis. Syft. veg. ed. I4. Knorr. del. vol. I. tab. 5. I.

Phyteuma Matth.

In Europa Septententrionalis afperis, \& fylyis umbrojis 24.

Radix Napiformis. Caul. cubital. fimpl, angulatus. Fol, alterna. Spica rara; pedunc, I-2-fl. Fl. magni, albi, vel azurrei .

Var. fl. duplici; pleno. Altera foliis (exceptis fummis caulinis) truncatis.

8. pyramida- C. fol. lavibus, ferratis, (inferioribus) cordatis; lis. caulinis lanceolat. caulibus iunceis, fimplicibus, umbellis lateralibus, feffilibus. Syft. veg.ed. 14. In Carniola, Sabaudia o7.

Altitudo humana, \& ultra. Cor. cœrul.

9. americana. C. fol. cordatis, lanceolatifque, petiolat. ciliatis : fl. fecundis; cor. 5-partit. planis. Syft. veg. ed. I4.

Trachelium \&c. Dudart, mem. 4. tab. III.

In Penfylvania đ'.

Caul. \& germina levia. Fol, acuminata. Fl. 3pl. ex fingulis alis. Cor. parva, cœrul. Styl. corolla longior.

Io. liliifoliu. C, fol. lanceolat. caulinis acute ferratis: fl. paniculat. nutantibus. Syft. veg. ed. I4. Gmel. Sib. 3. $t a b .26$.

In Sibiria, Tartaria 8 .

Folia ante florum explicationem quafi in rofulam difpofita, dein difperfa per caulem. Cor. pallide coerul.

II. Thamboi- C. fol. rhomboidibus, ferratis: fpica fecunda ; cadea. Jycibus dentat. Syft. veg. ed. i4. Beuk, hift. 2. p. 806 .

Rapunculus \&c. Barr. ic. 567.

In algibus Helvetie, Italia 4. 
Caul. cubiral. fumol. Fol. tenera, glabra, quandoq. afpera. Spica rara. Cor. cyanæa, vel alba. Capf, glabra, venofa .

12. unidente- C. erecta, glabra: fol. lanceol. acutis, ntrimq. ta. 74 unident, panicula divaricata, foliofa. Syft. veg. ed. I4. Lin. Suppl.

Ad cap. b. Spei.

Caul. fimpliciff. Fol, fetacea .

13. capillaiea. C. herbacea, erecta: fol. filiformibus, glabris: panicula terminali; fl. alternis. Syft. veg. ed. 14. Lin. Suppl.

Ad cup. b. Spei.

4. linearis. C. herbacea, erecta: fol. linearibus, integris, glabris: fl. cernuis: capful. hifpidis. Syft. veg. ed. I4. Lin. Suppl.

Ad cap. b. Spei.

Differt a priore calyc. longitudine : cor. \& capfulis hifpidis .

15. Lobelioi- C. glaberrima, ramofiflima: fol. lanceol, ferratis, des. feffilibus : paniculis terminalibus, fecundis: cor. infundibulif. Syft. veg. ed. 14. Lin. Suppl.

In locis Latebrofis Maderie.

Planta habitu Lobelice, adeo tenera, eodemq. modo divifa, etiam inflorefc. Cal, 3-5-phyll. Cor. minutiff. albido-purpurafc.

16. carpatica . C. fol. cordat. ferratis, glabris, petiolat. pedunc. elongatis: calyce reflexo, glutinofo; cor. patula. Syft. veg. ed. 14. Lin. Suppl, Jacq. h. I. tab. 57 .

In alpibus Carpaticis 24.

Caul. herbac. debiles, fubramofi, r-paucifl. (culta multi-ramofa, muliflora). Fol. radical, reniformi-fubrotun. caulina petiolat. cordata, nitida, ferraturis undulatis. Cor. ampla, parentiff. cœrul. Capf. oblonga .

17. grandiflo- C. caul, fub $\mathrm{x}-\mathrm{fl}$. fol. fublancecl. ferratis : cor. ra.

patente, Jacq. Hort, 3. tab. 2.

C. fol. ternis \&c. Syft. veg. ed. 14. Lin. Suppl.

in Sibiria, \& Tartaria.

Differe a priore poriffmum caul. fimplici : fol. nullis cordatis \&c.

Planta glaberrima. Caul. pauci, pedal. fumplice toti foliofi, quandoq. 2-ft. Fol, inordinare fpar$\mathrm{fa}_{\mathrm{a}}$, raro ternata, brevifime periol. ovata, vel fublanceol. acuta, argute ferrata, fubtus di- 
lutiora. Cor. ampla, valde patens, ex cœerul. 78. aurea fature violac. Anth. flava. Capf, ovato-acuta. C. capf. s-locul. ftigmaribus 5-fid. caul. paniculato: fol. duplicaro-fersatis. Syjt. veg. ed. I4. Lin. Suppl.

In Infula Madera.

Fol. lanceul, glabra. Cal, coloratus . Cor.tubus a calyce diftans; laciniis linearibus, reflexis.

19. tenella. C. caulibus diffulis, filiformibus: fol. ovatis, fub I-dent. reflexis, fl. terminalibus, folitar. $S y f$. veg. ed. 14. Lin, Suppl.

Ad cap. b. Spei.

Simil. Lobeliur tenella. Caul, durus, ramofus. Fol. minuta, confertiufc. alrerna, feffil. fubimbricata, ovata, obrufa, recurvata, canaliculata, lavia; in quorum friu foliol. minima, fimilima. Cor. 5-part. Raro carent fol. dente laterali.

30. porofa. C. caul. erecto, furfum punctis porofo: fol. lanceol. lavibus. Syjl. veg. ed. I4. Lin. Suppl. Ad cap. b. Spei.

Planta difficile cognofcenda, nifi poris vix nudis oculis confpicuis, qui non deor $\int u m$, fed furfum caluli intrufz.

Caul. erectus, pedal. teres, ramis numerofis, brevibus, erectis. Fol. fuperiora linear. integerr. Racemi terminal. erecti . Fl. parvi, C. rotundifolie minores, erectiufculi.

2r. undulata . C. fol. lanceol. dentatis, undulatis: fl. fubfolitar. pedunculat, Syft. veg. ed. 14. Lin. Suppl. Ad cap. b. Spei.

Caul. erectus, fefquiped. filiform. fuperne fubram fus, lævis. Fol, feffil. fubdecurrent, repanda, laviufcula. Pedunc. terminal. longi, aphylli. Fl. folitar. magnitudine C. rotundifolia.

$$
\text { ** Fol. Seabris, latioribus. }
$$

22. latifolia. C. fol, ovato-lanceol. caul, fimplicifl. tereti: fl. fubfolitar. pedunculat. fruatibus cernuis. Syft. veg. ed, 14. Fl. Dar. tab. 85.

Trachelium \&c CIuf. hift 2. p. 172.

In Helvetix, Anglia Ec, montibus, Sepious 24.

Caul. 3-pedal. \& ulira, angulofus, gl ber. Fol. breviter petiolat. acute ferrata, hirfuta, obfcure viridia, venof,, rigida. Pedunc. axill. Cor, magna, cyanza. 
446

23. rapunculoides.

riat fpicis foliofis.

24. bononien- C. caul. paniculato: foll. feffilibus, ovat-lanceol. fis. fubtus fcabris. Syft. veg. ed. 14. Bauh. hift. 2. p. 804. Morif. hift. 2. f. 3. tab. 4. f. 38.

In Carniola; Baldi, Bononia Ec. collibus 4.

Caul, habitu $V_{e r b a f c i}$ nigri, erectus, 3-ped. \& ultra, ramis pl. coniugatis, adfcendentibus. Fol. amplexicaul. fubferrata, nervis fubtus ferruginea lana pubefcentibus. Thyrfus longiff. Pedunc, frpius 3 -fl. Cor. violac.

25. graminifo- C. fol. lineari-fubulat. capitulo terminali. Syft. lia. veg. ed, 14 .

Trachelium \&c. Barr. ic. 332. Bauh, hift. 2. p. 802. In Italix montibus.

Simil. Phyteume hemifplearica, fed grandior. Radix multis cefpitibus. Fol. bafi ciliata : caulina fubamplexic. Caul. fimplic. vix fol. longiores. Bract. ovatæ, apice fubulatæ. Cor. cœrul-violac. Stigm. 2-fid.

26. cinerea. C. erecta, tomentofa: fol. fubulatis, erectis, adproximatis, integris: fl. terminalibus, folitar. Syft, veg. ed. 14. Lin. Suppl.

Ad cap. b. Spei.

27. hifpidula . C. hifpida : fl. erectis; calyc. longitudine cor. Syf. veg. ed. 14. Lin. Suppl. Comm. hort. 2, tab. 37. Ad cap. 6. Spei.

Caul. palmar. fuperne magis ramofus. Fol. alterna, linear. acumin. ciliata, pracipue carina . Calycis carina ciliata. Cor, infundibulif. pallide violacea.

28. Trache- C. caul. angulato: fol petiolat. pedunc. 3-fid. lium. calyc. ciliatis. Syft. veg. ed. 14. Garid. Aix. tab. 19 .

Rapum. Dodon, cer. 31. 32.

In Eu ropa fepibus 24 .

Caul, 2-pedal. \& ultra, hirfutus, nutans. Fol. 
Urticæform. læte virent. dura, afpera, venofa. Fl. axillar, bini-terni-quini, nutantes. Cor. magna, coerul. alba. Var.fl. pleno, \& fl.monftrofo.

29. glomera- C. caul. angulato, fimpl. fl. feffilibus; capitulo terta. minali. Syft. veg. ed. I4.

Trachelium \&ac. Herm. par. tab. 235. Bauk, hift. 2. p. 300 .

Rapunculus \&c. Tragi,ic. 8. Barr. ic.523. Pluk, pliyt. tab. 152. f. 5 .

b. Trachelium \&c. Bocc. muf. $t_{a} b .58$.

In Auftria, Helvetire \&c. pratis aridis 4.

Caul, pedal. Fol, ovat-oblong. obtufiufc. radical. longe petiolat. caulina femiamplexicaul. pallide virent, venofa. Fl. ex fupremis alis glomerati, cyanæi, raro albi. $V a r . f l$. pleno; \& fl. per caulem fparfis: \& alcera fol. confertioribus \& $\mathrm{fl}$. denfe fpicatis.

30. Cervica- C. hifpida ; fol. lanceol-linearibus, undulatis : carie. pitulo terminali: fl. feffilibus. $S_{y j t}$.veg.ed. I4. Fl. Dan. tab. 787. Gmel. Sib. 3. tab. 31.

Rapunculus \&c. Thal. ic. 8. n. I.

In Helvetia, Germania \&cc. afperis fylvaticis ơ" Simil. priori, fed magis hifpida, duploque altior; $\&$ fol. lingulat, Caul. 3-ped. fimpl. Fol, ima petiolar. ovat-lanceol. ferrata, fubtus albotoment. caulina lingulata, linear. Fl. min. quam in priore, glomerati, e cœrul-purpur.

31. thyrfoi- C. hifpida; racemo ovat-oblong. terminal, caul. dea. fimpliciff, fol. Ianceol-linearibus Syft. veg. ed. 14. Jacq. Obf. 1, tab. 21, Auftr. 5. tab, 411 . Cervicaria \&c. Thal. harc, tab. 4 .

In alpibus Helvetia, Harcynia, Carnivla \&c. $\delta$. Caul. 2-ped. purpur. cum pilis albidis. Fol. radical. humifufa, ovat-lanceol. caulina longiora, lingulata: feffil. integerr. afpera, pilofa, ciliata. Bract. 2. ciliatæ, pallidæ. Fl. feffil. longi, hirfuti, albi .

32. petrea. C. caul. fimpl. angulato: fol. fubtus tomentofis : $\mathrm{A}$. feffilibus, capitato-glomeratis. Syft. veg. ed. I4. Pluk. pkyt. I52. f. I.

Trachelium \&c. Bauh, hift. 2. p. 301.

In Baldi, Pedemontii alpibus 24.

Videtur var. C. glomerata. Fol. ovat-oblong. obrufiufc. ferrata, fupra fcabra, fubtus nivea. Cor, alba . 
*** Capful, obrectis calyc. finubus reflexis.

33. dichetome. C. capful. 5-locul, obrectis : caul. dichot: fl. cernuis. Syft. veg. ed. I4, Bocc. Sic. tab. 45, f. 2. Morif. hift. 2. S. 5. tab. 3. f. 26.

In Syria, Sicilia.

Caul. palmar. hífutus. Fol, oblong. fcabra. Fl. folitar. purpur. ftructura C. Medii, fed dimidio min. \& duplo ma: quam in Stbirica.

34. Medium . C. capful. 5-locularibus, obtectis: caul. erecto, indivifo, foliofo: fl, erectis. Syft. veg. ed. 14. Knorr. del. I. tab. 52. Garid. Aix tab. 20. Viola \&c. Dod. pempt. 163.

In Italia, Germania \&c. fylvis apricis $\delta$.

Caul. hirfutus. Fol, fubcrifpa, crenata, hirfuta . Pedunc. rerminal. 2-3-fl. Calyc. lacinia reflexa. Cor. cœrul. violac. purpur. alba .

35. barbata, C. capful. 5-locularibus, obtectis: caul. fimpl。 fub-I-fol: fol. lanceol: cor. barbatis. Syft. veg. ed. I4. Jaq. Obf. 2. tab. 37. Pluk, pyht. I53. f. 6 .

In alpibus Auftria, Helverice, Pedemontii §

Caul. fpitham. Fol. obtuliufc. integerr. fcabra. Fl. lecundi, intus valde barbati. Cor. plerumq: dilute corul, raro alba.

36. Spicata. C. hifpida: fol. linearibus, integerr. fpica laxa; fl. alternis. Syft. veg. ed. I 4. All. Fl. Ped. tab. 46. f. 2. \& tab. 47. f. I. Pluk. alm. tab. 153. f. 3 . Trachelium \&rc. Bauh. hift. 2. p. 801.

In Valefia inferiuri \&c. aridis, apricis, monto/ss. Radix craffitie digiti. Caul. pedal. ramis alternis. Spica longiffima. Fl. plurimi, remoti, feffil. Cor. fubcylindr. Variam faciem exhibet ad radices alpium.

37. alpine, C. caul. fimpl. pedunc, axillar. 2-phyll. I-fl. Syjt. veg. ed. 14. Jacq. Auftr, 2, tab. 118.

Trachelium \& c, Claf. hift, r7 I.

In alpibus Helvetice, Auftria Ec. 24.

Sintil. C. barbata. Fol, lineari-oblong. fuperne latefcent. obtufa, integerr, hirfuta. Pedunc. longi. Bract. 2. Flos magnus, pallide cœrnl.

38. mollis. C. capful. 5-locularibus, obrectis, pedunculat: caul, proftrato : fol Tuborbicul. Syft. veg. ed. I4.

b. C. hirfuta \&xc. Boce. Sic. $a a b$. 45. f. 1. Morif, hif.. 2. $\int$. .5. tabb. 3. f. 26 . 
Viola \&c. Barr. ic. 759.

In Sycia, Sivilia, Hifpania.

Caul. decumbent. fubramofi, rigidiufc. villofi. Fol. parva, feffil, fubintegerr tomentofa, pubefcent. Fl. axill. longe peduncul. folitar. Cal, ragnus. Fl, folitis fextuplo ma. Herba Antinhini molits. Fl. Canpan. Medii ; \& Jatura $C$. heterophylle.

39. Saxatilis. C. capful. quinquecarinatis, obtectis: fol. obovatis, crenatis: $\mathrm{f}$. alternis, nutantibus. $S_{y j t}$. veg. ed, 14. Barr. rar. tab. 813.

Trachelium \&c. Bocc. muf. 2. tab. 64.

In Creta fropulis foxofis.

Cor. magnd, coerulea.

40. fibirica, C. capiul. trilocularibus, obtedtis: caul, paniculato. Syft. veg. ed. 14. Jacq. Auftr. 2, tab. 2co. Gmet. Sib. 3. tab. 29. Bacc. Sic. 1ab. 45. In Sibiria, Aujtria, Pedemontio $\sigma^{\star}$.

Caul. pedal. reckus, fubhifpid. angulatus, indivifus. Fol. femi mplexicaul. linear. caulina fcabra. Panicula rarior, laxa. Fl. parvi, oblungi. Pedunc fapius 3-fl. Cal. hifpid. Cor. purpuro-cœrul, Variat caul. Jubdivifo; fol. Latioribus.

41. tridentate. C. capf. quinquelocul, obtecta: caul. I-fl: fol. radicalibus 3-dent. Syft. veg. ed. 14. Schreb. dec. 3. $u a b .2$.

In Oriente.

Fol, radical. Statices reticulati, lanceol, cuneifurm. apice fape fub. 3-dent. Caul. foliis duplo longior, fol. aliquot linearibus. Flos erectus, maiufcul. Cal. finubus reflexis, germen tegentibus .

42. laciniata. C. capful. obrectis, pedunculat: fol. ferratis; radicalibus lyratis; saulinis lanceol. (fubcuneiformibus) Syft. veg. ed. 14. Tourn. it. I. tab. 99. Morif. hij]. 2, f. 5. tab. 3. f. 31 ,

In Gracia, Libano.

Planta laviufcula.

43. ftriza. C. capful. obtectis: caul. fimpliciff: fol. hirtis: caulinis lanceol. ferratis: fl. fefflibus . Syft. veg. ed, 14.

In Syria, Palafina.

Caul. fefquiped. hirtus. Fol, radical. cordata ; feu ovata, petiolat. obtufufcula, ferrata. Cau- 
lina remota, alterna, feffil. obtufa, ferratodentata, bafi anguftiora. Fl. axill. erecti, fo. litarii .

44. canarien-C. capful. quinquelocularibus: fol. (rameis) fis. oppofitis, haltatis, dentatis, petiolat. Syft. veg. ed. I4.

In Canariis 24.

Radix tuberofo-fufiform. Caul. erectus, 3-ped. fimpl. teres, levis, articulis incraffatis. Rami terni, fuperioribus longioribus, apice dichotomis. Fol. lævia, venofa; caulina terna. Fl. e dichotomia ramorum fuperior. folitar. peduncul. cernui. Cal. germine hexagono, coronato foliol. lanceol. recurvatis, lavibus. Cor. campanul. fol, maior, rufa Fritillaria imperialis. Nectar, valvul. diftantibus. Filam. patentia. Anth. apice pendulæ. Siyl. clavatus. Stigm. fiffum. Pleramque num. Senarius in partibus fructificationis.

45. fruticofa. C. capful. columnaribus, quinquelocularibus : caul. fruticofo: fol. lineari-fubular: pedunc. longiffim. Syft. yeg. ed. I4. Herman. Afric. S.

Ad cap. b. Spei b.

Flos patulus, corruleus.

46. Speculum. C. caul diffuí, ramofiffimo: fol, oblong: fubcrenatis: fl. (fæe ternis) capful. prifmaticis . Syfl. veg. ed. I4. Dod. pempt. 168.

Inter fegetes Europx auftralis $\odot$.

Caul. femiped. Fol. alterna, feffil. obtufa, apice latiore, undulata. Pedunc. axill, prælongi. Cal, cor, longior. Cor. patens, purpurea.

47. hybrida. C. caule bafi fubramofo, ftricto: fol, oblong. crenulat. calycibus adgregatis, cor. longioribus : capful, prifmatic. Syjt. veg. ed. 14. Morif. hift. 2. f. 5. tab. 2. f. 22.

In Helvetio, Anglia \&c. inter fegetes $\odot$.

Differt a Speculo, feu matre, caul. bafi tantum ramofo, erecto, fuperne vix ramofo, ftricto: f. feffilibus 3-4. fimul: cor. fæpius non explicatis.

48. limonifo- C. ramis patentibus, indivifis : fol. radical. elliptilia. cis, integerr. lævibus: fl. fefflibus, fubternis. igft. veg. ed. I4.

In Oriente.

Caul, ramis fimpliciff, virgatis; fol, fubulatis . Fl. axill, remoti, bracteati. 
49. pentagonia. C. caul. fubdivifo, ramofif: fol. linearibus, acuminatis. Syft. yeg. ed. 14.

In Thracia $\odot$.

Caul. palm. debilis. Fol, digitum longa, feffil. inferiora latiora. $F$ l, in fummis caulibus, \& ramul. duplo ma: quam in C. Speculo, rotati, purpur. umbilico albo.

50. perfoliata.C. caul fimplici: fol. cordatis, dentatis, amplexicaulibus: fl. feffilibus, adgregatis. Syft. veg. ed. I4. Morif, hift. 2. S. 5. tab. 2. f. 23. Barr. rar. tab. 1133 .

In Virginia $\odot$.

Caul. erectus, plerumq. fimplex, Fol. parva, alcerna, fubrotun. aurita. F1. axill. purpur.

5r. capenfis. C. fol. lanceol. dentatis, hifpidis: peduncul. longiff: capful. ftrigofis, Syft. veg. ed, i4. Comm. hort. 2. tab. 35 .

Ad cup. b. Spei $\odot$.

Caul, teres. Fol. oppofita, longa, lata, mucronata. Pedunc, axill, rainofi. Cal, hirfurus. Cor. cœrul.

52. elatines. C. fol. cordat. dentat, pubefcentibus, petiolat. caul, proftratis : peduncul. capillaribus, multifl. Syf. veg. ed. I4.

In-alpinis Europe auftralis $\mathcal{4}$.

Caul. pl. rotundi, plerumq. fimpl. Fol. alterna, longe petiol, fubcinerea. Pedunc. axillar. aphylli, laxi, fæpius 3-fl. Cor. coerul-purpur. Tota planta molliter hirfuta .

33. hederacea. C. fol. cordatis, 5-lob. petiolat. glabris: caul. laxo. Syft, veg. ed. 14. Fl. Dan. 330. Morif: hift. 2. S. 5. tab. 5. f. I8. Pluk, phyt. 23. f. I. In Anglia, Gallia \&i. Locis umbrofis, humidiufculis.

54. erinoides.C. caulibus diffufis: fol. lanceol: fubferrat. decurrentibus, linea fcabra: fl, folitar. pedunculatis. Syjt. yeg. ed. I4, Herm. Lugd, tab. III? In Africa.

Simil. Lobelix erinoidi. Caul, ramoffiff. Fol. alterna, margine aculeis ciliato. Fl. terminal. erecti. Germ, lave. Styl, 3-fid.

55. Iseterophylla. C. fol. fubovat. integerr. glabris : caulibus diffufis. Syft, veg, ed. I4. Tourn. it. I. tab. 243.

In Oriente 4.

Tom, I, 
Caul. alterne ramofus . Fol. pulbefcent. apice undulata. Fl. penduli, cœrulefc.

56. Erinus, C. caul. dichotomo; fol. feffilibus; fuperior, oppofitis, 3-dent. Syft. veg. ed. I4.

Erini \&c, Column. phytob. tab. 28.

Alfine \&c. Bauh, hift. 3. p. 367.

In Italia, Hifpania \&c. ().

Ramificutio oppolita. Cor, regul, calyce min. Stigm. 3-fid.

Caul, ramofiff. flaccidus, 4-gon. hifpido-pubefc. Rami alterni, patenres. Fol. oblong. acuta, ferrata, ferraturis paucis, magnis. Fi. axill. parvi, folitarii, erecti, breviter peduncul. coerul.

57. Seffiliflora, C, proftrata; fol. lineari-fubulat. integris: fl. axillar. folitar. feffilibus. Syjt. veg. ed. 14. Lin。 Suppl.

Ad cap. b. Spei .

58. fafcicula- C. fruticofa, erecta: fol. ovatis, fub 1-dent. reta. curvis: fl, terminalibus, glomeratis. Syft. veg. ed. I4. Lin. Suppl.

Ad cap. b. Spei.

39. panicula - C. herbacea : caul, paniculato ; ramis divaricatis: ta. fol, lanceolat, integerr. fl. terminalibus, folitar. Syft. veg. ed. 14. Lin. Suppl.

Ad cap. b. Spei.

6o. adpref $a$, C. herbacea, erecta : fol. adpreffis, lanceol. dentat, recurvis, bafi ciliatis: panicula decompofita. Syft. veg. ed. 14. Lin. Suppl.

Ad cap. b. Spei.

6r. verticilla- C, fol. floribufque verticillatis. Syft. yeg. ed. I4. ta. Lin. Suppl. Pallaf. It. 3. tab. G. f. I.

In Dauurin 24.

Caul. pl. I-fefquiuln, recti. Fol. 5-6. ovar-lanceol. ut in Veronica Sibirica, fed plerumq. lanceol. ferrata. Fl. terminal. per verticillos plerumq. quinos, remotiff. difpofiti; peduncul. fubramofis. Calyc. laciniæ feraceæ. Cor. minuf́cula, dilute cyanæa, 5 -dent.

62, procum- C. caul. diffufo, dichotomo: fol. obovatis, obbens. tufis, crenatis : fl. folitar. exectis. Syf. yeg, ed. 14. Lin. Suppl.

Ad cap. b. Spei.

Planta tenella. 


\section{PENTANDRIA MONOGYNIA.}

63. tripkylla. C. fol. ternis, linearibus : fl. verticillato-tennis. Syft. veg. ed. I4. Thumb. Japon.

In Japonia.

Radix fufiform. Caul. herbac. erectus, glaber. Fol. pollic feffil, integerr. patentia, margine reflexo, glabra. Fl, axill. peduncul.

64. tetraphyl- C. fol. quaternis, oblong, ferratis. Syft. veg. la. ed. 14. Thumb. Japon.

In Japonia.

Caul.2-ped, angulatus, articulatus, glaber, fuperne panicular. Rami 4. oppofiti, \& alterni, diffufi, virgati, fub-4-goni, glabri, floriferi. Fol. pollic. vel paulo ultra, feffil. inferne attenuata, erecta, glabra, nervo medio attenuato, fupra viridia, fubtus pallida. FI, in ramis racemofi, cernui. Bract. fetaceæ, glabra. Cor. albida.

65. glauca. C. fol. feffitibus, ovatis, terratis, fubtus glaucis: caul, angulato, paniculato; pedunc, $1-1$. Syft. veg. ed. I4. Thumb. Jupon.

In Japonia.

Caul. erectus, 2-ped. fuffruticofus, glaber. Rami fubfaftigrati, erecti, flexuofi, glabri, Fol. pollic. Sparfa, erecta, acuta, margine parum reflexo. Fl. axill. in ramis, folitar, peduncul. bracteati, Cor. magna, cornl.

66. margina- C. fol. lanceolat. ferratis, undulatis, marginatis, ta. raınis debilibus: fl. terminalibus, folitar. $S y / t$. veg. ed. I4. Thumb, Japon.

In Japonia 4.

Caul. decumbens, fublignofus, bafi craffus. Rami fpitham, erectiufe. capillar, parum ramulofi, glabri. Fol, unguicul. in infer. parte ramorum, alterna, feffil lineari-lanc. margine albo, ferraturis remoris, pilis albis obfita.

Bellardi.

C. caul, nudo, I-fl. fol, petiolat, elliptico-Ianceol. dentatis. All. Fl. Psd. tab. 85. f. 5.

In fummis montibus Pedemontii 4.

Fol. aliquot ex imo, fuberecta, longe petiolata, ex eudem puncto non nafcentía, dentibus acutiufculis $2-3$ utrimque, intenfe viridia, fubafpera, firmula. Caulicul. dimidit digiti longitudine, erectus. Flos minime nutans, coerul. 
vefula. arsill C.1-fl. fol. ovalibus, dentatis, glabris : caul. fubnudo; calyce glabro. All. Ped. tab. 7. f. I. In montibus Pedemontii 4 .

Fol. ad rad. pluriona, per petiolum decurrentia, fubtus nervofa. Caul. fpitham, rotundus. Cal. livens. Flus patens. Parcius pilofa quam icon oftendat.

valdenfis. C. hirfuta; fol. elliptico-lanceol, raro denticulatis: caule I-fl. All. Spec. Ped. tab.6, f, 2. Fl. Ped. tab. 6. f. $\mathrm{I}$.

Ad alpium radices in umbrofis 4 .

Proxima C. Linifalia Bauls differt fol. latioribus, \& dentatis, ftrigufulis, hirfutis.

alpeftris. C.fol, hifpidis: caule 1-fl. Spec, Ped. tab.6.f.3. All. Fl. Ped. tab. 6. f. 3 .

C. trilocularis. Turr, Fl. Ftal, prod. p. 64 n. 10.

In alpium editiffrmis inter diffractos lapides 4.

Diverfa a C. barbata. Vur. fl. a.bo.

cefpitofa. C. caull. anguldto: fol, imis ovatis, ferratis, glabris: germinibus décagonis. Scop. Fl, Car. 2. tab. 4 .

In montibus faxofis.

Var. C. alpina C. B. Haller. Caul. pl, celpitofi. Surculi fola gerunt fol. petiolat. acumin. altero anno floriferi evadunt, fpitham. longi, ramofi, ramis paucifl. Fol. fparfa, feffilid, lanceol. ad bafin imbricata, \& fubtus punctata: fol. fumma remotiora, linear. integerr. Fl. nutantes, farure cœrul, Var. fol, omnibus lanceulas.

Urticafolia. C. caul. erectiuf. fol. fuperior. feffilibus: fpica fecunda; peduric, iff, calyc. glabris. Turre Giornale di Veneria tab. 1. Ponted.

In Italia.

Planta glabra. Caul. 2-cub. fimpl. ftriatus. Fol. ovato-lanceol. inæqualiter \& acute dent. Fl. ex fingulis alis, breviter peduncul. Similis C. rhomboiduli.

edulis.

C. fol. ovat-acut. feffilibus, ferratis. Forsk, $\mathbb{E}_{\mathscr{g}}$. In Arabia.

Raclix craffa, pueris edulis. Caul, ramofus, hifpidus. Cal. fructus parens, ciliatus . Cor. pallide corul. venis violac, vel alba .

265. ROELIA. Cor, infundibulif. fundo claufo valvulis ftaminiferis. Stigm. 2-fidum. Capf, cylind, 2-3-10= cul, infera. 
I. cilinta. R. fol. ciliatis; mucrone recta. Syft. yeg. ed. I4. Hort. Cliff. tab. 35 .

Campanula \&c. Comm. kort.2,tab. 30. Seb. thef. I. $t a b, 16 . \mathrm{f}, 5$.

Aculeora \&c.Pluk. alm. tab. 252, f. 4.

In Mauritania, Ethiopia 24.

Caul. fefquiped. ramofus. Fol. parva, ultra lineam longa, angufta, patentia. Bract. foliis ma. Fl. terminal. 5-part, cœrul, in medio atropurpur.

2. reticulata, R. fol. ciliatis, mucrone reflexo. Syft. veg. ed. 14,

Campanula \&sc, Pet. muf. $2 a b .157$.

Ad cap. b. Spei 24.

Caul. fruricofus, dodrant. Fol. Gorterice ciliaris, fparfa, feffil, linearia. Fl, folitar. feffil. Cor. violac.

3. Squarrofa. R. diffufa, herbacea; fol. ovat. dentat. recurvatis: ff. terminalibus, adgregat. Syft, veg. ed. 14. Lin. Suppl. Berg. Fl, cap.

Ad cap. b. Spei.

4. $m u \int c n \int a$. R. diffufa, herbacea; fol, ovat, dentat, reflexis: f. terminalibus, folitariis, Syft.veg. ed, I4. Lin. Suppl.

Ad cap, b. Spei.

Planta parvula

5. Spicata. R. erecta, fruticola : fol. lanceol. integris, ciliat. fl, terminalıbus, fubfpicat. Syft. veg. ed. I4. Lin. Suppl.

Ad cap. b. Spei .

pedunculata. R. fol. linearibus, ciliat. rectis: fl. pedunculat, germinibus longiffim. Berg. $\mathrm{Fl}$. cap. Ad cap. b. Spei $\hbar$.

Siml. R ciliata, fed caul. maior. Fol. unguicul. fparfa, feffil. fupra nuda, fubtus fpinulis ciliata ; foliol. min. axillaribus mixtis. Pedunc. palm. fubnudi, fub 2-fl. Bract. lineari-fubul. cilidtæ. 266. PHYTEUMA . Cor. tubulofo-corniculata, 5-part. laciniis linearib., bafi coalitis in fpeciem tubi. Stigm. 2-3-fid. Capf, 2-3-locul, infera. Sem. exigua. FI. in capitulum, aut fpican collecti .

1. pauciflara . P. capitulo fubfoliofo: fol. omnibus lanceolat, Syjt. yeg, ed. 14. Bauk. hift. 2. p. 8I I. In alpibus Helvetix, Styria, Pedemontii 4. Habitus humilis. Caul, 2-unce unico foliol, ors F f iij 
natus. Fol. petiolata, fine obtufo, non lanceol. crenata, fubhirfuta, fub capitulo maiora . Bract, cortatæ. Capitulum 2-3-fl. Petal. ovata, patentia, cœrul. Styl. fape 2-fid.

2. hemifphari-P. capitul, fubrot, fol. linearibus, fubintegers. cu. Syjt. veg. ed. I4.

Rapunculus \&c. That, herc. tab. 3 .

JRapuntium \&c. Column. ecphr. 2. tab. 26.

In alpibus Helvetia, Itailie \&c. 4.

Caul. fubtriental. pene nudus, I-fl. Fol. radical. multa, Graminea, etiam ferrata : caulina amplexicaul, longe caudata. Flos corul, vel albus. Siyl. 3-fid.

3. comofa . P. faf́ciculo terminali, feffli : fol. denratis; radicalibus cordatis. Syf. veg.ed. 14. Jacq. App. 50. Barr. ic 839 .

Trachelium \&c. Pon, bald, tab. 326.

Campanula \&c. Pluk, alm. tab. 152. f. 6.

In Baldi, Carniola, \& Tyrolenfibus montibus 5.

Caul, vix fpitham. Fol. ima petiolit. fuper. femiamplexicaul. Capitulum 2, fol. fuffultum , Cor, inverfe pyriformis, coerul.

4. orbicularis. P. capitulo fubrot. fol, ferratis : radicalibus cordatis, oblongis (caulinis feffilibus, acutis .) Syft. veg. ed. 14. Jacq. Auftr, tab. 447.

Rapunculus \&c. Morif. hift. 2. f. 5. tab. s. f. 47. Barr. ic. 526 .

In alpibus Italia, Helvetix \&e.

Caul, pedal. fimpl. foliofus. Fol. acumin. late virent. glabra, venola; radical. longe petiol. obtufa, vel acuta. Bract. ovato-lanceol. Fol. radical. peracta fructificat. Autumno prodeunt. Spica hemifphær. dein ovalis. Cor. fature cyanæa. In collibus adnata variat, cum vix digital. fit: alvera var. latifol. \& angufifol. multis Jpicis cauli harentibus.

5. firicate. P. fpica oblong: fol. radicalibus cordatis; (caulinis lanceol.), capful. 2-locul. Syft. veg. ed. I4.

Rapunculus \&c. Bauh. prodr. teb. 32. Morifo hift. 2. f. 5. tab. 5. f. 46 .

In alpeftribus lealia, Helvetix, Aufria \&ic.

Fol. alterna ; radical. longe petiolat. Viole Martiax fimilia, fæpe cum maculis nigris: caulina feffil. longiora, anguftiora . Bract. linear. an- 
gufta. Spica longa. Cor. coerul, purpur, alba, ochroleuca.

6. pinnata. P. fol. pinnatis: f1. fparfis. Syft. vez. ed. I4.

Rapunculus \&c. Bauh. hifz. 2, tab. 712. In Cresa.

americana, P. H.ll. hart. Kevens.

In America o".

Caul. 3-ped. erectus, ramofus. Fol. lanceol. Fl. axill. cœrul.

Michelii. P. fpica oblonga: fol. lineari-lanceol. fubintegerrimis. All, Fl. Ped. tab. 7. f. 3. Comm. Bonon. 4. tab. 1, f. 2 .

In pratis montofis 4.

Rad. tuberofa, \& nodofa. Ciul, cubitalis, rotundus, ftriatus. Fol. feffilia, amplan bafin habentia, ut amplexicaulia videantur, glabra, ad originem pilis ciliata, longifime Janceol. fine anguftiffmo, raris, \& exiguis denticulis prædita. Spica primum obæefa, dein gracilis, 2-uncial.

Sckeuckzeri, P. (Rapunculus) fol. imis longe petiolat. caulinis linearibus integris; bracteis linearibus duabus; imis longiffimis : Haller. hif.. n. 682 . All. Fl. Ped. tab. 39. f. 2.

Rapunculus \&c. Scheuchz. it. 6. p. 460.

Ad rupes umbrofis 24 .

Fol. longiffrme elliptica. Spica fubrotunda, non ovata: fol. caulina ad ufque fummum caulem. Bract. inæquales.

Halleri . P. (Rapunculus) fol. radicalibus cordiformibus, acute incifis; tubis longiff. hirfutis, emarginatis. Hall. Helv. n. 683 . An hac pertinet Fl. Dan. $t u b$. 362.?

12apunculus \&c. Scheuch. it. p. 518.

In pratis fubalpinis 2 .

Caul. cubital-2-ped, non ramofus. Fol, radical. longe petiol: Urticæform: caulina inferior.cordifor. fumma longe lanceol. graciliora. Spica longa, craffa, ovalis. Bract. longæ, linearilanc: quarum fape 2 . pramagnæ fpica fubiiciuntur. Cor. fature violac.

267. TRACHELIUM - Cor, infundibulif. Stigm, globofum . Capf. 3-lacul, infera.

3. diffufum, T. diffufum, ramofiff, ramis divaricatis, recur$F f$ iv 
vis: fol. fubulatis . iyft. veg, ed. i4. Lin. Suppl.

Ad cap. b. Spei .

2. tenuifolium. T. erectiufcul: fol. linearibus, ciliat. hifpidis. Syft. veg. ed. 14. Lin. Suppl.

Ad cap, b. Spei.

3. caruleum. T. erectum, ramofum; fol. ovat. ferratis, planis. Syft. veg. ed. I4.

In Italia, \& Orientis umbrofis б .

Caul. ramofus. Fol. alterna. Corymbi compofiti. Fl. purpuro-cœrul.

268. SAMO-Cal. 5-fidus. Cor. hypocraterif: 5-fida. Stam. LUS. munita fquamulis cor. Capf. I-locul. infera, 5-valv, polyfperma.

1. Valerandi. S. Syft. veg. ed. 14. Fl. Dan. tab. 1y8. Sabb. hort. 2. tab. 47.

Alfine \&c. Morif. hift. 2. f. 3. tab. 24. f. 28.

b. S. africanus. Walt, hort, $t a b, 23$,

In maritimis Europa, Afia, \& Amer. boreal, ad litora, fontes $\sigma$.

Caul, ped-cubital, etiam ramofus, fufco-virens. Fol. petiol. obovata, fubcrenata, nitida. Fl. racemofi, a'bi. Capf. fufca, glabra.

b. Differt caul. magis ramofo, \& firmiore.

269. NAU- Cor. infundibulif. Sem. $\mathrm{r}$. inferum, 2-locul. Re-

CLEA.

I. orientalis. N. Syft. veg. ed. I4.

Katu-Tfiacca , hort. Malab. 3. $a b$. $33^{\circ}$.

In India afiacica $\hbar$.

Arbor procera, ramofa. Fol. magna, Limoniiform. breviter petiolat. utrimq: geminata, decuffata, fupra obfcuro virore nitentia, fubtus dilutiora. Capitula magna. Florculi flavefcent. Fruct. globof, primum virides, dein rubri, tandem nigri.

270. RONDE-Cor. infondibulif. Capf. 2-locul, infera, polyfper: LETIA. fubrotunda, coronata.

1. americane, R. fol, feffilibus: panicula dichotoma. Syjt. veg. ed. I4. Ptum. ic. 342. f. I.

In America b.

Arbufcula. Fol, oppofita, cruciata, lanceol. integerr. Pedunc. comm. longiff. folitarii, nu$\mathrm{di} ;$ in fingula dichotomia flos feffilis, cum involuc. 2 -phyllo.

2. afistica, R. fol, petiol, oblong, acutis. Syfz, veg. ed, 14, Pluk, pliys. tab. I 40 . f. 2 , 
Cupi . Hort. Mal, 2, tab. 23.

In Melabaria, Zeylonia b.

Frutex orgyal. ramofus. Fol. alterna, breviter petiol. angufta, crafla, nervofa, fupra fature viridia, \& nitentia, fubtus dilutiora, odore iucundo. Fl, fubumbellati, dein flavefcent。 odori. Fruct. Lauriform. maturus vigricans.

3. obovate. R. fol. petiolat, fubovat. obtufis. Syft. veg. ed. 14. Jacq. am, tab. 42, ed. 2, piala cab. 61.

In America.

Frutex 6-ped. Fol, oppofita, integerr. fcabriufc. Pedunc. terminal. terni, 3-fl. Fl. miniati, margine tubi aurantiaco, odore Violæ.

4. trifoliata. R. fol. ternis. Syft. veg. ed. I4. Jacq. amer. tab. 43. ed. 2. piata tab. 62, Elwret, piç. sab. Is.

In America .

Frutex 12-ped. Fol, verticillata, 3-pollic. petiolat. lanceol. acuta, int gerr. fubtus fubtoment. Racemi axill. Fl. exigui, rubelli.

difperma . R. fol. petiulat. ovalibus, obtufis. Jacq. amer. pag. 59. ed. 2. pia. tab. 259. f. 18.

In Carthagence rupeftribus $b$.

Arbufcula erecta, fub is-ped. ramofa. Fol. magrnitudine varia, oppofita, integerr. glabra. Racemi axill. compoliti, laxi, 5-tidi ; pedunc. communibus partialibus dichotomis. Fl, multi feffil. \& peduncul, e purpureo-albicantes, leviter odori.

271. MACROCNEMUM . COr. campanul, Capf. infera, 2locul. Sem. imbricata.

I. jamaicenfe. M. Syft. veg. ed. I4.

In Jamaica.

Frutex ramis compofitis, inæqualibus. Fol. oppofita, fubpetiol. ovat-lanceol. integerr. lxvia. Panicul. bi-trichot. vix fol. longiores. Cor. tubo brevi, fauce barbata; laciniis apice recurvis. Capf. oblonga, inferne anguftior.

272. BELLONIA . Cor, rotata. Capf. I-locul. infera, polyfperma, calyce roftrata.

1. afpera. B. frutefiens, fol. Melifiz afpero. Syft. veg. ed. 14.

In Americn b. 
Arbufcula. Fol. oppofita, ovalia, inæqualiter ferrata, fubtus afpera, petiolis breviff. Fl. in corymbum, \& per caulem fparfi . Capf, ovatacumin.

273. PORTLANDIA . Cor. clavato-infundibulif, Antl. longitudinal. Capf. pentagona, retufa, 2-locul. polyfperm. coronata cal. 5-phyll.

I. tetrandre. P. fl, tetrandris: fol, oblong. obrufis: ftipulis latis. Syft. veg. ed. 14. Lin. Suppl.

In infula Fera diäa.

Fol. in apice ramorum adproximata, petiolat. ellipt, integerr. glaberr. Fl. axill. folitar. peduncul. Cor. 4-gona, alba .

2. grandiflo- P. fl. pentandris: (fol, bafi inæqualibus). Syft. - re. yeg. ed. 14. Jacq. am, tab. 44. Brown. Jam. tub. II. f. I.

In Jamnica $\hbar$.

Arbor fub Is-ped. coma oblong, rara, ramis korizontalibus. Fol. oppofita, breviter petiolat. fub 5-poll. ovata, acuta, craffiufc. integerr. nitida. Stipul. oppofitæ. Pedunc. axill. breviff. oppofiti, folitar. plerumq. 3-f. Fl. grandes, femiped. pulcherrimi, noctu odori. Cal. e viridi-ruber. Cor. Daturze, candida, mar-

3. hexandra. P. fl. hexandris (fol. bafi æqualibus). Syft. veg. ed. I4. Jacq. amer. tab. 182, f.20. ed.2, piä. tab. 65 .

Coutarea fpeciofa. Aubl. Guian. tab. 122. In Carthagena fylvis $b$.

Ad Cinchona genus fpectat, monente $V d h t$.

Arbor 25-ped. apice ramofa. Fol, fuper. inferioribus alterne ma. oppofita, breviter petiolat. ovata, acuta, integerr. glabra. Stipul. utrimq. ad bafin periolat. Fl. axillar. \& terminal. corymbofi, peduncul. Cor. ampla, purpur. Capf. ovato-cordata, rufefc.

274. SCAEVOLA. Cor. monop. tubo longitudinaliter fiffo: limbo 5-fid. laterali. Drupa infera, I-fperm. Nux bilocul.

I. Lobelia. S. Syf. veg. ed. 14. Jacq. amer. tab. 179. f. 88. $e d, 2$, pict. $t a b$. 199 .

Lobelia \&tc. Plum. gen. ic. I65. f, r. Catef. car, I. $t a b .79$.

Bugloffum \&c. Rumph, $a m b, 4,6 a b, 54$. In Indiis 4 . 
Planta non lactefcens. Frutex 2-ped. procumb. bafi ramofus, habitu neglecto. Fol. obverfe ovata, integerr. glabra, fere enervia, craffa, fucculenta, nitida, petiolat. fuper. conferta, decidua. Racemus axill dichoromus, bract. op. pofitis, fubulatis, interne ad bafin villofis. Cor. albefc. intus villofa. Drupa pifiform. fubrotun, atra.

275. CINCHONA. Cor. infundibul. apice lanata . Capf. infera, 2-loc. diffepimento paralello. Sem. imbricata .

1. officinalis. C. fol. ellipticis, fubtus pubefcentibus: cor. limbo lanato. Syft. veg. ed. 14. Lin. Suppl. Comm. noric. 1744 . $t a b$. I. f. 3 .

In Loxa Peruvia to.

Arb. 12-15-ped. Fol. 2-3. poll. longa, I-2. lata, oppofita, petiolat. ovato-aćun. nervofa, fubtus dilutiora, colta rubra. Fl. paniculati, pedicell. Cor. extus albicans, intus coccinea, margine punctulato .

Oribine naturali contortis accedit.

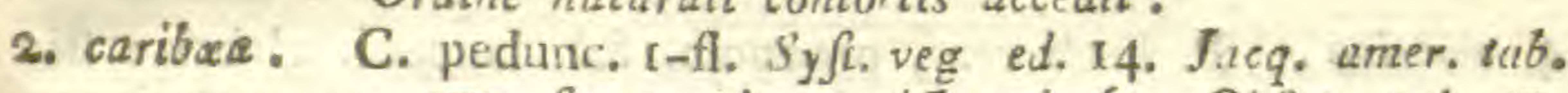
179. f. 95. ed. 2. piz. tab.63. O,f. 2. tab. 47. Periclymeno \&c. Pluk, alia, tab. 103. f. 3.

In Caribais 1 .

Arbufc. 10 ped. ramola , Fol. 2-5-pollic. oppofita, petiol. glabra, lanceol-acumin. apicius reflexis. Pedunc, axil! breves, I-fl. Fl. $f=f-$ quipollic. e carneo-albidi, odoratiff. Cor. tubus longiff. limbo reflexo.

3. corymbife-C. fol. oblong - lanceol corymb. axillaribus. S $S_{\mathrm{V}}$. re. yeg. ed. I4. Lin. Suppl. Forft. AZ. Upfal. 3. p. 176.

In Infulis maris pacifici.

Cor. non barbata, ut in C. officin.

Corticis fapor amariffin. fubadjtringens, fimill. cortici Peruana.

276. PSYCHOTRIA . Cal. 5-dentat. coronatus. Cor. tubulofa, Bacca globofd. Sem 2. hemifphærica, fulcata.

I. afiatica, P. ftipul ema ginatis: fol. obovat-acut. Syft.veg. ed. I4. Jacg. amer, tab. 174. f 22, ed. 2, piä. tab. 260 . f. 19.

Pfichotraphum. Brown. Jam, tab. 17. f. 2. In Jamaica, \& Indix Orint. b.

Altitudo humana. Eol. oppofita, petiolat, inte- 
gerr. nitida. Racemi terminal. Cor. alba, tubo erecto, triplo longiore limbo. Bacca rubra, ficuti \& caro. Sem. alba .

2. Serpens. P. caul. fubherbaceo, repente: fol. ovalibus. Syft. veg. ed. I4.

In India Orient. 24.

Simil. Sequenti, fed diftinça. Caul. 2-ped-orgyal. ramis erectis, alternis, teretibus, articulatis. Fol. oppofitd, petiolat utrimq. lævia. Stipul. fubrotun. decidua . Corymb terminal, brachiati .

3. herbacea. P. caul. herbaceo, repente: fol. cordatis, petiolat. Syft. veg. ed. 14. Jacq. amer. tab. 46. el. 2. pič. tab. 67.

Karinta-Kali . Hort. Mal. ro. tab. 2 r.

Mapouria. Aubl. Guian, tab. 67.

In Iidia utriufque umbrofis roridis.

Radix reptans. Caul. 3-pollic. fimpl. 4-fol. Fol. oppofita, cordato-fubrot. integerr. infer. longe petiolat. Pedunc. terminal. 2-4-fl. Cor. alba, limbo patentiff. Baccæ, \& caro rubra. Sem. alba.

4. emetica. P. herbacea, procumb. fol. lanceol. glabris : ftipulis extrafoliac. fubulatis : capitul. axillaribus: peduncul, paucifl. Syfl.veg. ed. I4. Lin. Suppl. Ipecacuanha. Pif. Braf. 4. p. 101.? Margr. Braf. p. 17.?

Sub temperie calidiff. Amer. Septent. Provin. Gironenjis.

Radix perpendicul. teretiufc. fubramofa. Fol. adproximata, oppofita, acumin. patentiff, integerr. fubtus colta tereti, prominente, lævia, plana, 2-3-pollic. Fl. parvi, feffil. albi .

violacea.

P. repens: fol. petiolat, cordatis: fl. cymolis: fruct. violac. Aubl. Guian. 6ab. 55 .

In Guiana, \& Cażenna.

Planta humillima, terræe adfixa; ramis expanfis, ad fingulos nodos radicantibus. Fol. oppofita, glabra. Fl. bini-terni-quaterni, longe peduncul. Cor. \& bacca violac.

domingenjis. P. fol. ovat-lanceol. Jacq. amer. 66.

In Domingo $b$.

Frutex fuberect. 5-ped. ramofus. Fol. 5-pollic. oppofita, petiolat. integerr. nitida. Racemi terminal, ramofi, plerumq. bini. Fl, pollic. 
feffil. Cor. alba, tubo cylindrico, incurvo, inodora. Baccæ Pifiform. atræ, nitidæ, pulpa aquea, non colorata.

277. COFFEA . Cor, hypocraterif. Stam, fupra tubum. Bacca infera. Sem, arillata .

I. arabica, C. fl. 5-fiu, baccís difpermis, Syf, yeg, ed, I4. Black. 337.

Jafminum \&c. Juff. act. 1713. tab. 7. Tilli. pif. tab. 32 .

Evonymo \&c. Plak. phyt. 272, f. I.

Bon. Alp. Agyp, tab. 36.

In Arabia felici, Ethiopia $\hbar$.

Frutex 12-ped. \& ultra. Fol oppofita, breviter petiol. ovat-lanceol. acumin. glabra, fupra atro-virent, nitida, fubrus djlutiora. Fl, ex finguia ala 2-4. feffil. Cor. alba. Fruct. ovatus, utrimq. obtufus, fubcompreffus, ruber, cortice molli, tenui. Sem. cartilaginea, hinc convexa, inde plana.

2, occidenta- C. fl, 4-fid, baccis I-fperm. Syft. veg. ed, I4. lis. Jucq. amer. tab. 47. ed, 2, piä. tab. 68.

Pauetta. Brown. Jam, tab. 6, f. I.

Jafminum \&c. Plum. Sp. 17. ic, 156, f. 2.

In America calidiore $\hbar$.

Arbufc. 6-ped. Fl. oppofita, petiol. lanceolovata, acumine obtufo, integerr. nirida. Stipul. oppofitæ, fubulatæ. Racemi axillar. \& terminal. trichotomi, interdum paniculati . Cor. alba, fuaveolens.

An Jem, ujla prebent Coffe?

Guianenfis. C. fl. 4-fid: baccis exiguis, violac, difpermis . Aubl. Guian. tab. 57.

In Guiana $\hbar$.

Fruticul. 1-2-pedal. ramulis 4--gon. nodofis . Fol, oppofita, breviter petiolar, oblon-acuta, integerr. glabra. Stipula utrinq. ad bafin petiolat. oblon-acuta. Fl. axill, fafcicul. feffil. Cor. alba .

paniculate. C. ramis 4-gon: fol, amplis, ovat-oblong, acutis: cor. 4-fid: baccis dífpermis. Aubl. "Gutian. tab. 58.

In Guiana 方.

Frutex 8-ped. ramis, \& ramufcul. oppofitis, 4-gon, nodofis. Fol, utrinq. intra bafin petiol. 
Fl. terminal. paniculati, pedicell. oppofitis. Cor. alba, odora. Bacca iubcorul. Sem. ovata.

278. CHIO. Cor. infundibulif: aqualis. Bacca 1-looul. 2COCCA.

I. paniculata. fper. infera.

C. erectd: fol. ovatis: fl. terminalibus, paniculat. dentibus ftipularibus binis. Syft. veg. ed. 14. Iin. Suppl.

In Surinamo, \& Amer. merid. 万。 .

Arbor alia, iannofa. Fol. oppofita, breviter petiol. utrimy: acumin. integerr. venofa. Mem. brana tenuis combinat fol. Panic. ramofa. Fl. lutei. Bacca compreffa, lutea .

2. racemofa. C. fcandens; fol. laco-lanceol: fl. lateralibus, paniculato-racemofis, dente ftipulari, unico. S) ft. veg. ed. I4. Lin. Suppl. Jacq. amer. ed. 2. pict. tab. 69.

Periclymenum \&c. Plum, ic. tab, 217. f. 2, Dill. elth. tab. 228. f. 295.

In Jamaica, Barbados, locis confragofis $\hbar$.

Altitudo hãa, Rami longi, declinati. Fol. 2pollic. oppofita, fubpetiol. integerr, nirida . Racemi axill. \& terminal. oppofiti, 2-pollic. penduli. Fl. albi, inodori; vel flavefcentes, odori. Baccæ parvæ, niveæ.

279, HAMELIIA. Cor, 5-fid, Bacca 5-locul: infera, polyfperma,

1. patens. H. racemis patentibus, Syf. veg. ed. 14. Jacq. amer, tab. 50. ed. pia. tab. 72 .

In Amer. meridion. $\hbar$.

Frutex pedal. Fol, petiol, terná, ovat-acumin. integerr, utrimq. fubtomentofa. Racemi revoluti, fub -6-fl. Cal. \& germ, coccineum . Cor. miniata, yel luted, tubo oblong. s-angul. Bacca uvat-oblong.

erecta. H. racemis erectis. Jacq. amer. $t a b, 7 \mathrm{I}$,

In filvis Carthaginenfibas b.

Frufex 5-pedal, erectus, ramofus, Fol. 3-4. pollic. longa, petiolis in dorfo venis, nervoq. medio utrimq: rubentibus terna, ovata, acumin. integerr. utrimg: fubtomentofa . Racemi terminal. quaterni, fecundi, fubdivifi, rubri : racemuli ultimi 3-4-fl. pedunculis breviff. rubris. Fl. pollic. toti fubcoccin, inodori . Baccæ nigræ, fucco atro-purpur. 
yentricufa, H. racemis terminalibus: fl. fubfeffil, cor. campanulatis, ventricol: fol, ternatis . Hompt. Journal. des Scavans 1785 .

In Jomaica itil

axillaris. H. racemis axillar, patentibus: fol. fubfecun. feffil. Hompc. Journ. des Sygavans 1785 .

In Jamaica.

patens. H. racem, terminalibus, patentibus: fl. pedicellat. Hompt, Journ. des Sçavans 1785.

280. LONI- Cal. 5-dent. Cor. monopet. irregularis (varia ;

CERA. tubulofa, vel campanulata, limbe 5-fid, irregulari: lab. fuper. 2-4-fid: infer. 3-fid. vel integro). Bacca poly(perma; 2-locul. infera.

* Periclymena, caul. volubil.

x. C'aprifolium. I. A. terminalibus verticillat. fefflibus : for. fummis connato-perfoliat. Syft. veg. ed. 14 . Jacq. Auftr. 4. tab. 357. Knorr. del, I. tab. S. 4. Garid. Aix, tab. 2 I.

Periclymeno. Matth.

In Europa euffrali 24.

Planta fubvolub. 6-ped. Fol, oppolita, longe ovata, obtufe acumin. concava, glabra, glauca . Verticil. 6-fl. Fl, lab. fuper. 4-fid. fegment. reflexis, mediis brevioribus; infer. lingulato, divaricato, tubo longiore, Cor. es purpuro-albefcens, aut luteola, odora. Nectar, macula lutea in inferiore tubi parte pofira, innumeris parvis glandulis melliferis conftans. Baccæe feffil, aurantiacæ, nitidæ, fed rore tectæ, ut nitor haud appareat.

2. Sempervi- L. verticill. terminalibus aphyllis: fol. fummis rens. connato-perfoliat. Syft. veg. ed. 14. Hort. anglo tab. 7. Knorr. del, tab. 53 .

Periclymenum \&cc. Herm. Lugd, tab. 483.

In Virginia, Mexico \$.

Minor in omnibus fui partibus priore. Fol. rotundiora, lucida, fubtus magis incana. Fl. fere regular. coccin. nitidi, inodori .

3. dioica. L. verticill. terminalibus, aphyllis: fol. omnibus connato-perfoliat. Syft. veg. ed. 14 .

\section{Habitat.}

4. Periclyme- L. capitul, terminalibus, ovat, imbricat. fol. omnum. nibus diftinctis (oppofitis, ovatis). Syft. veg. ed. 14. Blak, tab, 25. Fuchf. 646.

In Europa media b. 
Erutex 6-ped. Fol. pubefcent. quandoq. glabra, fubrus cœerulefcent. Rami purpur. E fupremis fol. prodeunt pedunc, 4-6-fl. verticillati. Fl. patentes, rubri, interne flavi, odori. Fruct. rubri.

5. japonica. L. caul, volub. fol. omnibus diftinctis: fl. terminalibus, binis, fefflibus. Syft. veg. ed. I4. Thumb. Jap.

In Japonia.

Caul, parum ramofus, hirfutus . Rami oppo- fiti, patentes, 2-phylli: florentes valde hirfuri, unguicul. Fol. infer. pollic, oppofita, petiolat. ovata, acutiufc. integerr. villofa, fubtus pallida, petiolis hirfutis. Fl. in apice ramorum. Cor. parva, pollic, rubra .

6. media.

L. capitul, terminalibus : verticillis aphyllis: cor. brevi, gibbo bafeos didymo: fol. fummis connato-perfoliat. Syft. veg. ed. 14. Comm. Gott. 1776. $t a b, 3$.

\section{Habitat}

Caul. \& efflorefcentia qualis in Perielymenis: cor. autem brevis, tubo gibbofo, ut in Chamecerafis.

** Chamecerafa, pedunc. bifloris.

7. nigre. L. pedunc, bifloris : baccis diftinctis: fol. ellipticis, integerr. Syft. veg. ed.14. Jacg. Auftr. 4. tab. 314 .

Periclymenum \&c. Gefn. fa/c. 37, tab. 8. f. 48 . Bauls. hist. 2. p. 107. Cluf. hijt. 1. p. 58.

In Helvetia, Italia, Gallia $\hbar$.

Frurex 3-5-pedal. Rami valde divaricati, villofi. Fol. oppofita, breviter petiol. nervofa, iuniora hirfuta, fub-plicata, unde quafi ferrata. Stipul. ovat-lanceol. Bract. fquamis 2. aridis, \& foliol, tribus tranfverfis, latis. Cal. latiufcul. Cor. extus fordide purpur. intus alba, \& pubefc., interdum tota alba. Lab. fuper. erectum, latiffim. obtufe 4-dent; infer. integerr. reflexum. Baccæ nigræ. Sem. 5.

8. tatariea. L. pedunc. bifloris: baccis diftinctis: fol. cordatis, obtufis. Syft. yeg. ed. I4.

In Tartaria b.

Caul, orgyal, \& ultra . Fol, breviter petiol. glabra. Involuc, lanceol, involucc, obovata .

Cor. 
Cor. pallide incarnata; lab. fuper. 3-part. lacinia media 2 -fida ; inferiori fimplici.

9. Xylofeum. L. pedunc. bifloris: baccis diftinctis: fol. (ferrulatis), pubefcentibus. Syft. veg. ed. 14. Fl. Dan. $t a b .808$. Duham. arbr. 2, $t_{a} b .54$. Allobrogum \&c. Lob. ic. 633.

Xylofteum. Riv, irreg. tab, 120.

In Europce fepibus frigidioribus, collinis, \& mantanis 古.

Frutex 6-ped. cortice ramorum fature rubente. Fol. ovata, obtufa, vel acuminata, fubtus glauco-virid. Fl, exalbidi. Cor. lab, inferius longius. Frust. obfcure rubri.

10. pyrenaica. L. pedunc, biflor: baccis diftinctis: fol, oblong: glabris. Syft. veg. ed. I4.

Xylofteum \&c. Magnol, hort, tab, 20\%, Dukam. $a r b r .2, t a b$. IIn.

In Pyrenais, Sibiria \&c. 方.

Differt a priore cor, regularibus ; ramis divaricatis : fol. glabris.

Ir. alpigena, L. pedunc, bifloris: baccis coadunatis, didymis : fol, oval-lanceol, syjt, veg, ed, 14, Javq. Auftr. 3. $t a b .274$.

Chamæcerafus, Gefn. fafc. 33, tab, I4, f. 44.

Periclymenum \&c, Cluf. 1, p. 59. Lob. ic. 173. Xylofteum \&c. Riv, irreg. tab, I2r.

In alpibus Helveticis, Italicis \&c. 4.

Frutex diffufus, I-5-pedal. Fol. oppofita, quandoq. terna, brevirer petiolat. integerr. fape denfe ciliata, fubtus nitida. Bract. 2. Pedunc. axill. Cor. geminæ, intus obfolete fanguineæ, foris dilutiores, rore albido; galea triloba .

I2. cartulea, L. pedunc. bifloris: baccis cosdunatis, globofis: ftyl. indivifis. Syft. veg.ed. 14 Jacq. App.tab.17. Periclymenum III. Cluf. hift. 58.

In Helvetia \&c. b.

Frutex 3-ped. cortice flavo. Fol. oblong. obtu$\mathrm{fa}$, integerr, nervofa, fubtus dilutiora, oppofita, breviter petiolat. iuniora ciliata, adulta pallentia. Stipul. 2. lineares. Bract. 2. lanceol. Pedunc. axill, breves. Cor. geminæ, ochroleucæ. Fruct, cœrul. Sem. frepe Io.

*** Caul, ereẫo: pedinnc, multiflaris.

13. fymplooricarpos : I. capitul. lateralibus, pedunculat: fol, peTom. I.

G $g$ 
tiolat. Syft. veg. ed. 14. Dill. elth. $2 a b, 268$. f. 370. Du-Hamel. arbr. 2. tab. 82 .

Vitis \&c. Hortul. angl. tab, 20, Pluk, phyt, tab. 420. f. 6.

In Virginia, Carolina.

Fruticul. 2-3-cubital. totus ramofus, ramis oblique vergentibus, fubfufcis. Fol. oppofita, oblongo-rotunda, tubhiriuta, venis obliquis, fupra virid. fubcus fubglauca. Fl. axill. fafciculati, parvi, albido-herbac. Fruct. globoli, purpuratc.

14. Bubalina, L. capiul. terminalibus, pedunculat, fol, oblong. integerr. glubris. Syjt. veg. ed. 14. Lin. Supplo

Rondeletia capitata. Fl. Cap,

Ad cup. b. Sper.

Arbuf́cula. Fol. oppofita, breviter petiolat, venofa. Capiculum involuc. brevift. polyphyll, 4-6-fl. Cor. fi. Symphysi .

15. Diervilla, L. racemis terminalibus: fol, ferratis. Syft. veg. ed. 14. Duham. arb. 1. tab. 87.

In Acadia, Noycboraco b.

Caul. fruticofus, penl. raro ramofus. Fol. op= pofita, breviter petiolat, ovato-lanceol. glabra. Fl. fafciculati, lurei.

36. corymboja. L. corymb. terminalibus: fol. ovatis, acutis . Syf. yeg. ed. 14.

Periciymenum \&c. Fewill. pertiv. I. tab. 45.

In Peru ந.

Frutex I2-ped, ramofus. Fol, oppofita, petiolat. pulchre virent. Cor. fanguinea. Fruct. Olivæforma, \& col.

Mangolica, I. Pall. It. 3. Gmel. Sib. 3. tab. 25. fed fl. copiefiores.

In Dauuria $\hbar$.

Frutex L. Xylofteo minor, erectus, ramis oppofit, rectis; patentibus. Fol. rariora, oppofita, petiol. ovata, ferrata, fubtus incana. Pedunc. terminal. inter ultimum par foliorum, 2 fid. Singuli fubftinentes fl. 2-4-5. feffil. Cor。 parva, campanulata, flavefcenti-alba .

28r. TRIO- Cor, monopet, fubrqual. Cal. longitudine cor.

STEUM . Bacca 3-locul. I fperm. infera .

1. perfoliatum, T. fl, verticillat. feffilibus. Syf., veg, ed. I4 Dill. elih. tab. 293. f. 378.

In Amer. Septentr. $\bar{b}$. 
Caul. pl. 2-ped. pilofi, pallide virentes; geniculis diftantibus. Fol, perfoliara, palmum, \& ultra longa, 3 . unc. leta, acumin. in medio latiora: axillar. min. rugofa, fubhirfuta, integerr. margine undulato, dilute virid. fubrus pallidiora. Fl. ad genicula verticill: villofi, obfcure purpur. punctul. albicantibus. Bacca lutefcens.

2. anguftifolium. T. fl. oppofitis, pedunculat, Sy/t, veg. ed. I4. Periclymenum \& \&c. Pluk, alm, tab, 104. f. 2.

In Virginia 24.

Caul. ped. \& ultra; pubefcent. in 6-8. nodos diftincti. Fol. 3-4. unc. oppofita, mucronata, in medio latiora, pubefcent. Fl. axillar. verticillati, ochroleuci. Bacca oval. flava .

282. MORIN-Fl. adgregati, monopet. Stigm. 2-fid. Drupæ DA. adgregatæ.

I. umbellata, M. erecta: fol. lanceolato-ovat, pedunc, confertis, Sy.t. veg. ed. I4.

Bancudus \&c. Rumph. Amb. 3. tab. 98.

In India,

Arb. fol. Cephalanthi, 4-9. pollic, longis, 3. latis, oppofitis, petiolat, inregerr, fupra obfcure viridibus. Singulis pedunc. capitula infident, axillar. forma ftrobili Piai, magnirudine Prunorum, ex meris verrucis conftantia. In cuiufvis apice longum, anguftum, \& albicans petalum. Perala obliqua ut in Papaya. Fructus non edulis ,

2. citrifolia. M. arborea; peduncul. folitariis. Syft. veg. ed. 14. Zann. tnb. 124.

Bancudus lazifol. Rumph. Amb. 3. rab. 99.

Coda-pilaua. Hurt, mal. I, tab. 52.

In India $b$.

Fol. grandia, petiol. ovat-acum. craffa, mollia, Surure virid. nitentia, plerumq: fpithamæa, binas palmas lata. Periunc, longi . Petal. 4-5. oblong. ftelliform. culpidata, intus candida, extus e viridi-albicant. Fruct. oblong. Piniform. albidi, odure foetido, ftercoraceo.

3. Royoc. M. procumbens. Syft. veg. ed. 14. Jacq. hort. I. $t a b, 16$.

Royoc. \&cc. Plum, Sp, tab, 26. Periclymenum \&c. Pluk, alm, tab. 212. f. 4. In Amer. calidiore b. 
Truncus cortice cinereo. Fol. oppofita, petiolat. obverfe-ovat. vel lanceol. integerr. nirida. Fl. axill. peduncul, glomerati . Cor. alba. Fructus flavus, fucculentus, fotidus.

mufcofa.

M. arborea ; capitul. terminalibus, feffilibus . $J_{a c q \text { : }}$ amer. tab. 45. ed. pia. tab. 66.

In Martinica $b$.

Arbor 15-pedal. Rami dichotomi, Mufcis, \& Algis veftientibus femper foedi. Fol. 3-4. pul. lic. longa, oppofita, breviter petiol. lanceolovatd, acumin. integerr. vencfa, glabra. Stipul. inter petiol. pi. Tetacea, ferrugin. Fl. exigui. Palea cor. intermixta. Cor, alba. Sem. 2. hinc convexa, inde plana.

283. CONO- Cal. campanulat, Cor. 5-petal, aut nulla. Sem. CARPUS. nuda, folitar, infera. (Fl. aggregati, excepta racemofa. )

I. ereza. C. erecta: fol, lanceolat. Syft, veg, ed, i4, Jacq. amer. $t a b$. 52. f. 1. edit, 2, piż. $t a b, 78, C_{a-}$ tefb. car. 2. tab. 33.

Alni \&c. Sluan. Jam, hift, 2, tab. I6r. f, 2.

A!nus \&ce. Pluk, alm. tab, 240. f. 3.

Innominata. Plum, ic. tab. 144. f. 2.

In Jamaicre, Brafilia Ec. maritimis $\hbar$.

Arb. 30-pedal. Fol. multa, alterna, petiolat. fuper. angultata ; infer. cuneiform, integerr. pinguia. Racem. axill. \& terminal. fimpl. laxi . Fl. exigui, flavefcent. Strobili fubrotundi , fquamis imbricat. reflexis, incanis .

2. procumbens, C. procumb. fol. obovatis, Syft. veg. ed. I4. Jacq: amer, $t a b, 52$, f. 2, ed, 2, piaz. $t a b, 260$. f. 22. quoed folia.

In montibus maritimis $C u b a b$.

An prioris varietas? Fol. fub-pollic. obtufa cum acumine, vel fubrotun. nitida. Fl, ut in priore, fed omnia min.

3. racernofa. C. fol, lanceol-ovat, obtufiufc: fructibus fegregatis . Sy/t. veg. ed. 14. Jacq: amer. tab. 53. ed. 2. piä. $t a b .79$.

Mangle \&c. Sloan. Jam. hift. 2, tab. 187. f. I. In maritimis arenofis Caribaarum $b$.

Pet. 5. Jubrotun: in prioribus nulla. Stam. huic 10. Arbor procera, a terra in 3-4. truncos divifa. Fol. 3-poll. oppofita, petiolis rubentibus fu- 


\section{PENTANDRIA MONOGYNIA.}

bovalia, obtula, integerr. craffiufc., nitida, ad tactum pinguia, fature virid. Fi. parvi, aibi, odori. Fruct. fimil, tetradynamis filiculo/2s.

284. KUHNIA. Flos compofitus, flotculofus: fem. Colitar. pappo plumofo. Receptac. nudum .

I, eupatorioides. K syft. veg. ed.14. Lin. iun, dec. 2I, tab. Ir, Eupatorium \&c. Ard. Sp. 2. tab. 20. Pluk, alm. $t a b .87$. f. 2 ?

In Penfolvania $\mathbf{4}$.

Differt ab omnibus fl. compofitis antho Sepurntis; etiam ab Eupatorio fol. alternis. Caul. erecti, fefquiped læses, rigiduli. Fol. alterna, petiol. lato-lanceol, nuda, fubrugofa, fubtus venofa, ferraturis medis ma: fubuncial: caulina lineari-lanceol. integerrima. Rami alterni, e medio caule, Corymb. parvi . Cor. fubalbica. Stam, albo-flavefcen.

285. ERI- Cor. 5-raro 6 part. lacin. (linearibus) recurvis . THALIS. Cal. urceol tus. Bacca io-locul, infera.

I. frusicofa. F. S,yt. veg. ed. I4.

E, odorifera. Jacqu, amer. $t a b .173 . \mathrm{f}, 23 . \mathrm{ed}$. 2. pia. tab. 260, f, 20, Brown. Jam, tab, 17. f. 3 .

Sambucus \&c. Plum, ic. tab. 249, f. 2.

In Jamaica, Martinica b.

Arb. elegans, 15-ped, ramofa. Fol. 2-pollic. oppofita, petiolat. fubovat. obrufa, cum exiguo acum. integerr. fature virid. nitida. Racemi axillar. oppofiti. Fl. caduci. Cor, alba, odora. Baccæ parvæ, rotundæ, purpur.

inodora.

E, fruticofa, procumb. Jacq: Amer. pag. 72.

In Curacao $\hbar$.

An var. E. fruticufa? Frutex 2-pedal. ramis procumbentibus, diffufis. Fl. \& bacca min. Fl. inodori. Baccæ plerumq. albidæ.

286. MENAIS, Cor. hypocrat. Cal. 3-phyll, Bacca 4-locul. Sem. folitar.

I, topiaria. M. Syft. veg. ed. 14. Loefl. it. 306.

In Amer, meridion. $\$$.

Caul. teretes, fubvillofi. Fol. alterna, ovata, integerr, afpera. Cor. lacin. rotundat. Bacca globofa.

287. MUS- Cor. infundibul, Srigm. 2. craffiufcula. Bacca obSAENDA. longa, infera. Sem, 4-fariam difpofita. 


\section{PENTANDRIA MONOGYNIA.}

5. frondofe. M. panicula fol, coloratis. Syft. veg. ed. I4. Bur. Zeyl. tab. 76 .

Fo'ium \&c. Rumph. amb. 4. tab. 5I.

Belilla. Hori, Mal, 2. tab. 18.

Ophiorrhiza lanceol. Forsk, AIg. monente Vahl. In India 方.

Frutex ramis tortuofis, finuofis. Fol. oppofita, etiam terna-plura, petiol. ovata, integerr. in culpidem angultum terminata, nervofa, pilofa. Panic, termina!. dichoroma, hirfuta. Cor. intus fcarlatina, exrus albefcens, aut fubflavefc. umbilico flavo. Bacca oblon-rotunda, fubpilofa, flava, carne viridi.

2. fpinofa. M. fpinofa: A. feffilibus, a'gregatis. Syft. veg. ed. 14. Jacq: amer. tab. 49. ed. 2. pil. tab. 71 .

Palicourea Guinnens, Aubl. Guian, tab. 66.

In Martinica, Carthagence fylvis $\hbar$.

Frutex ro-ped. Rami ultimi fpinis quaternis cruciation pofitis, Fol, petiolat, magnitudine varia, obnvata, integerr. venofa, utrinq. fubhirfuta. Cor. candila, odora. Bacca prius flavefcens, dein fufca.

288. MATHI-Cor. (Iongiff.) tubulofa, indivifa, fupera. Cal, OLA. integer. Drupa nucleo globofo.

T. Scabra. M. fol. fubrotundo, afpero: fructu nigricante. S. A. veg. ed. 14. Plum. ic. 173. f. 2.

Rategal \&zc. Zan. hift. tab. 75 ?

In America b.

Arbor ramis divifis. Fol. fparfa, petiolat. ovata, obtufa, integerr. ad apices ramorum conferta, \& min. Pedunc. longi, fubdivifi, bract. pinnatis intercepti. Drupa globofa, calyce coronata.

289. MIRA- Cor. infundibulif. fupera. Cal, inferus. Necta= BILIS. rium globofum, germen includens.

I. dichotome . M. fl. folitar, axillar. erectis, feflilibus. Syft. veg. ed. 14.

Jalapa \&c. Martin, cent, I. tab, I.

In Mexica.

Simil. fequenti, fed differt, præter fl., fol. anritis .

2. Jelapa. M. fl. terminalibus, congeftis, erectis. $S_{y} / f_{0}$ veg。 ed. 14. Rumph, am3. 5. tab. 89. Black, tab. 404. Knorr. del. I. tab. 3. Sabb. hort, 2, tab, II.

In India utraque. 


\section{PENTANDRIA MONOGYNIA.}

Caul. 4-ped. herbac, ramofi. Fol. oppofita, breviter petiolat, curdat-lanceol, fature virid. Cor. col. varia.

3. longiflora, M. fl.congeftis, longiff. terminalibus, fubnutantibus : ful. fubvillod, Sylt. yeg, ed, 14. AZ., holm。 1755. tab. 6. f. 1. Hern. mex. f. 2.

In Mexica frigidis montibus.

290. CORIS. Cal, to dent. Cor. fubringens, 5-fid. Capf. 5valv.

I. monfpelienfis. C. Syft. seg. ed. 14.

In Europe arenofis maritimis, \& in collibus fuccis $\odot .24$.

Caul, fruticofus, palmar. ruber. Fol. alterna, fparfa, linearia, patentia, crafiufc. fucculenta, ciliata. Fl. capitato-fpicati. Cor. ex purpuro-coerul.

391. BROSSEAA. Cor. truncata . Cal, carnofus. Capf. s-locul. polyfper.

1. cuccinea. B. frutefc. Al. coccio, fruct, nigro. Syft veg, ed, 14. Plum, ic, 64, f, 2.

In Amer. calidiore $\hbar$.

Planta obfcura. Planta frutefcens, ramis alternis, lignofis. Fol.alternd, petiolat. fimplicia, ovata, ferrata. Fl, terminal rariores, alterni .

292. VERBASCUM . Cor, rotata, fubinæqual. limbo s-fido . Stam. inæqualia . Capf, 2-locul, 2-valv.

In plerifque fpeciebus Stam. funt inclinata, \& inaqual. villifque coloratis inferne veftita.

I. Thapfus . V. caul, fimpl, fol. decurrentibus, utrimq. tomentofis. Syf. veg. ed. 14. Black. tab. 3. \& 502. Ludw. ea. tub. 124. Knorr. del. 2. tab. V. Fl. Dan. 631. Morif. Hift. 2. f. 5. tab. y. f, x. Sabb. hort. 2. $t a b .53$.

Verbafco I. Matth.

In Europre glareofis ferilibus 87.

Caul. 6-ped. leviter alatus, tomentofus. Fol. magna, alterna, cruciata, longe ovata, \& elliptica, undulata, obiter incifa. Fl. multi, maiufe, in longum thyrfum fpicati. Cor. pallide lutea, alba, vel flava.

2. Thapfol- V. caul, ramofo: fol, decurrentibus, Syft. veg. des. ed. 14. Bauk, hift, 3. p. 856.

In locis fuxofis, \& collibus $\bar{x}$.

Hybrid, V. Thap/i. Fol, totaliter non decurrunt, \& minus alba.

$$
G \mathrm{~g} \text { iv }
$$


3. Boerhavii. V. fol. fublyratis: fl. feffilıbus. Sy/t. veg. ed. r4: Mill. ic. 273. Tilli pif. tab. 50.?

In Europa auftrali.

Fol. fpathulata, finuata, fupra nudiufc. fubtus fubroment. Spica V. Thapfi, fl, non confertiff. fed ad bracteas fingulas pl, maioribufque. Cor. lutea, genitalibus purpur.

4. phlomoides.V. fol, ovat, utrimque tomentolis; inferior. petiolat. Sy/t. veg. ed. 14. Moench. haff. tab. 4.

In Italia, Germania $\delta$.

Tomentum per atutem evanefcit. Caul, erect. fpicat. valde tomentofus. Fol. crenata. Racem. fpiciform. ex bracteis fparfis, lanceol. Fl. intra fingulds bract. 4. Cor. pallida, lineol. rubris. Stam. purpur. Capf. oblong.

5. Iychnitis, V. fol, cuneiformi-oblong. (pulverulent, imis petiolat.). Syft. veg. ed. I4 Fl. Dan, tab. 586. Bauh, hift. 3. pag. 812. 813.

In Europa ruderatis cultis 6 .

Species omnium maxima. Caul. 3-ped. ramofus . Fl. parvi, lutei, aut albi .

6. nigrum, V. fol. cordat-oblong. (inferioribus) petiolat. duplicato-ferrat. Syft. veg. ed. I4. Bauh, hijt. 3 . pag. 870.

Verbafco fecondo, e terzo. Matth.

In Europa ad pagos, vias 4.

Caul. 3-pedal, angulat, ruber, vilis ramofis. Fol. fupra nigro-virefc. glabra, fubtus albida. Spica rara. Fl. multi, flavi, vel albi. Var. humilior; $f$. infundibulif, herbac. pafjim prolifero. Gmel. Sib. 4. tab. 47.

7.pheniceum. V.caul. fubnudo, racemofo: fol, radical. ovatis, crenatis, nudis, rugofis. Syft. veg. ed. 14. Jacq. auftr. 2, tab. 125 .

In Germania, Curniola \&c. $\delta$.

Caul. erectus, fimpl. 2-pedal. villofus. Rami ex alis infinis. Fol. caulina cordata, seffil. rugofo-venofa. Racem, pedal. Pedunc. fimpl. folitar. Cal. villofus, fol. inferior, fere min. Cor. fature purpur. Filam. purpur. barbata, barba alba.

8. Blettarie, V. fol, amplexicaulibus, oblong. glabris: pedunc, folitar. Syft. veg. ed. 14. Snbb. hort. 2, tab. 56. In Europe auftralis locis argillojis 7 .

Caul, erect. 2-ped. Fol. fature virid, nitida, oris 
crifpis, \& dentatis : ima finuata ; fuper, ovatlanceol. ferrata. Spica rara. Cor. flava, vel alba, ftaminibus purpur. Capf. rotunda .

9. finuatum, V. fol. radicalibus pinnatifido-repandis, tomentofis : caulin. amplexicaulibus, nudiufcul, rameis primis oppofitis. Sy ft. veg. ed. 14. Cam. hijt. tab. 403.

Verbafco laciniato. Matik.

6. V. gracum \&cc. Tour. it. I. tab. 335.

In Etruria, Monfpelii \&c. ठ大.

Caul. pl. 2-ped. ramofi, fubhirfuti. Fil. caulina oblonga, undalata, fubdecurrent. Fl. laxe fpicati. Cor. lutea. Stam. purpur. tomento albefcente.

10. Osbeckii. V. caul, foliofo: fol, incifis, nudis: pedunc. 2-fl. calycibus lanatis. Syft, veg. ed. 14.

Blattaria \&c. Tourn, it, 2. tab. 83. Buxb. cent. 5. $t a b, 32$.

In Hifpania; circa Bofphorum.

Caul. femiped. \& ultra, fimplex fubtoment. Fol. radical. ovalia, Bugula fimilia, pollic petiolat. undulata, purpur. glabra: caulina min. leviter tomentofa. Fl. fpicati, magni, virefcent. lituris luteis.

II. Spinofum . V. caul. fpinofo, frutefc. foliofo. Sy/t. veg, ed. I4 . Leucoium fpinofum. Alp. exot. ta $b .36$.

In Creta b.

Caul. pl. 2-ped. lignofi, ramofi, tomentofi. Fol. fafciculi feffil. alterni. Fol. oblonga, ferrata, fubtomentofa. Pedunc. laxe fpicati . Cor. ex albo-flava. Stam. purpur.

12. Myconi. V. fol. radicalibus, lanatis: fcapo nudo. Syft. veg. ed. I4. Mill. ic. 277. Trew. ehret. tab. 57.

Auricula \&cc. Dalech. hift. 837. Bauh, hift. 3. pag. 869.

In Pyrencorum nemorofis 24.

Scap. 2-3-dodrant, purpurafc. hirfuti. Fol. Boraginis forma, repanda, craffa, nervofa, pilis ambitu rufefcentibus. Cor. ccerul. Stam. Jutea.

293. DATURA. Cal. tubulof. angulat. deciduus. Cor. infundibulif. 5-angularo-plicata. Capf. 4-valv. poJyfperma, fæpe echinata. Odor plantæ virofus. Fl, magni, interfoliacei, folirarii .

I. ferox. D. pericarp. fpinolis, erestis, ovatis; fpinis fum- 
mis maximis, convergentibus. $S_{y f f}$, veg.ed. 14. Mont. in Zan. iab, 162.

Stramonium. Morif. hift, 3. f, 15, tab. 2, f. 4 . Barr. rar. ic. riliz.

In China $\odot$.

Simil. fequent. fed humilior, latior; fol. min. minus glabra, finuata. Fl. mi: albi. Capf. 4. fpinis, fupremis maximis .

2. Stramoni- D. pericarp. fpinofis, erect is, ovat. fol. ovat. glatIm, . bris. Syft. veg. ed. I4. Fl. Din. 436. Black, tab. 313. Knorr. del. I. tab. S. 13. Sabb. hort. I. tub. 92. Gurid. Aix. tab. 86.

In Amer, nunc indigena Europe $\odot$.

Caul. latus, diffufus, dichotomus. Fol. magna, longe petiol. angulara, flaccida, venofa. Fl. magni, albicant.

3. Tatula. D. pericarp. fpinofis, erectis, ovatis: fol. cordat, dentat. glabris. Sy/t. veg. ed. 14.

In Infubric ruderatis $\odot$.

Simil. D. Atramonio, Caul. purpurafc. punctis albis adfperfus, ad angulum acutum divifus, lævis. Cor. pallide coerul.

4. faftuofa. D. pericarp. nutantibus, globofis, tuberculatis: fol. ovat. angulatis. Syft. veg. ed. I4. Sabb. hort. 1, tab.93. Rumph. amb. 5. tab. 2+3. f.2.

b. Solanum \&c. Knorr, del. I. tab. S. II.

In Egypto $\odot$.

Caul. rufus punctis albis. Cor. extus violac. intus alba, fæpe duplicata.

5. Metel. D, pericarp. nutantibus, globofis, fpinofis: fol. cordat. fubintegris, pubefcentibus. Syjl. veg. ed. 14. Ludw. eä. tab. 158. Kniph. cent, tab. 24. Rumpl. $a m b$. 5, $a a b, 87$.

Hummatu. H. Mal, 2, tab. 28.

In Afia, Africa $\odot$.

Cal. non angulatus, fed teres, tumidus, peniformis. Cor. funpl. plerumq. alba.

6. arborea, D. pencarp. nurantibus, glabris, inermibus: caul. arbor. Syf. veg. ed. 14 .

Stramonioides \&c. Few, peruw. 2. $t_{a} b .46$.

In Peru b.

Arbor ramis capitulum efformantibus. Fol. veluti racemofa, longe petiolat. ovar-oblon. nervofa, fupra fature, fubtus dilure virid. utrimq. fubtomentofa. Fl, 6-pollic. albi, apice lineis fubluteis sotato. 
7. Levis. D. caul, herbac. pericarp. erectis, ovatis, inermibus, glabris. Syfl, yeg. ed. 14, Lin, Suppl.

D. inermis, Jacq App. tab. 82.

Habitu cum D. tramonio convenit, fed altior . Differt potiffmum a D. arborea capf. ereza, glabra.

294. HYOSCYAMUS. Cor. infundibulif. obtufa, inæqualis, 5-fid. Stam. inclinata. Capf, operculdra, 2locul.

I. niger. H. fol amplexicaul, finuatis: fl. feffilibus. Syft. veg.ed, 14. Black, tab. 550, Ludw. ect. tab.85. Knorr, del. I. tab. P. 3. Riv, irreg, $t a b$, 102. Hiofciamo. Mutth,

In Europa ruderatis pinguibus 6 .

Tota planra longiufc. pilis barbara, foerida. Caul. cubital. ramolus. Fol. cinereo-virent. glutinofa. Spicze heteromalle. Cor, fufca, cum lineis purpureis.

2. albus. H, fol, petiolit. obtufis, finuatis: fl, feffiritious o Syft. veg. ed. 14. Black, tab. III. Sabb horto 1. tab. yi. Matth. Cluf. hift. 3. paz. 118.

In Europa दु.

Fol. albidiora priore. C 3 l. ftriis elevatis . Cor. alb fcens, fauce atropurpur. aut viridi.

3. aureus. H. fol petiolatis, acutis, dentat. fl. peduncul. fru= ctibus pendulıs. Syfl, veg. ed, 14. Cluf, hift.2. pag. 84 .

b. H. creticus \&c. Alp. exst, tab, 98 .

In Creta, Oriente; ad muros Unelize \&c. 24.

Caul. ped. pilofus. Fol. lobata, denticul. petiolis valde pilofis. Pedunc. luteral. Cor. aurea, fauce atro-purpur. Atriata. Stam. purpur.

4. muticus. H, fol, petiolar. ovatis, acutangulis; calycibus muticis; bract. indivifis. S, ft. veg. ed. 14. Alp. exot. tab. 192.?

H. Datora, Forsk. Ats. tab. 5. monente Vahl. In Agypto, Aribin $\zeta^{3}$.

Caul. pedal, teretiufc, fubpubefe, ramofus, Fol. alterna, acuta, integerr. lævia pallefcent. Floral. fubpetiol, ovata, feu ovar-oblong. a'ternis fl. bina, alternis folitar. Racem. fecundus, apice incurvatus. Cor. primum extus viridis, dein albida, intus atro-purjur. Stam. purpurea.

5. pufllus. H, fol, lanceol, dentat, Al, inferioribus binis; ca- 
lycibus fpinofis. Syft. yeg. ed. I4, Pluk, alm. $t_{a} b$. 37. f. 5 .

In Perfut $\odot$.

Caul. palmar, pilofus. Fol. alterna, pinnatif. pilofd, petiolis longis, pilofis. Flordl, bina, integra. Cal. ro-angulat. Cor. flava, fauce ni6. gra, latere inferiore divifa ultra limbum.

6. phyfaloi- H. fol, ovat. integerr. calyc. inflatis, fubglobofis . des. In Sibirin 24.

Caul. ped. fimpl. teretes, hirti. Fol. alterna, petiolat. lurido--virid. venofa, hirta, fuper. fenfim maiora. Fl, terminal, peduncul, fafciculati. Cal. breviff. Cor. erecta, purpurafc.

7. Scopolia. H. fol. ovat. integris; calycibus inflatis, campanulat. lævibus. Syft. veg. ed. I4.

Scopolia \&c. Jacq. $O b \int$. I. $t a b .20$.

Circa Idriam in fylvis 24.

Caul. erectus, fere pedal. 2-fid. Fol. petiolat. lanceol-ovata, fubrugofa, patentia : caulina alterna, folitar. fub bifurcatura terna, quorum 2. adproximata: ramea gemina, quorum alterum paulo minus. Fl, ramei, axill. folitar. penduli. Cor. Atrope obtufa, extus ferrugin. ftriis aliquot pallidis, intus flava.

295. NICOTIANA. Cor, infundibulif. limbo plicato. Stam. inclinata. Capf. 2-valv. 2-locul.

I. Tabacum, N. fol, lanceol-ovat, feffilibus, decurrentibus: $f$. acutis. Syft, veg. ed. 14. Black, tab 146. Sabb。 hort. 1. $t a b$. 89. Ludw. ea. tab. 167. Knorr. del, I. $t a b$, Iт.

Blennochoes. Reneal. Sp. $6 a b .38$.

In America $\odot$.

Alritudo humana. Fol. alrerna, villofa, glutinofa. Fl. racemofi. Cor. rofea .

2. fruticofa. N. fol. lanceol. fubpetiol, amplexicaulibus: Al, acutis: caul. frutefcente. Syft, veg. ed. I4. Ad cap. b. Spei, China b.

Simil. priori .

3. ruftica. N. fol. petiolat, ovat. integerr. Al, obtufis. Syft. veg. ed. 14. Black. tab. 437. Sabb. hort. 1. tab.90. In America $\odot$.

Caul. pedal. Fl. fubcapitati . Cor, viridi-flavefc. Capf. non adeo oblonga.

4. paniculuta. N. fol, petiolat, cordat, integerrimis: fl, paniculat, 

obtufis, clavatis. Syft. veg.ed. 14. Few. Peruv, I. $t a b$. 10.

In Peru $\odot$.

Differt a priore caul. altiore, teneriore, paniculato: cor. anguftioribus, limbo breviff, obtuffif: calycibus, capfulifq. acuris .

5. urens, N. fol, cordar, crenatis: racemis recurvatis: caui. hifpido, pruriginofo. Syjt, veg. ed. 14. Plum. ic. 21 r.

In Amer. meridion. 5 .

Arbor tota hifpida. Fol. N. rufica, cordatovata, coltis fpinofis, hirfutis. Racemi alterni, compofiti, fecundi, revoluti, toti hifpidi . Cal. hirtus . Cor. campanul, albida. Capf. bicornis, glabra.

6. glutinofa. N. fol. petiolat. cordat. integers: fl. racemofis, fecundis, fubringentibus. Syft. veg. et. I4. Ac. holm. 1753, tab. 2.

In $P_{\varepsilon \rightarrow u}$ ○.

Fol. glutinofa, magis cordata, Racemi pauci, longi. Cal, una lacinia reliquis duplo ma: Cor. rofea.

7. pufilla. N. fol, oblong-ovalibus, radicalibus: fl. racemofis, acutis. Syj. veg. ed. 14. Mill. ic. 185. f. 2.

In vera Cruce.

Fol. obtufa, rugofa . Cal. breviff.

296. ATRO- Cor. campanul. Stam. diftantia. Bacca globofa, PA . 2-locul.

I. Mandra- A. acaulis: fcap. I-fl. Syft. yeg. ed. 14. Black. gora. tab. 364. Sabb. hort, 1. tab. I. Mill, ic, tab. 173. Lob. ic. 267.

Mandragora mafchio. Matth.

In Itulia, Helvetix, Hifpania, Sibirice \&c. apricis montofis.

Radix bicruris. Fol. femipedal. ovat, lanceol. undulara, foetida. Cor. ex cœrul-purpurafc. Bacca magna, rotunda, lutea .

2. Belledon- A, caul, herbac, fol, ovat, integris. (geminana. tis). Syft. veg. ed. 14. Jacq. Auftr, 4, tab. 309. Mill. ic, 62, Black, tab. 564. Sabb. hart. I. tab. 3. Kniph. cent. 9, tab. 16. Ludw, ę, tab. 128 .

Solano maggiore, Matth.

In Europa montofis fylvis 4 . 
Caul, 6-pedal. Fol. petiolar. fature virid. rigida, venc fa. Fl. axill. peduncul, cernui . Cor. tubulota, albido-fufca, cum lineis nigris. Bacca nigra, lucida, cal. perfiltente. Var. fol. min.

3. phyfoloides. A. caul. herb c. fol, finuato-angulat: calycibus claufis, acutangulis. Syft. veg. ed. I4. Jacg. Obf. 4. tab. 98 .

Alkekengi \&c. Fewil. peruv. tab. 16.

In Peru (1).

Caul. erectus, 3-4-cubital. patulus, ramis angulatis. Fol. aiterna, per petiolum decurrent. oblonga, obtufe finuata (Datura), glabra. Pedunc. ad lacus petiol. folitar. nudi, I-fl. Cal, ovalus, bafi excifus, profunde 5part. folicl. fagittato-ovat. Cor. campanulata, parum 5-loba, ubtufa; limbo fubplicato; cœrul. fundo olbo, radiato maculis 5. cœrul. Bacca cernua, exfucca, tect cal. ma: $^{2}$

4. Solanacea. A. caul. fruticofo: fol. fubovat: pedunc. folitariis : cor. campanul. S $j$. veg. ed. 14.

S. lignofum \&c. Comm. hort, 2, tab. 96.

Ad cop. b. Spei litora maritima $\hbar$.

Caul. 6-ped. minus ramofus, lubangulat. Fol. alterna, frepius ex gemmis plura, petiolit. integerr. nuda. Pedunc. ix,1l. I-fl. fl. penduJo. Cor. albo-purfuiafc. lacin. erectis, lan-

5. arborefcens. A. caul. frutefcent. fol. oblong: pedunculis confertis: ccr, revelutis. Syft, veg. ed. 14.

A. Solanacea. Allion. auâ.?

Belladonna \&c. Plum, ic. 46. f. I.

In Amer. merid.

Fol. alterna, lanceol. integerr, venofa. Pedunc.

6. frutefcens, A. caul, fruticofo: fol. cordat-ovat. obtufis : peduncul. confertis: Syft. veg. ed. 14. Barr.

In Hifpania t.

Habitus, \& omnia Phyfalid. fomnifere, ut limi-

297. PHYSA-Cor. rotata Stain, conniventia. Bacca intra ca.
LIS, LIS, lycem inflatum, claufum; 2-locularis. 


\section{*Perennes.}

I. Somnifera. P. caul, fruticofo: ramis rectis: fl. confertis. Syft. veg. ed. I4. Cluf, hift, 2. p. 85.

In Mexico, Creta, Ht/pania 24.

Caul, pedaj, tomentofo-cinereus. Fol, ovata, integerr. quandog. geminata, cinerea. Cor. virid. Bacca parva, rubra .

2. flexuofe. P, caul, fruticolo; ramis flexuofis: fl. confertis . Syft. veg. ed. 14.

Peuetti. H. Mal. 4. tab. 55.

In India $b$.

Habirus, \& fatura prioris: differt fl. minor. ramis bifariam valde flexuofis; hinc fol. quafi diftiche difpoftra, flexura angulis exterioribus inferta.

3. arborefcens. 1. caul. fruticofo: fol, ovat. pilofis: fl. folitar: cor. revolutis. Syft, veg. ed. I4. Mill, diz. tab. 206. f. 2 .

In Campechia $\hbar$.

Fol. oppofita, ovat-lanceol. integerr.

4. cura\ayica. P. caul. fruticofo: fol. ovat. tomentofis, Syft. veg. ed. 14.

Solanum \&c. Pluk. alm. tab, III, f, 5.

In Curabiao b.

Caul. tefquiped. e viridi-purpur. Fol. alterna, petiol. fubdent. craffa, viridi-nigricant. Fl. axill. folitar. Cor. pallida .

5. vifcofa. $\quad$ P. fol. geminis, obtufis, repandis, fubtoment. caul. herbac. fuperne paniculato. Syjt. veg.ed. 14. Jacq, hort, $t a b$. 136 .

Alkekengi \&c. Dill. elth, tab. 10, f. 10.

In Virginia, Bonaria 4.

Planta fubtoment, foetida. Caul. pl. fefquiped. bafi ramofi, debiles. Fol, alterna, ramea fæpe oppofita, petiolat. pallide virent. Fl, peduncul. folitar. Cal. campanif. Cor, flava, unicolor. Bacca pifiform. lutea .

6. penfylvani-P. fol, ovat, obtufis, fubrepandis, nudiufcul: fl. ce. geminis: caul, herbac. Syft. veg. ed. I4.

In Virginia 4.

Caul. multi, nunc procumbent. nuac erecti, vix pedal, fubflexuofi, tomento obfoleto adfperfi, apice ramofi. Fol, alterna (Buerhaavic) petiolat. fubtus obfolete tomentofa, ad 
fl. gemina. Pedund, axill. folitar. Cal, bafi rem tufus. Cor. Jurea, fundo obfcuriore. Bacca pifiform. ylobola, rubra .

7. Alkekengi, P. fol, geminis, acutis, integris: caul. herbac. inferne fubramofo. Syjt. veg. ed. 14. Blick. tab. 161. Knorr. del. 1. tab. I. 4. Ludw. eä. tab. 151. Sabb. hort. 2, tab. 63.

Solanum veficarium. Garid. tab. 6.

Solatro Alicacabo. Matth.

In Italia, Germania, Japonia ferobibus 24.

Caul. cubital, fubrubens. Fol. petiolat. cordatacumin. Pedunc, axill. I-fl. Cor. fubalbida, villofa. Fructus, \& cal. magni, maturi coccin.

8. peruviana. P. pubef: : fol, cordat. integerrim. Syft. veg. ed. I4.

Lima 24. 万.

Planta fimil. Dature Metel. Caul, altus, divaricatus . FI, folitar. penduli, lutei, umbilico maculis 5. fufcis, fauce hirfuta.

\section{** Annue.}

9. angulaca. P. ramofiff. ramis angulat, glabris: fol. ovat. dentat. Syft, veg. ed. I4.

Halicacabum. Cam, hort, tah. I7.

Alkekengi \&c. Dill. elth, tab. I2. f. 12. b. $t a b$. II. f. II.

In India utraque $\odot$.

Fl. parvi, albidi. Cal. angulat, Bacca lutea.

ro. pubefcens. P. ramofiff: fol, villofo-vifcidis: A. pendulis . Syft. veg. ed. 14.

Alkekengi \&cc. Fewil. peruw. 3. tab. I.

Solanum \&c. Morif. hift. 3. $\int .13 . t a b .3$. f. 24. In India utraq: precipue in Virginia $\odot$.

Cor. maculæ fufcæ, nec pallidæ. Bacca globofa, Iutea, villofo-vifcida.

I1. minima. P. ramofif, pedunc. fructiferis fol. villofo longioribus. Syft. veg. ed. 14 .

Solanum \&c. Sabb. hort. 2. tab. 64. Herm. Lugd. tab. 571 . Hort. mal. Io, $t a b$. 140. f. 71 .

In India $\odot$.

Planra parva, pilis oblong: ad ramorum alas. Caulic. dodrant, media fui parte bumifufi. Fol. Solani vulg. fimil. fed min:- atro-virid, quandoq. crenata. Fl, axill. parvi, pallide flave- 
fcent, fauce fufcis maculis notata. Cal. \& bacca herbac.

12. pruinofa. P. ramofiff: fol. fubvillofis : pedunc. frictis. Syft. veg. ed. I4.

In America (-).

Fol. antecedentium 9. I0. Ir. fed anth. flavæ, nec corul. Rami teretes, fupra plani, villofi. Fol, villolo-vifcola. Fl. cernui, Bacca fubturbin. lutea.

13. barbaden-P. ramolif: fol. cordat, villofis: calycibus frufis. ctefc. pendulis, ovat. acutis, 5-gon. fructu maioribus. Syft. veg. ed. 14. Jacq: mifc. z. Alkekengi \&c. Dill. elth, tab. 9, f. 9. Habicat in Barbados $\odot$.

Caul, erectus, teres, craffus, villofus, ramis divaricatis. Fol. longe petiol. acuta, dentat. mollia, utrimq. fubvillofa, fed non vifcida. Pedunc. breves. Fl. cernui. Cor, ochroleu$c 2$, cum maculis ad bafin 5 fuligineis. Fruct. penduli, decidui. Cal. inflatus, cinereus, venofus. Bacca fubrotun. pallide virens, nitida, glaberrima, acidula.

$O b$ enth. purpur; fol. non vifcofn; defectum pruinac; peduncul. floriferos nutantes, non admodum longos, a P. pruinofa diftinate videtur.

ramofa.

P. fol. fimplicibus, geminifq: lare ovatis, acutis, finuato-dentat. fubvillofis. Forsk. Suppl. $E_{g}$. In Agypto.

Habitus P. Alkekengi . Fl, flavi. Cal. valde inflatus, 5-gonus. Bacca ficca, rubra.

proftratn. P. ramofiffima ; caul. procumb. tereti, hirfuto: fol. fubcarnofis . Herit. Jirp. fajc. 3, tab. 22.

In arenafis Lima (9).

Planta humifufa. Cotyledon. oblongæ. Caul. herbac. pedal, ab ipfa bafi ramofus, fragilis, aquofus. Rami, \& ramuli mulci, flexuofi, alterni. Fol. ima oppofita; caulina alterna; ramea gemina, altero min. petiolat. cordata, patentia, fumma bafi inæqualia, obtufiulcula, repando-fubangulara, fubtus villofa, craffrufcula, plana, fragilia, aquofa, læte virid. 2430 lin. long. 18-21. lin. lata. Fl. axillar. folitar-gemini, pedunculat. fragrantes, fat fugaces, I poll. lati. Cor. violac, intus umbone Tom. $\boldsymbol{I}$.

$\mathrm{H} h$ 
exalbido, radiato lineis violaceo-intenfioribus: Pedunc. villofi, floriferi breves, erecti; fructiferi elongati, rèflexi. Cal. ventricofo-tubulofus, inflatus, brevis, decangulus, 5-fid: fructiferus claufus, fubrotund. pellucidus, exalbidus. Bacca fubrotun, virefc. 3-4. lin. lata.

298. SOLA-Cor, rotata. Anth. fubcoalitæ, apice poro geNUM. mino dehifcentes. Bacca 2-locul. (calyc. patulo, nec turgido tecta).

\section{* Inermia.}

I. laurifolium, S, caul, inermi, arboreo: fol, petiolat. ovatoblong. fubtus tomentofis : panicula terminal. dichotoma, divaricata. Syft. veg. ed. 14. Lin, Suppl.

In Amer. auftrali b.

Fol. fpitham, integerr. fufca. Panicula racemis fecundis. Bacca nigra.

2. verhafcifo- S. caul. inermi, fruticof. fol. ovat. integerr. lium. tomentofis: umbellis compofit. Syft. veg. ed. 14. Jacq. hort. I, tab. 13. Pluk. alm. tab. 2I6. f, I,

In America b.

Altitudo humana. Planta tota tomentofa. Pedunc. terminal. femper 2-fid. ramis denuo 2fid. Cor. alba, Bacca lutea .

3. pfeudo-eap-S, caul. inerm. fruticolo: fol lanceol, repanficum. dis: umbell. feffilibus. Syft. veg. ed. I4. Dod. pempt 718 .

In Madera $\hbar$.

Altitudo humana. Planta ramofa, diffufa. Fol. integerr. quandoq: geminata. Cor. alba. Bacca Cerafiformis, rubra.

4. diphyllum, S. caul, inerm. fruticofo: fol. geminis, altero min: fl. cymofis. Syft, veg. ed. 14. Pluk, alm, tab. III. f. 4. mala.

In America? b.

Caul. erectus: rami pauci, erecti. Fol. longitudine digiti, periolat. ovat-lanceol. glabra . Pedunc. axill, \& terminal. Cor. parva, dilure carnea. Bacca rubra.

5. Dulcame- S. caul, inerm, frutefc. flexuofo: fol. fuperior. $r a$. haft tis: racemis cymofis. Syft. veg. ed. 14. Fl. Dan, tab. 607. Black, tab. 34, Duharm. arbr. 2. tow. 72. Ludw, ez. tab, 58, Knorr. del, 1, tabo T. H. 3 . 
Vite falvatica. Matth.

In Europa fepilus humentibus $\$$.

Fol. petiolat. infer. fimplic. cordato-lanceol. fordide virent. flaccida, venofa, glabra. Racemi 2 fidi, dichotomi, nudi. Fl. I-lateral. penduli . Cor. fegment, reflesis, purpuro-corul. ad bafin nectaria 2. fubrotunda, ovata, ex fluvovirefcentia ; apicibus croceis. Bacca ovat. coccinea. 1. Var. fol, variegat. 2. fol.cragls, hirfutis. = Dill, elch. 2ab. 273. f. $352.3 . f l . a l-$ bis: 4. fl. pleno.

6. quercifoli- S. caul. inermi, fubherbac. angulato-flexuofo, um. fcabro: fol, pinnatifid, racemis cymofis, Syft. yeg. ed. 14. Few, peruw. tab. 15.

In Peru $\hbar$.

Suror S. Dulcamara. Caul. fcabri. Fol. in petiol. decurrent, venofa, glabra, fubtus fcabra. Pedunc. ramofi. Cor. violac. obtufior quam in priore, maculis 2. viridibus ad bafin fingula laciniæ. Anth, flavæe. Bacca ovata.

7. radicans. S. caul, inerm, herbac, teretiufc. lavi, proftrato, radicante : fol. pinnarifid. racemis cymufis . $S_{y} f$. veg. ed, 14. Lin, sec. 1, tab. 10.

In Peru 24.

Cor. parva, dilute coerul. Bacca' parva, lutea .

8. havanenfe. S. caul. inermi, frutefc. fol, lanceol, integerr. nitidis: pedunc. fub-2-fl. Syft. veg.ed.14. Jacq. amer. tab, 35. ed. 2. picz. tab. 48.

In Martinice fylvis maritimis $\bar{b}$.

Frutex 5-ped. Fol. alteraa, petiolat. obtufuic: Cor, ampla, tubo breviff. lacin. latis, fubemarginat, cœruled. Bacca oyat, coerul.

9. trifle. S. caul, inerm. frurefcen. fol. lanceol-oblon. fubrepandis, glabris: racemis fubcymofis. Syft. veg. ed. 14. Jacq. am. tab. 40. f. 2, ed. 2. piá, tab. 49.

In Martinicn $b$.

Frutex erect. 8-ped. Fol, 7-8-pollic, longa, alterna, petiol, acuta, atro-virent. Racemi lateral. fefquipollic, craffi, fimpl, vel 2 fid. Fl. parvi, albi. Bacca globofa, fordide flavefcens.

10, racemo-

fum,

S. caul. inerms, frutefcen. fol. lanceol. repandis, undular. racemis longis, erectis. Syft. veg. ed. 14. Jacq. amer, tab. 36. ed, 2. piê. tab. 5o.

In Martinice, Surinami b.

$\mathbf{H} \mathrm{h}$ ij 
Frutex 4-ped. Fol alterna, petiolat. nitida. Pedunc. apice craffiores, nutantes. Cor.profunde diffecta, alba. Bacca piliform. rubra.

II. bonarien-S. caul. fubinerm. fruticofo: fol, ovat-oblong. fe. finuato-repandis, fcabris. Syft. veg. ed. I4. Dill. elth. tab. 272 , f. 351 .

In agro Bonarienfi $\hbar$.

Caul. orgyal. \& ultra, flexuofus, fufcus. Fol. deltoidea, fubrepanda, nuda. Pedunc, lateral. fubumbell, fub s-fid. Fl. magni, nutantes, albi, extus tomentofi. Anth. flavæ. Bacca magnitudine Sorbi Aacmparia.

I2. macrocar- S. caul. inermi, fuffrutic. fol. cuneatis, repandopon. angulatis, giabris. Syf. veg. ed. I4. Mont. in Zan, zab. 158. Few. peruv. tab. 46. Plum, ic. 224. f. 2 .

In Peri b.

Caúl. pedal. rigens, læevis. Fol. mazna, oleracea. Fl. magni, erecti, campanulati, breviter peduncul. cœerul. Bacca magnitud. pomi, globofa, fubf fill. flava.

13. tubero- S. caul. inerm. herbac. fol. impari-pinnatis, inSum. tegerr. peduncul. fubdivif. Syft. veg. ed. 14. Black. tab. 523. \& tab. 587 . Knorr. del.2. tab. S. 9. ro. Bank. prodr. tab. 89.

In Peru $\odot$. 4.

Radix tuberofd. Caut. 2-3-cubital. puctul. rubris adfperfus. Petiol. decurrent. Foliol. 5-7. fubrotun, hirfuta, impari ma: Fl. fafciculati . Cor. fubalbida .

14. pimpinelli-S. caul. inerm, herbac. fol. impdri-pinnar. integerr. folium. racemis fimplicibus. Syft. veg. ed. I4.

In Peru $\hbar$.

Habitus lequentis . Foliol. glabra.

35. Lyeoperfi- S. caul, inerm, herbac, fol. impari-pinnat. incifis : cum. racemis fimplicibus. Sy/t. veg. ed. 14 .

Pomum amoris. Black. tab. 133. Rumph. amb.5. tab. I54. f. $\mathrm{I}$.

In Amer. calidiore $\odot$.

Fol. interrupte-pinn. foliol. fubæqual. hirfuta, pallide virent. Cor, dilute lutea. Poma orbicul. fubcomprefía, e luteo-rubent.

I6. $p$ feudo-Ly.S. caul, inerm, herbac, fol. pinnat. incifis : racecoperficum . mis fimplicibus: fructibus fubvillofis. Syft. veg. ed. I4. Jacq. Hort, I, tab. II. 

Simil. priori. Difcrimen in racemis; $\&$ fructu
min. flavefcente. 17. peruvia- S. caul. inerm. herbac. fol impari-pinnat. incifis, numb. tomentof raceinis 2-part. foliofis: baccis pilofis. Syft. veg. ed. 14 .

Iycopericon \&c. Few. peruw. 3. tab. 25.
In Peru 24.

Ito lycopericon \&c. Few, peruw. 3. tab. 25.
In Peru 4.

Fol. itucana. Cor. læte flava, maior quam in Lycoperfico. Bacca parva, rotunda.

I8. misnta-

num.

$\rightarrow 7008$ (indisey)

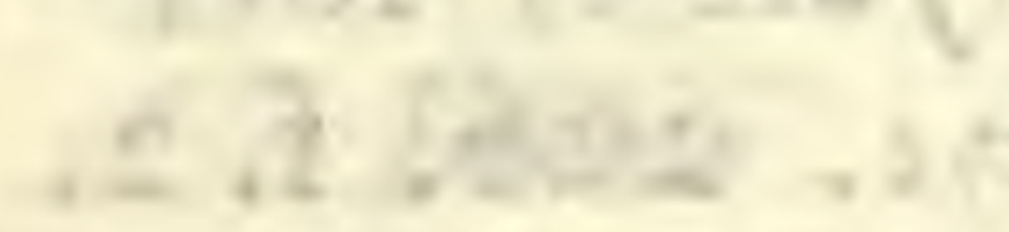

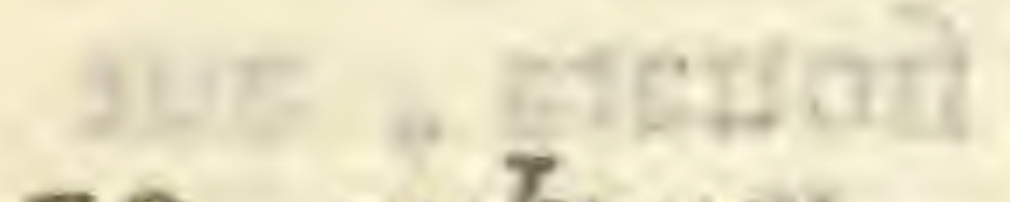

19. rubrum.

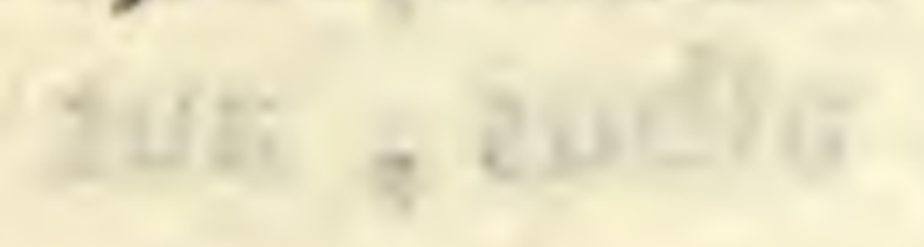

20. nigrum,

S. caul. inerm. herbac. fol. fubcordat. repandis. Syft. veg. ed. 14. Few. peruw. 3. tab. 46. 112 In Peru 4.

Radix oval, carnofa. Caul. 3-pollic. Fol, pollicar. (axilldria mio.) 3-4. alcerna, petiolat. Fl.ter-

minal, biai. Cor. rofea. Stam. purpur.

S. caul. inerm. fubperennante: fol, geminis, ovat. integerr. pedunculis fubumbellat. Syft, veg. ed. I4.

Habitat ....

S. caul inerm. herbac. fol. ovatis, dentato-angulatis: racemis diftichis, nutantibus. Syft. veg.ed. 14. Fl. Dan, tab. 460, Black. tab. 107. Ludw, ect. tab. 172. Knorr. del. 2, tab. S. 3. Sabb. hort. 2. $t a b .60$.

Solatro degli Orti . Matth.

In Orbis totius cultis $\odot$.

Caul. pedal. anceps, ramofus . Fol. alterna, longe periolar, fubpendula, mollia, villofa, tenera, nervofa, atro-virent. Fl. corymbofi. Cor. parva, alba, apicibus luteis. Bacca parvd, nigrd. Var. 1. fol. laciniat: 2. fol. minus undojus, baccis rubris: 3 . fol. hirfutioribus, baccis luteis.

21. feandens. S. caul, inerm. volubil. fol. cordat, ovatis, dependentibus, fubtus molliffunis: panicul, terminalibus, $S_{j} f$. veg. ed. 14. Iin. Suppl.

In Surinamo.

Caul. herbac. Fol. alterna, petiolat. remota . Cor. laciniis lanceol, recurvis. Bacca globofa, Cerafi magnitudine.

32. quadran- S, caul. inerm. herbac. 4-gono, fcabro: fol, rhomgulare. bris, dentat. integrifque. Syft. veg. 'ed. I4. Lin. Suppl.

Ad cop. 6. Spei.

Differt praecipue caul. 4-gono, hirfuto. Fol,fæpe decurrunt, \& caulis angulos crifpus format. Var, fol, lanceol, integris , 
33. athiopi- S. caul. inerm. herbac. fol. ovatis, repando-ancum. gulatis: peduncul, fertilibus I-fl. cernuis. Syft. veg. ed. 14. Jicq. hort. 1. tab. 12. Pluk, phyt. 226. f. 4. Lab. ic. 265.

In Athiopia, China $\odot$.

Catul, rigidulis. Fol. S. Bonarienfis, paimar. obtufa, cofta aculeata. Cal. aculear. Cor, alba, Fructus magnus, globolus, depreffus, profunde torulofus, \& quafi in lobos fectus, durus, ex phceniceo-ruber.

34. Melonge- S. caul. inerm. herbac. fol. ovatis, tomentofis: na. pedunc. pendulis, incraffatis : calycibus inermibus.. Syft. veg. ed. 14. Pluk. phyı. 226. f. 2. In Indiis $\odot$.

Caul. fubruber. Fol. Ionge petiolat. finuata, aut plicata, dentata, nigricant. Cor, albida, aut purpur. Fruct. magnus, pendulus, albus, aut purpur.

25. lyratum. S. caul. inerm. herbac. erecto : fol. lyrato-haftatis, tomentofis. Syft.veg. ed.14. Thumb. Jap. In Japonia.

Planta tota tomentofa, \& inermis. Caul. flexuofus, ramofus, teres. Fol. fparfa, petiol. ovata ; inferior. lyrato-pinnatifida ; fuper. haftata, pollicar. pinnæ lateral. fuboppofitæ, 4-raro pl. integræ; terminalis ma: acumin. integra. FI. verfus apicem axill. \& terminal. paniculati. Panicul, fubdichot.

\section{** Aculeata.}

26. infanum. S. caul, herbac, aculeat. fol, ovat. tomentofis: pedunc. pendulis, incraffatis; calycibus aculeat. Syft, veg, ed. I4. Black, tab. 549. Konrr. fl. r. tab. T. 10. Pluk. alm. tab. 226. f. 3. Morif. hift. 3. f. 13. tab. 2. f. 2.

Trongum hortenfe. Rumph, amb. 5. tab. 85.

In Indiis $\odot$.

Valde adfine S. Melongene. Caul, vix ramofus, tomento ftellato. Fol, fubfinuata. Pedunc. folitar. penduli, incraffati, r-fl. Poma magna, oblong. quandoq. ftriata, lutea, magnitudine varia.

2\%. ferost : S. caul, herbac. aculeato: fol. cordat. angulatis, fubtus tomentofis : baccis hirtis, calyce obtectis. Syft. veg. ed. I4. 


\section{PENTANDRIA MONOGYNIA:}

Statura S. Melongena. Fol. ampla, petiolat. aculeis erectis adiperfa, fupra villofa. Cal, campanulat. tomentofus, valde aculear.

28. campe- S. caul, acultat. hirto: fol, cordat-oblong. 5chienfe. lobis; finubus obtufis, elevatis. Syjt. veg. eds 14. Dill, elth. tab. 368 . f. 347 .

In America $\odot$.

Caul. frutefc. pedal. aculeis patentibus, rectis, purpurafe. Fol. petioli latere fuper. purpur. Pedunc. lateral. gemini, altera 1-fl. aitero fub4-fl. Cor, alba, vel cœerulefc.

29. mammo- S, caul. herbac, aculeat. fol. cordatis, angulatofumb. lobatis, utrinq. villofis, aculeatis. Syft. veg. ed. 14. Merian. Surinam. tab. 27. Pluk, alma tab. 225 . f. I.

In Virginia, Barbados ๑ .

Fol. longitud, \& latitud, æqual. obtufiufc. nervis, $\&$ aculeis flavefcentibus. Bacca pyri parvi inverfi forma, \& magnitud. Iutea.

30, panicula- S. caul. petiolifque aculeatis: fol. finuato-angul. titm, fupra glabris: fl. paniculat. Syjt. vey. ed. 14. In Brafilia.

Caul. \& petiol, albo-tomentofi, aculeis rectis, rarioribus. Caul, 5-6-ped. Fol. lata, cordata, acutiufc. Panicul. compofita, tomentofa. Cor. coerıl. alba .

3r. virginia- S. caul. aculeat, angulat. fol, pinnatifid. undiq. num . aculeat. lacin. finuat. obtufis; calycibus aculeat. Syft. veg. ed, 14. Dill. elt. tab. 267, f, 346. Pluk. alm. tab. 62, f. 3 .

In America $\odot$.

Spinæ multæ, valida, niveæ

Differt a S. Sodomeo ramis angulatis, fed annuum. Bacte parpe, variegate e viridi, \& albo.

32. indicum. S. caul. fruticofo, aculeato; fol. cuneiformibus, angulatis, fubtus tomentofis, aculeis utrimq. rectis. Syft, veg. ed. 14. Sabb, hort. 2, tab. 58. Burm. Zeyl. tab. I02. Robert. ic. 28. Dill. clth. tab. 270 , f. 349 .

In India utraque $\mathrm{b}$.

Caul. hirfurus, fpinis confertis, rettis, flavis, apice fufcis. Fol. periol. utrimq, hirta, aculeis ut in caul. F1. peduncul. Cal, inerm, fed hifpidus. 
Differt potifimum a S. Sodomeo fol. fubtus tomentofis: fl, min, vulgaris magnitudine: pedunc, ramofis : fructibus croceis ; \& fol. laciniis acutis .

33. fiskatum. S. cłul. fruticofo, aculeat. fol, ovat. obtufe lobat. aculeis utrimq. rectis; fuperioribus coloratis. Syft. veg. ed. I4.
Hableat.

34. carolinen $\int e . S$. caul. aculeat. annuo: fol. haftato-angulatis ; acul. utrimq: rectis: racemis laxis. Syjt. veg. ed. I4. Dill. elth. tab. 269. f. 348.

In Carolina $\odot$.

Caul. I-2-ped. brachiati, hirfuti, e viridi aIbicant. Fol. I-fefquipalmar. 2-3. unc. lata, raro, \& irregulariter finuata, finubus oblique fibi refpondentibus, bafi integra, fcabra, vix tomentofa, fpinis in cofta, non laceribus, utrimq. virentibus. Racemi fimpl. Cor. ampla, Borraginea, e violac. dilute purpur. Bacca pifiform. lutea.

35. fodomeum. S. caul, fruticofo, aculeat, tereti: fol. pinnatifido-finuat. fparfe aculeat. nudis: calycibus aculeat. Syf. veg. ed. 14. Herm. Lugd. tab. 575. Morif. kift. 3. f. 13. tab. I. f. 15. Pluk, almo tab. 316. f. 4 .

In Africa $\hbar$.

Caul. fubvillor, aculeis fparfis, remotis, compreffis, recurvis, luteis. Fol. oblong. finubus rotundat. utrimq: viridia . Pedunc. lateral. longi, ramoli, aculeati. Cor. Borraginea, ex coerul. pallefcens. Bacca magna, rotunda, lutea .

36. Sanctum. S. caul. frutic of. aculeat. aculeis toment: foliifq. oblique ovat. repandis. Syft. veg. ed. 14. Pluk. alm. tab. 316. f. 52 .

In Palafina b.

Caul cinereus, acul. craffis, rectis, brevibus, flavefcentibus, apice tomentof. Fol. craffa, toment. obtufa : tenella pinnatim finuata, margine albido. Petiol. fubrus aculeati. Pedunc. lateral. pedicello prímario cum calyce fpinofo. Cor. Borraginea, cœrul. purpurafc. Bacca lutea. 37. hybridum. S. caul, fruticof aculeat: fol. ovat. acut. fubinermibus, repandis; tenellis, dorfo, \& ad oras violac-pulverulentis. Syft. veg. ed. 14 . Jac, hort. 2. tab. II 3 . 
Aculei validi. Caul, 2-ped. ramis tomento pulverul. obfitis. Fol. petiolat. undulata, pallide virent. Pedunc. racemofi, tomentofi, umbellati, fufco-violac. pauci, I-fl. Cal. tomentofus. Cor. pallide cœrul. Bacca fubrotunda, depreffa, fubfulcata, pendula, col. aurantiaco, nitida.

38. coccineum. S. caul. fruticor. aculeat. fol. ovatis, fubrepandis, uno, alterove aculeo armatis, fubtomentof. Syjl. veg. ed. 14. Jacq. ic. rar, tab. 24.

Habitat

Frutex 2-ped. breviter, \& rariter aculeatus . Rami patuli, teretes, aculeis rectis, fubulatis, fufcefcent, armantur. Fol. late ovata, obrufa, alterna, petiolat. fordide virent. nervo medio utrimq. \& petiolo rariter aculeato. Rac $\in$ mi oppofitifol. breves, fimplic. fubinerin. tomentof. Cal. parvus, fubinermis, tomentofus. Cor. rotata, profunde 5-fid. calyc. multoties longior, albida, vel fubpurpurafc. lacin. ovatlanceol. acutis. Bacca pifiform. rubra, dein fordide aurantiaca.

39. tomento- S. caul. fruticof. aculeat. acul. acerofis: fol. fum. cordatis, inermibus, fubrepandis: tenellis purpureo-pulverulent. Sy/f, veg. ed. 14. Mont, in Zan. tab. 157. Triumf. pral. tab. 6. Bocc. Jic. tab. 5 .

In ALthiopia b.

Planta tota tomentofa, aculeis anguftiff. Fol. utrimq. virid. obtufa, fere fola cofta fpinofa . Baccæ fulvæ, magnitudine GrolJularia.

40. bahamenfe.S. caul. fruticofo, aculeat: fol. lanceol. obtufis, repandis, margine reflexis : racemis fimplicibus. Syft. veg. ed. 14. Dill. elth. tab. 27 r. f. 350. Sloan. Jum. hift. I, tab. II. f. 3 .

In Amer. Infula Providentic b.

Caul. I-2-pedal. Fol. Caftanea fimil parum finuata, fpinofa, fupra atro-virent. \& fubhirfuta; fubtus dilutiora. Fl. parvi. Cor. e cœrul-gilute purpurafc. Bacca pifiform. e croceorubra.

4.1. igneum. S. caul. fruticofo, aculeat. fol. Ianceclat, acumin. bafi utrimq, revolut: racemis fimplicibus . Syft, veg. ed. 14. Jacq. hor. I, tab. I4. Pluk. alm. tab. 225, f. 5 .

In Amer, \$, 
Simil. priori, fed fl. albi \&c. Spince copiofiores, validiores, rubro-ignea.

Altitudo hña. Fol. iuniora villofa; adulta glabra. Cor. alba, vel fubpurpuratc. Bacca pifiform. flava .

42. trilobatum. S. caul. fruticof. aculeato: fol. cuneiformibus, obtulis, fubtrilob. glabris. Syft. veg. ed. 14. Burm. Ind. tab. 22. f. 2. Pluk, alm. tab. 316. f. 5 .

In Jamaica, ad cap. b. Spei b.

Caul. altus, anguftus. Fol, parva. Aculei reflexi in caul, petiol. fol, pedunc. Pedunc. I-fl. Cal. minim. Bacca parva, Sambuci.

An 2. fp. cum una fl. parvis, albis; alters magris, violac.?

43. Stramoni- S. caul. fruticof. aculeat. fol. cordat. acutis, folium. lobatis, aculeat. fubvillofis : calyc. inermibus.

\section{Habitut} Syft, veg. ed. 14. Jacq. mifc. 2. ic, rar.

Caulis, fol. utrimque, petioli, rami denfe aculeati : in caule plurimi recurvi; reliqui recti . Truncus cinereus, exafperatus. Fol. ampla, maiora cum petiolo pedalia, alterna, utring. villofa, \& mollid, lobis fublanceolat: acutis. Petioli teretes, villofo-afperi. Pedunc. breves in caule, \& ramis inter proxima fol. enafcuntur, folio fuperiori oppofiti, horizontaliter patentes. Pedicilli plurimi, circulariter difpofiti, fubvillofi, ficuti calyx. Cdl. minimus, lacin. fubrotund. Petal, pallide purpurafcent. aut albida, lacin. longis, lanceolat. patentifim.

44. margina- S. caul. fruticofo, aculeat, fol. cordat. repandis, tum. margine albis, Syft. veg. ed. 14. Murr. Comm. Gootin. 1783 , tab. 4.

S. niveum. Allion. Auct. Mifc. Taur.

S. Albyfinicum. Juciq, hort.

Schunda, aut Chunda. H, Mal. 2.

In $A b_{y}$ Jinin $\hbar$.

Caul. albo-tomentof. Fol. fupra virid. fubtus alba, tomentofa, acul. utrimq. rectis. Fl. racemofi, campanul. plicari. tomentofi, albi, fimil. S, tuberofo. Cal. inerm: fructiferi aculeati .

45. capenfe. S. caul, fruticof, aculeat, tereti: fol, finuat- 
pinnatifid. aculeat, nudis; lacin. alternis, obtufis, integris. Syft, yego ed. 14. Lin. Suppl.

ni 2 , govilAd. cap. b. Spei.

Planta copia aculeorum horrida.

*** Spinofa.

46, Iycioides. S. caul, fpinofo, fruticofo: fol. ellipticis. Syft. veg. ed, 14.

admirarg In Peru? $\hbar$. Frutex facie

thited . Frutex facie Iycii. Caul, inermis, ramis omnibus in fpinam definentibus. Fol, parva, petiolat, lævia. Fl. lateral, folitar. Cor. rotata, fub-s-fid.

bombenfe S. caul. frutefc. inermi ; fol. ovalibus, integerr. racemis corymbofis. Jacq: amer.

In fruticetis circa Carthagenam b. . Astrases 10it Arbufc. 12 ped. comofa. Fol, in planta iuniofubinerme. S. caul. frutefc. fubinerm: fol. Lan eol-ovat, integerr. Jacq: amer. tab. 40, fil3, ed. 2. piä. tab. 259. f. 15 .

In Carthagenx fruticetis $\$$.

Frutex 6-ped. Fol. 3-4. poll. longa, alterna, gatgitir e zing petiol. acuta, fupra glabra, fubtus fubtoment. Racem. lateral. 2,3 -pollic. peduncul. fecundis. Cor, coerul. Bacca globofa.

trifoliaturn s. caul, fruticof, actuleat: fol, teriatis, ovat, integerrim. Burm. Ind, tab. 22, f, 3 .

Hablzat Coromandeli b.

Caul. ipinis incurvatis, rarioribus. Fol, altern. petiol. glaberr. nuda.

serminale. S. caul. frutefc. inerm. fol. ovalibus, acut: umbell. terminalibus. Forsk, $A g$.

In Arabia $\mathrm{b}$.

Caul. decumben. verrucofi, fummi pubefient. raro apice volubili. Fol. alterna, patent. pubefcent. Petioli teviter alati: lamina 2-pollic. integra, villofa, fubciliata. Cor, patens, alba. Anth. flavæ.

agyptiacum. S. fructu rubro: fol. fubangulat. glabris, Forsk. Ig.

In Arabia.

Var. fol. integris, villofid: fruat. nigro.

In Ceplablalgio fronti ibliniswr fuccus fol, expreffus. 
incanum.

S. Forsk. Ag.

In Arabin.

Caul. pedunc. petiol. \& colta fol. fupra, \& intra valde aculeati. Cal. fubinerm. Fl. racemofi, albidi. Bacca pifform. rubra.

Fol. recentia vulneribus imponuntur.

armatum.:sgil S, Forsk. 压g.

In Arabia.

Planta borridis fpinis armata. Caul. procumb. Aculei femipollic. albi, Fol. \& cor. S. Bakamenfis.

coagulens. S. Forsk. $\mathbb{E}_{\text {g. }}$.

In Arabia 24.

Caul. fæe aculeati. Fol. ovat-obl. obtufa, fi-

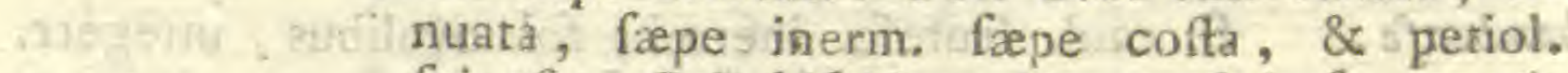
fpinofis, Cal. hifpidus. Bacca globofa, nucis magnitudine, coriacea, flava .

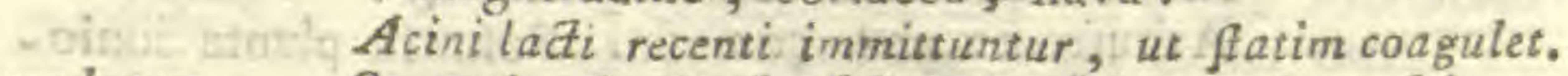
cordatum, S, caul, fruticof, fubacul: fol. cordato-fubrot: -bi tatrados integris, inermibus. Forsk. AEg.

Init is as . In Arabin.

Fol. femipollic. petiolat. Pedunc. lateral. folitarii, I-fl. Cor. deflexa, violac. Anth. flavæ. Bacca piliform. pulpofa, rubra.

villofum. S. fol. villofis, ovalibus, bafi obliquis, margine repandis. Forsk. $\mathbb{E g}$.

In Arabia.

zeylanicum . S. fruticofum : caule; fol. finuatis; pedunculis; calycibufque aculeatis. Scop, Delic. Infub. fafc. I. $t a b$. I.

Habitat . . b.

Caul. fufcus, villofus, ramis ramulofis; aculeis violaceis, rectis, ftriatis. Fol. ovata, obtufa, villofa, aculeis fupra crebrioribus. Petiol. aculeati, fol, breviores, teretes, villofi. Pedunc, folitar. petiolis oppofiti, frepius $2-\mathrm{fl}$. aculeati, villofi. Membrana violac. pellucida, dentibus calyc. interpofita. Cor. rubro-violac. tubo flavo. Bacca flaya, ovata, aut fpherica, pendula, glabra. Planta odore, \& fapore nullo.

Differt a S. indico, flatura multo minore; fol. obuufis ; jinubus rotundatis; \& fructu luteo.

mauritianum, S. frutefcens; ramis fuperioribus lanatis: fol. oblongis, integris, tomentofis : racemis ter- 
minalibus, glandulofis. Scop, Delic. Infub, fafc. 3. $t a b .8$.

In Infülis Mauritianis $\hbar$.

Differt a S. Verbafcifolio, cui caulis rimofus; ranificatio irregularis; fol. ovata, oppofita, duplo breviora, ex quorum alis nullum exit foliol. Racem. unicus, multo longior, ex angulo divifionis ramulorum fupremorum prodiens; cor. alba; glandula nulla.

Noftro cotyledones lanceol, tomentofæ, breviter petiolatæ. Fol. in ultimis dumtaxat ramulis; ex quorum alis foliola folitaria, recurva. Racemus dichotomus, lanatus. Fl. congefti. Cor, parva, violac.

299. CAPSICUM - Cor, rotata . Bacca exfucca .

I. annuum. C. caul. herbac: pedunc. folitar. Syft. veg. ed. 14. Knorr. del. hort. 2. tab. C. 6. Black, teb. 129.

Vallia-capo-molago: Hort, mal. 2. tab. 35.

b. C. tetragonum. Mill. Dia.

In Amer. mlerid. $\odot$.

Caul. 2-ped. angulat. Fol. alterna, geminata, longe petiol, ovat-acumin, integerr. atro-virent, glabra, nitida . Fl. oppofitifol. Cor. alba . Fruct, ovat-acumin. corallinus, fplendens.

2. Baccatum . C. caul. fruticof. lævi; pedunc, geminis. Syft. veg. ed. I4. Sloan. Jnm. hift. I. tnb. 146. f. $I$.

Piper \&c. Rumph, amb. 5. $t_{a} b, 88$. f. 2.

In Indiis $b$.

Differt a C. fruticofo, caul. teneriore, magis frutefc. nec fcabriufc. baccis ovat, minimis, magoitudine Ribeos, nec Cerafi ; ramis divaricatis; calyc. dentibus fubulatis, patulis, nec obfoletis .

3. finenfe, C. caul. fruticof. fl. fruetibufque pendulis. Syft. veg. ed. 14. Jacq. Hort. app. cab. 62.

In Martinica 4.

Caul. lignofus, perennans. Fol. alterna, longe petiol, ovat-acumin. integerr. Pedunc. breves, 1-fl. folitar, vel gemelli, nutantes. Cor. alboflavefc. Fructus ovati, obtufi, obfolete anguJar. nitidi, flavi.

4. groffum, C. caul. fuffrutefcent, fructibus incraffatis, variis . Syft, sweg, ed, I4, 
Piper \&c. Befl. eyft. uut. tab. 2. f. I. In India 24.5 .

Simil. C. annuo, fed caul, perennans, fpitham. fubramofus. Fruct, relate ad plantam maximus, Mali fere magnitudine, erectus, folitar.

3. frutefcens. C. caul, fruticof. fcabriufcul. pedunc. folitar. Syft. yeg. ed. 14. Cluf, exot.340. f. 2. Rumph, amb. 5. tab. 88. f. I. 3.4 .

In Indiis $\$$.

Frutex non bene fefe fubftentans, Fruct, oblong. compreffus, ruber.

300. STRYCHNOS, Cor. 5-fid. Bacca I-locul, cortice lignofo. 1. Nux vomi- S. caul, inerm. fol. ovatis. Syft. veg. ed. I4. Black. $c a$. tab. 395.

Caniram. Hort, Mal. I. tab. 37.

In India b.

Arbor procera, ramis denfis, late fparfis. Fol. oppofita, fe mutuo oblique decuffantia, fupra fubnitentia, nervofa, faporis amari. Fl. fubumbell. parvi. Pet. e viridi-lutea. Fruct, rotundus, glaber, abfque rugis, per maturitatem candidus, cortice craffiufc. \& fragili, amarus. Sem, intra carnem, rotunda, comprefla.

2. colubrina. S. fol. ovat-acutis, cirrhis fimplicibus. Syft. veg. ed. I4.

Arbor ligni \&c. Rumph. amb. 2. $t a b .37$.

Lignum colubrinum. Black, tab. 403.

Modira-caniram. H. Mal. 7. tab. s.

In India t.

Arbor Malo Punica fimil. fpinis brevibus, \& f $\mathrm{r}$ mis horrida. Rad, lignofa, brachii craflitie, acris, amariffuna, cortice ferrugin, maculis ciner, notato. Caudex cort, candido. Fol. lutea, afpectu pulcherrima, binata, trinervia. Fruct, orbicul. ma: fufcus, Sem. orbicul-compreflum.

Contendunt India Botanici, hanc a Nuce vom, non elle diverfam. Lin. Suppl.

3. potatorum, S, inerm. fol. oppofit, petiolat. ovat, acutis: panicul, verticillat. Syf., veg. ed. 14. Lin. Suppl. In montofis ad Madraff:

Arb. ramis oppofit. Fol. breviff. integerr, glabra , 5-nervia, venola, Panicul, ad arriculos fuperior. ramorum, 4-6. parvæ, fimplo peduncul. paucitl. Fl, parvi, nutantes. Bacca Cerafffor- 

mis, obfcure rubra, guftui primum dulcis, dein amara, \& adftringens .

30I. GENIPA. Cor, rotata. Stigm, clavatum. Bacca 2-locul. Sem, nidulant. cordata.

I. emericans. G. Syft. veg. ed. 14. Plum, ic. I36.

In Amer. merid. $\hbar$.

Arb. 8o-ped. ramofa. Fol. denfa, petiolat. oblon-rotund. glabra, nitida, venofa, fupra atro-virid. fubtus dilutiora. Racemi multifl. Fl. breviter peduncul. Cal, e viridi-flavefc. Cor. alba, aut albo-flavefc. odora. Fruct. fig: ovi Gallinacei, gratus, fubacidus, fed atro col. ora inficit, col. primuin fubvirid. dein rubro, tandem ciner. Caro albicans. Sem. rubicunda.

302. IGNA-Cal. 5-dent. Cor. infundibulif, longiff. Drupa TIA. I-locul. polyfper.

I. amara. I. Syft. veg. ed. 14. Lin. Suppl.

In India $\hbar$.

Arbor. ramofiff. ramis longis, farment. fcandentibus . Fol. fpitham. oppofira, petiolat. ovata, acuta, plana, integerr. venofa, glaberr. Panicul, axill. parva, ex pedunc. 3-5fl. Fl. longiff. nutantes, albi, odore Jafmini . Fructus ovatus, collo attenuato, cortice ficco glaberrimo, magnitudine Pyri bon-chretien dicti.

Vulgo Faba S. Igratii offic. 